DOE/WIPP 94-019

Revision 0

\title{
Compliance Status Report for the Waste Isolation Pilot Plant
}

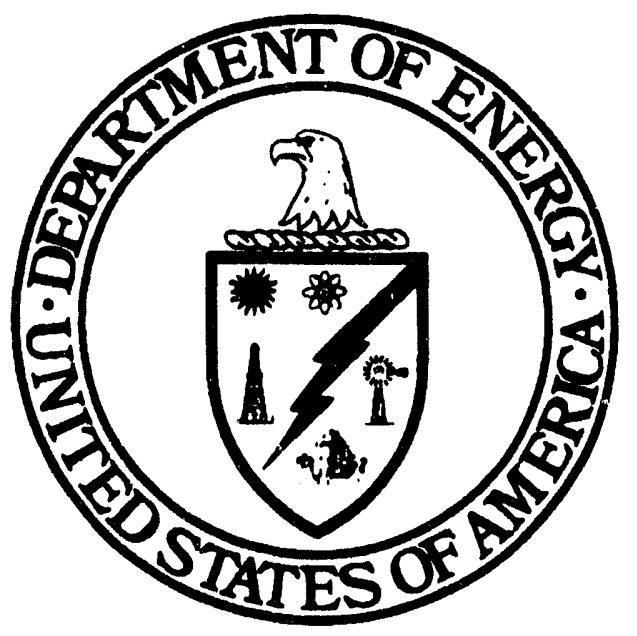

March 1994

United States Department of Energy Carlsbad Area Office Carlsbad, New Mexico 


\section{TABLE OF CONTENTS}

Section

Page

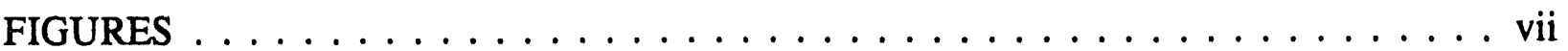

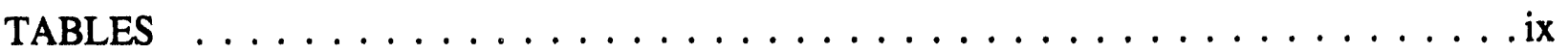

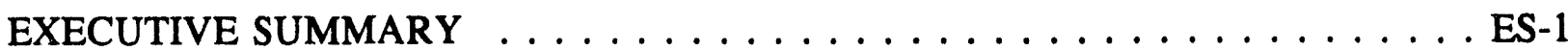

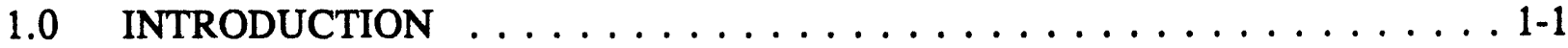

1.1 Project Overview ......................... . . . .

1.2 Site Selection Process ...................... . . . . . .

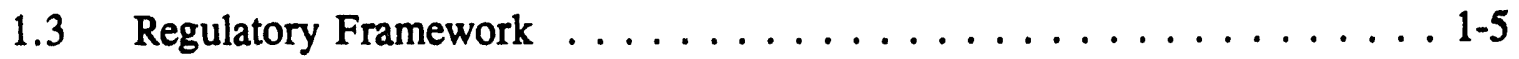

1.3.1 Hazardous Waste Disposal Standards . . . . . . . . . . . . . . 1-8

1.3.2 Radioactive Waste Disposal Standards . . . . . . . . . . . . . 1-8

$1.4 \quad$ References ........................... 1-10

2.0 SITE DESCRIPTION/SITE CHARACTERIZATION . . . . . . . . . . 2-1

2.1 Geology ............................. . . . . . . .

2.1 .1 Regional Geology .................... 2-1

2.1 .2 Stratigraphy ... . . . . . . . . . . . . . . . . 2-9

2.2 Surface and Groundwater Hydrology . . . . . . . . . . . . . . . . 2-24

2.2.1 Physical Hydrogeology of the

Shallow Flow Regime . . . . . . . . . . . . . . 2-25

2.2.2 Chemical Hydrogeology of the

Shallow Flow Regime . . . . . . . . . . . . . . . . 2-30

2.2.3 Physical Hydrogeology of the

Salado/Castile Flow Regime . . . . . . . . . . . . . . . . 2-40

2.2.4 Chemical Hydrogeology of the

Salado/Castile Flow Regime . . . . . . . . . . . . . . . 2-42

2.2.5 Physical Hydrogeology of the

Bell Canyon/Capitan Flow Regime . . . . . . . . . . . . 2-42

$2.3 \quad$ Resources . . . . . . . . . . . . . . . . . . . . 2-43

2.4 Background Environmental Conditions . . . . . . . . . . . . . . . 2-44

2.5 Climatology and Meteorology . . . . . . . . . . . . . . . 2-48 
2.6 Natural Processes and Events . . . . . . . . . . . . . . . . 2-49

2.7 Summary of Repository Processes . . . . . . . . . . . . 2-52

2.7.1 Gas Generation . . . . . . . . . . . . . . . . 2-52

2.7.2 Brine and Gas Flow Processes . . . . . . . . . . . . 2-54

2.7.3 Brine Chemistry Processes . . . . . . . . . . . . . 2-58

2.7.4 Room Closure Processes . . . . . . . . . . . . . . . . . 2 2-60

2.7.5 Room Pressurization Processes . . . . . . . . . . . . . 2-62

2.7.6 Coupling Between Processes . . . . . . . . . . . . 2-66

2.7.7 Potential Release Pathways . . . . . . . . . . . . . . 2 2-67

2.8 References . . . . . . . . . . . . . . . . . . . 2-73

3.0 FACILITY DESCRIPTION $\ldots \ldots \ldots \ldots \ldots \ldots \ldots \ldots \ldots \ldots \ldots$ 3-1

3.1 Design Specifications $\ldots \ldots \ldots \ldots \ldots \ldots \ldots \ldots \ldots \ldots$. . . . . . . . .

3.1.1 DOE Facility Acquisition Process . . . . . . . . . . . . 3-2

3.1.2 Configuration Control . . . . . . . . . . . . . . . 3-2

3.2 As-Built Design . . . . . . . . . . . . . . . . . 3-2

3.2.1 Surface Structures $\ldots \ldots \ldots \ldots \ldots \ldots \ldots \ldots \ldots$ 3-3

3.2.2 Underground Structures $\ldots \ldots \ldots \ldots \ldots \ldots \ldots . \ldots \ldots$. . . . . . . . . .

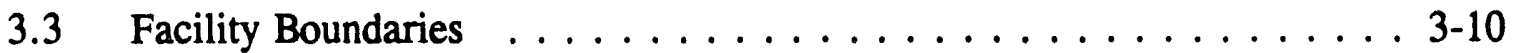

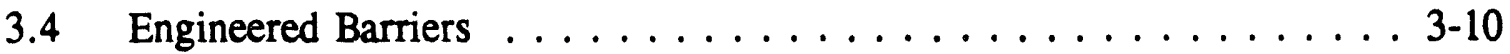

3.4.1 Seals and Plugs . . . . . . . . . . . . . . . 3-10

3.4 .2 Backfill . . . . . . . . . . . . . . . . . . . 3-18

3.5 Performance of the Waste Isolation System $\ldots \ldots \ldots \ldots \ldots$. . . . . . .

3.6 Operations . . . . . . . . . . . . . . . . . . . 3-19

3.6.1 Disposal Operations . . . . . . . . . . . . . 3-20

3.6.2 Decommissioning . . . . . . . . . . . . . . 3-20

3.6.3 Post-Closure Activities $\ldots \ldots \ldots \ldots \ldots \ldots \ldots \ldots \ldots$ 3-22

3.7 References . . . . . . . . . . . . . . . . . . . . . 3-26

4.0 WASTE DESCRIPTION $\ldots \ldots \ldots \ldots \ldots \ldots \ldots \ldots \ldots \ldots \ldots \ldots$

4.1 Waste Inventory $\ldots \ldots \ldots \ldots \ldots \ldots \ldots \ldots \ldots \ldots . \ldots \ldots \ldots .2$

4.1.1 Contact-Handled TRU Wastes $\ldots \ldots \ldots \ldots \ldots \ldots \ldots$. . . . . . .

4.1.2 Remote-Handled TRU Wastes . . . . . . . . . . . . . . . . 4-3

4.1 .3 TRU Mixed Wastes $\ldots \ldots \ldots \ldots \ldots \ldots \ldots \ldots . \ldots . \ldots . \ldots . \ldots$ 
4.1.4 Hazardous Constituents . . . . . . . . . . . . . . . . . 4-5

4.1.5 Radionuclide Inventory $\ldots \ldots \ldots \ldots$. . . . . . . . . . .7

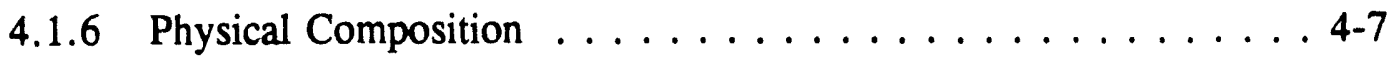

4.1 . Chemical Compatibility . . . . . . . . . . . . . 4-20

4.2 Waste Envelope $\ldots \ldots \ldots \ldots \ldots \ldots \ldots \ldots \ldots \ldots \ldots \ldots . \ldots 4-21$

4.2.1 Performance-Based Waste Envelope . . . . . . . . . . . . 4-22

4.2.2 Boundary Conditions and Process Tolerance Limits . . . . . . 4-23

4.2.3 Waste Acceptance Criteria . . . . . . . . . . . . . . 4-25

4.3 Waste Characterization . . . . . . . . . . . . . . 4 4-39

4.3.1 Program Summary . . . . . . . . . . . . . . . . 4-39

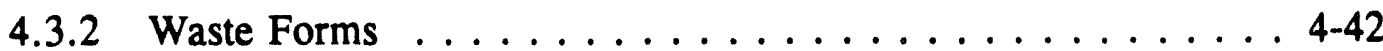

4.3.3 Analytical Methodologies . . . . . . . . . . . . . . . 4-43

4.3.4 Waste Characterization Information Summary . . . . . . . . 4 4-43

4.4 Waste Transformation Processes in the Repository Environment . . . . 4-44

4.4.1 Gas Generation . . . . . . . . . . . . . . . 4-45

$4.5 \quad$ References . . . . . . . . . . . . . . . . . . . . 44-49

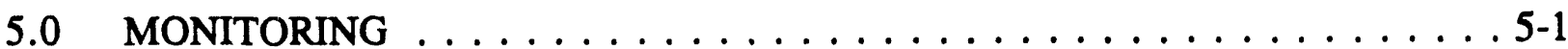

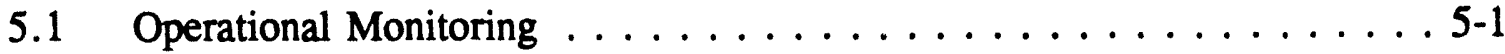

5.1 .1 VOC Monitoring Program $\ldots \ldots \ldots \ldots \ldots \ldots \ldots$ 5-2

5.1.2 Radionuclide Emissions Monitoring Program . . . . . . . 5 5-3

5.1.3 Supplemental Operational Monitoring $\ldots \ldots \ldots \ldots \ldots$ 5-4

5.2 Confirmatory Monitoring . . . . . . . . . . . . 5-6

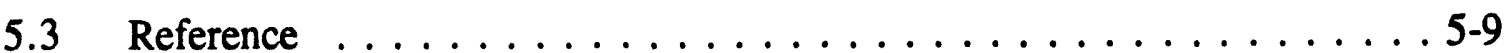

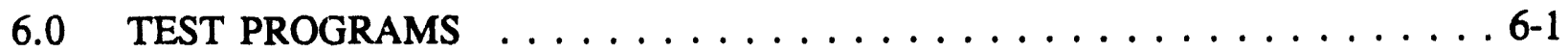

6.1 Status of Experimental Program Relevant to

a Compliance Demonstration . . . . . . . . . . . . . . . . 6-1

6.1.1 Geological/Geochemical Compliance Issues . . . . . . . . 6-1

6.2 References ........................ o-31 
7.0 QUALITY ASSURANCE/QUALITY CONTROL PROGRAM $\ldots \ldots \ldots \ldots 7-1$

7.1 Waste Characterization Program $\ldots \ldots \ldots \ldots \ldots \ldots \ldots \ldots$ 7-3

7.2 Models and Codes $\ldots \ldots \ldots \ldots \ldots \ldots \ldots \ldots \ldots \ldots \ldots$

7.3 Experimental Programs ................... $7-5$

7.4 Facility Data Collection Programs $\ldots \ldots \ldots \ldots \ldots \ldots \ldots \ldots . \ldots \ldots$

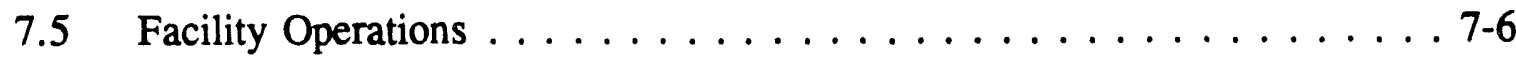

7.6 References . . . . . . . . . . . . . . . . . . . . 7-7

8.0 COMPLIANCE ANALYSIS $\ldots \ldots \ldots \ldots \ldots \ldots \ldots$. $\ldots \ldots \ldots \ldots$

8.1 Performance Assessment Methodology . . . . . . . . . . . . 8-1

8.1.1 Conceptual Models . . . . . . . . . . . . . . . 8-2

8.1.2 Computational Models and Codes . . . . . . . . . . 8-3

8.1.3 Statistical Techniques $\ldots \ldots \ldots \ldots \ldots \ldots \ldots \ldots$. . . . . .

8.1 .4 Selection of Scenarios . . . . . . . . . . . . . . . 8-11

8.1.5 Calculation of Regulatory Performance Measures . . . . . . 8 8-25

8.2 Reasonable Expectation/Reasonable Degree of Certainty . . . . . . . . 8-29

8.2.1 Role and Use of Expert Judgement . . . . . . . . . . . . . . 8-29

8.2.2 Treatment of Uncertainty Associated with Alternative Conceptual Models . . . . . . . . . . . . . . 8 8-30

8.2.3 Documentation of Assumptions . . . . . . . . . . 8 8-30

8.3 Summary of Compliance Determination Data . . . . . . . . 8 8-35

8.3.1 40 CFR $191 \ldots \ldots \ldots \ldots \ldots$. . . . . . . . . . . 8-35

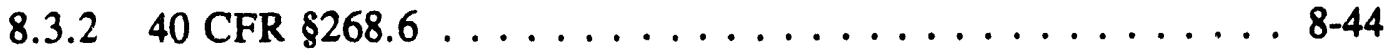

8.3.3 Sensitivity Analyses Results from the 1992 PA . . . . . . . . 8-48

8.4 References . . . . . . . . . . . . . . . . . . . 8-52

9.0 REGULATORY COMPLIANCE ASSESSMENT $\ldots \ldots \ldots \ldots \ldots \ldots$. $\ldots \ldots$

9.1 Containment of Releases $\ldots \ldots \ldots \ldots \ldots \ldots \ldots \ldots$. . . . . . . .

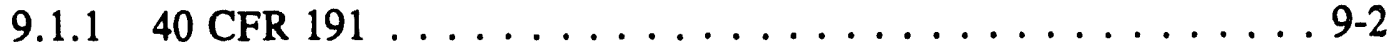

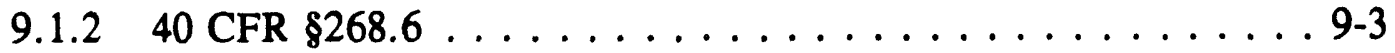

9.2 Human Intrusion $\ldots \ldots \ldots \ldots \ldots \ldots \ldots \ldots \ldots \ldots . \ldots \ldots$

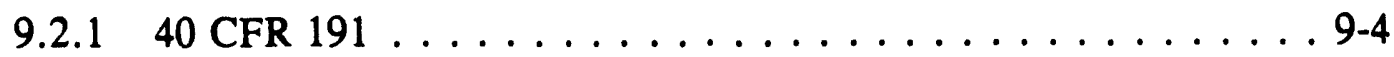

$9.2 .2 \quad 40$ CFR $\$ 268.6 \ldots \ldots \ldots \ldots \ldots \ldots \ldots \ldots$ 
9.3 Groundwater Protection . . . . . . . . . . . . . . . . 9-7

9.3.1 40 CFR $191 \ldots \ldots \ldots \ldots \ldots$. . . . . . . . . . . . .

9.4 Individual Protection $\ldots \ldots \ldots \ldots \ldots \ldots \ldots \ldots \ldots . \ldots \ldots$

9.4 .140 CFR $191 \ldots \ldots \ldots \ldots \ldots$. . . . . . . . . . . 9-8

9.5 Assurance Requirements . . . . . . . . . . . . . . . . 9-8

9.5.1 Active Institutional Controls . . . . . . . . . . . . . . 9-8

9.5.2 Monitoring . . . . . . . . . . . . . . . . 9-9

9.5.3 Passive Institutional Controls . . . . . . . . . . . . 9-10

9.5.4 Multiple Barriers . . . . . . . . . . . . . . . 9.12

9.5.5 Resource Characteristics Evaluation . . . . . . . . 9 9-12

9.5.6 Waste Removal . . . . . . . . . . . . . . . . . . . . . 9 9-13

9.6 Monitoring Requirements . . . . . . . . . . . . . . . . . 9-13

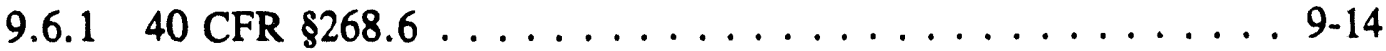

9.7 Infrequent Events and Processes . . . . . . . . . . . . 9-14

9.8 Program/Facility Modifications Designed to

9.9 Waste Acceptance/Waste Compliance . . . . . . . . . . . 9-15

9.10 References . . . . . . . . . . . . . . . . . . . . . 9-17

10.0 FUTURE TEST PROGRAMS $\ldots \ldots \ldots \ldots \ldots \ldots \ldots$ 10-1

10.1 Summary of Future Experimental Activities Necessary

to Support a Compliance Demonstration . . . . . . . . . . . . . 10-1

10.1.1 Natural Barriers . . . . . . . . . . . . . . . 10-1

10.1.2 Repository Design and Engincered Barriers . . . . . . . . 10-10

10.1.3 Waste Interactions . . . . . . . . . . . . . . 10-15

10.1.4 Human Intrusion Modeling . . . . . . . . . . . . . . . 10-19

10.1.5 Performance Assessment . . . . . . . . . . . . . . . 10-20

10.2 References . . . . . . . . . . . . . . . . . . . . . 10-27

11.0 OTHER FEDERAL LAWS $\ldots \ldots \ldots \ldots \ldots \ldots \ldots \ldots \ldots \ldots$

11.1 National Historic Preservation Act $\ldots \ldots \ldots \ldots \ldots \ldots \ldots \ldots$ 11-1

11.2 Endangered Species Act . . . . . . . . . . . . . . 11-2

11.3 Clean Air Act . . . . . . . . . . . . . . . . . . . 11-2

11.4 Clean Water Act (or Federal Water Pollution Control Act of 1972) . . 11-4 
11.5 Safe Drinking Water Act $\ldots \ldots \ldots \ldots \ldots \ldots \ldots \ldots \ldots$

11.6 Comprehensive Environmental Response,

Compensation, and Liability Act $\ldots \ldots \ldots \ldots \ldots \ldots \ldots$

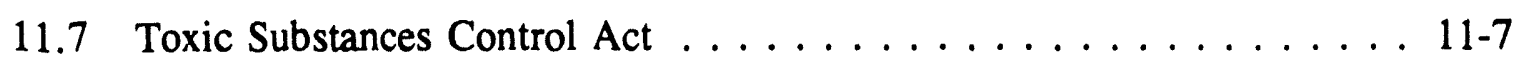

11.8 National Environmental Policy Act . . . . . . . . . . . . 11-7

11.9 Resource Conservation and Recovery Act of $1976 \ldots \ldots \ldots$. . . . 11-8

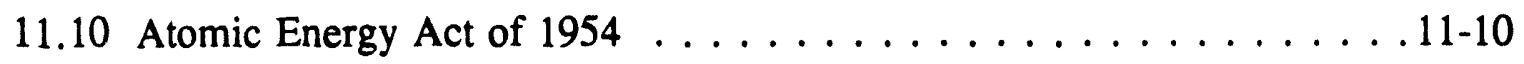

11.11 Hazardous Materials Transportation Act $\ldots \ldots \ldots \ldots \ldots \ldots \ldots$. . . . . . .

11.12 Packaging and Transportation of Radioactive Material . . . . . . . 11-12

11.13 Department of Energy National Security and Military Applications of Nuclear Energy Authorization Act of $1980 \ldots \ldots$. . . . . . 11-13

11.14 Waste Isolation Pilot Plant Land Withdrawal Act . . . . . . . . . 11-13

11.15 Federal Land Policy and Management Act . . . . . . . . . . . 11-14

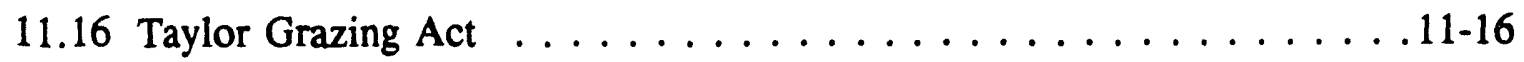

11.17 Public Rangelands Improvement Act $\ldots \ldots \ldots \ldots \ldots \ldots \ldots \ldots$. . . . . . . .

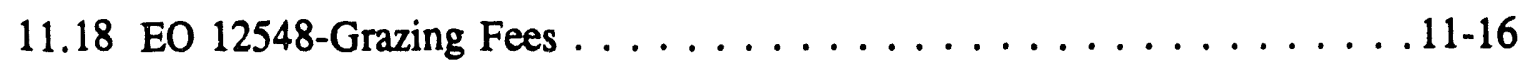

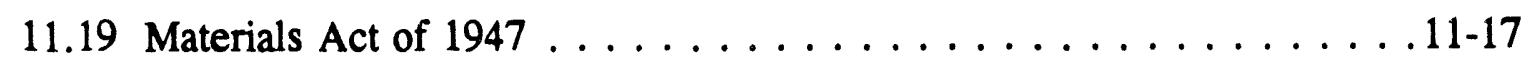

11.20 Federal Mine Safety and Health Act of $1977 \ldots \ldots$. . . . . . . . 11-17

11.21 Bald and Golden Eagle Protection Act . . . . . . . . . . . 11-17

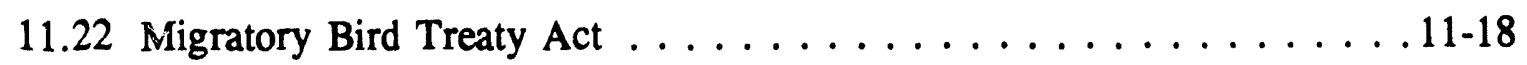

11.23 Noise Control Act of $1972 \ldots \ldots \ldots$. . . . . . . . . . . . 11-18

11.24 Federal Insecticide, Fungicide, and Rodenticide Act . . . . . . . . 11-19

11.25 National Defense Authorization Act - Fiscal Year 1989 . . . . . . . 11-19

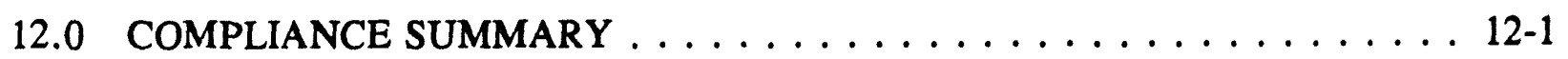

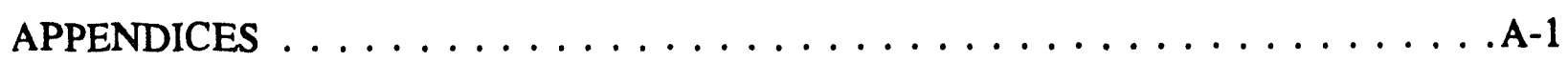

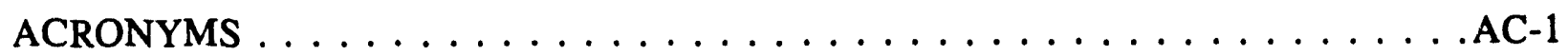

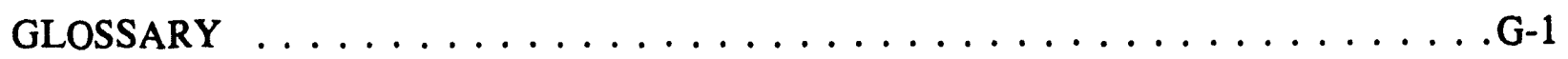




\section{FIGURES}

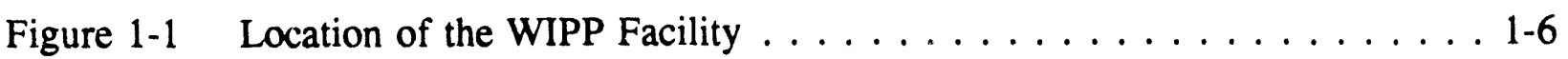

Figure 2-1 Generalized geology of the Delaware Basin, showing the location of the Capitan Reef and erosional limits of the basinal formations $\ldots \ldots \ldots \ldots \ldots . \ldots 2-2$

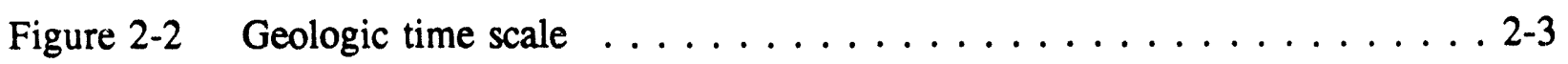

Figure 2-3 Stratigraphy of the Delaware Basin . . . . . . . . . . 2-4

Figure 2-4 Schematic east-west cross section, through the northern Delaware Basin . . . . . . . . . . . . . . . 2-6

Figure 2-5 Schematic north-south cross section through the Delaware Basin . . . . . . . . . . . . . . . . . . 2-7

Figure 2-6 Map of the WIPP vicinity showing the land-withdrawal area and the location of wells for which hydrologic data are available . . . . . . . . . . . . . . 2-8

Figure 2-7 East-west cross section showing stratigraphy of the Rustler Formation and the Dewey Lake Red Beds . . . . . . . . . . 2-13

Figure 2-8 Extent of halite in the Rustler Formation in the

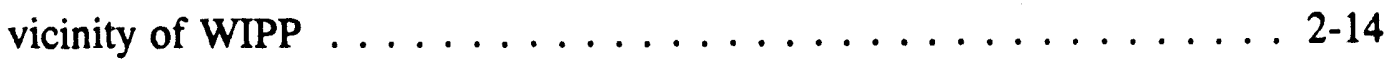

Figure 2-9 Log hydraulic conductivities of the Culebra Dolomite Member of the Rustler Formation . . . . . . . . . . . 2-16

Figure 2-10 Isopach of overburden for the Culebra Dolomite

Member . . . . . . . . . . . . . . . . 2-18

Figure 2-11 Interpreted extent of Salado dissolution $\ldots \ldots \ldots \ldots \ldots$. . . . . . . . .

Figure 2-12 Percentage of natural fractures in the Culebra

Dolomite Member filled with gypsum . . . . . . . . . . . 2-20

Figure 2-13 Estimated freshwater heads in the Culebra Member . . . . . . . . . 2-28

Figure 2-14 Idealized dual-porosity conceptualization represented as (a) a system of parallel fractures or as (b) a system of three orthogonal, intersecting fracture sets with equal spacing in all directions $\ldots \ldots \ldots \ldots \ldots \ldots . \ldots 2-31$

Figure 2-15 Schematic illustration of a (a) fluid flow and

(b) solute transport in an idealized dual-porosity system $\ldots \ldots \ldots$ 2-32

Figure 2-16 Relationship between occurrence of halite in the Rustler Formation and hydrochemical facies of the Culebra . . . . . . 2-34 
Figure 2-17 Staple-istopes compositions of ground waters from the Rustler

Formation and other rocks in southeastern New Mexico . . . . . . 2-36

Figure $2-18{ }^{87} \mathrm{Sr} /{ }^{86} \mathrm{Sr}$ ratios in Ochoan and related rocks . . . . . . . . . . . 2-38

Figure 2-19 Boreholes within a one-mile radius of the WIPP

land-withdrawal area . . . . . . . . . . . . . . . 2-45

Figure $2-20$ Fracture conceptual model tree diagram . . . . . . . . . . . . 2-65

Figure $3-1 \quad$ WIPP Site Boundary . . . . . . . . . . . . . . . . 3-4

Figure $3-2 \mathrm{a}$ WIPP Surface Facilities $\ldots \ldots \ldots \ldots \ldots \ldots \ldots \ldots \ldots$

Figure $3-2 b$ WIPP Surface Facilities . . . . . . . . . . . . . . . . . 3-6

Figure $3-3$ Waste Handling Building . . . . . . . . . . . . . . . 3-7

Figure $3-4$ WIPP Underground Facilities . . . . . . . . . . . . . . . . 3-9

Figure 3-5 Typical Shaft Seal System . . . . . . . . . . . . . . . . . 3-12

Figure 3-6 Reference Seal System - Near Surface and

Rustler Formation . . . . . . . . . . . . . . . . . . . 3-13

Figure 3-7 Reference Seal System - Upper and Middle

Salado Formation . . . . . . . . . . . . . . . . . . . . 3-14

Figure 3-8 Reference Seal System - Lower Salado Formation . . . . . . . . . . . . 3-15

Figure 3-9 Approximate locations of boreholes in relation

to the WIPP underground . . . . . . . . . . . . . . 3-17

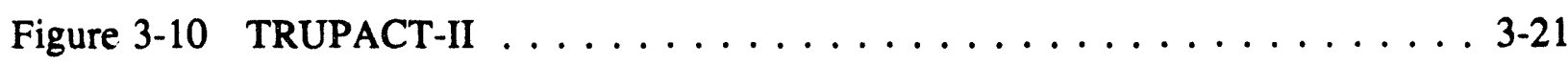

Figure 8-1 Conceptual models for (a) the undisturbed performance scenario and (b) the E1 scenario . . . . . . . . . . . . . . . 8-22

Figure 8-2 Conceptual models for (a) the E2 scenario and (b) the E1E2 scenario ........................ 8-23

Figure 8-3 Example single CCDF derived as the mean of a family of conditional distribution functions $\ldots \ldots \ldots \ldots$ 8-28

Figure 8-4 Process of Managing Uncertainty Associated with Alternative Conceptual Models . . . . . . . . . . . . . . 8-31

Figure 8-5 Comparison of mean CCDFs for total release from intrusions occurring at 1,000 yrs showing the impact of including specific components of the natural and institutional barrier system ................... 8-43 


\section{TABLES}

Table 2-1 Hydralic-Head Data for the Culebra

Table 2-2 Ranges of Mean Values Measured for Radioactive

Isotopes at Sites at WIPP, five mi from WIPP, and

beyond five mi from WIPP .

Table 4-1 Estimated Physical Composition of Retrievably Stored and Newly Generated TRU Waste at DOE Sites . . . . . . . . . . . . . . . . 4-4

Table 4-2 Quantities of TRU Mixed Waste By Generator Site . . . . . . . . . . . . 4-6

Table 4-3 TRU Mixed Waste Hazardous Constituents . . . . . . . . . . . . . . . 4-8

Table 4-4 Radionuclide Inventory and Half-Lives of Isotopes Disposed or Created in the WIPP . . . . . . . . . . . . . . . . . . . . . 4-9

Table 4-5 Boundary Conditions and Process Tolerance Limits Established by the Waste Isolation Pilot Plant . . . . . . . . . . . . . . . . . 4-23

Table 4-6 WIPP Waste Acceptance Criteria . . . . . . . . . . . . . . . . 4-26

Table 4-7 Summary of WAC Limiting Parameters for CH TRU Waste . . . . . 4-32

Table 8-1 Summary of Computer Codes Used in PA . . . . . . . . . . . . . 8 8-4

Table 8-2 Potentially Disruptive Events and Processes . . . . . . . . . . . . 8-12

Table 8-3 Summary of Screened Events and Processes . . . . . . . . . . . 8-15

Table 8-4 Partial List of Assumptions Made in Consequence

Modeling for Disturbed Performance . . . . . . . . . . . . . . 8-32

Table 8-5 Parameters Sampled in the 1992 WIPP

Performance Assessment for 40 CFR $191 \ldots$. . . . . . . . . . . . 8 8-36

Table 8-6 Parameters Sampled in the 1992 Performance Assessment for 40 CFR $\$ 268.6 \ldots \ldots$. . . . . . . . . . . . . . . . . . . . . . . 8-45

Table 8-7 Significance of Sampled Parameters with Respect to 40 CFR 191, Subpart B . . . . . . . . . . . . . . . . . . . . 8 849

Table 8-8 Significance of Sampled Parameters with Respect to 40 CFR $\$ 268.6 \ldots \ldots \ldots$. . . . . . . . . . . . . . . . 8-50

Table 12-1 Compliance Summary . . . . . . . . . . . . . . . . 12-3 


\section{Executive Summary}

The Department of Energy's (DOE) Waste Isolation Pilot Plant (WIPP), located in southeastern New Mexico, has been sited and constructed to meet the criteria established by the scientific and regulatory community for the safe, long-term disposal of transuranic (TRU) and TRU-mixed waste. The Compliance Status Report (CSR) describes the approach to be taken by the DOE in future compliance applications and details the DOE's current understanding of the repository's performance with respect to the long-term disposal regulations set forth in Title 40 CFR 191, Subparts B and C, and Title 40 CFR \$268.6. This report will serve as a tool to focus project resources on the areas necessary to ensure complete, accurate, and timely submittal of the compliance applications. This document is not intended to constitute a statement of compliance or a demonstration of compliance; data/information used in past analyses are not considered to be sufficient for a compliance demonstration, and the strategy for assessing the quality of data used in past analyses has yet to be implemented. The DOE plans to submit draft compliance documentation and the necessary supporting data/information commensurate with traditional compliance applications to the regulatory agencies in March 1995. Future compliance submittals will be responsive to technical deficiencies identified in the CSR.

It must be noted that the scope of information conveyed in the CSR is not the same as that presented in the Experimental Program Plan (EPP), as the CSR addresses only those issues/programs necessary for a demonstration of compliance. The CSR generally parallels the Regulatory Criteria Document (RCD); however, the RCD is intended to be a more general description of the DOE's approach to compliance with 40 CFR 191 and the Resource Conservation and Recovery Act (RCRA) regulations, whereas the CSR, particularly the regulatory interpretations listed in Appendix $\mathrm{A}$, is a site-specific implementation of the approach described generally in the RCD.

The Environmental Protection Agency (EPA) has submitted comments to the DOE addressing the 1992 WIPP Performance Assessment (PA) report, which was the basis for much of the information presented in the CSR. While responses to some of these comments are reflected in this document, formal responses will be provided in a separate submittal to the EPA in the second quarter of 1994.

The primary purpose of the CSR is to address the WIPP Project's status relative to demonstrations of compliance with the long-term disposal regulations. However, certain 
facility operational aspects are also included for completeness. These aspects are limited to the short-term environmental requirements of 40 CFR $\$ 268.6$ and 40 CFR 191, Subpart A (specifically, some of the Regulatory Interpretations in Appendix A that are present because they permeate into Subparts B and C).

The DOE was authorized by the Department of Energy National Security and Military Applications of Nuclear Energy Authorization Act of 1980 (Public Law 96-164) and funded by Congress to provide a research and development facility to demonstrate the safe disposal of radioactive waste resulting from U.S. defense activities and programs. The process by which the current WIPP site was celected involved three stages: 1) extensive reviews of existing information on geologic properties of bedded-salt formations, 2) the selection of candidate regions, and 3) site-specific studies. The site eventually chosen for the WIPP facility, the Los Medaños site in the Delaware Basin, is located 26 mi east of Carlsbad, New Mexico.

The CSR details the site description/characterization and facility design of the WIPP. Also provided in the report are descriptions of the current waste characterization, monitoring, and quality assurance/quality control (QA/QC) programs in place at the facility and plans for future activities in these areas related to long-term compliance.

The EPA's long-term performance standards require that effective containment of regulatedwaste contaminants be evaluated through the use of PA analyses. Performance assessment uses well-defined procedures to simulate system performance under reasonably expected conditions, including the effects of natural and man-induced processes and events. The methodology used for PA analyses includes the development of conceptual models, scenarios, mathematical and computer codes, and the use of measured data and other information to perform calculations to analyze the disposal system's compliance with the regulatory requirements. At this time, data and numerical models are not all considered to be sufficient and qualified to be used in a compliance determination. Consequently, results from the 1992 PA calculations, as reflected in the CSR, have not been determined to be suitable for compliance determinations and are to be regarded as preliminary. However, programs are underway to complete the process of establishing data and models that are suitable for compliance determinations.

The DOE's strategy for compliance demonstration purposes is based on the concept of selfassessment leading to the submittal of compliance documents for stakeholder comment and, 
ultimately, for regulator decisionmaking. This process includes a review of existing data, quantitative and qualitative reviews of applicable program elements, and calculated repository performance measures. With respect to the containment requireınents of 40 CFR $\$ 191.13$, the 1992 PA calculations show it is likely that the WIPP disposal system will provide the level of containment required by the standard, assuming that the mean complementary cumulative distribution function (CCDF) is an adequate measure of compliance; for a demonstration of compliance with 40 CFR \$268.6, additional work is required to include a source term and transport model for hazardous constituents. Human intrusion analyses for 40 CFR 191, Subpart B, presently concentrate on inadvertent human intrusion during exploratory drilling for resources. The three intrusion scenarios used for PA assume that borehole properties are such that releases to the Culebra are maximized; this may be an extremely conservative assumption relative to subsurface releases, and a more reasonable assumption that the DOE plans to consider is that all borehole plugs behave in a similar manner. The EPA has emphasized that under RCRA, long-term passive institutional controls must be imposed to ensure that the likelihood of human intrusion is appropriately reduced. With respect to the groundwater protection standards and the individual protection requirements of 40 CFR 191, Subpart C, and 40 CFR $\$ 191.15$, respectively, PA calculations to date indicate that no radionuclides escape from the regulated area during the 10,000 -year period of regulatory interest. A Plan for the Implementation of Assurance Requirements in Compliance with 40 CFR Part 191.14 at the Waste Isolation Pilot Plant describes the implementation of the applicable requirements of the assurance requirements, which include active and passive institutional controls, monitoring, multiple barriers, and resource characteristics evaluation. A volatile organic compound (VOC) monitoring system has been installed at the WIPP facility. This system is likely to be adequate to verify compliance with the no-migration standards during the disposal phase. Post-closure monitoring for RCRA will consist of methods designed to focus on indicators of effective long-term performance of the repository. Based on the information available regarding the WIPP site and surrounding areas, the DOE believes that it can demonstrate minimal potential for any natural process or event to thureaten the long-term integrity of the repository. When the final PA models are completed, the DOE will evaluate the areas where increased confidence in repository performance is necessary to comply with the various standards; potential engineered alternatives and specification of waste acceptance criteria that will decrease uncertainties in the PA are viable options. 
The experimental program relevant to a compliance demonstration has evaluated issues that have concerned the project from early WIPP site-characterization studies to the present day. To date, several issues remain unresolved and will require future work before a compliance demonstration can be made. Future experimental programs will focus only on obtaining the information needed to resolve issues required for a demonstration of compliance. 


\subsection{Introduction}

The U.S. Department of Energy (DOE) is responsible for the disposition of transuranic (TRU) waste generated through national defense-related activities. Approximately $53,700 \mathrm{~m}^{2}$ of these wastes have been generated and are currently stored at government defense installations across the country. The Waste Isolation Pilot Plant (WIPP), located in southeastern New Mexico, has been sited and constructed to meet the criteria established by the scientific and regulatory community for the safe, long-term disposal of TRU and TRUmixed wastes. This Compliance Status Report (CSR) provides an assessment of the progress of the WIPP Program toward compliance with long-term disposal regulations, set forth in Title 40 CFR 191 (EPA, 1993a), Subparts B and C, and Title 40 CFR \$268.6 (EPA, 1993b), in order to focus on-going and future experimental and engineering activities. The CSR attempts to identify issues associated with the performance of the WIPP as a long-term repository and to focus on the resolution of these issues. This report will serve as a tool to focus project resources on the areas necessary to ensure complete, accurate, and timely submittal of the compliance application. This document is not intended to constitute a statement of compliance or a demonstration of compliance.

\subsection{Project Overview}

The DOE was authorized by the Department of Energy National Security and Military Applications of Nuclear Energy Authorization Act of 1980 (Public Law 96-164) (PL, 1980) and funded by the Congress to provide a research and development facility to demonstrate the safe disposal of radioactive waste resulting from U.S. defense activities and programs. The WIPP facility near Carlsbad, New Mexico, has been constructed to determine the efficacy of an underground repository for disposal of TRU waste. The WIPP Land Withdrawal Act (LWA) of 1992 (Public Law 102-579) (PL, 1992) transferred jurisdiction of the land used for the WIPP Project from the U.S. Bureau of Land Management (BLM) to the DOE and provided additional authorization to continue the activities initiated by Public Law 96-164. The LWA requirements focus on the criteria for certification of compliance with the long-term disposal regulations developed by the U.S. Environmental Protection Agency (EPA). Once the WIPP facility has obtained regulatory approval, it will be used for the permanent disposal of TRU waste, including TRU waste containing hazardous constituents regulated under the Resource Conservation and Recovery Act (RCRA). TRU waste containing RCRA-regulated constituents are referred to as TRU-mixed wastes. 
Safe disposal of the waste destined for the WIPP facility must be demonstrated for 10,000 years. The phased development of the WIPP facility that DOE has chosen to follow is intended to provide adequate knowledge of how the disposal system will perform in this time frame.

Development of the WIPP facility began with a siting phase, during which several sites were evaluated and the present site was selected on the basis of extensive geotechnical research, supplemented by surface-based testing (see Section 1.2). Based upon the geologic properties of the selected site, the repository was designed and safety analyses were prepared.

Subsequent research has expanded the understanding of the geologic, hydrologic, geochemical, and rock-mechanics properties of the host rock and surrounding strata at the site. The siting phase ended with the publication of a Final Environmental Impact Statement (FEIS) in 1980 (DOE, 1980), which evaluated alternatives for the safe, long-term isolation of TRU waste at the WIPP facility. The DOE Record of Decision (ROD) (DOE, 1981) concluded that the phased development of the WIPP facility was the preferred alternative of those considered.

The Site and Preliminary Design Validation Phase (SPDV) followed the siting phase. During this phase, two shafts were constructed, an underground testing area was excavated, and various studies were initiated that did not involve the use of hazardous or radioactive wastes. Geologic, hydrologic, and other geotechnical investigations continued, further expanding the site-characterization database, and methods for assessing the long-term performance of the WIPP facility were evaluated. In 1984, a series of geologic and hydrologic studies was begun by agreement between the DOE and the State of New Mexico in light of the issues remaining at the end of the SPDV phase. The majority of these studies are summarized in Lappin (1988) which, in effect, brought to termination the WIPP site characterization phase. However, limited geologic and hydrologic studies of the WIPP continue.

The construction phase followed, during which surface structures for receiving waste were built and underground excavations were completed for one panel of rooms designed for permanent waste emplacement. The end of the construction phase was marked by a decision by the DOE Energy Systems Acquisition Advisory Board (ESAAB). This decision was reached after all prerequisites for ending construction were met and documented to the satisfaction of DOE's executives. These documents used the data collected since 1980 to evaluate the potential short-term and long-term impacts of the WIPP facility. The Final Safety Analysis Report (FSAR) (DOE, 1990a) was then published. 
At the conclusion of the construction phase, the DOE proposed to proceed into a test phase that would include testing with TRU and TRU mixed waste at the WIPP facility. Although the DOE has made the decision not to conduct underground tests with radioactive wastes in the WIPP facility, information needs regarding a compliance demonstratinn have not changed. Compliance needs relative to 40 CFR 191 and 40 CFR $\$ 268.6$ are discussed in Chapter 9.

Upon a successful demonstration of compliance with applicable federal and state laws and regulations, and once the certification and approval requirements of the LWA are met, the WIPP facility will proceed through three other distinct phases: a disposal phase, a decommissioning phase, and a post-decommissioning phase. The disposal phase, projected to last 25 years, will consist of receiving, handling, and emplacing TRU and TRU- mixed waste in the repository. Additional scientific studies may continue during the disposal phase. The disposal phase will end when a decision is made to terminate further disposal activities.

The decommissioning phase will follow the disposal phase and will have as its objective the preparation of the repository for permanent closure. Surface facilities will be decontaminated and decommissioned, and underground excavations will be prepared for closure and shaft seals will be emplaced. This phase is projected to last ten years.

The post-decommissioning phase will include active and passive institutional controls. Active institutional controls may include activities such as site access control. Such controls will be implemented consistent with applicable regulations and permit conditions. Only the first 100 years of such controls will be included in the performance assessment (PA). Passive institutional controls will include notification devices such as permanent markers. These will be designed to reduce the likelihood of human intrusion.

\subsection{Site Selection Process}

Salt deposits have been recognized as a medium of choice for radioactive waste disposal since the completion of a National Academy of Sciences (NAS) study in 1955 (NAS-NRC, 1957). Salt has relatively high thermal conductivity, which serves to conduct heat away from waste rapidly, and has favorable plastic (creep) properties which permit sizeable strains to be absorbed without fractures. The existence of large salt deposits demonstrates isolation from 
circulating groundwaters for long periods of geologic time; the depositional nature and preservation of large salt deposits demonstrates regional stability for long periods of time.

The site selection process for the WIPP was initiated in 1973, with a review of available information on potential disposal-site media. This work was directed toward salt beds and salt domes. The tentative selection criteria used in the initial stage of the process were geological and logistical in nature and stressed radiation and mine safety, hydrologic isolation, and ease of construction. The criteria specified the following conditions: 1,000 to $2,500 \mathrm{ft}$ ( 305 to $762 \mathrm{~m}$ ) depth to salt, $200-\mathrm{ft}(61-\mathrm{m})$ minimum salt thickness, lateral extent of salt sufficient to protect against dissolution, favorable tectonics (low historical seismicity and no salt-flow structures nearby), minimal groundwater, low resource potential, minimum number of boreholes, low population density, and maximum involvement of federal lands. From the bedded salt regions surveyed in this stage, the U.S. Geological Survey (USGS) and the Oak Ridge National Laboratory (ORNL) selected eastern New Mexico as the area which best satisfied the tentative selection criteria.

During the second stage of the selection process, two of three New Mexico locations were determined to be inadequate: the Clovis-Portales site, because the shallow salt was very clayey and the purer salt was too deep, and the Mescalero Plains area, because of extensive oil-field development. After shifting the potential site twice (in order to avoid drillhole penetrations through the salt within two mi $[3.2 \mathrm{~km}]$ of the repository border), ORNL selected a site in the Delaware Basin for extensive characterization.

In the final stage of the selection process, eight areas in the Delaware Basin in Eddy and Lea Counties were evaluated. Eight additional selection criteria were used in this analysis:

1. The site should be at least six mi (ten $\mathrm{km}$ ) from the Capitan Reef, a major aquifer, to avoid any possible dissolution hazard related to the nearness of the reef.

2. To minimize potential conflicts with mineral resources, the central four square $\mathrm{mi}\left(\operatorname{ten} \mathrm{km}^{2}\right.$ ) designated for the repository itself, should not be in the known Potash District, and as little as possible of the surrounding buffer zone should be in the district.

3. No part of the central area should be less than one mi $(1.6 \mathrm{~km})$ away from holes drilled through the Castile Formation into underlying rocks to avoid 
potential dissolution by water flowing upward through an inadequately plugged borehole.

4. Known oil and gas stratagraphic trends should be avoided.

5. The nearest dissolution front should be at least one mile from the site.

6. Bedding should be nearly flat, so far as can be determined by surface geophysical investigations, to ensure mine safety and ease of construction and to avoid the need for numerous exploratory holes with a subsequent risk to the integrity of the repository.

7. Salt of high purity should be available at depths between 1,000 and $3,000 \mathrm{ft}$ ( 305 and $914 \mathrm{~m}$ ) to ensure mine safety and ease of construction. In addition, a salt thickness of $200 \mathrm{ft}(61 \mathrm{~m})$ or more is preferred to confine thermal and mechanical effects to the salt.

8. The use of state and private land should be minimized, especially in the central area, to simplify land acquisition and to make residential relocation unnecessary.

The Los Medaños site was found to best meet the additional selection criteria. The selection process is described in more detail in Section 2.2.3 of the WIPP FEIS. The FEIS provided the basis for making the final decision regarding siting the WIPP facility at the Los Medaños site. This decision weighed the numerous advantages of the location and its suitability against potential adverse environmental impacts. The final selection of the WIPP site (Figure 1-1) was made as the best of the available areas considered. Subsequent site validation and facility construction activities have confirmed that site features are favorable for the long-term isolation of radioactive and hazardous waste constituents. These favorable features are reasonably expected to offset any enhanced risk of human intrusion associated with resources around the WIPP site.

\subsection{Regulatory Framework}

The EPA is responsible for developing generally applicable environmental standards for the protection of the public and the environment from radioactive and hazardous waste constituents. The authority for establishing and implementing the regulatory standards 


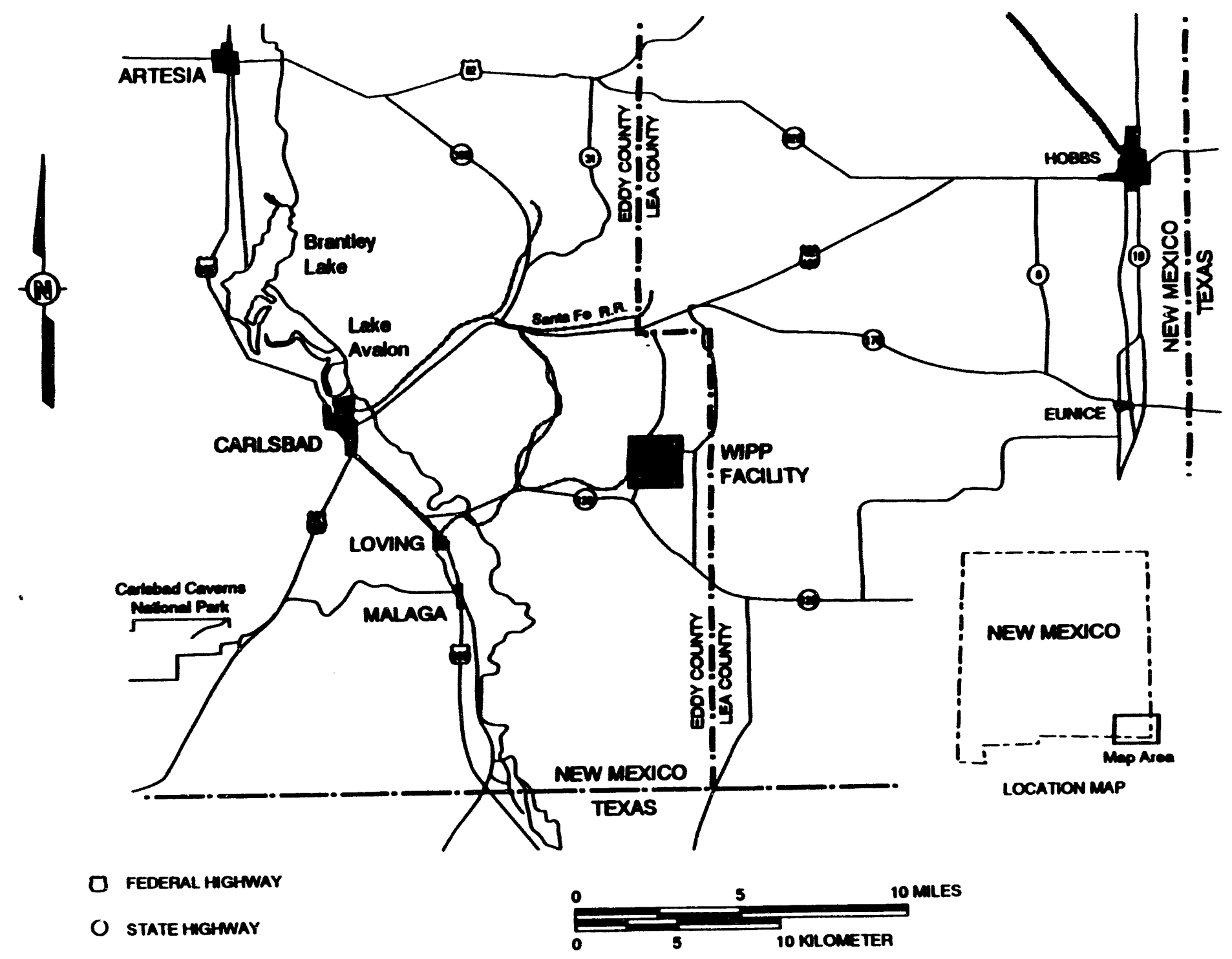

Figure 1-1 Location of the WIPP Facility 
covered by this CSR applicable to the operation, closure, and post-closure performance of the WIPP facility are found in the 1984 Hazardous and Solid Waste Amendments (HSWA) of RCRA, the Atomic Energy Act of 9154, and in the Nuclear Waste Policy Act (NWPA) of 1982. The regulations affecting the radioactive and hazardous waste-disposal operations that will occur at the WIPP facility are found at 40 CFR 268, Land Disposal Restrictions, and 40 CFR 191, Environmental Radiation Protection Standards for the Management and Disposal of Spent Nuclear Fuel, High Level and Transuranic Radioactive Waste. The DOE's regulatory interpretations used for assessing compliance with these standards may be found in Appendix A.

The EPA is also responsible for establishing criteria for certifying whether the WIPP facility complies with the 40 CFR 191 radioactive waste disposal standards. Pursuant to the WIPP LWA, EPA is currently developing these criteria which will appear in 40 CFR 194, Criteria for the Certification and Determination of the Waste Isolation Pilot Plant's Compliance with Environmental Standards for the Management and Disposal of Spent Nuclear Fuel, HighLevel and Transuranic Wastes.

Within a broader context, the WIPP LWA assigns authorities for the management of WIPP lands, responsibilities for WIPP Program direction, limitations on WIPP operations, and prerequisites for initiating disposal activities. Specifically, this includes EPA review and approval of key WIPP programmatic documents as well as responsibilities for the Department of Interior (DOI), Department of Labor (DOL), Environmental Evaluation Group (EEG), NAS, and the State of New Mexico.

The DOE has defined a strategy for achieving compliance with long-term disposal standards. The DOE's Regulatory Compliance Strategy and Management Plan (RCSMP) (DOE, 1993), which has recently been issued for comments, serves to communicate to WIPP Project participants, regulatory agencies, and stakeholders the DOE's understanding of the regulations related to long-term repository performance. In addition, the RCSMP is intended to provide an efficient strategy that:

- integrates WIPP Project elements,

- ensures sufficiency of information, and

- $\quad$ provides flexibility to accommodate change. 


\subsubsection{Hazardous Waste Disposal Standards}

The land disposal restrictions (LDRs), set forth in 40 CFR 268, prohibit the land disposal of untreated hazardous waste. Although the LDRs specify that waste must be treated to diminish its hazard or reduce the likelihood that hazardous constituents will migrate into the environment, operators may receive permission to dispose of certain wastes if a demonstration can be made, in accordance with 40 CFR $\$ 268.6$, that there will be no migration of hazardous constituents from the disposal unit for as long as the waste remain hazardous.

Pursuant to the provisions of 40 CFR \$268.6, the DOE submitted a No-Migration Variance Petition (NMVP) for the WIPP facility in March 1989 and revised it in 1990 (DOE, 1990b). A final No-Migration Determination (NMD) was granted by the EPA in November, 1990 (EPA, 1990). The NMD for the test phase allows the DOE to emplace a limited quantity of untreated TRU mixed waste in the WIPP facility for the purpose of testing. Although DOE does not plan to conduct waste tests at the WIPP facility, the petitioning process and final NMD set precedents that will likely be applicable and appropriate for future compliance decisions.

In the NMD, "no migration" was interpreted by the EPA to mean no movement of hazardous constituents beyond the unit boundary in concentrations exceeding health-based levels. The unit boundary for the WIPP facility was defined as the Salado Formation within the area controlled by the DOE. The period for which no-migration of hazardous constituents must be demonstrated was determined to be 10,000 years.

The NMD set forth several conditions and limitations related to waste characterization, waste retrieval, air monitoring, control of airborne emissions, and reporting that will be considered in subsequent no-migration petition submittals for the disposal phase. In addition, the EPA announced through a proposed rulemaking in the Federal Register on August 11, 1992, that it will be modifying the definition of health-based levels to be applied to no-migration assessments. This rule is currently scheduled to be finalized in August 1994.

\subsubsection{Radioactive Waste Disposal Standards}

Since the mid 1970's, the EPA has been developing guidance and standards for the management and disposal of radioactive waste. The EPA's final rule, 40 CFR 191, was 
published on September 19, 1985 (EPA, 1985). This standard was vacated and remanded to the EPA by a Federal Court of Appeals in 1987. The LWA reinstated the 1985 disposal standard except for the aspects of the standard that were specifically questioned by the court (i.e., §191.15, Individual Protection Requirements, and \$191.16, Ground Water Protection Requirements). On December 20, 1993, the EPA promulgated amendments to the final standard pertaining to individual and grounci water protection requirements, which became effective on January 19, 1994.

The 40 CFR 191 rule establishes standards and measures of performance that apply to the following operational and performance aspects of a disposal system:

- waste management and storage

- $\quad$ protection of individuals from radiation exposures for a period of 10,000 years

- protection of groundwater from contamination with radioactive materials for a period of 10,000 years

- isolation of radionuclides sufficient to meet the containment requirements of the disposal system

To demonstrate that a disposal system will comply, a reasonable expectation with regard to each performance measure must be demonstrated.

The need for assurance requirements is also called out in 40 CFR $\$ 191.14$. The EPA designed these assurance requirements to complement the containment requirements of 40 CFR \$191.13. These assurance requirements include active and passive institutional controls to preclude disturbance of the repository for an extended period of time, natural and engineered barriers to ensure the integrity of the containment system, and other measures taken to reduce the likelihood for human intrusion.

The LWA requires that by October 1994, the EPA must finalize criteria for certifying compliance with 40 CFR 191. These criteria will be codified as 40 CFR 194 . Once the EPA establishes these criteria, the DOE will evaluate these criteria as part of its compliance with the 40 CFR 191 disposal standards. 


\subsection{REFERENCES}

Lappin, A.R., 1988. Summary of Site Characterization Studies From 1983 Through 1987 at the Waste Isolation Pilot Plant (WIPP) Site, Southeastern New Mexico, SAND 88-0157, Albuquerque, NM, Sandia National Laboratories

U.S. Department of Energy (DOE), 1980. Final Environmental Impact Statement, Waste Isolation Pilot Plant, DOE/EIS-0026, Volumes 1 and 2, Department of Energy Office of Environmental Restoration and Waste Management, Washington, D.C.

U.S. Department of Energy (DOE), 1981. Waste Isolation Pilot Plant: Record of Decision, Federal Register, Volume 46, No. 18, p. 9162, January 28, 1981 (46 FR 9162), Department of Energy Office of Environmental Restoration and Waste Management, Washington D.C.

U.S. Department of Energy (DOE), 1990a. Final Safety Analysis Report: Waste Isolation Pilot Plant, WP02-9, Revision 0, Westinghouse Electric Corporation, Waste Isolation Division, Carlsbad, New Mexico.

U.S. Department of Energy (DOE), 1990b. Waste Isolation Pilot Plant No-Migration Variance Petition, Rev. 1, DOE/WIPP 89-003, March 1990.

U.S. Department of Energy (DOE), 1993. Waste Isolation Pilot Plant Requlatory Compliance Strategy and Management Plan, Rev. 1, DOE/WIPP 86-013, November 1993.

U.S. Environmental Protection Agency (EPA), 1985. Environmental Radiation Protection Standards for the Management and Disposal of Spent Nuclear Fuel. High-Level and Transuranic Radioactive Waste: Final Rule, Federal Register, Volume 50, No. 182, p.38066, September 19, 1985 (50 FR 38066), Environmental Protection Agency Office of Radiation and Air, Washington, D.C. 
U.S. Environmental Protection Agency (EPA), 1990. Conditional No-Migration

Determination for the Department of Energy Waste Isolation Pilot Plant (WIPP), Federal

Register, Volume 55, No. 220, p. 47700, November 14, 1990, (FR 55 47700),

Environmental Protection Agency Office of Solid Waste and Emergency Response,

Washington D.C.

U.S. Environmental Protection Agency (EPA), 1993a. Environmental Radiation Protection Standards for the Management and Disposal of Spent Nuclear Fuel, High-Level and

Transuranic Radioactive Waste, Federal Register, Volume 58, No. 242, p. 66398, December 20, 1993, (58 FR 66398), Environmental Protection Agency Office of Radiation and Indoor Air, Washington D.C.

U.S. Environmental Protection Agency (EPA), 1993b. Land Disposal Restrictions, Code of Federal Regulations, Office of the Federal Register National Archives and Records Administration, Washington, D.C.

National Academy of Sciences-National Research Council (NAS-NRC), 1957. The Disposal of Radioactive Waste on Land: A Report of the Committee on Waste Disposal, Division of Earth Sciences, Publication 519.

Public Law (PL), 1980. Public Law 96-164, Department of Energy National Security and Military Applications of Nuclear Energy Authorization Act, 96th Congress, Washington, D.C., 1980.

Public Law (PL), 1992. Public Law 102-579, Waste Isolation Pilot Plant Land Withdrawal Act, 102nd Congress, Washington, D.C., October 1992. 


\subsection{Site Description/Site Characterization}

The Waste Isolation Pilot Plant (WIPP) is located in southeastern New Mexico east of t're Pecos River and west of the high plains of West Texas, in a region of sand dunes known locally as Los Medaños (The Dunes). Most dunes in the area are stabilized by vegetation; there is relatively little local topographic relief.

The characteristics of the WIPP site are described in detail in many other reports including Hiss (1975); Cheeseman (1978); Williamson (1978); Hills (1984); Ward et al. (1986); Harms and Williamson (1988); Holt and Powers (1988,1990); Beauheim and Holt (1990); Brinster (1991); Powers et al. (1978a,b); Bechtel (1986); Lappin et al. (1989); the WIPP Final Environmental Impact Statement (FEIS) (DOE, 1980a); the WIPP Final Safety Analysis Report (FSAR) (DOE, 1990a); and the WIPP Final Supplemental Environmental Impact Statement (FSEIS) (DOE, 1990b). Additional detailed discussion is contained in Volumes 2 and 3 of 1992 Preliminary Performance Assessment (PA) report for the WIPP (SNL, 1992). An overview of site characteristics relevant to waste isolation is presented in this section.

\subsection{Geology}

\subsubsection{Regional Geology}

The WIPP is located near the northern end of the Delaware Basin, a structural depression that formed during the Late Pennsylvanian and Permian Periods, approximately 300 to 245 million years ago (Figures 2-1 and 2-2). Sedimentation within the subsiding basin resulted in the deposition of up to $13,000 \mathrm{ft}(4,000 \mathrm{~m})$ of marine strata. Organic activity at the basin margins produced massive carbonate reefs that separated deep-water facies from the shallowwater shelf sediments deposited landward.

Permian-age rocks in the vicinity of the WIPP are those of the Guadalupian and Ochoan Series, deposited between approximately 265 and 245 million years ago (Figure 2-3).

During this time, subsidence in the Delaware Basin was initially rapid, resulting in deposition of deep-water shales, sandstones, and limestones of the Delaware Mountain Group (DMG). Intermittent connection with the open ocean and a decrease in clastic sediment supply, possibly in response to regional tectonic adjustments, led to the deposition of a thick evaporite sequence. Anhydrites and halites of the Castile Formation are limited to the 


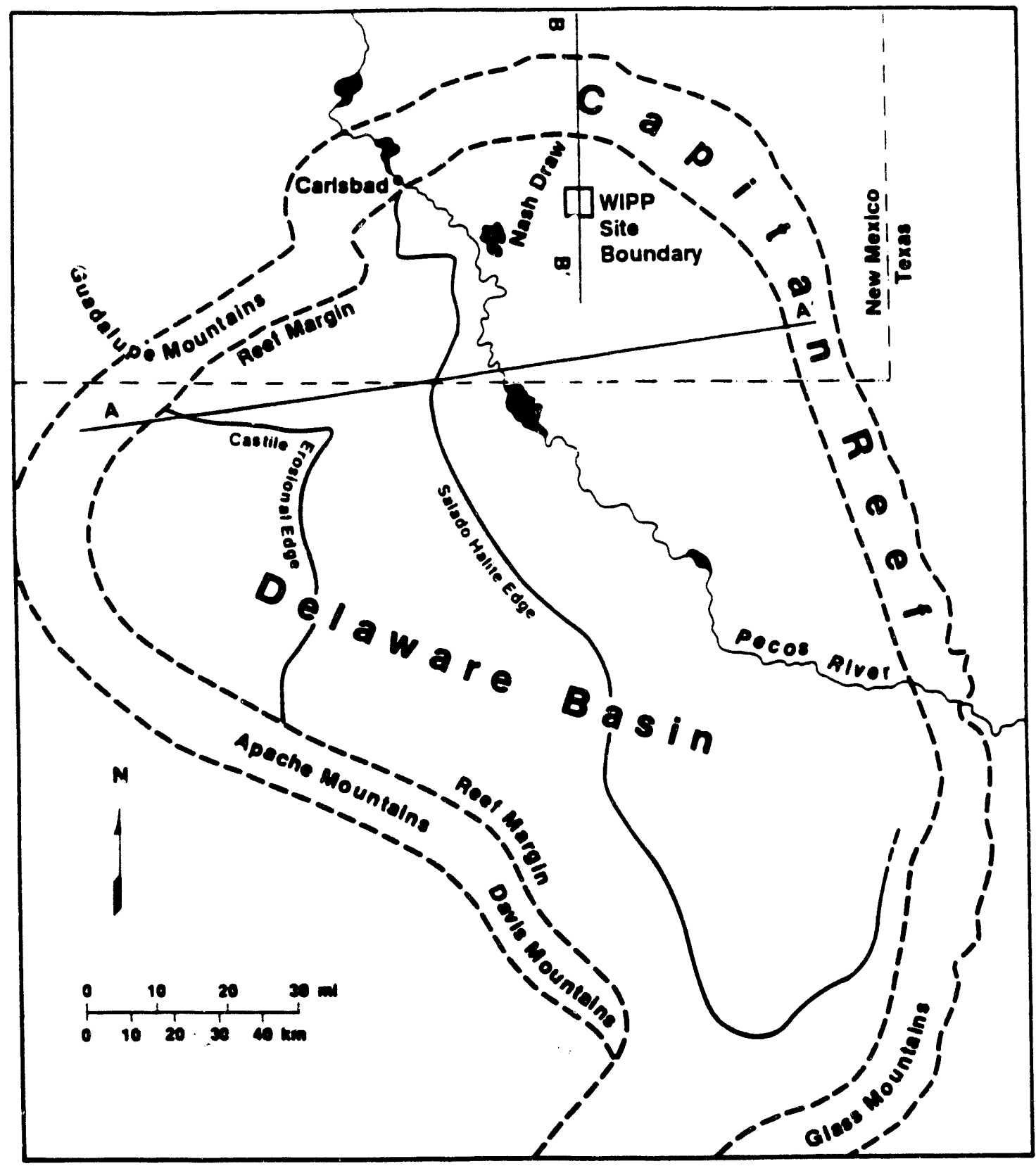

TRI-6342.237.4

Figure 2-1 Generalized geology of the Delaware Basin, showing the location of the Capitan Reef and erosional limits of the basinal formations (Lappin, 1988). 



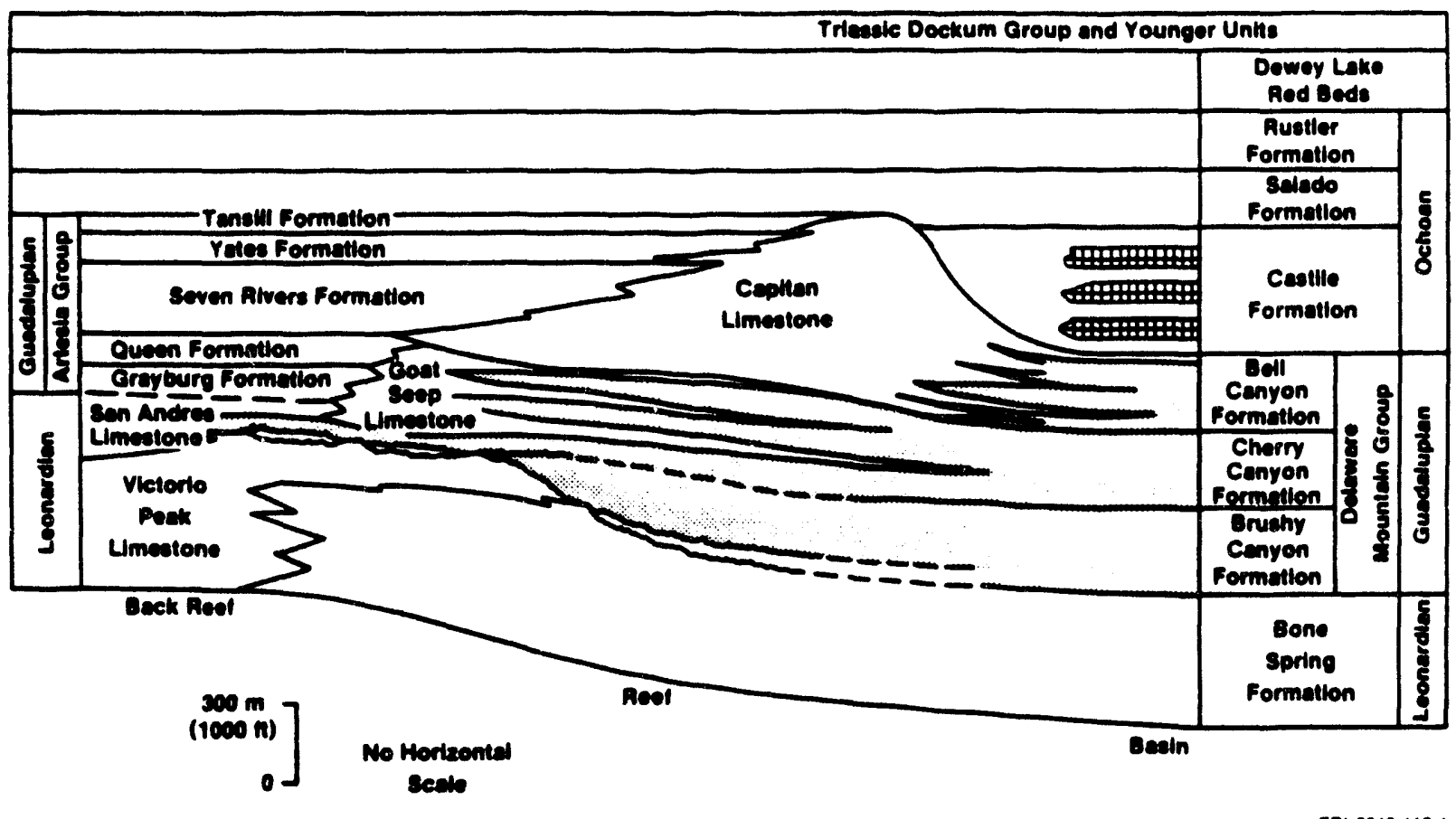

T91-6342-1191

Figure 2-3 Stratigraphy of the Delaware Basin (modified from Mercer, 1983; Brinster, 1991). 
structurally deeper portion of the basin, enclosed within the reef-facies rocks of the Capitan Limestone. Subsidence within the basin slowed in the late Permian epoch, and the halites of the Salado Formation, which include the host strata for the WIPP, extend outward from the basin center over the Capitan Reef and the shallow-water shelf facies. Latest Permian-age evaporites, carbonates, and clastic rocks of the Rustler Formation and the Dewey Lake Red Beds record the end of regional subsidence and include the last marine rocks deposited in southeastern New Mexico during the Paleozoic. The overlying sandstones of the Triassic-age Dockum Group reflect continental deposition and mark the onset of a period of regional tectonic stability that lasted approximately 240 million years, until late in the Tertiary period.

Permian-age strata of the Delaware Basin now dip gently (generally less than $1^{\circ}$ ) to the east, and erosion has exposed progressively older units toward the western edge of the basin (Figures 2-1 and 2-4). This tilting reflects the Late Pliocene and early Pleistocene (approximately 3.5 million to 1 million years ago) uplift of the Capitan Reef to form the Guadalupe Mountains more than $37 \mathrm{mi}(60 \mathrm{~km})$ west of the WIPP (Figures 2-1 and 2-4). Field evidence suggests that additional uplift may have occurred during the late Pleistocene and Holocene, and some faults of the Guadalupe Mountains may have been active within the last 1,000 years (Powers et al., 1978a,b). North and east of the WIPP, the Capitan Reef has not been uplifted and remains in the subsurface (Figure 2-5).

The present landscape of the Delaware Basin has been influenced by near-surface dissolution of the evaporites (Bachman, 1984, 1987). Karst features created by dissolution include sinkholes, subsidence valleys, and breccia pipes. Most of these features formed during wetter climates of the Pleistocene, although active dissolution is still occurring wherever evaporites are exposed at the surface. Some dissolution may also be occurring in the subsurface where circulating groundwater comes in contact with evaporites; for example, modern subsidence in San Simon Swale east of the WIPP (Figure 2-6) may be related to localized dissolution of the Salado Formation (Anderson, 1981; Bachman, 1984; Brinster, 1991). Nash Draw, which formed during the Pleistocene by dissolution and subsidence, is the most prominent karst feature near the WIPP. Evaporites in the Rustler Formation have been affected by dissolution near Nash Draw.

The largest karst feature in the Delaware Basin is the Balmorhea-Loving Trough, south of the WIPP along the axis of the basin (Figure 2-6). Dissolution of evaporites, perhaps 


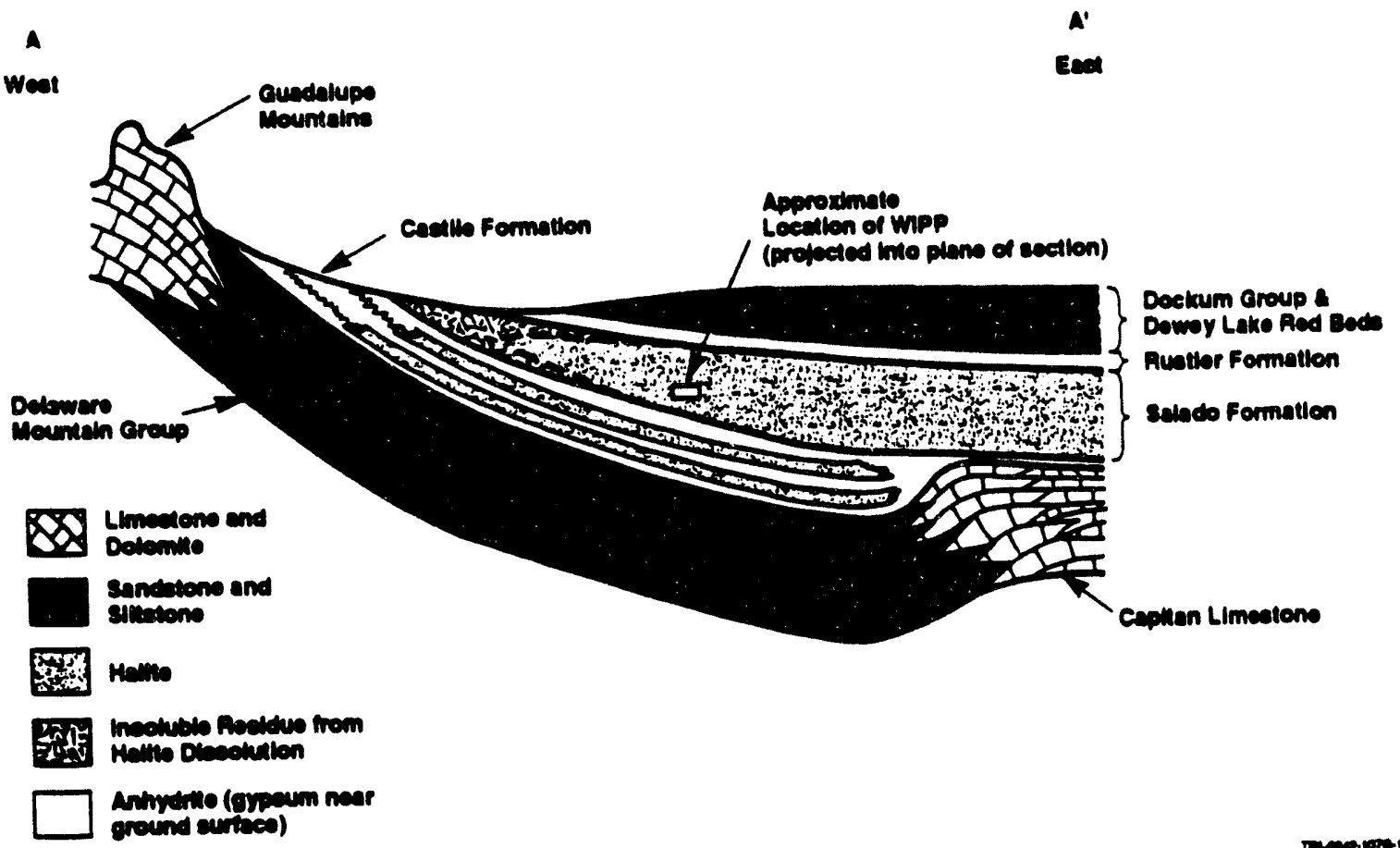

Figure 2-4 Schematic east-west cross section through the northern Delaware Basin (modified from Davies, 1984). The cross section is vertically exaggerated. Approximate location of line of section shown on Figure 2-1. 


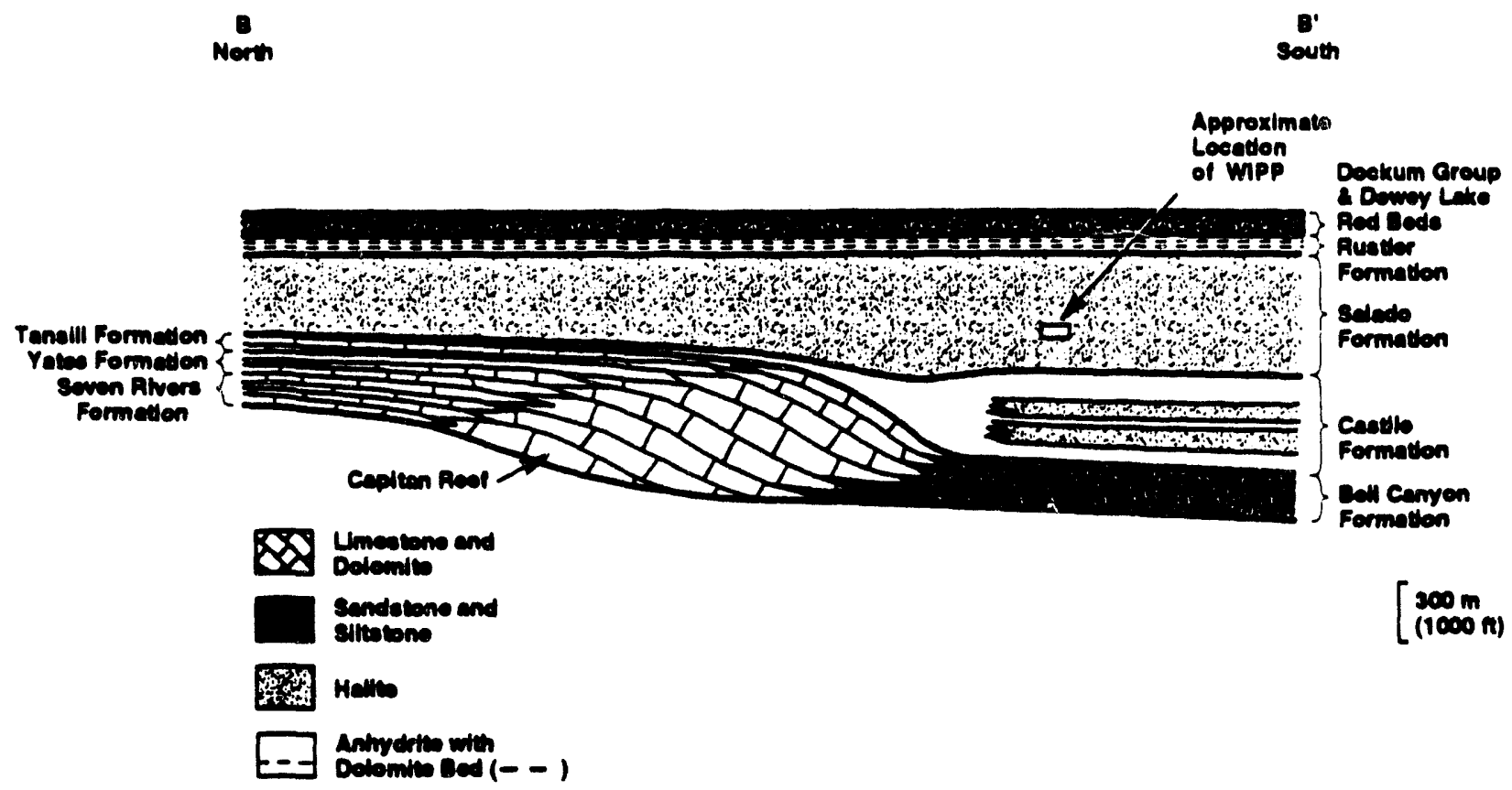

Then. $10 n \cdot 1$

Figure 2-5 Schematic (not to scale) north-south cross section through the Delaware Basin (modified from Davies, 1984). The cross section is vertically exaggerated. Approximate location of line of section shown on Figure 2-1. 


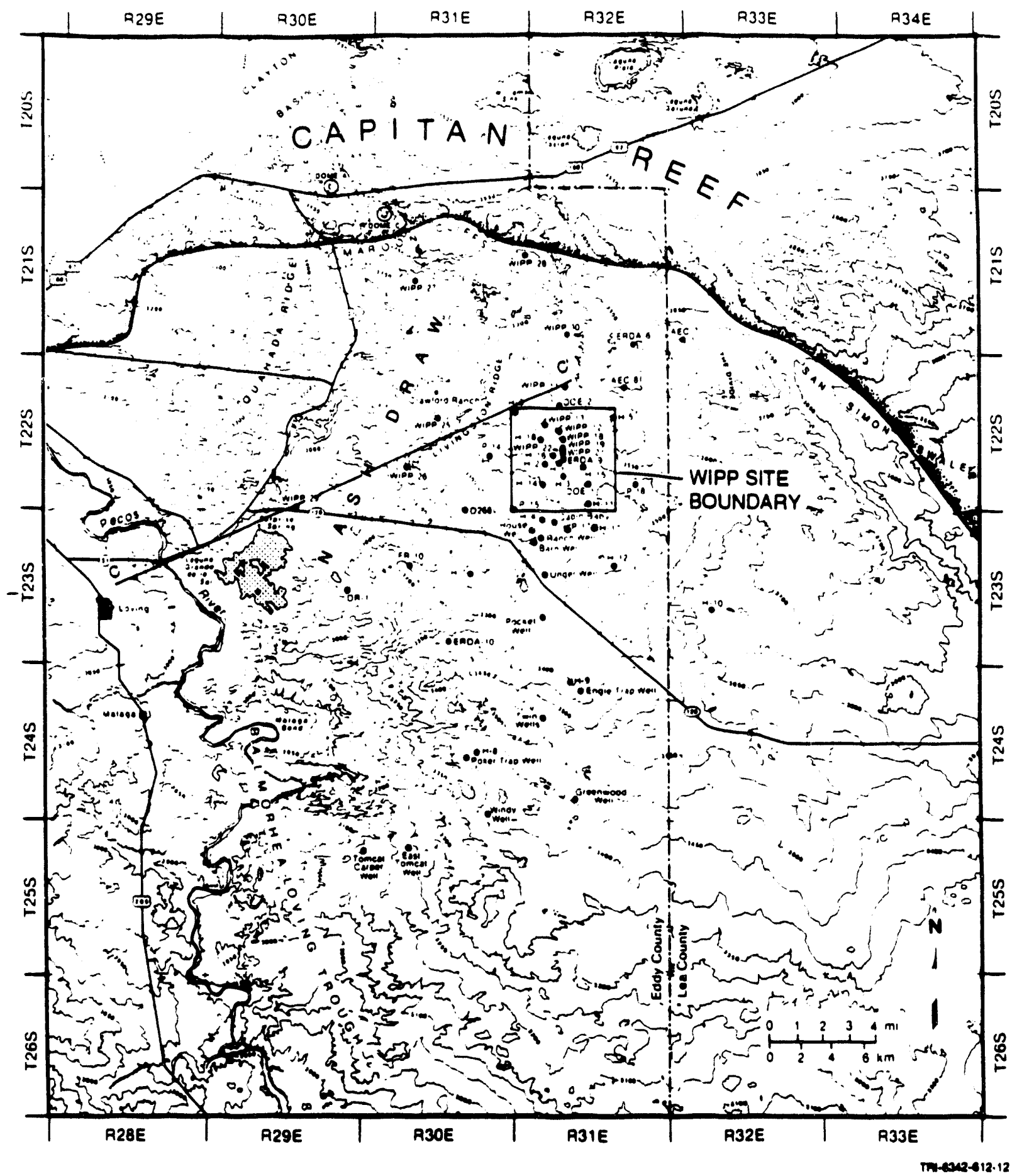

Figure 2-6 Map of the WIPP vicinity showing the land-withdrawal area (labeled "WIPP Site Boundary") and the location of wells for which hydrologic data are available (Haug et al., 1987; Brinster, 1991). 
along the course of a predecessor of the modern Pecos River, resulted in subsidence and the deposition of Cenozoic alluvium up to $984 \mathrm{ft}(300 \mathrm{~m})$ thick in southern Eddy County, and up to almost $1,970 \mathrm{ft}(600 \mathrm{~m})$ thick across the state line in Texas (Bachman, 1984, 1987; Brinster, 1991).

\subsubsection{Stratioraphy}

\subsubsection{Bell Canyon Formation}

The Bell Canyon Formation consists of 690 to $850 \mathrm{ft}$ (210 to $260 \mathrm{~m}$ ) of sandstones and siltstones with minor limestones, dolomites, and conglomerates (Williamson, 1978; Mercer, 1983; Harms and Williamson, 1988). Sandstones within the upper portion of the Bell Canyon Formation occur as long, sinuous channels separated by siltstones, reflecting their deposition by density currents that flowed into the deep basin from the Capitan Reef (Harms and Williamson, 1988). These sandstones have been targets for hydrocarbous exploration elsewhere in the Delaware Basin.

\subsubsection{Capitan Limestone}

The Capitan Limestone is not present at the WIPP but is a time-stratigraphic equivalent of the Bell Canyon Formation to the west, north, and east (Figures 2-1 and 2-3). The unit is a massive limestone ranging from 250 to $750 \mathrm{ft}(76$ to $230 \mathrm{~m})$ thick. Dissolution and fracturing have enhanced effective porosity, and the Capitan is a major aquifer in the region, providing the principal water supply for the city of Carlsbad. Upward flow of groundwater from the Capitan aquifer may be a factor in dissolution of overlying halite and the formation of breccia pipes. Existing breccia pipes are limited to the vicinity of the reef, as is the active subsidence in San Simon Swale (Figure 2-6) (Brinster, 1991).

\subsubsection{Castile Formation}

The Castile Formation is approximately $1,540 \mathrm{ft}(470 \mathrm{~m})$ thick at the WIPP and contains anhydrites with intercalated limestones near the base and halite layers in the upper portions. Primary porosity and permeability in the Castile Formation are extremely low. However, wells in the region have encountered brine reservoirs in fractured anhydrite in the Castile Formation. Pressurized brine in the Castile Formation is modeled in PA because 
occurrences have been found at WIPP-12 within the WIPP land-withdrawal area and at ERDA-6 and other wells in the vicinity. This pressure is slightly greater than the nominal hydrostatic pressure for a column of equivalent brine at that depth. Therefore. brine could reach the repository, overlying strata, and the ground surface through an intrusion borehole.

Early geophysical surveys mapped a structurally disturbed zone in the vicinity of the WIPP that may correlate with fracturing or development of secondary porosity within the Castile Formation; this zone could possibly contain pressurized brine (Borns et al., 1983). Later electromagnetic surveys indicated that the brine could underlie part of the waste panels (Earth Technology Corporation, 1988). WIPP-12 data are therefore used to develop a conceptual model of the brine reservoir for analyzing scenarios that include the penetration of pressurized brine.

\subsubsection{Salado Formation}

The 250-million-year-old Salado Formation, which hosts the repository, is about $2,000 \mathrm{ft}$ $(610 \mathrm{~m})$ thick and consists of the following three separate and distinct members (Jones 1978):

- A lower member, which is mostly halite with lesser amounts of anhydrite, polyhalite, and glauberite, with some layers of fine clastic material. The unit is $960 \mathrm{ft}$ to $1,160 \mathrm{ft}$ (293 to $354 \mathrm{~m}$ ) thick, and the WIPP repository is located within it, $2,150 \mathrm{ft}(655 \mathrm{~m})$ below the land surface.

- A middle member, the McNutt Potash Zone, which is reddish-orange and brown halite with deposits of sylvite and langbeinite from which potassium salts are mined.

- An upper member, which is reddish-orange to brown halite interbedded with polybalite, anhydrite, and sandstone.

These lithologic layers are nearly horizontal at the WIPP, with a regional dip of less than one degree.

Where the Salado Formation is intact and unaffected by dissolution, natural groundwater flow is extremely slow or nonexistent because the permeability is so low. Additionally, chemical studies show that the brine in the Salado probably originated as sea water precipitated halite and has been in contact with the rock-forming minerals for geologic periods of time. If 
infiltrating rainwater had dissolved the salt, the resulting brine would have a very different chemical composition (Deal et al., 1989).

The Salado is saturated. Porosity is estimated to be approximately 0.015 , and permeability of the formation is very low to unmeasurable. State-of-the-art in-situ testing of halite in the repository was unable to measure any permeability in the undisturbed, pure halite units, indicating that if any intrinsic permeability exists, it is below the limits of testability (approximately $1 \times 10^{-23} \mathrm{~m}^{2}$ [Beauheim et al., 1591; Beauheim et al., 1993]). The halite units that contain small amounts of impurities, such as polyhalite and clay, are slightly more permeable, typically less than $1 \times 10^{-20} \mathrm{~m}^{2}$. The undisturbed interbedded anhydrite units have still slightly higher permeability, typically between $1 \times 10^{-19}$ and $1 \times 10^{-18} \mathrm{~m}^{2}$ (Beauheim and Holt, 1990).

\subsubsection{Rustler-Salado Contact Zone}

In the vicinity of Nash Draw, the contact between the Rustler and Salado Formations is an unstructured residuum of gypsum, clay, and sandstone created by dissolution of halite. The residuum becomes thinner to the east and intertongues with clayey halite of the Unnamed Lower Member of the Rustler Formation. On a regional basis, Mercer (1983) concluded, on the basis of brecciation at the contact, that dissolution in Nash Draw occurred after deposition of the Rustler Formation. The residuum ranges in thickness in the vicinity of the WIPP from $7.9 \mathrm{ft}(2.4 \mathrm{~m})$ in P-14 east of Nash Draw to $108 \mathrm{ft}(33 \mathrm{~m})$ in WIPP-29 within Nash Draw (Mercer, 1983). Measured hydraulic conductivity values for the residuum are highest at Nash Draw (up to $10^{-6} \mathrm{~m} / \mathrm{s}$ ) and three to six orders of magnitude lower to the east (Brinster, 1991). Porosity estimates range from 0.15 to 0.33 (Robinson and Lang, 1938; Hale and Clebsch, 1958; Geohydrology Associates, Inc., 1979; Mercer, 1983).

In the shafts at the WIPP, the residuum shows evidence of channeling and filling, fossils, and bioturbation, indicating that some erosion occurred before Rustler deposition (Holt and Powers, 1988). Very little moisture was observed seeping out of this zone into the shafts.

\subsubsection{Rustler Formation}

The Rustler Formation is of particular importance for WIPP PA because it contains the most transmissive units above the repository and, therefore, provides the most reasonable pathway 
for the subsurface transport of radionuclides and hazardous constituents to the accessible environment.

The Rustler Formation is $312 \mathrm{ft}$ ( $95 \mathrm{~m}$ ) thick at the WIPP (as measured in ERDA-9) and ranges in the area from a minimum of $28 \mathrm{ft}(8.5 \mathrm{~m})$, where thinned by dissolution and erosion west of the repository, to a maximum of $709 \mathrm{ft}(216 \mathrm{~m})$ to the east (Brinster, 1991). Overall, the formation is composed of about 40 percent anhydrite, 30 percent halite, 20 percent siltstone and sandstone, and ten percent anhydritic dolomite (Lambert, 1983). On the basis of outcrops in Nash Draw west of the WIPP, the formation is divided into four formally named members and a Unnamed Lower Member (Vine, 1963). These five units (Vine, 1963; Mercer, 1983) are, in ascending order, the Unnamed Lower Member (oldest), the Culebra Member, the Tamarisk Member, the Magenta Member, and the Forty-niner Member (youngest) (Figure 2-7).

\subsection{The Unnamed Lower Member}

The Unnamed Lower Member is about $118 \mathrm{ft}(36 \mathrm{~m})$ thick at the WIPP and thickens slightly to the east. The unit is composed mostly of fine-grained silty sandstones and siltstones interbedded with anhydrite (converted to gypsum at Nash Draw) west of the WIPP. Increasing amounts of halite are present to the east. Halite is present over the WIPP (Figure 2-8) but is absent north and south of the WIPP where the topographic expression of Nash Draw extends eastward. Distribution of halite within this and other members of the Rustler Formation is significant because, as is discussed in the following section, an apparent correlation exists between the absence of halite and increased transmissivity in the Culebra Member.

The basal interval of the Unnamed Lower Member contains siltstone and sandstone of sufficient transmissivity to allow groundwater flow. Transmissivities of $2.9 \times 10^{-10} \mathrm{~m}^{2} / \mathrm{s}$ and $2.4 \times 10^{-10} \mathrm{~m}^{2} / \mathrm{s}$ were calculated from tests at $\mathrm{H}-16$ that included this interval (Beauheim, 1987). Assuming all flow in the $112 \mathrm{ft}(34 \mathrm{~m})$ test interval came from the $64 \mathrm{ft}(20 \mathrm{~m})$ of the basal interval, these transmissivity values correspond to hydraulic conductivities of $4.2 \mathrm{x}$ $10^{-6} \mathrm{ft} / \mathrm{d}\left(1.5 \times 10^{-11} \mathrm{~m} / \mathrm{s}\right)$ and $3.4 \times 10^{-6} \mathrm{ft} / \mathrm{d}\left(1.2 \times 10^{-11} \mathrm{~m} / \mathrm{s}\right)$. Hydraulic conductivity in the lower portion of the unnamed member is believed to increase to the west in and near Nash Draw, where dissolution in the underlying Rustler-Salado contact zone has caused subsidence and fracturing of the sandstone and siltstone (Beauheim and Holt, 1990). 


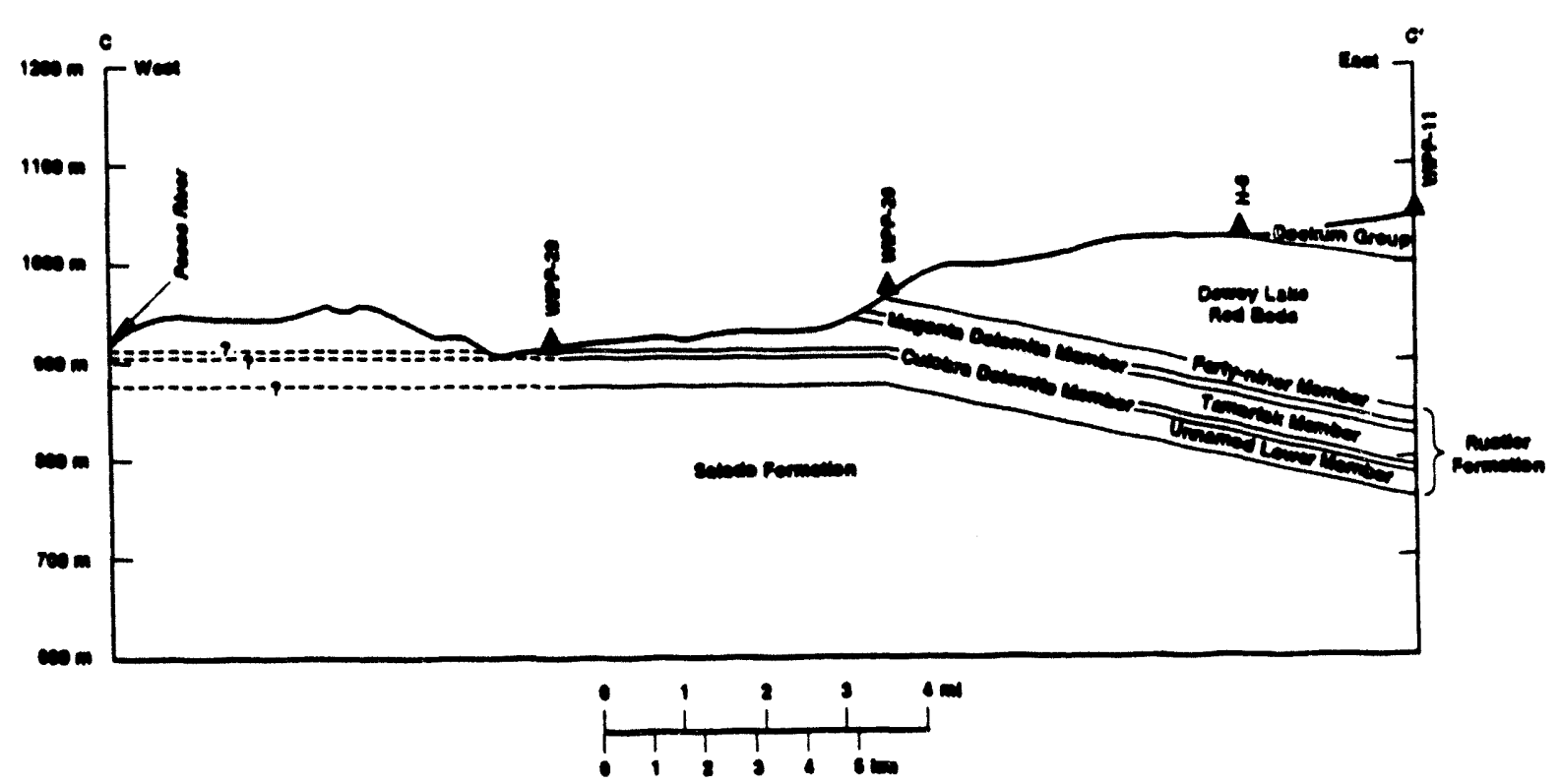

menom

Figure 2-7 East-west cross section showing stratigraphy of the Rustler Formation and the Dewey Lake Red Beds (modified from Brinster, 1991). Note vertical exagseration. Location of cross section is shown on Figure 2-6. 


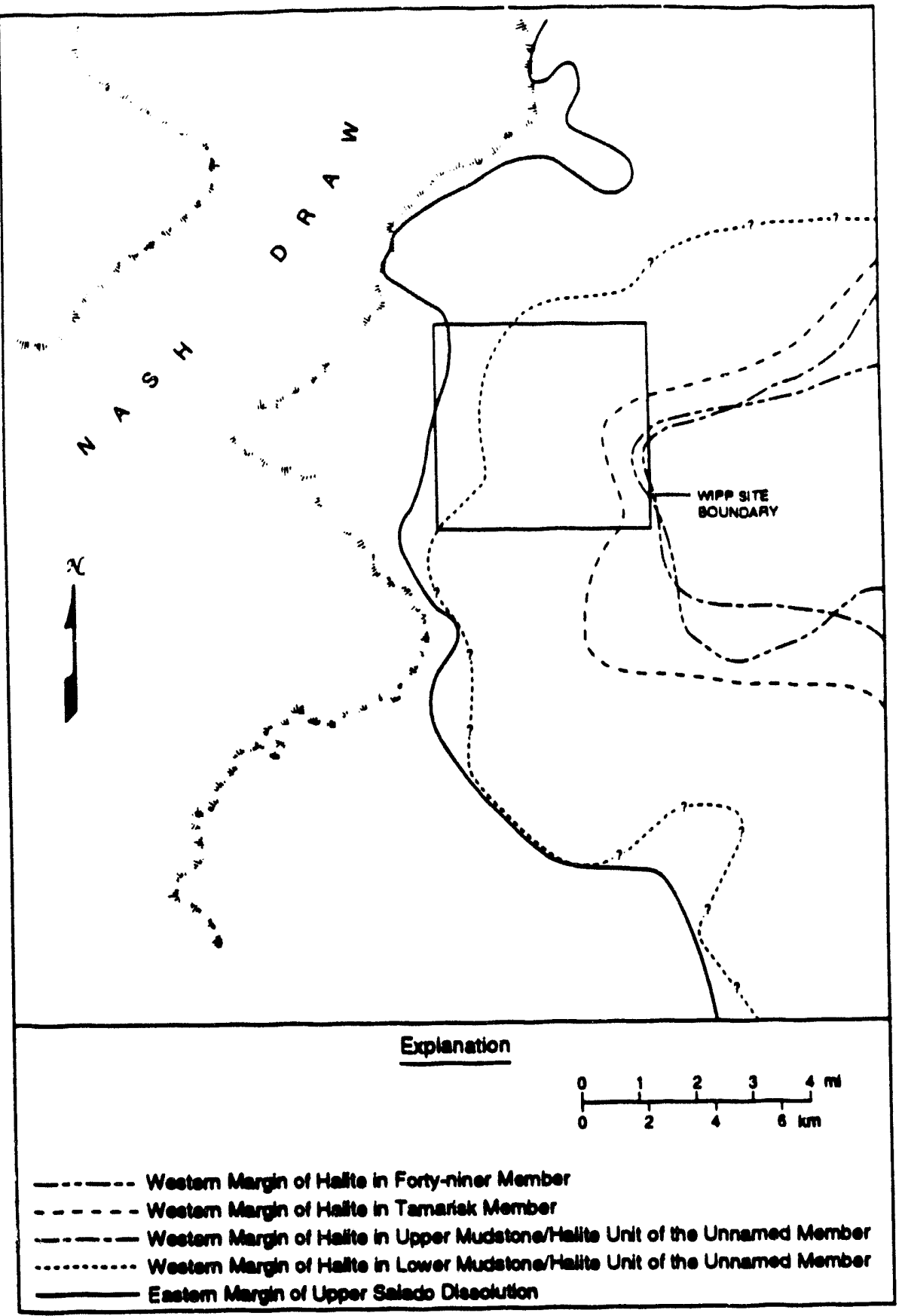

TRI 6300004

Figure 2-8 Extent of halite in the Rustler Formation in the vicinity of WIPP (Lappin et al., 1989). 
The remainder of the Unnamed Lower Member contains mudstones, anhydrite, and variable amounts of halite. Hydraulic conductivity of these lithologies is extremely low; tests of mudstones and claystones in the waste-handling shaft gave hydraulic conductivity values ranging from $2 \times 10^{-9} \mathrm{ft} / \mathrm{d}\left(6 \times 10^{-15} \mathrm{~m} / \mathrm{s}\right)$ to $3 \times 10^{-8} \mathrm{ft} / \mathrm{d}\left(1 \times 10^{-13} \mathrm{~m} / \mathrm{s}\right)$ (Saulnier and Avis, 1988; Brinster, 1991).

\subsection{Culebra Member}

The Culebra Member of the Rustler Formation is microcrystalline dolomite or dolomitic limestone with solution cavities (Vine, 1963). In the vicinity of the WIPP, it ranges in thickness from 13 to $38.3 \mathrm{ft}(4$ to $11.6 \mathrm{~m}$ ) and has a mean thickness of about $23 \mathrm{ft}(7 \mathrm{~m})$. Outcrops of the Culebra occur in the southern part of Nash Draw and along the Pecos River.

Hydraulic data are available from 41 well locations in the WIPP vicinity (Cauffman et al., 1990). Hydraulic conductivity of the Culebra varies six orders of magnitude from east to west in the vicinity of the WIPP (Figure 2-9), ranging from $2 \times 10^{-10} \mathrm{~m} / \mathrm{s}\left(6 \times 10^{-5} \mathrm{ft} / \mathrm{d}\right.$ ) at P. 18 east of the WIPP to $1 \times 10^{-4} \mathrm{~m} / \mathrm{s}\left(3 \times 10^{2} \mathrm{ft} / \mathrm{d}\right)$ at $\mathrm{H}-7$ in Nash Draw (Brinster, 1991). Present understanding of the geologic controls on this variation in conductivity is based primarily on studies of core samples from 17 boreholes, exposures in the walls of three shafts excavated at the WIPP, and approximately 600 geophysical logs from boreholes throughout the vicinity (Holt and Powers, 1988; Powers and Holt, 1990; Beauheim and Holt, 1990).

Measured matrix porosities of the Culebra range from 0.03 to 0.30 (Lappin et al., 1989; Kelley and Saulnier, 1990). Fracture porosity values have not been measured directly, but interpreted values from tracer tests at the $\mathrm{H}-3$ and $\mathrm{H}-11$ hydropads are $2 \times 10^{-3}$ and $1 \times 10^{-3}$, respectively (Kelley and Pickens, 1986). Data are insufficient to reliably map spatial variability of porosity.

Variations in hydraulic conductivity in the Culebra are believed to be controlled by the relative abundance of open fractures (Snyder, 1985; Beauheim and Holt, 1990; Brinster, 1991) rather than by primary (i.e., depositional) features of the unit. Lateral variations in depositional environments were small within the mapped region, and primary features of 


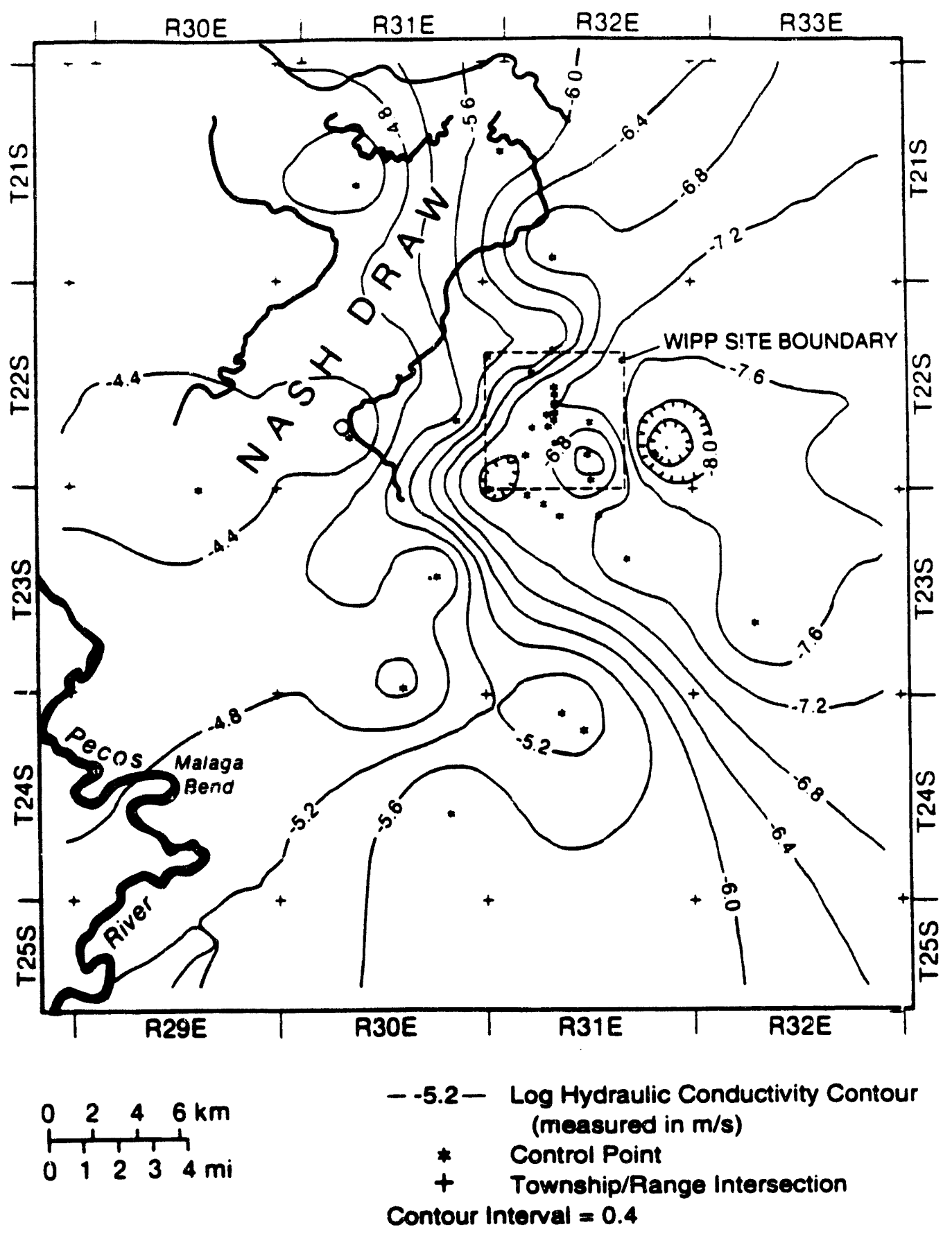

Thereas-272-2

Figure 2-9 Log hydraulic conductivities $(\mathrm{m} / \mathrm{s})$ of the Culebia Dolomite Member of the Rustler Formation (Brinster, 1991). 
the Culebra show little map-scale spatial variability (Holt and Powers, 1988). Direct measurements of the density of open fractures are not available from core samples because of incomplete recovery and fracturing during drilling, but comparisons between highly fractured outcrops of the Culebra in southern Nash Draw and the relatively unfractured exposures in the WIPP shafts suggest that density of open fractures in the Culebra decreases to the east. Qualitative correlations have been noted between hydraulic conductivity and several geologic features possibly related to open-fracture density, including 1) the distribution of overburden above the Culebra (Figure 2-10) (Holt and Powers, 1988; Beauheim and Holt, 1990), 2) the distribution of halite in other members of the Rustler Formation (compare Figures 2-8 and 2-9) (Snyder, 1985), 3) the dissolution of halite in the upper portion of the Salado Formation (Figure 2-11) (Beauheim and Holt, 1990), and 4) the distribution of gypsum fillings in fractures in the Culebra (Figure 2-12) (Beauheim and Holt, 1990).

Regional tilting of the Delaware Basin during the Late Pliocene and early Pleistocene (see Section 2.1.1) and subsequent erosion have resulted in a westward decrease in overburden above the Culebra (Figure 2-12). The decrease in confining stress during erosional unloading may have caused fracturing in the Culebra (Beauheim and Holt, 1990) and may also have controlled the degree to which fractures opened. Locally, however, variations in conductivity do not correlate precisely with variations in overburden thickness, and other geologic phenomena must contribute to the variations (Beauheim and Holt, 1990).

Where the present distribution of halite in the Rustler Formation (Figure 2-8) results from post-depositional dissolution, subsidence over areas of dissolution may have caused fracturing in the Culebra (Snyder, 1985). Mapping of depositional environments in the Rustler Formation indicates, however, that the present limits of halite in the formation coincide, in general, with a depositional transition from evaporites to mudstones near the margins of a saline pan (Holt and Powers, 1988; Powers and Holt, 1990). Dissolution of the upper portion of the Salado Formation (Figure 2-12), as inferred from stratigraphic thinning observed in geophysical logs, may also have caused subsidence and fracturing in the Culebra (Beauheim and Holt, 1990).

Detailed examination of core samples from the Culebra shows that the percentage of fractures that are filled with post-depositional gypsum crystals increases eastward across the site (Figure 2-12) (Beauheim and Holt, 1990). Furthermore, the crystalline structure of the 


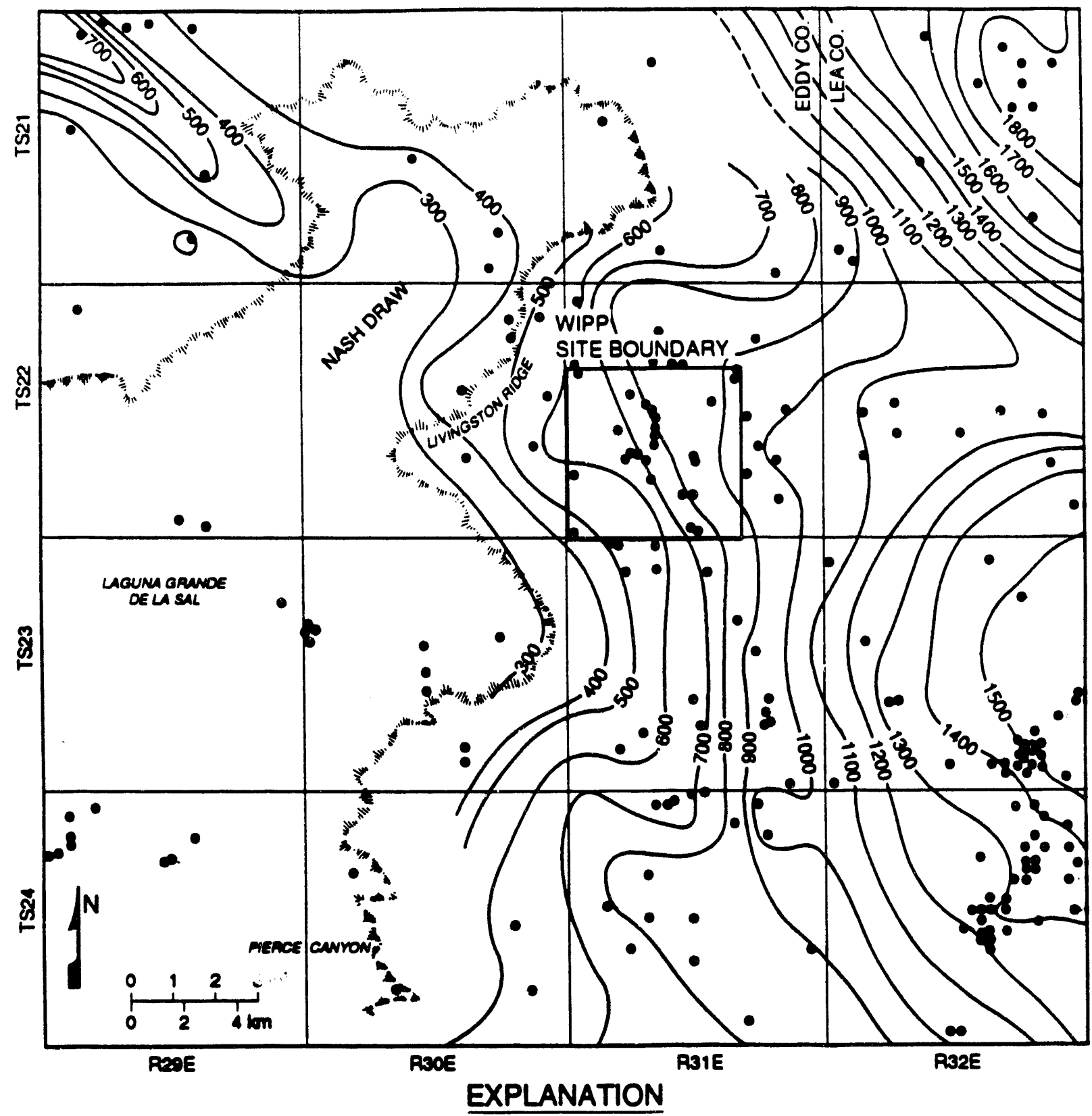

- DRILL hOLES

CONTOUR INTERVAL $=100$ FEET

TR1-6342-3432-1

Figure 2-10 Isopach of overburden for the Culebra Dolomite Member (Beauheim and Holt, 1990). 


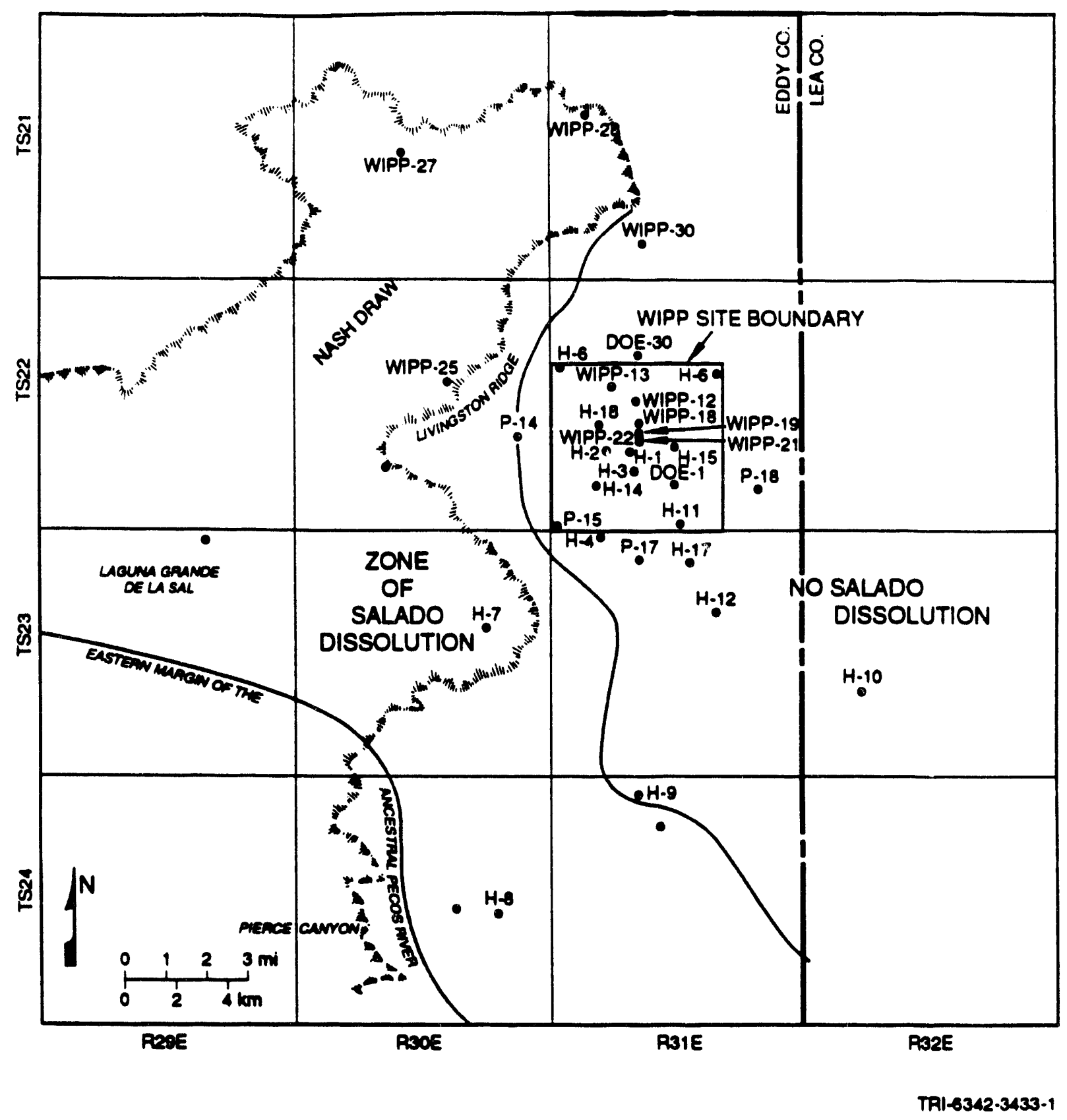

Figure 2-11 Interpreted extent of Salado dissolution (Beauheim and Holt, 1990). 


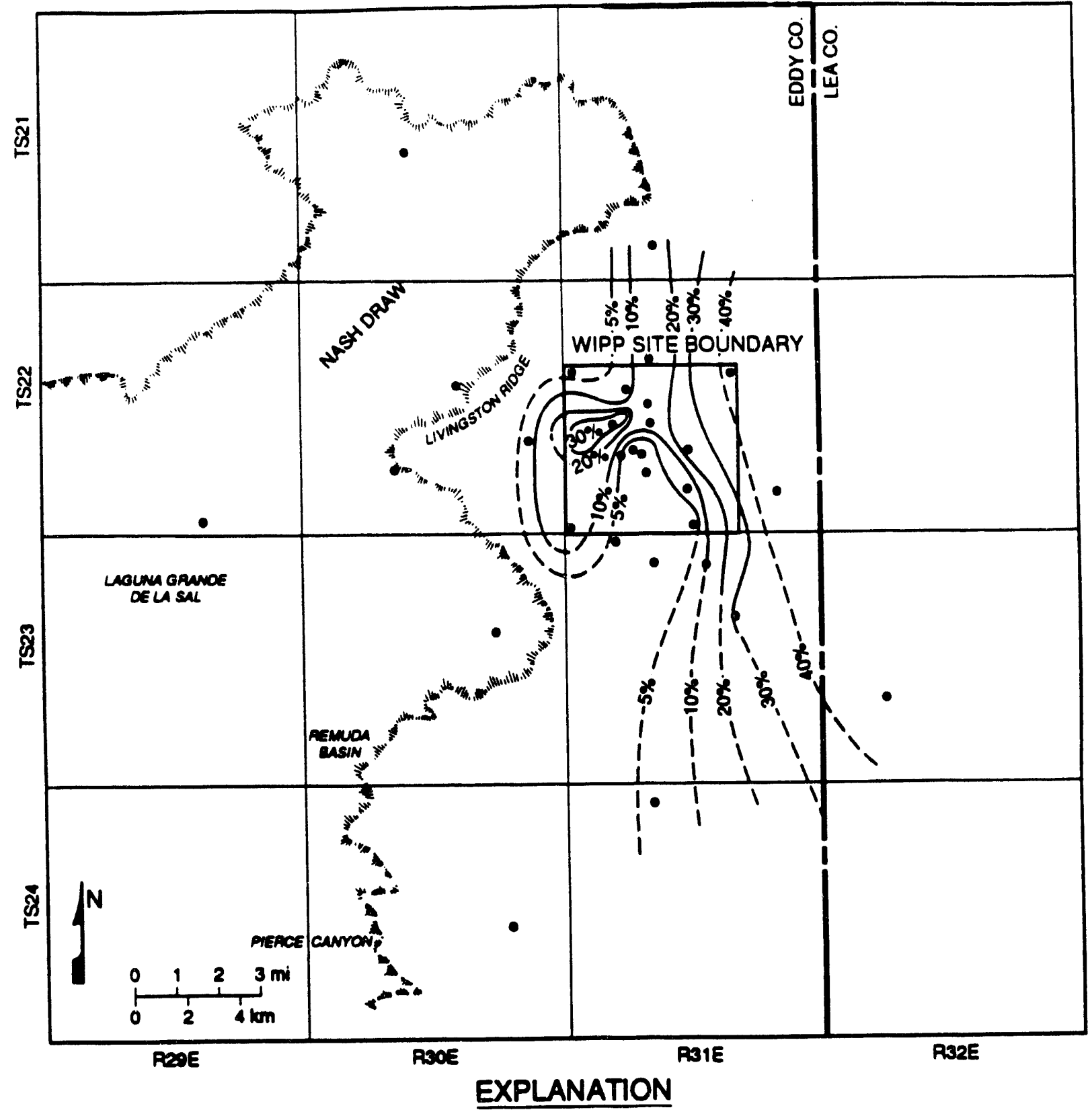

- WELLS EXAMINED CONTOUR INTERVAL = $10 \%$

5\% LINE SHOWN FOR CLARITY

TRI-6330-3434.1

Figure 2-12 Percentage of natural fractures in the Culebra Dolomite Member filled with gypsum (Beauheim and Holt, 1990). 
fracture fillings changes across the site, suggesting that the present conductivity distribution may reflect spatial variability in the processes that formed fracture fillings. East of the WIPP, fracture-filling crystals have predominantly incremental growth forms, indicating gradual growth as the fractures opened and no subsequent dissolution. Fractures with incremental fillings probably have had relatively small apertures and little groundwater flow through them throughout their history. From the WIPP west, fracture fillings, where present, are predominantly passive gypsum crystals that grew in pre-existing void spaces. By implication, any early, incremental fillings in these fractures must have been dissolved at some time in the past, and the fractures may have had relatively large groundwater flow through them before passive crystal growth. In places where early, incremental fillings have been removed by dissolution and passive crystal growths have not formed, or where they have been removed by further dissolution, conductivity is high. In places where either passive or incremental crystals fill most fractures, conductivity is low.

As observed in core samples from the Culebra, clay minerals commonly occur on the surfaces of subhorizontal fractures in dolomite (Sewards, 1991; Sewards et al., 1991a,b). Present distribution and composition of clay in the Culebra (and other members of the Rustler Formation) reflect both depositional and diagenetic processes (Sewards et al., 1992). Clays are most abundant in horizontal layers that represent original bedding planes in the evaporite sequences. These clay-rich layers are found within the Culebra throughout the WIPP vicinity. Because they are less competent than the dolomite above and below, clayrich layers are preferentially opened during fracturing, creating clay-lined subhorizontal fractures. Clay minerals identified by $x$-ray diffraction analysis include corrensite (ordered mixed-layer chlorite/saponite) and illite, with minor amounts of serpentine and chlorite. Corrensite is the most abundant of the clay minerals, usually constituting about 50 percent of the clay assemblage (Sewards et al., 1991a). Original detrital clays were illite and smectite; alteration of smectite into corrensite occurred during early diagenesis as magnesium-rich pore waters migrated through the formation (Sewards et al., 1992). Isotopic analyses (Rb/Sr) indicate that clay minerals reached their present composition during the late Permian epoch (Brookins et al., 1990). Because the cation exchange capacity of clay minerals in general and corrensite in particular is higher than that of dolomite or gypsum, clay fracture-linings may play an important role in the chemical retardation of radionuclides transport through the Culebra occur (Siegel et al., 1990; Sewards et al., 1992). 


\subsection{Tamarisk Member}

Where present in southeastern New Mexico, the Tamarisk Member ranges in thickness from 26 to $276 \mathrm{ft}$ ( 8 to $84 \mathrm{~m}$ ) in southeastern New Mexico and is about $118 \mathrm{ft}$ ( $36 \mathrm{~m}$ ) thick at the WIPP. The Tamarisk consists of mostly anhydrite or gypsum interbedded with thin layers of claystone and siltstone. Near Nash Draw, dissolution has removed evaporites from the Tamarisk Member, and the Magenta and Culebra are separated only by a few meters of residue (Brinster, 1991).

Attempts were made in two wells, $\mathrm{H}-14$ and $\mathrm{H}-16$, to test a 7.9-ft $(2.4-\mathrm{m})$ sequence of the Tamarisk Member that consists of claystone, mudstone, and siltstone overlain and underlain by anhydrite. Permeability was too low to measure in either well within the time allowed for testing; consequently, Beauheim (1987) estimated the transmissivity of the claystone sequence to be one or more orders of magnitude less than that of the tested interval in the Unnamed Lower Member.

\subsection{Magenta Member}

The Magenta Member of the Rustler Formation is a fine-grained dolomite that ranges in thickness from 13 to $26 \mathrm{ft}(4$ to $8 \mathrm{~m})$ and is about $19 \mathrm{ft}(6 \mathrm{~m})$ thick at the WIPP. The Magenta is saturated except near outcrops along Nash Draw, and hydraulic data are available from 14 wells. Hydraulic conductivity ranges over five orders of magnitude from $1.4 \times 10^{-4}$ to $1.4 \times 10^{1} \mathrm{ft} / \mathrm{d}\left(5.0 \times 10^{-10}\right.$ to $\left.5.0 \times 10^{-5} \mathrm{~m} / \mathrm{s}\right)$. In most locations, conductivity of the Magenta is one to two orders of magnitude less than that of the Culebra.

\subsection{Forty-niner Member}

The uppermost member of the Rustler Formation, the Forty-niner Member, is about $66 \mathrm{ft}$ $(20 \mathrm{~m})$ thick throughout the WIPP area and consists of low-permeability anhydrite and siltstone. Tests in H-14 and H-16 yielded hydraulic conductivities of about $1.4 \times 10^{-3} \mathrm{ft} / \mathrm{d}$ $\left(5.0 \times 10^{-9} \mathrm{~m} / \mathrm{s}\right)$ and $1.4 \times 10^{-4} \mathrm{ft} / \mathrm{d}\left(5.0 \times 10^{-10} \mathrm{~m} / \mathrm{s}\right)$ respectively (Beauheim, 1987).

\subsubsection{Supra-Rustler Rock}

Strata above the Rustler Formation are not believed to represent a significant pathway for the migration of radionuclides from the repository to the accessible environment because of 
relatively low transmissivities within the saturated zone. These units are important to PA. however, because vertical flux through them may play an important role in the inflow and outflow of water from the Rustler Formation (see Section 2.2.1).

Where present, the supra-Rustler units collectively range in thickness from 13 to $1758 \mathrm{ft}$ (4 to $536 \mathrm{~m}$ ). Regionally, the supra-Rustler units thicken to the east and form a uniform wedge of overburden across the region (Brinster, 1991). Fine-grained sandstones and siltstones of the Dewey Lake Red Beds (Pierce Canyon Red Beds of Vine, 1963) conformably overlie the Rustler Formation at the WIPP and are the uppermost Permian rocks in the region. The unit is absent in Nash Draw, is as much as $196 \mathrm{ft}(60 \mathrm{~m})$ thick where present west of the WIPP, and can be over $656 \mathrm{ft}(200 \mathrm{~m})$ thick east of the WIPP (Figures 2-4 and 2-7). East of the WIPP, the Dewey Lake Red Beds are unconformably overlain by Mesozoic rocks of the Triassic Dockum Group. These rocks are absent west of the repository and reach a thickness of over $328 \mathrm{ft}(100 \mathrm{~m})$ in western Lea County. East of the WIPP, Triassic and, in some locations, Cretaceous rocks are unconformably overlain by the Pliocene Ogallala Formation. At the WIPP, Permian strata are overlain by $25 \mathrm{ft}(8 \mathrm{~m})$ of the Triassic Dockum Group, discontinuous sands and gravels of the Pleistocene Gatuna Formation, the informally named Pleistocene Mescalero caliche, and Holocene soils (Holt and Powers, 1990).

Drilling in the Dewey Lake Red Beds has not identified a continuous zone of saturation. Some localized zones of relatively high permeability were identified by loss of drilling fluids at DOE-2 and H-3d (Mercer, 1983; Beauheim, 1987). Thin and apparently discontinuous saturated sandstones were identified in the upper Dewey Lake Red Beds at H-1, H-2, and H3 (Mercer and Orr, 1979; Mercer, 1983). Several wells operated by the J. C. Mills Ranch (James Ranch) south of the WIPP produce sufficient quantities of water from the Dewey Lake Red Beds to supply livestock (Brinster, 1991).

Hydrologic properties of supra-Rustler rocks are poorly understood because of the lack of long-term hydraulic tests and the difficulty of making those measurements. Hydraulic conductivity of the Dewey Lake Red Beds, assuming saturation, is estimated to be $3 \times 10^{-3}$ $\mathrm{ft} / \mathrm{d}\left(10^{-8} \mathrm{~m} / \mathrm{s}\right)$, corresponding to the hydraulic conductivity of fine-grained sandstone and siltstone (Mercer, 1983; Davies, 1989). Porosity is estimatet to be about 0.20 , which is representative of fine-grained sandstone (Brinster, 1991). 


\subsection{Surface and Groundwater Hydrology}

The Pecos River, the principal surface-water feature in southeastern New Mexico, flows southeastward, draining into the Rio Grande in western Texas. At its closest point, the river is $12 \mathrm{mi}(19 \mathrm{~km})$ southwest of the WIPP. Surface drainage from the WIPP does not reach the river or its ephemeral tributaries.

The only other water body in the vicinity of the WIPP site is Laguna Grande de la Sal, which is located about $6 \mathrm{mi}(9.6 \mathrm{~km})$ west-southwest of the WIPP. It is a large playa about $2 \mathrm{mi}(3.2 \mathrm{~km})$ wide and $3 \mathrm{mi}(4.8 \mathrm{~km})$ long. In the geologic past, a relatively permanent, saline lake occupied the playa. In recent history, the lake has undergone numerous cycles of filling and evaporation, in response to wet and dry seasons. Effluent introduced by the potash industry has enlarged the lake.

The balance of this section is a short summary of the physical and chemical subsurface hydrogeology of the WIPP site. Much of the material is this section is from Lappin et al. (1989), Brinster (1991), Siegel et al. (1991), SNL (1992), and Corbet and Wallace (1993). This material has been updated to reflect current thinking or uncertainty about previously presented conceptual models. The hydrogeology of the WIPP site is described here in terms of three flow regimes. Each regime is characterized by the hydrologic processes that are most important and by the role that regime possibly plays in the performance of the repository.

The uppermost regime, referred to as the shallow hydrogeologic regime, comprises all of the strata above the Salado Formation. Its importance lies in the fact that hydrostratigraphic units within the shallow regime, particularly the Culebra, are potential transport pathways in human intrusion scenarios. The shallow regime is characterized by fluid pressures that are approximately hydrostatic, i.e., approximately equal to the pressure at the base of a hypothetical column of water extending from the measuring point to the land surface. There are current conceptual models being considered that support one or more of the following mechanisms for flow: relief of the water table, differences in the elevation between recharge and discharge areas, or slow draining after past periods of higher precipitation.

The Salado/Castile hydrogeologic regime is made up of the Salado and Castile Formations. It is the primary geologic barrier for undisturbed conditions and is characterized by 
extremely slow groundwater flow and high fluid pressures that approach lithostatic. High pressures are maintained because of the plastic nature of evaporite rocks, which transmit the load to the fluid.

The Bell Canyon Formation and the Capitan Limestone make up the deepest hydrogeologic regime that is discussed. The Bell Canyon is the first relatively permeable unit below the repository.

\subsubsection{Physical Hydrogeology of the Shallor Flow Regime}

The shallow flow regime occurs in a sequence of layered evaporites and fine-grained clastic rocks of Permian and Triassic age that overlie the Salado Formation. The saturated portion of this regime is primarily in the Rustler Formation. There are five relatively permeable zones within the Rustler Formation. In ascending order, these zones are the siltstone portion of the Unnamed Lower Member and the Rustler/Salado contact; the Culebra; the Tamarisk; the Magenta; and the Forty-niner.

The main hydrostratigraphic features are as follows:

1) It is a layered system with large contrasts in hydraulic conductivity between the relatively permeable dolomite layers and aquitards containing anhydrite, gypsum, and halite.

2) The most permeable unit is the Culebra. The transmissivity of the Culebra ranges over four orders of magnitude at the WIPP site and in Nash Draw, from less than $10^{-7}$ to greater than $10^{-3} \mathrm{~m}^{2} / \mathrm{s}$. The difference is thought to be due to the spatial variation in fracturing and the degree to which mineral precipitation has filled fractures.

3) Culebra tests indicating transmissivities between $10^{-6}$ and $10^{-4} \mathrm{~m}^{2} / \mathrm{s}$ usually show evidence of flow both in fractures and in the rock matrix. Open fractures are not present in boreholes with lower transmissivity.

4) The transmissivity of the Magenta is generally at least an order of magnitude below that of the Culebra, i.e., generally less than $10^{-7} \mathrm{~m}^{2} / \mathrm{s}$ east of Nash Draw.

5) Dissolution of the upper Salado in the vicinity of Nash Draw has disrupted the layering and caused the Rustler to behave, in places, as a single hydrostratigraphic unit. The Dewey Lake Red Beds have been eroded away in this vicinity. 
6) Most of the Dewey Lake Red Beds Formation is unsaturated. The position of the water table is not known.

Hydraulic heads have been measured in about 60 wells that are currently or were once completed in the Culebra at and around the WIPP site. Heads in some wells have fluctuated in response to drainage into one or more WIPP shafts completed since late 1981, and pumping tests and water-quality sampling exercises conducted since 1980 . Therefore, it is difficult to define the undisturbed potentiometric surface of the Culebra. LaVenue et al. (1988) thoroughly reviewed Culebra water-level data, fluid-density data, and WIPP-related hydraulic stresses and estimated the undisturbed freshwater-heads at 31 wells. These estimates (Table 2-1) are contoured in Figure 2-13. Davies (1989) reported that flow directions in this southern area of low hydraulic gradients are difficult to define reliably because variations in fluid density within this part of the Culebra may be as important as pressure differences in determining flow directions. In general, modern flow within the Rustler Formation is toward the west and then parallel to the axis of Nash Draw. The notable exception is the Culebra in which flow near the site is to the south.

Various conceptual models have been used to describe groundwater flow in the shallow regime. The differences in these models reflect evolution of thinking, as more information has become available, as well as the different objectives of the models. For this discussion, the hydrogeological understanding of the shallow system is presented in terms of two conceptual models, the confined model and the groundwater basin model.

The confined model was developed during the site characterization phase of the WIPP project (Mercer, 1983) to help identify potential release pathways in the event that radionuclides reach the Rustler Formation. This model is the basis of flow and transport calculations performed for the 1992 PA report. The groundwater basin model was originally applied to the WIPP site to test the hypothesis that flow in the Rustler Formation is slowly draining in response to a drying of the climate at the end of the Pleistocene (Davies, 1989). It provides a more complete description of groundwater flow in the shallow regime and is the basis of transient, three-dimensional simulations of regional groundwater flow (Corbet and Wallace, 1993). The objectives of these simulations are to predict future flow fields according to PA climate change and mine subsidence scenarios, to examine possible roles of vertical flux, and to provide a better link between hydrology and geochemistry. In addition, these simulations will be sued to test the assumptions that considering the Culebra as the only release pathway in strata above the Salado Formation is conservative for the purpose of PA calculations. 
Table 2-1 Hydraulic-Head Data for the Culebra

\begin{tabular}{|c|c|c|c|c|c|c|}
\hline Well & $\begin{array}{l}\text { Ground- } \\
\text { Surface } \\
\text { Altitude } \\
\text { (m) }\end{array}$ & $\begin{array}{c}\text { Freshwater- } \\
\text { Head } \\
\text { Altitude } \\
(\mathrm{m})^{\circ}\end{array}$ & $\begin{array}{l}\text { Depth to } \\
\text { Middle of } \\
\text { Culebra } \\
(m) \\
\end{array}$ & $\begin{array}{c}\text { Fluid } \\
\text { Specific } \\
\text { Gnvity }\end{array}$ & $\begin{array}{l}\text { Depth to } \\
\text { Middle of } \\
\text { Magenta } \\
\text { (m) }\end{array}$ & $\begin{array}{l}\text { Freshwater- } \\
\text { Head } \\
\text { Altitude } \\
\text { at Midpoint } \\
\text { of Magenta } \\
\text { (m) }\end{array}$ \\
\hline $\begin{array}{l}\text { Cabin Baby-1 } \\
\text { DOE-1 }\end{array}$ & 1056 & 915 & 254 & & & \\
\hline DOE-2 & 1042 & 935 & 255 & 1.041 & 217 & 934 \\
\hline \multirow{2}{*}{$\begin{array}{l}H-1 \\
H \cdot 2 b 1\end{array}$} & 1036 & 922 & 210 & 1.022 & 176 & 921 \\
\hline & 1030 & 924 & 193 & 1.009 & 161 & 923 \\
\hline $\mathrm{H}-3 \mathrm{bl}$ & 1033 & 917 & 208 & 1.036 & 174 & 916 \\
\hline $\mathrm{H}-4 \mathrm{~b}$ & 1016 & 913 & 155 & 1.016 & 118 & 913 \\
\hline H.5b & 1068 & 934 & 277 & 1.102 & 243 & 930 \\
\hline $\begin{array}{l}H-6 b \\
H-7 b\end{array}$ & 1020 & 932 & 188 & 1.039 & 153 & 931 \\
\hline \multirow{2}{*}{$H-8 b$} & 964 & 913 & 79 & & & \\
\hline & 1047 & 912 & 183 & 1.000 & 145 & 912 \\
\hline $\mathrm{H}-9 \mathrm{~b}$ & 1038 & 907 & 202 & 1.001 & 164 & 907 \\
\hline $\mathrm{H}-10 \mathrm{~b}$ & 1124 & 921 & 419 & 1.047 & 386 & 919 \\
\hline$H-1162$ & 1040 & 913 & 226 & & & \\
\hline H-12 & 1044 & 914 & 255 & & & \\
\hline H-14 & 1020 & 915 & 170 & 1.008 & 133 & 915 \\
\hline H-15 & 1061 & 918 & 266 & & & \\
\hline $\mathrm{H}-16$ & 1039 & $916^{\circ}$ & 217 & $1.04^{\circ}$ & 184 & $915^{\circ}$ \\
\hline $\mathrm{H}-17$ & 1031 & 913 & 219 & & & \\
\hline$P-14$ & 1024 & 927 & 178 & & & \\
\hline P.15 & 1009 & 916 & 129 & & & \\
\hline P-17 & 1017 & 913 & 174 & & & \\
\hline USGS-1 & 1044 & 909 & 162 & & & \\
\hline WIPP-12 & 1058 & 932 & 251 & & & \\
\hline WIPP-13 & 1038 & 934 & 217 & & & \\
\hline WIPP-18 & 1053 & 930 & 243 & & & \\
\hline \multirow{2}{*}{$\begin{array}{l}\text { WIPP-25 } \\
\text { WIPP-26 }\end{array}$} & 979 & 931 & 140 & 1.008 & 96 & 931 \\
\hline & 961 & 918 & 60 & & & \\
\hline WIPP-27 & 968 & 938 & 93 & 1.092 & 56 & 934 \\
\hline WIPP-28 & 1020 & 938 & 132 & 1.032 & 91 & 937 \\
\hline WIPP-29 & 907 & 905 & 8 & & & \\
\hline WIPP-30 & 1045 & 935 & 196 & 1.020 & 160 & 934 \\
\hline Data I & on LaVenue & al. (1988) exce & as noled & & & \\
\hline Lower & $d$ by drainage & into WIPP shaft & converted fro & pressure dat & Stensrud et al. & 1988) \\
\hline Avere & values fin & IPP-19 and & I-2a (Randall & al., 1988) & & \\
\hline
\end{tabular}




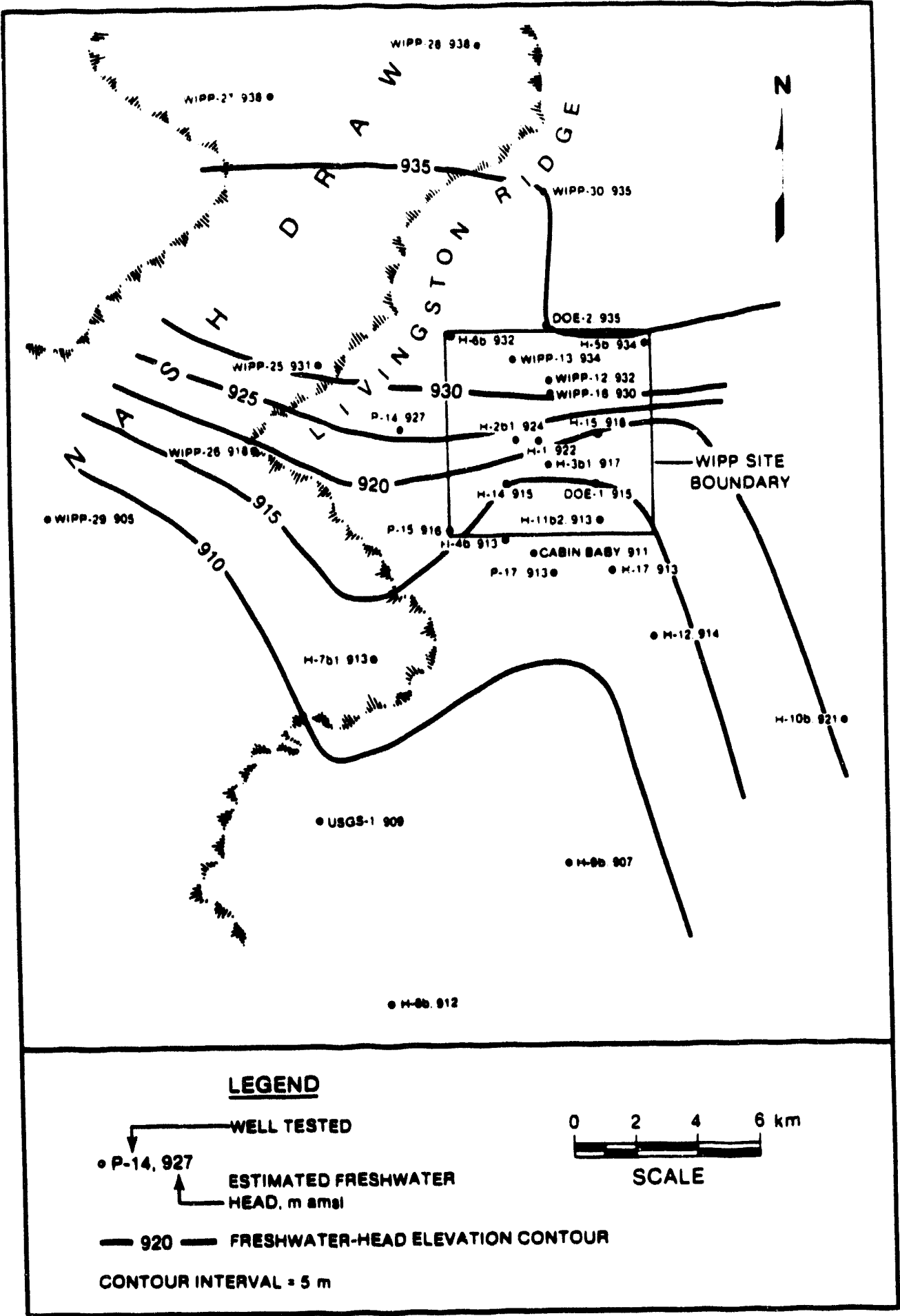

TRI-0330-85-1

Figure 2-13 Estimated freshwater heads in the Culebra Member (data from Cauffman et al., 1990). 
The confined conceptual model focuses on lateral flow in the relatively more permeable units. It is based primarily on hydrologic and geochemical data collected as part of the site characterization process. For example, the present day north to south flow in the Culebra can be established by pressure and water elevation data without knowing the locations of discharge and recharge areas. This model recognizes that there appears to be a potential for vertical flow across confining layers but assumes this flow to be insignificant except in regions where the confining units have been disturbed and are more permeable. The domain of this conceptual model is thought to be a subdomain of the hydrologic system that controls its behavior, and therefore, calculations based on this model require boundary conditions that represent hydrologic processes outside of the model domain. This model is, therefore, not well suited for understanding the large-scale natural system or for predicting long-term changes to flow patterns.

The groundwater basin conceptual model has a strong theoretical basis (Hubbert, 1940; Tóth, 1963) and is widely accepted and applied by hydrogeologists. A groundwater basin is a three-dimensional, closed hydrologic unit bounded on the bottom by an "impermeable" rock unit (actually a stratigraphic layer with much smaller permeability than the layers above), on the top by the ground surface, and on the sides by groundwater divides. The upper boundary of the flow domain is the water table, which may or may not coincide with the land surface. All rocks in the basin have finite permeability, i.e., hydraulic continuity exists throughout the basin. Implicit in this description of the groundwater basin is that the entire length of each flow path is contained within the basin. All recharge to the basin (if it occurs) is by infiltration of precipitation to the water table, and all discharge from the basin (if it occurs) is by flow across the water table to the land surface.

Within the groundwater basin model, differences in elevation of the water table across the basin generate the hydraulic gradients to drive groundwater flow. Water flows along gradients of hydraulic head from regions of high head to regions of low head. The highest and lowest heads in the basin occur at the water table at its highest and lowest points, respectively. Therefore, groundwater generally flows from the elevated regions of the water table, downward across aquitards (layers with relatively low permeability), laterally along layers with relatively high permeability, and finally upward to exit the basin in regions where the water table (and by association, the land surface) is at low elevations. Infiltration is necessary to maintain relief on the water table. If infiltration were to stop for a sufficient period of time, flow from regions of high to low head would "level" the water table, and groundwater would become stagnant. However, a lack of infiltration rarely, if ever, actually 
results in stagnant conditions because long periods of time are required for groundwater to "drain" from the regions of high head. The time required for a system to drain is controlled by the thickness, permeability, and compressibility of aquitards in the basin, as well as the initial relief of the water table. The adjustment time could be tens of thousands of years or longer.

The pattern of groundwater flow within the groundwater basin model depends on the lateral extent and depth of the basin, the shape of the water table, and the heterogeneity of the permeability of the rocks in the basin. Field observations and numerical studies have demonstrated that flow in strata with relatively high permeability is mainly horizontal, and flow in strata with low permeability is vertical. Even extremely slow vertical flow is significant, on a regional scale, because it is summed over the very large areas of the upper and lower surfaces of rock layers.

An important need of the compliance demonstration is a conceptual model of transport in the Culebra. Open fractures in Culebra core, dual-porosity behavior during hydraulic testing of the Culebra, and rapid tracer transport along at least one flow path during tracer tests in the Culebra have been identified at the $\mathrm{H}-3, \mathrm{H}-6$, and $\mathrm{H}-11$ hydropads. For these reasons, the convergent-flow tracer tests conducted at these locations were interpreted using a doubleporosity approach which conceptualizes the Culebra as a system of fractures separated by porous matrix blocks. Low flow but high storage in the matrix and rapid flow but low fluid storage in the fractures characterize fluid flow in an idealized dual-porosity system (Figure 2-14). The processes characterizing solute transport in an idealized dual-porosity system include diffusive transport of solutes from the fractures to the matrix, high solute storage in the matrix, rapid solute transport in the fractures, and low solute storage in the fractures (Figure 2-15). Based on the interpretations of the tracer tests, diffusive loss of solute from the fractures to the high matrix porosity found in the Culebra is expected to be an important physical retardation process during potential radionuclide transport through the Culebra.

\subsubsection{Chemical Hydrogeology of the Shallow Flow Regime}

Knowledge of the chemical hydrogeology of the shallow flow regime is necessary to support the development of conceptual models. Groundwater samples have been collected from the Culebra at over 30 locations (hydropads or wells), from the Magenta at 12 locations, and 
Parallel - Not Intersecting Fractures

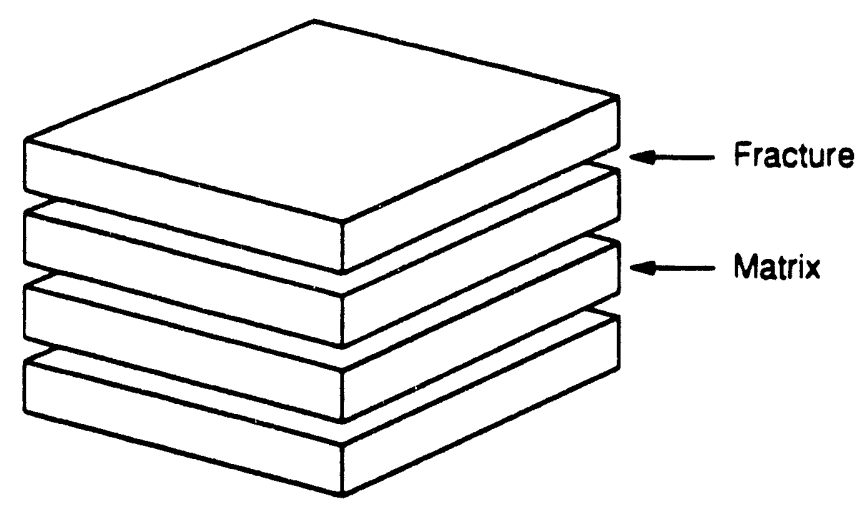

(a)

Three Orthogonal, Intersectirig Fracture Sets

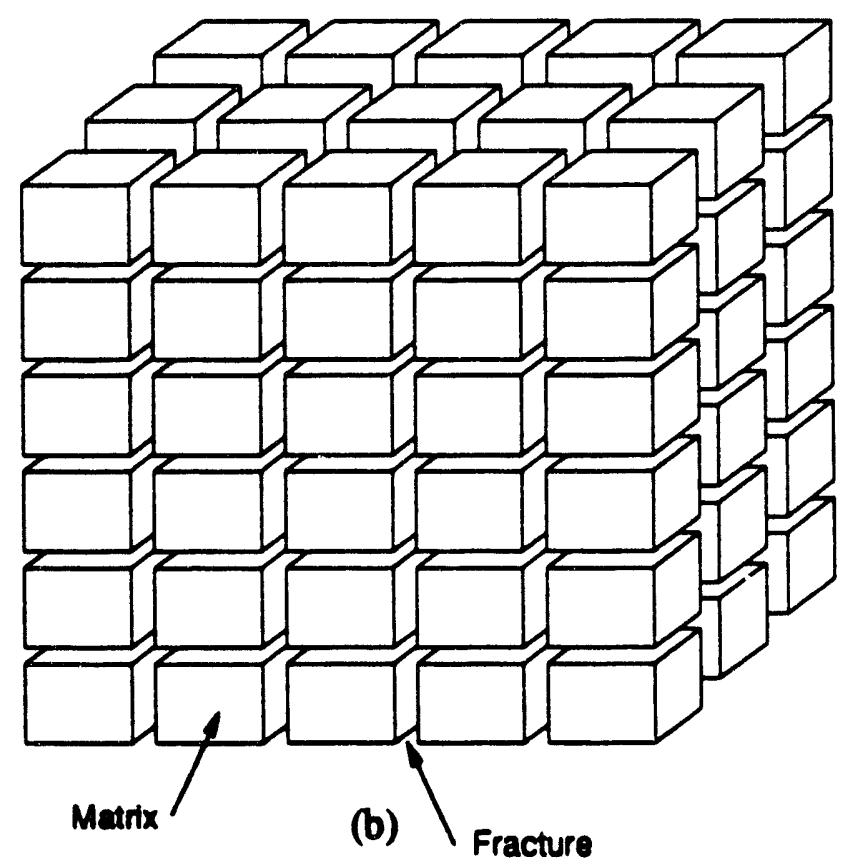

Figure 2-14 Idealized dual-porosity conceptualization represented as (a) a system of parallel fractures or as (b) a system of three orthogonal, intersecting fracture sets with equal spacing in all directions. 


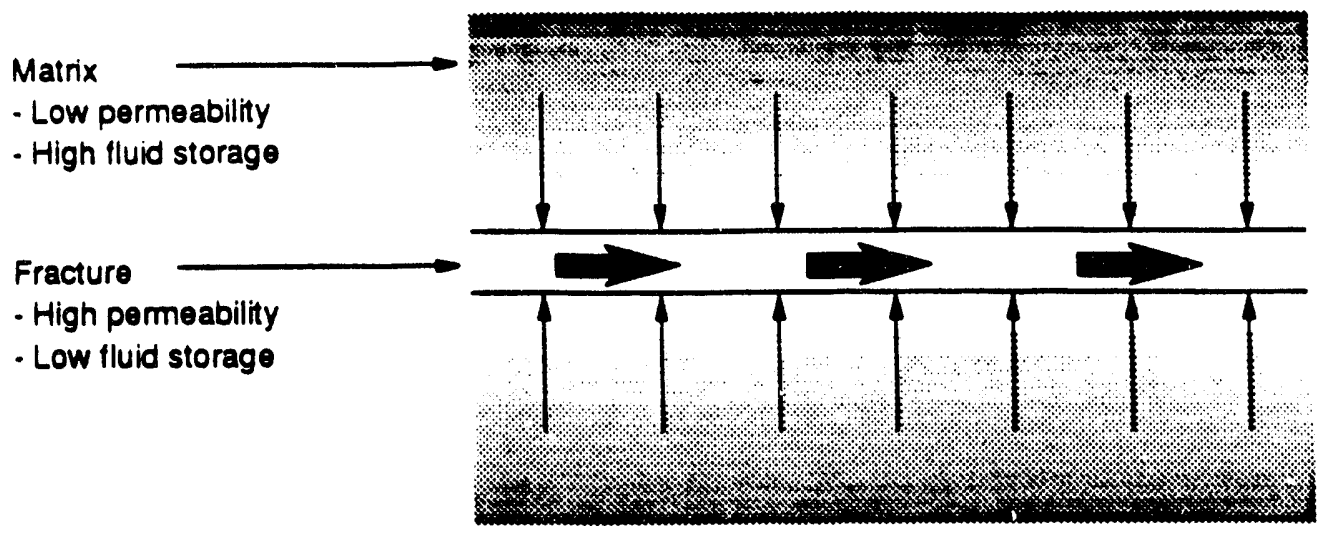

(a)

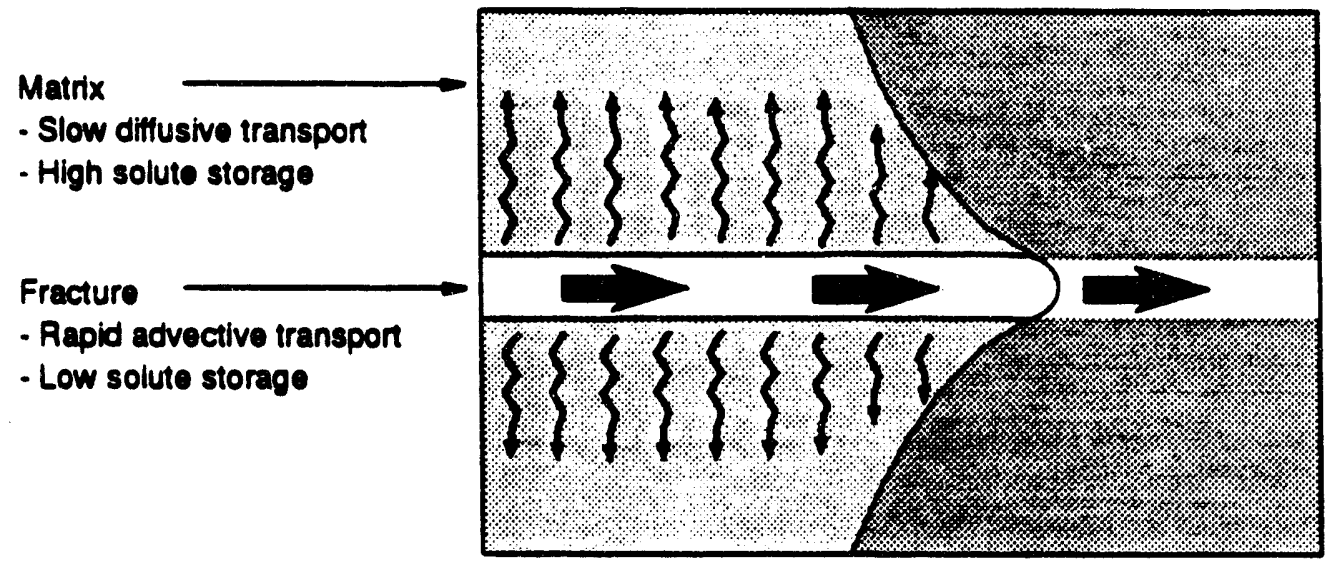

(b)

Figure 2-15 Schematic illustration of (a) fluid flow and (b) solute transport in an idealized dual-porosity (fracture/matrix) system. 
from the Rustler/Salado contact zone at 20 locations. These samples have been analyzed for a variety of constituents including dissolved solids and a suite of naturally occurring stable and radioactive isotopes. Additional analyses have been performed on samples collected from the rock matrix of Rustler units and from minerals in fractures. This section describes the results and hydrologic inferences from selected geochemical studies.

\subsubsection{Hydrochemical Facies}

Concentrations of dissolved solids in groundwaters from three water-producing horizons of the Rustler Formation vary widely in the study area. Specifically, total dissolved solids ranges from less than 3,000 to greater than $300,000 \mathrm{mg} / \mathrm{L}$. Major solute ranges are $\mathrm{Cl}^{-}, 30$ to $300,000 \mathrm{mg} / \mathrm{L} ; \mathrm{SO}_{4}{ }^{2-}, 400$ to $20,000 \mathrm{mg} / \mathrm{L} ; \mathrm{Na}, 50$ to greater than $100,000 \mathrm{mg} / \mathrm{L} ; \mathrm{K}, 4$ to greater than $20,000 \mathrm{mg} / \mathrm{L} ; \mathrm{Ca}, 500$ to $18,000 \mathrm{mg} / \mathrm{L}$; and $\mathrm{Mg}, 10$ to greater than 80,000 $\mathrm{mg} / \mathrm{L}$.

Siegel et al. (1991) recognized four zones containing distinct hydrochemical facies (Figure 2-16) in the Culebra. These zones appear to be related to the distribution of halite in overlying and underlying strata. Zone A contains a saline (about two to three molal) sodium chloride brine with a magnesium/calcium molar ratio greater than 1.2. Zone A waters occur eastward from the repository, in a region that corresponds roughly with the area of lowest transmissivity in the Culebra. Halite is present in the Unnamed Lower Member of the Rustler Formation throughout Zone A, and in the eastern portion of the region, halite occurs in the upper members as well (Figure 2-16). Zone B is an area of dilute, calcium sulfaterich water (ionic strength less than 0.1 molal) south of the repository. This region generally has high transmissivity in the Culebra, and halite is absent from all members of the Rustler Formation. Zone C, extending from the repository west to Nash Draw, contains waters of variable composition with low to moderate ionic strength ( 0.3 to 1.6 molal), with magnesium/calcium molar ratios less than 1.2. Transmissivity is variable in this region, and halite is present in the Rustler Formation only to the east, in the Unnamed Lower Member. Salinities are highest near the eastern edge of the zone. Zone D waters, found only in two wells in Nash Draw, are anomalously saline (three to six molal) and have high potassium/sodium ratios that reflect contamination by effluent from potash mines. 


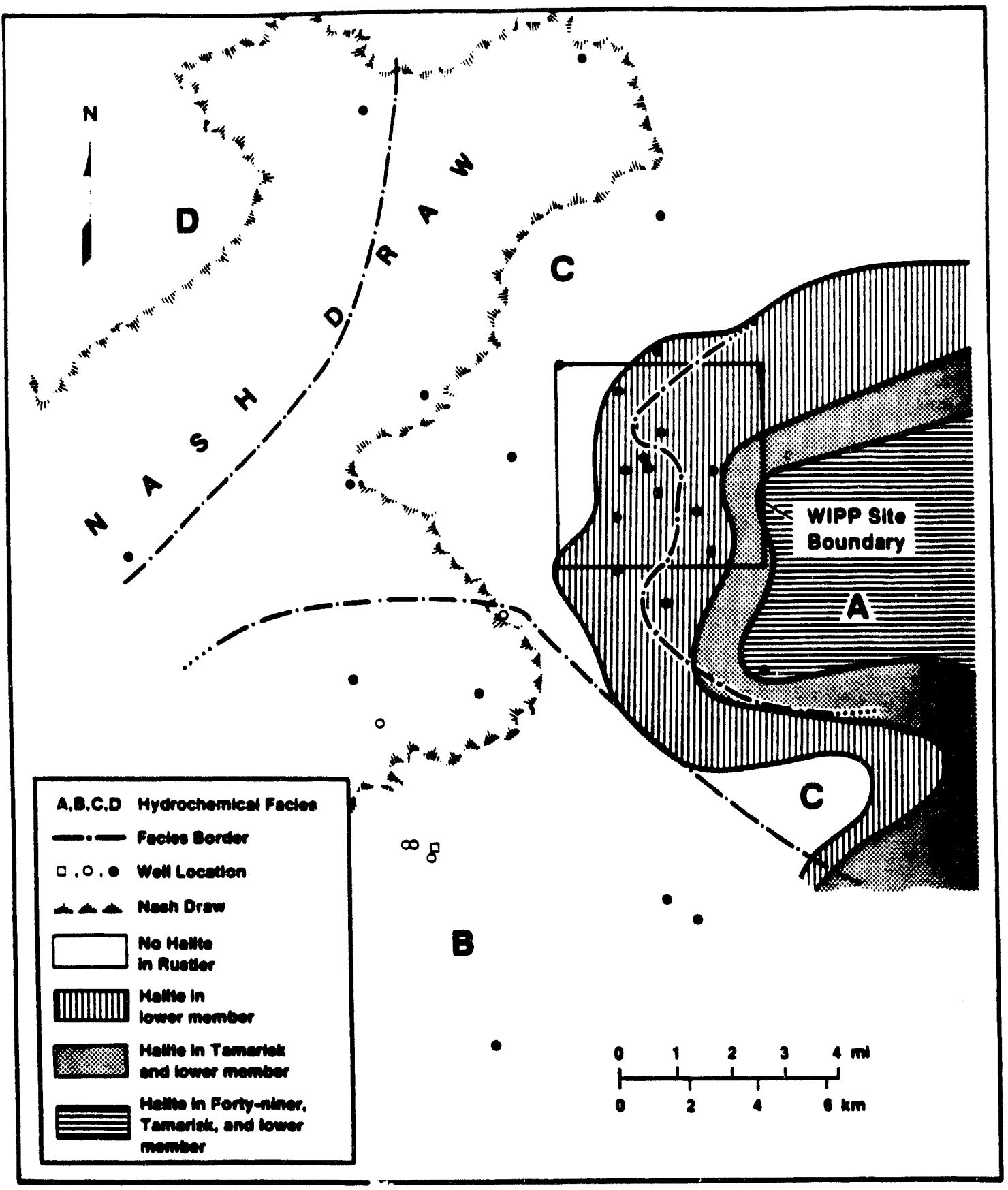

TRI-6344-551-0

Figure 2-16 Relationship between occurrence of halite in the Rustler Formation and hydrochemical facies of the Culebra. 
Dilute $\mathrm{CaSO}_{4}$ waters south of the site (Facies B) lie directly downstream along the modern flow directions in the Culebra from more saline and variable brines (Facies $\mathrm{C}$ ). This condition is interpreted to be inconsistent with steady-state confined flow in the Culebra (Ramey, 1985; Chapman, 1988).

\subsubsection{Hydrogen and Oxygen Isotopes in Groundwaters}

Confined Rustler groundwaters near the WIPP and in Nash Draw have isotopic compositions very tightly clustered along the worldwide meteoric field in $\delta D-\delta^{18} O$ space (Figure 2-17). Groundwaters whose stable-isotope compositions deviate markedly from that of a characteristically meteoric signature occur at the Rustler/Salado contact in the lowpermeability portions of that zone in the central and eastern parts of the WIPP site (Lambert, 1989) and near the surface in the Culebra and Tamarisk Members in the southwest portion of Nash Draw, where these units are near the land surface. Deviations in waters at the Rustler/Salado contact are attributable to rock/water interaction involving a large rock/water ratio. The isotopic signatures observed in southwestern Nash Draw can arise from partial evaporation from the vadose zone and the capillary fringe above the water table. Confined meteoric Rustler waters are virtually identical in stable-isotope composition to confined meteoric Capitan waters at the basin margin, indicating recharge of both types of confined waters under similar climatic conditions.

By comparison, vadose Capitan waters from the Carlsbad Caverns system, groundwater from a water table in alluvium, and near-surface accumulations that homogenize seasonal variations in isotopic composition also have meteoric isotopic signatures, but have isotopic compositions more positive in $\delta \mathrm{D}-\delta^{18} \mathrm{O}$ space than confined Rustler and Capitan waters (Lambert and Harvey, 1987). The envelope of $\delta$-values for confined Rustler water does not overlap with that of waters from the Carlsbad Caverns system (Figure 2-17). The data of Nativ and Smith (1987) reveal that in Ogallala groundwaters underlying the High Plains to the east, climatically similar to the Delaware Basin, the only groundwaters containing tritium levels indicative of recent (post-1950) meteoric derivation (greater than $10 \mathrm{TU}$ ), all have $\delta \mathrm{D}$ values greater than $-42 \%$, comparable to near-surface unconfined meteoric waters in the Delaware Basin. Thus, the isotopic signatures of confined Rustler and Capitan waters are distinct from those of both Ogallala water with discernable modem input and vadose Capitan and alluvial water. It is likely that the isotopic compositions of confined Rustler and Capitan groundwaters in the northern Delaware Basin are not characteristic of groundwaters receiving 


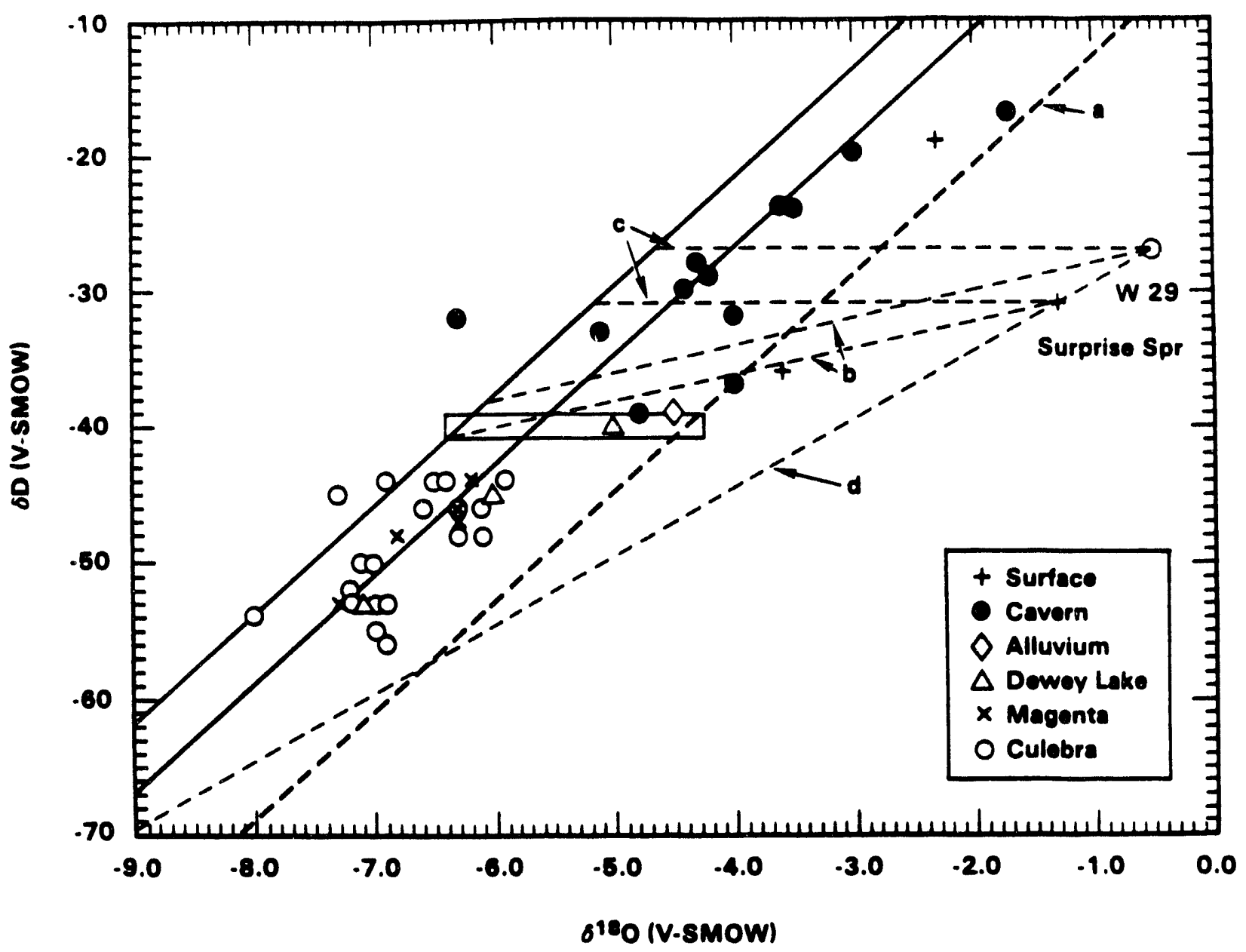

TRI-6330-30-0

Figure 2-17 Stable-isotope compositions of ground waters from the Rustler Formation and other rocks in southeastern New Mexico (Lambert, 1989). Small deviations of groundwaters from the meteoric field (up to -10\%), within which nearly all the data lie (line a), are not considered significant (cf. Allison et al., 1985). WIPP-29 Culebra and Surprise Spring may have evolved by evaporation from a shallow water table, with a $\delta \mathrm{D} / \delta^{10} 0$ trajectory having a slope of 2 (lines b; Allison, 1982), form modern southeastern New Mexico water from the Ogallala aquifer (rectangle; $\delta \mathrm{D}$ range determined by Yapp, unpublished) likely to have been imported for use in nearby potash-refining operations.

Alternatively, they may also have evolved from modern-type water by oxygenisotope shift (horizontal dashed lines c). They probably did not criginate from partial evaporation of confined Rustler-type water with a trajectory slope of 5 (line $\mathrm{d}$; Craig et al., 1983), a slope representing partial evaporation from a water surface exposed to the atmosphere. 
modern meteoric recharge under the present climatic conditions (Lambert and Harvey, 1987). This interpretation suggests that the climate at the time that groundwater residing in the Culebra today entered the groundwater system as recharge was different from the present-day climate. That is, the time required for groundwater to flow from the near-surface recharge area to the sub-surface at the WIPP site was long enough for the climate to change enough to modify the isotopic composition of precipitation. Chapman (1986) gives an alternative interpretation of the isotope data. She concludes that the isotopic composition of most samples of groundwater from the Rustier Formation is similar to the isotopic composition of other, verifiably young, groundwater in southeastern New Mexico. This interpretation suggests that the travel time from the recharge area to the subsurface near WIPP might be much shorter.

\subsubsection{Radiocarbon $\left({ }^{14} \mathrm{C}\right)$ Ages of Groundwater}

Four radiocarton ages calculated on samples from the WIPP area indicate that these waters (three from the Culebra and one from the Dewey Lake Red Beds) were isolated from the atmosphere at least 12,000 to 16,000 years ago. Other analyzed waters reflect complex contamination from drilling fluids, lost-circulation materials, and the metabolic products of their degradation. The calculated radiocarbon ages represent minimal values, because some undetected contamination may still be present in all samples. The locations of the successful radiocarbon measurements effectively bracket the WIPP site, but do not imply any single flow direction, i.e., calculated ages do not increase in any one direction. The calculated ages suggest that a period of time exceeding 10,000 years is required for meteoric recharge to reach the Culebra in the WIPP area. The long length of this time period is consistent with both conceptual models of flow presented above.

\subsubsection{4 "Sr/" Sr Ratios of Dewey Lake and Rustler Rock Matrix and Fracture Fillings}

The strontium isotopic composition of the rock matrix and minerals deposited in fractures were determined by analyzing anhydrite, gypsum, and other minerals containing calcium (Brookins and Lambert, 1988). Figure 2-18 shows a systematic increase in ${ }^{87} \mathrm{Sr} /{ }^{86} \mathrm{Sr}$ of the rock matrix upwards in the section from the Castile Formation through the Rustler Formation. This systematic increase reflects the increase in this ratio in seawater at the time these rocks were deposited. The ${ }^{87} \mathrm{Sr} /{ }^{86} \mathrm{Sr}$ ratios of the fracture filling are indistinguishable from those of their host rocks. 


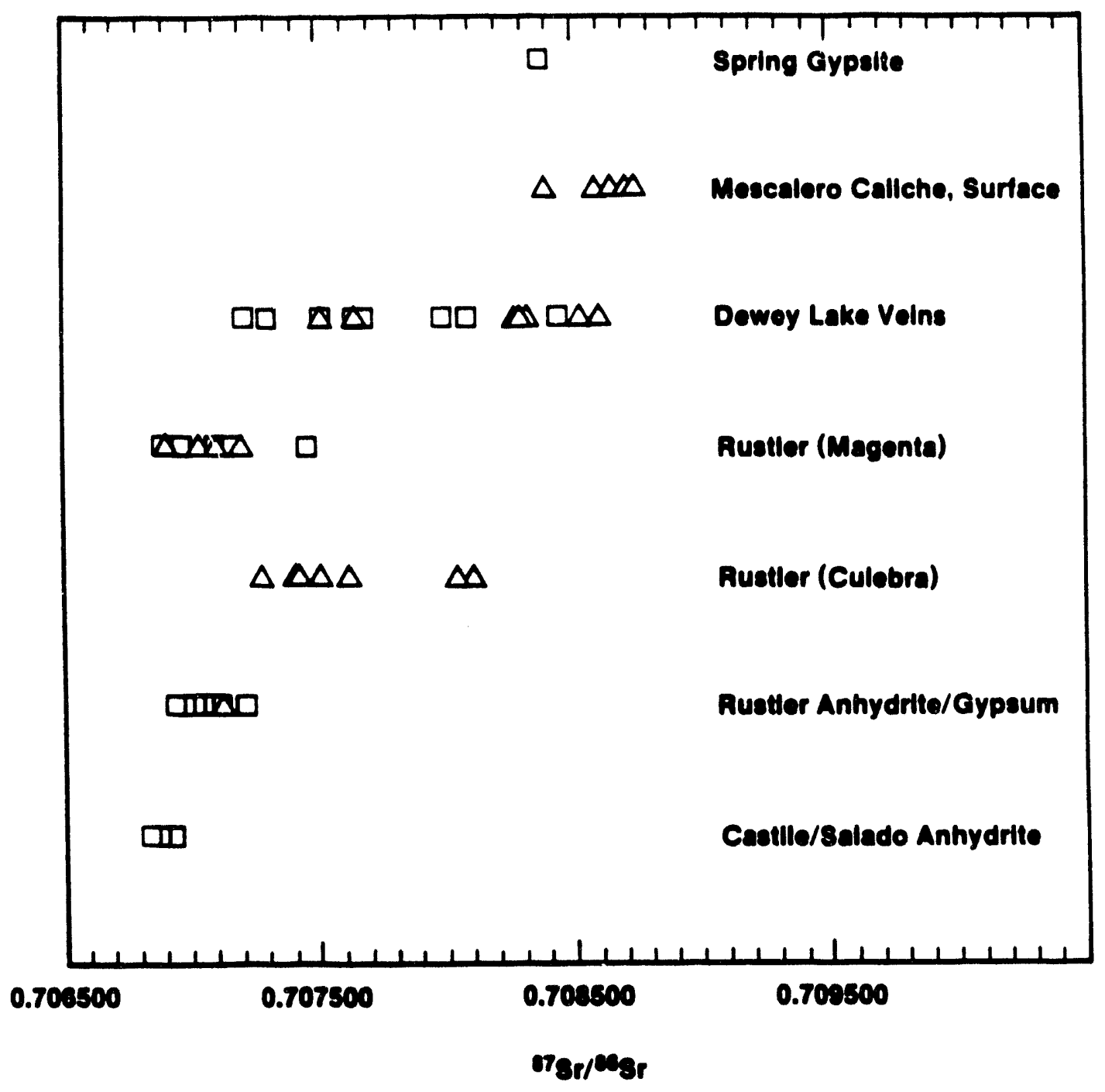

TA1-6330-37-0

Figure 2-18 ${ }^{87} \mathrm{Sr} /{ }^{16} \mathrm{Sr}$ ratios in Ochoan and related rocks (Lambert, 1989). Higher ${ }^{87} \mathrm{Sr} /{ }^{86} \mathrm{Sr}$ ratios progressively higher in the stratigraphic section reflected a greater contribution of surface-derived cations. Sulfates are indicated by squares; cartonates are indicated by triangles. 
The data show a large range of ${ }^{87} \mathrm{Sr} /{ }^{86} \mathrm{Sr}$ that reflects the role of detrital $\mathrm{Sr}$ deposited with the Dewey Lake Red Beds sediments as well as a later exchange of $\mathrm{Sr}$ with moving groundwaters. The Culebra, and to a lesser extent the Magenta, show a larger range in ${ }^{87} \mathrm{Sr} /{ }^{86} \mathrm{Sr}$ than other units in the Rustler. Higher ${ }^{87} \mathrm{Sr} /{ }^{86} \mathrm{Sr}$ values in Rustler rocks suggest more interaction between rock and surface-derived water (i.e., a higher water/rock ratio). The stratified distribution of Sr ratios has been interpreted to indicate that flow in the Rustler has occurred mainly in the Culebra and Magenta and that vertical flow is very slow or nonexistent (Lambert, 1991; Brookins and Lambert, 1988). This conclusion is compatible with both of the conceptual models presented for flow in the Rustler Formation.

\subsubsection{Hydrogen-isotope Ratios in Secondary Gypoum}

The hydrogen-isotope ratios of waters of hydration of secondary gypsums in the Rustler Formation also indicate that the rock to water ratio during the formation of these gypsums varies vertically. As expected, the larger water/rock ratios are inferred for the more permeable (Culebra and Magenta) units.

\subsubsection{Uranium-isotope Disequilibrium Data}

According to a model described by Osmond and Cowart (1976), the ratio of the activity of ${ }^{234} \mathrm{U}$ to that of ${ }^{231} \mathrm{U}$ is expected to increase along the flow path in a confined aquifer under reducing conditions (Lambert and Carter, 1987). The ${ }^{234} U /{ }^{238} U$ activity ratio has been measured for water samples collected from nine wells completed in the Culebra. Although there are few data points to the east and south of the WIPP site, the data show an eastward increase in ${ }^{234} \mathrm{U} /{ }^{231} \mathrm{U}$. This relationship has been interpreted to indicate that groundwater flow at the time of Rustler recharge (greater than 12,000 to 16,000 years ago on the basis of radiocarbon studies) had an easterly component, in contrast to the modern southerly flow within the Culebra (Lambert and Carter, 1987). Modeling studies (LaVenue et al., 1990) suggest that the velocity of modern flow decreases by as much as six orders of magnitude in the same direction. An altemative explanation of the uranium isotope data is that the distribution of ${ }^{234} \mathrm{U} /{ }^{238} \mathrm{U}$ reflects much longer residence times in the slower part of the flow field.

The geochemical data discussed above have been used as the basis for the conceptual model of flow in strata above the Salado Formation that emphasizes confined flow and a lack of modern recharge. According to this model, flow in the Rustler Formation is dominated by 
horizontal flow in the relatively permeable units, and vertical flow across aquitards is negligible. The Rustler Formation has not received recharge for the past 10,000 years. The direction of present-day flow in the Culebra is apparently inconsistent with the distribution of dissolved solids. In addition, the uranium-isotope disequilibrium data are interpreted to show that groundwater flow at the time of recharge had an easterly component. Lambert (1989) suggested that the apparent inconsistency between the steady-state hydrologic model and solute-distribution pattern can be explained by a change in flow direction in the past 30,000 , or perhaps 12,000 , years. Prior to the change in flow direction, the climate was wetter and recharge to the Culebra is thought to have occurred in Nash where the Culebra crops out or is near the surface.

The conceptual model for geochemistry is considered to be tentative because, as discussed above, there are alternative hydrologic inferences that can be drawn from the geochemical data that support different conceptual models of flow. In addition, aspects of the current conceptual model are not clearly developed and tested, and some seem to be hydrologically improbable. As geochemical interpretations are better integrated with current thinking about the hydrology of the shallow regime, it is likely that some issues will have to be reevaluated.

\subsubsection{Physical Hydrogeology of the Salado/Cartile Flow Regime}

As described in Section 2.1, the Salado and Castile Formations consist mainly of halite and anhydrite. A considerable amount of information about the hydraulic properties of these rocks has been collected as part of a ongoing program of field and laboratory experiments. Permeabilities of anhydrite and impure halite (argillaceous and polyhalitic halite) beds in the Salado Formation have been calculated from the experimental data. The permeabilities of the halite and anhydrite range from less than $10^{-23}$ to $10^{-18} \mathrm{~m}^{2}$ and from $10^{-19}$ to $10^{-17} \mathrm{~m}^{2}$ respectively. The data for the anhydrite and impure halite can be simulated using models based on Darcy's Law, suggesting that the flow rate in these lithologies is directly proportional to the gradient of hydraulic head (Beauheim et al., 1991; Beauheim et al., 1993; McTigue, 1993). To date, there have been no pressure or flow responses durning tests conducted in pure halites in the vicinity of the WIPP excavations. Therefore, it is possible that the permeability of pure halite is essentially zero (Beauheim et al., 1991).

A hydrologic characteristic of the Castile and Salado Formations that plays an important role in the repository behavior is fluid pressures that are much higher than hydrostatic. It is 
difficult to accurately measure natural pressures in these formations because the drill holes or repository excavations required to access the rocks decrease the stress in the region measured. Stress release instantaneously decreases fluid pressure in the pores of the rock, so measured pressures must be considered as a lower bound of the natural pressures. Because anhydrite is a stiffer rock than halite, pressures decrease less in anhydrites than halites as stress is reduced. This is probably why the maximum pressures measured in halite are less than those measured in anhydrite (Beauheim et al., 1993). The fluid pressures measured in halite and anhydrites close to the WIPP excavations, including the disturbed rock zone (DRZ), range from zero to four $\mathrm{MPa}$ and $12.5 \mathrm{MPa}$, respectively. For comparison, the hydrostatic pressure at the depth of the repository is about seven $\mathrm{MPa}$ and the lithostatic pressure is about $15 \mathrm{MPa}$.

Fluid pressures in sedimentary basins that are much higher or much lower than hydrostatic are referred to as "abnormal pressures" in the literature of the petroleum industry, where they have received considerable attention. The explanations of how these pressures can be maintained over very long periods of time, perhaps millions of years, generally fall into two schools of thought. The first is based on the concept that the maintenance of abnormal pressures indicates the rock volumes containing the high pressures must be "hydraulically isolated" from normally pressured sediments. The second school of thought maintains that all rocks have finite permeability and that abnormal pressures must be viewed as a transient phenomenon. In the absence of a generating method, according to the second school, these pressures would decay away over geologic time even in rocks with extremely low permeability.

It has been demonstrated that the rocks of the Salado and Castile Formations, except for the pure halites, have a small but finite permeability. The high pressures are almost certainly maintained because of the large compressibility and plastic nature of the halite, and to a lesser extent, the anhydrite. The lithostatic pressure at a particular horizon must be supported by a combination of the stress felt by the rock matrix and the pore fluid. In highly deformable rocks the portion of the stress that must be borne by the fluid exceeds hydrostatic pressure, but cannot exceed lithostatic pressure.

The hydrology of the Castile differs from that of the Salado in that fracturing in the upper anhydrite has generated regions with much greater permeability than the surrounding intact anhydrite. These regions are located in the deformed zone discussed in Section 2.1. The high-permeability regions of the Castile are saturated with brine at pressures greater than 
hydrostatic and have been referred to as "brine reservoirs". The fluid pressure measured in the WIPP-12 drill hole (12.7 MPa) is greater than the nominal hydrostatic pressure for a column of equivalent brine at that depth (11.1 MPa). Therefore, brine could flow to the repository, overlying strata, and the ground surface through an intrusion borehole.

Hydraulic tests performed in the ERDA-6 and WIPP- 12 boreholes have suggested that the highly permeable portions of the Castile are limited in extent (Popielak et al., 1983). The vast majority of brine is thought to be stored in low-permeability microfractures; about five percent of the overall brine volume is stored in large open fractures. The volumes of the ERDA-6 and WIPP-12 brine reservoirs are estimated to be $100,000 \mathrm{~m}^{3}$ and $2,700,000 \mathrm{~m}^{3}$, respectively (Popielak et al., 1983).

\subsubsection{Chemical Hydrogeology of the Salado/Castile Flow Regime}

Results from several geochemical studies provide information about the origin of brine in the Castile Formation. Popielak et al. (1983) concluded that the ratios of major and minor element concentrations in the brines indicate that these fluids originated from ancient seawater and that there is no evidence for fluid contribution from present meteoric waters. The gas and brine chemistries of Castile water from the ERDA-6 and WIPP-12 reservoirs are distinctly different from each other and from local ground waters. The brines are saturated, or nearly so, with respect to halite and, consequently, have little or no halite dissolution potential. In a later study of brine geochemistry using uranium-disequilibrium methods, Lambert and Carter (1984) reached a different conclusion regarding the origin of the Castile brine fluids than did Popielak et al. (1983). They concluded that Castile brine occurrences are the result of the isolation of waters transmitted to the Castile Formation from the adjacent Capitan Reef via an intermittent or episodic hydrologic connection and that the isolation times for the Castile brines at ERDA-6 and WIPP-12 are between 360,000 and 880,000 years, respectively.

\subsubsection{Physical Hydrogeology of the Bell Canyon/Capitan Flow Regime}

The Bell Canyon Formation is the first unit with relatively high permeability below the Castile Formation. It consists mainly of sandstones and siltstones. The Capitan limestone is a reef facies that is the time-stratigraphic equivalent of the Bell Canyon. The Capitan limestone is not present under the WIPP site, but the Bell Canyon grades into the Capitan to the west, north, and east. Together, the Bell Canyon Formation and the Capitan limestone 
form a laterally extensive and relatively permeable hydrostratigraphic unit. The hydrogeology of this unit has been examined in terms of human intrusion scenarios in which a future drill hole provides a hydraulic connection between the Bell Canyon and overlying formations.

Mercer (1983) used information from three test holes (AEC-7, AEC-8, and ERDA-10) to examine permeability and flow conditions in the Bell Canyon in the vicinity of WIPP. He found that the hydraulic conductivities of the Bell Canyon sandstones, siltstones, and shales ranged from $6 \times 10^{-2}$ to $2 \times 10^{-6} \mathrm{ft} / \mathrm{d}\left(2 \times 10^{-7}\right.$ to $\left.7 \times 10^{-12} \mathrm{~m} / \mathrm{s}\right)$. Mercer updated Hiss' (1975) potentiometric-surface map for the upper Bell Canyon Formation and confirmed the interpretation of Hiss that flow in the Bell Canyon is northeastward, toward the Capitan Reef. Mercer also concluded that flow would be downward, not upward, if the Rustler and Bell Canyon Formations were ever interconnected.

Beauheim et al. (1983) and Beauheim (1986) reported on drill-stem-tests performed later in the Bell Canyon Formation at two additional drill holes (Cabin Baby-1 and DOE-2). Hydraulic conductivities reported for the sandstone/siltstone members of the Bell Canyon Formation ranged from $3 \times 10^{-3}$ to $6 \times 10^{-5} \mathrm{ft} / \mathrm{d}\left(1 \times 10^{-3}\right.$ to $\left.2 \times 10^{-10} \mathrm{~m} / \mathrm{s}\right)$ at Cabin Baby- 1 and from $6 \times 10^{-3}$ to $2 \times 10^{-4} \mathrm{ft} / \mathrm{d}\left(2 \times 10^{-8}\right.$ to $\left.7 \times 10^{-10} \mathrm{~m} / \mathrm{s}\right)$ at DOE-2. From hydraulic heads measured in the Bell Canyon Formation and Culebra at DOE-2, Beauheim (1986) concluded that the direction of flow in a cased borehole open only to the Bell Canyon and Culebra would be upward. In an open borehole, however, dissolution of halite in the intervening Castile and Salado Formations would increase the specific gravity of the Bell Canyon fluid so that, at the elevation of the Culebra, the Culebra head would be higher than the Bell Canyon head, resulting in downward flow.

\subsection{Resources}

Potash, oil, and gas are the only known economically attractive mineral resources in the vicinity of the WIPP site. Estimates of the volumes and locations of these resources are reported in the FEIS. 
As of March 23, 1994, 48 producing oil and/or gas wells were located within a radius of one mile of the WIPP land withdrawal area (Figure 2-19). Well depths vary from approximately 7,000 to $14,000 \mathrm{ft}(2,100$ to $4,300 \mathrm{~m})$. Production zones generally occur in the Livingston Ridge/Delaware, Delaware/Brushy Canyon, and Morrow formations respectively.

The hydrocarbon well that has drawn significant attention is $2 \mathrm{mi}(3 \mathrm{~km})$ to the south-southwest of the waste panels, and has produced natural gas since 1982 (Silva and Channell, 1992). The surface location of the well is outside the land-withdrawal boundary, but the borehole is slanted to withdraw gas from rocks below the WIPP horizon (within the lateral but below the vertical boundary defined in the Land Withdrawal Act [LWA]). Within the withdrawal area, the slanted well is at depths greater than $6,000 \mathrm{ft}$ below the land surface. The LWA prohibits resource extraction within the 16 sections except for the existing leaseholds beneath Section 31 at depths greater than $6,000 \mathrm{ft}$.

Three potash mines and two associated chemical-processing plants are located between 5 and $10 \mathrm{mi}$ (8 and $16 \mathrm{~km}$ ) from the WIPP (DOE, 1990a). As discussed in Section 2.3 of the 1992 PA report, potash-enriched beds are found stratigraphically above the repository horizon. Neither mining of potash nor exploratory drilling for potash reserves reaches the repository horizon. The nearest economically exploitable potash reserves are approximately $0.6 \mathrm{mi}$ (1 km) laterally from the waste panels (Brausch et al., 1982; Guzowski, 1991), although the extraction of the reserves within the land-withdrawal area is precluded.

\subsection{Background Environmental Conditions}

The effort to establish environmental baseline conditions at the WIPP facility was initiated in 1975. These studies are continuing under the auspices of the WIPP Environmental Monitoring Plan (EMP) (DOE, 1994) which is designed to characterize the local environment through radiologic and nonradiologic sampling activities. The WIPP EMP provides for data collection for a comprehensive set of parameters selected to detect and quantify any present or potential environmental impacts. Nonradiological portions of the program focus on the immediate area surrounding the WIPP site. The radiological surveillance covers a broader geographic area including nearby ranches, villages, and cities. 


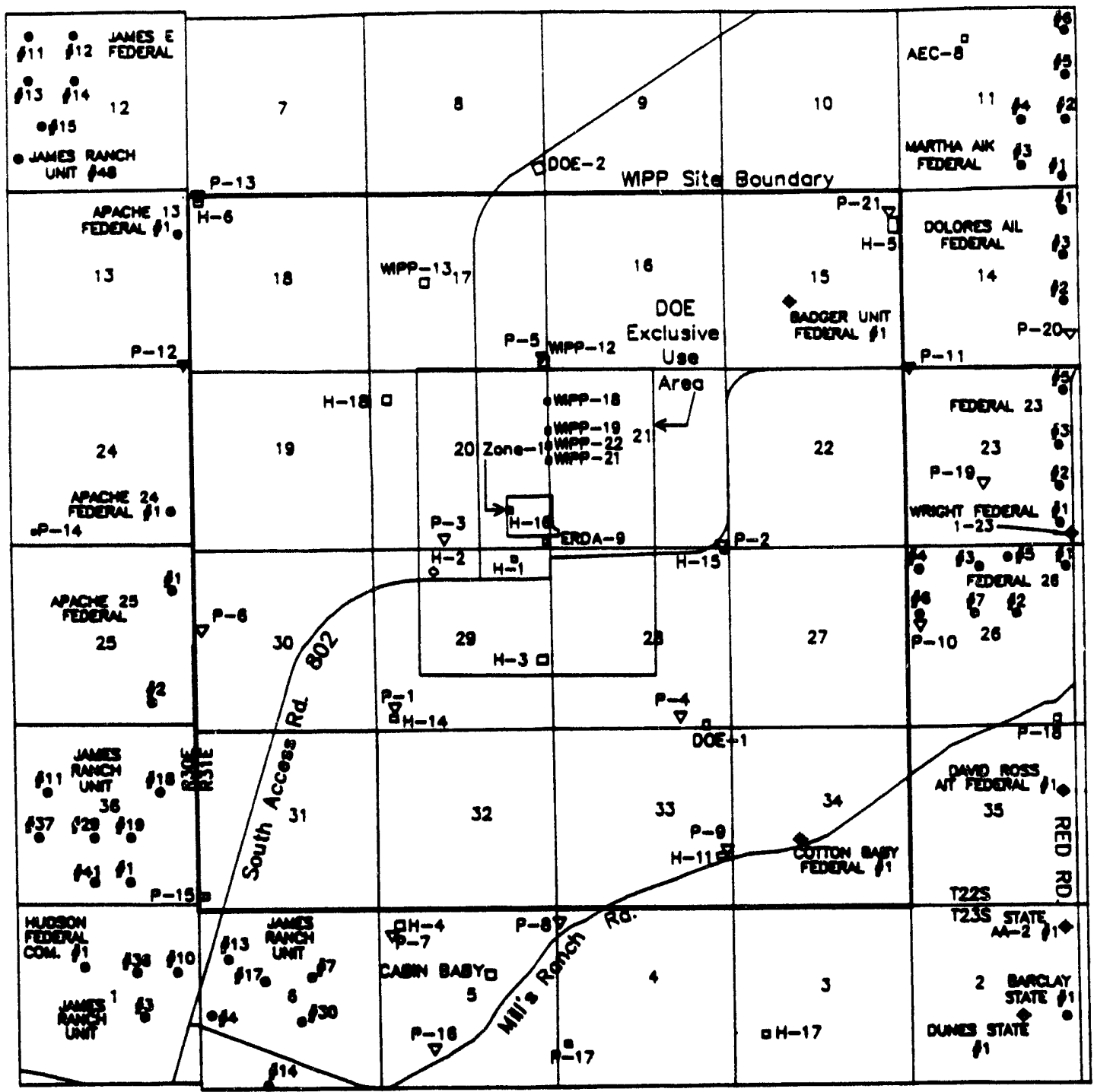

$N_{-n-1}$

BOREHOLES WITHIN

ONE MILE OF THE WIPP LAND WITHDRAWAL AREA

(ENATACE LOCATIONS OAKY)

- mencos mas

- mocuens ol mo/or cas wal

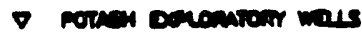

- Ancoming

- men meroror mal

Figure 2-19 Boreholes within a one-mile radius of the WIPP land-withdrawal area. 
Nonradiological environmental surveillance (NES) includes several subprograms designed to collect meteorological data, establish a baseline of surface and aerial environmental photography, monitor air quality, monitor groundwater and surface water quality, monitor wildlife population dynamics, and monitor vegetation. Surface and subsurface soil and soil microbiota monitoring activities were conducted from 1984 to 1990. One emphasis of the nonradiological monitoring activities was to document the potential environmental impacts of fugitive salt dust generated by the surface stockpiling of materials mined from the WIPP facility. With the exception of localized and expected effects of construction activities, no environmental impacts of the WIPP facility have been observed.

Environmental radiological surveillance includes atmospheric, ambient, terrestrial, hydrologic, and biotic radioactivity baseline subprograms. The atmospheric radiation program was measured by sampling airbome particulate at multiple locations. This program has established that gross alpha activity in airborne particulate is within the range of 1 to $3 \mathrm{x}$ $10^{-15}$ microcuries per milliliter $(\mu \mathrm{Ci} / \mathrm{ml})$; mean gross beta activity is within the range of 1 to $4 \times 10^{-14} \mu \mathrm{Ci} / \mathrm{ml}$, and mean gamma activity is 7.5 microroentgens per hour $(\mu \mathrm{R} / \mathrm{hr})$.

Ambient radiation measurements using a pressurized ionization chamber detector has established a background of $7.4 \mu \mathrm{R} / \mathrm{hr}$. This is equivalent to an annual dose of 65 millirems.

In order to establish the terrestrial radiation baseline, soil samples were collected at 37 locations within an $80-\mathrm{km}$ radius of the WIPP and were analyzed for 19 radionuclides. The results are shown in Table $2-2$.

Hydrological background radioactivity was established based on surface water, sediment, and groundwater samples from several locations around the WIPP. Surface water was sampled at 12 locations. The sample mean radioactivity levels for most radionuclides were below their respective detection limits. Peak levels of ${ }^{40} \mathrm{~K}$ from Laguna Grande de la Sal were $2.7 \times 10^{-5}$ $\mu \mathrm{Ci} / \mathrm{g}$, whereas the mean level at all other sampling locations was less than $2.7 \times 10^{-7} \mu \mathrm{Ci} / \mathrm{g}$. In addition to ${ }^{40} \mathrm{~K}$, levels of uranium were highest in Laguna Grande de la Sal. Only ${ }^{60} \mathrm{Co}$, ${ }^{137} \mathrm{Cs}$, ${ }^{228} \mathrm{Ra}$, ${ }^{234} \mathrm{U}$, and ${ }^{238} \mathrm{U}$ were found to be above detection limits. Sediments were collected at six locations and were analyzed for 17 radionuclides. Stock tanks showed the highest concentrations of radionuclides, posșibly indicating an accumulation effect from the closed nature of the tanks. Laguna Grande de la Sal sediments contained significantly higher concentrations of ${ }^{234} \mathrm{U}$ than did the stock tanks. Groundwater samples were collected from 
Table 2-2

Ranges of Mean Values Measured for Radioactive Isotopes at Sites at WIPP, five mi from WIPP, and Beyond five mi from WIPP

\begin{tabular}{|c|c|}
\hline Isotope & Range of Mean Values ${ }^{1}(\mu \mathrm{Ci} / g)$ \\
\hline${ }^{40} \mathrm{~K}$ & 4.9 to $9.3 \times 10^{-6}$ \\
\hline${ }^{60} \mathrm{Co}$ & $--^{2}$ \\
\hline${ }^{90} \mathrm{Sr}$ & -- \\
\hline${ }^{137} \mathrm{Cs}$ & 1.3 to $2.2 \times 10^{-7}$ \\
\hline${ }^{226} \mathrm{Ra}$ & 2.6 to $5.4 \times 10^{-7}$ \\
\hline${ }^{228} \mathrm{Ra}$ & -- \\
\hline${ }^{228} \mathrm{Th}$ & 2.1 to $4.9 \times 10^{-7}$ \\
\hline${ }^{230} \mathrm{Th}$ & 2.5 to $52 \times 10^{-7}$ \\
\hline${ }^{232} \mathrm{Th}$ & $3.0 \times 10^{-7}$ \\
\hline${ }^{233} \mathrm{U}$ & -- \\
\hline${ }^{234} \mathrm{U}$ & 1.5 to $3.3 \times 10^{-7}$ \\
\hline${ }^{235} \mathrm{U}$ & 4.4 to $17 \times 10^{-9}$ \\
\hline${ }^{238} \mathrm{U}$ & 1.6 to $3.0 \times 10^{-7}$ \\
\hline${ }^{237} \mathrm{~Np}$ & -- \\
\hline${ }^{238} \mathrm{Pu}$ & - \\
\hline${ }^{2391240} \mathrm{Pu}$ & -- \\
\hline${ }^{241} \mathrm{Pu}$ & - \\
\hline${ }^{241} \mathrm{Am}$ & -- \\
\hline${ }^{24} \mathrm{Cm}$ & -- \\
\hline
\end{tabular}

'The ranges of mean values are expressed in terms of microcuries per gram of soil $(\mu \mathrm{Ci} / \mathrm{g})$.

${ }^{2}$ Below minimum detection limit. 
37 wells and were analyzed for the same 18 radionuclides as the surface-water samples.

Elevated levels of ${ }^{40} \mathrm{~K}$ were found in the Magenta/private and Culebra groundwater, possibly due to the generally high levels of dissolved solids in groundwater in these formations. Only ${ }^{60} \mathrm{Co},{ }^{137} \mathrm{Cs}, \mathrm{Ra},{ }^{234} \mathrm{U}$, and ${ }^{238} \mathrm{U}$ were found above the detection limits.

The biotic baseline program characterizes background radiation levels in key organisms along possible food-chain pathways to man. Vegetation, rabbits, quail, beef, and fish are sampled, and palatable tissues are analyzed for concentrations of transuranics and common naturally occurring radionuclides.

The Statistical Summary of the Radiological Baseline Program for the WIPP (DOE, 1992a) provides an in-depth analysis of the radiological data required by the DOE Order 5400.1 (DOE, 1988). Additional background information and radiological surveillance results are summarized in the Waste Isolation Pilot Plant Site Environmental Report for Calendar Year 1921 (DOE, 1992b) and the Waste Isolation Pilot Plant Site Environmental Report for Calendar Year 1992 (DOE, 1993).

\subsection{Climatology and Meteorology}

The present climate of southeastern New Mexico is arid to semi-arid (Swift, 1992). Annual precipitation is dominated by late summer monsoons, when solar warming of the continent creates an atmospheric pressure gradient that draws moist air inland from the Gulf of Mexico (Cole, 1975). Winters are cool and generally dry.

Mean annual precipitation at the WIPP has been estimated to be between 10.9 and 13.5 in per year (28 and $34 \mathrm{~cm}$ per year) (Hunter, 1985). At Carlsbad, $26 \mathrm{mi}(42 \mathrm{~km})$ west of the WIPP and $330 \mathrm{ft}(100 \mathrm{~m})$ lower in elevation, 53-year (1931-1983) annual means for precipitation and temperature are 12.6 in per year $\left(32 \mathrm{~cm}\right.$ per year) and $63^{\circ} \mathrm{F}\left(17.1^{\circ} \mathrm{C}\right)$ (University of New Mexico, 1989). Freshwater pan evaporation in the region is estimated to be 110 in per year (280 cm per year) (DOE, 1980b).

Short-term climatic variability can be considerable in the region. For example, the 105 -year (1878 to 1982) precipitation record from Roswell, $84 \mathrm{mi}(135 \mathrm{~km})$ northwest of the WIPP and $200 \mathrm{ft}(60 \mathrm{~m})$ higher in elevation, shows an annual mean of 10.6 in per year $(27 \mathrm{~cm}$ per 
year) with a maximum of 32.9 in per year ( $84 \mathrm{~cm}$ per year) and a minimum of 4.4 in per year (11 cm per year) (Hunter, 1985).

Based on the past record, it is anticipated that the climate of the region may change during the next 10,000 years and analyses of the long-term performance of the WIPP repository must allow for climatic variability. PA modeling uses past climates to set limits for future variability (Swift, 1991, 1992). Climatic variability is incorporated into the modeling system by varying the hydraulic head along the model boundaries for groundwater flow in the Culebra Member of the Rustler Formation. The hydraulic head is varied as a scaled function of precipitation (Swift, 1991).

\subsection{Natural Processes and Events}

Natural process and events that could affect the ability of the repository to isolate wastes are identified in this subsection. A qualitative assessment of the likelihood of these processes and events occurring in a manner that might impact the facility is also presented.

Near-surface processes and events of interest include flooding, tornados, range fires, meteorite impact, erosion, dissolution, and sedimentation. Other natural processes of interest are tectonic phenomena including seismic activity, faulting and folding, and igneous processes.

Flooding will not pose a threat to the WIPP during the disposal or post-disposal phases of the project. The WIPP facility is located $500 \mathrm{ft}(152 \mathrm{~m})$ above the level and $14 \mathrm{mi}$ east of the Pecos River. Estimates of maximum probable flood on the Pecos result in an increase in water elevation of approximately $80 \mathrm{ft}(24 \mathrm{~m})$ (DOE, 1980b). Protection of the site from flooding caused by intense local precipitation is provided by a system of peripheral berms and drainage ditches. Grade elevations of roads and other surface facilities are designed so that storm water will drain away from the facility, under severe rainfall conditions. Shaft collars and surface buildings prevent water from entering shafts. Upon closure of the WIPP, floods will have no impact on the WIPP.

Tornados may potentially affect WIPP surface structures. A site-specific study of wind and tornado probabilities was performed by Fujita (1978). This study identifies the tornado recurrence interval in the Pecos River Valley as being about 2,832 years. The design-basis 
tornado for WIPP structures has a million-year return period. The design-basis tornado has a maximum wind speed of $183 \mathrm{mi}$ per hour (295 km per hour), a tangential velocity of $124 \mathrm{mi}$ per hour (200 km per hour), a maximum translational speed of $41 \mathrm{mi}$ per hour ( $66 \mathrm{~km}$ per hour), a radius of maximum wind of $325 \mathrm{ft}(99 \mathrm{~m})$, a maximum pressure drop of $0.5 \mathrm{lb} / \mathrm{in}^{2}$ $(3.4 \mathrm{kPa})$, and a maximum pressure-drop rate of $0.09 \mathrm{lb} / \mathrm{in}^{2}$ per second $(0.62 \mathrm{kPa}$ per second). Upon closure of the WIPP, tornados will have no potential to impact waste isolation.

During operations, range fires are not expected to cause significant damage to surface structures because of the buffer afforded by the clearing of vegetation around the site perimeter and because of fire protection systems and practices employed at the site. DOE (1980b) analyzed the effects of a range fire near the WIPP site assumed to occur after the projected operating life of the facility. For this analysis, it was assumed that the fire would release radionuclides that accumulated in the surrounding vegetation during routine operations. During routine operations, very small quantities of nuclides are conservatively assumed to be released as a result of routine handling of waste containers, some of which may be externally contaminated with radioactivity. The fire analysis concluded that the maximum individual radiation doses as a result of a range fire would be a small fraction of the doses delivered by natural background radiation. Range fires will have no impact on waste isolation once the facility is closed.

Meteorite impact is a phenomenon of sufficient improbability that it will not significantly contribute to risk from the operation of the WIPP. Burkholder (1980) concluded that meteorite impact is one of the scenarios that is unimportant to the performance of nuclear waste isolation systems.

Erosion rates so extreme that they could impact the repository over long time periods have not been observed at the WIPP site. The region in which the WIPP is located has been geomorphically stable since the mid-Pleistocene epoch.

Karst topography is present in the vicinity of the WIPP, primarily to the north and west of the site. Karst landscapes typically feature shallow depressions in the land surface. In the vicinity of the WIPP site, these are most likely the result of shallow dissolution of the Rustler and upper Salado Formations during periods of wetter climates. Most of these features formed during deposition of the Gatuña Formation (Bachman, 1985). During this period of greatest dissolution, only geologic units within $200 \mathrm{ft}(61 \mathrm{~m})$ of the land surface 
were affected. Shallow dissolution can only become a major process at the WIPP site if large quantities of unsaturated water gain access to the Rustler Formation (Bachman, 1985). Several geologic and hydrologic characteristics of the site combine to inhibit recharge of water and hence, future dissolution of the geologic units above the Salado Formation.

Breccia pipes, another type of dissolution feature, are present in the region. These are indicative of deep dissolution wherein a void is created and overlying material collapses into the void. Breccia pipes appear to form only where soluble units overlie the Capitan Reef aquifer system. The nearest known breccia pipes are $9 \mathrm{mi}(14 \mathrm{~km})$ from the WIPP-site boundary (see Figure 2-1). The WIPP site itself does not overlie the Capitan Reef, and thus, it is not reasonable to expect that this type of dissolution will occur at the site.

Sedimentation will have no impact on the WIPP repository. Sedimentation would only be of concern to a facility at or near the land surface, over geologic time periods. Sedimentation has not been a significant geomorphic process at the WIPP site since at least the midPleistocene epoch.

Seismic activity in the region has been historically low and has not been definitively linked to known tectonic features. A conservative design-basis earthquake has been established based on an estimate of the 1,000-year recurrence interval peak acceleration of 0.1 times the acceleration due to gravity (g). The use of extremely conservative assumptions in developing the design-basis earthquake for the WIPP facility assures that seismic events will not impact repository integrity.

No active folding or faulting has been identified at the WIPP site. All fault activity in the Delaware Basin is believed to have occurred in pre-Tertiary time. Outside the Delaware Basin, Cenozoic faulting has been identified along the flank of the Sacramento Mountains and San Andres Range. Uplift of the Delaware and Guadalupe Mountains is believed to be continuing. The closest Cenozoic fault is $60 \mathrm{mi}(97 \mathrm{~km})$ from the WIPP site, within the Basin and Range subregion. The seismic design of the WIPP takes into consideration a 7.8magnitude earthquake in this subregion, so activity along these faults is not considered a threat to repository integrity.

Folds in the region occurred prior to the early Tertiary. At the site, there are no folds of tectonic origin. Folding and flexuring of geologic units at the site are related to salt movement in the Castile. Similar deformation has not occurred in the Salado Formation to 
the extent that it has in the Castile. No structural features have been identified within the WIPP site. If salt flow continues in the Castile, the Salado would continue to be unaffected. Minor salt flow in the Salado in the repository closure phase will contribute to the isolation of the waste in the repository.

Geophysical surveys, mining experience, and data from drill holes show that an intrusive dike exists nine mi northwest of the WIPP site. Radiometric dating shows it to be 35 million years old (Powers et al., 1978a,b). No other intrusive features are known to exist near the site. The tectonic regime of the site does not include igneous processes, so igneous activity is not expected to occur in the future. No impact upon waste isolation is expected to result from igneous processes.

\subsection{Summary of Repository Processes}

\subsubsection{Gas Generation}

From a geochemical standpoint, gas generation is an important process because of its potential effects on chemical conditions in the repository, especially Eh and $\mathrm{pH}$. Eh and $\mathrm{pH}$ may in turn affect the chemical behavior of $\mathrm{Pu}, \mathrm{Am}, \mathrm{Np}, \mathrm{Th}$, and $\mathrm{U}$.

Gas generating reactions may also affect the geomechanical properties of the contents of WIPP disposal rooms (porosity, shear strength, etc.), and the nearby anhydrite interbeds, by precipitating or dissolving solids on/from pre-existing solids. Davies et al. (1991) described the highly coupled nature of gas generation, hydrologic, and geomechanical processes.

Gas production caused by the decomposition of cellulosic waste, corrosion of metals, and radiolysis of waste (described in detail in Section 4.4.1) may impact repository performance. The gas generation, in conjunction with the creep closure and consolidation of the disposal room contents, is the source of driving pressures that may prevent the complete closure of the disposal room, cause room expansion, cause migration of gases out of the repository, cause crack dilation or fracture initiation or both in the interbeds and marker beds, and drive brine out of the disposal room, thus limiting radionuclide transport by isolating the waste from the brines. 


\section{Gas-Generation Modeling}

The primary objective of modeling gas generation is to simulate the types and quantities of gases present in WIPP disposal rooms as a function of time. However, because of the highly coupled nature of the processes expected in the repository (Davies et al., 1991), gas generation may also affect the water budget and the chemical behavior of radionuclides and hence, the radionuclide source term, the transport of volatile organic compounds (VOCs), room closure, and the geomechanical state of the contents of the repository.

The gas-generation model is a multi-use model used along with other models in simulations of seal performance, room consolidation, and flow and transport as well as its direct use in PA. The modeling is evolving from a constant gas generation rate for a given reaction (called the average stoichiometric model) to a thermodynamic and kinetic simplified reaction path model. The simplified reaction path approach is thought to be more appropriate for simulating gas generation behavior at the WIPP.

For the 1991 and 1992 calculations, a gas-generation model referred to herein as the "average-stoichiometry model" is used. This model contains several possible reactions for both anoxic corrosion of steels and other Fe-base alloys and microbial degradation of cellulosics. These reactions occurred in laboratory studies for the WIPP Project and for other, similar applications, or in analogous natural systems. Because these reactions result in different corrosion products or use different electron acceptors, they may produce gases in different proportions, or even different gases than the other possible corrosion or microbial reactions. This model uses the average stoichiometric gas-production ratios for all of the corrosion and microbial reactions at measured or estimated gas-production rates and allows gas production to proceed until one or more of the reactants is consumed (note that the stoichiometric ratios and reaction rates are sampled over a range of values to account for uncertainty in the PA calculations). It assumes that anoxic corrosion and microbial activity proceed independently of each other.

Development of a simplified reaction-path gas-generation model is also under way. This thermodynamic and kinetic model currently includes: 1) oxic and anoxic corrosion of steels and other Fe-base alloys, including passivation by the adherent corrosion products $\mathrm{FeCO}_{3}$ and $\mathrm{FeS}_{2}$ and depassivation due to destabilization of these phases caused by changes in the composition of the gaseous phase, 2) microbial degradation of cellulosics with $\mathrm{O}_{2}, \mathrm{NO}_{3}$; $\mathrm{Fe}(\mathrm{OH})_{2}, \mathrm{SO}_{4}{ }^{2-}$ or $\mathrm{CO}_{2}$ as the electron acceptor, 3) brine radiolysis, and 4) consumption of 
$\mathrm{CO}_{2}$ by $\mathrm{Ca}(\mathrm{OH})_{2}$ (in hydrated cementitious materials) and/or $\mathrm{CaO}$ (a potential backfill additive). In cases where greater detail is needed than available in the reaction path model, other geochemical models such as EQ3/6 (Wolery, 1992) will be used (e.g., for the effects of high $\mathrm{CO}_{2}$ partial pressures on brine $\mathrm{pH}$ ).

The main differences between the average-stoichiometry model used in the 1991 and 1992 PA calculations and the reaction-path model are that: 1) the reaction-path model includes more gas-producing reactions than the average-stoichiometry model, 2) the reaction-path model includes gas-consuming reactions, and 3) the reaction-path model includes interactions among gas-producing and gas-consuming processes, such as passivation of steels by microbially-produced $\mathrm{CO}_{2}$ and $\mathrm{H}_{2} \mathrm{~S}$ and depassivation of steels due to consumption of $\mathrm{CO}_{2}$ by $\mathrm{Ca}(\mathrm{OH})_{2}$ and $\mathrm{CaO}$. The reaction-path model is the preferred model. Because of these improvements, the reaction-path model will simulate gas generation and its effects on the water budget, the chemical behavior of radionuclides, the transport of VOCs, room closure, and the geomechanical state of the room contents more realistically. Because in the final analysis gas generation is a coupled process (see Section 2.7.6), the results from hydrologic and geomechanical models will be used to estimate the effects of two-phase (brine and gas) flow and room closure on the volume, brine content, and gas content of the repository.

\subsubsection{Brine and Gas Flow Processes}

The Salado Formation consists primarily of a series of subhorizontal layers of pure and impure halite and anhydrite beds, which are generally thought to be brine saturated. Gas is expected to be introduced into the system from the initial repository void and gas generated by the waste. As the repository closes due to salt creep and gas is generated by corrosion and microbial activity, the gas pressure might be sufficient to either dilate existing fractures or induce the formation of new fractures in the surrounding halite, and gas will flow out of the repository into the surrounding Salado Formation. A combination of relatively high intrinsic permeability, low gas-brine threshold pressure, and location relative to the repository suggests that the anhydrite interbeds will provide the primary pathway for conducting gas away from the repository.

Quantifying gas and brine flow at the WIPP is important for assessing long term repository performance. Brine is a potential medium for transporting contaminants. In addition, brine flow is important because the amount of gas generated is thought to depend partially on brine availability. Geological heterogeneities, including stratigraphic layering, could also be of 
importance in representations of the repository. The appropriate conceptual models for brine and gas flow in the Salado Formation strata surrounding the repository will be used for simulation of the repository behavior.

This section summarizes the important issues impacting brine and gas flow in the repository, in the DRZ, and in the intact Salado Formation.

\subsubsection{Repository}

Gas and brine movement occur in the repository in response to repository depressurization, gas generation, and gravitational effects. Gas generation within the repository may be highly dependent on the availability and mobility of brine within the disposal rooms. Two-phase gas and brine flow within the room will be controlled by the two-phase characteristics, which are strongly dependent on the pore structure within the waste and backfill. Each phase has a residual saturation, below which a continuous phase throughout the pore structure does not exist and the phase is not mobile. If gas and brine are present in sufficient quantities (i.e., at greater than residual saturations), the phases could stratify due to density differences and create a condition where the lower part of a disposal room is highly saturated with brine and the upper part is highly saturated with gas. The gas generation process may also affect the brine mobility and distribution within the room.

\subsubsection{Disturbed Rock Zone}

A DRZ exists around the mine openings where the Salado Formation properties have been altered from their undisturbed values. This DRZ is generally expected to form within the first few meters of the repository (Nowak and McTigue, 1987; Stormont et al., 1987; Boms and Stormont, 1988, 1989; Beauheim et al., 1991). Within the DRZ, intrinsic permeability and porosity are increased due to fracturing and possibly dilatation. Also, elastic and inelastic changes in pore volume, driven by excavation-related stress redistribution, may cause variations in the near-field fluid pressure distribution that are superimposed on fluidpressure gradients associated with brine flow toward the excavation. Within the DRZ, dilatation, drying, and exsolution of dissolved gas that occurs naturally in Salado brines may cause varying degrees of brine desaturation. Increased permeability, decreased pore-fluid pressure, and partially saturated conditions within the DRZ all contribute to enhancing potential gas flow pathways between the waste disposal rooms and nearby higherpermeability interbed units. The DRZ is expected to undergo time-dependent changes in 
properties, with disturbed halite possibly healing to a final state equivalent to undisturbed halite (Lappin et al., 1989).

\subsubsection{Salado Formation}

The geology of the Salado Formation is described in Section 2.1.2.4. The Salado Formation consists of layers of relatively pure halite and impure halite containing interspersed clay and polyhalite. Layers are usually .3 to $1 \mathrm{ft}(0.1$ to $0.3 \mathrm{~m})$ thick. Thin interbeds of anhydrite, with associated underlying clay seams, are present in laterally continuous layers. Several of the more laterally extensive anhydrite interbeds have been designated as marker beds. The repository horizon is separated by a few meters of halite from the overlying Marker Bed (MB) 138 and the underlying MB 139. A stratigraphic section of the Salado Formation in the vicinity of the repository is shown in Figure 2-3. These layers generally dip about 1 degree to the southeast. The repository also dips gently to the southeast, following the general stratigraphy.

A potential source of brine to the repository is the Salado Formation. Therefore, determining the appropriate conceptual models for the various strata is critical in determining repository performance.

Experimental data (Beauheim et al., 1991, 1993; Finley et al., 1992) suggest that Darcy flow occurs in the anhydrite interbeds in the Salado Formation, suggesting that these layers have continuous interconnected porosity and permeability. Flow in the anhydrite interbeds occurs primarily in naturally occurring subhorizontal bedding-plane fractures (Beauheim et al., 1993). These existing fractures may expand and propagate, or new fractures may form, in response to pressure increases above some critical value in the interbeds, causing increases in porosity and permeability. The gas threshold pressure of the natural fractures is $1 \mathrm{MPa}$ or less. The gas threshold pressure is much higher for the anhydrite matrix such that fracturing would occur before gas enters the matrix. The far-field pore pressure of the anhydrite interbeds is at least $12.5 \mathrm{MPa}$ and may be as high as $15 \mathrm{MPa}$, the lithostatic pressure.

For halite, the choice of conceptual models is not as clear. Two widely different conceptual models have been proposed and are discussed separately below. Implications of the two different halite conceptual models differ primarily in the brine availability to the repository for gas generation and total brine inventory as well as brine storage in halite as gas migrates out the interbeds. 
The first halite model is based on Darcy flow (Beauheim et al., 1991, 1993; McTigue, 1993). For impure halite (argillaceous and polyhalitic halite), continuous interconnected porosity and permeability occur with Darcy flow. Gas threshold pressure in impure halite might be sufficiently high that gas flow into halite will not occur without fracturing. Farfield pressure in impure halite is nearly lithostatic (15 MPa). For pure intact halite, permeability is practically zero (less than $10^{-23} \mathrm{~m}^{2}$ ) as all tests of pure halite have resulted in no pressure or flow response during the test period (Finley et al., 1992; Beauheim et al., 1991). Therefore, pure halite may act as a barrier between other layers, essentially isolating them from one another and restricting vertical brine flow on a regional scale.

The second halite model assumes that there is no pressure gradient and, consequently, no flow in the far field (Deal et al., 1993). Brine flows into the repository from consolidation of clays due to high deviatoric stress near the excavations. Locally present brine may also be redistributed around the repository in halite where porosity has become interconnected by deformation near the excavations.

Fracturing in the halite is necessary for gas to flow from the repository to the anhydrite interbeds due to the expected high threshold pressure in intact halite. Fracturing, if it occurs, in the anhydrite interbeds is expected to increase significantly the lateral permeability and to affect the lateral gas-migration distance. The flow processes will be significantly different in the fracture system, in which gas and brine may occur, than in the matrix, where only brine is anticipated.

Due to phase stratification in the rooms, potential gas migration from the repository is expected to occur primarily in the upper marker beds. Gas migration is expected to occur in the lower marker beds after the brine in the lower part of the room has been expelled or consumed. Brine inflow and gas migration will also be influenced by the layering sequence, specifically the location of the marker beds and the adjacent halite layers. The source of brine is primarily the higher permeability marker beds and the adjacent halite layers. If gas migration occurs, brine may flow into marker beds and adjacent halite layers. Therefore, the layering sequence near the repository may be important to the repository performance.

The non-horizontal orientation of the repository and layering and its impact on brine inflow and gas migration processes due to gravitational effects has not yet been assessed by PA. The study of these effects is currently underway. Consequences of the stratigraphic dip could include increased brine saturation in down-dip rooms and preferred directions of 
migration of gas. In addition, heterogeneity occurs within each of these layers in the Salado Formation. The nonuniformity of properties within each layer may additionally affect the brine inflow and gas migration behavior.

Displacement of one phase by another, such as occurs in the anhydrite interbeds, involves a number of complex processes. Two-phase Darcy equations with characteristic curves are commonly employed to analyze these situations; however, in certain situations, their accuracy may be limited. When gas displaces brine, the two-phase interface may be unstable because a less viscous fluid is displacing a more viscous fluid, and capillary forces may dominate as discussed by Lenormand et al. (1988) for porous media. In addition, heterogeneity of properties within porous media and fractures may lead to a preferred direction of migration. Channeling of tracers for single-phase flow in fractures caused by aperture variation has been the subject of a number of investigations as exemplified by studies by Tsang and Tsang $(1987,1989)$.

\subsubsection{Process Coupling}

Simulation results (Davies e $\quad 1$; Webb, 1991; Bertram-Howery et al., 1990; SNL, 1992) suggest that gas generau. uld brine and gas flow are characterized by a strong coupling between chemical, hydrologic, and geomechanical processes. A description of process coupling is presented in Section 2.7.6.

\subsubsection{Brine Chemistry Procesces}

Gas generation processes described in Section 2.7.1 will affect the chemical conditions in WIPP disposal rooms, especially the Eh and pH of any brine present. For example, microbial production of $\mathrm{CO}_{2}$ and $\mathrm{H}_{2} \mathrm{~S}$ may decrease the $\mathrm{pH}$ to acidic values. Waste matrix materials such as cement (and potential backfill materials that could be used for engineering modifications) will also affect the brine chemical conditions. The brine present in the disposal room during a human intrusion scenario can vary from Salado composition to Castile, or mixtures of these. A potential brine pathway from the disposal room to the accessible environment involves mixing disposal room brine with Culebra brine. Hence, radionuclide concentrations in brine may need to be known for a range of brine chemical compositions and conditions. 
Radionuclide concentrations in brine include dissolved species as well as colloids. Sensitivity studies of prior 40 CFR 191 PA calculations indicate that actinide (not all radionuclides) concentrations are important parameters. The Actinide Source-Term Program has been designed to meet this 40 CFR 191 PA information need. This program includes the development of an actinide concentration model based on laboratory experiments and a transuranic (TRU) waste test to assess the suitability of the model.

The actinide concentration model includes sub-models for solubility and stable colloids. Sorption on backfill materials and corrosion materials may also occur, but may not determine dissolved species concenirations until all of the radionuclide inventory has been dissolved. The laboratory studies that support the development of the solubility sub-model include experiments to measure Pitzer model activity coefficients as well as "oversaturation" and "undersaturation" experiments for selected actinides in defined WIPP related brines. The "oversaturation" and "undersaturation" experiments have identified stable (or metastable) solid phases that control solubilities for a defined oxidation state. The experimental identification of solubility-controlling solid phases is necessary to develop the Pitzer model. The "oversaturation" and "undersaturation" experiments also provide measuremerits of dissolved actinide concentrations at particular brine compositions. These measurements will be used, in addition to concentration measurements from the TRU waste test, to evaluate the suitability of the solubility concentration sub-model. In general the measured concentrations have been within the range of $2 \times 10^{-3}$ to $10^{-8}$ Molar. The range of brine compositions under PA scenarios is much larger than the brine compositions studied in the laboratory to date. The laboratory studies that support the development of the colloid sub-model are organized by type of potential colloid. Both the carrier colloid and the intrinsic colloid laboratory studies have been initiated but have not been completed at this time.

Because of the lack of sufficient laboratory derived information to create a model which can simulate actinide concentrations for the range of brine compositions and conditions needed for PA, the 1992 PA is based on the elicitation of an expert panel (Trauth et al., 1992, Table 4-1). 


\subsubsection{Room Closure Processes}

\subsubsection{The Disposal Room Performance Model}

If the gas pressure increases above lithostatic pressure, it may support all of the overburden and may create large amounts of new gas storage volume by eventually lifting the overburden. Creation of this additional gas storage volume will limit the pressurization to slightly above lithostatic, at which point existing horizontal fractures will open or new ones will be created. Creation of new gas storage volume may also occur at gas pressures below lithostatic pressure if the lateral in situ stress in the interbed is less than the stress associated with the weight of the overburden. Thus, for one conceptual model, the principal mechanism for limiting the gas pressure and creating large amounts of new storage volume is considered to be the opening of existing or new fractures in the interbeds. A human intrusion into the waste by drilling has just the opposite effect. Gas pressure is relieved as the gas flows up the borehole when the drill penetrates the waste and more of the overburden load is transferred bacik onto the waste skeleton. If the load on the waste skeleton exceeds the load it previously supported, consolidation of the waste will begin again. Chemical and biological processes ongoing in the waste will also influence how much additional consolidation occurs, but calculations suggest that in most cases this increment will be small.

Three processes are expected to be ongoing during closure: 1) the volume of the excavation decreases as the salt deforms with time to consolidate and encapsulate the waste, 2) brine migrates towards the waste because fluid pressure adjacent to the excavation is lower than the equilibrium fluid pressure that existed in the salt prior to excavation, and 3) decomposition, corrosion, and radiolysis processes within the waste generate gas, which exerts back pressure against closure. The presence of gas within the disposal room is potentially important because gas pressurization may retard both the closure process and brine inflow, and also act as a vehicle for transport of VOCs. All three processes continue with time until the forces causing closure equilibrate with the backstress exerted by the waste, backfill (if present), brine saturation, or gas pore pressurization. Even after quasi-steady state, the state of the repository can be disrupted at any time by an inadvertent human intrusion by drilling into the repository. Because gas is released during an intrusion, the closure process may continue. Models for all the materials and processes affecting closure are being developed and incorporated into a computational method to quantitatively simulate the closure histories under various conditions and their consequences. 


\subsubsection{Waste Compaction}

After emplacement, unprocessed waste may undergo a natural change in its physical and mechanical state because of biodegradation of cellulosics and corrosion of metals. The final waste state is obscure. For example, microbiological degradation might reduce all cellulosics material to a small amount of inert residue, and corrosion would alter all iron to a high-strength oxide. Under these circumstances, the final form of the waste would probably not undergo any additional compaction and would be resistant to erosion during human intrusion by drilling. At the other extreme, the combination of cellulosics degradation and metal corrosion leading to hydroxide formation might produce a mixture of materials with low shear strength, high plasticity, and little resistance to erosion or sloughing during drilling. These bounds are reasonably well-defined but very broad.

The current model of compaction is for as-received waste, with no correction for changes in the waste over time. The reasons for not correcting for corrosion or decomposition effects are two-fold. First, precise definition of actual state of the waste at a given time is presently difficult. The second reason for omitting a correction in the waste compaction model for decomposition or corrosion is that it is not clear whether the end products of the chemical processes will increase or decrease the waste porosity. Development of experimental methods to accelerate waste decomposition and corrosion to time-scales sufficiently small to measure such structural changes in the laboratory are not practicable.

The end state of densification of the waste becomes much clearer if the waste is processed prior to emplacement. This simplification occurs because reprocessing generally reduces, stretches out in time, or eliminates chemical and biological changes in the waste. In most cases such changes to the waste should be easily incorporated in the present Disposal Room Model.

\subsubsection{Drill Cuttings Release}

As the drill penetrates the waste in the postulated borehole intrusion, material adjacent to the borehole wall may erode or may spall off into the hole, causing the borehole diameter to become greater than normally observed in salt-drilling operations (Berglund, 1992). This excess material may become entrained in the drilling fluid and carried to the surface, constituting a release of radioactive material in excess of that represented by the cross-sectional area of the borehole multiplied by the thickness of the waste layer. The total 
amount of cuttings release is also dependent on the radioactive actinide content of the waste intersected by the drilling operation.

\subsection{Erosion}

The conceptual model of borehole erosion is that the shear stress exerted by the moving drilling fluid on the wall of the borehole may be sufficient to remove waste material and enlarge the hole diameter. The assumption is made that the partially decomposed and corroded waste has a unique shear strength for erosion. If the shear stress exerted by the fluid is greater than the erosion strength of the waste, then material will be removed. Since the boundary shear exerted by the fluid becomes smaller as the hole enlarges, erosion will cease at some borehole radius. This radius, and the amount of waste removed, is determined by the condition that the shear stress exerted by the fluid is just equal to the erosion strength of the waste. The erosion strength of the waste is dependent on its composition and state of compaction.

\subsection{Spallation}

Spallation occurs when the fluid pressure in the borehole suddenly becomes less than the pore pressure of the gas-filled material adjacent to the borehole as a drill passes through the waste horizon. When this depressurization occurs, flow of gas into the borehole creates a tension in the waste skeleton because the waste would like to move in the same direction as the gas flow. If the force exerted by the gas on the skeleton becomes too large, the strength of the waste can be reduced or fracture and separation can occur. With the waste now in a weaker state, erosion may remove some of the damaged material, increasing cuttings release. For a first approximation, the spall strength of the waste is dependent on its composition and state of compaction, and the forces acting on it by flowing gas are dependent on the permeability of the waste and the magnitude and time history of the fluid pressure drop during intrusion.

\subsubsection{Room Prescurization Processes}

As discussed previously, immediately after excavation a shear stress field is created in the host halite close to the mined room or passageway that results in creep of the halite. Left empty, the room or passageway would eventually (on the order of hundreds of years) creep totally closed, i.e., the halite would totally fill the void space of the room or passageway 
(Butcher and Mendenhall, 1993). Ultimately, assuming no brine flow into the room, it would be as if the room or passageway never existed (in the subsequent discussion the term "room[s]" will refer to both rooms and drifts in the WIPP repository system).

However, the rooms at the WIPP are not expected to be empty. They are to be filled with both waste and potentially backfill. The waste is expected to be in 55 gallon drums or in standard waste boxes. The backfill is expected to be either crushed Salado halite or a mixture of crushed Salado halite with additives such as bentonite and/or gas getters. As the rooms close, both the waste and backfill will produce a resisting stress, called a backstress, on the walls, ceilings, and floors that will slow the creep closure process. In addition, gas generated by the degradation and corrosion of the waste as well as by radiolysis will pressurize the remaining void space (Butcher and Mendenhall, 1993).

As the combination of backstress and gas pressurization increases, the shear stresses near the rooms will decrease until the gas pressure equalizes with the lithostatic pressure of the overburden, causing the shear stresses to become very small. Under these conditions the stress fields around the rooms become very similar to the stress state of the undisturbed Salado Formation and rapid room closure ceases. Either the leakage of gas out of the rooms or the creation of additional gas in excess of that needed to achieve lithostatic pressure will change the room gas pressure and thus alter the closure processes.

Consequences that result in fracturing either the halite or the marker beds may significantly alter the flow and transport behavior of the fractured regions. Thus the concern for WIPP is that the appropriate conceptual fracture models are chosen for flow and transport modeling to and from the repository.

Fractures can be thought of as material discontinuities that have free surfaces, void space, and at least one fracture tip region (fracture process zone [FPZ]) in an otherwise continuous material. The initiation and propagation of a fracture requires the breaking of cohesive atomic bonds in order to create the required free surfaces. There are numerous conceptual models proposed for describing fracture behavior, and this is currently an area of intense research by the scientific community. Figure 2-20 shows a tree graph that attempts to organize various possible conceptual fracture models in a systematic fashion.

The right main branch of the tree in Figure 2-20 concerns fracture network conceptual models. Fracture networks can be thought of as material that contains an extensive network 
of fine, i.e., very thin, fractures (note that this is a scale argument; at some scale, small fine fractures behave as a continuum). In the limit, as the number of fractures becomes very large and/or very thin, the material behavior can be modeled as a continuous solid with altered mechanical and hydrologic properties. The altered properties represent damage caused by the fracture network that can be smeared over the domain of interest. This approach is of interest because the material can be treated as a continuous medium, which is relatively easy to model. Performance assessment modeling subsequent to the 1992 calculations have explored this type of conceptual fracturing model. However, at some scale this continuous view of fracture behavior breaks down.

The other main branch on the tree in Figure 2-20 is concerned with modeling discrete fractures. The linear and nonlinear medium branches, just below discrete fractures node, concern material behavior of the medium containing the fracture, i.e., whether the material behaves in a linear or nonlinear fashion. For the WIPP, the medium has generally been considered to be elastic/viscoplastic if the fracture is located primarily in halite and generally elastic if the fracture is contained in the marker bed.

The next issue shown in Figure 2-20 is the relative size of the FPZ with respect to the crack length. The FPZ can be defined in several ways, the simplest being that region near the crack that is dissipating energy through the breaking of atomic bonds, i.e., damaging the material. A more practical definition for the FPZ is that region near the crack that is dissipating energy through any mechanism that is not considered in the underlying continuum model. For example, if the linear elastic analysis is assumed, then the FPZ would include the zone where plastic energy dissipation and friction occur, as well as the region where material damage, atomic bond breaking occurs.

After deciding the aspects of the conceptual fracture model shown in Figure 2-20, other concerns regarding fracture models are determined by boundary-condition assumptions. If the initial fractures are short, i.e., their length is much less than the depth of the repository, the fractures can be thought of as embedded in an infinite medium. If the fractures are few in number and are much longer than the repository depth, the rock above the repository can be modeled as a plate and fracture dilation considered as the displacement of that plate. Again, the constitutive relitions may be linear or nonlinear depending on what concept of the rock materials are considered reasonable. For the WIPP, there is also a third case where the fracture is neither long nor short compared to its depth. In this third region of intermediate 


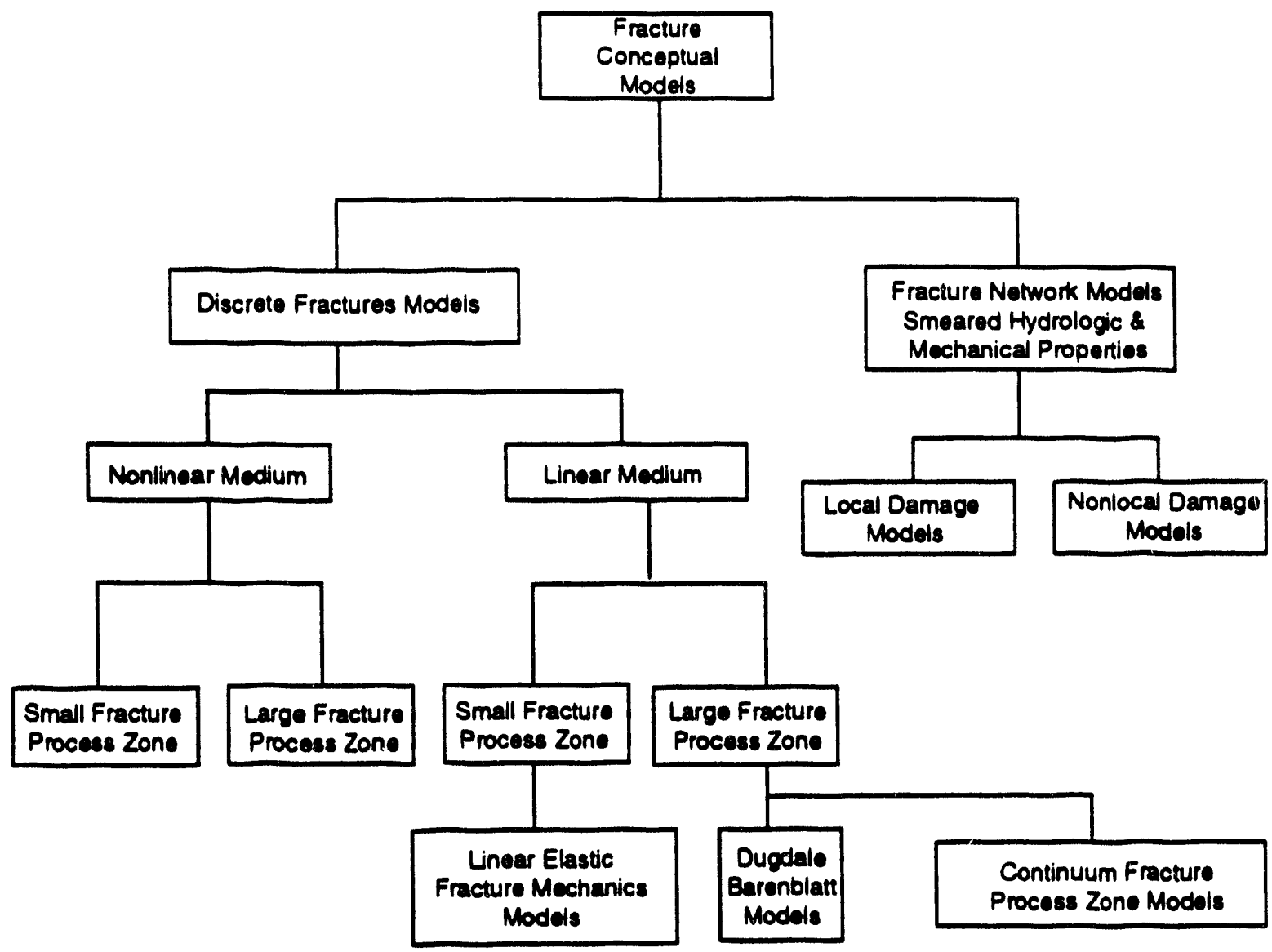

Tryea32-3951 to

Figure 2-20 Fracture conceptual model tree diagram. 
crack length, convenient boundary conditions for closed form analytical solutions of fracture behavior are not currently available. Numerical solutions for this third intermediate case are, however, possible. At the WIPP depth of about $2,200 \mathrm{ft}(660 \mathrm{~m})$, a short crack would roughly be something less than $1,000 \mathrm{ft}(300 \mathrm{~m})$ and a long crack would roughly be greater than $11,000 \mathrm{ft}(3,300 \mathrm{~m})$, with the intermediate cracks in between.

Fracture propagation is also important. The expectation is that a crack moving through the halite will maintain its original orientation until it meets a material weakness. This expectation results from a far-field state of hydrostatic stress in the Salado Formation, which has no unique minimum stress direction and, therefore, implies that cracks moving through the Salado Formation will not be strongly oriented. Material weaknesses are primarily found in the marker beds. The far-field state of stress in the marker beds is unknown; however, they do contain large partially healed sub-horizontal fractures (Borns, 1985). Furthermore, the fracture toughness of the marker beds is expected to be lower than that of the halite, but this has yet to be measured.

This leads to a conceptual model that halite fracturing, if it occurs, is local in nature until the fracture intersects the nearest marker bed, where the fracture will be contained and propagate horizontally away from the repository. Clearly, an alternative conceptual model is that a fracture starts in the halite or clay seam, then turns vertical and runs to the top of the Salado. While this alternative is not expected, a documented rationale rejecting this model is yet to be produced.

Whether fractures propagate quasi-statically (a slow steady process), dynamically (a very rapid pulselike process followed by a period of quiescence), axisymmetrically by fingers, and/or by following the local variation in the anhydrite dip are current areas of investigation. Sensitivity analyses are being conducted to determine the importance of the fracturing model and to determine the extent to which further investigations may be needed.

\subsubsection{Coupling Between Processes}

Sections 2.7.1 through 2.7.5 have discussed many waste-related processes that may independently impact repositcry performance: gas generation, brine and gas flow, brine chemistry, room closure, and room pressurization. In general, these processes are interdependent (Davies et al., 1991; Mendenhall et al., 1991). Many couplings are possible. The Department of Energy (DOE) is addressing these couplings with two approaches. First, 
the PA analysis itself couples appropriate interactions to the extent allowed by computational resources. For example, the simplified reaction-path gas-generation model is being written to allow it to be part of the PA systems codes, if necessary; also, room closure is coupled to fluid flow using a porosity surface inside the PA code. The second approach is the development of advanced deterministic coupled codes, such as PHENIX (a coupled room closure and two-phase flow code), that run specific detailed calculations. These advanced codes are used to determine which couplings are relevant and should be incorporated into the PA analysis. They also run specific benchmark cases, identical to the PA runs, to assess the adequacy of the PA analysis.

\subsubsection{Potential Release Pathways}

A description of potential pathways for contaminants to reach the accessible environment must address: 1) the amounts and characteristics of waste (see Chapter 4), 2) the transport mechanisms required to move the material away from the repository (see previous sections in $2.7), 3$ ) potential release path or paths from the repository to the accessible environinent, and 4) the transport mechanisms associated with movement along the release path (see Chapters 3 and 8). If any of these factors is not present, there will be no predicted release of regulatory interest.

This section is concerned with identifying potential release pathways. Potential release paths within the WIPP repository system fall into four broad categories. These include: 1) those related to the engineered aspects of the repository system (e.g., drum filters and repository ventilation during disposal operations), 2) those involved in direct interactions of engineeredbarrier systems and the natural system (e.g., flow paths around/through panel and shaft seals), 3) the geologic pathways, and 4) pathways resulting from inadvertent human intrusion into the region of the repository (e.g., plugged and unplugged boreholes). Note that release paths through far-field portions of tre geology may exist prior to excavation conditions and may also be generated in response to waste emplacement.

The time-dependent groups of potential contaminant-release pathways at the WIPP are briefly summarized here. For this document, emphasis is placed on pathways of potential interest in loisy, term performance. However, it is recognized that these pathways may generally be the result of long-term interactions within the repository system, often starting at the time of repository construction. 


\subsubsection{Potential Release Paths During the Post-Operation Phase of the Repository}

At the end of the decommissioning process, the potential contaminant-release paths will include flow through the seals and backfill emplaced into the shafts, as well as any remaining DRZ adjacent to the shafts, and will extend from the emplaced waste to the accessible enviornment. As the relative importance of the differential timing of individual wasteemplacement panels, panel and accessway seals, and shaft seals decreases with increasing time following decommissioning, the general degree of complexity which must be considered in evaluating conditions within the repository should decrease. Definition of the lengths and characteristics of the individual release paths, however, still depends upon the assumed permeabilities of individual emplaced panel and shaft seals and intervening lengths of backfill.

\subsubsection{Long-Term Release Paths at the Repository Scale in the Absence of Human Intrusion}

\subsection{Lateral release paths through the Salado Formation}

The portion of the Salado Formation where the WIPP repository is being constructed consists of a bedded sequence of halitic and non-halitic units. The non-halitic units of most interest are anhydritic marker beds present immediately above and below the repository horizon. Potential lateral release paths to regulatory boundaries may exist in the Salado Formation, especially in anhydritic units, in two general directions: 1) from the emplaced waste towards the boundary; and/or 2) from the emplaced waste to the base of one or more of the WIPP shafts or to boreholes drilled from the surface.

The effective thickness of the repository as a function of time, i.e., the thickness of stratigraphic units within the Salado which may include potential release paths, will depend on both the extent of creep closure of the repository and the extent to which both any DRZ at and near the repository horizon and any pre-existing boreholes remain connected with the repository horizon for purposes of contaminant transport. Definition of these potential paths requires characterization of: 1) the extent to which the halite interval between the floor of the repository workings and the top of MB 139 will isolate the waste from MB 139,2) the extent to which the area above the collapsed rooms is expected to include long-term highpermeability pathways to MB 138,3 ) the extent to which boreholes within the repository, drilled for purposes of either stratigraphic definition or gas-pressure relief, are expected to be 
maintained as high-permeability pathways to units above and/or below the repository horizon, and 4) the extent to which the shaft sumps might provide long-term contaminant access to potential pathways below the repository horizon.

In general, and in the absence of significant waste-generated gas, any lateral release path between the WIPP repository and the land-withdrawal boundary will extend through a rock mass which is largely undisturbed by the presence of the repository, although it will be affected by the extent and nature of any DRZ at and near the repository horizon. To the extent that the volume of rock affected by the repository is increased as a response to waste emplacement, e.g., in the event of dilation/fracturing in response to gas generation, the DRZ would play an increasing role as a function of time.

In contrast, if a relatively continuous $D R Z$ is present connecting waste-emplacement panels to the main accessways, and hence to the base of the shafts, a direct release path (or paths) may exist between the waste and the bottom of the shafts. Depending upon the relative permeabilities of the DRZ and emplaced seals and backfill, the release path may be primarily contained in the DRZ, if it exists. Excavation-induced fracturing beneath the floor, including MB 139, may provide a continuous pathway between waste-emplacement panels and the base of the shiafts or may be sealed by reconsolidation by the halite.

\subsection{Vertical (upward) release paths to the top of the Salado Formation}

In the absence of inadvertent human intrusion, six factors might lead to the presence of vertical flow paths from the emplaced waste. One or more of these paths might extend to a regulatory boundary: 1) vertical flow through the sealed shafts, 2) flow through any remaining DRZ related to the presence of the shafts, 3) vertical extension of any DRZ from the repository horizon, connecting the horizon with adjacent marker beds, 4) the presence of pre-existing borcholes within the repository, 5) the presence of ineffectively plugged boreholes from the ground surface within the land-withdrawal boundary that penetrate the repository horizon, and 6) any vertical structure within the Salado Formation resulting from the presence of the repository.

The shafts are an obvious potential vertical flow path through the Salado Formation. During disposal operations, the shafts will be a direct ventilation pathway. Only limited DRZ development adjacent to the shafts is expected. To the extent that any DRZ develops and 
persists adjacent to the shafts after seal emplacement, this DRZ may provide an additional release path.

Persistence of the DRZ near the repository horizon and/or of relatively permeable boreholes drilled from within the horizon may increase the effective thickness of the repository horizon by interconnecting it with adjacent stratigraphic zones. However, in the absence of inadvertent drilling into the repository itself, neither of these factors is expected to extend any great vertical distance.

However, several boreholes that reach the repository horizon, such as ERDA-9, already exist within the WIPP land-withdrawal boundary. The DOE is committed to plugging all of these holes.

Thus, under undisturbed conditions, two types of potential contaminant-release paths are expected within the Salado Formation: 1) potential lateral flow paths, extending from the emplaced waste to the site boundary within the Salado Formation; and 2) potential (combined) lateral and vertical flow paths, extending from the emplaced waste to and up the shafts, to the top of the Salado. Preliminary evaluations of the relative importance of these two broad types of release paths are contained in SNL (1992) and Helton et al. (1993).

\subsection{Lateral Release Through Unaltered Rustler Formation or Rustler Formation Potentially Altered by Potash Mining}

Overlying stratigraphic units must also be considered. To date, attention has focused on the Rustler Formation because of its higher permeability relative to other units. Within the Rustler Formation, the same combination of possible lateral and vertical release paths must be considered as in the Salado.

Based on potash-mining experience to date within the Delaware Basin, it appears that such mining can lead to generation/propagation of fractures directly to the land surface without increasing permeability significantly within the Salado Formation itself. This is apparently due to the creep characteristics of the predominantly halitic Salado, which is unable to sustain open fractures. 
However, the relatively brittle dolomites of the Rustler Formation do appear capable of supporting open fractures. Therefore, two sets of possible release paths within the Rustler Formation will be considered in evaluation of WIPP regulatory compliance:

- Release paths within the undisturbed Rustler Formation, in which conditions change only in response to climate/meteorological variations.

- Release paths within a Rustler Formation which has altered in response to potash extraction adjacent to the WIPP site. The qualitative expectation is that faulting in response to subsidence following extraction might locally increase Rustler permeabilities significantly.

To date, the need to include consideration of future potash mining on repository performance has been recognized; however, it was not included in the 1992 PA report.

\subsubsection{Release Paths in Response to Inadvertent Human Intrusion into the Repository}

Inadvertent human intrusion into the WIPP repository adds an additional series of potential contaminant-release paths for consideration. These flowpaths connect some or all of the repository with the land surface, with stratigraphic units between the repository and the land surface, and/or with deeper units. The nature of these pathways is very time-dependent.

Direct transport of liquid, gas, and/or particulate materials to the surface, in immediate response to a borehole intersecting the repository, may occur, depending on fluid-pressure relationships between the borehole and the repository. Particulates and/or solids may be directly removed from the repository as cuttings and/or core. If drilling continues, borehole erosion/spalling may both increase the effective borehole diameter and lead to increased releases.

The existence of specific potential release paths is dependent upon specific definition/assumption of the numbers, diameters, relative timing, locations, and the penetration of underlying pockets of Castile brines. The estimated constitutive properties of units intersected by the boreholes, waste/backfill, and engineered systems (panel seals) within the repository, borehole casings, and borehole plugs will control the long-term significance of any specific potential release path. 
In the long-term, it is assumed that any borehole inadvertently intersecting the WIPP repository or its "footprint," as projected at the land surface, will be plugged according to industry practice. However, the cementitious materials normally used in this practice are not permanently effective. Therefore, evaluation of the long-term characteristics and impacts of individual intrusion boreholes requires consideration of the long-term characteristics of both borehole plugs and borehole casings. As plugs and casings deteriorate with time, contaminants may be transported to the accessible environment depending on the final condition of the borehole.

Performance assessment calculations to date are also based on multiple borehole intrusions into the repository over 10,000 years. Thus, in addition to the characteristics of the flowpaths within the individual boreholes, it is necessary to estimate the properties of the flowpath or flowpaths connecting the pair or pairs of intrusion boreholes. For assumed boreholes within a single waste-emplacement panel, this only requires definition of the contaminant-transport characteristics within that panel. However, for pairs of boreholes which are in separate waste-emplacement panels (or which include one hole in a wasteemplacement panel and one penetrating within a fluid-accessible distance outside that panel, (e.g., perhaps in the repository "footprint" or in one of the accessways), the fluid-flow characteristics along the extended flowpath must also be defined. 


\subsection{References}

Allison, G.B., 1982. "The Relationship Between ${ }^{18} \mathrm{O}$ and Deuterium in Water in Sand Columns Undergoing Evaporation," Joumal of Hydrology, Vol. 55, pp. 163-169.

Allison, G.B., W.J. Stone, and M.W. Hughes, 1985. "Recharge in Karst and Dune Elements of a Semi-Arid Landscape as Indicated by Natural Isotopes and Chloride," Journal of Hydrology, Vol. 76, pp. 1-25.

Anderson, R.Y., 1981. "Deep-Seated Salt Dissolution in the Delaware Basin, Texas and New Mexico," Environmental Geology and Hydrology in New Mexico, Eds. S. G. Wells and W. Lambert, New Mexico Geological Society Special Publication No. 10., Roswell, NM, New Mexico Geological Society, pp. 133-145.

Bachman, G.O., 1984. Regional Geology of Ochoan Evaporites, Northern Part of Delaware Basin. New Mexico Bureau of Mines and Mineral Resources Circular 184, Socorro, NM, New Mexico Bureau of Mines and Mineral Resources.

Bachman, G.O., 1985. Assessment of Near-Surface Dissolution at and Near the Waste Isolation Pilot Plant (WIPP), Southeastern New Mexico, SAND84-7178, Albuquerque, NM, Sandia National Laboratories.

Bachman, G.O., 1987. Karst in Evaporites in Southeastem New Mexico, SAND86-7078, Albuquerque, NM, Sandia National Laboratories.

Beauheim, R.L., 1986. Hydraulic-Test Interpretations for Well DOE-2 at the Waste Isolation Pilot Plant (WIPP) Site, SAND86-1364, Albuquerque, NM, Sandia National Laboratories.

Beauheim, R.L., 1987. Interpretations of Single-Well Hydraulic Tests Conducted At and Near the Waste Isolation Pilot Plant (WIPP) Site. 1983-1987, SAND87-0039, Albuquerque, NM, Sandia National Laboratories.

Beauheim, R.L., B.W. Hassinger, and J.A. Klaiber, 1983. Basic Data Report for Borehole Cabin Baby-1 Deepening and Hydrologic Testing, WTSD-TME-020, Albuquerque, NM, U.S. DOE. 
Beauheim, R.L., G.J. Saulnier, Jr., and J.D. Avis, 1991. Interpretation of Brine-Permeability Tests of the Salade Formation at the Waste Isolation Pilot Plant Site: First Interim Report, SAND90-0083, Albuquerque, NM, Sandia National Laboratories.

Beauheim, R.L., R.M. Roberts, T.F. Dale, M.D. Fort, W.A. Stenbrud, 1993. Hydraulic Testine of Salado Formation Evaporites at the Waste Isolation Pilot Plant Site: Second Interpretive Report, SAND92-0533, Albuquerque, NM, Sandia National Laboratories.

Beauheim, R.L., and R.M. Holt, 1990. "Hydrogeology of the WIPP Site," Geological and Hydrological Studies of Evaporites in the Northern Delaware Basin for the Waste Isolation Pilot Plant (WIPP). New Mexico, Geological Society of America 1990 Anuual Meeting Field Trip \#14 Guidebook, Dallas, TX, Dallas Geological Society, pp. 131-179.

Bechtel, Inc., 1986. Design Validation Final Report, DOE/WIPP-86-010, prepared for U.S. Department of Energy, San Francisco, CA, Bechtel National, Inc.

Berglund, J.W., 1992. Mechanisms Goverming the Direct Removal of Wastes from the Waste Isolation Pilot Plant Repository Caused by Exploratory Drilling, SAND92-7295, Albuquerque, NM, Sandia National Laboratories.

Bertram-Howery, S.G., M.G. Marietta, R.P. Rechard, P.N. Swift, D.R. Anderson, B.L. Baker, J.E. Bean, Jr., W. Beyeler, K.F. Brinster, R.V. Guzowski, J.C. Helton, R.D. McCurley, D.K. Rudeen, J.D. Schreiber, and P. Vaughn, 1990. Preliminary Comparison with 40 CER Part 191. Subpart B for the Waste Isolation Pilot Plant. December 1990, SAND90-2347, Albuquerque, NM, Sandia National Laboratories.

Boms, D.J., 1985. Marker Bed 139: A Study of Drillcore from a Systematic Amay, SAND850023, Albuquerque, NM, Sandia National Laboratories.

Borns, D.J., L.J. Barrows, D.W. Powers, and R.P. Snyder, 1983. Deformation of Evaporites Near the Waste Isolation Pilot Plant (WIPP) Site, SAND82-1069, Albuquerque, NM, Sandia National Laboratories.

Boms, D.J., and J.C. Stormont, 1988. An Interim Report on Excavation Effect Studies at the Waste Isolation Pilot Plant: The Delineation of the Disturbed Rock Zone, SAND87-1375, Albuquerque, NM, Sandia National Laboratories. 
Borns, D.J., and J.C. Stormont, 1989. "The Delineation of the Disturbed Rock Zone Surrounding Excavations in Salt," Rock Mechanics as a Guide for Efficient Utilization of Natural Resources: Proceedings of the 30th US Symposium. West Virginia University, Morgantown, WV, June 19-22, 1989, Ed. A.W. Khair, SAND88-2230C, Brookfield, VT, A.A. Balkema, pp. 353-360.

Brausch, L.M., A.K. Kuhn, and J.K. Register, 1982. Natural Resources Study, Waste Isolation Pilot Plant (WIPP) Project. Southeastern. New Mexico, WTSD-TME-3156, Albuquerque, NM, D'Appolonia Consulting Engineers.

Brinster, K.F., 1991. Preliminary Geohydrologic Conceptual Model of the Los Medaños Region Near the Waste Isolation Pilot Plant for the Purpose of Performance Assessment, SAND89-7147 and addendum, Albuquerque, NM, Sandia National Laboratories.

Brookins, D.G., S.J. Lambert, and D.B. Ward, 1990. Authigenic Clay Minerals in the Rustler Formation. WIPP Site. New Mexico, SAND89-1405, Albuquerque, NM, Sandia National Laboratories.

Brookins, D.G., and S.J. Lambert, 1988. "WIPP Site Studies: Secondary Selenite Veins in the Rustler Formation and Dewey Lake Red Beds," Scientific Basis for Nuclear Waste Management XI. Boston, MA. November 30-December 3. 1987, Eds. M.J. Apted and R.E. Westerman, SAND87-1610J, Pittsburgh, PA, Materials Research Society, Vol. 112, pp. 233-241.

Burkholder, H.C., 1980. Engineered Components for Radioactive Waste Isolation Systems Are They Technically Justified?, ONWI-286, Columbus, Ohio, Office of Nuclear Waste Isolation, Battelle Memorial Institute.

Butcher, B.M. and F.T. Mendenhall, 1993. Summary of the Models Used for the Mechanical Response of Disposal Rooms in the Waste Isolation Pilot Plant with Regard to Compliance with 40 CFR 191. Subpart B, SAND92-0427, Albuquerque, NM, Sandia National Laboratories.

Cauffman, T.L., A.M. LaVenue, and J.P. McCord, 1990. Ground-Water Flow Modeling of the Culebra Dolomite. Volume II: Data Base, SAND89-7068/2, Albuquerque, NM, Sandia National Laboratories. 
Chapman, J.B., 1986. Stable Isotopes in Southeastern New Mexico Groundwater: Implications for Dating Recharge in the WIPP Area, EEG-35, Santa Fe, NM, Environmental Evaluation Group.

Chapman, J.B., 1988. Chemical and Radiochemical Characteristics of Groundwater in the Culebra Dolomite. Southeastern New Mexico, EEG-39, Santa Fe, NM, New Mexico Environmental Evaluation Group.

Cheeseman, R.J., 1978. "Geology and Oil/Potash Resources of the Delaware Basin, Eddy and Lea Counties, New Mexico," Geology and Mineral Deposits of Ochoan Rocks in Delaware Basin and Adjacent Areas, Ed. G.S. Austin, New Mexico Bureau of Mines and Mineral Resources Circular 159, Socorro, NM, New Mexico Bureau of Mines and Mineral Resources, pp. 7-14.

Cole, F.W., 1975. Introduction to Meteorology, 2nd. ed., New York, NY, John Wiley and Sons, Inc.

Corbet, T.F., and M.G. Wallace, 1993. "Post-Pleistocene Patterns of Shallow Groundwater Flow in the Delaware Basin, Southeastern New Mexico and West Texas," New Mexico Geological Society Guidebook. 44th Field Conference, Carlsbad Region. New Mexico and West Texas, SAND93-1318J, pp. 321-325.

Craig, R.W., R.L. Reen, and R.W. Spengler, 1983. Geohydrologic Data for Test Well USW H-6 Yucca Mountain Area, Nye County, Nevada, Open-File Report 83-856, Denver, CO, U.S. Department of Energy.

Davies, P.B., 1984. "Deep-Seated Dissolution and Subsidence in Bedded Salt Deposits," Ph.D. dissertation, Stanford, CA, Department of Applied Earth Sciences, Stanford University.

Davies, P.B., 1989. Variable-Density Ground-Water Flow and Paleohydrology in the Waste Isolation Pilot Plant (WIPP) Region. Southeastem New Mexico, U.S. Geological Survey OpenFile Report 88-490, Albuquerque, NM, U.S. Geological Survey.

Davies, P.B., L.H. Brush, and F. T. Mendenhall, 1991. "Assessing the Impact of WasteGenerated Gas from the Degradation of Transuranic Waste at the Waste Isolation Pilot Plant: An Overview of Strongly Coupled Chemical, Hydrologic and Structural Processes," Waste- 
Generated Gas at the Waste Isolation Pilot Plant: Papers Presented at the Nuclear Energy Agency Workshop on Gas Generation and Release from Radioactive Waste Repositories, Eds. P.B. Davies, L.H. Brush, M.A. Molecke, F.T. Mendenhall, and S.W. Webb, SAND91-2378, Albuquerque, NM, Sandia National Laboratories. pp. 1-1 through 1-24.

Deal, D.E. and F.J. Abitz, D.S. Belski, J.B. Case, M.E. Crawley, R.M. Deshler, P.E. Drez, C.A. Givens, R.B. King, B.A. Lauctes, J. Myers, S. Niou, J.M. Peitz, W.M. Roggentl en, J.R. Tyburski, and M.G. Wallace, 1989. Brine Sampling and Evaluation Program, 1988 Report, DOE/WIPP 89-015, Section 4.1, 1989.

Deal, D.E., R.J. Abitz, J. Myers, M.L. Martin, D.J. Milligan, R.W. Sobocinski, P.P.J. Lipponer, and D.S. Belski. 1993, Brine Sampling and Evaluation Program. 1991 Report, DOE-WIPP 93-026, Carlsbad, NM, Westinghouse Electric Corporation.

Earth Technology Corporation, 1988. Final Report for Time Domain Electromagnetic (TDEM) Surveys at the WIPP Site, SAND87-7144, Albuquerque, NM, Sandia National Laboratories.

Finley, S.J., D.J. Hanson, and R. Parsons, 1992. Small-Scale Brine Inflow Experiments - Data Report Through 6/6/91, SAND91-1956, Albuquerque, NM, Sandia National Laboratories.

Fujita, T.T., 1978. A Site-Specific Study of Wind and Tornado Probabilities at the WIPP Site in Southeast New Mexico, Research Pajer No. 155, Satellite and Mesometeorology Research Project, Chicago, Illinois, Department of Geophysical Sciences, University of Chicago.

Geohydrology Associates, Inc., 1979. Water-Resources Study of the Carlsbad Potash Area, New Mexico, Consultant Report for the U.S. BLM, Contract No. YA-S12-CT8-195 (Copy on file in the Waste Management and Transportation Library, Sandia National Laboratories, Albuquerque, NM).

Geological Society of America, Inc., 1984. Decade of North American Geology Geologic Time Scale, Geological Society of America Map and Chart Series MCH050, Boulder, CO, Geological Society of America, Inc.

Guzowski, R.V., 1991. Evaluation of Applicability of Probability Techniques to Determining the Probability of Occurrence of Potentially Disruptive Intrusive Events at the Waste Isolation Pilot Plant, SAND90-7100, Albuquerque, NM, Sandia National Laboratories. 
Hale, W.E., and A. Clebsch, Jr., 1958. Preliminary Appraisal of Ground-Water Conditions in Southeastern Eddy County and Southwestern Lea County. New Mexico, Trace Elements Memorandum Report 1045, United States Department of the Interior, Geological Survey (Copy on file in the Waste Management and Transportation Library, Sandia National Laboratories, Albuquerque, NM).

Harms, J.C., and C.R. Williamson, 1988. "Deep-Water Density Current Deposits of Delaware Mountain Group (Permian), Delaware Basin, Texas and New Mexico," American Association of Petroleum Geologists Bulletin, Vol. 72, No. 3, pp. 299-317.

Haug, A., V.A. Kelley, A.M. LaVenue, and J.F. Pickens, 1987. Modeling of Ground-Water Flow in the Culebra Dolomite at the Waste Isolation Pilot Plant (WIPP) Site: Interim Report, SAND86-7167, Albuquerque, NM, Sandia National Laboratories.

Helton, J.C., J.E. Bean, Jr., B.M. Butcher, J.W. Garner, J.D. Schreiber, P.N. Swift, and P. Vaughn, 1993. Uncertainty and Sensitivity Analyses for Gas and Brine Migration at the Waste Isolation Pilot Plant. May 1992, SAND92-2013, Albuquerque, NM, Sandia National Laboratories.

Hills, J.M., 1984. "Sedimentation, Tectonism, and Hydrocarbon Generation in Delaware Basin, West Texas and Southeastern New Mexico," American Association of Petroleum Geologists Bulletin, Vol. 68, No. 3, pp. 250-267.

Hiss, W.L., 1975. "Stratigraphy and Ground-Water Hydrology of the Capitan Aquifer, Southeastern New Mexico and West Texas," Ph.D. dissertation, Boulder, CO, University of Colorado.

Holt, R.M., and D.W. Powers, 1988. Facies Variability and Post-Depositional Alteration Within the Rustler Eormation in the Vicinity of the Waste Isolation Pilot Plant. Southeastern New Mexico, DOE/WIPP-88-004, Carlsbad, NM, Westinghouse Electric Corporation.

Holt, R.M., and D.W. Powers, 1990. Geologic Mappine of the Air Intake Shaft at the Waste Isolation Pilot Plant, DOE-WIPP 90-051, Carlsbad, NM, Westinghouse Electric Corporation.

Hubbert, M.K, 1940. "The Theory of Ground-Water Motion," The Joumal of Geology, Vol. 48, No. 8, Pt. 1, pp. 785-944. 
Hunter, R.L., 1985. A Regional Water Balance for the Waste Isolation Pilot Plant (WIPP) Site and Surrounding Area, SAND84-2233, Albuquerque, NM, Sandia National Laboratories.

Jones, C.L., 1978. Test Drilling for Potash Resources: Waste Isolation Pilot Plant Site, Eddy County, New Mexice, U.S. Geological Survey Open-File Report 78-592, Denver, CO, U.S. Geological Survey.

Kelley, V.A., and J.F. Pickens, 1986. Interpretation of the Convergent-Flow Tracer Tests Conducted in the Culebra Dolomite at the $\mathrm{H}-3$ and $\mathrm{H}-4$ Hydropads at the Waste Isolation Pilot Plant (WIPP) Site, SAND86-7161, Albuquerque, NM, Sandia National Laboratories.

Kelley, V.A., and G.J. Saulnier, Jr., 1990. Core Analyses for Selected Samples from the Culebra Dolomite at the Waste Isolation Pilot Plant, SAND90-7011, Albuquerque, NM, Sandia National Laboratories.

Lambert, S.J., 1983. Dissolution of Evaporites in and Around the Delaware Basin, Southeastern New Mexico and West Texas, SAND82-0461, Albuquerque, NM, Sandia National Laboratories.

Lambert, S.J., 1989. "Isotopic Constraints on the Rustler and Dewey Lake Groundwater Systems," Hydrogeochemical Studies of the Rustler Formation and Related Rocks in the WIPP Area. Southeastern New Mexico, M.D. Siegel, S.J. Lambert, and K.L. Robinson, eds., SAND88-0196, Albuquerque, NM, Sandia National Laboratories.

Lambert, S.J., 1991. "Isotopic Constraints on the Rustler and Dewey Lake Groundwater Systems," Hydrogeochemical Studies of the Rustler Formation and Related Rocks in the Waste Isolation Pilot Plant Area, Southeastem New Mexico, Eds. M.D. Siegel, S.J. Lambert, and K.L. Robinson, SAND88-1096, Albuquerque, NM, Sandia National Laboratories.

Lambert, S.J., and J.A. Carter, 1984. Uranium-Isotope Disequilibrium in Brine Reservoirs of the Castile Formation. Northern Delaware Basin, Southeastern New Mexico. I: Principles and Methods, SAND83-0144, Albuquerque, NM, Sandia National Laboratories.

Lambert, S.J., and J.A. Carter, 1987. Uranium-Isotope Systematics in Groundwaters of the Rustler Formation. Northem Delaware Basin. Southeastern New Mexico. I: Principles and Preliminary Results, SAND87-0388, Albuquerque, NM, Sandia National Laboratories. 
Lambert, S.J., and D.M. Harvey, 1987. Stable-Isotope Geochemistry of Groundwaters In the Delaware Basin of Southeastern New Mexico, SAND87-0138, Albuquerque, NM, Sandia National Laboratories.

Lappin, A.R., 1988. Summary of Site-Characterization Studies Conducted from 1983 through 1987 at the Waste Isolation Pilot Plant (WIPP) Site. Southeastern New Mexico, SAND88-0157, Albuquerque, NM, Sandia National Laboratories.

Lappin, A.R., R.L. Hunter, D.P. Garber, P.B. Davies, R.L. Beauheim, D.J. Borns, L.H. Brush, B.M. Butcher, T. Cauffman, M.S.Y. Chu, L.S. Gomez, R.V. Guzowski, H.J. Iuzzolino, V. Kelley, S.J. Lambert, M.G. Marietta, J.W. Mercer, E.J. Nowak, J. Pickens, R.P. Rechard, M. Reeves, K.L. Robinson, and M.D. Siegel, eds., 1989. Systems Analysis, Long-Term Radionuclide Transport. and Dose Assessments. Waste Isolation Pilot Plant (WIPP) Southeastern New Mexico: March 1989, SAND89-0462, Albuquerque, NM, Sandia National Laboratories.

LaVenue, A.M., A. Haug, and V.A. Kelley, 1988. Numerical Simulation of Groundwater Flow in the Culebra Dolomite at the Waste Isolation Pilot Plant (WIPP) Site: Second Interim Report, SAND88-7002, Albuquerque, NM, Sandia National Laboratories.

LaVenue, A.M., T.L. Cauffman, and J.F. Pickens, 1990. Ground-Water Flow Modeling of the Culebra Dolomite: Volume 1-Model Calibration, SAND89-7068/1, Albuquerque, NM, Sandia National Laboratories.

Lenormand, R., E. Touboul, and C. Zarcone, 1988. "Numerical Models and Experiments on Immiscible Displacements in Porous Media," Joumal of Fluid Mechanics, Vol. 189, pp. 165187.

McTigue, D.F., 1993. Permeability and Hydraulic Diffusivity of Waste Isolation Pilot Plant Repository Salt Inferred from Small-Scale Brine Inflow Experiments, SAND92-1911, Albuquerque, NM, Sandia National Laboratories.

Mendenhall, F.T., B.M. Butcher, and P.B. Davies, 1991. "Investigations into the Coupled Fluid Flow and Mechanical Creep Closure Behavior of Waste Disposal Rooms in Bedded Salt," Waste-Generated Gas at the Waste Isolation Pilot Plant: Papers Presented at the Nuclear Energy Agency Workshop on Gas Generation and Release from Radioactive Waste Repositories, Eds. 
P.B. Davies, L.H. Brush, M.A. Molecke, F.T. Mendenhall, and S.W. Webb, SAND91-2378. Albuquerque, NM, Sandia National Laboratories, pp. 3-1 through 3-15.

Mercer, J.W., 1983. Geohydrology of the Proposed Waste Isolation Pilot Plant Site, Los Medaños Area, Southeastern New Mexico, Water-Resources Investigations Report 83-4016, Albuquerque, NM, U.S. Geological Survey.

Mercer, J.W., and B.R. Orr, 1979. Interim Data Report on Geohydrology of the Proposed Waste Isolation Pilot Plant Site, Southeast New Mexico, U.S. Geological Survey WaterResources Investigations 79-98, Albuquerque, NM, U.S. Geological Survey.

Nativ, R., and D.A. Smith, 1987. "Hydrogeology and Geochemistry of the Ogallala Aquifer, Southern High Plains," Joumal of Hydrology, Vol. 1.

Nowak, E.J., and D.F. McTigue, 1987. Interim Results of Brine Transport Studies in the Waste Isolation Pilot Plant, SAND87-0880, Albuquerque, NM, Sandia National Laboratories.

Osmond, J.K., and J.B. Cowart, 1976. "The Theory and Uses of Natural Uranium Iostopic Variations in Hydrology," Atomic Energy Review, Vol. 14, pp. 621-679.

Popielak, R.S., R.L. Beauheim, S.R. Black, W.E. Coons, C.T. Ellingson, and R.L. Olsen, 1983. Brine Reservoirs in the Castile Formation. Waste Isolation Pilot Plant (WIPP) Project. Southeasterm New Mexico, TME 3153, Albuquerque, NM, U.S. DOE.

Powers, D.W., S.J. Lambert, S-E. Shaffer, L.R. Hill, and W.D. Weart, eds., 1978a. Geological Characterization Report. Waste Isolation Pilot Plant (WIPP) Site, Southeastern New Mexico, SAND78-1596, Albuquerque, NM, Sandia National Laboratories, Vol. I.

Powers, D.W., S.J. Lambert, S-E. Shaffer, L.R. Hill, and W.D. Weart, eds., 1978b. Geological Characterization Report. Waste Isolation Pilot Plant (WIPP) Site. Southeastem New Mexico, SAND78-1596, Albuquerque, NM, Sandia National Laboratories, Vol. II.

Powers, D.W. and R.M. Holt, 1990. "Sedimentology of the Rustler Formation near the Waste Isolation Pilot Plant (WIPP) Site," Geological and Hydrological Studies of Evaporites in the Northerm Delaware Basin for the Waste Isolation Pilot Plant (WIPP). New Mexice. Geological Society of America 1990 Annual Meeting. Dallas. IX. October 29 - November 1 
1990, Geological Society of America 1990 Annual Meeting, Field Trip \#14 Guidebook, Dallas, TX, Dallas Geological Society, pp. 79-106.

Ramey, D.S., 1985. Chemistry of Rustler Fluids, EEG-31, Santa Fe, NM, New Mexico Environmental Evaluation Group.

Randall, W.S., M.E. Crawley, and M.L. Lyon, 1988. 1988 Annual Water Quality Data Report for the Waste Isolation Pilot Plant. March 1988, DOE/WIPP 88-006, Westinghouse Electric Corproation, Carlsbad, NM.

Robinson, T.W., and W.B. Lang, 1938. Geology and Ground-Water Conditions of the Pecos River Valley in the Vicinity of Laguna Grande de la Sal. New Mexico. With Special Reference to the Salt Content of the River Water, New Mexico State Engineer 12th-13th Biennial Reports 1934-1938, Santa Fe, NM, State Engineer, pp. 77-100.

Sandia National Laboratories (SNL), 1992. Preliminary Performance Assessment for the Waste Isolation Pilot Plant. December 1992, SAND92-0700/1-5, Albuquerque, NM.

Saulnier, G.J., Jr., and J.D. Avis, 1988. Interpretation of Hydraulic Tests Conducted in the Waste-Handling Shaft at the Waste Isolation Pilot Plant (WIPP) Site, SAND88-7001, Albuquerque, NM, Sandia National Laboratories.

Siegel, M.D., J.O. Leckie, S.W. Park, S.L. Phillips, and T. Sewards, 1990. Studies of Radionuclide Sorption by Clays in the Culebra Dolomite at the Waste Isolation Pilot Plant Site. Southeastem New Mexico, SAND89-2387, Albuquerque, NM, Sandia National Laboratories.

Siegel, M.D., S.J. Lambert, and K.L. Robinson, eds., 1991. Hydrogeochemical Studies of the Rustler Formation and Related Rocks in the Waste Isolation Pilot Plant Area. Southeastern New Mexico, SAND88-0196, Albuquerque, NM, Sandia National Laboratories.

Sewards, T., 1991. Characterization of Eracture Surfaces in Dolomite Rock. Culebra Dolomite Member. Rustler Formation, SAND90-7019, Albuquerque, NM, Sandia National Laboratories.

Sewards, T., M.L. Williams, and K. Keil, 1991a. Mineralogy of the Culebra Dolomite Member of the Rustler Formation, SAND90-7008, Albuquerque, NM, Sandia National Laboratories. 
Sewards, T., R. Glenn, and K. Keil, 1991b. Mineralogy of the Rustler Formation in the WIPP19 Core., SAND87-7036, Albuquerque, NM, Sandia National Laboratories.

Sewards, T., A. Brearley, R. Glenn, I.D.R. MacKinnon, and M.D. Siegel, 1992. Nature and Genesis of Clay Minerals of the Rustler Formation in the Vicinity of the Waste Isolation Pilot Plant in Southeastem New Mexice, SAND90-2569, Albuquerque, NM, Sandia National Laboratories.

Silva, M.K., and J.K. Channell, 1992. Implications of Oil and Gas Leases at the WIPP on Compliance with EPA TRU Waste Disposal Standards, EEG-50, Albuquerque, NM, Environmental Evaluation Group.

Snyder, R.P., 1985. Dissolution of Halite and Gypsum, and Hydration of Anydrite to Gypsum. Rustler Formation, in the Vicinity of the Waste Isolation Pilot Plant. Southeastern New Mexico, Open-File Report 85-229, Denver, CO, U.S. Geological Survey.

Stensrud, W.A., M.A. Bame, K.D. Lantz, J.B. Palmer, and G.J. Saulnier, Jr., 1988. WIPP Hydrology Program. Waste Isolation Pilot Plant. Southeastem New Mexico. Hydrologic Data Report \#7. Parts: A. WIPP-30, WIPP-12, and P-18 Slug Tests, B. H-11b4 Drill-Stem, Slug, and Pumping Test. C. H-18 Pumping Test. D. Water-Level Data, SAND88-7014, Albuquerque, NM, Sandia National Laboratories.

Stormont, J.C., E.W. Peterson, and P.L. Lagus, 1987. Summary and Observations About WIPP Facility Horizon Flow Measurements Through 1986, SAND87-0176, Albuquerque, NM, Sandia National Laboratories.

Swift, P.N., 1991. Appendix A: Climate and recharge variability parameters for the 1991 WIPP PA calculations. Preliminary Comparison with 40 CFR Part 191. Subpart B for the Waste Isolation Pilot Plant. December 1991 - Volume 3: Reference Data. WIPP Performance Assessment Division (Report Author), Albuquerque, NM, Sandia National Laboratories, A-107 through A-122.

Swift, P.N., 1992. Long-Term Climate Variability at the Waste Isolation Pilot Plant. Southeastem New Mexico. USA, SAND91-7055, Albuquerque, NM, Sandia National Laboratories. 
Tóth, J., 1963. "A Theoretical Analysis of Groundwater Flow in Small Drainage Basins," Journal of Geophysical Research, Vol. 68, No. 16, pp. 4795-4812.

Trauth, K.M., S.C. Hora, R.P. Rechard, and D.R. Anderson, 1992. The Use of Expert Judement to Ouantify Uncertainty in Solubility and Sorption Parameters for Waste Isolation Plant Performance Assessment, SAND92-0479, Albuquerque, New Mexico, Sandia National Laboratories.

Tsang, Y.W., and C.F. Tsang, 1987. "Channel Model of Flow Through Fractured Media," Water Resources Research, Vol. 23, No. 3, pp. 467-479.

Tsang, Y.W., and C.F. Tsang, 1989. "Flow Channeling in a Single Fracture as a TwoDimensional Strongly Heterogeneous Permeable Medium, "Water Resources Research, Vol. 25 , No. 9, pp. 2076-2080.

University of New Mexico, 1989. New Mexico Statistical Abstract 1989, Albuquerque, NM, Bureau of Business and Economic Research, University of New Mexico.

U.S. Department of Energy (DOE), 1980a. Einal Environmental Impact Statement: Waste Isolation Pilot Plant, DOE/EIS-0026, Washington, D.C., U.S. Department of Energy, Vols. 1-2.

U.S. Department of Energy (DOE), 1980b. Waste Isolation Pilot Plant Safety Analysis Report, Washington, D.C., U.S. Department of Energy, Vols. 1-5.

U.S. Department of Energy (DOE), 1988. DOE Order 5400.1. General Environmental Protection Program, Washington, D.C.

U.S. Department of Energy (DOE), 1990a. Einal Safety Analysis Report. Waste Isolation Pilot Plant, WP 02-9, Rev. 0., Carlsbad, NM, Westinghouse Electric Corporation.

U.S. Department of Energy (DOE), 1990b. Einal Supplement: Environmental Impact Statement. Waste Isolation Pilot Plant, DOE/EIS-0026-FS, Washington, D.C., U.S. Department of Energy, Office of Environmental Restoration and Waste Management. 
U.S. Department of Energy (DOE), 1992a. Statistical Summary of the Radiological Baseline Program for the Waste Isolation Pilot Plant, DOE/WIPP 92-037, Westinghouse Electric Corporation, Carlsbad, New Mexico.

U.S. Department of Energy (DOE), 1992b. Waste Isolation Pilot Plant Site Environmental Report for Calendar Year 1991, DOE/WIPP 92-017, Westinghouse Electric Corporation, Carlsbad, New Mexico.

U.S. Department of Energy (DOE), 1993. Waste Isolation Pilot Plant Site Environmental Report for Calendar Year 1992, DOE/WIPP 93-017, Westinghouse Electric Corporation, Carlsbad, New Mexico.

U.S. Department of Energy (DOE), 1994. Waste Isolation Pilot Plant 1994 Environmental Monitoring Plan, DOE/WIPP 94-024, Westinghouse Electric Corporation, Carlsbad, New Mexico.

Vine, J.D., 1963. Surface Geology of the Nash Draw Quadrangle. Eddy County. New Mexico, U.S. Geological Survey Bulletin 1141-B, Washington, D.C., U.S. Government Printing Office.

Ward, R.F., C.G. St. C. Kendall, and P.M. Harris, 1986. "Upper Permian (Guadalupian) Facies and Their Association with Hydrocarbons - Permian Basin, West Texas and New Mexico," American Association of Petroleum Geologists Bulletin, Vol. 70, No. 3, pp. 239-262.

Webb, S.W., 1991. "Sensitivity Studies for Gas Release from the Waste Isolation Pilot Plant," Waste-Generated Gas at the Waste Isolation Pilot Plant: Papers Presented at the Nuclear Energy Agency Workshop on Gas Generatisn and Release from Radioactive Waste Repositories, Eds. P.B. Davies, M.A. Molecke, F.T. Mendenhall, and S.W. Webb, SAND91-2378, Albuquerque, NM, Sandia National Laboratories, pp. 4-1 through 4-A4.

Williamson, C.R., 1978. "Depositional Processes Diagenesis and Reservoir Properties of Permian Deep-Sea Sandstones, Bell Canyon Formation, Texas-New Mexico," Ph.D. dissentation, Austin, TX, University of Texas.

Wolery, T. J., 1992. EO3/6. A Software Package for Geochemical Modeling of Aqueous Systems: Package Overview and Installation Guide (Version 7), UCRL-MA-110662 PT I. Livermore, CA, Lawrence Livermore National Laboratory. 


\subsection{Facility Description}

The Waste Isolation Pilot Plant (WIPP) facility is designated as a research and development facility for radioactive wastes generated by Department of Energy (DOE) national defense activities. Defense-related radioactive wastes that meet the definition of transuranic (TRU) (as defined in Section 213 of Public Law 96-164) and that can be certified to the WIPP Waste Acceptance Criteria (WAC) will be emplaced in the WIPP.

These wastes fall into two categories: contact-handled (CH) TRU (as defined in DOE Order 5820.0A) waste, which has a dose rate on the surface of the container of less than 200 mrem per hour, and remote-handled (RH) TRU waste, which has a surface dose rate between 200 mrem per hour and 1,000 rem per hour. In accordance with an agreement between the DOE and the State of New Mexico (DOE, 1988), and Section 7 of the WIPP Land Withdrawal Act (LWA), only five percent of RH TRU waste received at the WIPP may exceed 100 rem per hour. Because of the nature of the processes that produce the TRU waste, many of the wastes are co-contaminated with chemicals that are classified as hazardous wastes under the Resource Conservation and Recovery Act (RCRA). These wastes are referred to as radioactive mixed wastes.

The WIPP facility is designed to receive up to 6.2 million $\mathrm{ft}^{3}\left(175,600 \mathrm{~m}^{3}\right)$ of CH TRU waste and $250,000 \mathrm{ft}^{3}\left(7,080 \mathrm{~m}^{3}\right)$ of RH TRU waste. However, the WIPP LWA of 1992 sets the maximum capacity for the WIPP at 6.2 million $\mathrm{ft}^{3}\left(175,600 \mathrm{~m}^{3}\right)$ for all waste. The maximum rates of waste emplacement are $500,000 \mathrm{ft}^{3}\left(14,160 \mathrm{~m}^{3}\right)$ per year of defense-generated CH TRU waste and approximately $10,000 \mathrm{ft}^{3}\left(283 \mathrm{~m}^{3}\right)$ per year of defense-generated RH TRU waste. However, significantly lower rates of waste emplacement are anticipated, as described in the Final Safety Analysis Report (FSAR) (DOE, 1990).

\subsection{Design Specifications}

As the Architect-Engineer for the WIPP project, Bechtel National, Inc. was responsible for the development of the detailed design of the facility. The U.S. Army Corps of Engineers managed the construction of the facility. As the owner of the facility, the DOE developed design criteria and performed independent review and verification of the adequacy of the design (DOE, 1986). This review was performed by Brookhaven National Laboratories, under contract to the DOE, as part of the facility safety analysis. 


\subsubsection{DOE Facility Acquisition Process}

Federal facility acquisition policies were applied to the design and construction of the WIPP facility, in accordance with standard procedures defined in DOE Order 4700.1, Project Management System. In addition, WIPP structures were designed to meet DOE design and quality assurance (QA) requirements specified in DOE Order 6430.1, General Design Criteria for Department of Energy Facilities. The WIPP Waste Handling Building (WHB) was designed to meet the requirements that apply for Design Class II structures and components for non-reactor nuclear facilities. The underground area is classified as a Design Class IIIB non-reactor nuclear facility. The design class designations are defined for structures, systems, and components in accordance with the importance of their functions relative to health and safety of the public and on-site personnel during plant operations.

\subsubsection{Configuration Control}

The configuration of the WIPP facility is controlled by written procedures and policies. Any changes to the facility, and subsequently configuration documentation (system design descriptions, as-built drawings, specifications, etc.), must be reviewed and approved by cognizant personnel. These documented reviews are performed to determine if the change will impact the ability of the facility to comply with applicable environmental, safety, and health requirements.

\subsection{As-Built Design}

The WIPP facility has been designed to ensure safety during operations and to ensure the protection of human health and the environment during and after the decommissioning of the project. The WIPP is designed to receive waste over a 25 -year period. When facility operations cease, the shafts will be sealed and surface structures will be removed. Within a period of 60 to 200 years, the repository rooms are expected to close and are expected to consolidate into a mass comparable to intact salt, restoring the excavation to a condition approaching its undisturbed state. 


\subsubsection{Surface Structures}

WIPP surface structures accommodate the personnel, equipment, and support services required for the receipt, preparation, and transfer of waste from the surface to the underground areas. The surface facilities are located in an area of approximately 35 acres $\left(0.14 \mathrm{~km}^{2}\right)$ within the eight-foot high perimeter fence designated as Zone I (Figure 3-1).

The principal surface structure is the WHB, which is divided into several separate areas: the CH TRU waste-handling area, the RH TRU waste-handling area, the Transuranic Package Transporter (TRUPACT) maintenance building, and support areas (Figures 3-2a \& b and 3-3). It houses offices, change rooms, a health physics laboratory, and equipment for ventilation and filtration. Safety equipment and measures for controlling radiation exposure are accommodated by the design of the building.

The CH TRU waste-handling area includes an outdoor rail and truck loading and off-loading area, a shielded storage room, an inventory and preparation area, and an overpack and repair room. The RH TRU waste-handling area includes a shipping and receiving area and a shielded cell for unloading a shipping cask, inspecting the waste canister, overpacking the canister as required, and loading the cask for transfer underground.

Other surface structures include the following:

Hoist Buildings

Support Building

Exhaust Filter Building

Security/Cafeteria Building

Water Pump House and Potable Water Storage Tanks

TRUPACT Maintenance Faciltiy
Office Trailers

Mined Rock Salt Pile

Sewage Treatment Lagoons

Shops/Maintenance Building

Engineering Building

Core Storage Building

Potable water for the WIPP facility is obtained from a City of Carlsbad water line. 


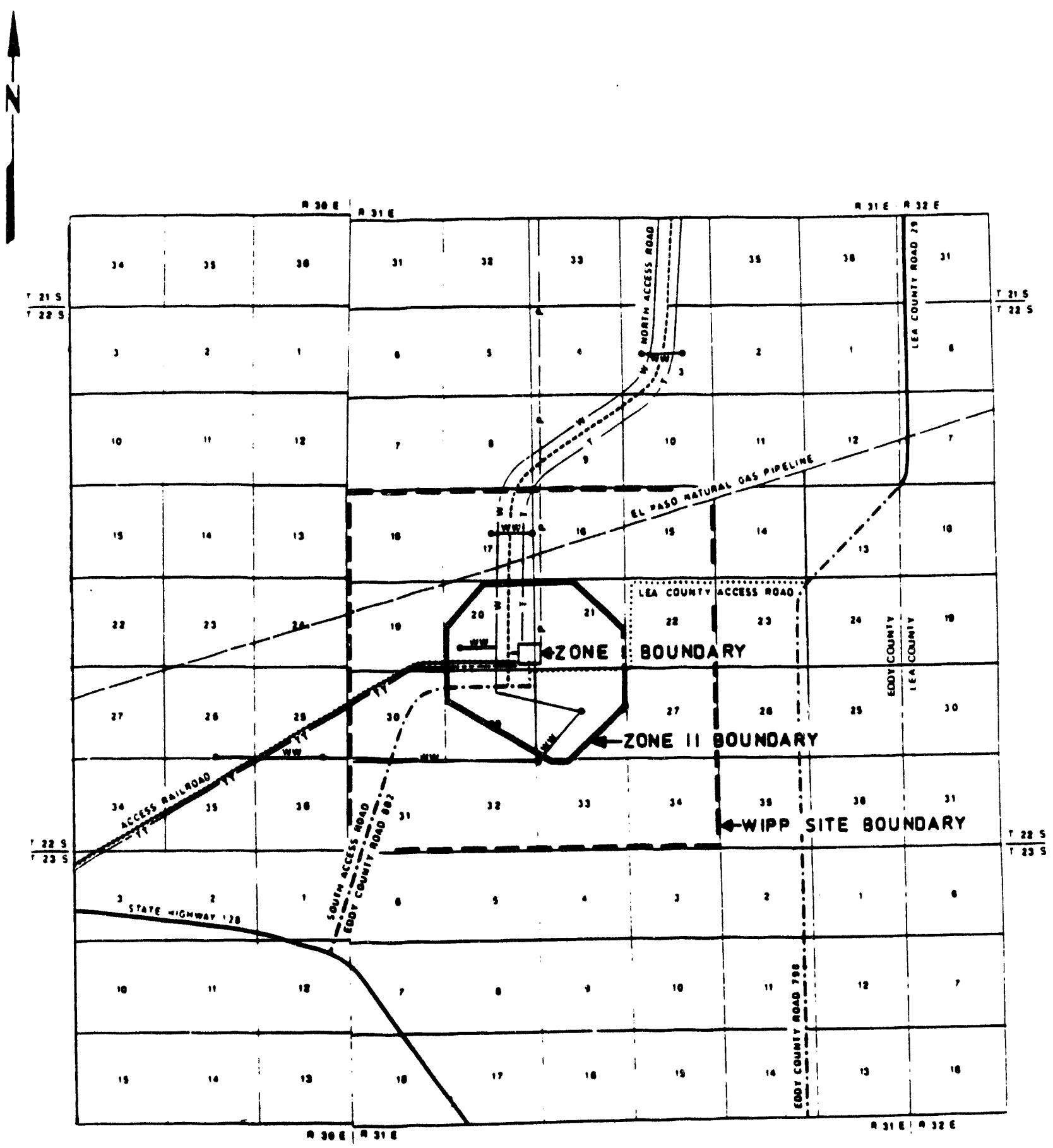

Figure 3-1 WIPP Site Boundary 


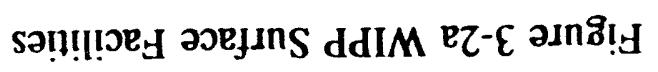

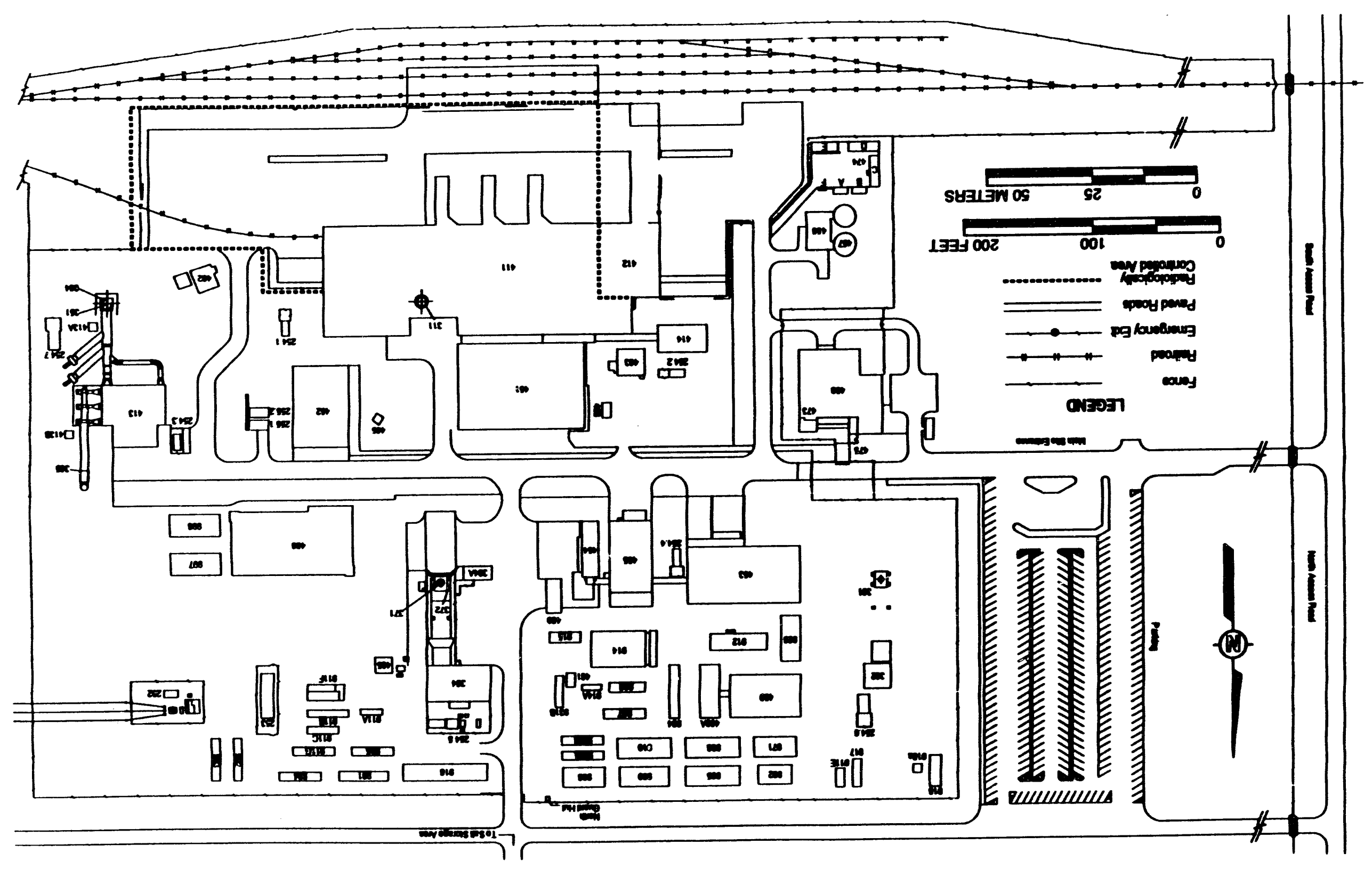

นodəy snuछฺs əour!!duo 
EACIUTES, USACE NDSTRUCTUREMUMBERS

\begin{tabular}{|c|}
\hline 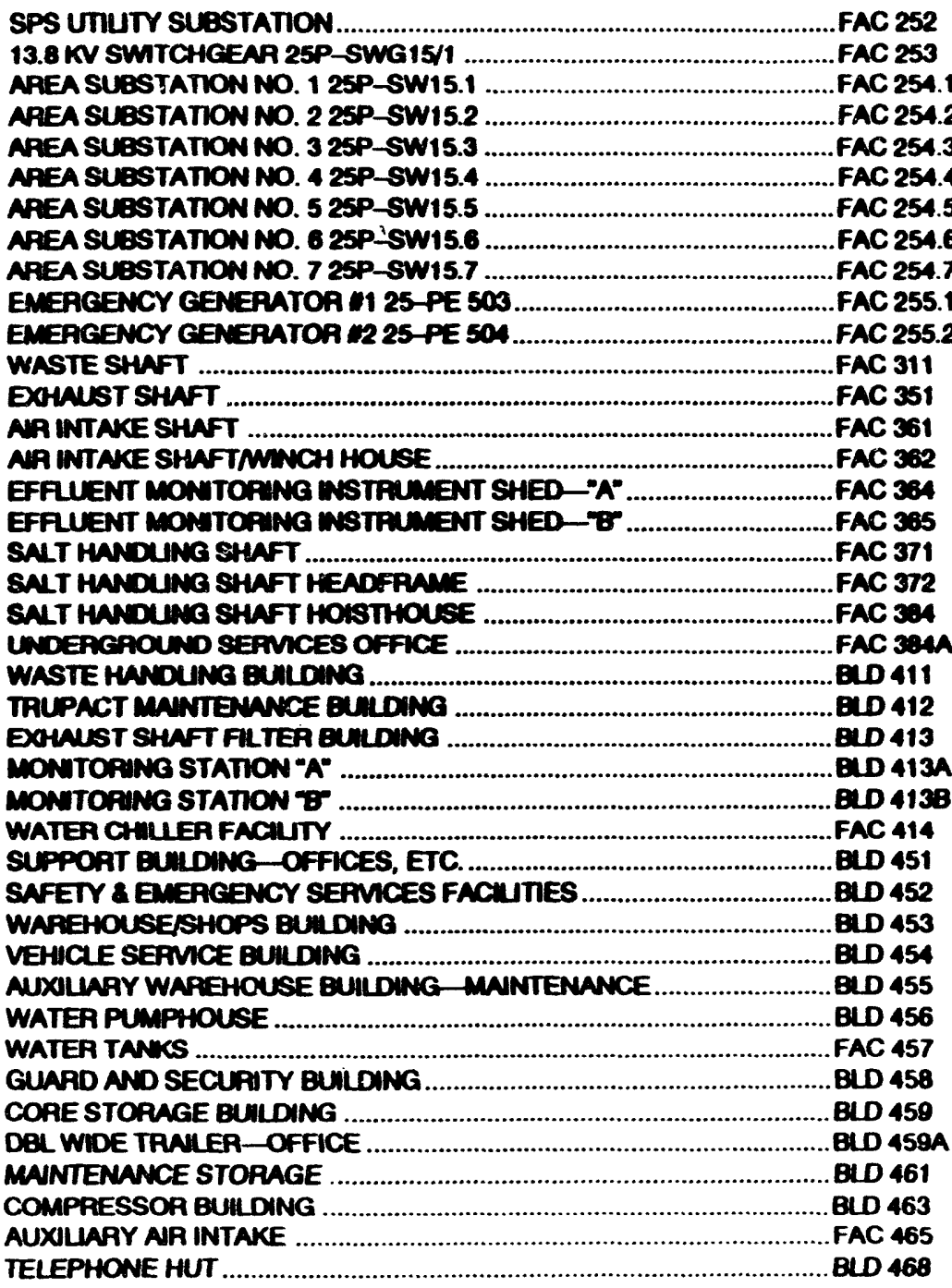 \\
\hline
\end{tabular}

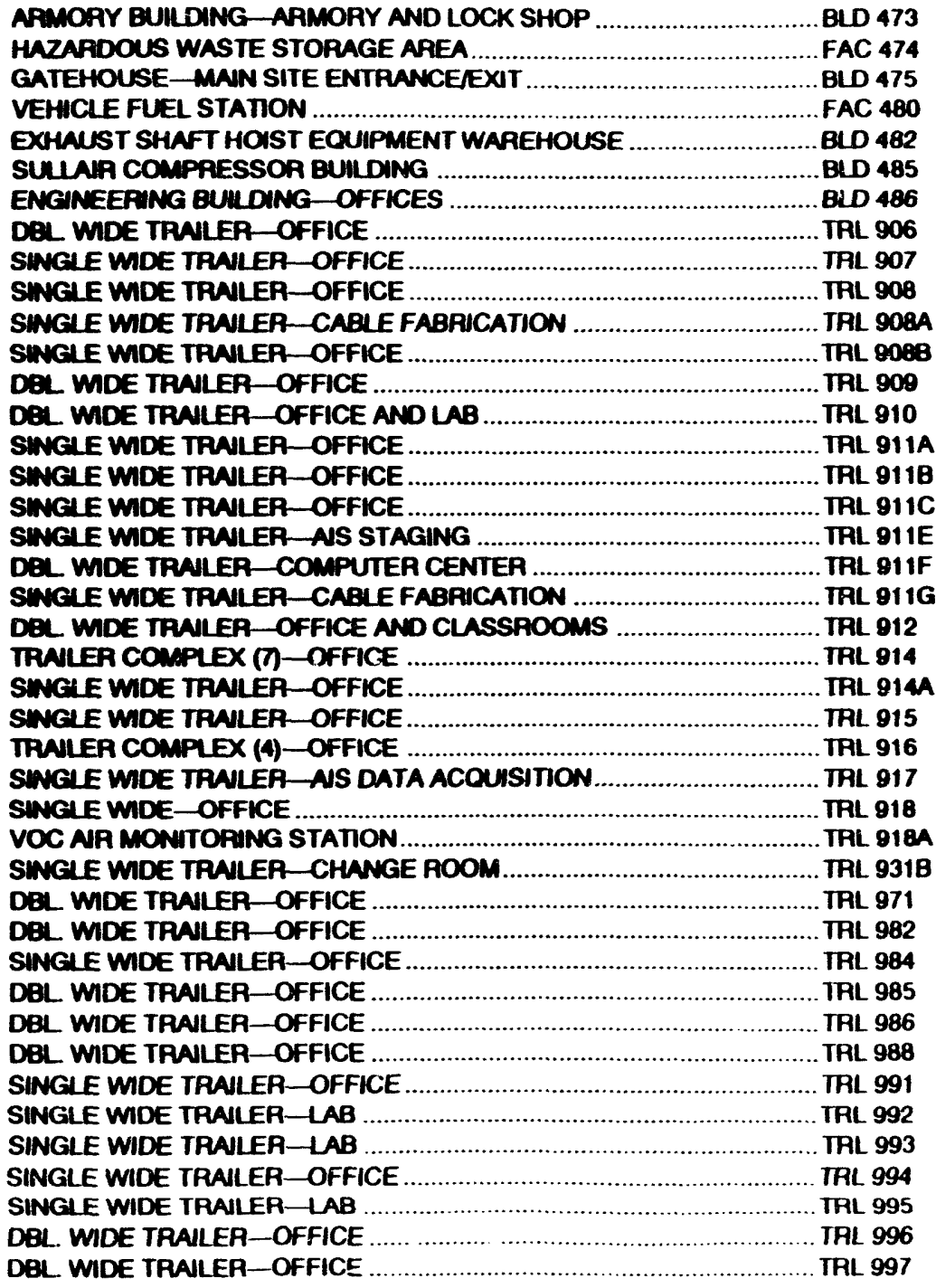

Figure 3-2b WIPP Surface Facilities 


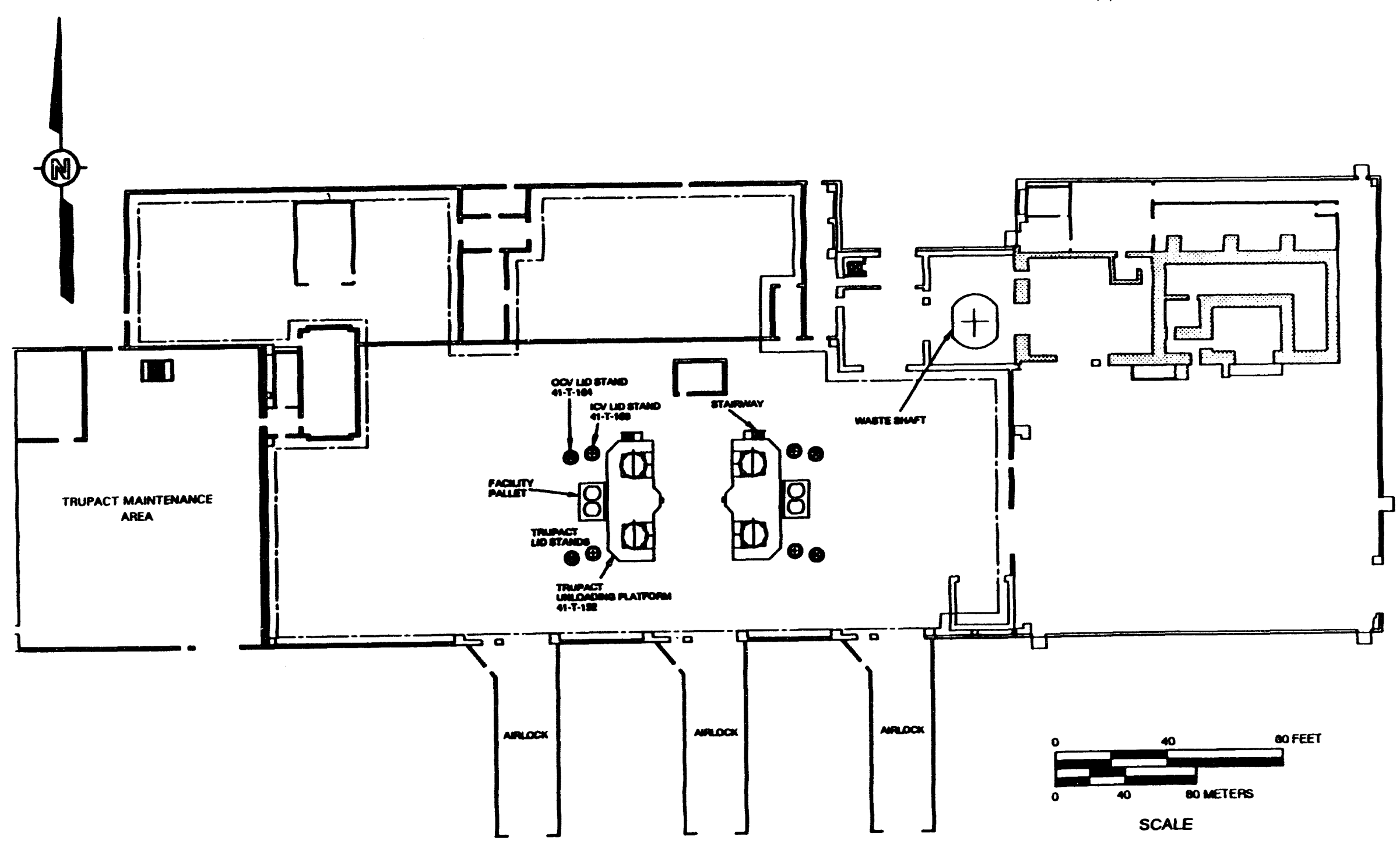

Figure 3-3 Waste Handling Building 


\subsubsection{Underground Structures}

Four shafts connect the underground facility to the surface. These are 1) the Air Intake Shaft, 2) the Exhaust Shaft, 3) the Salt Handling Shaft, and 4) the Waste Shaft (Figure 3-4). During operations, personnel, equipment, and salt will be transported via the Salt Handling Shaft. The Waste Shaft hoist will transport the waste, personnel, and equipment that cannot be accommodated by the Salt Shaft hoist. The Air Intake and Exhaust Shafts will provide for primary ventilation of the underground areas. The Air Intake Shaft will also serve as a backup for transporting personnel and equipment.

The underground facility consists of a "room and pillar" arrangement, including:

- A CH and RH TRU waste-disposal area which, when fully developed, will have an area of about 100 acres $\left(0.4 \mathrm{~km}^{2}\right)$, of which 31 acres $\left(0.128 \mathrm{~km}^{2}\right)$ contain wastes, and

- A research and development area for studies of rock mechanics and mine design, having an area of about 12 acres $\left(0.06 \mathrm{~km}^{2}\right)$.

Tunnels or drifts connect these areas to each other and to the shafts. Salt mined in the construction of these facilities is transported to the salt-handling shaft for removal to the surface.

Contact-handled TRU waste containers will be transferred to the underground waste receiving station in a conveyance. This conveyance is designed to handle a maximum load of 45 tons $(41,000 \mathrm{~kg})$. At this station, the waste will be unloaded and transported to the waste disposal area.

The total area available for waste emplacement will consist of eight panels with seven rooms in each panel. Each waste disposal room is $33 \mathrm{ft}(10 \mathrm{~m})$ wide, $13 \mathrm{ft}(4 \mathrm{~m}) \mathrm{high}$, and $300 \mathrm{ft}$ (91 m) long.

Remote-handled TRU waste will be packaged in a special facility cask. Each cask will be lowered to the disposal horizon through the waste shaft. The RH TRU waste canisters will be horizontally emplaced in holes in the walls of the waste disposal rooms. 


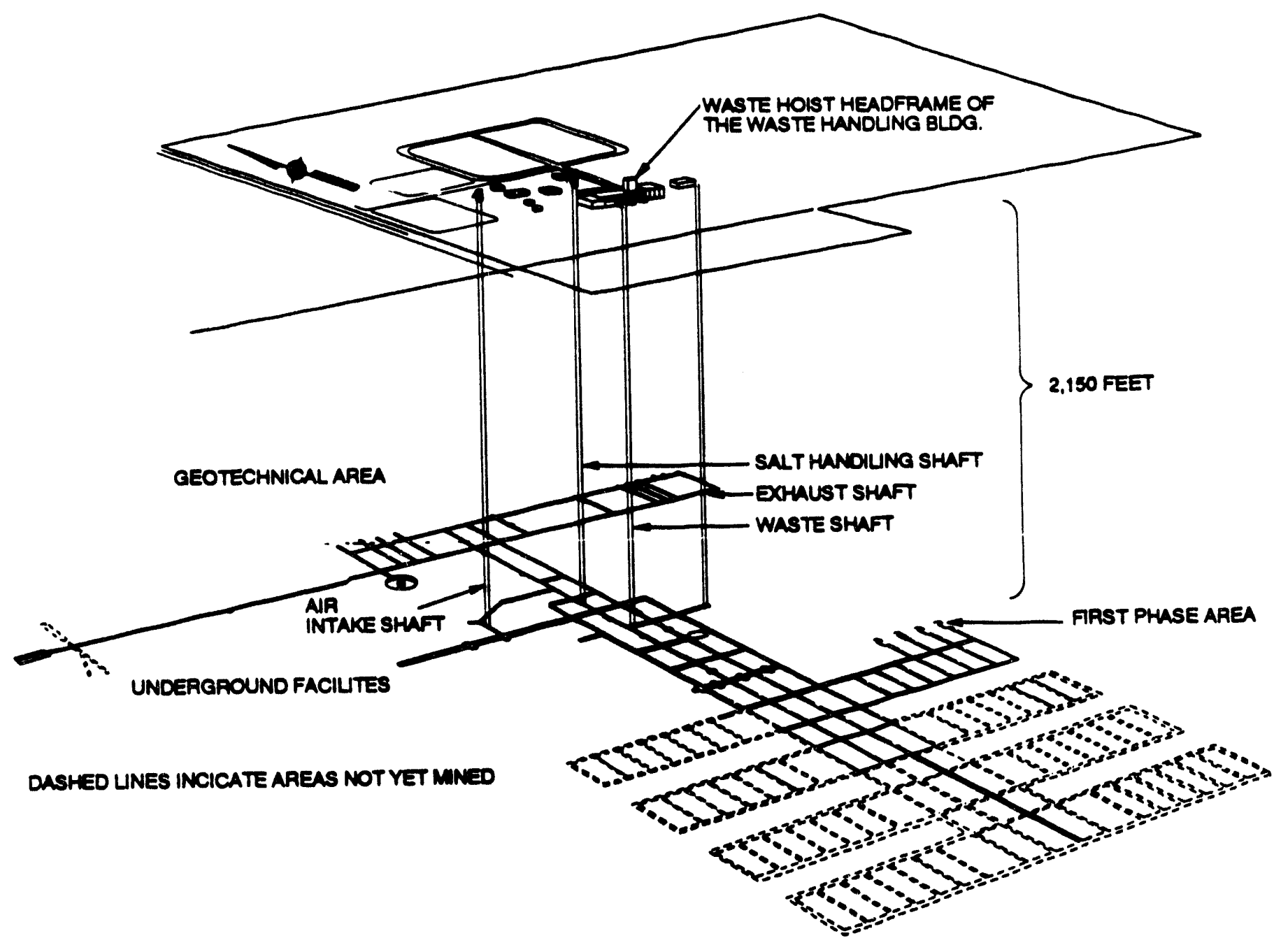

Figure 3-4 WIPP Underground Facilities 


\subsection{Facility Boundaries}

The WIPP facility is divided into zones as represented in Figure 3-1. Zone I, surrounded by a chain-link fence, includes all major surface structures. The Secured Area Boundary, marked by a barbed wire fence, includes other structures and areas associated with construction and operation. Zone II indicates the maximum extent of underground development. The WIPP facility surface boundary extends at least $1 \mathrm{mi}(1.6 \mathrm{~km})$ beyond any potential underground development and is defined on the surface by the 16-section land withdrawal area (shown as the WIPP Site Boundary in Figure 3-1).

The WIPP site boundary will be controlled both administratively and physically during the disposal phase. After closure, evidence of this boundary will be maintained by written records, shaft location markers, and site monuments. These controls are intended to prevent any undesirable intrusion upon the surface structures in the near term and in the long term to reduce the likelihood of any penetration into the subsurface repository.

\subsection{Engineered Barriers}

The design of the WIPP disposal system includes engineered barriers to prevent the migration of waste and waste constituents to the accessible environment. As presently designed, the repository relies on seals in shafts and boreholes to prevent migration through the excavated openings. If assessments of compliance with regulatory requirements indicate that additional barriers are needed to reduce potential transport of radionuclides or hazardous constituents, seals may be installed in drifts or panels, modifications can be made to the form of the waste and backfill of drifts, panels, or rooms, or design of the waste-emplacement areas may be modified.

\subsubsection{Seals and Piugs}

\subsubsection{Shaft Seals}

The WIPP sealing system program has produced a sealing strategy that is embodied in a revised seal system reference design. The reference seal design provides a basis for calculations and analyses so that common input parameters are used for performance calculations that will lead to detailed seal designs and specifications. The sealing strategy 
combines short- and long-term seal components as barriers to fluid flow. In the reference design, long-term components, composed of compacted crushed salt, are emplaced at multiple locations within the shafts as shown in Figure 3-5.

Studies have indicated that salt will reconsolidate as a result of creep closure of the excavations. Creep closure and the attendant reconsolidation of emplaced salt have been topics of intense modeling efforts (Munson et al., 1992; Hansen et al., 1993). Studies have also indicated that, given sufficient time, fluid conductivity within the seal will be reduced nearly to that of the host rock salt within the Salado Formation. Because there will be very little compositional difference between the reconsolidated WIPP crushed salt and the surrounding rock from which it was mined, the crushed salt is expected to be exceptionally stable, mechanically and chemically, in the seal environment. Short-term seal components, including a salt-saturated concrete developed specifically for WIPP seals, coupled with swelling clay and chemical seal rings, provide the fluid-flow resistance during salt reconsolidation. These materials, known through industrial use and continuing research (Wakeley et al., 1993) to be stable and to retard flow of WIPP brines, provide the required sealing while creep consolidates the crushed salt components. Drawings of the reference seal system are shown in Figures 3-6 through 3-8. The disturbed rock zone (DRZ) that develops in the host rock salt near or around the excavated openings is expected to heal by creep closure (Chan et al., 1992). The fractured portion of the DRZ in non-salt lithologies near the shafts in the Rustler Formation and in the interbeds near the shafts in the Salado Formation will be sealed by grouting.

Confidence in the sealing strategy and reference design results from a combination of laboratory testing, numerical modeling, in-situ demonstration, and industry experience. Analyses of the expected creep behavior, the expected reconsolidated behavior of compacted crushed salt used for the shaft long-term seal components, and the brine inflow rate. These analyses indicate that crushed salt components, emplaced with sufficient precompaction, will sufficiently reconsolidate within 100 years after emplacement to meet performance requirements (Van Sambeek et al, 1993). This reconsolidation is expected to reduce the fluid conductivity of the seal to near that of the original formation.

Confidence in seal performance has also been provided by the successful development of sitespecific salt-saturated concretes and special cementitious grouts compatible with the host rock in the WIPP. Additional refinement of the seal system design and information for future 


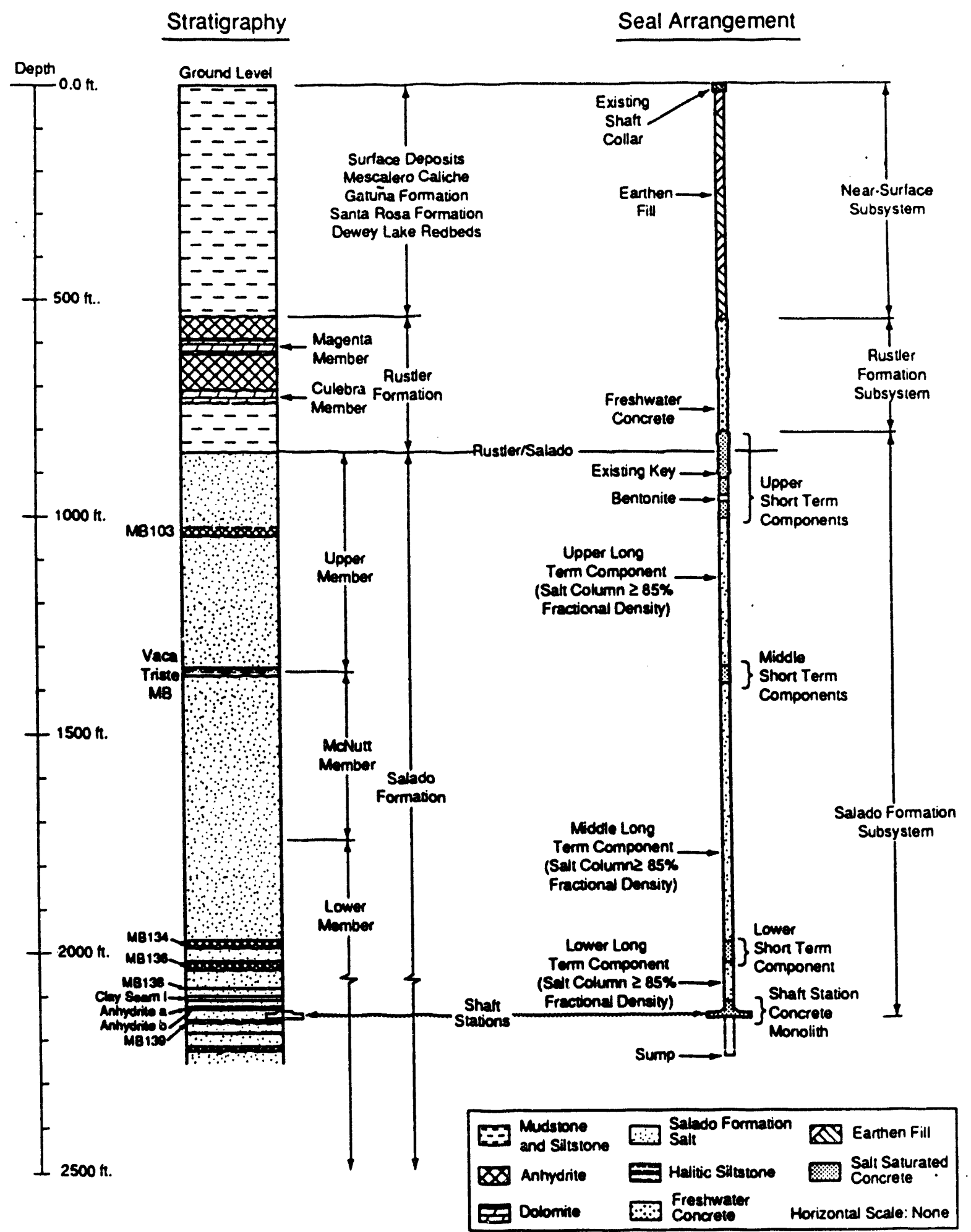

Figure 3-5 Typical Shaft Seal System 

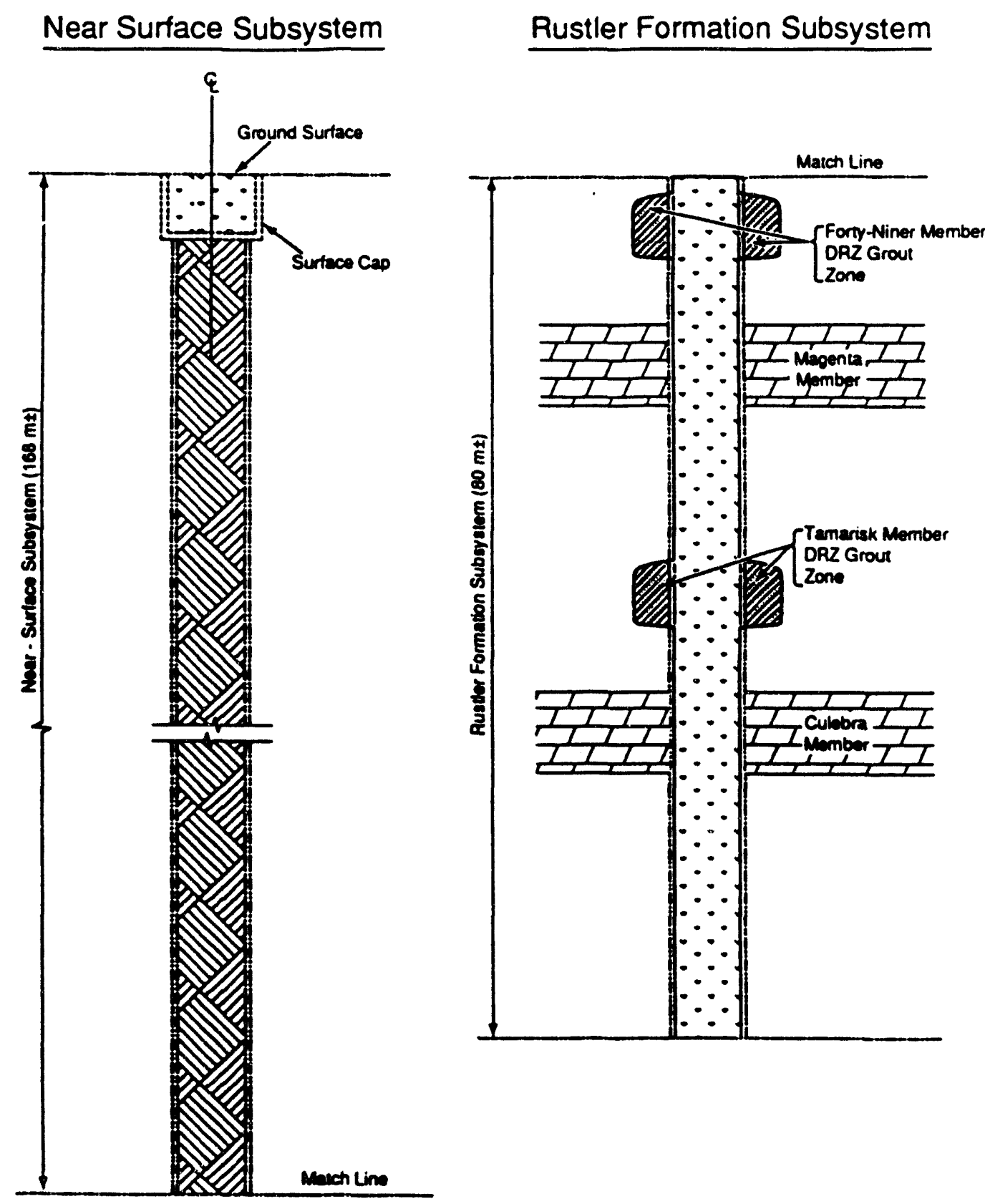

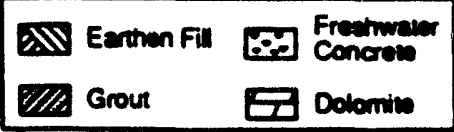

Figure 3-6 Reference Seal System - Near Surface and Rustler Formation 
Salado Formation Subsystem Components

Upper Short Term Components

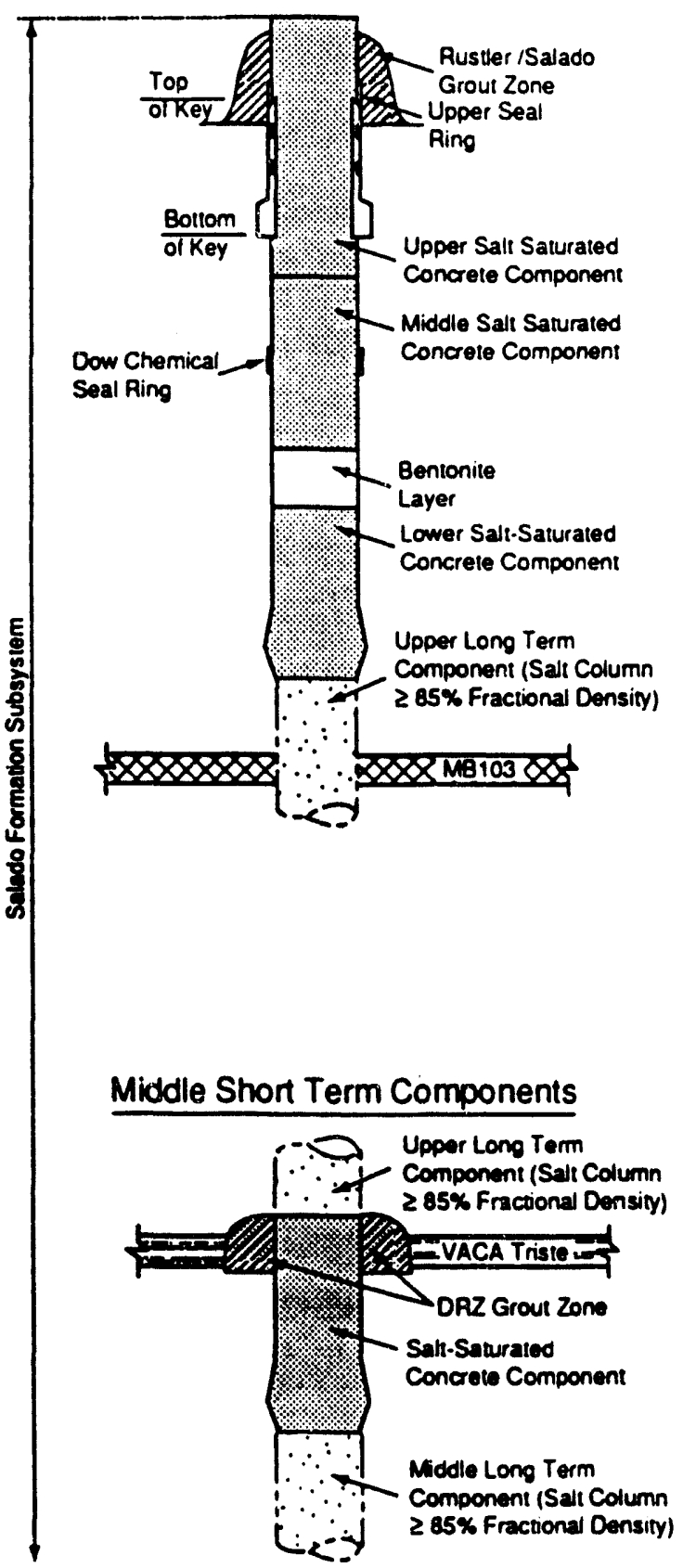

Figure 3-7 Reference Seal System - Upper and Middle Salado Formation 


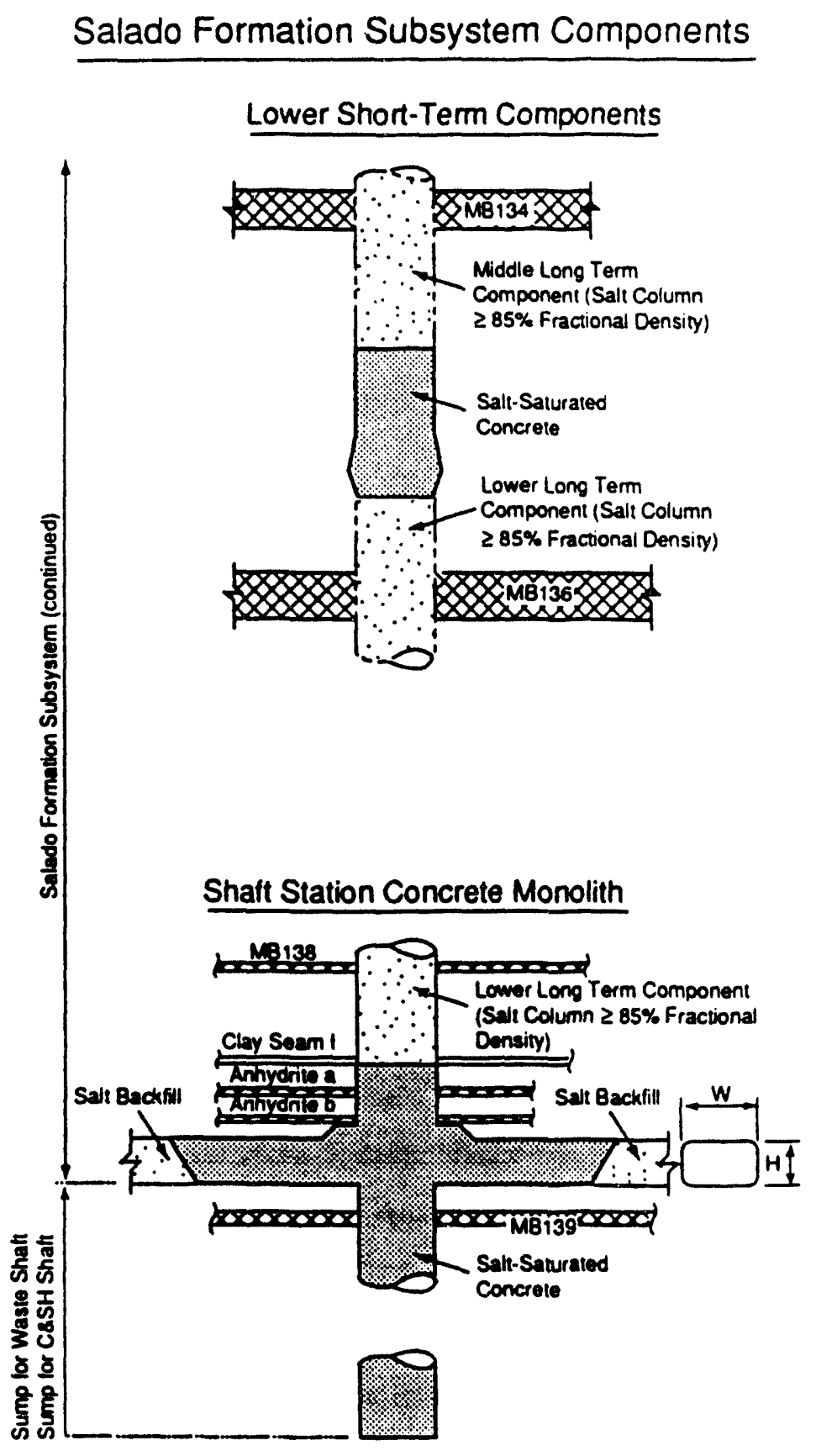

Figure 3-8 Reference Seal System - Lower Salado Formation 
development will be derived from current and future activities in the Seal System Development Program. Models of the seal system behavior, consistent with the seal designs and the data that characterize the host rock, are being used in seal system sensitivity studies and in overall performance assessment (PA). Field tests of seals and in situ measurements of the extent and properties of the DRZ are planned to secure data for evaluation of seal performance.

\subsubsection{Borehole Plugs}

Figure 3-9 shows existing boreholes that overlie the proximate area of the repository footprint. Of these identified boreholes in Figure 3-9, all but ERDA-9 are terminated hundreds of feet above the repository horizon. Only ERDA-9 is drilled to the repository horizon, and only ERDA-9 is near the WIPP underground. All boreholes are subject to abandonment criteria common to the oil industry standards. As an initial criterion, any borehole that connects a fluid-producing zone with the facility becomes a plugging candidate.

Two additional boreholes, WIPP-12 and DOE-1, have depths greater than the repository horizon of 3,927 and 4,057, respectively. WIPP-12 lies approximately $1 / 2 \mathrm{mi}$ north of WIPP-19, and DOE-1 lies approximately $3 / 4 \mathrm{mi}$ southeast of $\mathrm{H}-3$. Both boreholes have been plugged to industry standards.

To mitigate the potential for communication with the repository horizon, borehole seals will be designed to limit the volume of water that could be introduced to the repository from the overlying water-bearing zones or the volume of waste released from the repository to the surface or water-bearing zones.

Borehole plugging activities have been underway since the 1970 s, from the early days of the development of the WIPP facility. Early in the exploratory phase of the Project, a number of drill holes were sunk within Lea and Eddy Coun ${ }^{\dagger}$ s. After the WIPP site was situated in its current location, an evaluation of all vertical penetrations was made (Christensen et al., 1983). The governing regulations were evaluated to determine which boreholes were of potential significance to the WIPP site.

Grout plugging procedures are routinely performed in standard oil-field operations; however, quantitative measurements of plug performance are rarely obtained. The Bell Canyon Test reported by Christensen and Peterson (1981) was a field-test demonstration of the use of 


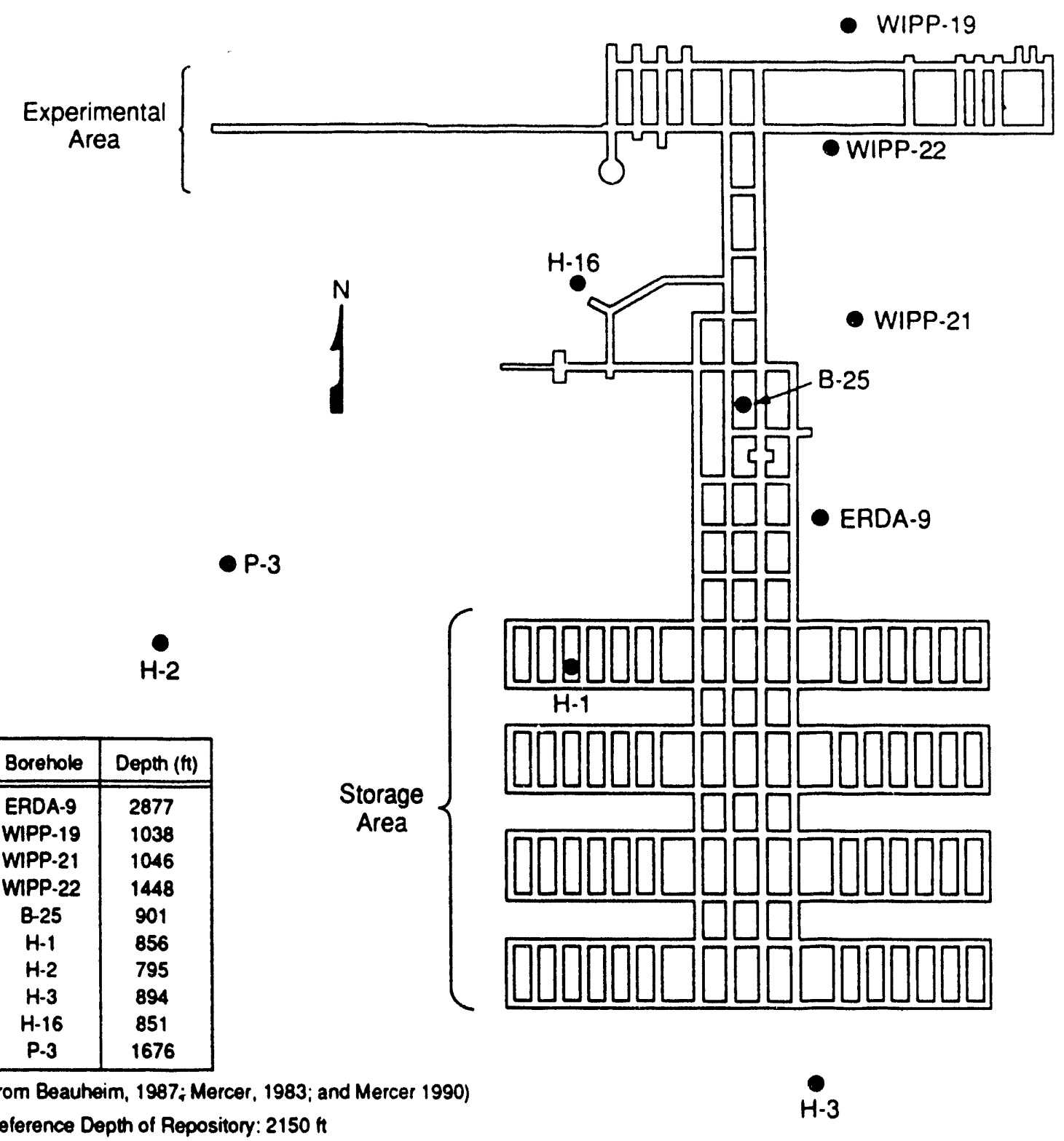

Figure 3-9 Approximate locations of boreholes in relation to the WIPP underground (modified from Lappin et al., 1989, p. 1-3). 
cementitious plugging materials and modification of existing industrial-emplacement techniques as needed to suit repository plugging requirements. Cement-emplacement technology was found to be "generally adequate to satisfy repository plugging requirements..." Christensen and Peterson (1981) also report "that grouts can be effective in sealing boreholes, if proper care is exercised in matching physical properties of the local rock with grout mixtures. Further, the reduction in fluid flow provided by even limited length plugs is far in excess of that required by bounding safety assessments for the WIPP."

\subsubsection{Backfill}

Performance assessment calculations for 1992 assume a backfill of pure, unconsolidated crushed salt, with a relatively high permeability that provides little resistance to fluid flow. Pure salt will not sorb radionuclides, and, therefore, retardation of radionuclides within the repository environment is not simulated. Studies are currently underway to establish if backfill is needed, and if so, to establish performance requirements for backfill. Design alternatives for backfill that contains bentonite as an additional barrier to retard radionuclides have been examined (DOE, 1991a; Butcher et al., 1991; Pfeifle and Brodsky, 1991; Brodsky and Pfeifle, 1992).

\subsection{Performance of the Waste Isolation System}

The manner in which the WIPP disposal system is expected to behave over the long term is described in this section. The description is of the undisturbed system, in which the repository is not affected by human intrusion or unlikely natural events. In describing this system, a number of potentially disruptive events and processes were considered and were either included in the scenario or eliminated. Those processes included in the scenario (because they are expected to happen), are erosion, sedimentation, climate changes, seismic activity, and shallow salt dissolution at the contact between the Salado and the Rustler Formations. Because none of these events or processes is expected to significantly affect the long-term performance of the planned repository, the undisturbed scenario only describes processes within the repository as the system equilibrates.

As soon as excavations are opened, because of the decrease in the confining pressure on the salt around the excavation, the salt begins to creep inward and close the openings. Modeling of salt creep indicates that creep closure of rooms and the resulting consolidation of the waste 
in the rooms could be largely complete within 100 years (Tyler et al., 1988; Munson et al., 1989a, 1989b). Based on the reference seal design, the lower parts of shafts will be filled with preconsolidated crushed salt (Stormont et al., 1987; Borns and Stormont, 1988; Nowak et al., 1990). Because of the high lithostatic pressures at the planned repository depth, salt creep is expected to exert sufficient pressure on the crushed salt to consolidate the material into low-permeability seals with properties similar to those of the host rock. Portions of the upper parts of the shafts will also be filled with salt, but pressure is not expected to be sufficient to cause the same degree of consolidation as is expected in lower portions of the shafts.

The potential for gas generation is an important process that is considered for the undisturbed scenario. Moisture in the repository, either inherent in the waste or seeping in from the Salado, will corrode metals, consuming water and generating gas during the process; radiolysis also will generate gases. In addition, because microbes transported into the repository with the waste are expected to be viable under sealed-repository conditions (Brush and Anderson, 1988), organic materials in the repository will biodegrade with concomitant generation of gases. Some gas may disperse into the surrounding anhydrite layers.

Continued gas generation could increase pressure within the repository sufficiently to reverse brine inflow or adversely impact repository performance.

A possible pathway for gas and brine flow, and hence contaminant transport, is through interbeds above and below the waste-disposal panel, and then up the shafts and into the Culebra (SNL, 1991). Gas, brine, and waste constituents could enter the interbeds either through fractures in salt or directly as a result of rooms and drifts intersecting the interbeds. The pressure gradient between the planned repository and the Culebra could tend to force brine from interbeds above and below the panel along fractures in the interbeds to the base of the shaft. The permeability of the seals in the lower portion of the shaft will control the upward flow of gas and brine. Hence, the shaft seals control the movement of radionuclides and hazardous constituents up the shafts.

\subsection{Operations}

The operation of the facility and plans for decommissioning and post-closure control of the site are described in this section. 


\subsubsection{Disposal Operations}

Contact-handled TRU mixed waste will be received at the WHB in "seven-packs" of 55-gallon drums or in boxes within Type B shipping packages (TRUPACT-II's) certified by the Nuclear Regulatory Commission (NRC) (Figure 3-10). The packages will be checked for surface contamination and, if clean, will be unloaded in the receiving and inspection area. Contaminated containers will be moved to the overpack and repair room where they will be examined and repackaged or repaired, if necessary. Containers will be stacked on pallets for uniform handling and will be transferred underground through the Waste Shaft. The empty TRUPACT-II's will be decontaminated, if necessary, and reloaded onto transport vehicles.

Remote-handled TRU waste will be received in NRC-certified shielded shipping casks. Each cask, which will contain one canister of waste, will be inspected and removed from the transport vehicles in the cask unloading and receiving area of the WHB and then moved to the cask preparation and decontamination area. Here, any contamination will be removed and special handling equipment will be attached to the cask.

The cask will be transferred to the cask unloading room where the canisters will be removed and placed in the hot cell. After inspection, during which a contaminated canister would be overpacked, the canister will be positioned in the transfer cell, loaded into a specially designed facility cask, and lowered underground through the waste shaft for emplacement. The shipping cask will be decontaminated, if necessary, and returned to the shipper for reuse.

\subsubsection{Decommissioning}

The WIPP facility will be closed and decommissioned at the end of its disposal phase. Decommissioning will involve decontaminating (if necessary) and dismantling the surface facilities and sealing the shafts. Salt originally excavated from the WIPP facility will be disposed of in accordance with the LWA. Boreholes will be plugged and the surface will be returned to as near its original condition as is practical. Markers will be placed at shaft locations. 


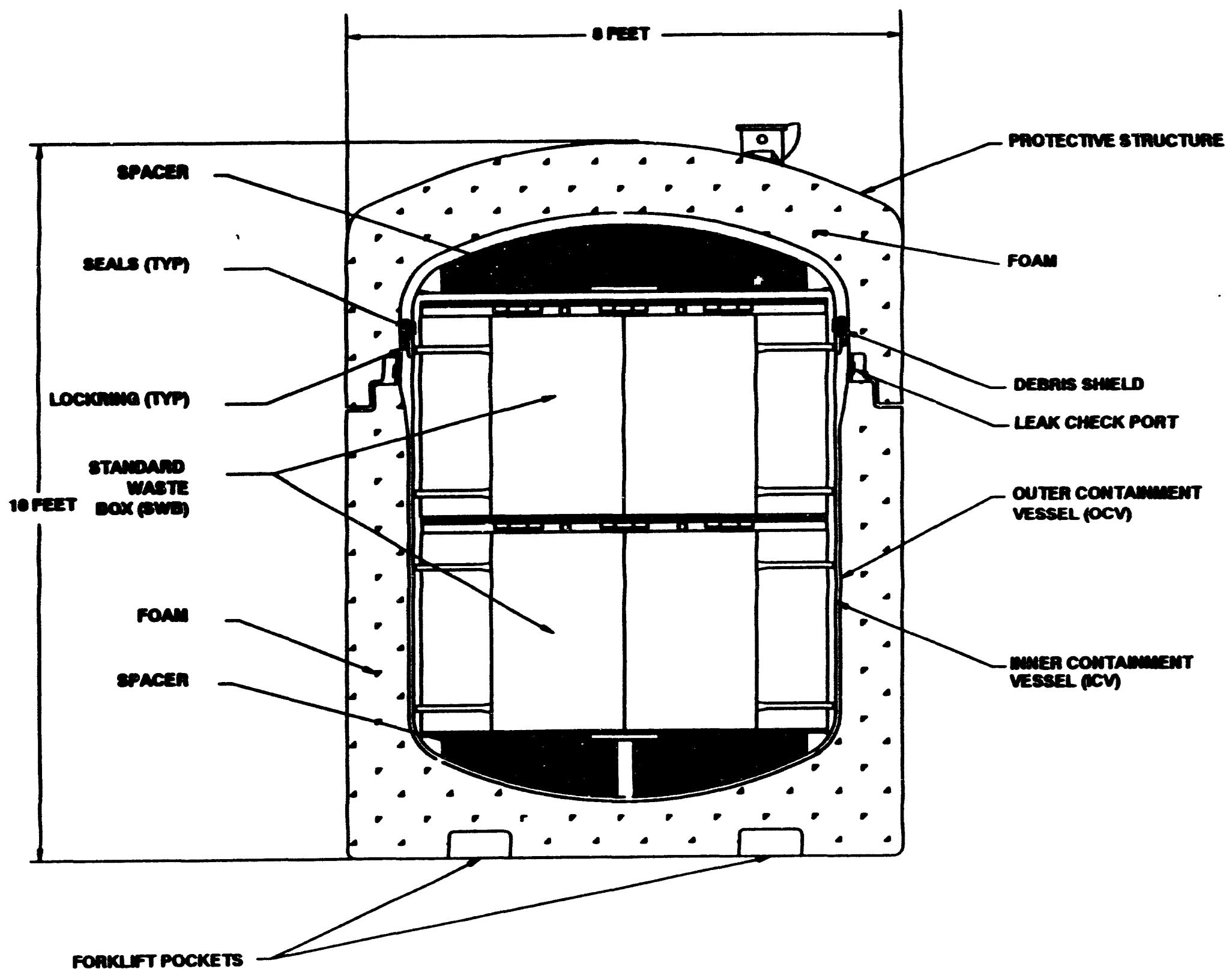

Figure 3-10 TRUPACT-II 


\subsubsection{Post-Closure Activities}

Post-closure environmental surveillance programs will be conducted. The frequency and duration of the environmental surveillance programs will be defined in a final decommissioning plan, as prescribed by the LWA and other applicable standards.

Post-operational requirements for the WIPP facility are included in the assurance requirements of $40 \mathrm{CFR} \$ 191.14$. These requirements are intended to ensure that cautious steps are taken to reduce uncertainties in projections of the behavior of natural and engineered components of the repository for many thousands of years. The application of these assurance requirements to the WIPP facility is described in detail in A Plan for the Implementation of Assurance Requirements in Compliance with 40 CFR \$191.14 at the Waste Isolation Plant (DOE, 1991b). The assurance requirements are generally described as passive and active controls.

\subsubsection{Passive Controls}

Passive controls are designed to deter future societies from intruding into the repository. The DOE has pursued an ongoing program over a period of many years to satisfy the passive controls requirements. Through this work, the objectives of the WIPP passive controls program have been defined. These are:

1. To restore the disposal site to as near its original condition as possible;

2. To ensure a record of the disposal site, its contents, and any land use restrictions is preserved in perpetuity; and

3. To warn those who enter the disposal site vicinity of the hazards associated with subsurface development activities (DOE, 1991b).

"Passive institutional controls" (or passive controls) have been defined by the EPA as: ". . .

1) permanent markers placed at a disposal site, 2) public records and archives,

3) government ownership and regulations regarding land or resource use, and 4) other methods of preserving knowledge about the location, design, and contents of a disposal system" (EPA, 1993). Passive controls, as opposed to active controls (see 40 CFR $\$ 191.14[a])$, are controls that once established, can be expected to remain effective with minimal human maintenance, or maintenance resulting from normal governmental activities. 
Passive controls may be instituted either at the site or at a remote location, or both. Passive controls should be in place prior to the end of the active control phase.

Long-term passive institutional controls can and should be relied upon to reduce the likelihood of inadvertent, intermittent human intrusion for the maximum period of time for which there is a reasonable expectation that such controls will remain durable and effective. The factors to consider in evaluating the validity of a demonstration and contribution to PA include the following:

- site-specific conditions that could affect the likelihood of intrusion, such as climate change, land use, and surface topography

- engineering design, based on site-specific conditions

- scientific studies to evaluate the durability of the passive institutional controls (e.g., markers) in the WIPP environment

- expert judgment to determine the appropriate markings and messages and to assess the extent to which they can be understood by future generations

If relied upon in the PA, the use of such passive institutional controls should then become a condition in the compliance certification or determination for the facility.

This approach to reliance on passive institutional controls is consistent with the approach taken by EPA to such controls under the RCRA as reflected in the proposed No-Migration Determination (NMD) for the WIPP facility issued by the EPA on April 6, 1990 (EPA, 1990). In the proposed NMD for the WIPP, the Agency addressed the use of institutional controls for the protection of the WIPP facility from intrusion by humans. In this context, the EPA stated the following: "EPA believes that, in the context of the RCRA no-migration variance decisions, the question of human intrusion, and the imposition of controls to make such intrusions unlikely events" (EPA, 1990). EPA further pointed out that this approach was consistent with EPA's general approach under RCRA, where EPA typically "relies on institutional both active and passive, imposed through general regulatory standards and sitespecific conditions ... to ensure that access to a hazardous waste disposal site is appropriately restricted" (EPA, 1990). Finally, in the proposed NMD for the WIPP facility, the EPA stated its belief that it is incumbent upon the Agency "...to impose long-term passive institutional controls, such as land withdrawal, records, and markers-to ensure that the 
likelihood of human intrusion is appropriately reduced, even after active control of the facility has ceased and any permits at the site may have terminated" (EPA, 1990).

Institutional controls are a major component of nearly all waste management strategies. There is no reason to assume that effective passive controls cannot be designed and implemented for periods of time well beyond the active control period.

Final conceptual and detailed designs for the permanent markers system for the WIPP will be developed. The purpose of the permanent markers system is to ensure that those who enter the disposal site vicinity are warned of hazards associated with subsurface development activities.

The DOE has committed to using the services of an "expert panel" in addressing the passive controls programs (DOE, 1991b). A panel has been established to develop design characteristics for permanent markers and to judge the efficacy of the markers in deterring inadvertent human intrusion into the repository. The nature and scope of this panel, and the methods used to perform its functions, are described in the 1992 PA report. One of the functions of this panel is to develop probability estimates for the occurrence of potential events that would affect the effectiveness of the passive controls programs. These will be factored into the design of the markers system and into predictions of the performance of the repository.

Detailed plans for a permanent records-management system will be defined. Development needs related to written records management include defining the messages and records to be maintained, specific locations for maintaining these records, the media to be used to record the information, and defining systems for the long-term maintenance of the records.

\subsubsection{Active Controls}

"Active institutional control" is defined in 40 CFR $\$ 191.12$ as: ". . 1) Controlling access to a disposal site by any means other than passive institutional controls; 2) performing maintenance operations or remedial actions at a site; 3 ) controlling or cleaning up releases from a site; or 4) monitoring parameters related to disposal system performance." Active institutional controls that will be employed at the WIPP site are expected to include controls on land use, the maintenance of fences and buildings and guarding the facility during active cleanup, decontamination and decommissioning, land reclamation, and post-operational 
monitoring. The objectives of these activities will be to provide a facility and presence at the site during active cleanup, to restore the land surface as closely to its original condition as possible to avoid future preferential selection of the area for incompatible uses, and to monitor the disposal system. 


\subsection{REFERENCES}

Borns, D.J. and J.C. Stormont, 1988. An Interim Report on Excavation Effect Studies at the Waste Isolation Pilot Plant: The Delineation of the Disturbed Rock Zone, SAND871375, Albuquerque, NM, Sandia National Laboratories.

Brodsky, N.S. and T.W. Pfeifle, 1992. Consolidation of the Waste Isolation Pilot Plant Crushed Salt/Bentonite Mixtures as a Function of Confining Pressure and Moisture Content as Compared With Constitutive Model Predictions, SAND91-7071, Albuquerque, NM, Sandia National Laboratories.

Brush, L.H., and D.R. Anderson, 1988. Appendix A.2: Effects of Microbial Activity on Repository Chemistry, Radionuclide Speciation, and Solubilities in WIPP Brines. Systems Analysis, Long-Term Radionuclide Transport, and Dose Assessments, Waste Isolation Pilot Plant (WIPP). Southeastern New Mexico, March 1989, SAND89-0462, Eds. A.R. Lappin, R.L. Hunter, D.P. Garber, and P.B. Davies, Albuquerque, NM, Sandia National Laboratories.

Butcher, B.M., C.F. Novak, and M. Jercinovic, 1991. The Advantages of a Sal/Bentonite Backfill for Waste Isolation Pilot Plant Disposal Rooms, SAND90-3074, Albuquerque, NM, Sandia National Laboratories.

Chan, K.S., S.R. Bodner, A.F. Fossum, and D.E. Munson, 1992. "A Constitutive Model for Inelastic Flow and Damage Evolution in Solids Under Triaxial Compression," Mechanics of Materials, SAND92-0546J, Vol. 14, No. 1, pp. 1-14.

Christensen, C.L., and E.W. Peterson, 1981. "Field-Test Programs of Borehole Plugs in Southeastern New México," The Technology of High-Level Nuclear Waste Disposal. Advances in the Science and Engineering of the Management of High-Level Nuclear Wastes, Eds. P.L. Hofmann and J.J. Breslin, SAND79-1634C, DOE/TIC-4621, Oak Ridge, TN, Technical Information Center, U.S. repartment of Energy, Vol. 1, pp. 354-369.

Christensen, C.L., C.W. Gulick, Jr., and S.J. Lambert, 1983. Sealing Concepts for the Waste Isolation Pilot Plant (WIPP) Site, SAND81-2195, Albuquerque, NM, Sandia National Laboratories. 
Hansen, F.D., G.D. Callahan, and L.L. VanSambeek, 1993. "Reconsolidation of Salt as Applied to Permanent Seals for the Waste Isolation Pilot Plant," 3rd Conference on the Mechanical Behavior of Salt. Ecole Polytechnique, Paliseau, France, September 14-16, 1993, SAND93-1348C, Albuquerque, NM, Sandia National Laboratories.

Lappin, A.R., R.L. Hunter, D.P. Garber, P.B. Davies, R.L. Beauheim, D.J. Borns, L.H. Brush, B.M. Butcher, T. Cauffman, M.S.Y. Chu, L.S. Gomez, R.V. Guzowski, H.J. Iuzzolino, V. Kelley, S.J. Lambert, M.G. Marietta, J.W. Mercer, E.J. Nowak, J. Pickens, R.P. Rechard, M. Reeves, K.L. Robinson, and M.D. Siegel, eds., 1989. Systems Analysis, Long-Term Radionuclide Transport. and Dose Assessments. Waste Isolation Pilot Plant (WIPP). Southeastern New Mexico, March 1989, SAND89-0462, Albuquerque, NM, Sandia National Laboratories.

Munson, D.E., A.F. Fossum, and P.E. Senseny, 1989a. Advances in Resolution of Discrepancies Between Predicted and Measured In Situ WIPP Room Closures, SAND88-2948, Albuquerque, NM, Sandia National Laboratories.

Munson, D.E., A.F. Fossum, and P.E. Senseny, 1989b. Approach to First Principles Model Prediction of Measured WIPP In Situ Room Closure in Salt, SAND88-2535, Albuquerque, NM, Sandia National Laboratosies.

Munson, D.E., K.L. DeVries, D.M. Schiermeister, W.T. DeYonge, and R.L. Jones, 1992. "Measured and Calculated Closures of Open and Brine Filled Shafts and Deep Vertical Boreholes in Salt," Rock Mechanics, Proceedings of the 33rd U.S. Symposium, Santa Fe, NM, June 3-5, 1992, Ed. J.R. Tillerson and W.R. Wawersik, SAND91-1869, Brookfield, vT: A.A. Balkema, pp. 439-448.

Nowak, E.J., J.R. Tillerson, and T.M. Torres, 1990. Initial Reference Seal System Design: Waste Isolation Pilot Plant, SAND90-0355, Albuquerque, NM, Sandia National Laboratories.

Pfeifle, T.W. and N.S. Brodsky, 1991. Swelling Pressure. Water Uptake, and Permeability of 70/30 Crushed Salt Bentonite, SAND91-7070, Albuquerque, NM, Sandia National Laboratories. 
Stormont, J.C., E.W. Peterson, and P.L. Lagus, 1987. Summary of and Observations About WIPP Facility Horizon Flow Measurements Through 1986, SAND87-0176, Albuquerque, NM, Sandia National Laboratories.

Sandia National Laboratories, WIPP Performance Assessment Group (SNL), 1991. Preliminary Comparison with 40 CFR 191. Subpart B for the Waste Isolation Pilot Plant. December 1991, SAND91-0893, Albuquerque, NM, Sandia National Laboratories.

Tyler, L.D., R.V. Matalucci, M.A. Molecke, D.E. Munson, E.J. Nowak, and J.C. Stormont, 1988. Summary Report for the WIPP Technology Development Program for Isolation of Radioactive Waste, SAND88-0844, Albuquerque, NM, Sandia National Laboratories.

U.S. Department of Energy (DOE), 1986. Waste Isolation Pilot Plant Design Validation Final Report, DOE-WIPP-86-010, Bechtel National, Inc., Job 12484, October 1986.

U.S. Department of Energy (DOE), 1988. 1988 Modification to the Working Agreement of the Consultation and Cooperation Agreement between the Department of Energy and The State of New Mexico on the Waste Isolation Pilot Plant, March 1988.

U.S. Department of Energy (DOE), 1990. Final_Safety Analysis Report. Waste Isolation Pilot Plant, WP 02-9, Rev. 0, Carlsbad, NM, Westinghouse Electric Corporation.

U.S. Department of Energy (DOE), 1991a. Draft Report: Evaluation of the Effectiveness and Feasibility of the Waste Isolation Pilot Plant Engineered Alternatives: Final Report of the Engineered Alternatives Task Force, DOE/WIPP 91-007, Revision 0, Carlsbad, NM:, Westinghouse Electric Corporation.

U.S. Department of Energy (DOE), 1991b. A Plan for the Implementation of Assurance Requirements in Compliance with 40 CFR \$191.14 at the Waste Isolation Pilot Plant, DOE/WIPP 87-016, Rev. 1, Waste Isolation Pilot Plant, Carlsbad, NM.

U.S. Environmental Protection Agency (EPA), 1990. Notice Proposing to Grant a Conditional Variance to the Department of Energy Waste Isolation Pilot Plant (WIPP) from Land Disposal Restrictions, Federal Register, Vol. 55, No. 67, April 6, 1990, Office of Solid Waste, Washington, D.C. 
U.S. Environmental Protection Agency (EPA), 1993. Environmental Radiation Protection Standards for the Management and Disposal of Spent Nuclear Fuel, High-Level and Transuranic Radioactive Waste: Final Rule, Federal Register, Volume 58, No. 242, pp. 66398-66416, December 20, 1993.

Van Sambeek, L.L., D.D. Luo, M.S. Lin, W. Ostrowski, and D. Oyenuga, 1993. Seal Design Alternatives Study, SAND92-7340, Albuquerque, NM, Sandia National Laboratories.

Wakeley, L.D., P.T. Harrington, and C.A. Weiss, Jr., 1993. Properties of Salt-Saturted Concrete and Group after Six Years In Situ at the Waste Isolation Pilot Plant, SAND937019, Albuquerque, NM, Sandia National Laboratories. 


\subsection{Waste Description}

This chapter presents a description of wastes to be disposed of in the Waste Isolation Pilot Plant (WIPP), including waste types, volumes, constituents (radioactive and hazardous), and compatibility, and a discussion on how these affect long-term repository performance is included. Programs associated with waste characterization are also discussed, including the identification of waste acceptance criteria and analytical methods used to ensure compliance with these criteria.

Transuranic (TRU) waste results primarily from plutonium reprocessing and fabrication as well as from research and development activities at various Department of Energy (DOE) defense program facilities. In the future, significant quantities of TRU waste will be generated from environmental restoration and decontamination and decommissioning activities. TRU waste is defined as material contaminated with alpha-emitting radionuclides having atomic numbers greater than 92 , half-lives greater than 20 years, and concentrations greater than 100 nanocuries per gram $(\mathrm{nCi} / \mathrm{g})$ of waste. Prior to 1982 , TRU waste was defined as having greater than $10 \mathrm{nCi} / \mathrm{g}$ of alpha-emitting radionuclides; however, waste with TRU concentrations between ten and $100 \mathrm{nCi} / \mathrm{g}$ has been reclassified as low-level waste and will not be disposed of in the WIPP. TRU waste exists in a variety of physical forms, ranging from unprocessed laboratory trash (e.g., tools, paper, glassware, gloves) to solidified wastewater treatment sludges.

Prior to 1970, all defense-generated TRU waste was buried at several DOE facilities. In 1970, the DOE concluded that TRU waste should have greater confinement from the environment than that provided by shallow land burial. Consequently, since 1970, TRU waste has been placed in retrievable storage pending shipment to a permanent geologic repository. Listed quantities of newly generated waste are based on projections, provided by the generator sites, that extend through the year 2018. These estimates are based on known and anticipated waste-generating activities and are updated periodically to reflect more accurate quantity projections and waste characterization data.

Information provided in this chapter was derived primarily from waste characterization data from the Waste Characterization Program Plan for WIPP Experimental Waste (DOE, 1991a), Waste Isolation Pilot Plant No-Migration Variance Petition (DOE, 1990a), and the Preliminary Performance Assessment for the Waste Isolation Pilot Plant (SNL, 1992), except as noted. 


\subsection{Waste Inventory}

Information regarding the quantities and compositions of existing DOE inventories of TRU waste must define both 1) radionuclide and hazardous constituent content and 2) inventory variability in other parameters of interest to assess long-term repository performance, such as gas-generation potentials, factors possibly affecting the concentrations of radionuclides in brine, and the potential migration of hazardous constituents.

The ten TRU waste generator and/or storage sites that are currently scheduled to ship waste to the WIPP (DOE, 1990b) are as follows:

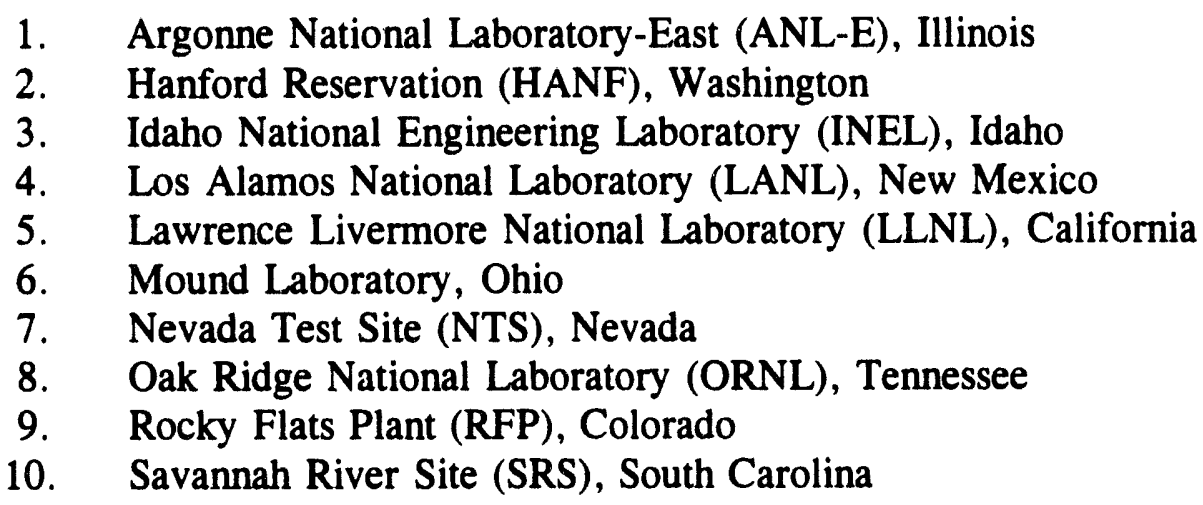

Existing TRU waste inventories, as reflected in the current performance assessment models, are derived from the Integrated Data Base (IDB) (DOE, 1992). The IDB program compiles current data on inventories and characteristics of commercial spent fuel and both commercial and U.S. government-owned radioactive wastes. An annual summary of the current inventory and projected generation of TRU waste from DOE defense activities is compiled from completed surveys or data calls required by DOE. The 1992 IDB includes data on TRU waste volumes, TRU elemental mass, and radioactivity.

The information in the IDB is categorized as either retrievably stored or newly generated (future generation) waste. The volume (stored plus projected generation) for each TRU waste generator/storage site reported in the IDB represents the total waste inventory. The total volume for all generator/storage sites is less than the design capacity for TRU waste to be emplaced at the WIPP. Since current performance assessment (PA) calculations are based on total repository design volume, there is a scaling factor applied to the existing waste inventory to reach the design capacity. The scaling factors are used for extrapolating existing waste volume parameters to WIPP-specific TRU waste values (SNL, 1992). 


\subsubsection{Contact-Handled TRU Wastes}

TRU waste is classified according to the type of radiation emitted. The greatest percentage of TRU waste emits principally alpha, with some beta and gamma, radiation. Alpha particles are dangerous if inhaled or ingested, but do not represent an external radiation hazard. Beta emissions, like alpha, have limited energy, and the waste container provides adequate personnel protection. Gamma radiation, however, is more penetrating. The upper limit for the dose rate at the surface of a container of contact-handled $(\mathrm{CH})$ TRU waste is $200 \mathrm{mrem} / \mathrm{hr}$. Contact-handled TRU waste contains predominately alpha-emitting radioisotopes and is managed in closed containers that provide protection from inhalation or ingestion.

The volume limit of TRU waste to be emplaced at the WIPP is 6.2 million $\mathrm{ft}^{3}\left(175,600 \mathrm{~m}^{3}\right)$ as specified in the 1992 WIPP Land Withdrawal Act (LWA). The estimated volume supplied by the ten waste-generator and/or storage sites of CH TRU waste in the 1992 IDB was approximately 2.23 million $\mathrm{ft}^{3}\left(63,100 \mathrm{~m}^{3}\right)$ of currently stored waste with an additional 1.44 million $\mathrm{ft}^{3}\left(40,900 \mathrm{~m}^{3}\right)$ of waste to be generated by the year 2018 . Volume estimates for waste to be generated are expected to change in the future as a result of remediation activities due to changing DOE facility missions. In order to maintain a consistent volume for PA, the data in the current IDB is scaled to full repository capacity.

The estimated total quantities and waste forms of newly generated and retrievably stored $\mathrm{CH}$ TRU waste from each DOE site and the corresponding scaled quantities are listed in Table 4-1.

\subsubsection{Remote-Handled TRU Wastes}

Remote-handled (RH) TRU waste has a measured radiation dose rate at the container surface greater than $200 \mathrm{mrem} / \mathrm{hr}$. A small percentage of TRU waste contain isotopes that emit high gamma and some neutron radiation as well as alpha radiation. Gamma radiation can pass through several inches of lead and must be heavily shielded for safe management and storage. The upper limit for RH TRU waste to be emplaced at the WIPP facility is a surface dose rate of $1,000 \mathrm{rem} / \mathrm{hr}$. However, the LWA limits the volume such that only up to $5 \%$ of the emplaced RH TRU waste may exhibit a dose rate in excess of $100 \mathrm{rem} / \mathrm{hr}$. Neutron emissions, which are of higher energies than gamma, are limited to $270 \mathrm{mrem} / \mathrm{hr}$ and any 
Table 4-1 Estimated Physical Composition of Retrievably Stored and Newly Generated TRU Waste at DOE Sites

\begin{tabular}{|c|c|c|c|c|c|c|c|}
\hline \multirow[b]{3}{*}{ Site } & \multicolumn{7}{|c|}{ Waste composition, Volume $\left(\mathrm{m}^{3}\right)$} \\
\hline & \multicolumn{4}{|c|}{ Contact-Handled } & \multicolumn{3}{|c|}{ Remote-Handled } \\
\hline & $\begin{array}{l}\text { Retrievably } \\
\text { Stored } \\
\text { Waste }\end{array}$ & $\begin{array}{l}\text { Newly } \\
\text { Generated } \\
\text { Waste }\end{array}$ & Scaled & $\begin{array}{l}\text { Total } \\
\text { CH }\end{array}$ & $\begin{array}{l}\text { Retrievably } \\
\text { Stored } \\
\text { Waste }\end{array}$ & $\begin{array}{l}\text { Newly } \\
\text { Generated } \\
\text { Waste }\end{array}$ & Total RH \\
\hline ANL-E & $1.50 \times 10^{1}$ & $2.48 \times 10^{2}$ & & $2.63 \times 10^{2}$ & & $8.80 \times 10^{1}$ & $8.80 \times 10^{1}$ \\
\hline HANF & $9.99 \times 10^{3}$ & $1.13 \times 10^{4}$ & $2.57 \times 10^{4}$ & $4.70 \times 10^{4}$ & $2.01 \times 10^{2}$ & $6.25 \times 10^{3}$ & $6.45 \times 10^{3}$ \\
\hline INEL & $3.74 \times 10^{4}$ & $4.04 \times 10^{3}$ & & $4.14 \times 10^{4}$ & $5.55 \times 10^{1}$ & $1.38 \times 10^{2}$ & $1.94 \times 10^{2}$ \\
\hline LANL & $7.68 \times 10^{3}$ & $3.27 \times 10^{3}$ & $1.32 \times 10^{4}$ & $2.42 \times 10^{4}$ & $7.85 \times 10^{1}$ & $1.44 \times 10^{1}$ & $9.29 \times 10^{1}$ \\
\hline LLNL & $2.00 \times 10^{2}$ & $3.70 \times 10^{2}$ & & $5.70 \times 10^{2}$ & & & \\
\hline MOUND & $2.55 \times 10^{2}$ & $4.78 \times 10^{0}$ & & $2.60 \times 10^{2}$ & & & \\
\hline NTS & $5.96 \times 10^{2}$ & & & $5.96 \times 10^{2}$ & & & \\
\hline ORNL & $6.70 \times 10^{2}$ & $4.48 \times 10^{2}$ & & $1.12 \times 10^{3}$ & $1.32 \times 10^{3}$ & $2.16 \times 10^{2}$ & $1.54 \times 10^{3}$ \\
\hline RFP & $9.34 \times 10^{2}$ & $1.28 \times 10^{3}$ & $2.67 \times 10^{3}$ & $4.88 \times 10^{3}$ & & & \\
\hline SRP & $5.37 \times 10^{3}$ & $1.99 \times 10^{4}$ & $3.05 \times 10^{4}$ & $5.58 \times 10^{4}$ & & & \\
\hline GRAND TOTAL & $6.31 \times 10^{4}$ & $4.09 \times 10^{4}$ & $7.2 \times 10^{4}$ & $1.76 \times 10^{5}$ & $1.65 \times 10^{3}$ & $6.71 \times 10^{3}$ & $8.36 \times 10^{3}$ \\
\hline
\end{tabular}

Source: DOE, 1992 and SNL, 1992 
neutron source over $20 \mathrm{mrem} / \mathrm{hr}$ has to be identified in the data package. The total volumes of newly-generated and retrievably stored RH TRU waste from each DOE site are listed in Table 4-1. The volume of RH TRU waste that may be emplaced in the WIPP is subject to a $5,100,000$ total curie limitation per the 1992 LWA.

\subsubsection{TRU Mixed Wastes}

Hazardous constituents, as defined in 40 CFR 261, Subparts C and D, often occur as cocontaminants with TRU waste from defense-related operations, resulting in "mixed waste." The DOE established the WIPP TRU Mixed Waste Characterization Data Base to estimate the quantities of Resource Conservation and Recovery Act (RCRA) regulated TRU waste to be shipped from each generator site. Summaries of this information were used in preparing Part A of the RCRA permit application for the WIPP facility, as well as other documentation prepared as required for compliance with hazardous-waste facility requirements. A summary of the most recent estimates of $\mathrm{CH}$ and $\mathrm{RH}$ TRU mixed wastes to be sent to the WIPP facility is provided in Table 4-2. As of December 1992, the estimated total volume of TRU mixed waste (including projected generation estimates for the next five years) is 2.01 million $\mathrm{ft}^{3}\left(57,247 \mathrm{~m}^{3}\right)$ of $\mathrm{CH}$ and 0.142 million $\mathrm{ft}^{3}\left(4,038 \mathrm{~m}^{3}\right)$ of $\mathrm{RH}$ TRU wastes (DOE, 1993a).

\subsubsection{Hazardous Constituents}

Some of the mixed waste planned to be emplaced in the WIPP contain very small quantities (a few parts per million) of spent halogenated solvents identified in 40 CFR $\$ 261.31$ by the Environmental Protection Agency (EPA) hazardous waste numbers F001 through F005. Presence of these compounds has been confirmed by analytical results of headspace gas sampling of stored TRU waste for the test phase.

Other mixed waste planned for disposal in the WIPP may contain metals for which EPA toxicity criteria have been established under 40 CFR $\$ 261.24$ (EPA codes D004 through D011). Lead and other metals are known to be present, based on knowledge of wastegenerating processes and some analytical results. Lead is a frequent hazardous constituent in TRU mixed waste, present predominantly in the form of shielding, glove box parts, and leaded rubber gloves and aprons. Other metals (e.g., cadmium, chromium, uranium, and barium) are also present in some of the mixed waste (e.g., sludges) but in much smaller 
Table 4-2 Quantities of TRU Mixed Waste By Generator Site

\begin{tabular}{|c|c|c|c|c|}
\hline \multirow[b]{3}{*}{ GENERATOR } & \multicolumn{4}{|c|}{ VOLUME (cubic meters) } \\
\hline & \multicolumn{2}{|c|}{ CONTACT HANDLED } & \multicolumn{2}{|c|}{ REMOTE HANDLED } \\
\hline & $\begin{array}{c}\text { Retrievably } \\
\text { Stored } \\
\text { Waste }\end{array}$ & $\begin{array}{c}\text { Newly* } \\
\text { Generated } \\
\text { Waste }\end{array}$ & $\begin{array}{c}\text { Retrievably } \\
\text { Stored } \\
\text { Waste }\end{array}$ & $\begin{array}{c}\text { Newly* } \\
\text { Generated } \\
\text { Waste }\end{array}$ \\
\hline $\begin{array}{l}\text { Argonne National Laboratory- } \\
\text { East }\end{array}$ & 2 & 2 & 0 & 0 \\
\hline Hanford & 168 & 1,312 & 2,767 & 241 \\
\hline $\begin{array}{l}\text { Idaho National Engineering } \\
\text { Laboratory }\end{array}$ & 38,100 & 0 & 102 & 0 \\
\hline $\begin{array}{l}\text { Lawrence Livermore National } \\
\text { Laboratory }\end{array}$ & 0 & 0 & 2 & 4 \\
\hline $\begin{array}{l}\text { Los Alamos National } \\
\text { Laboratory }\end{array}$ & 8,198 & 626 & 0 & 0 \\
\hline Mound & 3 & $<1$ & 0 & 0 \\
\hline Nevada Test Site & 612 & 0 & 0 & 0 \\
\hline $\begin{array}{l}\text { Oak Ridge National } \\
\text { Laboratory }\end{array}$ & 662 & 48 & 831 & 88 \\
\hline Rocky Flats Plant & 1,480 & 273 & 0 & 0 \\
\hline Savannah River Plant & 5,002 & 140 & 0 & 0 \\
\hline Other Sites & 14 & 105 & 1 & 2 \\
\hline Totals & 54,241 & 2,506 & 3,703 & 335 \\
\hline
\end{tabular}

* 5 year projection

Data from DOE, 1993a. 
quantities. Organic solvents (e.g., methylene chloride and 1,1,1 trichloroethane) are present in some waste types. These solvents exist primarily in residual quantities and result from the cleaning of equipment, plastics, and glassware.

The hazardous constituents of the currently-identified TRU mixed waste and each constituent's EPA Hazardous Waste Number are listed in Table 4-3. The results of headspace sampling of TRU mixed waste drums have provided data on concentrations of volatile organic compounds (VOCs), but an insufficient variety of waste forms prevents reporting these results at this time. The waste characterization program will include additional analytical data from more waste forms this year.

\subsubsection{Radionuclide Inventory}

The 1992 PA assumed CH and RH radionuclide inventories as reflected in Table 4-4. The way this inventory is handled within the PA is to calculate a waste unit factor $\left(f_{m}\right)$ consistent with the instructions in Table 1 of Appendix A of 40 CFR 191. The $f_{m}$ is related to the quantity of radionuclides that may be released to the accessible environment. However, the $f_{m}$ calculated in this manner only includes concentrations of radionuclides with atomic numbers greater than or equal to 92. Other radionuclides, though known to exist in the waste, are not used in calculating the allowable release. The result is the establishment of a release limit that is conservative (e.g., smaller than what the standard allows).

\subsubsection{Physical Composition}

In general, $\mathrm{CH}$ TRU mixed waste forms include the following:

Combustibles and Noncombustibles - Combustible and noncombustible wastes are common in waste generated in hot cells and gloveboxes. This waste category contains various mixtures of combustible waste, such as paper, and noncombustible waste, such as metal. The project-specific nature of the operations that generate many of the combustibles and noncombustibles make the detailed segregation of various waste materials unnecessary. Small-scale projects that use specific radionuclides do not require extensive segregation of waste materials for plutonium accountability or recovery. 
Table 4-3 TRU Mixed Waste Hazardous Waste Codes

\begin{tabular}{|cl|}
\hline $\begin{array}{c}\text { EPA Hazardous } \\
\text { Waste Code }\end{array}$ & Basis for Classification \\
\hline F001 & Spent, halogenated solvents \\
F002 & Spent, halogenated solvents \\
F003 & Spent, non-halogenated solvents \\
F004 & Spent, non-halogenated solvents \\
F005 & Spent, non-halogenated solvents \\
D005 & Barium \\
D006 & Cadmium \\
D007 & Chromium \\
D008 & Lead \\
D009 & Mercury \\
D010 & Selenium \\
D011 & Silver \\
D018 & Benzene \\
D019 & Carbon Tetrachloride \\
D020 & Chlordane \\
D021 & Chlorobenzene \\
D022 & Chloroform \\
D023 & o-Cresol \\
D024 & m-Cresol \\
D025 & p-Cresol \\
D026 & Cresol \\
D027 & 1,4-Dichlorobenzene \\
D028 & 1,2-Dichloroethane \\
D029 & 1,1-Dichloroethylene \\
D030 & 2,4-Dinitrotoluene \\
D034 & Hexachloroethane \\
D035 & Methylethyketone \\
D036 & Nitrobenzene \\
D038 & Pyridine \\
D039 & Tetrachloroethylene \\
D040 & Trichloroethylene \\
D043 & Vinylchloride \\
P015 & Beryllium \\
\hline & \\
\hline
\end{tabular}

Source: DOE, 1993a 
Table 4-4 Radionuclide Inventory and Half-Lives of Isotopes Disposed in the WIPP

\section{PA Inventory \\ In Curies}

Radioisotope

Actinium

Americium

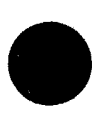

Barium

Bismuth

Californium

Cerium

Cesium

Chromium

Cobalt

Curium
Half-life $\left(t_{1 / 2}\right)$

$\underline{\mathrm{CH}}$

$\underline{\mathrm{RH}}$

$6.13 \mathrm{~h}$

$2.177 \times 10^{1} \mathrm{yr}$

10 day

$7.38 \times 10^{3} \mathrm{yr}$

$4.322 \times 10^{2} \mathrm{yr}$

$7.14 \times 10^{5}$

$1.06 \times 10^{3}$

$2.77 \mathrm{yr}$

$3.23 \times 10^{2} \mathrm{~s}$

$2.552 \mathrm{~min}$

$19.9 \mathrm{~min}$

$45.65 \mathrm{~min}$

$60.55 \mathrm{~min}$

$2.14 \mathrm{~min}$

5.012 day

$2.638 \mathrm{yr}$

$3.37 \times 10^{2}$

$8.63 \times 10^{1}$

284.3 day

$30.0 \mathrm{yr}$

$6.30 \times 10^{4}$

$5.70 \times 10^{5}$

$2.062 \mathrm{yr}$

27.7 day

$5.221 \mathrm{yr}$

70.8 day

$3.39 \times 10^{5} \mathrm{yr}$

$18.11 \mathrm{yr}$

$2.06 \times 10^{4}$

$4.26 \times 10^{3}$ 
Table 44 Radionuclide Inventory and Half-Lives of Isotopes Disposed in the WIPP

\section{PA Inventory \\ In Curies}

Radioisotope

Europium

Francium

Iron

Lead

Manganese

Neptunium

Niobium

Plutonium

${ }^{244} \mathrm{Pu}$

${ }^{242} \mathrm{Pu}$

${ }^{241} \mathrm{Pu}$

${ }^{240} \mathrm{Pu}$

${ }^{239} \mathrm{Pu}$

${ }^{238} \mathrm{Pu}$
Half-life $\left(t_{1 / 2}\right) \quad \underline{\mathrm{CH}}$

$\underline{\mathrm{RH}}$

$4.96 \mathrm{yr}$

$8.80 \mathrm{yr}$

$13.33 \mathrm{yr}$

$4.8 \mathrm{~min}$

44.53 day

$26.8 \mathrm{~min}$

$10.64 \mathrm{~h}$

$36.1 \mathrm{~min}$

$22.3 \mathrm{yr}$

$3.253 \mathrm{~h}$

312.5 day

2.355 day

$2.14 \times 10^{6}$

$2.08 \times 10^{1}$

$9.20 \times 10^{-1}$

35.15 day

$8.26 \times 10^{7} \mathrm{yr}$

$3.763 \times 10^{5} \mathrm{yr}$

$2.35 \times 10^{1}$

$2.94 \times 10^{0}$

$14.4 \mathrm{yr}$

$3.60 \times 10^{6}$

$1.20 \times 10^{5}$

$6.537 \times 10^{3} \mathrm{yr}$

$1.00 \times 10^{5}$

$2.28 \times 10^{3}$

$2.407 \times 10^{4} \mathrm{yr}$

$3.35 \times 10^{5}$

$8.50 \times 10^{3}$

$87.74 \mathrm{yr}$

$3.06 \times 10^{6}$

$2.73 \times 10^{4}$ 
Table 4-4 Radionuclide Inventory and Half-Lives of Isotopes Disposed in the WIPP

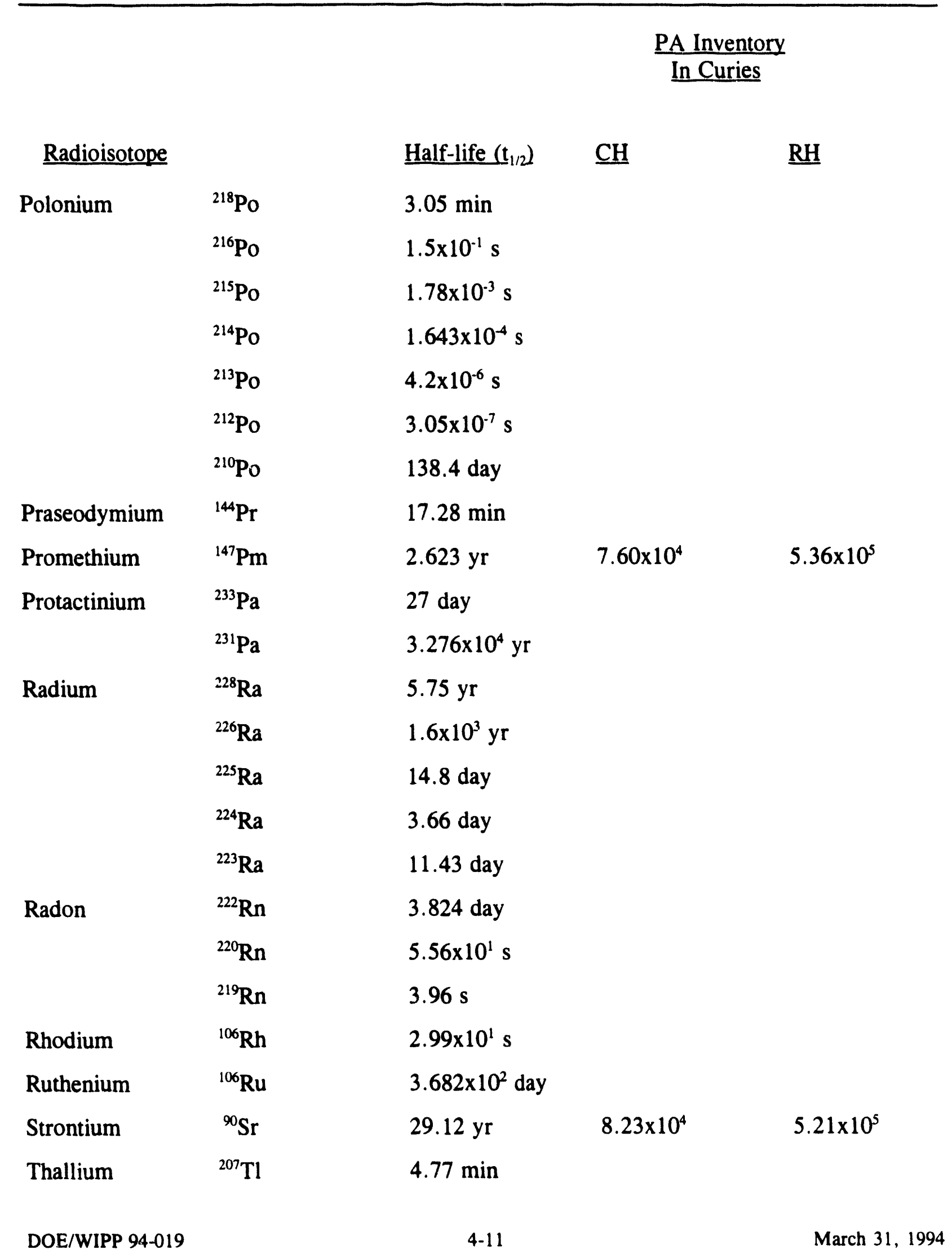


Table 4-4 Radionuclide Inventory and Half-Lives of Isotopes Disposed in the WIPP

PA Inventory

$\underline{\text { In Curies }}$

\section{Radioisotope}

Thorium

$\begin{array}{ll}{ }^{232} \mathrm{Th} \\ { }^{231} \mathrm{Th} \\ \text { Uranium } & { }^{230} \mathrm{Th} \\ & { }^{229} \mathrm{Th} \\ & { }^{228} \mathrm{Th} \\ & { }^{227} \mathrm{Th} \\ & { }^{240} \mathrm{U} \\ { }^{238} \mathrm{U} \\ & { }^{236} \mathrm{U} \\ & { }^{235} \mathrm{U} \\ & { }^{234} \mathrm{U} \\ & { }^{233} \mathrm{U}\end{array}$

Yttrium

TOTAL

${ }^{90} \mathrm{Y}$ $\underline{\text { Half-life }\left(\mathfrak{t}_{1 / 2}\right)}$

24.1 day

$1.405 \times 10^{10} \mathrm{yr}$

$25.52 \mathrm{hr}$

$7.7 \times 10^{3} \mathrm{yr}$

$7.34 \times 10^{3} \mathrm{yr}$

$1.913 \mathrm{yr}$

18.72 day

$1.41 \times 10^{1} \mathrm{hr}$

$4.468 \times 10^{9} \mathrm{yr}$

$2.342 \times 10^{7} \mathrm{yr}$

$7.038 \times 10^{8} \mathrm{yr}$

$2.445 \times 10^{5} \mathrm{yr}$

$1.585 \times 10^{5} \mathrm{yr}$

$64.0 \mathrm{~h}$
CH

$\underline{\mathrm{RH}}$

$2.90 \times 10^{-1}$

$5.66 \times 10^{0}$

$2.68 \times 10^{0}$

$1.80 \times 10^{0}$

$5.38 \times 10^{-1}$

$6.13 \times 10^{-2}$

$1.53 \times 10^{3}$

$1.99 \times 10^{2}$

\section{$1.79 \times 10^{6}$}

Source: SNL, 1992 
The hazardous metals in this waste category are associated with specific items in the wastes (e.g., lead in equipment parts, leaded tape, or leaded glass). Based on the original materials comprising this waste and waste generation operations, only residual concentrations of RCRA-regulated VOCs are expected to be present.

Combustibles - Combustible waste consists of waste material generated during a variety of processes and may contain trace organics from cleaning operations or from the absorption of spills in gloveboxes. These wastes consists of paper, plastics, cloth rags and clothing, and wood resulting from almost all plutonium operations. Cloth and paper wipes are used to clean parts and gloveboxes during most operations. Depending on the operations, damp combustibles are usually used and then wrung out, drained, or dried. A small quantity of noncombustible wastes, such as concrete, scrap metal, and equipment, may also be present in this waste category.

Graphite - Graphite waste is produced from molds that are broken, cleaned, or scraped in gloveboxes to remove excess plutonium. Graphite is a uniform, well-defined material.

Plutonium casting operations include the use of solvents from the cleaning of graphite molds, and thus, residual spent solvents may be present on the surfaces of graphite pieces. In addition, residual metals may be present from impurities in plutonium metal. Hazardous waste constituents that may be associated with the Graphite waste category include 1,1,1-trichloroethane.

Filters - Filter wastes include the following types of filters:

- $\quad$ High Efficiency Particulate Air (HEPA) filters

- Ful-Flo filters

- Filter media

- $\quad$ Processed filter media

- Prefilters

Prefilters and HEPA filters are used on all ventilation intake and exhaust systems associated with all plutonium operations. Filter frames can be either wood, aluminum, or stainless steel; the filter media may be Fiberglas ${ }^{\star}$, Nomex ${ }^{\star}$, or similar material. Fiberglas ${ }^{\star}$ is a trade name for a variety of products made of or with glass fibers or glass flakes. Nomex ${ }^{\oplus}$ is a trade name for an aramide fiber commonly derived from p-phenylenediamine and terephthaloyl chloride. Ful-Flo ${ }^{\star}$ filters consist of fibrous polypropylene (a synthetic, crystalline, thermoplastic polymer) filter media. 
Filter media are generated from splitting absolute dry box and HEPA filters apart from their frames in the plutonium process areas. Loose particulate materials that are dislodged from the filters are stabilized and packaged separately from the media. Filter media are packaged in 1-gallon plastic bottles or bags.

Processed filter media consist of Ful-Flo ${ }^{\star}$, filter media, and whole filters removed from acid and nonacid environments. Filter media may be mixed with portland cement to neutralize residual nitric acid that may be present.

Filters are designed to remove and retain specific sizes of particulate materials from air or liquids. Although the filters associated with plutonium operations are not designed to retain organic vapors, they may contain these residues, depending on the operations conducted in a glovebox or building. Airborne metals, resulting from grinding or machining operations, also may be trapped in glovebox filters. However, based on knowledge of the original materials and the operations conducted, the concentrations of these metals are not expected to exceed RCRA toxicity levels.

Benelex $^{\oplus}$ and Plexiglas ${ }^{\otimes}$ - Benelex ${ }^{\otimes}$ consists of approximately 99.5 percent wood, with residual amounts of the phenolic resin. Plexiglas ${ }^{\circledast}$ is a poly methyl methacrylate polymer used for glovebox windows and is generated as waste during the change-out of the glovebox windows.

This waste category is composed of well-defined materials that are used as neutron shielding material and in glovebox construction. Organic residues may be present as a result of glovebox cleaning prior to disassembly. Because lead is present as part of the glovebox shielding or leaded glass, this waste may exceed RCRA toxicity levels.

Firebrick and Ceramic Crucibles - Firebrick is a high-density refractory clay composed of silica, magnesite, dolomite or alumina, carbon, and silicon carbide.

Firebrick becomes TRU waste when plutonium processing furnaces or incinerators are dismantled or repaired. Firebrick is cleaned with dilute acids and then rinsed, dried, and scraped to remove excess plutonium before disposal. Oil-Dri ${ }^{\star}$, an absorbent clay material, is usually placed in packages of damp firebrick. Depending on the operation, firebrick may be packaged in Fibre-Paks ${ }^{\star}$ or poly bags. Ceramic crucibles are included in this waste category because they consist of a similar, heat-resistant type of material. 
The surfaces of firebrick or crucibles may have residual concentrations of metals; however, the predominant metals associated with this waste (e.g, magnesium, iron, aluminum, and titanium) are not RCRA-regulated. Because the processes in which these materials are used involve very high temperatures, organic constituents are not typically associated with this waste category but could occur because these materials may have been used in the same room.

Leaded Rubber - Leaded rubber waste contains layers of Hypalon ${ }^{\circledR}$ and lead oxideimpregnated neoprene. Hypalon ${ }^{\star}$ is a trade name for chlorosulfonated polyethylene, a synthetic rubber. Neoprene is also a synthetic rubber available commercially in solid form as a latex or as a flexible foam. It is resistant to oils and has a high flame resistance (e.g., less combustible than natural rubber). Lead oxides are noncombustible, toxic materials that are insoluble in water but soluble in acids.

Sources of TRU-contaminated, leaded rubber waste include gloves removed from glovebox lines and aprons. Leaded rubber from wet-chemistry glovebox lines are washed with water to remove nitrate contamination associated with nitric acid environments. Leaded rubber is dried, drained, or packaged to ensure no free liquids are included. In addition, adsorbents may be added directly to the waste to sorb residual moisture that may be present. Leaded rubber waste also may contain a small portion of tools and equipment components that contain other metals.

Metal - Metal waste includes "light" metals, "heavy" metals, equipment, tanks, and machinery formerly in or attached to gloveboxes. "Light" metals, in engineering terminology, are metals or alloys of low density that are strong enough for use in construction. "Light" metals include aluminum, magnesium, and beryllium. "Heavy" metals are metals whose specific gravity is approximately five or higher and include metals such as lead, cobalt, and iron.

TRU-contaminated metal waste containing economically recoverable amounts of plutonium is leached with nitric acid and/or hot water or mechanically treated for plutonium recovery prior to declaring it waste. Metal waste may include glovebox parts, hand tools, sheet metal, trays, clamps, pipe, valves, nuts and bolts, wire, and equipment consisting of a variety of metals, such as iron, copper, aluminum, lead, tantalum, and stainless steel. Smaller items, such as nuts and bolts, are often packaged in metal cans or plastic wide-mouthed bottles prior to removing them from the glovebox lines. 
Large pieces of equipment, tanks, or machinery are disassembled or otherwise reduced in size to increase the waste container packaging efficiency. Gearbox oil, hydraulic fluid, or other liquids are drained from machinery. Sharp metal pieces are often taped to decrease the handling hazards and preclude containment punctures.

Depending on the operation in which the equipment or tools were used, this waste may have been in contact with organic solvents and may have residual surface contamination.

Glass - Glass waste is created during most TRU operations at DOE generator sites. Two general types of glass waste are generated. Raschig rings, are borosilicate glass rings used as neutron absorbers in storage tanks holding liquid radioactive waste. The other type of glass waste is a variety of laboratory glassware, fluorescent lights containing small amounts of mercury, and glovebox windows.

Glass waste may contain small quantities of oil and organic solvents that remain in emptied glassware or as residues on Raschig rings from the solvent present in storage tanks. Lead is the predominant metal reported in the waste category and is associated with leaded glass and lead tape.

Supercompacted Waste - Supercompacted waste includes solid materials previously described above that are amenable to compaction. This treatment technology is used to decrease waste volume and increase management efficiency through reduction in required storage capacity. Waste containers are scanned prior to supercompaction using Real Time Radiography (RTR) to verify the original waste category. Other waste characterization and verification activities (e.g., radioassay, headspace gas sampling, and visual examination) are also conducted prior to compaction.

Waste is segregated based on the type of material (i.e., hard versus soft waste), plutonium content, TRU versus TRU mixed waste, and final overpack drum weight (e.g., 800 pounds). Soft materials may include combustibles, filters, and leaded rubber, while hard materials may include metal, glass, and graphite. Waste is packaged or repackaged and precompacted into 35-gallon drums prior to supercompaction. A maximum of four 55-gallon drums of soft waste can be precompacted into one 35-gallon drum. Hard waste is not precompacted. Each 35-gallon drum of precompacted soft waste (all within the same waste category) as well as hard waste is pierced with four holes to allow entrapped air to escape during supercompaction. Each 35-gallon drum of waste is supercompacted into one "puck." A 
maximum of four pucks are placed into one 55-gallon loadout drum. During compaction, waste undergoes a physical transformation (volume reduction). No chemical transformations or reactions are known to occur.

Because supercompacted waste may consist of any of the above described waste categories, it may contain any or all of the hazardous wastes associated with those categories

Inorganic Wastewater Treatment Sludge - Inorganic wastewater treatment sludge results from the acid/base neutralization of aqueous waste slurries, the filtration of solids, and the subsequent solidification of oxide and hydroxide precipitated solids. The three physical forms of this waste are 1) dry, solid monoliths, 2) highly viscous gel-like solids, or 3) crumbly solids. Consistent with similar industrial or municipal wastewater treatment processes, the sludge is vacuum-filtered. Diatomaceous earth is often included in the sludge as part of the filtration process. Solidifying' or absorbent agents, such as cements, Oil Dri ${ }^{\star}$, or vermiculite, may be added to create the final waste form. Sludge is stabilized with cements or other appropriate agents prior to packaging. Using knowledge of the materials and processes generating the waste, generators determine the amounts and types of absorbent necessary to ensure proper solidification and then verify the final waste form using RTR.

The predominant chemical components of wastewater treatment sludge are silica, calcium, sodium, magnesium, and iron oxides resulting from the neutralization and stabilization process. Acidic wastewaters are generated from a variety of processes, including cleaning and dissolution chemistry. As a result, generators have reported a variety of solvents and heavy metals as possible contaminants in the final wastewater treatment sludge. Based on the input materials for the various processes generating this waste and the wastewater treatment processes themselves (including sludge vacuum filtration and stabilization), VOCs, although reported, are expected to be a minor component of this waste category.

Organic Liquid and Sludge - Organic sludge is produced by stabilization of organic liquids such as oils, solvents, and lathe coolants. TRU-contaminated organic liquid is collected at or near the point of origin in appropriate tanks or containers as they are generated. In the past this waste was mixed with calcium silicate to form a paste-like substance. Some organic liquid waste is converted to a sludge using the Envirostone ${ }^{\circledast}$ process, which involves the addition of water and an oil and solvent emulsification agent, and finally the stabilization and solidification of the mixture with gypsum-based Envirostone ${ }^{\star}$. Other organic liquids, 
primarily from research and development activities, may be absorbed on inert materials such as vermiculite and diatomaceous earth.

This waste category is expected to contain relatively high concentrations of VOCs. Because a portion of this waste was generated prior to 1982, the potential exists for waste oils in this waste category to contain polychlorinated biphenyls (PCBs).

Solidified Liquid - Solidified liquid is composed of aqueous waste that is not compatible with the primary aqueous wastewater treatment process because of the presence of complexing chemicals. This liquid waste is excluded from the production liquid waste because of the potential presence of complexing chemicals that would interfere with the recovery of actinides. Complexing chemicals include organic acids, alcohols, or other chelating agents. Batches of this waste may be as little as one liter or as much as several hundred liters and may be solidified with portland and magnesium cement. Other nonflammable aqueous waste is solidified with vermiculite. Similar to inorganic wastewater treatment sludge, the chemical constituents reported in this waste include small quantities of spent solvents and RCRA-regulated metals.

Inorganic Process Solids and Soil - This waste category consists of solids that cannot be reprocessed or process residues from evaporator and other types of storage tanks, grit, firebrick fines, ash, salts, metal oxides, and filter sludge. This waste is typically solidified in portland or gypsum-based cements. Contaminated soil, asphalt, and sand are generated from the cleanup of spills, as well as decontamination and decommissioning activities at DOE generator sites, and may also be present in this waste. This waste category includes materials from a variety of sources with the potential for an accumulation of metals or organics.

Pyrochemical Salt - Pyrochemical salt waste is comprised of salts used in molten salt and direct oxide reduction processes. Molten salt is a fused halide salt mixture of sodium, potassium, and magnesium salts. In molten salt extraction, the salt serves as a solvent for plutonium and americium. Plutonium and americium are removed from spent molten salt by the salt-scrub process to yield a waste salt and an aluminum-magnesium-plutonium-americium alloy.

Direct oxide-reduction salt is a calcium chloride salt containing unreacted calcium metal (one to three weight percent) and calcium oxide. The direct oxide reduction process is a one-step 
reduction of plutonium oxide to plutonium metal. The process employs a calcium metal reductant and a molten calcium chloride salt flux. The uncertainty in the quantities of unreacted calcium metal present in the salt results in the need to process the salt by air oxidation. Air oxidation ensures that residual calcium metal, a nonradionuclide pyrophoric material, is oxidized in the waste salt so that it will not exhibit the characteristic of reactivity. Molten and direct oxide reduction salts are packaged in metal cans prior to being placed in 55-gallon drums.

Because pyrochemical salt is used in a high-temperature process, metals are the only hazardous constituents typically reported. The types and concentrations of metals present in the waste will depend on the impurities present in the feed-stock materials and the impurities retained in the salt after plutonium is recovered.

Cation and Anion Exchange Resins - This waste category consists of leached and unleached spent ion exchange resins. The resins, synthetic polymers, typically consist of polystyrene copolymerized with divinyl benzene. Nitrate or chloride anion exchange is used to separate and purify plutonium from nitric acid or chloride solutions, respectively. After the impurities have been removed from the effluent, the plutonium sorbed on the resin is eluted and precipitated.

Feed solutions requiring plutonium separation and purification may contain trace quantities of spent solvents from various operations. Lead may be present in the package for shielding. In addition, the following VOCs have been reported:

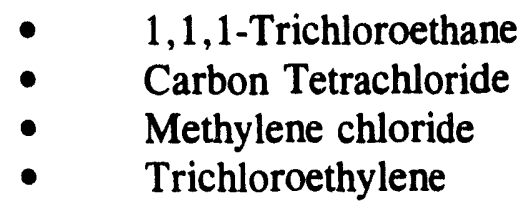

Solid and Solidified Materials - This waste category consists of a mixture of solid materials, which include the following waste categories: Combustibles and Noncombustibles, Combustibles, Graphite, Filters, Benelex ${ }^{\circledR}$ and Plexiglas ${ }^{\circledR}$, Firebrick and Ceramic Crucibles, Leaded Rubber, Metal, and Glass and solidified materials (which include the waste categories of Inorganic Wastewater Treatment Sludge, Organic Liquid and Sludge, Solidified Liquid, Inorganic Process Solids and Soil, Pyrochemical Salt, and Cation and Anion Exchange Resins). 
Some RH TRU mixed waste forms are similar to some CH TRU mixed waste forms (Warrant, 1985). Although the study was conducted several years ago, the processes have not changed. Remote-handled TRU waste forms similar to CH TRU are:

- Combustibles and Noncombustibles,

- Filters,

- Inorganic Wastewater Treatment Sludge,

- $\quad$ Solidified Liquids, and

- $\quad$ Solid Materials.

One other similar form is a heterogeneous solid consisting of metalographic samples of fuel elements, fines, and combustibles packaged in metal cans and plastic bags or buckets; this waste form may contain a variety of solvents and heavy metals.

\subsubsection{Chemical Compatibility}

The TRU waste that is to be emplaced in the WIPP is limited in form to dewatered, solid, or solidified material. The constituents of the waste are also restricted so that there is less than one percent free liquids and there are no corrosives, explosives, or nonradioactive pyrophorics. The purpose of these restrictions is to ensure that the waste is in a form that is safe for shipping, handling, storage, and disposal.

A detailed assessment of the chemical components of the wastes has been performed to determine chemical compatibility within and between the different waste forms from the various generator sites. The analysis of chemical compatibility was based on A Method for Determining the Compatibility of Hazardous Wastes (EPA, 1980). Compounds found within the waste are classified as "incompatible" if the potential for a chemical reaction exists that might result in an explosion, heat generation, gas generation, pressure build up, or the generation of toxic by-products.

A comprehensive list of all chemicals that could be present in a given waste form was obtained from each generator site. These lists were compiled based on process technology and flow analysis. All chemical inputs into the process system were accounted for when compiling the lists. The concentration levels of these chemicals were reported as either trace (less than one percent), minor (one to ten percent), or dominant (greater than ten percent). These waste constituents were then divided into groups based on their chemical structure and nature (e.g., aldehydes, caustics, cyanides, etc.). An example of an "incompatible" situation 
is a reaction between Group 1 (acids, minerals, nonoxidizers) and Group 10 (caustics). The result could be heat generation. All combinations of such potential incompatibilities were identified. Incompatibilities were identified both within a given waste form and for hypothetical accident scenarios (during transportation) wherein a mixing of waste forms could potentially occur. In the latter case, potential incompatibilities were examined across all waste forms from a generator site.

Interaction of compounds with any other compounds present in trace quantities in any one waste form are not of concern in terms of the consequences. By the very nature of the waste forms (solidified or solid materials), and the very low quantities of any trace chemicals present, reactions with the other compounds will either be precluded or will not result in an unacceptable consequence. In most cases, any possible reactions take place before the waste is generated in its final form.

Potential incompatibilities between minor and dominant components of the different waste forms were compiled for each site and analyzed on a case-by-case basis. Given the physical and chemical nature of each waste form (cemented, solidified, etc.), it was possible to determine whether any interaction between the potentially incompatible compounds could occur. Typically, potentially reactive species listed as present in the waste are no longer in a reactive state. For example, a site listing a caustic (Group 10) and an acid (Group 1) as part of the waste has only the neutralized product in an immobilized form in the waste. No further reactions are possible once the waste is generated in its final form.

Incompatibilities between minor and dominant waste constituents that were not resolved by the physical nature of the waste or from waste generation practices were identified, and incompatible wastes were segregated. The sites that generate these waste forms were informed that these wastes could not be shipped until it could be adequately demonstrated by testing that they posed no shipping or storage related hazard. In other words, no chemical incompatibilities will exist in the wastes that are to be disposed of at the WIPP site.

\subsection{Waste Envelope}

Only those wastes that meet established acceptance criteria will be emplaced in the repository. These criteria result from restrictions on waste acceptability established by the DOE. In addition, restrictions may result from the continued evaluation of the expected 
performance of the repository and from interactions with regulatory authorities. The associated concepts of the "performance-based waste envelope" and "boundary conditions and process tolerance limits" are described in this section. The process for controlling the types of wastes to be sent to the WIPP is also described.

\subsubsection{Performance-Based Waste Envelope}

The performance-based waste envelope identifies the bounding characteristics of wastes acceptable for the WIPP based on repository performance. This envelope considers only physical and chemical form of the waste and its potential interaction with the repository (see Section 2.7). Information used to formulate and identify this envelope includes characterization data, process knowledge, and modeling. It is anticipated that some waste forms or constituents will be identified which may require additional quantitative analysis through waste characterization or additional experimental evaluation prior to their inclusion in the performance-based waste envelope.

As PA activities provide insight relative to the importance of specific waste parameters, some may be found to require increased characterization if it is determined that they would likely have significant impact on the performance of the repository. Waste parameters shown to have little or no impact on repository performance will be candidates for reduced characterization. The PA results, combined with interactions with state and federal regulators, will provide guidance for future waste generation practices, therefore allowing the DOE to optimize future sampling and analysis programs.

Waste characterization programs will iteratively provide additional evaluation data. These data will be evaluated in future compliance evaluations to determine if expanding the envelope of acceptable wastes is feasible. The results of these compliance analyses, if beneficial, will be presented to the regulator in compliance submittals for approval and will be communicated to the generators to optimize their decontamination and decommissioning programs so as to generate WIPP-bound wastes in acceptable forms.

The performance-based waste envelope will contain the criteria for waste acceptance based on possible effects of wastes on the performance of the repository. There are several other compliance programs that may also impose criteria applicable to waste acceptance at the WIPP. These include criteria required by final RCRA permit conditions, transportation and certification, and WIPP operational safety. These criteria will be published and implemented 
at all DOE generator/storage facilities through a revision to the WIPP Waste Acceptance Criteria (WAC) (DOE, 1991b).

\subsubsection{Boundary Conditions and Process Tolerance Limits}

The WIPP facility will have both facility-established boundary conditions and process tolerance limits (e.g., no explosives or compressed gases within containers, labeling on containers) and boundary conditions established by the New Mexico Environment Department (NMED) in its RCRA permit for the WIPP facility and the EPA in its NoMigration Determination (NMD) for the disposal-phase activities. Facility-established boundary conditions and process tolerance limits are summarized in Table 4-5. Regulatorestablished boundary conditions, including safety related conditions, are unknown at this time but will likely be based on concentration limits for wastes to be placed in the facility.

"Boundary conditions" are defined as the maximum acceptable limit values for waste properties. "Process tolerance limits" are defined as those characteristics of a waste that a waste-management process can tolerate while maintaining permit compliance. Waste that exceeds boundary conditions or could lead to an exceedance of process tolerance limits will not be approved for acceptance at the WIPP facility or will be returned to the generator site upon verification that these criteria have not been met.

TABLE 4-5

BOUNDARY CONDITIONS AND PROCESS TOLERANCE LIMITS ESTABLISHED BY THE WASTE ISOLATION PILOT PLANT

\begin{tabular}{||l|l|l||}
\hline \multicolumn{1}{|c|}{ Determination } & \multicolumn{1}{|c|}{ Parameter } & \multicolumn{1}{c|}{ Boundary Condition or } \\
\hline \multirow{3}{*}{$\begin{array}{l}\text { lgnitability, reactivity, and } \\
\text { corrosivity }\end{array}$} & Liquids or aqueous waste & $\begin{array}{l}\text { Residual liquid only with all internal containers well } \\
\text { drained (<1\% free liquids) }\end{array}$ \\
\cline { 2 - 4 } & Oxidizers & No oxidizers \\
\cline { 2 - 4 } & Explosives & No explosives \\
\cline { 2 - 4 } & Compressed gases & No compressed gases \\
\cline { 2 - 4 } & Pyrophoric materials & No nonradionuclide pyrophoric materials \\
\hline Compatibility & Waste form & Only those waste forms described in Section 4.1.6 \\
\hline Waste category & Waste form & Only those waste forms described in Section 4.1.6 \\
\hline
\end{tabular}

Source: DOE, 1993a 


\subsubsection{Facility-Established Boundary Conditions and Process Tolerance Limits}

Boundary conditions and process tolerance limits have been established to ensure compliance with the WIPP facility's RCRA waste management requirements (Table 4-5). The following wastes are unacceptable for management at the WIPP facility:

- Incompatible wastes as defined under 40 CFR 264, Appendix V

- Ignitable, reactive, and corrosive wastes as defined under 40 CFR 261, Subpart C

- Wastes not described by one of the waste forms

- Wastes that do not meet the regulator-established boundary conditions

Wastes that exhibits the characteristics of ignitability, reactivity, or ccrrosivity will niot be emplaced in the WIPP. DOE has established the WIPP WAC to control the chemical and physical forms of TRU waste, including TRU mixed waste at the generator sites that will be destined for the WIPP facility. The WIPP WAC are implemented by DOE generator/storage sites through WAC waste certification programs.

The WIPP program manages TRU mixed waste in a manner that prevents the buildup of explosive or flammable gases within the waste. Containers are allowed to "aspirate" so that any gases that are generated within a waste container are allowed to escape through a HEPAgrade filter vent to prevent pressurization. Aspiration maintains the levels of flammable gases at safe levels via diffusion. Discussions with the NMED have resulted in an agreement that TRU waste containers that use HEPA-grade filters to prevent internal pressurization, conform to the requirements of 40 CFR 264, Subpart I, regarding closed containers.

The WIPP facility is designed to manage only compatible wastes. Using 40 CFR 264 , Appendix V, and the EPA document, A Method for Determining the Compatibility of Hazardous Wastes, DOE has determined that all of the WIPP waste forms are mutually compatible. To ensure waste compatibility, the WIPP facility cannot accept any waste form that, if mixed with one of the acceptable waste forms, would produce toxic fumes, generate a violent reaction, or initiate a fire or explosion. 
Waste forms have been established based on the original materials used in an operation or the processes generating a waste. Analytical requirements are determined by waste form. Waste forms also ensure that process tolerance limits are maintained. For example, pressurized containers are unacceptable because they may exhibit the characteristic of reactivity.

The WIPP facility will accept only those waste forms identified. The waste form is assigned by the generator sites. The WIPP Project regards RTR analysis as an acceptable waste examination technique for TRU waste and will review RTR data records and the Waste Profile Form to ensure that the container holds an acceptable waste form. If discrepancies or inconsistencies are detected during the RTR data review, WIPP Project personnel will review the RTR tape to verify the waste form.

\subsubsection{EPA-Established Boundary Conditions}

In accordance with 40 CFR $\$ 268.6$, boundary conditions are likely to be established by regulatory agencies for the WIPP facility. These will likely be based on ensuring safe container management and ensuring compliance with environmental performance standards.

\subsubsection{Waste Acceptance Criteria}

A formal procedure has been developed for controlling the total inventory of TRU wastes to be shipped to WIPP. This procedure is defined in the WAC. These criteria establish limits for the physical, radiological, and chemical composition of the waste, in addition to specifications for the waste packaging. The primary objectives of the WIPP WAC are to ensure that all TRU wastes are packaged so that handling and subsequent disposal can be performed safely and so that the ability of the proposed repository to isolate the waste is maintained. A summary of the current WAC is provided in Table 4-6; a summary of WAC limiting parameters for CH TRU waste is provided in Table 4-7.

Revision 4.0 of the WAC includes restrictions resulting from RCRA requirements as well as operational, transportation, and safety criteria. Section 3.3 of WAC Revision 4.0 contains PA criteria for the test phase which may also be applicable to disposal-phase wastes pending final PA and certification conditions. These criteria should be considered in waste generation practices along with WAC certification requirements. These criteria will be published and implemented at all DOE generator/storage facilities through the final WIPP WAC. The Inventory Control Criteria will guide future waste generation practices throughout the 
Table 4-6 WIPP Waste Acceptance Criteria

\section{Crerterron}

Waste Containers

Waste Package Size

Waste Package Handling

Specific Activity of Waste

Waste Package Weight

\author{
Contact-HandLEd
}

Waste containers for emplacement in the WIPP shall be noncombustible and meet all the applicable requirements of 49 CFR $\$ 173.412$ for Type A packaging. Waste containers of various sizes shown to meet DOT Type $A$ requirements by the methods detailed in MLM 3245 are acceptable at the WIPP. In addition, waste containers shall be used, handled, and stored in a manner that is expected to maintain their Type A packaging specification from the time of certification to emplacement in the WIPP.

CH TRU waste packages or package assemblies shall no exceed $12 \times 8 \times 8.5$ feet $(3.7 \times 2.4 \times 2.6$ meters $)$ in overall L $\times \mathrm{W} \times \mathrm{H}$ dimensions.

Standard 55-gallon metal drums in two seven-pack configurations or two SWBs are the only currently authorized loading configurations for shipment in TRUPACT-II. An experimental bin or up to four drums may be overpacked in a SWB. If only seven-pack or SV'B of waste is scheduled for shipment in TRUPACT-II, a dunnage seven-pack or SWB must be added to the TRUPACT-II for transport, as specified in Appendix 1.3.7 of the TRUPACT-II SARP.

All waste packages shall be provided with cleats, offsets, chimes, skids, or seven-pack handling fixture for handling by means of fork trucks, cranes, or similar handling devices. Lifting rings and other auxiliary lifting devices on the waste packages, if provided, shall be recessed, offset, or hinged in a manner which does not inhibit stacking the packages. All 55-gallon drums will be seven-packed and the SWBs shall be configured as specified in the TRUPACT-II SARP.

For purposes of TRU waste certification, the lower limit of $>100 \mathrm{nCi} / \mathrm{g}$ of TRU radionuclide shall be interpreted as $>100 \mathrm{nCi} / \mathrm{g}$ of waste matrix. The weight of added external shielding and the containers (including any rigid liners) all be subtracted prior to performing the $\mathrm{nCi} / \mathrm{g}$ calculation. This is also applicable to wastes managed as TRU under the provisions of DOE Order 5820.2A (e.g., U-233 and Ra-226).

CH TRU waste packages or package assemblies shall weigh no more than 21,000 pounds $(9,550$ kilograms). The following weight limits shall apply for waste package assemblies transported in the TRUPACT-Il package:

- 1,000 lbs per drum

- $\quad 1,450 \mathrm{lbs}$ per drum overpacked in a SWB

- 4,000 lbs per SWB

- $\quad 7,265$ lbs per TRUPACT-II payload

- $\quad 19,250$ lbs per TRUPACT-II payload, including weight of the TRUPACT-II

Recent enhancements in the TRUPACT-II design have resulted in an average payload weight of approximately 6.200 lbs. The total weight of the top seven-pack of drums or SWB including error shall be less than or equal to the total weight including error of the lower seven-pack of drums or SWB. The DOT limit of 80,000 lbs gross vehicle weight (GVW) must also be met.
RH TRU waste containers shall be noncombustible and meet. as a minimum, the structural requirements and design conditions for Type A packaging contained in 49 CFR $\$ 173.412$. In addition, all RH TRU waste containers shall be certified to the WIPP-approved specifications and shall be used, handled, and stored in a manner that is expected to maintain their Type A packaging specification from the time of certification to emplacement in the WIPP

RH TRU waste packages shall be no larger than a nominal 26 inches $(0.66$ meter in diameter, with a maximum length of ten feet, one inch ( 3.1 meters), including the pintle, per WID Operation Drawing H-2-91273.

RH TRU waste packages shall be equipped with an axial lifting pintle of a design acceptable to the WIPP (Drawing H2-91273). The packages shall have no other lifting devices.

Same as $\mathrm{CH}$.

RH TRU waste packages shall weigh no more than 8,000 pounds (3,630 kilograms) 
Table 4-6 (Continued)

\section{Crtterion}

Nuclear Criticality

Pu-239 Equivalent Activity

Surface Dose Rate

Surface

Contamination

Thermal Power
The fissile or fissionable radionuclide content for $\mathrm{CH}$ TRU waste packages shall be no greater than the following values. in Pu-239 fissile gram equivalent:

- 200 grams per 55 -gallor (0.21 cubic meter) drum

- 5 grams per cubic foot ( 0.028 cubic meter) in boxes, up to 350 grams maximum.

The Pu-239 FGE shall be calculate using the methods detailed in Appendix 1.3.7 of the TRUPACT-II SARP. The fissile or fissionable radionuclide content of $\mathrm{CH}$ TRU waste in the TRUPACT-II. including two times the measurement error, shall be less than 200 grams for a 55 -gallon drum or less than 325 grams for a SWB. The sum of the fissile equivalents of all waste packages in the entire payload quantity including two times the error may not exceed 325 grams. See the calculational methods detailed in Appendix 1.3.7 of the TRUPACT-II SARP for details.

Waste packages shall not exceed 1,000 curies of $\mathrm{Pu}-239$ equivalent activity (PE-Ci).

Waste packages shall have a maximum surface dose rate at any point no greater than $200 \mathrm{mrem} / \mathrm{hr}$. Neutron contributions of greater than $20 \mathrm{mrem} / \mathrm{hr}$ to the total package dose rate shall be reported separately in the data package. The external dose rates on the loaded TRUPACT-II placed on the trailer are limited to $200 \mathrm{mrem} / \mathrm{hr}$ at the surface of the TRUPACT-II and $10 \mathrm{mrem} / \mathrm{hr}$ at two meters. Dose rates on the TRUPACT-II must comply with 10 CFR \$71.47. Drums of SWBs shall not exceed the $200 \mathrm{mrem} / \mathrm{hr}$ surface reading or $10 \mathrm{mrem} / \mathrm{hr}$ at two meters. Shielded waste containers are allowed for As Low As Reasonably Achievable (ALARA) purposes only and must comply with Section 12.0 of Appendix 1.3.7 of the TRUPACT-II SARP.

Removable surface contamination on waste packages or package assemblies to be emplaced in WIPP shall not be greater than 50 picocuries per $100 \mathrm{~cm}^{2}$ for alpha-emitting radionuclides and 450 picocuries per $100 \mathrm{~cm}^{2}$ for betagamma-emitting radionuclides. Fixation of surface contamination to meet the above criterion is not permitted.

Individual $\mathrm{CH}$ TRU waste packages in which the average thermal power density exceeds 0.1 watt per cubic foot $(3.5$ watt per cubic meter) shall have the thermal power recorded in the data package. There are two thermal limits for decay heat: 1) the total decay heat from the radioactive decay of the radioisotopes within an individual waste package and 2) the total decay heat from all waste packages in a TRUPACTII. The detailed limits are contained in the TRUPACT-II SARP. The decay heat limits for waste packages in each shipping category are presented in the TRUPACT-II SARP Table 1.2.3.3-1 for the Analytical Categories and Table 1.2.3.3-2 for the Test Categories. The total decay heat limits per TRUPACT-II for each shipping category are listed in Table 1.2.3.3-3. In determining whether or not a waste package or a group of waste packages meets the limits, the error must be added to the measured value. The design limit for TRUPACT-II is 40 watts.
RH TRU waste packages shall have a surface dose rate at any point no greater than $1.000 \mathrm{rem} / \mathrm{hr}$. Neutron contributions are limited to $270 \mathrm{mrem} / \mathrm{hr}$. Neutron contributions of greater than $20 \mathrm{mrem} / \mathrm{hr}$ to the total waste package dose rate shall be reported in the data package. At least $95 \%$ of the $\mathrm{RH}$ canisters must have dose rates of $\leq 100$ $\mathrm{rem} / \mathrm{hr}$, and no more than $5 \%$ of the $\mathrm{RH}$ canisters are allowed to have dose rates of $>100 \mathrm{rem} / \mathrm{hr}$ but $\leq 1000$ $\mathrm{rem} / \mathrm{hr}$. Prior approval by the WIPP is required before $\mathrm{RH}$ canisters having dose rates $>100 \mathrm{rem} / \mathrm{hr}$ but $\leq 1000 \mathrm{rem} / \mathrm{hr}$ may be shipped to the WIPP.

Same as $\mathbf{C H}$.

The thermal power generated by waste materials in any $\mathrm{RH}$ TRU waste package shall not exceed 300 watts. The thermal power shall be recorded in the data package. 
Table 4-6 (Continued)

\section{Criterion}

Gas Generation

Labeling
Waste containers with waste could generate gases shall be vented. The gas generation and release characteristics of the waste containers shall be controlled by complying with the following requirements:

- All waste containers, including any overpacks, shall be vented with filters that meet the specifications described in the TRUPACT-II SARP. The minimum number of filters shall be one per drum, two per overpacked experimental bin in a SWB, and two per SWB.

- Any rigid drum liners used in the waste containers shall either be filtered or punctured, as specified in the TRUPACT-II SARP.

- Any confinement layers (as defined in the TRUPACT-II SARP) used in the waste containers shall be closed only by a twist and tape or fold and tape closure. No sealed containers greater than one gallon in size shall be present as part of the waste.

- The maximum number of confinement layers in the waste containers shall be known, and shall conform to the shipping category description provided in the TRUPACTII SARP and the TRUPACT-II Content Codes document.

- Any chemical/material existing in the waste in excess of one weight percent must be evaluated to ensure that no adverse reactions could take place during transportation and that the chemical/material or any products of reactions are compatible with the materials of construction of the TRUPACT-II.

- The combine total quantity of all trace chemicals/materials (chemical/materials that occur in the waste in quantities less than one weight percent) in any waste package is restricted to less than tive weight percent.

- Chemicals and materials present in concentrations greater than one percent, shall conform to the allowable chemicals in each waste material type, as defined in the TRUPACT-II SARP.

- The total concentration of potentially VOCs be shall limited to $550 \mathrm{ppm}$ in the headspace of a waste package. (This value should include error measurement, as defined in the QAPP).

In addition to DOT labeling requirements, each waste container shall be uniquely identified by means of a label permanently attached in a conspicuous location. The package identification number shall be in medium to low density Code 39 barcode symbology per MIL-STD-11898 in characters at least 1 inch high, and alphanumeric characters at least $1 / 2$ inch high.

The identification marking must be reasonably expected to remain legible and affixed to the container for a period of 10 years under anticipated conditions of interim storage before shipment to the WIPP and emplacement underground. In addition, each waste package shall be marked with the shipping category after verification of all payload parameters.
Remote-Handled

All RH TRU waste canisters shall be vented.

Each RH canister shall be uniquely identified by means of an identification number permanently attached to the container in a conspicuous location using characters at least 2 inches high.

The identification marking must be reasonably expected to remain legible and affixed to the container for a period of 10 years under anticipated conditions of interim storage before shipment to the WIPP and emplacement underground. 
Table 4-6 (Continued)
Criterion
Contact-Handled
Remote-Handled

Data Package
A data package with certification attesting to the fact that the waste package meets the requirements of these criteria shall be transmitted to the WIPP operator in advance of shipment. This data package/certification shall be based upon a $\mathrm{QA}$ program subject to audit and verification and shall provide information on the items specified below:

- Package identification number

- Package assembly identification number (if applicable)

- Date of waste package certification

- WAC exception number (if applicable)

- Waste generation site

- Date of package (closure)

- Maximum surface dose rate in $\mathrm{mrem} / \mathrm{hr}$ and specific neutron dose rate if greater than $20 \mathrm{mrem} / \mathrm{hr}$.

- Weight (in kilograms)

- Container type

- Physical description of waste form (content code)

- Assay information, including PE-Ci, alpha $\mathrm{Ci}$, and Pu-239 FGE content

- Radionuclide information including radionuclide symbol, quantity, and measure (in grams or curies)

- Radioactive mixed waste (identity and quantity of listed wastes and those that exhibit the characteristics of a hazardous waste.)

- Weight and volume percent of organic materials content

- Measured or calculated thermal power (if over 0.1 watt per cubic foot)

- Shipment number

- Date of shipment

- Vehicle type

- TRUPACT-II number(s)(CH TRU waste) or cask number (RH TRU waste)

- Other information considered significant by the shipper

- Name of certifying official who approved the waste package

- Name of person who certifies that the shipment meets the TRUPACT-II TRAMPAC.

- A hard copy of the signed and dated Certification Statement, certifying that the waste content and packaging are in accordance with the WIPP WAC and that the waste is

unclassified, shall be maintained on file at each site for WACCC audits.
The data package requirements for RH TRU waste shipments are the same as those for $\mathrm{CH}$ TRU waste shipments with the following exceptions:

- The package assembly identification requirement does not apply to RH TRU waste

- The cask number shall be used in place of the TRUPACT number 


\section{Table 4-6 (Continued)}

\begin{tabular}{|c|c|c|}
\hline CRITERION & CONTACT-HANDLED & REMOTE-HANDLED \\
\hline & $\begin{array}{l}\text { The documentation required for the certification of an } \\
\text { individual waste package or a group of waste packages for an } \\
\text { additional TRUPACT-II is given in Section } 13.0 \text { of Appendix } \\
1.3 .7 \text { of the TRUPACT-II SARP. } \\
\text { A generator must prepare a specific hazardous waste manifest } \\
\text { in accordance with the EPA requirements of } 40 \text { CFR } \$ 262.20 \\
\text { through } \$ 262.23 \text {. A generator must also sign the certification } \\
\text { on the manifest that indicates that the generator has a } \\
\text { program in place to reduce the volume and toxicity of the } \\
\text { waste generated. Identification numbers that link each } \\
\text { RCRA-regulated waste container and its waste data package } \\
\text { must also accompany the manifest. The identification } \\
\text { numbers must be attached to the waste profile documentation. } \\
\text { the LDR certification required by the } 40 \text { CFR } 268 \text { must also } \\
\text { accompany the manifest and data package. }\end{array}$ & \\
\hline RH TRU Activity & No criterion. & $\begin{array}{l}\text { The maximum activity concentration for a RH TRU waste } \\
\text { package shall not exceed } 23 \text { curies/liter. The concentration } \\
\text { may be averaged over the waste container. }\end{array}$ \\
\hline $\begin{array}{l}\text { Immobili- } \\
\text { zation }\end{array}$ & $\begin{array}{l}\text { Powders, ashes and similar particulate waste materials shall } \\
\text { be immobilized if more than } 1 \text { weight percent of the waste } \\
\text { matrix in each package is in the form of particles below } 10 \\
\text { microns in diameter, or if more than } 15 \text { weight percent is in } \\
\text { the form of particles below } 200 \text { microns in diameter. }\end{array}$ & Same as $\mathrm{CH}$. \\
\hline Liquid Wastes & $\begin{array}{l}\text { Liquid waste will not be emplaced in the WIPP. TRU waste } \\
\text { for emplacement in the WIPP shall contain as little residual } \\
\text { liquid as is reasonably achievable. All internal (e.g., bottles, } \\
\text { cans, etc.) must be well-drained, but may contain residual } \\
\text { liquid in well-drained, but may contain residual liquids. As a } \\
\text { guidelines, residual liquid in well-drained containers will be } \\
\text { restricted to approximately one percent of the volume of the } \\
\text { internal container. In no case shall the total liquid equal or } \\
\text { exceed one volume percent of the waste container (e.g., drum } \\
\text { or SWB). }\end{array}$ & Same as $\mathrm{CH}$. \\
\hline $\begin{array}{l}\text { Pyrophoric } \\
\text { Materials }\end{array}$ & $\begin{array}{l}\text { Pyrophoric materials, other than radionuclides, shall be } \\
\text { rendered safe by mixing with chemically stable materials } \\
\text { (e.g., concrete, glass, etc.) or shall be processed to remove } \\
\text { their hazardous properties. Not more than one percent by } \\
\text { weight of the waste in each waste container may be } \\
\text { pyrophoric forms of radionuclides, and these shall be } \\
\text { generally dispersed in the waste. Same as CH. } \\
\text { Explosives and Compressed Gases TRU waste shall contain } \\
\text { no explosives or compressed gases as defined by } 49 \text { CFR } \\
\text { 173. Subparts C and G. }\end{array}$ & Same as $\mathrm{CH}$ \\
\hline
\end{tabular}




\section{Table 4-6 (Continued)}

\begin{tabular}{|c|c|c|}
\hline CrITERION & CONTACT-HANDLED & REMOTE-HANDLED \\
\hline $\begin{array}{l}\text { Radioactive Mixed } \\
\text { Waste }\end{array}$ & $\begin{array}{l}\text { TRU wastes shall contain no hazardous wastes unless they } \\
\text { exists as co-contaminants with transuranics. Waste packages } \\
\text { containing hazardous waste shall be identified with the } \\
\text { appropriate DOT label. All TRU contaminated corrosive } \\
\text { reactive, ignitable materials shall be treated to remove the } \\
\text { hazardous characteristic. Hazardous wastes to be reported are } \\
\text { listed in } 40 \text { CFR } 261 \text {. Subparts C and D. }\end{array}$ & $\begin{array}{l}\text { TRU wastes shall contain no hazardous wastes unless they } \\
\text { exist as co-contaminants with transuranics. TRU- } \\
\text { contaminated corrosive, reactive, and ignitable materials } \\
\text { shall be neutralized and rendered nonhazardous. Hazardous } \\
\text { waste to be reported are listed in } 40 \text { CFR } 261 \text {. Subparts C } \\
\text { and D. }\end{array}$ \\
\hline Transportation & $\begin{array}{l}\text { Other transportation waste package specific criteria include } \\
\text { the following: } \\
\text { - All of the waste packages in a single TRUPACT-II shall } \\
\text { belong to the same shipping category, as defined in the } \\
\text { TRUPACT-II SARP. } \\
\text { - Each of the waste packages to be shipped shall belong to } \\
\text { one of the content codes defined in the TRUPACT-II } \\
\text { Content Codes (TRUCON) document. } \\
\text { - Retrievably stored waste that has been stored in an } \\
\text { unvented condition shall be sampled and/or aspirated as } \\
\text { per the requirements specified in the TRUPACT-II SARP. } \\
\text { - The payload control procedures outlined in Section 7.4.3 } \\
\text { of the TRUPACT-II SARP shall be followed for the } \\
\text { shipment of CH TRU waste in the TRUPACT-II package. }\end{array}$ & \\
\hline
\end{tabular}

Source: DOE, 1991b 
TABLE 4-7

SUMMARY OF WAC LIMITING PARAMETERS FOR CH TRU WASTE

\begin{tabular}{|c|c|c|}
\hline $\begin{array}{l}\text { CRITERION/ } \\
\text { REQUIREMENT } \\
\text { AND SECTION } \\
\text { OF WAC }\end{array}$ & LIMITING PARAMETER(S) & SOURCE(S) \\
\hline \multicolumn{3}{|c|}{ WASTE CONTAINER REQUIREMENTS/CRITERIA } \\
\hline $\begin{array}{l}\text { Waste Containers } \\
3.2 .1\end{array}$ & $\begin{array}{l}\text { Containers shall be noncombustible and meet } \\
\text { DOT Type A packaging requirements. } \\
\text { Current TRUPACT-II requirements limit } \\
\text { acceptable containers to 55-gallon drums, standard } \\
\text { waste boxes (SWBs), or SWB overpack of 55- } \\
\text { gallon drums or test bins. }\end{array}$ & 1 \\
\hline $\begin{array}{l}\text { Waste Package } \\
\text { Size } 3.2 .2\end{array}$ & $\begin{array}{l}\text { Current TRUPACT-II limits are 55-gallon drums } \\
\text { in two seven-packs, or two SWBs. }\end{array}$ & 2 \\
\hline $\begin{array}{l}\text { Waste Package } \\
\text { Handling } 3.2 .3\end{array}$ & $\begin{array}{l}\text { - All packages shall be configured as specified in } \\
\text { the TRUPACT-II SARP (see } 3.2 .2 \text { above). }\end{array}$ & 2 \\
\hline \multicolumn{3}{|c|}{ WASTE FORM REQUIREMENTS/CRITERIA } \\
\hline $\begin{array}{l}\text { Immobilization } \\
3.3 .1\end{array}$ & $\begin{array}{l}\text { Waste materials shall be immobilized if }>1 \% \text { by } \\
\text { weight is particulate material }<10 \text { microns in } \\
\text { diameter, or if }>15 \% \text { by weight is particulate } \\
\text { material }<200 \text { microns in diameter. }\end{array}$ & 1 \\
\hline Liquids 3.3 .2 & $\begin{array}{l}\text { Only residual liquids; as a guideline, residual } \\
\text { liquid in well-drained internal containers to be } \\
\text { restricted to approximately } 1 \text { volume } \% \text { of the } \\
\text { internal container; aggregate amount of residual } \\
\text { liquid }<1 \text { volume } \% \text { of external container. }\end{array}$ & 1 \\
\hline $\begin{array}{l}\text { Pyrophoric } \\
\text { Materials } 3.3 .3\end{array}$ & $\begin{array}{l}\text { No non-radionuclide pyrophorics permitted. } \\
\text { Radionuclides in pyrophoric form ar limited to } \\
<1 \% \text { by weight in each waste package. }\end{array}$ & 2,3 \\
\hline $\begin{array}{l}\text { Explosives and } \\
\text { Compressed Gases } \\
3.3 .4\end{array}$ & $\begin{array}{l}\text { - No explosives (49 CFR Part 173, Subpart C) are } \\
\text { permitted. } \\
\text { - } \quad \text { No compressed gases are permitted. }\end{array}$ & $\begin{array}{c}1,2,3 \\
2\end{array}$ \\
\hline
\end{tabular}




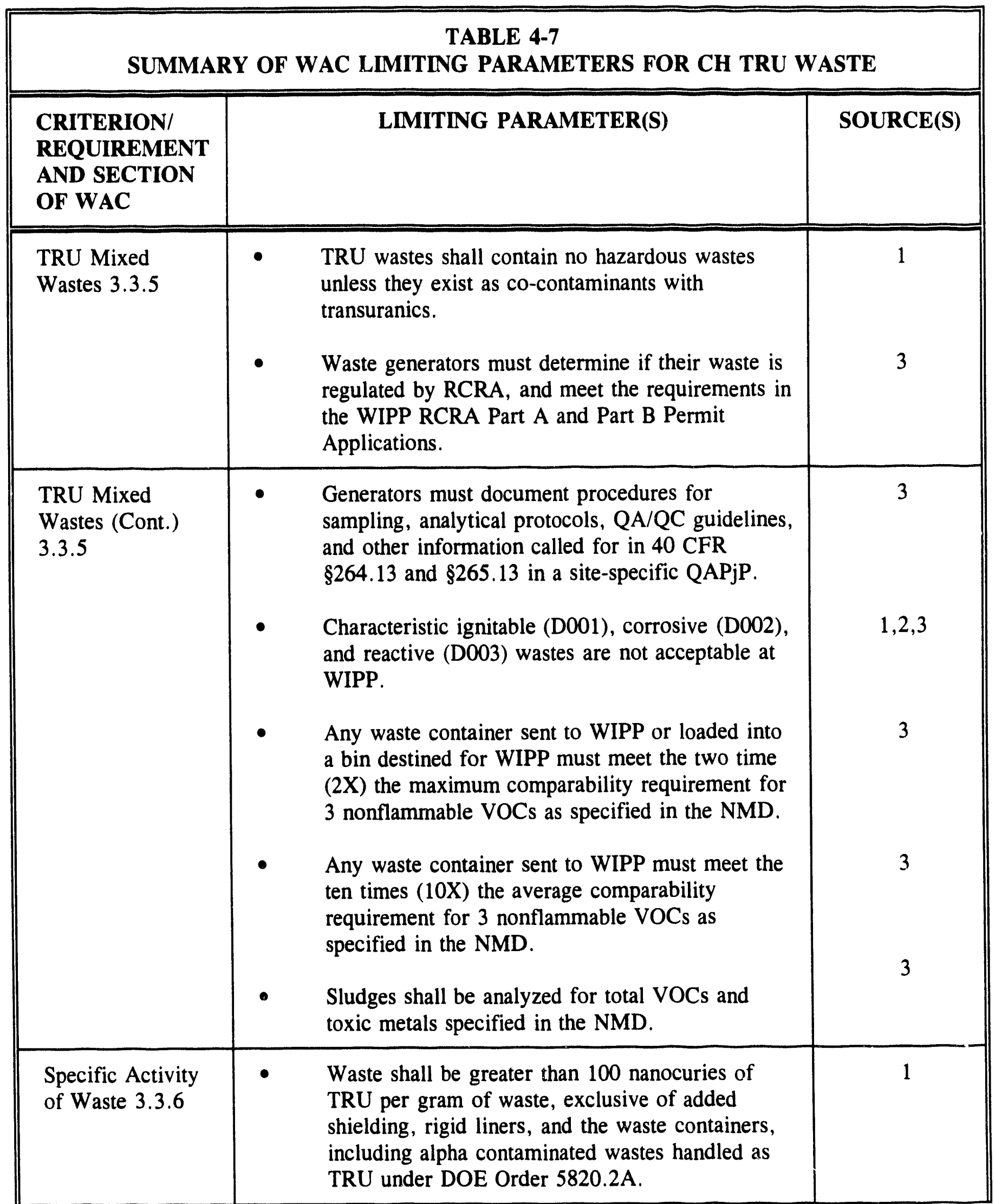




\begin{tabular}{|c|c|c|}
\hline \multicolumn{3}{|c|}{$\begin{array}{l}\text { TABLE 4-7 } \\
\text { SUMMARY OF WAC LIMITING PARAMETERS FOR CH TRU WASTE }\end{array}$} \\
\hline $\begin{array}{l}\text { CRITERION/ } \\
\text { REQUIREMENT } \\
\text { AND SECTION } \\
\text { OF WAC }\end{array}$ & LIMITING PARAMETER(S) & SOURCE(S) \\
\hline \multicolumn{3}{|c|}{ WASTE PACKAGE REQUIREMENTS/CRITERIA } \\
\hline $\begin{array}{l}\text { Waste Package } \\
\text { Weight 3.4.1 }\end{array}$ & $\begin{array}{l}\text { - Current waste package limits are } 1000 \mathrm{lbs} \text { per } 55- \\
\text { gallon drum, or } 4000 \mathrm{lbs} \text { per SWB. } \\
\text { - } \quad \text { TRUPACT-II payload is limited to } 7265 \mathrm{lbs} \text {. } \\
\text { - } \\
\text { TRUPACT-II is limited to } 19,250 \mathrm{lbs} \text { total gross } \\
\text { weigh, with a total shipment GVW of } 80,000 \mathrm{lbs} \text {. }\end{array}$ & $\begin{array}{l}2 \\
2 \\
2\end{array}$ \\
\hline $\begin{array}{l}\text { Nuclear Criticality } \\
\text { (Pu-239 FGE) } \\
3.4 .2\end{array}$ & $\begin{array}{l}\text { Accepted package limits, including two times the } \\
\text { error, are: } \\
-<200 \mathrm{~g} / 55 \text {-gallon drum } \\
-<325 \mathrm{~g} / \mathrm{SWB} \\
\text { - The sum of the FGE of all packages in a } \\
\text { TRUPACT-II payload shall be }<325 \mathrm{~g} \text {. }\end{array}$ & 2 \\
\hline $\begin{array}{l}\text { Pu-239 } \\
\text { Equivalent } \\
\text { Activity } 3.4 .3\end{array}$ & $\begin{array}{l}\text { - Waste packages shall not exceed } 1000 \mathrm{Ci} \text { of } \mathrm{Pu}- \\
239 \text { equivalent activity (PE-Ci). }\end{array}$ & 1 \\
\hline $\begin{array}{l}\text { Surface Dose Rate } \\
3.4 .4\end{array}$ & $\begin{array}{l}\text { Drums or SWBs shall not exceed } 200 \mathrm{mrem} / \mathrm{hr} \\
\text { surface reading, or } 10 \mathrm{mrem} / \mathrm{hr} \text { at } 2 \mathrm{~m} \text {. } \\
\text { - Shielded containers are allowed for ALARA } \\
\text { purposes only. } \\
\text { - Neutron contributions of }>20 \mathrm{mrem} / \mathrm{hr} \text { shall be } \\
\text { separately documented. } \\
\text { - External dose rates on the loaded TRUPACT-II } \\
\text { shall not exceed } 200 \mathrm{mrem} / \mathrm{hr} \text { surface, or } 10 \\
\mathrm{mrem} / \mathrm{hr} \text { at } 2 \mathrm{~m} .\end{array}$ & $\begin{array}{c}1,2 \\
2 \\
1 \\
2\end{array}$ \\
\hline
\end{tabular}




\begin{tabular}{||l|l|c||}
\hline \multicolumn{3}{|c|}{ TABLE 4-7 } \\
\hline \hline $\begin{array}{l}\text { SRITERION/ } \\
\text { REQUIREMENT } \\
\text { AND SECTION } \\
\text { OF WAC }\end{array}$ & \multicolumn{1}{|c||}{ LIMITING PARAMETER(S) } & SOURCE(S) \\
\hline \hline $\begin{array}{l}\text { Removable } \\
\text { Surface } \\
\text { Contamination } \\
3.4 .5\end{array}$ & $-\quad \begin{array}{l}\text { Removable package surface contamination shall } \\
\text { not be }>50 \text { pCi/100 } \mathrm{cm}^{2} \text { alpha, and not }>450 \\
\text { pCi/100 } \mathrm{cm}^{2} \text { beta/gamma. }\end{array}$ & 1 \\
\hline $\begin{array}{l}\text { Thermal Power } \\
3.4 .6\end{array}$ & $-\begin{array}{l}\text { Thermal (wattage) limits for individual waste } \\
\text { packages, including the error, are contained in the } \\
\text { TRUPACT-II SARP. }\end{array}$ & 2 \\
$\begin{array}{l}\text { TRUPACT-II loads limits are contained in the } \\
\text { TRUPACT-II SARP. }\end{array}$ & 2 \\
TRUPACT-II design limit is 40 watts. & 2 \\
\hline
\end{tabular}




\begin{tabular}{|c|c|c|}
\hline \multicolumn{3}{|c|}{$\begin{array}{c}\text { TABLE } 4-7 \\
\text { SUMMARY OF WAC LIMITING PARAMETERS FOR CH TRU WASTE }\end{array}$} \\
\hline $\begin{array}{l}\text { CRITERION/ } \\
\text { REQUIREMENT } \\
\text { AND SECTION } \\
\text { OF WAC }\end{array}$ & LIMITING PARAMETER(S) & SOURCE(S) \\
\hline $\begin{array}{l}\text { Gas Generation } \\
3.4 .7\end{array}$ & $\begin{array}{l}\text { - All confinement layers, such as bags, shall be } \\
\text { closed only by a twist-and-tape or fold-and-tape } \\
\text { method. } \\
\text { - No sealed containers }>1 \text { gallon may be in the } \\
\text { waste. } \\
\text { The maximum number of confinement layers shall } \\
\text { be known. } \\
\text { Waste packages emplaced in WIPP during the } \\
\text { experimental period shall not exceed } 50 \% \text { of the } \\
\text { lower explosive limit in any layer of confinement } \\
\text { for hydrogen and methane. } \\
\text { Total flammable VOCs are limited to } 500 \text { ppm in } \\
\text { the headspace gas of waste packages. } \\
\text { - } \quad \begin{array}{l}\text { If total flammable VOCs are }>500 \text { ppm in } \\
\text { headspace, a Le Chatelier calculation is necessary. }\end{array} \\
\text { All chemicals/materials > }>1 \% \text { by weight must be } \\
\text { evaluated for compatibility within the waste form } \\
\text { and with TRUPACT-II materials of construction. }\end{array}$ & $\begin{array}{l}2 \\
3 \\
2\end{array}$ \\
\hline
\end{tabular}




\begin{tabular}{|c|c|c|}
\hline \multicolumn{3}{|c|}{$\begin{array}{c}\text { TABLE 4-7 } \\
\text { SUMMARY OF WAC LIMITING PARAMETERS FOR CH TRU WASTE }\end{array}$} \\
\hline $\begin{array}{l}\text { CRITERION/ } \\
\text { REQUIREMENT } \\
\text { AND SECTION } \\
\text { OF WAC }\end{array}$ & LIMITING PARAMETER(S) & SOURCE(S) \\
\hline $\begin{array}{l}\text { Gas Generation } \\
3.4 .7 \text { (cont.) }\end{array}$ & $\begin{array}{l}\text { Trace chemicals ( }<1 \text { weight } \% \text { limit) must total } \\
<5 \% \text { by weight of the waste in any package. } \\
\text { - } \quad \text { Chemicals/materials present in concentrations } \\
\text { greater than one weight percent, shall conform to } \\
\text { the allowable chemicals in each waste material } \\
\text { type. } \\
\text { - } \\
\text { Real-time radiography or equivalent examination. } \\
\text { Visual characterization of solid waste for } 10 \text { waste } \\
\text { material categories listed in QAPP. } \\
\text { Analysis of sludges for pH and major cations and } \\
\text { anions listed in SNL Bin-Scale Test Plan. } \\
\text { - Total alpha activity of waste on a container basis } \\
\text { using methodology listed in QAPP. } \\
\text { All waste packages shipped in TRUPACT-II shall } \\
\text { be vented with one or more filters that meet } \\
\text { specifications listed in the TRUPACT-II SARP. } \\
\text { All rigid liners shall be punctured or vented. }\end{array}$ & $\begin{array}{l}4 \\
4 \\
4 \\
4 \\
2\end{array}$ \\
\hline Labeling 3.4 .8 & $\begin{array}{l}\text { A unique identification barcode label reasonably } \\
\text { expected to last } 10 \text { years shall be affixed. } \\
\text { Each package shall have appropriate DOT labels. } \\
\text { Each package shall be marked with the shipping } \\
\text { category. }\end{array}$ & $\begin{array}{l}1,2 \\
1,2,3 \\
2\end{array}$ \\
\hline
\end{tabular}




\begin{tabular}{|c|c|c|}
\hline \multicolumn{3}{|c|}{$\begin{array}{l}\text { TABLE } 4-7 \\
\text { SUMMARY OF WAC LIMITING PARAMETERS FOR CH TRU WASTE }\end{array}$} \\
\hline $\begin{array}{l}\text { CRITERION/ } \\
\text { REQUIREMENT } \\
\text { AND SECTION } \\
\text { OF WAC }\end{array}$ & LIMITING PARAMETER(S) & SOURCE(S) \\
\hline \multicolumn{3}{|c|}{ DATA PACKAGE REQUIREMENTS/CRITERIA } \\
\hline $\begin{array}{l}\text { Data Package! } \\
\text { Certification } \\
\text { 3.5.1 }\end{array}$ & $\begin{array}{l}\text { - A data package with certification shall be } \\
\text { transmitted prior to shipment. } \\
\text { - Documentation for certification of individual } \\
\text { packages or a group of packages for shipment in } \\
\text { each TRUPACT-II unit shall be submitted. } \\
\text { - A hazardous waste manifest shall be utilized for } \\
\text { each shipment of TRU mixed waste. } \\
\text { - Information required by the WCPP shall be } \\
\text { provided. }\end{array}$ & $\begin{array}{l}3 \\
4\end{array}$ \\
\hline \multicolumn{3}{|c|}{ OTHER REQUIREMENTS/CRITERIA } \\
\hline $\begin{array}{l}\text { Additional } \\
\text { Requirements } \\
3.6 .1\end{array}$ & $\begin{array}{l}\text { - All packages in a single TRUPACT-II shall } \\
\text { belong to the same shipping category. } \\
\text { - } \\
\text { Each package shipped shall belong to one of the } \\
\text { content codes defined in TRUCON. } \\
\text { Retrievably stored waste that has been unvented } \\
\text { shall be vented and aspirated per the TRUPACT- } \\
\text { Il SARP. } \\
\text { Payload control procedures outlined in Section } \\
7.4 .3 \text { of the TRUPACT-II SARP shall be } \\
\text { followed. }\end{array}$ & $\begin{array}{l}2 \\
2 \\
2\end{array}$ \\
\hline
\end{tabular}

Source(s) of Limit(s):

1. WIPP Operations and Safety Criteria

2. Transportation: Waste Package Requirements: TRAMPAC

3. RCRA Requirements

4. Performance Assessment Criteria 
disposal phase of the project. Waste currently stored or generated that do not meet the final WIPP WAC may require treatment or processing until certification can be attained.

Waste acceptance criteria certification programs are overseen by the DOE through periodic audits. DOE ensures that TRU waste received at the WIPP facility does not exhibit these characteristics through administrative and disposal procedures at the generator sites. The WIPP WAC certification programs result in controlled and consistent chemical and physical waste properties and final packaging.

\subsection{Waste Characterization}

Waste characterization refers to the sampling and analysis of TRU waste and/or the examination of TRU waste generation documentation and associated records to demonstrate compliance with the requirements of applicable regulations. The TRU waste characterization program has evolved over the past several years as a result of the addition of compliance programs and associated waste information requirements.

\subsubsection{Program Summary}

The waste characterization program consists of testing, sampling, and analytical activities that will be used to characterize retrievably stored and newly generated TRU waste at DOE facilities planning to send TRU waste to the WIPP facility. There are two objectives to the waste characterization program. The first is to confirm the radionuclide and physical waste form inventories on which the PA is based (40 CFR 191 and 194). The second is to provide data in support of a no-migration variance petition (NMVP) (40 CFR \$268.6) to describe each waste with regard to the EPA hazardous waste codes (40 CFR 261, Subparts C and D) and to quantify the hazardous constituents reported to be present in the waste (40 CFR 261, Appendix VIII).

The DOE is developing a WIPP TRU Baseline Inventory Report (BIR) for the WIPP facility that, when completed, will include the waste characterization information that will be used to assess compliance under both regulations. To maintain consistency between DOE waste management programs, the BIR will include physical waste form descriptors based on the Matrix Parameters Codes used to compile a the Interim Mixed Waste Inventory Report (IMWIR) (DOE, 1993b) as mandated by the Federal Facilities Compliance Act (FFCA). 
To certify compliance under 40 CFR 191 and 194, the BIR will include the radiological and physical characteristics of the waste proposed for disposal at the WIPP facility. The characterization information will be based on the materials and processes that result in retrievably stored and newly generated TRU wastes. The baseline inventory will include the species and curie quantity of each radionuclide that will be used in assessing compliance with 40 CFR 191. The data will reflect estimated future-generated quantities of TRU waste and be scaled to the maximum storage capacity of the repository.

During the WIPP disposal phase, radioassay will be conducted on waste prior to shipment to the WIPP to confirm the radionuclide inventory on which the PA is based. To ensure compliance, the DOE will determine and report the species and curie quantity of radionuclides that can be measured or derived, on a drum-by-drum basis, prior to shipment to the WIPP facility.

Compliance demonstrations include information on the physical form of the waste inventory within a repository panel; therefore, the physical waste form parameters of interest will be presented based on an average content of the total TRU waste inventory and not on a drumby-drum basis. The nhwrical waste form parameters will be determined based on their potential effects on I repository performance, including gas-generation potentials, radionuclide solubilit. $\rfloor$ final waste-form porosity under repository conditions over thousands of years. These final disposal-system conditions may influence potential radionuclide solubilities and the quantities potentially released to the environment during human intrusion scenarios.

Physical waste form parameters that do not affect compliance will be excluded from future waste characterization programs, and the waste characterization requirements will be revised, as necessary. If specific parameters are found to be important to compliance at the WIPP, possible load management alternatives will be considered to ensure the proper mix of waste forms on both panel and room scales. Because a large percentage of the potentially acceptable waste is not yet generated, the DOE will be in a position to control the types and quantities of waste forms generated in the future. Retrievably stored waste that cannot be accepted and managed through load management, or that is not described acceptable as defined by the performance-based waste envelope, will be excluded from the acceptable inventory, and may be assessed for potential treatment. 
To demonstrate compliance under 40 CFR \$268.6, the DOE will use conceptual models consistent with those developed for 40 CFR 191. Therefore, the importance of the physical waste form parameters also will be evaluated in terms of expected repository performance and the potential migration of RCRA-regulated hazardous constituents. The partitioning of hazardous constituents in the gas and liquid phase during long-term repository conditions will be evaluated to determine the potential concentrations migrating toward the WIPP unit boundary. As described above, the DOE will establish the TRU waste baseline inventory based on the maximum allowable physical waste form parameters that will not result in the migration of hazardous constituents above health-based limits.

Under 40 CFR \$268.6, petitioners also must include waste characterization information for each waste covered by a variance to the Land Disposal Restrictions (LDRs). The information is required to include: 1) the applicable EPA hazardous waste codes as defined under 40 CFR 261, Subparts C and D, and 2) the quantities of hazardous constituents as defined under 40 CFR 261, Appendix VIII.

Hazardous constituents in the headspace of containers to be sent to the WIPP facility will be identified and quantified. These activities will include sampling and analyses of the drum headspace (samples will not be collected from the area directly beneath the lid) for all waste containers and, if needed, statistical sampling of headspace from inner layers of confinement. The data generated relative to the relationship between gases found in the drum headspace and headspace gas from the inner layers of confinement will be used to demonstrate that drum headspace samples are adequate to characterize wastes for the purpose of management and disposal.

Drum headspace data will be used to determine the potential for VOCs to migrate beyond the WIPP unit boundary in concentrations that exceed EPA-determined health-based limits during the WIPP disposal phase. Data generated relative to quantities of flammable VOCs, hydrogen, and methane will be used to determine the potential flammability of TRU waste headspace gases.

Department of Energy generator/storage sites will determine if their waste is hazardous and assign the appropriate EPA hazardous waste codes. This information will be included in the appropriate compliance documentation. Transuranic waste classified in the BIR as debris waste (i.e., FFCA Matrix Parameter Code 5000) may $\}$ : characterized based on knowledge of the materiais and processes generating the waste. Transuranic waste classified as solid 
process residues (FFCA matrix Parameter Code 3000) and soils (FFCA Matrix Parameter Code 4000) characterized based on sampling and analysis.

Determinations of hazardous waste concentrations in the waste will be made using data from totals analyses rather than the Toxicity Characteristic Leaching Procedure (TCLP). Because the WIPP is a salt repository, total concentrations are more meaningful for a compliance demonstration. The TCLP methodology was designed to simulate conditions applicable to conventional land disposal facilities. If a generator chooses to make hazardous waste determinations using these analyses, such determinations will be conservative compared to TCLP-based determinations (leachable quantity $\leq$ total quantity). For waste classified under the FFCA IMWIR as solid process residues and soils, the mean total concentration of hazardous constituents will also be calculated at the 90 percent confidence level.

\subsubsection{Waste Forms}

As required by the FFCA, DOE has prepared the IMWIR, which provides information relative to the volumes of currently stored wastes and a five-year forecast of future generated TRU mixed wastes. Transuranic wastes are classified in the IMWIR according to their physical, chemical, and radiological characteristics. This classification scheme is based on RCRA waste treatabilities. For consistency in reporting, the DOE plans to classify all TRU wastes according to this system. Transuranic wastes fall into three main categories: debris, solid process residues, and soils. Further subdivisions within these broad groups will be provided by generator/storage sites.

For purposes of this program, retrievably-stored TRU waste is defined as that which has been generated prior to implementation of the quality assurance/quality control (QA/QC) requirements specified in the Quality Assurance Program Plan (QAPP) for the experimentalwaste characterization program (DOE, 1991c), which is currently being revised for the disposal phase. Once a waste characterization program is approved and implemented at a DOE generator/storage site, TRU waste shall be characterized by sampling at the frequencies specified for newly-generated TRU waste. The required sampling frequencies are one sample per year for process waste streams and one sample per batch for batch waste streams. Retrievably stored TRU waste will be statistically sampled, and the upper 90 percent confidence limit values for the measured contaminant concentrations will be compared to the specified regulatory threshold limit values (40 CFR 261, Subpart C). Data comparability 
between all participating DOE generator/storage sites will be achieved by compliance with the testing, sampling, and analytical requirement specified in the QAPP.

\subsubsection{Analytical Methodologies}

Waste testing and sampling and analytical methods, which have been evaluated and demonstrated adequate per the performance standards specified in the QAPP, will be included in the WIPP Sampling and Analysis Guidance Manual (currently in revision) (DOE, 1991d) or EPA Test Methods for Evaluating Solid Waste, Physical/Chemical Methods (SW-

846) (EPA, 1986). Transuranic waste characterization will employ the following techniques:

- $\quad$ radioassay for radionuclide identification and quantification

- $\quad$ radiography for physical waste form determinations

- headspace gas sampling and analysis for quantification of hydrogen, methane, flammable and nonflammable VOCs

- visual examination to assess results of radiography

- $\quad$ solid process residues and soil sampling and analysis to quantify RCRAregulated total metals, VOCs, and semi-VOCs

Process knowledge may also be used in conjunction with the above to identify and quantify constituents. For example, knowledge of the source of plutonium (weapons grade or heat source) is used in the radioassay algorithm to quantify the various radionuclides in the waste container.

\subsubsection{Waste Characterization Information Summary}

The DOE is currently updating the waste characterization information provided in the IMWIR based on on-going waste characterization programs at the DOE generator/storage facilities. The information provided in this report will be used to assess the needed design capacity for sampling and analytical facilities, as well as available waste repackaging and treatment capabilities.

\subsubsection{Process Knowledge Information}

Documenting existing process knowledge for wastes is the initial step in the waste characterization process. Process knowledge refers to documented knowledge of the materials that comprise a waste and the processes that generated a waste. Historically, 
mixed wastes generated at DOE facilities were not routinely sampled and analyzed. They have been characterized using process knowledge. Process knowledge is currently used to identify specific waste streams for purposes of waste testing and/or sampling and analysis.

\subsubsection{Analytical Data}

Currently, waste characterization programs are in place at INEL. Analytical methods evaluations to support this work are currently underway at LANL. In addition, analytical facilities are available at ORNL to support WIPP waste characterization efforts. Results of all analytical data will be summarized in the final compliance documents, along with the associated QC samples.

\subsection{Waste Transformation Processes in the Repository Environment}

An evaluation of waste transformation processes that could potentially impact the repository performance is required for both 40 CFR \$268.6 and 40 CFR 191 compliance demonstrations. The evaluations include processes such as corrosion, biodegradation, hydrolysis, oxidation and reduction, and volatilization. Some of these processes have been identified as important for the purposes of assessing repository performance and are discussed below. Others may be evaluated in the future, as required, for compliance purposes.

From a geocheınical standpoint, important waste transformation processes expected in WIPP disposal rooms are gas generation and its effects on chemical conditions in the repository, especially Eh and $\mathrm{pH}$. Eh and $\mathrm{pH}$ will in turn affect the chemical behavior of $\mathrm{Pu}, \mathrm{Am}, \mathrm{Np}$, $\mathrm{Th}$, and $\mathrm{U}$ brine chemical processes. The gases produced by the processes described below may create migration pathways for gaseous and solid contaminants.

Gas generating reactions will also affect the water budget of WIPP disposal rooms directly by producing and consuming water and indirectly by pressurizing the repository. Pressurization caused by gas generation will affect room closure and the geomechanical state of the contents of the repository, if backfill is required and emplaced. Gas generating reactions may also affect the geomechanical properties of the contents of WIPP disposal rooms (porosity, shear strength, etc.), and the nearby anhydrite interbeds, by precipitating or 
dissolving solids on/from pre-existing solids. Davies et al. (1991) described the highly coupled nature of gas generation, hydrologic, and geomechanical processes.

\subsubsection{Gas Generation}

The following sections describe the waste-related repository processes that result in gas generation. Corrosion and microbial activity are the two most important gas-generation mechanisms expected in the repository.

\subsubsection{Corrosion}

Corrosion of steel CH TRU waste containers (drums and boxes), steel RH TRU canisters and plugs, Fe-base alloys in the wastes, and perhaps other metals will affect the gas and water budgets of WIPP disposal rooms. Other corrodible metals include (but are not necessarily limited to) $\mathrm{Al}$ and Al-base alloys.

The quantity of $\mathrm{O}_{2}$ initially present in air trapped in WIPP disposal rooms at the time of sealing will oxidize less than one percent of the metals present (see Brush, 1990).

Anoxic corrosion may, if brine is present, produce significant quantities of $\mathrm{H}_{2}$ and consume significant quantities of $\mathrm{H}_{2} \mathrm{O}$. Laboratory studies for the WIPP Project have demonstrated that:

- under inundated conditions (specimens immersed in brine), anoxic corrosion of Fe-and Al-base materials produces $\mathrm{H}_{2}$ at significant rates;

- acidic conditions significantly accelerate and basic conditions significantly decelerate anoxic corrosion of steels and other Fe-base alloys and associated $\mathrm{H}_{2}$ production;

- high repository pressures accelerate $\mathrm{H}_{2}$ production rates;

- $\quad$ high partial pressures of $\mathrm{H}_{2}$ decelerate anoxic corrosion of steels and other Febased alloys, and associated $\mathrm{H}_{2}$ production;

- if sufficient $\mathrm{CO}_{2}$ or $\mathrm{H}_{2} \mathrm{~S}$ is present, formation of an adherent layer of $\mathrm{FeCO}_{3}$ (siderite) or $\mathrm{FeS}_{2}$ (pyrite), respectively, on the surfaces of steels and other Febase alloys effectively passivates these materials; 
- $\quad$ if $\mathrm{FeCO}_{3}$ or $\mathrm{FeS}_{2}$ becomes unstable with respect to nonadherent phases such as $\mathrm{Fe}(\mathrm{OH})_{2}, \mathrm{Fe}_{3} \mathrm{O}_{4}$, or $\mathrm{FeS}$, anoxic corrosion and $\mathrm{H}_{2}$ production will resume;

- $\quad$ under humid conditions (specimens suspended above brine), no detectable anoxic corrosion or $\mathrm{H}_{2}$ production occurs; and

- $\quad$ capillary rise (wicking) of brine by unsaturated backfill materials results in anoxic-corrosion and $\mathrm{H}_{2}$-production rates between those observed under humid and inundated conditions.

The likelihood of the presence of brine quantities sufficient to be of regulatory concern has not been established. The WIPP Engineered Alternatives Task Force (EATF) pointed out that corrosion requires and consumes brine and that the rate of corrosion is sufficiently high so that any brine coming in contact with the metals will be rapidly consumed. In other words, the rate of gas generation is controlled by the rate at which brine seeps into the waste, not the rate of corrosion. Deal et al. (1991) calculated that, if amakinite $\left(\mathrm{Fe}[\mathrm{OH}]_{2}\right)$ is the corrosion product, it would require approximately 220,000 liters of brine to completely corrode all of the susceptible metal emplaced in each waste storage room. Brine availability estimates range from 43 to 604 liters based on observations of brine weeps (Deal et al., 1993), through less than 6,000 liters in 200 years from calculating far-field seepage through anhydrite marker bed 139 (Deal and Bills, 1994) to approximately 150,000 liters in 200 years assuming brine flow from halite beds into the anhydrite based on modeling of flow to the repository.

\subsubsection{Microbial Activity}

Microbial degradation of cellulosics and, perhaps, plastics and rubbers in TRU waste may affect the gas and water budgets of WIPP disposal rooms. However, for microbial degradation to occur, there must be sufficient brine or $\mathrm{H}_{2} \mathrm{O}$ vapor, nutrients, and viable microorganisms.

Brush (1990) applied the conceptual model of sequential usage of electron acceptors (oxidants) by microorganisms in natural environments to WIPP disposal rooms. Based on this conceptual model and the potential electron acceptors expected in the repository, he concluded that microbial denitrification, $\mathrm{SO}_{4}{ }^{2-}$ reduction, fermentation, and methanogenesis may produce $\mathrm{CO}_{2}$ and $\mathrm{N}_{2}, \mathrm{CO}_{2}$ and $\mathrm{H}_{2} \mathrm{~S}$, and $\mathrm{CO}_{2}$ and $\mathrm{CH}_{4}$, revpectively. Alternatively, methanogenesis rnay consume similar quantities of $\mathrm{CO}_{2}$ and $\mathrm{H}_{2}$. Because the quantity of $\mathrm{O}_{2}$ initially present in the repository will oxidize less than one to two percent of the cellulosics 
present, aerobic respiration will probably not be important from the standpoint of the gas and water budgets of the repository.

Laboratory studies for the WIPP project have shown that:

- under inundated conditions, microbial degradation of papers produces $\mathrm{CO}_{2}$ and $\mathrm{N}_{2}$ at significant rates in experiments amended with nutrients and inoculated with halophilic microorganisms;

- under inundated conditions, microbial degradation of papers produces $\mathrm{CO}_{2}$ and $\mathrm{N}_{2}$ at lower but potentially significant rates in unamended, inoculated experiments;

- tests under inundated conditions have also provided preliminary evidence for microbial production of $\mathrm{H}_{2}$ and $\mathrm{H}_{2} \mathrm{~S}$ from degradation of papers and $\mathrm{CH}_{4}$ production from degradation of rubber;

- humid experiments suggest that microbial degradation of papers produces $\mathrm{CO}_{2}$ and $\mathrm{N}_{2}$ at lower rates than inundated tests.

\subsubsection{Radiolysis}

Molecke (1979) reviewed previous studies of gas-generation for the WIPP Project. The results of these studies imply that alpha-radiolysis of most materials will produce gas at significantly lower rates than anoxic corrosion and microbial activity, on the order of thousandths or hundredths of a mole per drum per year. However, radiolysis of water in process sludges produced gas at rates on the order of tenths of a mole per drum per year.

These results and estimates are consistent with more recent results from Reed et al. (1993). Lappin et al. (1989) did not estimate the radiolytic gas-production potential. However, preliminary calculations using results from Reed et al. (1993) and the PA code PANEL suggest that, during the 10,000-year period of performance of the repository, brine radiolysis will most likely produce on the order of a few moles of gas per drum and, at most, tens of moles per drum. This, too, is based on a conservative estimate relative to the availability of brine.

Radiolysis of plastic and rubber could cause physical decomposition, decreased saturation, and changes in the chemical composition of these materials such as uptake of $\mathrm{N}_{2}, \mathrm{O}_{2}$, and $\mathrm{S}$, 
which could in turn make them more biodegradable (see Brush, 1990). Furthermore, radiolysis of plastic and rubber could produce chemically hazardous VOCs as emissions. 


\subsection{REFERENCES}

Brush, L.H., 1990. Test Plan for Laboratory and Modeling Studies of Repository and Radionuclide Chemistry for the Waste Isolation Pilot Plant, SAND90-0266, Albuquerque, NM, Sandia National Laboratories.

Davies, P.B., L.H. Brush, and F. T. Mendenhall, 1991. "Assessing the Impact of WasteGenerated Gas from the Degradation of Transuranic Waste at the Waste Isolation Pilot Plant: An Overview of Strongly Coupled Chemical, Hydrologic and Structural Processes," WasteGenerated Gas at the Waste Isolation Pilot Plant: Papers Presented at the Nuclear Energy Agency Workshop on Gas Generation and Release from Radioactive Waste Repositories, Eds. P.B. Davies, L.H. Brush, M.A. Molecke, F.T. Mendenhall, and S.W. Webb, SAND91-2378, Albuquerque, NM, Sandia National Laboratories, pp.

1-1 through 1-24.

Deal, D.E., R.J. Abitz, J. Myers, J.B. Case, D.S. Belski, M.L. Martin, and W.M. Roggenson, 1991. Brine Sampling and Evaluation Program 1990 Report, DOE/WIPP 91036, 1991.

Deal, D.E., R.J. Abitz, J. Myers, M.L. Martin, D.J. Milligan, R.W. Sobocinski, P.P.J. Lipponer, and D.S. Belski, 1993. Erine Sampling and Evaluation Program, 1991 Report, DOE/WIPP 93-026, Carlsbad, NM, Westinghouse Electric Corporation.

Deal, D.E. and R.A. Bills, 1994. Conclusions After Eleven Years of Studying Brine At the Waste Isolation Pilot Plant, Waste Management Symposium 1994, Tucson, AZ, February 28 - March 4, 1994.

Lappin, A.R., R.L. Hunter, D.P. Garber, P.B. Davies, R.L. Beauheim, D.J. Borns, L.H. Brush, B.M. Butcher, T. Cauffman, M.S.Y. Chu, L.S. Gomez, R.V. Guzowski, H.J. Iuzzolino, V. Kelley, S.J. Lambert, M.G. Marietta, J.W. Mercer, E.J. Nowak, J. Pickens, R.P. Rechard, M. Reeves, K.L. Robinson, and M.D. Siegel, eds., 1989. Systems Analysis, Long-Term Radionuclide Transport, and Dose Assessments, Waste Isolation Pilot Plant (WIPP). Southeastern New Mexico: March 1989, SAND 89-0462, Albuquerque, NM, Sandia National Laboratories. 
Molecke, M.A., 1979. Gas Generation from Transuranic Waste Degradation: Data Summary and Interpretation, SAND79-1245, Sandia National Laboratories, Albuquerque, NM.

Reed, D.T., S. Okajima, L.H. Brush, and M.A. Molecke, 1993. Radiolytically-Induced Gas Production in Plutonium-Spiked WIPP Brine, Scientific Basis for Nuclear Waste Management XVI, Materials Research Society Symposium Proceedings, Boston, MA, November 30December 4, 1992, Eds. C.G. Interrante and R.T. Pabalan, SAND92-7283C, Pittsburgh, PA, Materials Research Society, Vol. 294, pp. 431- 438.

Sandia National Laboratories (SNL), 1992. Preliminary Performance Assessment for the Waste Isolation Pilot Plant, December 1992, SAND92-0700/1-5, Albuquerque, NM.

U.S. Department of Energy (DOE), 1990a. Waste Isolation Pilot Plant No Migration Variance Petition, Volume 1, Revision 1, DOE/WIPP 89-003, Carlsbad, NM, Westinghouse Electric Corporation.

U.S. Department of Energy (DOE), 1990b. Final Supplement: Environmental Impact Statement, Waste Isolation Pilot Piant, DOE/EIS-0026-FS, Washington, D.C., U.S. Department of Energy, Office of Environmental Restoration and Waste Management.

U.S. Department of Energy (DOE), 1991a. Waste Characterization Program Plan for WIPP Experimental Waste, DOE/WIPP 89-025, Rev.1, July 1991.

U.S. Department of Energy (DOE), 1991b. Waste Acceptance Criteria for the Waste Isolation Pilot Plant, DOE/WIPP-069, Revision 4.0, Westinghouse Electric Corporation, Carlsbad, NM.

U.S. Department of Energy (DOE), 1991c. Quality Assurance Program Plan for the Waste Isolation Pilot Plant Experimental-Waste Characterization Program, DOE/EM/48063-1, Revision 1, Washington, D.C.

U.S. Department of Energy (DOE), 1991d. WIPP Waste Characterization Sampling and Analysis Guidance Manual, DOE/WIPP 91-043, 1991. 
U.S. Department of Energy (DOE), 1992. Integrated Data Base for 1992: Spent Fuel and Radioactive Waste Inventories, Projections, and Characteristics, DOE/RW-006, Revision 7, Oak Ridge National Laboratory, Oak Ridge, Tennessee.

U.S. Department of Energy (DOE), 1993a. Resource Conservation and Recovery Act Part B Permit Application, DOE/WIPP 91-005, Revision 3, January 1993.

U.S. Department of Energy (DOE), 1993b. U.S. Department of Energy Interim Mixed Waste Inventory Report: Waste Streams, Treatment Capacities and Technologies, DOE/NMB-1100, April 1993.

U.S. Environmental Protection Agency (EPA), 1986. Test Methods for Evaluating Solid Waste. Physical/Chemical Methods, SW-846, 3rd ed., Office of Solid Waste and Emergency Response, Washington, D.C.

U.S. Environmental Protection Agency (EPA), 1980. A Method for Determining the Compatibility of Hazardous Wastes, EPA-600/2-80-076, Washington, D.C.

Warrant, M.M., 1985. A Characterization Study of RH-TRU Wastes Existing in Storage and Expected to be Generated, SAND85-1476, Albuquerque, NM, Sandia National Laboratories. 


\subsection{Monitoring}

Monitoring is required for compliance programs under 40 CFR \$268.6 (EPA, 1993a) and 40 CFR 191 (EPA, 1993b). Data derived from monitoring are used to describe current background environmental conditions and confirm repository-performance modeling. To demonstrate compliance, the Department of Energy (DOE) must address any credible pathways of release. Monitoring to ensure protection of site workers, the public, and the environment are required at the Waste Isolation Pilot Plant (WIPP) facility before wastedisposal operations, during waste handling and disposal operations, and during closure/postclosure operations.

Monitoring programs must be implemented through a quality assurance/quality control (QA/QC) program that is approved by the Environmental Protection Agency (EPA). The DOE has established and implemented quality assurance project plans (QAPjPs) for existing monitoring programs at the WIPP facility. Background concentrations of potential contaminants are being established during pre-operational monitoring to provide a baseline for future measurements. The monitoring systems are also being evaluated to assess sampling techniques and to ensure data quality objectives (DQOs), including accuracy and precision, are achievable. An assessment of compliance with monitoring requirements is discussed in Section 9.6. This section discusses the monitoring programs for the disposal phase, confirmatory monitoring for verifying assumptions made about waste and repository performance used in performance-assessment modeling, and closure/post-closure monitoring for assessing long-term repository integrity.

\subsection{Operational Monitoring}

During the disposal phase, several compliance-related programs are planned. These address the primary potential pathway for release of regulated contaminants which is the air pathway. Operational monitoring systems must detect chemical contaminant migration or radiation releases at the earliest practicable time. The following monitoring programs will detect these potential occurrences during the disposal phase:

- Volatile Organic Compounds (VOC) Monitoring Program

- Radionuclide Emissions Monitoring Program 
In addition, monitoring programs established under other Federal, State, and local laws and DOE Orders will supplement both programs by monitoring the local ecosystem, radiation levels, and explosive and hazardous gas concentrations in the unit. These monitoring programs include the following:

- Environmental Monitoring Program, which implements the requirements of DOE Order 5400.1 (DOE, 1988)

- Occupational Monitoring Program, which implements the requirements of 29 CFR 1910 (DOL, 1993)

\subsubsection{VOC Monitoring Program}

The VOC monitoring program activities will focus on the air pathway, because airborne emission is the only credible release pathway from the WIPP facility prior to repository closure (DOE, 1990a). The VOC monitoring program, originally planned for the test phase, will be modified as required for the disposal phase.

The VOC Monitoring Plan for the test phase (WID, 1991) is described in detail in Volume VII, Section 6.0 of the Waste Isolation Pilot Plant No Migration Variance Petition (NMVP) (DOE, 1990b). The program is designed to demonstrate that the concentration of hazardous constituents at the WIPP unit boundary will not exceed health-based levels. It consists of monitoring the exhaust gas air flow for VOCs that may be released from the wastes. To differentiate between ambient or background VOCs from aboveground and underground sources and VOCs released from transuranic (TRU) wastes, VOC concentrations have been measured in the following locations:

- Near main air intake shaft

- Ventilation air intake passageways to waste-containing rooms

- Ventilation air outlet passageways from waste-containing rooms

- Exhaust shaft

Sampling currently follows a regular schedule, but sampling frequency can be adjusted if anomalous results dictate change. Samples are analyzed for the quantities of five VOCs determined to be most common in the waste. The samples are then analyzed for other organics that are present in sufficient quantity to be detected. The five trarget compounds currently proposed for routine monitoring are carbon tetrachloride, trichloroethylene, 
methylene chloride, 1,1,1-trichloroethane, and 1,1,2-trichloro-1,2,2-trifluoroethane. These compounds have been selected due to their prevalence in TRU mixed wastes. The following DQOs, as outlined in the VOC QAPjP (WID, 1994) are anticipated for future VOC monitoring programs:

- $\quad$ Method detection limit of 0.5 ppbv or one-fifth of any health-based level for a targeted constituent, whichever is greater

- $\quad$ Precision (i.e., relative percent difference between field duplicate samples) of $+/-15$ percent

- Accuracy of $+/-10$ percent

- Data completeness of 90 percent, as adjusted statistically to account for the results of data validation audits

The EPA Compendium Method TO-14 (EPA, 1988), which specifies passivated stainless steel canisters for sample collection, has been used as guidance to meet these objectives. The analytical methods consist of cryogenic trapping and gas chromatography/mass spectrometry. Results of the VOC Monitoring Program are provided annually to the EPA (DOE, 1991a; DOE, 1993a and 1993b). The VOC monitoring program will be revised to fulfill the monitoring needs of disposal operations. A revised VOC Monitoring Plan will be submitted to the EPA in the next NMVP.

\subsubsection{Radionuclide Emissions Monitoring Program}

During the disposal phase, DOE will comply with 40 CFR Part 61, National Emission Standards for Hazardous Air Pollutants (NESHAPs) (EPA, 1993c), which establishes a release limit of 10 millirem per year effective dose equivalent, and 40 CFR Part 191, Subpart A, which establishes a release-limit of 25 millirems to the whole body and 75 millirems to any critical organ combined annual dose equivalent to any member of the public.

The Radionuclide Emissions Monitoring Program measures airborne radioactive particles at the three exhaust points in the WIPP facility: the underground exhaust shaft, the Exhaust Filter Building (EFB) exhaust duct, and the Waste Handling Building (WHB) exhaust duct. The effluent sampling site at the underground exhaust shaft contains three air sampling instrument arrays with four continuous air monitors (CAMs) for measuring alpha and 
beta/gamma radiation and five fixed air samplers (FASs). The effluent sampling site at the EFB exhaust duct contains two sets of instrument arrays with an alpha CAM, a beta/gamma CAM, and four FASs. The effluent sampling site located at the WHB exhaust ventilation duct is equipped with an alpha CAM, a beta/gamma CAM, and a FAS.

CAMS are part of the engineered controls system that mitigates potential airborne releases of radioactive material from the WHB and from the underground storage area. The FASs are used for assessing compliance with Federal and State standards and providing filter samples to other regulatory and oversight agencies. The underground exhaust shaft FAS filter is analyzed each working day, and an FAS filter from each of the other two stations is analyzed weekly.

DQOs for the FAS filter samples specify the accuracy and precision of sample flow rate data, exhaust effluent flow rate data, and laboratory analysis data. The DQOs are as follows:

- Sample flow rate through each FAS must be maintained within $+/-10$ percent, the readout must not vary more than $+/-4$ percent during calibration, and 95 percent of the FAS filters must be measured.

- Alpha counters must consistently read the activity of a check source within $+/-20$ percent, five one-minute readings must fall within the 3- $\sigma$ limit, and 95 percent of the FAS filters must be counted.

- Beta counters must consistently read the activity of a check source within $+/-20$ percent, five one-minute readings must fall within the 3- $\sigma$ limit, and 95 percent of the FAS filters must be counted.

\subsubsection{Supplemental Operational Monitoring}

The Environmental Monitoring Plan (EMP) (DOE, 1994) is intended to determine if waste operations at the WIPP facility impact the local ecosystem. The Occupational Monitoring Program measures ambient levels of radiation, explosive gases, hazardous gases, and oxygen in the WHB and the underground facility.

The EMP includes measurements of ambient environmental radiation levels, atmospheric conditions, air and water quality, soil properties, and the status of the local biological community. Most of the environmental monitoring is performed in the immediate vicinity of 
the site, but radiological monitoring will be expanded upon waste receipt to cover a broader area, including nearby cities, villages, and ranches. This program will compare measurements to the baselines established by the Radiological Baseline Program (RBP) and the Ecological Monitoring Program. Data from these programs are discussed in Chapter 2.

The RBP has measured airborne aerosol particulates since 1985, since the Safety Analysis Report (SAR) (DOE, 1980) identified the air pathway as the only credible release pathway that could result in a radiation dose to the public. Continuous particulate samplers operate at eight locations: three within $1,000 \mathrm{~m}$ of the facility boundary, four at local ranches and communities, and one at a sample control site. Weekly and quarterly averages for gross alpha and gross beta activities were measured in 1991 (DOE, 1992a).

The RBP has established radiological baselines for soil, surface water, and sediments with the required two years of sample data. Soil samples were collected in 1985 and 1987 and analyzed from 37 locations and three depths within an 80-km radius of the WIPP facility. Surface water samples were collected and analyzed from 12 locations: five stock tanks, four points along the Pecos River, and three playa lakes at the lower end of the Nash Draw. Sediment samples were collected and analyzed at six locations: Hill tank, Indian tank, Noye tank, Laguna Grande de la Sal, and two sites along the Pecos River (DOE, 1992b).

The RBP continues to monitor the groundwater and the local plants and animals. Groundwater sampling continues routinely at eight locations within the land-withdrawal boundary. Tissue samples are being collected and analyzed from surface vegetation, quail, rabbit, catfish, and domestic cattle (DOE, 1992b).

The current environmental monitoring programs for soil, surface water, and sediments are essentially unchanged from the baseline studies with the exception of soil monitoring. The number of soil sampling locations has been decreased from 37 to six sites. These six sites coincide with air sampling stations that are in the WIPP vicinity. The original number of sites was established to radiologically document a broad geographical area. With this being accomplished, and knowledge that the WIPP is not negatively impacting the environment, the number of sampling sites was reduced to minimal monitoring requirements as stated in the Environmental Regulatory Guide for Radiological Effluent Monitoring and Environmental Surveillance (DOE, 1991b). This document governs environmental monitoring activities at the DOE sites. 
The Ecological Monitoring Program has sampled environmental parameters surrounding the site and determined that the construction of the WIPP facility has had no significant impact on the local ecosystem. Sampling focused on seven permanent ecological monitoring plots. The Ecological Monitoring Program collected parameter information including meteorological data, air and water quality data, land use data, salt impact data, and vertebrate population data (DOE, 1992a).

The Occupational Monitoring Program is designed to provide a safe working environment for all waste handling personnel. CAMs located throughout the WHB and underground measure beta-gamma and alpha radiation activity. If threshold levels of radiation are exceeded, the system will signal an alarm and activate the high efficiency particulate air (HEPA) filtration system for exhaust air. Area radiation monitors (ARMs) measure ambient penetrating radiation throughout the WHB and underground and will sound an alarm if established levels are exceeded. Hydrogen gas concentrations are monitored at the surface, and an alarm will sound and ventilation will increase when concentrations reach 25 percent of the lower explosive limit for hydrogen. Methane gas concentrations are monitored underground, and an alarm will sound and corrective action will be taken when concentrations reach 25 percent of the lower explosive limit for methane. Hazardous gases signal alarms at 25 percent of the threshold limit value (TLV) for each gas, and corrective actions will be taken (DOE, 1990b).

\subsection{Confirmatory Monitoring}

Confirmatory monitoring, which is based upon the assurance requirements of 40 CFR 191, Subpart B, will consist of aspects of both operational (short-term) and post-closure (longterm) monitoring programs. This monitoring will be implemented to detect any substantial and detrimental deviations from expected performance and will continue until there are no significant concerns to be addressed by further monitoring.

A substantial portion of confirmatory monitoring may be executed before the post-closure period to meet one or more of the following objectives:

- to provide data to support the design of post-closure monitoring programs

- to provide data to address the uncertainty inherent in long-term performance predictions as long as such measurements are "meaningful" as defined by the standard 
- to provide data that will allow relaxing of conditions imposed on the DOE due to insufficient or incomplete data

Once waste is emplaced in the repository, meaningful data describing near-term waste interactions, the repository environment, and installed engineered barriers may be obtained. These data will provide an increased level of confidence in the assumptions and modeling predictions of the long-term behavior of the repository.

The design of post-closure monitoring programs will depend, in part, on the monitoring results obtained from the disposal phase. Long-term monitoring techniques, such as subsidence and seismic monitoring, may be used to evaluate aspects of repository performance without jeopardizing the containment capabilities of the repository.

No definitive confirmatory monitoring programs, that will be needed for a compliance submittal, have been developed to date. The draft document, Waste Isolation Pilot Plant Repository Monitoring Program Strategic Plan (DOE, 1993c), describes the plan of activities by which the DOE will implement confirmatory monitoring objectives. This plan includes developing the decision making process for determining if long-term monitoring is in fact needed, and if so, how suitable approaches will be selected.

Long-term monitoring activities are designed to ensure that any releases of hazardous constituents beyond the WIPP unit boundary do not exceed health-based levels (40 CFR \$268.6), and that the individual and groundwater protection standards established under 40 CFR 191, Subparts B and C, are not exceeded during undisturbed performance scenarios. The long-term monitoring will focus on evaluating the integrity of the repository rather than detecting specific contaminants to ensure containment of the waste throughout the closure/post-closure period of the WIPP facility.

Active institutional controls, including "monitoring parameters related to disposal system performance," will be maintained for as long as practical after closure. The techniques used to monitor the repository must not "jeopardize the isolation of the wastes" (40 CFR $\$ 191.14[\mathrm{~b}])$. In addition, the long-term monitoring program will be designed to detect substantial and detrimental deviations from the expected performance of the repository in isolating the wastes. 
A number of options are being evaluated to monitor the WIPP facility's long-term performance. These options include monitoring hydrological, geological, geochemical, and structural factors that are crucial to maintaining the integrity of the repository. Hydrological monitoring will be considered to compare the movement of fluids through the Rustler Formation to the assumptions made during facility modeling. Geological performance may be monitored by measuring subsidence at the surface of the repository. Geophysical techniques may also be of use to assess changes in the surrounding environment over time. Monitoring of seismic activity may be useful in assuring that natural processes, such as earthquakes, are not a factor in long-term performance.

The DOE has implemented a subsidence monitoring program at the WIPP. Subsidence monuments have been installed to monitor changes in surface elevations that might be associated with mining activities. The DOE will continue to monitor subsidence in the area of the WIPP facility to assess any impacts on the facility.

The WIPP seismographic network became fully operational in 1983. Extensive information has been compiled about past events, and predictions have been made with regard to the likelihood of future events. The DOE will continue to monitor seismic activity at and around the WIPP facility. 


\subsection{REFERENCES}

U.S. Department of Energy (DOE), 1980. Waste Isolation Pilot Plant Safety Analysis Report, Washington, D.C., U.S. Department of Energy.

U.S. Department of Energy (DOE), 1988. DOE Order 5400.1, General Environmental Protection Program, Washington, D.C.

U.S. Department of Energy (DOE), 1990a. Final Environmental Impact Statement: Waste Isolation Pilot Plant, WP 02-9, Carlsbad, NM, Westinghouse Electric Corporation

U.S. Department of Energy (DOE), 1990b. Waste Isolation Pilot Plant No-Migration Variance Petition, DOE/WIPP 89-003, Rev. 1, March 1990.

U.S. Department of Energy (DOE), 1991a. Waste Isolation Pilot Plant No-Migration Determination Annual Report for the Period November 1990 through September 1991, DOE/WIPP 92-057, Westinghouse Electric Corporation, Carisbad, New Mexico.

U.S. Department of Energy (DOE), 1991b. Environmental Regulatory Guide for Radiological Effluent Monitoring and Environmental Surveillance, DOE/EH-01737, January 1991.

U.S. Department of Energy (DOE), 1992a. Waste Isolation Pilot Plant Site Environmental Report for Calendar Year 1991, DOE/WIPP 92-007, Westinghouse Electric Corporation, Carlsbad, New Mexico.

U.S. Department of Energy (DOE), 1992b. Draft Waste Isolation Pilot Plant Site Environmental Report for Calendar Year 1992, DOE/WIPP 93-017, Westinghouse Electric Corporation, Carlsbad, New Mexico.

U.S. Department of Energy (DOE), 1993a. No-Migration Determination Annual Report for the Period October 1991 through August 1992, DOE/WIPP 92-057, Revision 1, Westinghouse Electric Corporation, Carlsbad, New Mexico. 
U.S. Department of Energy (DOE), 1993b. No-Migration Determination Annual Report for the Period September 1992 through August 1993, DOE/WIPP 93-062, Westinghouse Electric Corporation, Carlsbad, New Mexico.

U.S. Department of Energy (DOE), 1993c. Draft Waste Isolation Pilot Plant Repository Monitoring Program Strategic Plan, DOE/WIPP 93-029, Westinghouse Electric Corporation, Carlsbad, New Mexico.

U.S. Department of Energy (DOE), 1994. WIPP 1994 Environmental Monitoring Plan, DOE/WIPP 94-024, 1994.

U.S. Department of Labor, 1993. 29 CFR Part 1910, Occupational Safety and Health Standards, Code of Federal Regulations, Office of the Federal Register National Archives and Records Administration, Washington, D.C.

U.S. Environmental Protection Agency (EPA), 1988. Compendium Method TO-14, The Determination of Volatile Organic Compounds (VOCs) in Ambient Air Using SUMMA Passivated Canister Sampling and Gas Chromatographic Analysis, May 1988.

U.S. Environmental Protection Agency (EPA), 1993a. 40 CFR Part 268, Land Disposal Restrictions, Code of Federal Regulations, Office of the Federal Register National Archives and Records Administration, Washington, D.C.

U.S. Environmental Protection Agency (EPA), 1993b. 40 CFR Part 191, Environmental Radiation Protection Standards for Management and Disposal of Spent Nuclear Fuel, HighLevel, and Transuranic Radioactive Wastes, Code of Federal Regulations, Office of the Federal Register National Archives and Records Administration, Washington, D.C.

U.S. Environmental Protection Agency (EPA), 1993c. 40 CFR Part 61, National Emission Standards for Hazardous Air Pollutants, Code of Federal Regulations, Office of the Federal Register National Archives and Records Administration, Washington, D.C.

Waste Isolation Division (WID), 1991. WP 12-6, VOC Monitoring Plan for Bin-Room Tests, Rev. 0, July 1991. 
Waste Isolation Division (WID), 1994. WP 12-7, Volatile Organic Compounds Monitoring Quality Assurance Project Plan, Rev. 2, January 21, 1994. 


\subsection{Test Programs}

\subsection{Status of Experimental Program Relevant to a Compliance Demonstration}

This section includes a history of the Waste Isolation Pilot Plant (WIPP) experimental programs relevant to a compliance demonstration and is divided into subsections based on technical areas: Geology/Geochemistry, Hydrology, Rock Mechanics, and Performance Assessment (PA). Each subsection includes a brief summary of major compliance-related, technical issues that have concerned the Project from early WIPP site-characterization studies (early 1970s) to the present day and the resolution or current status of each issue. Some issues involve more than one technical area, so they may be covered in more than one subsection.

Within the context of this document, an issue is considered resolved if all the current, compliance-related, technical aspects of the issue have been addressed. There may be instances where the Department of Energy (DOE) believes it is beneficial to pursue some experimental and/or model development activities to substantiate or bound the current reasonable expectation that compliance can be demonstrated. Any such issues will be identified as resolved in this chapter and in Chapter 12. A description of the scope of work and its potential benefit can be referenced in the appropriate sections of Chapter 10 .

\subsubsection{Geologica//Geochemical Compliance Issues}

\section{A. ISSUE: Breccia Pipes}

In southeastern New Mexico, breccia pipes refer to generally columnar collapse structures through the evaporite section. Surface manifestations of breccia pipes were known from the late 1950s (Vine, 1960, 1963), but they were not known to affect the Salado until 1975. Breccia pipes were perceived as a potential pathway for radionuclide and/or hazardous constituent transport if they existed under the WIPP site. As the issue developed, two main approaches were identified and pursued: 1) screen the site to determine if breccia pipes are present and 2) identify the origin of breccia pipes to determine the likelihood of their existence and potential impact on future development at the WIPP.

\section{RESOLUTION:}

Various geophysical techniques were applied to known breccia pipes at the site during 
1976-77 to identify promising techniques and use them to screen the site for anomalies that might represent breccia pipes (e.g., Elliot, 1976a, b, 1977a-e, 1979a-c; Elliot Geophysical Company, 1977; Powers et al., 1978). Several holes were drilled to confirm the presence or absence of breccia pipes in the area. WIPP-13 was drilled on site in 1978. No evidence was found that would indicate the presence of a breccia pipe (SNL and USGS, 1979). WIPP-32 was drilled during 1979 at the nearest off-site feature likely to represent a breccia pipe, again finding no evidence of deeper collapse (SNL and USGS, 1980). DOE-2 was drilled into a series of structural depressions which were determined to be related to salt flow in the Castile and not to dissolution. Known breccia pipes were mapped, drilled, and tested with geophysical techniques, and these features are now interpreted to have formed only over the Capitan reef in response to previously existing hydrological conditions (Bachman, 1980; Snyder and Gard, 1982).

In summary, breccia pipes are not known to exist at the WIPP site. Evidence indicates that they form only over the Capitan reef (which does not underlie the site). Therefore, it is a reasonable expectation that breccia pipes are not a threat to isolation of waste at the WIPP facility.

\section{STATUS: Resolved}

\section{B. ISSUE: Borehole and Shaft Plugging}

Boreholes at and around the WIPP site, as well as shafts that provide access to the disposal horizon, are potential conduits for fluids to transport radionuclides and/or hazardous constituents from the repository horizon to the boundaries imposed by regulation. Seals and borehole plugs have been proposed to limit the flow into, through, and out of the repository (Stormont, 1988). The adequacy of these plugs and seals is therefore an important compliance-related issue.

\section{RESOLUTION:}

An extensive field and laboratory research program was developed, and various cementitious plug materials have been tested (e.g., Buck et al., 1983; Christensen and Hunter, 1981; Christensen et al., 1980). Borehole plugs were considered to have reached acceptable performance in reducing flow or leakage through boreholes (Christensen and Peterson, 1981). Shaft plugs have been modeled for the behavior of different materials, such as salt, bentonite, and concrete; halite or bentonite may provide acceptable seals (Stormont and Arguello, 1988; Torres, 1988). A reference seal design has been described (Nowak et al., 
1990) and is currently being reevaluated. The coupled mechanical and hydrological behavior of elements of the reference design have been modeled (Ehgartner, 1991). Since the longterm seals consist of salt, which will reconsolidate to its original conditions through the creep process, the reasonable expectation is that these seals will be effective. Final design and testing of short-term seal components remain to be demonstrated. Additional detail regarding seals and plugs is provided in Section 3.4.1.

\section{STATUS: Open}

\section{ISSUE: Brine Reservoirs}

A pressurized brine reservoir underlying the repository horizon was encountered while ERDA-6 was being drilled in 1975 during investigation of an original candidate site near the location of the present WIPP site. Further research revealed other drillholes in the region had also encountered pressurized brine in the Castile Formation (Popielak et al., 1983; Lappin and Hunter, 1989). A brine reservoir under portions of a repository might provide a high-pressured fluid which could carry waste from a repository to the accessible environment if connected by a drillhole or natural fractures.

\section{RESOLUTION:}

The WIPP site was initially thought to be free from brine reservoirs, but WIPP-12, located one mile north of the site center, encountered pressurized brine in the upper Castile Formation (Black, 1982; Black et al., 1984; Popielak et al., 1983). The extent of brine in the Castile formation beneath the WIPP has been estimated with an electromagnetic survey (Earth Technology Corporation, 1988), and it is generally accepted that a brine reservoir underlies at least part of the site. PA therefore includes scenarios that involve drilling into a pressurized brine pocket.

\section{STATUS: Open}

\section{ISSUE: Brine Weeps and Seeps}

At WIPP, as well as in potash mines, very small volumes of brine seep from some areas of the exposed salt units. Various studies have attempted to determine the volume of brine in the rock, its chemistry, distribution, and migration. The brine and its chemistry could affect decomposition of radioactive waste and generation of gas. The brine could affect the consolidation of backfill. Saturated porosity in the waste panels affects various scenarios for contaminant migration. A demonstration that brine migrates from the far field toward the 
repository (with respect to waste panels) would imply that gas (and brine) could migrate away from the waste repository.

\section{RESOLUTION:}

The observed brine seepage rates are slow and difficult to quantify, and a number of approaches have been pursued to bound the estimates of the amount of brine that might enter the repository during operations and after sealing and closure (see Section 2.1.2)

\section{STATUS: Open}

\section{E. ISSUE: Dissolution}

It has been understood from the time southeastern New Mexico was first investigated as a potential location for a waste repository that the evaporite section has been partially dissolved (Brokaw et al., 1972). The initial concern was that the repository be located at sufficient depth to be protected from dissolution from the top of the evaporites down to the waste disposal horizon (Jones et al., 1973). As the WIPP site was being characterized, concepts were developed that distinguished shallow dissolution (from the top down), point dissolution (such as breccia pipes), and deep dissolution (salt beds at depths are attacked by lateral dissolution). These processes, all variations of dissolution, were considered potential threats to isolation of waste at the WIPP.

\section{RESOLUTION:}

Jones et al. (1973) and Bachman and Johnson (1973) provided the basis for the conclusion that shallow dissolution can be dismissed as a potential threat to a repository in the area where WIPP is located. This conclusion is based on evidence from WIPP drilling, geophysics, surface mapping, and other sources (e.g., commercial potash drilling). Bachman (1985), though he focused on karst phenomena, provided one of the more recent summaries indicating shallow dissolution will not affect the WIPP repository horizon within the period of regulatory concern.

Both point source dissolution and breccia pipes were intensively investigated (see above), and neither have been found at the WIPP. They are believed to be restricted to the area above the Capitan reef (Bachman, 1980; Snyder and Gard, 1982), which does not underlie the WIPP site. 
Deep dissolution was introduced as a concept mainly through a report by Anderson (1978) that provided a basic summary of the distribution of halite in the basin and provided testable concepts of dissolution. Most of the discussion and analysis of "deep dissolution" have been focused by considering the following questions: 1) Does deep dissolution exist?, 2) How extensive is (or was) deep dissolution?, 3) By what mechanism could, or does, it occur?, and 4) Is deep dissolution a threat to WIPP? Anderson (1978, 1981, 1982), Bachman (1980), and Lambert (1983) have provided various approaches to answering the first three questions. No drilling at or in the immediate vicinity of the WIPP facility has been interpreted to indicate deep dissolution (e.g., Mercer et al., 1987; Anderson, 1987), and even the shorter estimated time periods (e.g., Anderson, 1979) during which the WIPP might be affected by deep dissolution are an order of magnitude greater than the regulatory period of concern. Based on these observations, it is reasonable to expect that the WIPP facility will not be subjected to deep dissolution activity.

\section{STATUS: Resolved}

\section{F. ISSUE: Igneous Activity}

An igneous dike was encountered during mining of potash at the New Mexico Potash (formerly Kerr-McGee) mine, 9 mi north of the WIPP facility. The issue investigated was whether the presence of an igneous dike is indicative of regional igneous activity which could be disruptive to the site.

\section{RESOLUTION:}

Early in WIPP investigations, geophysical and drilling data about the dike were summarized and interpreted by Elliot $(1976 \mathrm{a}, \mathrm{b})$, showing that a single dike trend existed from the area south of White's City to north-northeast of the WIPP site. The closest approach of the dike trend to the WIPP is several miles, indicating no direct consequence to the WIPP (e.g., Griswold, 1977; Powers et al., 1978). The age of the dike is about 32-34 million years (Calzia and Hiss, 1978), and it is the youngest known igneous rock in the northern Delaware Basin. The composition of the dike is lamphophyre suggesting low igneous activity. The tectonic regime of the site does not include igneous processes, so igneous activity is not expected to occur. Therefore, there is a reasonable expectation that waste isolation will not be impacted.

\section{STATUS: Resolved}




\section{G. ISSUE: Karst}

Southeastern New Mexico is known to include areas of limestone and evaporite karst in which near-surface to shallow dissolution creates many features, ranging from caverns or cavernous porosity to surface sinks, domes, and mounds. While the processes are another form of dissolution and some of the features resemble those created by distinct dissolution processes (e.g., point source dissolution), karst has somewhat differing implications. Karst features at the surface and underground could significantly change recharge and flow patterns and velocity for groundwater flow. Barrows et al. (1983) and Barrows and Fett (1985) inferred that geophysical and geological data for the WIPP site were consistent with karst conduits within the Rustler Formation. Some surface features around the WIPP site were interpreted by Barrows et al. (1983) as alluvial dolines, features associated with karst processes. Karst conduits within the Rustler at the WIPP site would significantly alter assumptions about radionuclide and hazardous constituent transport within the formation.

\section{RESOLUTION:}

Bachman (1985) further investigated surface and near-surface features inferred to be the result of karst processes at the WIPP site and surrounding area. He concluded that certain of the features nearer the site (e.g., at WIPP-14) were surficial blowouts in sand dune fields and that there was no evidence of active near-surface dissolution in the vicinity of the immediate WIPP site. LeGrand (in Chaturvedi and Channell, 1985) visited the site and reviewed data, but he did not specifically interpret the surface feature at WIPP-14. Barrows (in Chaturvedi and Channel, 1985) reasserted his opinion that this feature is an alluvial doline rather than a blowout.

Barrows also concluded that hydrological parameters obtained in a karst plain are generally irrelevant because the greater area (and volume) is occupied by matrix-dominated porosities that are observed through normal hydrological testing while most or all karst conduits may be missed. Thus the lack of borehole hydrological evidence of karst conduits is considered by Barrows not to preclude the existence of karst features. The potential existence of karst features is included in the conceptual model used for PA. However, regional surface studies (Bachman, 1985 and 1987) integrated with hydrological and chemical investigations (Lappin and Hunter, 1989) have determined that it is reasonable to expect that karst formation is not a process at the WIPP site which will result in significant compliance-related consequences.

\section{STATUS: Resolved}




\section{H. ISSUE: Natural Background Radiation}

Surface sources of background radiation, both natural and due to human activities, in the general vicinity of the WIPP need to be identified and characterized adequately before radioactive waste is brought to the WIPP site. If these sources are not known, it might be mistakenly inferred, in the future, that nearby areas had been contaminated during transport of the waste or that the WIPP had not isolated the waste.

\section{RESOLUTION:}

An aerial radiological survey in the vicinity of the WIPP identified two areas with higher than normal naturally occurring radionuclides and one site exhibiting human-created radiation sources (Berry, 1989). The human-rreated anomaly was located at the Gnome site, $7.5 \mathrm{mi}$ south of the WIPP, where a small-yield nuclear device was detonated underground in 1961. One anomaly from ${ }^{40} \mathrm{~K}$, a naturally occurring radionuclide, is centered over the surface facilities of the New Mexico Potash mine. Another anomaly, indicating uranium series decay, is located just south of NM Hwy 128 near the easternmost of the brine lakes in Nash Draw.

A baseline program for the WIPP site area has also been established to monitor naturally occurring and transuranic radiation sources in the area and establish a pre-operational baseline (Fischer, 1986; Reith et al., 1985, 1986). Based on the aerial observations and the radiologic baseline program, a reasonable background radiation level has been established.

\section{STATUS: Resolved}

\section{ISSUE: Paleoclimate and Climatic Changes}

The site hydrology may be sensitive to changes in climates over the period of regulatory concern, affecting the assessment of isolation by the WIPP. Past climatic changes and conditions are considered an indicator of the range of climatic conditions to be expected from natural causes in the future.

\section{RESOLUTION:}

WIPP 15 was drilled in San Sirnon Sink to obtain geological and age evidence related to the collapse of the feature and paleoclimatic evidence. Core samples were analyzed for fauna and flora that might indicate paleoclimatic data (SNL and University of New Mexico, 1981), and some general information was obtained. Generalized paleoclimatic inferences have also been drawn by Bachman $(1974,1976)$, and he provided an annotated bibliography of other 
paleoclimatic studies related to southeastern New Mexico (Bachman, 1989). The most comprehensive summary of paleoclimatic evidence and assumptions for southeastern New Mexico was provided by Swift (1992) and has been used to develop a reasonable expectation relative to future climate variation for the WIPP vicinity. This clumate variation is used in PA.

\section{STATUS: Resolved}

\section{J. ISSUE: Resources}

Natural resource issues at the WIPP are twofold. First, the resources required an assessment for the purposes of determining compensation to lessees for denial of access to the resources. Second, natural resources also represent potential exploration targets and exploitable deposits that may lead to inadvertent drilling into the repository.

\section{RESOLUTION:}

Oil and gas resources have been estimated from broader geological and statistical perspectives (Foster, 1979) as well as by petroleum geology methods (Sipes, Williamson, and Aycock, Inc., 1976; Sipes, Williamson, and Associates, 1980). The fair market values and future net revenue from oil and gas for various tracts have also been estimated (e.g., Keesey, 1977). In addition, directional drilling practices and costs for accessing oil and gas under the site were evaluated for the WIPP site (Sipes, Williamson \& Associates, Inc., 1979) to provide the project with baseline information.

Potash resources were estimated using WIPP drilling and studies (John et al., 1978; Jones, 1978; Seedorff, 1978), and the loss of potential potash related revenue was compared to the economic impact of the WIPP facility. Other resources (salt, caliche, etc.) were also evaluated to determine their extent and availability (Siemers et al., 1978).

Resources are present at the site, and they have been recognized as an attraction for drilling and other exploration/exploitation posing a potential threat to the integrity of the WIPP (e.g., Foster, 1979). The nature of such threats is being assessed in part through investigation or modeling of the mechanics of the exploration methods (e.g., Berglund, 1992) and by including them in WIPP PA calculations. The Department of Energy (DOE) has published a report documenting the manner and extent to which resource related issues were considered in the site-selection process. This report was prepared to demonstrate that the favorable characteristics of the site more than compensate for the risk posed by the presence of natural, 
extractable resources based on the current economy and available technologies (DOE, 1991 Resource Disincentives Report).

\section{STATUS: Closed}

\section{K. ISSUE: Salt Deformation}

Salt deformation was considered important for two reasons. First, siting criteria required the selection of a site with flat-lying beds. Second, deformation could indicate the presence of other characteristics that would be of importance to the repository. ERDA-6, drilled in 1975 by Sandia National Laboratories (SNL) encountered severe deformation in the lower Salado and upper Castile Formations (SNL and USGS, 1983a). Because ERDA-6 also encountered pressurized brine (see Brine Reservoirs) in the highly deformed evaporites, the two phenomena were considered related. The site was abandoned because it would not have been possible to mine within a single horizon and maintain any nearly level workings (Powers et al., 1978). Further investigations also showed that drilling by some oil and gas companies had also encountered pressurized brine in areas that were known to be structurally deformed (Griswold, 1977; Register, 1981). As a consequence, the WIPP site was initially selected in part to try to avoid structural complications and possible brine reservoirs. Therefore, salt deformation was a site selection and characterization issue that was addressed by determining whether or not the present site met the requirements for relatively uniform lithology and minimal dips.

As the site was characterized, seismic reflection data and drilling revealed salt deformation in the northern part of the site area (Powers et al., 1978). The issues were then to determine the extent of deformation and possible effects on expected facility horizons, to understand the possible association with brines and whether brine reservoirs might exist at or near the site, and to determine if the salt might continue to deform over any period of interest relative to waste isolation.

\section{RESOLUTION:}

Seismic reflection data (Hern et al., 1979) and drilling generally established that salt beds to the lower Salado were not significantly deformed in the central $4 \mathrm{mi}^{2}$ of the WIPP site. The Site and Preliminary Design Validation (SPDV) program provided two shafts and underground access to the facility horizon; initial mining and previous drilling confirmed that the horizon was not significantly deformed (Jarolimek et al., 1983). 
The relationship to brine reservoirs was tested by drilling WIPP-12 ( $1 \mathrm{mi}$ north of the site center) into the lower Castile. WIPP-12 was losated on a modest anticline; this structure was nearest the site and was not expected to have brine as the structure was not severe. WIPP-12 did encounter pressurized brine and was extensively tested and sampled (Popielak et al., 1983). The brine was significant in volume, but the reservoir was evidently not connected to the ERDA-6 reservoir several miles distant. Further geophysical work (Earth Technology Corporation, 1988) indicates brine possibly underlies a significant portion of the inner WIPP site several hundred feet below the disposal horizon. The presence of a Castile Brine Reservoir is therefore still a part of inadvertant human intrusion scenarios related to exploratory drilling for resources (see Section 8.1.4.5.2).

From among possible explanations of the origin of the salt deformation, Borns et al. (1983) proposed that foundering of more dense anhydrites into underlying less dense halite is the principal factor in salt deformation around the WIPP site. Rock mechanics and geological data indicate that the reasonable expectation for the WIPP site is that no significant natural deformation will occur at the site over the period of regulatory concern.

\section{STATUS: Resolved}

\section{ISSUE: Seismic Activity}

In general, there is little seismic activity in the vicinity of the WIPP site (Powers et al., 1978). The seismic activity around the site was, and is, of concern relative to designing the facility to withstand ground motion. The analysis of seismicity included consideration of the long-term record indicated by faults and other tectonic activity in the region (see Subsidence and Tectonic Stability/Faulting).

\section{RESOLUTION:}

Data have been acquired from instruments located in the WIPP area since 1974 to supplement more distant instrumental records (e.g., Sanford et al., 1978) and historical, noninstrumental records. Most seismic activity in the region occurs in the Kermit, Texas, area, and it may be related to injection activities (Sanford et al., 1978, 1980; Keller et al., 1981).

Seismic motion studies for WIPP (in Powers et al., 1978) and analyses performed by Bechtel National, Inc. (DOE, 1990) indicate that the expected value for the 1,000 -year acceleration is less than $0.06 \mathrm{~g}$. A value of $0.1 \mathrm{~g}$ was used as a part of the basis for the facility design. It is 
therefore reasonable to expect that the facility will withstand disturbances related to local seismic activity.

\section{STATUS: Resolved}

\section{ISSUE: Specific Site Geological Characteristics: Salt Depth, Thickness, Purity, etc.}

A number of geological characteristics were identified during the site selection process as desirable based on a variety of considerations ranging from construction to isolation from long-term processes (e.g., dissolution) (see Griswold, 1977; Powers et al., 1978). Of these characteristics, several are discussed as separate issues. For instance, a thickness of $200 \mathrm{ft}$ $(61 \mathrm{~m})$ of high purity salt between depths of 1,000 and 3,000 ft (305 and $915 \mathrm{~m})$ was desirable for the purposes of site selection. These characteristics do not supplant PA, but they were used to help identify a prospective site and were further used as a basis for qualifying the SPDV program (DOE, 1983).

\section{RESOLUTION:}

ERDA-9 was drilled very near the center of the (then) prospective site during the early summer of 1976. The interval from near the top of the Salado to the top of the Castile was cored continuously, and the borehole was very extensively logged with geophysical techniques (Griswold, 1977; Griswold and McWhirter, 1981). The geology of the borehole was reported by SNL and USGS (1983b). Horizons were identified as potential hosts for the repository based on these data, and core from ERDA-9 was extensively used for mineralogical analysis (Bodine, 1978) and rock mechanics studies (e.g., Wawersik and Hannum, 1979). ERDA-9 provided information indicating that intervals of salt with appropriate thickness, purity, and depth were present at the site.

The SPDV program provided verification of the site selection/characterization activities with data/information obtained during facility construction. Under this program, initial shafts were drilled and connected, and the facility horizon was selected based on inspection in the initial shaft (Jarolimek et al., 1983). Underground exploration further indicated that the selection criteria, as then known, for thickness, continuity, and purity had been satisfied (DOE, 1983). Characterization studies confirmed a gentle basin tilt and continuity of bed thickness (greater than $2,000 \mathrm{ft}[610 \mathrm{~m}]$ of evaporite section exist at the WIPP site between the base of the Rustler Formation and the top of the Bell Canyon Formation). The reasonable expectation for the WIPP facility is that as the remaining portions of the facility 
are excavated, existing data relative to thickness and purity of the salt will be confirmed accurate.

\section{STATUS: Resolved}

\section{N. ISSUE: Subsidence}

Subsidence at the WIPP may be an issue from two different perspectives: natural and induced. Subsidence may occur because of naturally occurring tectonic activity or dissolution. Subsidence may also occur in response to mining or oil pumping. Subsidence is accompanied by deformation of overlying and nearby units and has been observed to affect the hydrologic properties of those rocks.

\section{RESOLUTION:}

Natural subsidence due to tectonic activity is broadly monitored by a regional first-order leveling network (Balazs, 1978, 1982). Natural subsidence from tectonic activity is generally a broad-scale event and is not likely to specifically disrupt the WIPP site. Upper units at the WIPP site can be inferred to have subsided due to dissolution of salt units within the Rustler Formation (cf. Snyder, 1985), although Holt and Powers (1988) have proposed that postRustler dissolution at the WIPP site is quite limited. Beauheim and Holt (1990) indicate the most likely areas for dissolution of Rustler units, along with the potential consequences for the hydrology of the Culebra Dolomite Member.

Subsidence and its effect on the groundwater flow due to future mining outside the WIPP site boundary has not been directly considered. Information about subsidence from potash mining in the district has been assembled and broadly summarized (DOE, 1980) providing some evidence of "angle of influence" and magnitude of subsidence in the district. The potential for subsidence due to WIPP itself is being addressed by numerical modeling studies.

While the reasonable expectation is that subsidence will not be a factor affecting the longterm integrity of the WIPP, an appropriate scenario will be considered.

\section{STATUS: Open}

\section{O. ISSUE: Tectonic Stability/Faulting}

Faulting or tectonic disruption in the repository horizon could potentially connect waterbearing units and provide additional pathways to the regulatory boundaries. Likewise, 
tectonic stability and faulting could affect design criteria and facility operations (see Seismic Activity, above).

In particular, six criteria were focused upon: 1) whether the magnitude of maximum historical seismic events represents a low seismic risk to the site, 2) whether major faults and pronounced linear structural trends can be avoided, 3 ) whether major salt flow (halokinetic) structures can be avoided, 4) whether areas of active uplift or subsidence can be avoided, 5) whether areas of active or recent volcanism or igneous intrusions can be avoided, and 6) whether areas of high geothermal gradient can be avoided.

\section{RESOLUTION:}

The Delaware Basin is generally a stable tectonic area (Powers et al., 1978), with limited seismic activity and no recent volcanism, intrusive activity, or tilting. Focus on the six criteria identified in the issue statement resulted in the following: 1) The maximum possible acceleration for 10 million years was estimated to be $0.3 \mathrm{~g}$ and for 10,000 years $0.06 \mathrm{~g}$ (DOE, 1980). The upper magnitude limit for the WIPP site was estimated to be 4.5 to 5.0 on the Richter scale (DOE, 1980). 2) Seismic reflection surveys and exploratory drilling confirmed the absence of major faulting. There are no known faults of tectonic origin in the WIPP site area displacing the upper units and Mescalero caliche. The nearest inferred fault that has been active in Quaternary time (Kelley, 1971), along the eastern escarpment of the Guadalupe Mountains, was investigated by Hayes and Bachman (1979) and was determined not to be a fault. The known faults of tectonic origin to the west and probably of Holocene age are along the western Guadalupe Mountain escarpment along the boundary with the West Texas salt flat graben (Muehlberger et al., 1978). To the east, the faults of the Central Basin Plaiform may have shown recent tectonic movement associated with the 1992 Rattlesnake Canyon event. 3) Seismic reflection studies and exploratory drilling confirmed that the site area displays a relatively low amount of halokinesis relative to the area 1-2 mi north.

4) Geodetic surveys determined that subsidence across the site is less than $5 \mathrm{~mm} / \mathrm{yr}$.

5) Industry aeromagnetic and gravity surveys indicated that no intrusive feature crosses the site except for the dike that intercepts the New Mexico Potash mine to the north of WIPP. 6) Downhole heat flow surveys in WIPP exploratory boreholes confirmed that the site does not have a high geothermal gradient. Based on these observations, the reasonable expectation is that the WIPP site will remain tectonically stable for the period of regulatory interest.

\section{STATUS: Resolved}




\section{P. ISSUE: Identification and quantification of chemical processes that retard radionuclide transport in the Rustler Formation, particularly the Culebra Member.}

The rock units overlying the Salado Formation are modeled as pathways for radionuclide release in WIPP human intrusion scenarios; the principal radionuclide transport pathway is in the Culebra Member of the Rustler Formation. One result of the PA is the identification of radionuclide chemical retardation transport parameters as critical WIPP performance parameters. Therefore, knowledge of radionuclide chemical retardation transport parameters is required for calculations of transport through the Culebra.

\section{RESOLUTION:}

In the 1988 Modification to the Working Agreement of the Consultation and Cooperation Agreement Between the Department of Energy and the State of New Mexico on the Waste Isolation Pilot Plant, the DOE and the State of New Mexico agreed that the DOE would conduct laboratory studies related to sorption. The DOE committed to arrive at a range of conservative but reasonable values "based on the lowest reasonable values experimentally obtained." Furthermore, DOE agreed that the selection of these values would be "after consultation with the State." Finally, the DOE committed that "in the absence of experimentally justifiable values, $K_{d}$ will equal zero... in the performance assessment calculations." Based on laboratory studies, it appears that $\mathbf{K}_{d}$ 's are not zero for all radionuclides. Consequently, a reasonable expectation for the WIPP facility includes the modeling of chemical retardation using non-zero $\mathrm{K}_{\mathrm{d}}$ values. Core flow experiments will serve to test for chemical retardation during fracture flow on a small scale and further enhance the existing data base. Those laboratory-scale studies are now underway.

\section{STATUS: Open}

\subsubsection{Issues in Rock Mechanics}

\section{A. ISSUE: Thermal Expansion}

Thermal expansion and the potential thermal uplift of the overburden resulting in tensile cracks above the repository needed to be evaluated. 


\section{RESOLUTION:}

The issue of the thermal uplift was resolved by the calculations of Thorne and Rudeen (1980) which showed a thermal uplift on the order of a meter, essentially compensated by the expected subsidence. Consequently, the reasonable expectation is that the resultant overburden stress could not lead to fractures.

\section{STATUS: Resolved}

\section{B. ISSUE: What is the best approach to simulating salt creep?}

B.1 Subissue: Is the uncertainty arising from differences in 1) physics and numerical method and 2) the calculational procedures of the numerical codes proposed for use in the analysis of room response significant?

Resolution: Uncertainty associated with various codes used to simulate salt creep was the subject of a nine-code benchmark exercise against two boundary value problems (Krieg et al., 1980). The result of this benchmark (Morgan et al., 1981) resolved the issue by showing that the variation in the codes was within acceptable limits. Code issues related to input quality control were essentially resolved by another exercise based on refereed blind parallel calculations of two separate analysis teams (Munson and Morgan, 1986). At this point there are three well-documented and benchmarked solid structural codes with reasonable capabilities for performing WIPP-specific design and PA tasks (Biffle, 1993; Callahan et al., 1989).

\section{Status: $\quad$ Resolved}

B.2 Subissue: Are the constitutive description and material properties adequate representations of the behavior of salt?

Resolution: The preliminary constitutive model technology was based on the steady-state creep of salt employing the material parameters and the stratigraphy evaluated from core specimens from deep boreholes from the ground surface. These were given as the 1984 reference conditions (Krieg, 1984). When the 1984 reference conditions were used to calculate the response of the first underground excavations (Morgan et al., 1985), the 
predicted closure was a factor of nearly three less than the measured closure. Because the difference between the predicted and measured closure was larger than acceptable, a number of efforts resulted in attempts to resolve the discrepancy. For example, simple backfitting by reduction of the elastic moduli could produce agreement between the calculated and measured results (Morgan et al., 1986). Because a predictive technology based on the arbitrary reduction of elastic moduli cannot be extended with confidence to other geometric configurations, this method was not considered an acceptable resolution to the discrepancy in closure. However, the reduced modulus approach continues to be used in special situations, the most notable of which is the calculation of the permeability of the room contents as it is compacted by the room closure for the case of concurrent gas generation from brine and microbial interactions with drums and waste (Butcher and Mendenhall, 1993). In this case, the steady state creep model was expedient because it permitted a savings in computer time.

The discrepancy between predicted and measured in-situ room closure resulted in a careful reexamination of the predictive technology and three new subissues. These concerned the importance of transient creep in the constitutive model, the reevaluation of material parameters to include both clean and argillaceous salt, and the proper choice of the flow potential which permits the generalization of the model as framed in uniaxial stress into the three dimensional stress field of the in-situ tests (Munson et al., 1989). As a result of the reexamination, the discrepancy was resolved through the use of a creep model initially developed by Munson and Dawson $(1979,1982)$ and modified by Munson et al., (1989). This model, referred to as the M-D model, is based on multimechanism deformation steady state with work hardening/recovery transient creep. The material parameters were determined for the M-D model with specific properties for the two major salt layers (Munson et al., 1989). The proper flow potential was determined through laboratory tests on thin walled cylinders of salt where the Lode angle (direction of loading) could be varied between pure shear and uniaxial compression. The tests are directly interpretable, with the conclusion that the correct choice of flow potential is a Tresca maximum shear criterion, rather than the von Mises potential used previously (Mellegard et al., 1992). Also, during the reevaluation, the stratigraphy was updated (Munson et al., 1989). 
A very significant subsequent result of the resolution of these subissues is that agreement between the predicted and measured room closures has now been clearly demonstrated with the modified M-D model and Tresca criterion for a number of different single room geometries, multiple room arrays, and shafts, for both heated and unheated conditions (Munson and DeVries, 1991). Successful analysis also includes a complicated three-dimensional test with marked differences in excavation dimensions (Munson et al., 1993). These successful comparisons indicate that the simulation technology based on the M-D model is a reasonable approach for the WIPP facility.

\section{Status: $\quad$ Resolved}

\section{RESOLUTION: (Overall)}

The successful comparisons of the predictive technology based on the modified M-D model, the appropriate material parameters, and the Tresca flow potential, together with the updated stratigraphy and with measured field behavior, indicate that the issue of being able to reasonably predict room closure has been resolved. The recommended M-D model, appropriate material parameters, and updated stratigraphy are used to confirm the accuracy of the closure model used in PA analyses (SNL, 1992).

\section{STATUS: Resolved}

\section{ISSUE: Rock Mechanics Concerns in Seal Performance}

A question arises on whether the performance of seals and seal systems under repository and seal emplacement conditions can be adequately simulated where there is the potential for creation, growth, and healing of the disturbed rock zone (DRZ) in the salt adjacent to underground openings (Lin and Van Sambeek, 1992).

\section{RESOLUTION:}

Program development aimed at producing an adequate simulation technology is currently being pursued. This involves a constitutive model, material properties, and numerical analysis capabilities. The current model is based on the M-D creep model, coupled with a pressure and time dependent accumulation of fracture damage to simulate the onset of tertiary creep and eventual failure (Chan et al., 1992). Although not yet approaching the level of the M-D creep model, the model has been incorporated into the numerical codes, material 
parameters have been determined, and preliminary simulations of the DRZ have been made.

This model also includes the healing kinetics of repressurized fractures.

\section{STATUS: Open}

\subsubsection{Issues Related to WIPP Hydrology}

\section{A. IGSUE: Focus on the Culebra Dolomite}

The WIPP Project focused on hydrogeological characterization of the Culebra Dolomite to the near-exclusion of the other strata above and below the repository horizon. In the draft EPA comments, for example, on the 1992 PA report (Volumes 1-3), the following concerns are expressed:

1. Could the Bell Canyon be a source of ter to the repository? What Bell Canyon head data are available?

2. More data need to be acquired for all relevant stratigraphic units at the WIPP site (i.e., Castile through Dewey Lake Redbeds).

3. What is the effect on the release when the Magenta and Culebra Dolomites are combined in the calculations?

\section{RESOLUTION:}

Early hydrogeological studies performed in support of the Geological Characterization Report (Powers et al., 1978) focused on water-bearing zones in the Rustler Formation. Earlier USGS studies in the Delaware Basin had shown the Culebra and Magenta dolomites and the Rustler-Salado contact to be the only water-producing horizons in the Rustler. Mercer and Orr (1979) reported on testing performed in wells H-1, H-2, H-3, P-14, P-15, P-17, and P18. The Culebra and Rustler-Salado contact were tested in all these wells, and the Magenta was also tested in the three $\mathrm{H}$ wells. In all cases, the Culebra was found to be the most transmissive unit. This observation was borne out by additional testing performed at the H-4 through H-10 and WIPP-25 through WIPP-30 well sites reported by Mercer (1983).

Furthermore, on the WIPP site proper, the Magenta was found to be more transmissive than the Rustler-Salado contact. Barr et al. (1983) used transmissivity and head data from the HP-and WIPP series wells to model contamiraant transport through the Culebra and Magenta from a location above the repository. This study showed that transport rates and distances were much greater in the Culebra than in the Magenta. From this finding, the project concluded that the Culebra was the most important transport medium at the site. If transport 
through the Culebra did not result in unacceptable results, then neither would transport through any other unit. Accordingly, most of the hydrogeological characterization effort since 1983 has concentrated on the Culebra. Later testing of the Rustler Formation in wells H-14 and H-16 (Beauheim, 1987) showed that the claystone/mudstone horizons in the Fortyniner, Tamarisk, and unnamed lower member were pernieable and saturated with water (or brine), but that they were several orders of magnitude less permeable than the Culebra.

Other units were surveyed during the early site characterization studies, and some have been studied in more depth in response to specific issues or questions. The Bell Canyon Formation of the Delaware Mountain Group (DMG) was tested in wells AEC-7, AEC-8, and ERDA-10 (Mercer, 1983). Weart (1983) reported that flow in a hole connecting the Rustler and DMG would be downward because of brine density differences, and that water passing under the WIPP site in the DMG would take 500,000 years to reach the Capitan Reef 6.2 to 9.3-mi (10 to $15-\mathrm{km})$ downgradient. Therefore, detailed characterization of the Bell Canyon was not considered to be warranted. Additional tests of the Bell Canyon were performed as opportunities arose in wells Cabin Baby-1 (Beauheim et al., 1983) and DOE-2 (Beauheim, 1986), confirming the conclusions drawn from the tests in the previous three wells. However, the Bell Canyon could be a source of brine at the repository level if the repository were not already pressurized. The consequences of such an event are expected to be less than the consequences of an intrusion into Castile brine pocket which is already modeled by PA.

Characterization of the hydrogeological properties of the Castile Formation has focused on the brine reservoirs found locally in the upper anhydrite of the Castile. These brine reservoirs are highly pressurized and are capable of flowing to the ground surface (Popielak et al., 1983). Castile brine reservoirs provide the driving pressure in PA release scenarios.

The Dewey Lake Redbeds could be important for the purposes of evaluating WIPP compliance under disturbed scenarios including future wetter climates. According to these scenarios, the water table could rise into the more permeable upper portion of the Dewey Lake thereby generating a possible release pathway.

The Salado has generally been considered to be unimportant for evaluating compliance with 40 CFR 191, Subpart B and 40 CFR $\$ 268.6$, because its permeability, and hence flow potential, is extremely low. While Salado pressures are theoretically high enough to drive brine to the Culebra (Beauheim et al., 1993a), the amount of brine and dissolved 
radionuclides that could reach the Culebra is generally much less than that produced by breaches involving Castile brine reservoirs.

The PA is looking at a number of conditions involving the geohydrological characteristics of rock units other than the Culebra and their consequences.

\section{STATUS: Resolved}

B. ISSUE: Reconciling present-day distribution of solutes with Culebra flow direction The current distribution of solutes in the Culebra appears to be inconsistent with the presentday north-to-south flow direction in the Culebra and the assumption that the Culebra is completely confined (Ramey, 1985; Chapman, 1988). The concentration of total dissolved solids in the Culebra decreases in the direction of flow.

\section{RESOLUTION:}

Several hypotheses have been advanced to explain this apparent inconsistency. However, these hypotheses have not yet been reconciled with an ongoing modeling study of groundwater flow. A set of simulations will be performed to test the proposed hypotheses. The effects of the simulation results on the Culebra groundwater chemistry will be evaluated.

\section{STATUS: Open}

\section{ISSUE: Rustler Formation Recharge}

Recharge areas and rates have never been conclusively identified for the Rustler Formation (Chapman, 1986, 1988), raising questions about how Rustler flow systems have changed since the last glacial period and about simulations over the next 10,000 years.

\section{RESOLUTION:}

Recharge areas and rates remain unidentified. The interpretation of Siegel et al. (1991) and Lambert (1992) is that there has been no vertical recharge to the Culebra at the WIPP site since the last pluvial period of 10,000-20,000 years ago. This interpretation is inconsistent with current hydrogeological thinking and basin-scale modeling (Corbet and Wallace, 1993). Leakage (or influx) to the Culebra from the Tamarisk and/or unnamed lower member seems to occur at all times. The time during which that influx fell on the land surface as precipitation is undefined. Outcrops of the Culebra in southern Nash Draw and outcrops of the Rustler Formation north of the site in Clayton Basin and Bear Grass Draw represent 
potential recharge areas, although recharge in that area would not reach the WIPP site given current flow directions.

\section{STATUS: Open}

\section{ISSUE: Model for the Culebra Flow and Transport}

PA currently uses a double-porosity continuum model to simulate radionuclide transport through the Culebra. Alternative models, such as channeling models, have been proposed as possible replacements for the current model. At issue is the question of whether or not an alternative model, consistent with all tracer test data, would imply significantly different radionuclide releases to the accessible environment than the current model.

\section{RESOLUTION:}

A number of alternative models are being investigated to assess their consequences with respect to off-site transport. In addition, non-sorbing tracer tests are planned to provide defensible transport parameters and to test the conceptual model (Beauheim and Davies, 1992).

\section{STATUS: Open}

\section{E. ISSUE: Transmissivity Variation in the Culebra Dolomite}

The transmissivity of the Culebra dolomite has been found to vary over six orders of magnitude in the vicinity of the WIPP site (Mercer, 1983). Given this wide variation, calculations of radionuclide transport through the Culebra will depend heavily on assumptions made about transmissivities along the transport path. Approximately 42 measurements of Culebra transmissivity have been made over a $250-\mathrm{mi}^{2}$ region around the WIPP site (Cauffman et al., 1990). Considering the sparsity of data, quantifying the uncertainty of models that must interpolate values of transmissivity between measurement points is important.

\section{RESOLUTION:}

Numerous geostatistical approaches to defining the Culebra transmissivity field are being pursued through the PA Geostatistical Expert Group, INTRAVAL, and PA (LaVenue and RamaRao, 1992). The different approaches are being used to generate multiple transmissivity fields that are consistent not only with the measured transmissivities, but also with transient fluctuations in water levels observed over wide regions during hydraulic tests 
at the WIPP site. By comparing simulations of solute transport made using all the different transmissivity fields, the uncertainty associated with Culebra transport calculations will, to some extent, be quantified.

\section{STATUS: Open}

\section{F. ISSUE: Brine Content of Salado Evaporites}

Early NAS studies of potential host rocks for radioactive-waste repositories concluded halite to be a suitable host rock because it was "dry." However, observations within the first WIPP excavations showed that the Salado Formation was not dry, but that brine seeped out of anhydrite and clay layers and out of some halite layers. If the Salado is not dry, then the volume of brine that might flow into the repository becomes important. The quantity of brine in the repository affects how much metal might be corroded to produce gas, and might also affect the rate and degree of reconsolidation of the backfill in the repository and shafts. At issue, then, is the mechanism causing brine to flow into the repository and quantitative estimates of the parameters involved in that mechanism.

\section{RESOLUTION:}

Numerous experimental programs were started to understand Salado hydrology. Small-scale brine-inflow experiments examined the rates and volumes of accumulation of brine in open boreholes. These experiments were interpreted by McTigue (1993) as being consistent with a Darcy-flow mechanism (flow driven by a pressure gradient through interconnected porosity). McTigue inferred halite permeabilities to be between $10^{-22}$ and $10^{-21} \mathrm{~m}^{2}$.

Beauheim et al. $(1991,1993 a)$ reported on permeability tests performed over different intervals within the Salado. They found intact halite permeabilities at less than $10^{-23} \mathrm{~m}^{2}$ and anhydrite permeabilities typically less than $10^{-20} \mathrm{~m}^{2}$. A large-scale brine-inflow experiment, Room Q (Nowak, 1990), examined inflow to a room-sized excavation.

Two areas of uncertainty remain with respect to inflow into the WIPP repository. First, pore pressures in the rock are being affected not only by flow to the excavations but also by the release of solid stress on the rock caused by the creation of the excavations. This stress relief tends to decrease the driving pressure gradient for brine flow to the excavations, but may also increase the permeability and porosity of the rock. Coupling between hydrological and geomechanical models may be needed to gain a better understanding of the interrelationships between these processes. Second, storage properties (e.g., volume of brine produced per unit drop in pressure) of inelastic media, such as halite, are poorly understood. 
Long-term simulations of brine production based on properties of elastic media might be incorrect for the Salado. Coupled hydrological-geomechanical modeling will help to resolve this uncertainty.

\section{STATUS: Open}

\section{G. ISSUE: Effects of Gas Generation}

After the WIPP facility is filled with waste and closed, corrosion of metals and microbial degradation of cellulosics will generate some quantities of gas. Depending on the amount of gas generated, the effects of increasing gas pressure on repository performance are uncertain. The gas may be able to displace brine within halite and/or anhydrite beds and flow away from the repository, or the halite and/or anhydrite beds may have such high gas threshold pressures that gas cannot displace brine at pressures below the fracturing pressure of the rock. If the latter scenario occurs, consideration must be given to the effects of high gas pressures on the integrity of the panel and shaft seals in the repository. If threshold pressures are low, the permeability of the halite and/or anhydrite beds may be sufficient to allow gas to flow away as rapidly as it is generated. If not, fracturing pressures may still be reached. If the existing permeability is too low to release all the gas being generated, preexisting fractures in anhydrite interbeds may dilate as the pressure increases, providing adequate permeability and storage volume for the gas short of the fracturing (failure) pressure of the rock.

\section{RESOLUTION:}

Permeabilities of Salado anhydrite and halite have been measured and reported by Beauheim et al. (1991, 1993a). PA (SNL, 1992, Volume 5) uses these data along with a correlation presented by Davies (1991) between permeability and threshold pressure to simulate the effects of gas generation in the repository. This correlation suggests that gas will be able to enter anhydrite interbeds but not halite. Experimental field and laboratory programs (Saulnier, 1992; Howarth, 1994) are underway to test Davies' correlation for anhydrite. Another experimental program is underway to evaluate the hydraulic fracturing pressure of anhydrite interbeds (Wawersik and Beauheim, 1991; Beauheim et al., 1993b).

The most recently reported PA calculations (SNL, 1992, Volume 5) did not consider possible pressure-dependence of anhydrite permeability and porosity. Ongoing PA modeling uses an exponential relationship between fracture porosity and fluid pressure, and a power-law relationship between porosity and permeability to evaluate the effects of gas generation on 
repository performance. Other modeling has been performed to show that the functional forms of these relationships affect the calculated results. Experimental lab and field programs are underway to provide data to define and support correct relationships among fluid pressure, porosity, and permeability.

\section{STATUS: Open}

\section{H. ISSUE: Effects of Groundwater Below the Salado ard Castile Formations}

The evaporite section that includes the Salado and Castile Formations is underlain by waterbearing sedimentary rocks, the DMG. The potential for water in the DMG to dissolve the overlying evaporites and threaten the integrity of the WIPP repository requires consideration.

\section{RESOLUTION:}

Wood et al. (1982) performed a modeling study of this issue. They considered permeabilities, porosities, and hydraulic gradients in the DMG along with the degree of halite and anhydrite saturation of the DMG brines. They concluded that less than a 3.9-in $(10-\mathrm{cm})$ thickness of halite could be dissolved over a 10,000-yr period and, therefore, it is a reasonable expectation that dissolution by DMG waters do not constitute a threat to the WIPP repository over the 10,000 -yr regulatory period of interest.

\section{STATUS: Resolved}

\subsubsection{Performance Assessment (PA)}

\section{A. ISSUE: CCDF Confidence Bounds}

Appropriate confidence bounds are to be developed around the mean Complementary Cumulative Distribution Function (CCDF).

\section{RESOLUTION:}

Beginning in 1990, PA has used a methodology that allows for construction of a family of CCDFs from which both a mean CCDF and selected percentile CCDFs can be derived. This methodology is first discussed in detail in Bertram-Howery et al (1990), and is further discussed in Volumes 1 and 2 of the 1991 PA report (SNL, 1991) and Volume 2 of the 1992 PA report (SNL, 1992). References for additional publications can be found in Volume 2 of the 1992 PA report. Note that all CCDFs presented in the PA reports do not address the confidence associated with the models or data assumptions used in the analyses. The use of 
the mean CCDF as the single representation of predicted repository performance is the appropriate way to demonstrate the reasonable expectation. This topic is expected to be dealt with in 40 CFR 194 and will remain open until that time.

\section{STATUS: Open}

\section{B. ISSUE: Scenarios}

A determination is to be made on how best to construct scenarios from the events and processes that remain following the screening process.

\section{RESOLUTION:}

Since 1988, WIPP PA has used a "logic diagram" procedure to construct all possible combinations of events. This procedure differs from the "event tree" approach used in reactor safety assessments and in earlier PAs in that order of occurrence is not considered, and a smaller number of scenarios can be considered while maintaining comprehensiveness. Documentation of this technique is available in Bertram-Howery et al. (1990), in Volume 1 of the 1991 PA report, in Guzowski (1990), and in Cranwell et al. (1990).

The application of the methodology is an ongoing process, and each cycle of publication and review of PA iterations has identified the need for additional work in documenting and justifying the identification and screening of events and processes and construction of scenarios for analysis. The DOE believes that the logic diagram approach is both reasonable and appropriate for this purpose.

\section{STATUS: Resolved}

\section{ISSUE: Complexity and Realism of PA Models}

Development and implementation of more complex modeling of total system performance is important to provide more useful sensitivity analyses.

\section{RESOLUTION:}

Beginning with the 1990 PA, the one-dimensional network code NEFTRAN was replaced with two-dimensional modeling of flow and transport using the BOAST, BRAGFLO, SUTRA, STAFF, and SWIFT codes. By the 1991 PA, the SECO flow code was available, and BRAGFLO and SECO were identified as the most suitable codes for WIPP PA modeling of flow and transport in the repository and Culebra, respectively. The CUTTINGS code was 
added in 1990 to provide the capability for modeling direct releases at the ground surface during drilling. The GRASP-INV and SECO-TRANSPORT codes were added in 1992. Documentation of these modeling changes can be found in the 1990, 1991, and 1992 PA reports.

Formal system-level sensitivity analyses (stepwise linear regression analyses, partial correlation coefficient analyses, and scatterplot interpretations) have been performed since the 1990 PA. Documentation of sensitivity analyses was published in 1990, 1991, and 1992 (Rechard et al., 1990; Helton et al. 1991; Helton et al., 1992; and SNL, 1992, Volumes 4 and 5).

The sensitivity analysis techniques currently in use are an important part of each PA, and total system-level sensitivity analyses will continue to be performed with each future iteration of PA to provide guidance to the Project.

\section{STATUS: Resolved}

\section{ISSUE: Uncertainty in Radionuclide Solubility and Retardation}

Characterization of uncertainty in radionuclide solubility and retardation is needed both to help design experimental programs and to give preliminary estimates of compliance relative to long-term regulations.

\section{RESOLUTION:}

Expert panels were convened to address these two topics in 1990. Data elicited from these panels were used in the 1991 and 1992 PA reports, and the subsequent sensitivity analyses using the uncertainties suggested by expert panels provided useful guidance to the design of column experiments, nonsorbing tracer tests, and the actinide source term program to gather site-specific experimental data. Documentation of the panel elicitations is available in Trauth et al. (1992). Relevant sensitivity analyses are described in Helton et al. $(1991,1992)$. Transmittal of specific guidance to the experimental programs is documented in Appendix D of Volume 4 of the 1992 PA report.

Uncertainty in actinide concentrations and retardations used in PA will be reduced by replacing expert judgement values with experimental data when they become available.

\section{STATUS: Open}




\section{E. ISSUE: Human Intrusion}

A means for estimating the probability of human intrusion and quantifying the effectiveness of potential passive marker systems, other than by ad hoc estimates of fixed probabilities would be useful.

\section{RESOLUTION:}

Beginning in the 1990 PA, a Poisson model for intrusion probability (intrusions are random in time, with a maximum expected valuc equal to the EPA guidance of $30 / \mathrm{km}^{2} / 10,000 \mathrm{yr}$ ) was substituted for previous ad hoc estimates of probability. Expert panels were convened to consider future societies and the degree to which passive markers would be effective in communicating with them. Results of the expert judgment were used in the 1992 PA. Documentation of the Poisson model is available in Volume 2 of the 1991 and 1992 PA reports, and in references provided therein. Documentation of the expert judgment elicitation is provided in Hora et al. (1991) and Trauth et al. (1993). The algorithm for deriving drilling rates from the expert judgment is described in a memorandum by Hora in Appendix A of Volume 3 of the 1992 PA report. This topic is expected to be dealt with in 40 CFR 194 and may be reopened at that time.

\section{STATUS: Resolved}

\section{F. ISSUE: Climate Change}

The effects of reasonably expected climate changes should be included in the PA.

\section{RESOLUTION:}

A study of long-term climatic variability at the WIPP was undertaken in 1989, and potential hydrologic changes due to climatic variability have been included in two-dimensional groundwater flow modeling since 1991. Documentation of the study of long-term climate variability is available in Swift (1992). Implementation of the effects of climate variability in two-dimensional groundwater flow modeling is described in Volume 2 of the 1991 PA report and Volume 4 of the 1992 PA report. The effects of climate change are currently being investigated as part of a regional three-dimensional flow modeling study.

\section{STATUS: Open}

\section{G. ISSUE: Two-Phase Flow and Gas Generation}

The effects of gas generation and two-phase flow should be included in PA modeling. 


\section{RESOLUTION:}

The capability to model two-phase flow in human intrusion scenarios was developed in the fall of 1990 and is based on the use of the BRAGFLO code. Gas-generation reactions and their dependency on reactant (i.e., brine, iron, and cellulosic waste) availability are included in the code. The use of BRAGFLO is first documented in Bertram-Howery et al. (1990). and subsequently described in Volume 2 of the 1991 and 1992 PA reports, as well as in Volumes 4 and 5 of the 1992 PA report.

\section{STATUS: Resolved}

\section{H. ISSUE: Transmissivity of the Culebra}

The treatment of spatial variability in the Culebra transmissivity field should be improved.

\section{RESOLUTION:}

Early PAs (1989 and 1990) used a zonal approach to characterizing spatial variability in transmissivity. Beginning in 1991, PA has sampled from multiple random calibrated transmissivity fields. The 1992 PA marked the first use of an automated pilot-point calibration technique using the GRASP-INV code. This technique is summarized in Volumes 2 and 4 of the 1992 PA report and is described in detail in LaVenue and RamaRao (1992).

A carefully controlled, user-blind test problem is in progress comparing the automated pilotpoint calibration technique to five other methods for generating random calibrated transmissivity fields.

\section{STATUS: Open}

\section{ISSUE: Displays of Uncertainty}

Displaying uncertainty in performance estimates resulting from alternative conceptual models for waste-form properties and radionuclide transport in the Culebra is considered useful.

\section{RESOLUTION:}

Beginning in 1990, PA examined conceptual model uncertainty by replicating Monte Carlo analyses in which vectors of input values were the same for each conceptual model except for the parameters used to describe the specific model change. This technique allows direct comparison of probabilistic outcomes from system-level models using alternative conceptual models for those cases in which the alternative conceptual models can be described by 
parameter variations within the existing computational models. For example, potential effects of waste-form modification were examined by repeating the Monte Carlo analyses using various fixed values for radionuclide solubility and waste-form porosity and hydraulic conductivity. Dual- and single-porosity transport models for the Culebra were compared by repeating dual-porosity simulations with matrix porosity set to zero. The first of these analyses is described by Bertram-Howery and Swift (1990). Later analyses are described in Bertram-Howery et al. (1990), in Helton et al. (1992), and in Volume 4 of the 1992 PA report.

\section{STATUS: Resolved}

\section{J. ISSUE: Coupling of Models}

The coupling of creep closure process with gas generation and two-phase flow is needed.

\section{RESOLUTION:}

The 1992 PA included the effects of creep closure for the first time. Computational complexity prevented a full coupling of the mechanistic creep models implemented in the finite-element code SANCHO with the two-phase flow code BRAGFLO. Instead, SANCHO output, in the form of waste/backfill porosity as a function of moles of gas generated, was used to define time- and pressure-dependent waste/backfill porosity in BRAGFLO calculations. Additional information may be found in Volume 4 of the 1992 PA report.

Given the relative insensitivity of system performance to the creep closure model indicated in the 1992 PA, coupling issues are planned to be examined in auxiliary calculations as needed.

\section{STATUS: Open}

\section{K. ISSUE: Fracture Modeling}

Evaluation of the effects of pressure-dependent fracturing of anhydrite interbeds in the Salado Formation as part of the PA is needed.

\section{RESOLUTION:}

Beginning in the fall of 1993, PA calculations have used an approximation of possible changes in fluid flow properties related to pressure-dependent fracturing in which porosity and permeability of the anhydrite interbeds are varied as a function of pressure at pressures 
close to lithostatic. Work is underway to evaluate the adequacy of this approximation and develop others and to justify the parameter distributions used.

\section{STATUS: Open}

\section{ISSUE: Confirmation of the Adequacy of Two-Dimensional Models}

Confirmation of the adequacy of two-dimensional modeling in the repository environment (BRAGFLO) and the Culebra (SECO) with three-dimensional modeling is needed.

\section{RESOLUTION:}

This issue has not been addressed in PA analyses to date. Preliminary three-dimensional versions of BRAGFLO and SECO-FLOW and TRANSPORT are now available, and 3-D SECO and TOUGH 2 analyses have begun. Three-dimensional BRAGFLO analyses have also begun. Upon completing these modeling exercises, the two-dimensional models will either be verified, or modifications will be made to the two-dimensional versions of BRAGFLO and SECO-FLOW and TRANSPORT based on observed deficiencies.

\section{STATUS: Open}

\section{ISSUE: Events/Process Screening}

Need to seexamine the event and process screening procedure used in scenario construction because the screening may be out of date or incomplete, and some cases have never been adequately analyzed.

\section{RESOLUTION:}

A detailed analysis of scenarios not previously considered has begun along with a reexamination of the basis for all event and process screening decisions. The documentation of past screening activities that resulted in the removal of some events and processes must be reviewed.

\section{STATUS: Open}




\subsection{REFERENCES}

Anderson, R.Y., 1978. Report to Sandia Laboratories on Deep Dissolution of Salt. Northern Delaware Basin. New Mexico, (Copy on file in the Nuclear Waste Management Library, Sandia National Laboratories, Albuquerque, NM).

Anderson, R.Y., 1979. Mechanism and Rates of Development of Regional and Localized Dissolution Features in and Below Evaporites, Santa Fe, NM, Environmental Evaluation Group, (Copy on file in the Nuclear Waste Management Library, Sandia National Laboratories, Albuquerque, NM).

Anderson, R.Y., 1981. "Deep-Seated Salt Dissolution in the Delaware Basin, Texas and New Mexico," Environmental Geology and Hydrology in New Mexico, Eds S.G. Wells, W. Lambert, and J.F. Callender, New Mexico Geological Society Special Publication No. 10, Roswell, NM, New Mexico Geological Society, pp. 133-145.

Anderson, R.Y., 1982. "Deformation-Dissolution Potential of Bedded Salt, Waste Isolation Pilot Plant Site, Delaware Basin, New Mexico," Scientific Basis for Nuclear Waste Management $V$. Proceedings of the Materials Research Society Fifth International Symposium on the Scientific Basis for Nuclear Waste Management. Berlin. Germany, June 7-10, 1982, Ed. W. Lutze, New York, NY, North-Holland, Vol. II, pp. 449-458.

Anderson, R.Y., 1987. Report to New Mexico Environmental Evaluation Group (EEG) on Evaluation of Drillhole DOE-2, (Copy on file in the Nuclear Waste Management Library, Sandia National Laboratories, Albuquerque, NM).

Bachman, G.O., 1974. Geologic Processes and Cenozoic History Related to Salt Dissolution in Southeastern New Mexico, Open-File Report 74-194, Denver, CO, U.S. Geological Survey.

Bachman, G.O., 1976. "Cenozoic Deposits of Southeastern New Mexico and an Outline of the History of Evaporite Dissolution," Journal of Research. US Geological Survey, Vol. 4, No. 2, pp. 135-149. 
Bachman, G.O., 1980. Regional Geology and Cenozoic History of Pecos Region, Southeastern New Mexico, Open-File Report 80-1099, Denver, CO, U.S. Geological Survey.

Bachman. G.O., 1985. Assessment of Near-Surface Dissolution at and Near the Waste Isolation Pilot Plant (WIPP), Southeastern New Mexico, SAND84-7178, Albuquerque, NM. Sandia National Laboratories.

Bachman, G.O., 1987. Karst in Evaporites in Southeastern New Mexico, SAND86-7078, Albuquerque, NM, Sandia National Laboratories.

Bachman, G.O., 1989. Annotated Bibliography of Paleoclimate Studies Relevant to the Waste Isolation Pilot Plant. Southeastern New Mexico, SAND89-7087, Albuquerque, NM, Sandia National Laboratories.

Bachman, G.O., and R.B. Johnson, 1973. Stability of Salt in the Permian Salt Basin of Kansas, Oklahoma. Texas, and New Mexico, With a section on Dissolved Salts in Surface Water, USGS-4339-4, Denver, CO, U.S. Geological Survey.

Balazs, E.I., 1978. Report on First-Order Leveling Survey for Sandia Laboratories Waste Isolation Pilot Plant (WIPP) Project, (Copy on file in the Nuclear Waste Management Library, Sandia National Laboratories, Albuquerque, NM), Rockville, MD, National Geodetic Survey.

Balazs, E. I., 1982. Vertical Movement in the Los Medanios and Nash Draw Areas, New Mexico. As Indicated by 1977 and 1981 Leveling Surveys, NOAA Technical Memorandum NOS NGS 37, Rockville, MD, National Geodetic Survey, (Copy on file in the Nuclear Waste Management Library, Sandia National Laboratories, Albuquerque, NM).

Barr, G.E., W.B. Miller, and D.D. Gonzalez, 1983. Interim Report on the Modeling of the Regional Hydraulics of the Rustler Formation. SAND83-0391. Albuquerque, NM: Sandia National Laboratories.

Barrows, L. J. and J.D. Fett, 1985. "A High-Precision Gravity Survey in the Delaware Basin of Southeastern New Mexico," Geophysics, Vol. 50, No. 5, pp. 825-833. 
Barrows, L. J., S-E. Shaffer, W.B. Miller, and J.D. Fett, 1983. Waste Isolation Pilot Plant (WIPP) Site Gravity Survey and Interpretation, SAND82-2922, Albuquerque, NM, Sandia National Laboratories.

Beauheim, R.L., 1986. Hydraulic-Test Interpretations for Well DOE-2 at the Waste Isolation Pilot Plant (WIPP) Site, SAND86-1364, Albuquerque, NM, Sandia National Laboratories.

Beauheim, R.L., 1987. Interpretations of Single-Well Hydraulic Tests Conducted At and Near the Waste Isolation Pilot Plant (WIPP) Site, 1983-1987, SAND87-0039, Albuquerque, NM, Sandia National Laboratories.

Beauheim, R.L., and R.M. Holt, 1990. "Hydrogeology of the WIPP Site." Geological and Hydrological Studies of Evaporites in the Northern Delaware Basin for the Waste Isolation Pilot Plant (WIPP), New Mexico, Field Trip \#14 Guidebook. Geological Society of America 1990 Annual Meeting. Dallas. TX. October 29-November 1, 1990, Dallas, TX, Dallas Geological Society, pp. 131-179.

Beauheim, R.L., B.W. Hassinger, and J.A. Klaiber, 1983. Basic Data Report for Borehole Cabin Baby-1 Deepening and Hydrologic Testing, WTSD-TME-020, Albuquerque, NM, U.S. DOE.

Beauheim, R.L., G.J. Saulnier, Jr., and J.D. Avis, 1991. Interpretation of Brine-Permeability Tests of the Salado Formation at the Waste Isolation Pilot Plant Site: First Interim Report, SAND90-0083, Albuqquerque, NM, Sandia National Laboratories.

Beauheim, R.L., and P.B. Davies, 1992. "Experimental Plan for Tracer Testing in the Culebra Dolomite at the WIPP Site," Revision A, Albuquerque, NM, Sandia National Laboratories.

Beauheim, R.L., R.M. Roberts, T.F. Dale, M.D. Fort, and W.A. Stensrud, 1993a. Hydraulic Testing of Salado Formation Evaporites at the Waste Isolation Pilot Plant Site: Second Interpretive Report, SAND92-0533, Albuquerque, NM: Sandia National Laboratories. 
Beauheim, R.L., W.R. Wawersik, and R.M. Roberts, 1993b. "Coupled Permeability and Hydrofracture Tests to Assess the Waste-Containment Properties of Fractured Anhydrite," International Journal of Rock Mechanics and Mining Sciences \& Geomechanics Abstracts. Vol. 30, No. 7, 1159-1163.

Berglund, J. W., 1992. Mechanisms Governing the Direct Removal of Wastes from the Waste Isolation Pilot plant Repository Caused by Exploratory Drilling, SAND92-7295, Albuquerque, NM, Sandia National Laboratories.

Bertram-Howery, S.G., M.G. Marietta, R.P. Rechard, P.N. Swift, D.R. Anderson, B.L. Baker, J.E. Bean, Jr., W. Beyeler, K.F. Brinster, R.V. Guzowski, J.C. Helton, R.D. McCurley, D.K. Rudeen, J.D. Schreiber, and P. Vaughn, 1990. Preliminary Comparison with 40 CFR Part 191. Subpart B for the Waste Isolation Pilot Plant. December 1990, SAND90-2347, Albuquerque, NM, Sandia National Laboratories.

Bertram-Howery, S.G., and P.N. Swift, 1990. Early-1990 Status of Performance Assessment for the Waste Isolation Pilot Plant. December 1990, SAND90-2095, Albuquerque, NM, Sandia National Laboratories.

Berry, H.A., 1989. An Aerial Radiological Survey of the Waste Isolation Pilot Plant and Surrounding Area, Carlsbad, New Mexico, EGG-10617-1189, Las Vegas, NV, EG\&G

Energy Measurements, Inc, (Copy on file in the Nuclear Waste Management Library, Sandia National Laboratories, Albuquerque, NM).

Biffle, J.H., 1793. JAC-3D - A Three-Dimensional Finite Element Computer Program for the Nonlinear Quasistatic Response of Solids with the Conjugate Gradient Method, SAND871305, Albuquerque, NM, Sandia National Laboratories.

Black, S.R., 1982. Basic Data Report Borehole WIPP-12 Deepening Waste Isolation Pilot Plant (WIPP) Project Southeastern New Mexico, TME 3148, Albuquerque, NM, D'Appolonia Consulting Engineers, Inc, (Copy on file in the Nuclear Waste Management Library, Sandia National Laboratories, Albuquerque, NM).

Black, S.R., R.L. Beauheim, and J.K. Register, 1984. "Hydrogeology of a Brine Occurrence in Bedded Evaporites, Delaware Basin, New Mexico," Abstracts with Programs, Geological Society of America, Vol. 16, No. 6, p. 446. 
Bodine, M.W., Jr., 1978. "Clay-Mineral Assemblages from Drill Core of Ochoan Evaporites, Eddy County, New Mexico," Geology and Mineral Deposits of Ochoan Rocks in Delaware Basin and Adjacent Areas, Carlsbad, NM, May 4, 1977, Ed. G.S. Austin, New Mexico Bureau of Mines and Mineral Resources Circular 159, Socorro, NM, New Mexico Bureau of Mines and Mineral Resources, pp. 21-30.

Borns, D.J., L.J. Barrows, D.W. Powers, and R.P. Snyder, 1983. Deformation of Evaporites Near the Waste Isolation Pilot Plant (WIPP) Site, SAND82-1069, Albuquerque, NM, Sandia National Laboratories.

Brokaw, A.L., C.L. Jones, M.E. Cooley, and W.H. Hays, 1972. Geology and Hydrology of the Carlsbad Potash Area. Eddy and Lea Counties, New Mexico, USGS-4339-1, Denver, CO, U.S. Geological Survey.

Buck, A.D., J.E. Rhoderick, J.P. Burkes, K. Mather, R.E. Reinhold, and J.A. Boa, Jr., 1983. Modification of Bell Canyon Test (BCT) 1-FF Grout, SAND83-7097, Albuquerque, NM, Sandia National Laboratories.

Butcher, B.M., and F.T. Mendenhall, 1993. A Summary of the Models Used for the Mechanical Response of Disposal Rooms in the Waste Isolation Pilot Plant with Regard to Compliance with 40 CFR 191. Subpart B, SAND92-0427, Albuquerque, NM, Sandia National Laboratories.

Callahan, G.E., A.F. Fossum, and D.K. Svalstad, 1989. Documentation of SPECTROM32: A Finite Element Thermomechanical Stress Analysis Program, DOE/CH/10378-2, Rapid City, SD, RE/SEPC Inc., Vols. 1-2.

Calzia, J.P., and W.L. Hiss, 1978. "Igneous Rocks in Northern Delaware Basin, New Mexico and Texas," Geology and Mineral Deposits of Ochoan Rocks in Delaware Basin and Adjacent Areas. A Symposium on Ochoan Rocks of Southeast New Mexico and West Texas, Carlsbad. NM, May 4, 1977, Ed. G.S. Austin, New Mexico Bureau of Mines and Mineral Resources Circular 159, Socorro, NM, New Mexico Bureau of Mines and Mineral Resources, pp. 39-45. 
Cauffman, T.L., A.M. LaVenue, and J.P. McCord, 1990. Ground-Water Flow Modeling of the Culebra Dolomite, Volume II: Data Base, SAND89-7068/2, Albuquerque, NM, Sandia National Laboratories.

Chan, K.S., S.R. Bodner, A.F. Fossum, and D.E. Munson, 1992. "A Constitutive Model for Inelastic Flow and Damage Evolution in Solids under Triaxial Compression," Mechanics of Materials, SAND92-0546J, Vol. 14, No. 1, pp. 1-14.

Chapman, J.B., 1986. Stable Isotopes in Southeastern New Mexico Groundwater. Implications for Dating Recharge in the WIPP Area, EEG-35, Santa Fe, NM, Environmental Evaluation Group.

Chapman, J.B., 1988. Chemical and Radiochemical Characteristics of Groundwater in the Culebra Dolomite, Southeastern New Mexico, EEG-39, Santa Fe, NM, Environmental Evaluation Group.

Chaturvedi, L., and J.K. Channell, 1985. The Rustler Formation as a Transport Medium for Contaminated Groundwater, EEG-32, Santa Fe, NM, Environmental Evaluation Group.

Christensen, C.L., and T.O. Hunter, 1981. "The Bell Canyon Test and Results," Scientific Basis for Nuclear Waste Management. Proceedings of the Third International Symposium, Boston. MA, November 17-20, 1980, Ed. J.G. Moore, New York, NY, Plenum Press, Vol. 3, pp. 561-568.

Christensen, C.L., and E.W. Peterson, 1981. The Bell Canyon Test Summary Report, SAND80-1375, Albuquerque, NM, Sandia National Laboratories.

Christensen, C.L., C.W. Cook, and C.W. Gulick, 1980. Borehole Plugging Program Status Report, October 1, 1978-September 30,1979, SAND79-2141, Albuquerque, NM, Sandia National Laboratories.

Corbet, T.F., and M.G. Wallace, 1993. "Post-Pleistocene Patterns of Shallow Groundwater Flow in the Delaware Basin, Southeastern New Mexico and West Texas," New Mexico Geological Society Guidebook, 44th Field Conference, Carlsbad Region. New Mexico and West Texas: SAND93-1318J, pp. 321-325. 
Cranwell, R.M., R.V. Guzowski, J.E. Campbell, and N.R. Ortiz, 1990. Risk Methodology for Geologic Disposal of Radioactive Waste, Scenario Selection Procedure, NUREG/CR1667, SAND80-1429, Albuquerque, NM, Sandia National Laboratories.

Davies, P.B., 1991. Evaluation of the Role of Threshold Pressure in Controlling Flow of Waste-Generated Gas into Bedded Salt at the Waste Isolation Pilot Plant, SAND90-3246, Albuquerque, NM, Sandia National Laboratories.

Earth Technology Corporation, 1988. Final Report for Time Domain Electromagnetic (TDEM) Surveys at the WIPP Site, SAND87-7144, Albuquerque, NM, Sandia National Laboratories.

Ehgartner, B., 1991. A Coupled Mechanical/Hydrologic Model for WIPP Shaft Seals, SAND90-2826, Albuquerque, NM, Sandia National Laboratories.

Elliot, C.L., 1976a. A Laboratory Investigation of Magnetic Physical Properties of Igneous Dike Samples from Kerr-McGee Hobbs Plant, Section 31, T20S, R32E and Surface Outcrop. Section 31. T26S, R25E, Tucson, AZ, Elliot Geophysical Company (Copy on file in the Nuclear Waste Management Library, Sandia National Laboratories, Albuquerque, NM).

Elliot, C.L., 1976b. A Preliminary Geophysical Study of a Trachyte Dike in Close Proximity to the Proposed Los Medaños Nuclear Waste Disposal Site, Eddy and Lea Counties. New Mexico, Tucson, AZ, Elliot Geophysical Compan (Copy on file in the Nuclear Waste Management Library, Sandia National Laboratories, Albuquerque, NM).

Elliot, C.L., 1977a. Maps to Accompany Evaluation of the Proposed Los Medaños Nuclear Waste Disposal Site by Means of Electrical Resistivity Surveys, Eddy \& Lea Counties, New Mexico, Tucson, AZ, Elliot Geophysical Company (Copy on file in the Nuclear Waste Management Library, Sandia National Laboratories, Albuquerque, NM).

Elliot, C.L., 1977b. An Experimental Detailed Resistivity Survey of Hills C and D. Eddy County, New Mexico, Tucson, AZ, Elliot Geophysical Company.

Elliot, C.L., 1977c. An Experimental Detailed Resistivity Survey of Suspected Breccia Pipes, Eddy County, New Mexico, An Addendum Report, Tucson, AZ, Elliot Geophysical Company. 
Elliot, C.L., 1977d. Experimental Resistivity Surroundings Near a Known Breccia Pipe. Weaver Area, Eddy County, New Mexico, An Addendum Report, Tucson, AZ, Elliot Geophysical Company (Copy on file in the Nuclear Waste Management Library, Sandia National Laboratories, Albuquerque, NM).

Elliot, C.L., 1977e. Resistivity and Gravity Survey Data, 1976 and 1977, Los Medaños Site Area and Experimental Surveys of the Surrounding Areas, Eddy and Lea Counties, New Mexico, Volume 1, Tucson, AZ, Elliot Geophysical Company (Copy on file in the Nuclear Waste Management Library, Sandia National Laboratories, Albuquerque, NM).

Elliot, C.L., 1979a. A Detailed Resistivity Survey of a Suspected Breccia Pipe Anomaly in Section 17, T22S, R31E, Eddy County, New Mexico, Tucson, AZ, Elliot Geophysical Company (Copy on file in the Nuclear Waste Management Library, Sandia National Laboratories, Albuquerque, NM).

Elliot, C.L., 1979b. Evaluation of Schlumberger Resistivity Soundings in and Associated with Nash Draw, T21S, T22S, R30E, R31E, Eddy County, New Mexico, Tucson, AZ, Elliot Geophysical Company, (Copy on file in the Nuclear Waste Management Library, Sandia National Laboratories, Albuquerque, NM).

Elliot, C.L., 1979c. Resistivity Survey Data 1978 Los Medaños Site Area Eddy County, New Mexico, Tucson, AZ, Elliot Geophysical Company (Copy on file in the Nuclear Waste Management Library, Sandia National Laboratories, Albuquerque, NM).

Elliot Geophysical Company, 1976a. An Experimental Detailed Gravity Survey of Known or Suspected Breccia Pipes at Weaver Hill, Hill A\&B, and Hills C\&D, Eddy County, New Mexico, Tucson, AZ, Elliot Geophysical Company (Copy on file in the Nuclear Waste Management Library, Sandia National Laboratories, Albuquerque, NM).

Elliot Geophysical Company, 1976b. An Experimental Detailed Resistivity Survey of Known or Suspected Breccia Pipes, Eddy County. New Mexico, Tucson, AZ, Elliot Geophysical Company (Copy on file in the Nuclear Waste Management Library, Sandia National Laboratories, Albuquerque, NM).

Elliot Geophysical Company, 1977. Evaluation of the Proposed Los Medanos Nuclear Waste Disposal Site by Means of Electrical Resistivity Surveys, Eddy \& Lea Counties, New 
Mexico, Tucson, AZ, Elliot Geophysical Company (Copy on file in the Nuclear Waste Management Library, Sandia National Laboratories, Albuquerque, NM)

Fischer, N.T., 1986. "Statistical Considerations in the Design of a Baseline Radiological Surveillance Program at the Waste Isolation Pilot Plant," Waste Management '86. Waste Isolation in the U.S. Technical Programs and Public Education, Tucson, AZ, March 2-6. 1986, Ed. R.G. Post, Tucson, AZ, University of Arizona, Vol. 2, pp. 225-230.

Foster, R.W., 1974. Oil and Gas Potential of a Proposed Site for the Disposal of HighLevel Radioactive Waste, ORNL/SUB-4423/1, New Mexico Bureau of Mines and Mineral Resources, Socorro, NM, New Mexico Institute of Mining and Technology.

Griswold, G.B., 1977. Sites Selection and Evaluation Studies of the Waste Isolation Pilot Plant (WIPP), Los Medaños, Eddy County, NM, SAND77-0946, Albuquerque, NM, Sandia National Laboratories.

Griswold, G.B., and V.C. McWhirter, 1981. Interpretation of Wireline Geophysical Logs ERDA No. 9 Stratigraphic Test Borehole DOE WIPP Site, Eddy County, New Mexico, SAND80-7119, Albuquerque, NM, Sandia National Laboratories.

Guzowski, R.V., 1990. Preliminary Identification of Scenarios That May Affect the Escape and Transport of Radionuclides From the Waste Isolation Pilot Plant, Southeastern New Mexico, SAND89-7149, Albuquerque, NM, Sandia National Laboratories.

Hayes, P.T., and G.O. Bachman, 1979. Examination and Reevaluation of Evidence for the Barrera Fault, Guadalupe Mountains. New Mexico, Open-File Report 79-1520, Denver, CO, U.S. Geological Survey.

Helton, J.C., J.W. Garner, R.D. McCurley, and D.K. Rudeen, 1991. Sensitivity Analysis Techniques and Results for Performance Assessment at the Waste Isolation Pilot Plant, SAND90-7103, Albuquerque, NM, Sandia National Laboratories.

Helton, J.C., J.W. Garner, R.P. Rechard, D.K. Rudeen, and P.N. Swift, 1992. Preliminary Comparison with 40 CFR Part 191. Subpart B for the Waste Isolation Pilot Plant, December 1991-Volume 4. Uncertainty and Sensitivity Analysis Results, SAND91-0893/4, Albuquerque, NM, Sandia National Laboratories. 
Hern, J.L., D.W. Powers, and L.J. Barrows, 1979. Seismic Reflection Data Report Waste Isolation Pilot Plant (WIPP) Site, Southeastern New Mexico, SAND79-0264. Albuquerque, NM, Sandia National Laboratories, Vol. 1-2.

Holt, R.M., and D.W. Powers, 1988. Facies Variability and Post-Depositional Alteration Within the Rustler Formation in the Vicinity of the Waste Isolation Pilot Plant, Southeastern New Mexico, DOE/WIPP 88-004, Carlsbad, NM, U.S. DOE.

Hora, S.C., D. von Winterfeldt, and K.M. Trauth, 1991. Expert Judgment on Inadvertent Human Intrusion into the Waste Isolation Pilot Plant, SAND90-3063, Albuquerque, NM, Sandia National Laboratories.

Howarth, S.M., 1994. "Test Plan: Two-Phase Flow Laboratory Program for the Waste Isolation Pilot Plant (WIPP)," Albuquerque, NM, Sandia National Laboratories.

Jarolimek, L., M.J. Timmer, and R.F. McKinney, 1983. Geotechnical Activities in the Exploratory Shaft -- Selection of the Facility Interval, Waste Isolation Pilot Plant (WIPP) Project Southeastern New Mexico, TME 3178, Albuquerque, NM, U.S. DOE.

John, C.B., R.J. Cheeseman, J.C. Lorenz, and M.L. Millgate, 1978. Potash Ore Reserves in The Proposed Waste Isolation Pilot Plant Area. Eddy County, Southeastern New Mexico, Open-File Report 78-828, Denver, CO, U.S. Geological Survey.

Jones, C.L., 1978. Test Drilling for Potash Resources, Waste Isolation Pilot Plant Site, Eddy county, New Mexico, Open-File Report 78-592, Denver, CO, U.S. Geological Survey.

Jones, C.L., M.E. Cooley, and G.C. Bachman, 1973. Salt Deposits of Los Medaños Area, Eddy and Lea Counties, New Mexico, USGS-4339-7, Denver, CO, U.S. Geological Survey.

Keller, G.R., A.M. Rogers, R.J. Lund, and C.D. Orr, 1981. A Seismicity and Seismotectonic Study of the Kermit Seismic Zone. Texas, Open-File Report 81-37, Denver, CO, U.S. Geological Survey.

Kelley, V.C., 1971. Geology of the Pecos County, Southeastern New Mexico, Socorro, NM, New Mexico Bureau of Mines and Mineral Resources. 
Keesey, J.J., 1977. Hydrocarbon Evaluation, Waste Isolation Pilot Plant Site Area To State and Federal Royalty Interest. Eddy County, New Mexico, Midland, TX. Sipes, Williams, and Aycock. Inc. (Copy on file in the Nuclear Waste Management Library, Sandia National Laboratories, Albuquerque, NM).

Krieg, R.D., 1984. Reference Stratigraphy and Rock Properties for the Waste Isolation Pilot Plant (WIPP) Project, SAND83-1908, Albuquerque, NM, Sandia National Laboratories.

Krieg, R.D., H.S. Morgan, and T.O. Hunter, 1980b. Second Benchmark Problem for WIPP Structural Computations, SAND80-1331, Albuquerque, NM, Sandia National Laboratories.

Lambert, S.J., 1983. Dissolution of Evaporites In and Around the Delaware Basin. Southeastern New Mexico and West Texas, SAND82-0461, Albuquerque, NM, Sandia National Laboratories.

Lambert, S.J., 1992. "Geochemistry of the Waste Isolation Pilot Plant (WIPP) Site, Southeastern New Mexico, U.S.A.," Applied Geochemistry, SAND91-0612, Vol. 7, No. 6, pp. 513-531.

Lappin, A.R., and R.L. Hunter, 1989. Systems Analysis, Long-Term Radionuclide Transport, and Dose Assessment, Waste Isolation Pilot Plant (WIPP), Southeastern New Mexico: March 1989, SAND89-0462, Albuquerque, NM, Sandia National Laboratories.

LaVenue, A.M., and B.S. Rama Rao, 1992. A Modeling Attempt to Address Spatial Variability within the Culebra Dolomite Transmissivity Field, SAND92-7306, Albuquerque, NM, Sandia National Laboratories.

Lin, M.S., and L.L. Van Sambeek, 1992. Waste Isolation Pilot Plant Alcove Gas Barrier Final Design Report, SAND92-7307, Albuquerque, NM, Sandia National Laboratories.

Mellegard, K.D., G.D. Callahan, and P.E. Senseny, 1992. Multiaxial Creep of Natural Rock Salt, SAND91-7C83, Albuquerque, NM, Sandia National Laboratories.

McTigue, D.F., 1993. Permeability and Hydraulic Diffusivity of Waste Isolation Pilot Plant Repository Salt Inferred from Small-Scale Brine Inflow Experiments, SAND92-1911, Albuquerque, NM, Sandia National Laboratories. 
Mercer, J.W., 1983. Geohydrology of the Proposed Waste Isolation Pilot Plant Site, Los Medaños Area, Southeastern New Mexico, Water-Resources Investigations Report 83-4016. Albuquerque, NM, U.S. Geological Survey.

Mercer, J.W., and B.R. Orr, 1979. Interim Data Report on the Geohydrology of the Proposed Waste Isolation Pilot Plant Site. Southeastern New Mexico, USGS WaterResources Investigation 79-98, Albuquerque, NM, U.S. Geological Survey.

Mercer, J.W., R.L. Beauheim, R.P. Snyder, and G.M. Fairer, 1987. Basic Data Report For Drilling and Hydrologic Testing of Drillhole DOE-2 at the Waste Isolation Pilot Plant (WIPP) Site, SAND86-061, Albuquerque, NM, Sandia National Laboratories.

Morgan, H.S., R.D. Krieg, and R.V. Matalucci, 1981. Comparative Analysis of Nine Structural Codes used in the Second Benchmark Problem, SAND81-1389, Albuquerque, NM, Sandia National Laboratories.

Morgan, H.S., C.M. Stone, and R.D. Krieg, 1985. "The Use of Field Data to Evaluate and Improve Drift Response Models for the Waste Isolation Pilot Plant (WIPP)," Research and Engineering Applications in Rock Masses. Proceedings of the US Symposium on Rock Mechanics, Rapid City, SD, June 26-28, 1985, Ed. E. Ashworth, SAND84-2126C, Boston, MA, A.A. Balkema, Vol. 2, pp. 769-776.

Morgan, H.S., C.M. Stone, and R.D. Krieg, 1986. An Evaluation of WIPP Structural Modeling Capabilities Based on Comparisons with South Drift Data, SAND85-0323, Albuquerque, NM, Sandia National Laboratories.

Muehlberger, W.R., R.C. Belcher, and L.K. Goetz, 1978. "Quaternary Faulting in TransPecos Texas," Geology, Vol. 6, No. 6, pp. 337-340.

Munson, D.E., and P.R. Dawson, 1979. Constitutive Model for the Low Temperature Creep of Salt (with Application to WIPP), SAND79-1853, Albuquerque, NM, Sandia National Labsratories.

Munson, D.E., and P.R. Dawson, 1982. A Transient Creep Model for Salt During Stress Loading and Unloading, SAND82-0962, Albuquerque, NM, Sandia National Laboratories. 
Munson, D.E., and H.S. Morgan, 1986. Methodology for Performing Parallel Design Calculations (Nuclear Waste Repository Application), SAND85-0324, Albuquerque, NM, Sandia National Laboratories.

Munson, D.E., and K.L. DeVries, 1991. "Development and Validation of a Predictive Technology for Creep Closure of Underground Rooms in Salt," Proceedings, 7th International Congress on Rock Mechanics. Aachen. Federal Republic of Germany September 16-20,1991, Ed. Wittke, SAND90-1147, Vol. 1, pp. 127-134.

Muinson, D.E., A.F. Fossum, and P.E. Senseny, 1989. Advances in Resolution of Discrepancies Between Predicted and Measured In-Situ WIPP Room Closures, SAND882948, Albuquerque, NM, Sandia National Laboratories.

Munson, D.E., J.R. Weatherby, and K.L. DeVries, 1993. "2-D and 3-D Calculations of Scaled In-Situ Tests using the M-D Model of Salt Creep, "Proceedings 34th U.S. Symposium on Rock Mechanics, Madison. WI. June 27-30, 1993, SAND92-2063C, Madison, WI, University of Wisconsin, pp. 507-510.

Nowak, E.J., J.R. Tillerson, and T.M. Torres, 1990. Initial Reference Seal System Design, Waste Isolation Pilot Plant, SAND90-0655, Albuquerque, NM, Sandia National Laboratories.

Popielak, R.S., R.L. Beauheim, S.R. Black, W.E. Coons, C.T. Ellingson, and R.L. Olsen, 1983. Brine Reservoirs in the Castile Formation. Waste Isolation Pilot Plant (WIPP) Project. Southeastern New Mexico, TME 3153, Albuquerque, NM, U.S. DOE.

Powers, D.W., S.J. Lambert, S.-E. Shaffer, L.R. Hill, and W.D. Weart, eds., 1978. Geological Characterization Report. Waste Isolation Pilot Plant (WIPP) Site, Southeastern New Mexico, SAND78-1596, Albuquerque, NM, Sandia Laborator, Vols. 1-2.

Ramey, D.S., 1985. Chemistry of Rustler Fluids, EEG-31, Santa Fe, NM, Environmental Evaluation Group.

Rechard, R.P., W. Beyeler, R.D. McCurley, D.K. Rudeen, J.E. Bean, and J.D. Schreiber, 1990. Parameter Sensitivity Studies of Selected Components of the Waste Isolation Pilot 
Plant Repository/Shaft System, SAND89-2030, Albuquerque, NM, Sandia National Lat.'- tories.

Register, J.K., 1981. Brine Pocket Occurrences In the Castile Formation, Southeastern New Mexico, TME 3080, Albuquerque, NM, U.S. DOE.

Reith, C.C., E.T. Louderbough, R.J. Eastmond, and A.L. Rodriguez, 1985. Ecological Monitoring Program at the Waste Isolation Pilot Plant, First Semiannual Report, WTSDTME-058, Carlsbad, NM, U.S. DOE.

Reith, C.C., K. Prince, T. Fischer, A.L. Rodriguez, D. Uhland, and D. Winstanley, 1986. Annual Site Environmental Monitoring Report for the Waste Isolation Pilot Plant, Calendar Year 1985, DOE-WIPP-86-002, Carlsbad, NM, Westinghouse Electric Corporation.

Sandia National Laboratories (SNL) and U.S. Geological Survey (USGS), 1979. Basic Data Report for Drillhole WIPP 13 (Waste Isolation Pilot Plant - WIPP), SAND79-0273, Albuquerque, NM, Sandia National Laboratories.

Sandia National Laboratories (SNL) and U.S. Geological Survey (USGS), 1980. Basic Data Report for Drillhole WIPP 32 (Waste Isolation Pilot Plant - WIPP), SAND80-1102, Albuquerque, NM, Sandia National Laboratories.

Sandia National Laboratories (SNL) and U.S. Geological Survey (USGS), 1983a. Basic Data Report for Drillhole ERDA 6 (Waste Isolation Pilot Plant - WIPP), SAND79-0267, Albuquerque, NM, Sandia National Laboratories.

Sandia National Laboratories (SNL) and U.S. Geological Survey (USGS), 1983b. Basic Data Report for Drillhole ERDA 9 (Waste Isolation Pilot Plant - WIPP), SAND79-0270, Albuquerque, NM, Sandia National Laboratories.

Sandia National Laboratories (SNL) and University of New Mexico, 1981. Basic Data Report for Drillhole WIPP 15 (Waste Isolation Pilot Plant - WIPP), SAND79-0274. Albuquerque, NM, Sandia National Laboratories. 
Sandia National Laboratories (SNL) 1991. Preliminary Comparison with 40 CFR Part 191. Subpart B for the Waste Isolation Pilot Plant. December 1991, SAND91-0893/1-2, Albuquerque, NM, Sandia National Laboratories.

Sandia National Laboratories (SNL), 1992. Preliminary Performance Assessment for the Waste Isolation Pilot Plant. December 1992, SAND92-0700/1-5, Albuquerque, NM, Sandia National Laboratories.

Sanford, A.R, S. Sandford, F. Caravella, L. Merritt, J. Sheldon, and R. Ward, 1978. $\underline{\text { A }}$ Report on Seismic Studies of the Los Medaños Area in Southeastern New Mexico, Socorro, NM, New Mexico Institute of Mining and Technology (Copy on file in the Nuclear Waste Management Library, Sandia National Laboratories, Albuquerque, NM).

Sanford, A.R., S. Sandford, T.C. Wallace, L.J. Barrows, J. Sheldon, R.M. Ward, S. Johansen, and L. Merritt, 1980. Seismicity in the area of the waste Isolation Pilot Plant (WIPP), SAND80-7096, Albuquerque, NM, Sandia National Laboratories.

Saulnier, G.J., Jr., 1992. "Test Plan, Gas-Threshold-Pressure Testing of the Salado Formation in the WIPP Underground Facility," Albuquerque, NM, Sandia National Laboratories.

Seedorff, W.A., Jr., 1978. Resource Study for the Waste Isolation Pilot Plant Site, Eddy County. New Mexico, San Carlos, CA, Agricultural and Industrial Minerals, Inc. (Copy on file in the Nuclear Waste Management Library, Sandia National Laboratories, Albuquerque, NM).

Siegel, M.D., S.J. Lambert, and K.L. Robinson, eds., 1991. Hydrogeochemical Studies of the Rustler Formation and Related Rocks in the Waste Isolation Pilot Plant Area, Southeastern New Mexico, SAND88-0196, Albuquerque, NM, Sandia National Laboratories.

Siemers, W.T., J.W. Hawley, C. Rautman, and G. Austin, 1978. Evaluation of the Mineral Potential (Excluding Hydrocarbons, Potash, and Water) of the Waste Isolation Pilot Plant Site, Eddy County, New Mexico, Open-file Report 87, Socorro, NM, New Mexico Bureau of Mines and Mineral Resources (Copy on file in the Nuclear Waste Management Library, Sandia National Laboratories, Albuquerque, NM). 
Sipes, Williamson \& Aycock, Inc., 1976. Hydrocarbon Evaluation, Proposed Southeastern New Mexico Radioactive Material Storage Site, Eddy County, New Mexico, SAND77-7033, Albuquerque, NM, Sandia National Laboratories, Vols. 1-2.

Sipes, Williamson \& Associates, Inc., 1979. Evaluation of Directional Drilling for Oil and Gas Reserves Underlying the Waste Isolation Pilot Plant Site Area, Eddy County, New Mexico, Houston, TX, Sipes, Williamson \& Associates, Inc. (Copy on file in the Nuclear Waste Management Library, Sandia National Laboratories, Albuquerque, NM).

Sipes, Williamson \& Associates, Inc., 1980. Estimation of Potential Hydrocarbon Reserves and Associated Costs and Income for Oil and Gas Reserves Underlying the Waste Isolation Pilot Plant Site Area, Eddy County, New Mexico, Midland, TX, Sipes, Williamson \& Associates, Inc. (Copy on file in the Nuclear Waste Management Library, Sandia National Laboratories, Albuquerque, NM).

Snyder, R.P., 1985. Dissolution of Halite and Gypsum, and Hydration of Anhydrite to Gypsum, Rustler Formation, in the Vicinity of the Waste Isolation Pilot Plant, Southeastern New Mexico, USGS-OFR-85-229, Denver, CO, U.S. Geological Survey.

Snyder, R.P., and L.M. Gard, Jr., 1982. Evaluation of Breccia Pipes In Southeastern New Mexico and Their Relation to the Waste Isolation Pilot Plant (WIPP) Site. With Section on Drill-Stem Tests, Open-File Report 82-968, Denver, CO, U.S. Geological Survey.

Stormont, J.C., 1988. Preliminary Seal Design Evaluation for the Waste Isolation Pilot Plant, SAND87-3083, Albuquerque, NM, Sandia National Laboratories.

Stormont, J.C., and J.G. Arguello, 1988. Model Calculations of Flow Through Shaft Seals in the Rustler Formation, SAND87-2859, Albuquerque, NM, Sandia National Laboratories.

Swift, P.N., 1992. Long-Term Climate Variability at the Waste Isolation Pilot Plant. Southeastern New Mexico, USA, SAND91-7055, Albuquerque, NM, Sandia National Laboratories.

Thorne, B.J, and D.K. Rudeen, 1980. Regional Effects of TRU Repository Heat, SAND807161, Albuquerque, NM, Sandia National Laboratories. 
Torres, T.M., 1988. Design Evaluation, Structural Calculations for the Construction and Salt Handling Shaft and the Waste Handling Shaft at the Waste Isolation Pilot Plant (WIPP), SAND87-2230, Albuquerque, NM, Sandia National Laboratories.

Trauth, K.M., S.C. Hora, R.P. Rechard, and D.R. Anderson, 1992. The Use of Expert Judgment to Quantify Uncertainty in Solubility and Sorption Parameters for Waste Isolation Pilot Plant Performance Assessment, SAND92-0479, Albuquerque, NM, Sandia National Laboratories.

Trauth, K.M., S.C. Hora, and R.P. Rechard, 1993. Expert Judgment as Input to Waste Isolation Pilot Plant Performance-Assessment Calculations. Probability Distributions of Significant System Parameters, SAND91-0625, Albuquerque, NM, Sandia National Laboratories.

U.S. Department of Energy (DOE), 1980. Final Environmental Impact Statement, Waste Isolation Pilot Plant, DOE/EIS-0026, Washington, D.C., U.S. DOE, Vols. 1-2.

U.S. Department of Energy (DOE), 1983. Summary of the Results of the Evaluation of the WIPP Site and Preliminary Design Validation Program, WIPP-DOE-161, Albuquerque, NM, U.S. DOE.

U.S. Department of Energy (DOE), 1990. Final Safety Analysis Report for the Waste Isolation Pilot Plant, WP 02-9, Carlsbad, New Mexico.

U.S. Department of Energy (DOE), 1991. Implementation of the Resource Disincentive in 40 CFR Part 191.14(e) at the Waste Isolation Pilot Plant DOE/WIPP 91-029, Department of energy, Carlsbad, NM.

Vine, J.D., 1960. "Recent Domal Structures in Southeastern New Mexico," American Association of Petroleum Geologists Bulletin, Vol. 44, No. 12, pp. 1903-1911.

Vine, J.D., 1963. "Surface Geology of the Nash Draw quadrangle, Eddy County, New Mexico," US Geological Survey Bulletin 1141-B, Washington, D.C., U.S. Government Printing Office. 
Wawersik, W.R., and R.L. Beauheim, 1991. "Test Plan -- Hydraulic Fracturing and Hydrologic Tests in Marker Beds 139 and 140," Albuquerque, NM, Sandia National Laboratories.

Wawersik, W.R., and D.W. Hannum, 1979. Interim Summary of Sandia Creep Experiments on Rock Salt from the WIPP Study Area, Southeastern New Mexico, SAND790115, Albuquerque, NM, Sandia National Laboratories.

Weart, W.D., 1983. Summary Evaluation of the Waste Isolation Pilot Plant (WIPP) Site Suitability, SAND83-0450, Albuquerque, NM, Sandia National Laboratories.

WIF? Performance Assessment Division, 1991b. Preliminary Comparison with 40 CFR Part 191. Subpart B for the Waste Isolation Pilot Plant. December 1991-Volume 2: Probability and Consequence Modeling, SAND91-0893/2, Albuquerque, NM, Sandia National Laboratories.

Wood, B.J., R.E. Snow, D.J. Cosler, and S. Haji-Djafari, 1982. Delaware Mountain Group (DMG) Hydrology -- Salt Removal Potential, TME 3166, Albuquerque, NM, U.S. DOE. 


\subsection{Quality Assurance/Quality Control Program}

The purpose of the Carlsbad Area Office (CAO) Quality Assurance (QA) program is to ensure that processes, activities, and products which potentially impact waste isolation, health and safety, and environmental protection are appropriately planned, implemented, and assessed and are subjected to sufficient controls, inspection, and independent oversight. Within the CAO program, QA is applied to work processes, activities, and products in areas such as:

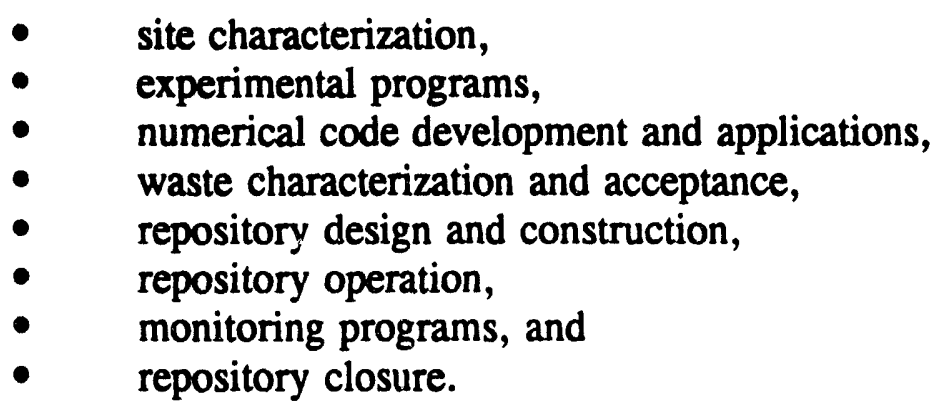

The applicable QA requirements for work processes, activities, and products at the Waste Isolation Pilot Plant (WIPP) have evolved over time. These requirements have varied with the intended purpose of work processes and activities. A brief chronology of the applicable requirements and their implementation at the WIPP is provided below.

From 1975 to late 1977, there were no Department of Energy (DOE) QA requirements or formal QA programs applied to WIPP geotechnical data collection activities. Drilling and other related site activities were controlled by commonly accepted field geotechnical practices. In January 1978, near the peak of the WIPP exploratory drilling program, Sandia National Laboratories (SNL) initiated the development of a Site Investigation QA Program, which was issued in May 1978, for implementation at the WIPP. Initially, emphasis was placed on QA programs for structures, systems, and components of the WIPP facility, and requirements were based on the Nuclear Regulatory Commission's (NRC) QA regulations contained in 10 CFR 50, Appendix B (NRC, 1993a). The general criteria of 10 CFR 50, Appendix B were eventually supplemented by the requirements of the national consensus standard, ANSI/ASME N45.2 (1977), which was replaced by ASME NQA-1 (1979), Quality Assurance Requirements for Nuclear Facilities. When Congress declared WIPP to be an TRU waste research and development facility not subject to the NRC requirements, 10 CFR 50, Appendix B requirements were dropped, however, ASME NQA-1 based QA program remained in effect until 1982. 
In 1982, the WIPP Project Management Plan (DOE, 1982) invoked DOE Order 5700.6A, as implemented by AL Order 5700.6A, as well as ANSI/ASME NQA-1. This standard remained in effect from 1982 to 1991. During this period, WIPP QA Program Plans (QAPPs) were revised as appropriate to reflect project changes. Since 1991, the WIPP QA program has focused on meeting the DOE Order 5700.6C Quality Assurance (DOE, 1991a) requirements through ASME NQA-1 activities.

The future QA program for the WIPP will be based on the new CAO Quality Assurance Requirements and Description (QARD). The CAO QARD is expected to be issued in August 1994. This new QARD will be based on applicable requirements of the DOE Order 5700.6C, ANSI/ASQC E-4 (ASQC, 1993), QAMS-005/80 (EPA, 1980), and ASME NQA-1 (ASME, 1989). Relevant guidance from documents such as NUREG-1297 (NRC, 1988a), NUREG-1298 (NRC, 1988b), NUREG-0856 (NRC, 1983), Regulatory Guide 7.10 (NRC, 1986), and NUREG/BR-0167 (NRC, 1993b) will be included, as appropriate, in the CAO QARD.

The QARD will be the principal QA document for the CAO program. This document will establish the minimum requirements for the development and implementation of QA programs by all participants of the WIPP program, National Transuranic Waste Program, and any other programs managed by the CAO. The CAO QARD will be organized to be consistent with the U.S. Environmental Protection Agency (EPA) QA requirements. This document will provide a description and statement of management, performance, and assessment requirements, as well as supplementary QA requirements for specific application areas, that all CAO program participants will incorporate into their QA programs. Each CAO program participant will be required to develop a Quality Management Plan (QMP), which will describe how work activities will be managed to achieve the planned objectives and goals and list the procedures that implement the QA program. Program participants' QMP's will be submitted to the CAO Manager for review and approval. The requirements for the development, review approval, and revision of the CAO program participants' QMPs will be provided in this QARD.

The requirements contained in this CAO QARD will be based on the principle that all work will be planned, documented, and performed under controlled conditions and periodically assessed to establish quality and process effectiveness and to promote improvement. The requirements described in this document will reflect the responsibilities assigned to management and line personnel of the CAO program participating organizations for planning, 
achieving, verifying, and assessing quality and for promoting continuous improvement. The revised CAO QA program will recognize the quality contribution of all CAO program personnel and encourages their active participation in accomplishing the CAO program's quality objectives.

The revised CAO QA program also will provide controls for activities which assess the quality of previously completed work processes, activities, and products included in regulatory compliance demonstration and documentation. Each CAO program participant will develop and implement appropriate methodology for qualification of existing data and information that were collected prior to the revised CAO QA program and are to be used in regulatory compliance demonstration. The CAO program participants will use guidance available in documents such as NUREG-1298 for the development of this methodology for assessing the quality of previously collected data and information. The need and the degree of rigor to which the CAO program participants are required to qualify their existing data and information will be determined and documented on the basis of the intended use of the data and information in regulatory compliance demonstration.

All data and information used in compliance documentation will be subjected to the above screening process. Data and information quality will be required to correspond to their importance to compliance. If data of indefensible quality have a significant impact on compliance, corrective action will be implemented.

The following sections provide a brief summary of the status of selected WIPP processes and activities related to compliance with the long-term performance standards. Each section may be revised upon the issuance of the QARD.

\subsection{Waste Characterization Program}

Transuranic waste intended for emplacement at the WIPP facility must meet approved waste acceptance criteria as specified in the Waste Acceptance Criteria (WAC) for the WIPP (DOE 1991b). Quality assurance programs for certifying that the wastes meet the specified criteria are required to be developed by each TRU waste generator site. The QA programs are reviewed and approved by the Waste Acceptance Criteria Certification Committee (WACCC), chaired by the DOE. Verification that approved QA program requirements are being met is achieved through an audit process of the generator sites' certification programs. 
Characterization of TRU waste by the generator sites includes reliance on proceduralized operations, process knowledge, nondestructive examination, and sampling/analysis. In addition to the WACCC program, the DOE prepared the QAPP for the WIPP Experimental-Waste Characterization Program (DOE 1991c) ${ }^{1}$.

Implementation of this QAPP is conducted by TRU waste generators and storage sites which are required to write Quality Assurance Project Plans (QAPjPs) to ensure that site-specific waste characterization activities meet all the data quality objectives (DQOs). These QAPjPs are reviewed and approved by the CAO before they can be implemented. All sites shipping waste to the WIPP must develop and implement their QAPjPs and have their programs certified prior to readying any waste containers for shipment.

\subsection{Models and Codes}

Chapter 8 describes the performance assessment (PA) methodology used to evaluate the longterm performance of the WIPP disposal systems. The methodology includes conceptual model development, event scenario selection and screening, and code development to support an analysis consistent with the conceptual models. The numerical models and codes contain parameters for which values are required. These parameter input values must be obtained in order to perform the computer calculations to assess repository performance.

The SNL WIPP Quality Assurance Program Description (QAPD) (SNL, 1992) forms the basis for management and control of the experimental/testing programs and their related activities at SNL. A series of implementing procedures are used to control the development and use of computer software, the selection of values for parameters used in the PA process, the analytical activities, the preparation, review, approval, and issuance of reports, and the use of expert judgement panels for developing necessary parameter values where experimental data are either unreasonable or impossible to obtain.

\footnotetext{
' DOE, 1991c. The QAPP for the Waste Isolation Pilot Plant Experimental Waste Characterization Program is a subordinate document to the Waste Characterization Program Plan (WCPP) and provides the generator sites with guidance and data quality objective for implementing the WCPP. Among the topics treated in the QAPP are reporting requirements, including those for the real time radiography activities for each container of waste that will be used in the Test Phase. Data reporting includes such parameters as examining site, waste container identification number, content code or item description code (IDC), changes made to IDC, date of examination, operator signature and date, reviewer signature and date, presence/absence of liner, estimated inventory of container contents, description of packaging materials, estimated volume of free liquid if present, audio/videotape identification number, and whether or not it is a replicate examination.
} 
The QA requirements for numerical/computational codes are described in SNL WIPP QA Procedure 19-1, WIPP Computer Software Requirements. Many codes are currently considered preliminary as they are being developed or refined for preliminary calculations. These codes are subject to the following requirements: 1) an abstract form which documents the code version, description, source, language, and approval for use must be prepared; 2) a software listing must be provided; and 3) appropriate verification documentation must be compiled. Verification is performed to ensure that a computer code performs its numerical and logical operations correctly within the application intended (see Section 8.1.2.2). The computer codes used for the final compliance calculations will have the following additional requirements: 4) users guides/manuals will be prepared and 5) independent software reviews will be conducted and documented.

\subsection{Experimental Programs}

The QA requirements for experimental programs are described in the SNL WIPP QAPD. For specific experiments, QA requirements are defined in the test plan which is required for each experiment. Data requirements such as representativeness, accuracy, precision, and completeness are specifically required by the current QA program (SNL, 1992). Controls are in place for procedure development. Samples, including core, brine, and data, are controlled. Results are published in data or analysis reports. Independent technical peer and QA review are used throughout the process. The program also addresses training, records management, and purchasing.

\subsection{Facility Data Collection Programs}

The QA requirements currently applicable to environmental compliance data collection programs are derived directly from the EPA's QAMS-005/80 guidance document (EPA, 1980). These requirements are addressed in QAPjPs.

Other environmental monitoring activities that do not need individual QAPjPs fall under the general program requirements as described in the management and operating contractor QAPD (WID, 1992). The QAPD is the overall description of the QA program, is based on DOE Order 5700.6C, and addresses all basic and supplemental requirements of ASME/NQA-1. 


\subsection{Facility Operations}

Monitoring conducted to support operations, such as roof support monitoring, ventilation monitoring, and measurements on the availability of fire water, are conducted in accordance with the QAPD. 


\subsection{References}

American Society of Mechanical Engineers (ASME), 1989. "Quality Assurance Program Requirements for Nuclear Facilities", NOA-1, American Society of Mechanical Engineers, New York, New York.

American Society for Quality Control (ASQC), 1993. "Quality Assurance Program Requirements for Environmental Programs," Draft, ANSI/ASOC E-4, American Society for Quality Control, Energy Division, Environmental Waste Management Committee, May 1993.

Sandia National Laboratories (SNL), 1992. Sandia National Laboratories Waste Isolation Pilot Plant Quality Assurance Program Description, Rev. P, 10/1/92.

U.S. Department of Energy (DOE), 1982. WIPP Project Management Plan, WIPP/DOE 103, October 1982.

U.S. Department of Energy (DOE), 1991a. DOE Order 5700.6, "Quality Assurance," U.S. Department of Energy, Washington, D.C.

U.S. Department of Energy (DOE), 1991b. Waste Acceptance Criteria for the Waste Isolation Pilot Plant, WIPP-DOE-069, Rev. 4, December 1991.

U.S. Department of Energy (DOE), 1991c. Quality Assurance Program Plan for the Waste Isolation Pilot Plant Experimental-Waste Characterization Program, Rev. 1, DOE/1 EM/48063-1, July 1991.

U.S. Environmental Protection Agency (EPA), 1980. "Interim Guidelines and Specifications for Preparing Quality Assurance Project Plans," OAMS-005/80, Office of Research and Development, Washington, D.C.

U.S. Nuclear Regulatory Commission (NRC), 1983. "Final Technical Position on Documentation of Computer Codes for High-Level Waste Management," NUREG-0856, June 1983, Division of Waste Management, Office of Nuclear Material Safety and Safeguards. 
U.S. Nuclear Regulatory Commission (NRC), 1986. " Establishing Quality Assurance Programs for Packaging used in the Transport of Radioactive Material", Regulatory Guide 7.10, Rev. 1, June 1986, Office of Nuclear Regulatory Research.

U.S. Nuclear Regulatory Commission (NRC), 1988a. "Peer Review for High-Level Nuclear Waste Repositories," NUREG-1297, February 1988, Division of High-Level Nuclear Waste Management, Office of Nuclear Material Safety.

U.S. Nuclear Regulatory Commission (NRC), 1988b. "Qualification of Existing Data for High-Level Nuclear Waste Repositories," NUREG-1298, February 1988, Division of HighLevel Nuclear Waste Management, Office of Nuclear Material Safety and Safeguards, Washington, D.C.

U.S. Nuclear Regulatory Commission (NRC), 1993a. 10 CFR 50, Appendix B, "Quality Assurance Criteria for Nuclear Power Plants and Fuel Reprocessing Plants", Office of the Federal Register, Washington, D.C.

U.S. Nuclear Regulatory Commission (NRC), 1993b. "Software Quality Assurance Program and Guidelines," NUREG/BR-0167, February 1993.

Waste Isolation Division (WID), 1992. WP 13-1, Quality Assurance Program Description, Rev. 14, April, 1992. 


\subsection{Compliance Analysis}

The long-term performance standards require that effective containment of regulated-waste contaminants be evaluated through the use of performance assessment (PA) analyses.

Performance assessment uses well-defined procedures to simulate system performance under reasonably expected conditions, including the effects of natural and man-induced processes and events. This section describes the methodology used for PA analysis for both 40 CFR 191 and 40 CFR \$268.6, from the selection or development of conceptual models, scenarios, and the mathematical and computer codes use to the of measured data and other information to perform calculations to analyze the disposal system's compliance with regulatory requirements. The results of the most recent analyses are also presented in this section.

Much of the information in this chapter is from the 1992 PA calculations, which were documented in five volumes as the Preliminary Performance Assessment for the Waste Isolation Pilot Plant (WIPP), December 1992 (SNL, 1992).

\subsection{Performance Assessment Methodology}

Computer simulations are used to model reasonably expected events and processes (scenarios) that may lead to migration of radionuclides and/or hazardous constituents beyond a regulatory boundary after wastes are emplaced and the WIPP repository is closed.

The mechanical process of PA consists of six general tasks:

1. Characterization of conceptual models through collection of data on waste properties, facility design, and regional geology and hydrology.

2. Use of computational models and codes for consequence analysis that simulate quantitative contaminant releases.

3. Use of statistical techniques to help define parameter distributions for consequence and probability modeling, and probability modeling that provides estimates of the likelihood that retained scenarios will occur.

4. Scenario selection by identifying combinations of events and processes whereby contaminants could potentially be released beyond the unit boundary, and subsequent determination of which scenarios to model. 
5. Calculation of regulatory performance measures, e.g. construction of Complimentary Cumulative Distribution Functions (CCDFs) for comparison of modeling results with long-term performance criteria.

6. Uncertainty analysis that propagates uncertainties through the calculations and sensitivity analysis that determines which parameters could reasonably be expected to influence modeling results.

These steps are discussed in more detail below.

\subsubsection{Conceptual Models}

Information about the disposal system and its environment is used to construct conceptual models that, in conjunction with numerical models, are used to assess the disposal system performance.

As used here, a conceptual model is defined as a description used to assess the behavior of a system or subsystem with respect to a specific purpose. The description becomes a mechanism for evaluation/prediction through making assumptions that generally describe the geometry and dimensionality of the system, initial and boundary conditions, time dependence, and data distributions as well as the nature of the relevant physical and chemical processes. The assumptions should not be inconsistent with one another and/or with existing information within the context of the given purpose for the modeling. Alternative conceptual models are different descriptions of the same system for the same purpose, where each set of assumptions is not inconsistent with the existing information, but may differ from those assumptions in the original conceptual model.

Major components of the conceptual models used in the 1992 PA were developed to assess the following concerns: 1) generation of gas in the waste-emplacement panels by degradation of wastes and containers, 2) closure of the panels by salt creep, 3) migration of gas and/or brine potentially transporting contaminants from the undisturbed repository to the disposal unit boundary, 4) release of radionuclides at the ground surface and into the Culebra as a result of inadvertent intrusions resulting from exploratory drilling, 5) effect of passive marker systems on intrusion rates, 6) changes in groundwater flow in the Culebra resulting from future climatic changes, and 7) transport of radionuclides in the Culebra in a dualporosity medium with chemical retardation by sorption. 
Alternative conceptual models explicitly examined in the 1992 PA address the behavior $\sim f$ the system without creep closure, transport in the Culebra with no chemical retardation and no matrix diffusion (i.e., in a single-porosity fractured medium), and intrusion probabilities estimated without passive marker systems.

\subsubsection{Computational Models and Codes}

Conceptual models provide a framework in which information about the disposal system can be organized and linked to processes that can be simulated with quantitative models. Mathematical models are developed to quantify the effects of these processes. That is, the conceptual models provide the context within which these mathematical models must operate and define the processes they must assess. Among the processes represented by these mathematical models are fluid flow, mechanical deformation, radionuclide transport in groundwater, and removal of waste through intruding boreholes. Mathematical models for these processes and others are described in Volume 2 of the 1992 PA report.

The complexity of the mathematical models requires the use of computers and computer codes to facilitate calculations. Each of the codes used in the 1992 PA calculations are briefly described in Table 8-1; more information is available in the following text and in Volume 2 of the 1992 PA report.

\section{BRAGFLO}

A finite-difference code BRAGFLO has been developed to study gas and brine in the repository and surrounding strata and (for the purposes of 40 CFR 191) up an intrusion borehole. Specifically, BRAGFLO models the effects of the coupled, nonlinear, interactions of the following phenomena:

- Gas generation from corrosion and microbiological degradation of the waste and the consequent increase in pressure within the repository

- Flow of brine from the surrounding rock into the repository over time

- Flow of brine into the repository from an underlying pressurized reservoir penetrated by an intrusion borehole

- Gas and brine flow from the repository upward through an intrusion borehole 
Table 8-1 Summary of Computer Codes Used in the 1992 PA

Model

BRAGFLO

CCDFPERM

CUTTINGS

GENII-S

GRASP-INV

PANEL

SANCHO

SECO-FLOW

SECO-TRANSPORT

\section{Description}

Describes the multiphase flow of gas and brine through a porous, heterogenous reservoir. BRAGFLO solves simultaneously the coupled partial differential equations that describe the mass conservation of gas and brine along with appropriate constraint equation, initial conditions, and boundary conditions (SNL, 1992, Volume 2, Chapter 7).

Constructs probabilities for various computational scenarios associated with human intrusion by exploratory drilling (SNL, 1992, Volume 2, Section 1.4.2).

Calculates the quantity of radioactive material (in curies) brought to the surface as cuttings and cavings generated by an exploratory drilling operation that penetrates a waste panel (SNL, 1992, Volume 2, Chapter 7).

Estimates potential radiation doses to humans from radionuclides in the environment (Leigh et al., 1993).

Automatically generates simulation of transmissivity fields (estimates of transmissivity values) conditioned on measured transmissivity values and calibrated to steady-state and transient pressure data at well locations using an adjoint sensitivity and pilot-point technique (LaVenue and RamaRao, 1992).

Calculates rate of discharge and cumulative discharge of radionuclides from a repository panel through an intrusion borehole. Discharge is a function of fluid flow rate, nuclide solubility, and remaining inventory (SNL, 1992, Volume 2, Chapter 7).

Finite element program that solves quasistatic, large deformation, inelastic response of two-dimensional solids (Stone et al., 1985). Used in the 1992 performance assessment to determine porosity of the waste as a function of time and moles of gas generated (SNL, 1992, Volume 3, Section 1.4.7).

Calculates single-phase Darcy flow for groundwater-flow problems in two dimensions. The formulation is based on a single partial differential equation for hydraulic head using fully implicit time differencing (SNL, 1992, Volume 2, Chapter 7).

Simulates fluid flow and transport of radionuclides in fractured porous media (SNL, 1992, Volume 2, Chapter 7). 
- Gas and brine flow away from the waste-emplacement region through stratigraphic layers (including anhydrite interbeds) and shaft seals

- An approximation of the effects of creep closure on porosity of the waste and backfill

- $\quad$ Volatile organic compound (VOC) transport capabilities have been added to BRAGFLO since the publication of the 1992 PA report.

\section{SANCHO}

Three material models were used in calculating a porosity surface for a deformed room: 1) an elastic/secondary creep model for intact salt surrounding a room opening, 2) an elastic/secondary creep model for crushed-salt room backfill, and 3) a volumetric plasticity model of mechanical response of waste contained within a room. Gas pressure in the model disposal room was computed from the ideal gas law based on the instantaneous "void" volume in the room (i.e., the volume not occupied by liquids or solids), and the total amount of gas in the room. The effect of salt creep on porosity calculated for the waste and backfill by the SANCHO code is fed into the BRAGFLO flow calculations as discussed in Volume 4 of the 1992 PA report.

\section{PANEL}

The PANEL code is a waste mobilization model which computes radionuclide concentrations in brine assuming that, for each species, concentrations are uniform throughout the waste emplacement panel, are always in chemical equilibrium, and are limited by the solubility limits for each element. The code also calculates changes in the availability of radionuclides resulting from radioactive decay.

\section{CUTTINGS}

The CUTTINGS code is used to calculate the quantity of radionuclides brought directly to the ground surface in particulate waste removed from the panel during borehole intrusion. The code simulates the consequences of intrusion by standard rotary drilling techniques and calculates both cuttings (the volume of material intersected by the drill bit and carried to the surface in the circulating drilling fluid) and cavings (the volume of material er jded from the borehole wall by the circulating drilling fluid). The CUTTINGS code models the effects of 
fluid shear, which drilling industry experience has identified as the most important factor contributing to borehole erosion. Erosion is calculated for both laminar and turbulent flow regimes. The CUTTINGS code includes the radioactive decay equations.

\section{GRASP-INV}

The GRASP-INV code is used to assess uncertainty arising from spatial variability in the transmissivity field of the Culebra Dolomite Member of the Rustler Formation. GRASP-INV was used to generate 70 different calibrated transmissivity fields which are consistent with both steady-state and transient pressure data and measured aquifer parameters for use in SECO-FLOW calculations.

\section{SECO-FLOW and SECO-TRANSPORT}

The SECO-FLOW and SECO-TRANSPORT codes are used to model groundwater flow and radionuclide transport, respectively, in the Culebra Dolomite Member of the Rustler Formation.

The SECO-FLOW code simulates groundwater flow in either two-dimensional or threedimensional porous media. At present, only the two-dimensional version of the code is used in PA calculations, although the three-dimensional version will be used in the future to verify the two-dimensional modeling results.

SECO-TRANSPORT simulates solute transport in a dual-porosity system (matrix and fractures). Chemical retardation processes are modeled assuming sorption of solutes based on local chemical equilibrium existing at all times between solutes and solid phases. Surfaces of fracture walls may have clay lining. Diffusion occurs into both the pore space within the clay linings and the dolomite matrix. Chemical retardation (sorption) occurs within the dolomite matrix.

\section{CCDFPERM}

The CCDFPERM code is used to calculate probabilities and their radionuclide releases and resulting from combinations of intrusion events. CCDFPERM produces the CCDF used for compliance analyses. As discussed in Section 8.1.5.1 and in Volume 2 of the 1992 PA report, the PA uses two approaches to estimate rates of intrusion, one assuming no reduction 
in the rate of intrusion due to the presence of passive markers and the second based on expert judgement about the effectiveness of passive marker systems in reducing the likelihood of human intrusion.

CCDFPERM modifies the direct radionuclide releases calculated by CUTTINGS to account for the probability of intersecting waste of different activity loads. The adjusted CUTTINGS releases are combined with the integrated groundwater releases from SECO-TRANSPORT to construct the CCDFs used for preliminary regulatory comparisons.

\section{GENII-S}

The GENII-S code was developed to estimate potential radiation doses to humans from radionuclides in the environment. This code addresses both routine and accidental releases of radionuclides to air or water as well as other situations (e.g., residual contamination from spills or decommissioning operations).

\subsubsection{Model Validation}

Model validation is the process of assuring that a conceptual model and the corresponding mathematical and computational models reasonably represent a physical process for a given purpose. In a strict sense, model validation can imply direct testing against measured system performance. However, the regulatory time frame of 10,000 years precludes comparison of simulated results with empirical observations.

When model validation in the strict sense is not possible, sufficient confidence in model results can be provided by confirmative, corroborative, substantive, or supportive evidence. No proof of absolute correctness is possible; rather, the model may not be discounted or shown to be incorrect (Popper, 1959; Davis et al., 1991). This is a fundamental reason for use of the terms "reasonable degree of certainty," and "reasonable expectation."

In a practical sense, building confidence in a model used in waste disposal involves 1) testing of isolated processes and/or 2) matching previous uncontrolled observations. The first method in confidence building involves simulation of short-term laboratory experiments performed under controlled conditions. 
The second method of confidence building-calibration and history matching-refers to the process of fitting parameters used in computational models to reproduce uncontrolled historical data or partially controlled field data to some subjective level of accuracy. Just as with short-term laboratory experiments, calibration helps the analyst develop insight into the system and may bolster confidence in the applied model of the system. Hence, calibration can be an important part of confidence building. However, calibration can result in a nonunique solution. Many combinations of parameters can be selected and still reproduce the observations adequately. A successful calibration therefore is not evidence of validity in and of itself, but it can support confidence in a model.

\subsubsection{Model Verification}

Model verification is the process of assuring that the computer code correctly solves the mathematical model and correctly performs other required functional operations. Verification of codes may require testing in stages (i.e., testing of individual modules) followed by 1) numerical tests and comparison of results with analytic models or 2) benchmarking the code against other verified software that use similar or different mathematical or numerical formulations but are designed to solve comparable systems.

Examples of verification tests of the SECO codes can be found in Roache et al. (1990) and Salari (1993). Other PA codes have undergone similar verification tests, performed as part of the code development effort. As discussed in Rechard et al. (1991), complete verification of all PA codes is being pursued as part of the overall WIPP quality assurance (QA) effort (See Chapter 7).

\subsubsection{Statistical Techniques}

As discussed in more detail in by Helton et al. (1991) and Volume 4 of the 1992 PA report, the PA uses Monte Carlo techniques for uncertainty analysis and regression analyses of the Monte Carlo output for sensitivity analyses. Uncertainty analyses evaluate uncertainty in performance estimates that result both from the existence of alternative conceptual models and from the uncertainty about imprecisely known input variables. Sensitivity analyses determine the contribution of individual input variables to the uncertainty in model predictions. 
The PA analysis involves five steps: 1) selection of the variables to be examined and the ranges and distributions for their possible values, 2) generation of the sample parameter value sets to be analyzed, 3) propagation of the samples through the analysis, 4) display of the results of uncertainty analysis, and 5) sensitivity analysis. These steps are described briefly in the following sections.

\subsubsection{Selection of Variables and Their Ranges and Distributions}

The need for Monte Carlo analyses arises out of the uncertainty associated with model variables (See Section 8.3.1.1). Therefore, the first step in a Monte Carlo analysis is the selection of uncertain variables and of ranges and distributions that characterize the uncertainty in their possible values. These variables are typically input parameters to computer models, and the assigned ranges and distributions can greatly affect model output.

As discussed in detail in Volume 3 of the 1992 PA report, information about the ranges and distributions of possible values is drawn from a variety of sources, including field data, laboratory data, published scientific literature, and, in instances where site-specific information is unavailable or insufficient at the time of the analyses, subjective expert judgement. In many cases, data from these sources cannot be examined statistically for direct incorporation into the PA analyses because of issues inherent to the process of data collection. For example, data may be sparse or unavailable because obtaining measurements is infeasible (e.g., drilling sufficient boreholes to determine the regional heterogeneity of transmissivity in overlying aquifers), direct measurements would in themselves create undue hazards (e.g., drilling of boreholes through the repository to determine the extent of an underlying brine reservoir), and/or empirical data/information cannot be obtained (e.g., measuring future drilling technology).

The process that leads from the available data to the construction of the cumulative distribution functions used in the PA analyses is described in detail in Volume 3 of the 1992 PA report. Because of the nature of the available data and the type of analysis, the CCDF generation process is unavoidably subjective, and involves expert judgement.

\subsubsection{Generation of the Sample Parameter Sets}

A stratified sampling technique called Latin hypercube sampling (LHS) is used to ensure full coverage of the range of each sampled variable (McKay et al., 1979). The range of each 
variable is divided into $n$ intervals of equal probability, and one value is randomly selected from each interval. The $n$ values of the first parameter are randomly paired with the $n$ values of the second parameter, and so on until $n$ sample elements (vectors) from each probability interval are obtained. This procedure ensures that the distribution tails are sampled more efficiently than in conventional random sampling, and, therefore, fewer sample elements are required for a meaningful Monte Carlo analysis.

Most of the uncertain variables that were sampled during previous analyses were assumed to be independent, as the alternative would be to make unjustified linkages. Local porosity could be correlated with local permeability, but the correlation structure is unknown at this time. Controlling correlation within a sample for Monte Carlo analysis is important to ensure that uncertainty and sensitivity analysis results are meaningful. Performance assessment uses a rank correlation (i.e., on rank-transformed variables instead of on the original raw data) technique that effectively captures variable linkage while maintaining the integrity of the LHS intervals (Iman and Conover, 1982).

\subsubsection{Propagation of Parameter Uncertainty Through the Analysis}

In propagation of parameter uncertainty through the analyses, each vector comprised of the sampled parameters is supplied to the model as input, and the corresponding model predictions are saved for use in later uncertainty and sensitivity studies. The Compliance Assessment Methodology Controller (CAMCON) has been developed to facilitate the complex calculations and storage of the input and output files from each program (Rechard et al., 1989, 1992). This methodology incorporates data bases, sampling procedures, model evaluations, data storage, uncertainty and sensitivity analysis procedures, and plotting capabilities into a unified structure.

\subsubsection{Display of the Results of Uncertainty Analysis}

Results of the uncertainty analyses are useful for establishing a "reasonable degree of certainty" as required for 40 CFR $\$ 268.6$ compliance demonstrations. Once a sample has been generated and propagated through a model, uncertainty in the model simulations is displayed in the form of a CCDF for evaluations of compliance with 40 CFR \$191.13. Uncertainty in a simulated performance measure can also be displayed as a density function, 
a cumulative distribution function, or as box plots, as described in Volume 2 of the 1992 PA report.

\subsubsection{Sensitivity Analysis}

The final step in a Monte Carlo study is sensitivity analysis, which provides information about the sensitivity of the modeling system to uncertainty in specific input parameters. Sensitivity analyses can identify those parameters for which reductions in uncertainty (i.e., narrowing of the range of values from which the sample used in the Monte Carlo analysis is drawn) have the greatest reduction in uncertainty in the model output. Identification of sensitive parameters can help set priorities for additional research.

Qualitative judgement about the modeling system must be used in conjunction with sensitivity analyses to set priorities for data acquisition in support of PA and model development. Sensitivity analysis techniques used in the PA include scatterplots and stepwise linear regression analysis, and are described in detail by Helton et al. (1991).

\subsubsection{Selection of Scenarios}

Performance assessment analyses use a set of scenarios to simulate the performance of the repository system under a variety of conditions and as a result of a variety of events. A multi-step process, described in the following subsections, is used to develop and select the scenarios to be analyzed in PA calculations. The combined results (calculated performance measures) of PA using all selected scenarios are used to produce the CCDFs needed for 40 CFR 191 and 40 CFR \$268.6 compliance analysis.

\subsubsection{Identifying Events and Processes}

The PA uses the list of potentially disruptive events and processes as a starting point for scenario development (Table 8-2). This list was developed by a panel of experts that met in 1976 and again in 1977 under the auspices of the Nuclear Regulatory Commission (NRC) to identify events and processes that could compromise the performance of an engineered 


\section{Table 8-2 Potentially Disruptive Events and Processes}

Natural Events and Processes

Celestial Bodies

Surficial Events and Processes

Subsurface Events and Processes

\author{
Meteorite Impact \\ Erosion/Sedimentation \\ Glaciation \\ Pluvial Periods \\ Sea-Level Variations \\ Hurricanes \\ Seiches \\ Tsunamis \\ Regional Subsidence or Uplift \\ Mass Wasting \\ Flooding
}

Diapirism

Seismic Activity

Volcanic Activity

Magmatic Activity

Formation of Dissolution Cavities

Formation of Interconnected Fracture Systems

Faulting

Human-Induced Events and Processes

Inadvertent Intrusions

Hydrological Stresses

Repository- and Waste-Induced

Events and Processes
Explosions

Drilling

Mining

Injection Wells

Withdrawal Wells

Irrigation

Damming of Streams and Rivers

Caving and Subsidence

Shaft and Borehole Seal Degradation

Thermally Induced Stress Fracturing in Host Rock

Excavation-Induced Stress Fracturing in Host Rock

Gas Generation

Explosions

Nuclear Criticality 
disposal system for nuclear waste constructed in deep geologic media. ${ }^{1}$ Concerns raised during the development of the WIPP have led to the inclusion of three additional events and processes not identified by the panel: gas generation by the degradation of the waste, waste-related explosions, and nuclear criticality.

\subsubsection{Screening Events and Processes}

The initial list from the expert panel was not specific to WIPP or to the assessment of WIPP with regard to compliance with 40 CFR 191, Subpart B. Therefore, events and processes are screened using three criteria: probability of occurrence, consequence, and physical reasonableness, as well as additional, applicable regulatory requirements. All are applied in the context of the 1985 version of 40 CFR 191, Subpart B, and screening will be reexamined because the regulation has been recently repromulgated. The "probability of occurrence" and "consequence" criteria are based directly on guidance provided in Appendix C of 40 CFR 191:

The [EPA] assumes that...performance assessments need not consider categories of events or processes that are estimated to have less than one chance in 10,000 of occurring over 10,000 years. Furthermore, the performance assessments need not evaluate in detail the releases from all events and processes estimated to have a greater likelihood of occurrence. Some of these events and processes may be omitted from the performance assessments if there is a reasonable expectation that the remaining probability distribution of cumulative releases would not be significantly changed by such omissions. (EPA, 1985, p. 38088)

For PA, individual events and processes (as well as "categories of events and processes") that have a probability of at least one chance in 10,000 of occurring over 10,000 years will be retained for further evaluation. Lower-probability phenomena are identified but not considered further. Low-consequence phenomena (i.e., those that would not significantly change the CCDF) are identified qualitatively in the PA methodology and are eliminated regardless of their probability of occurrence.

\footnotetext{
'As listed in Cranwell et al., (1990), the Scenario Identification Panel Members and their affiliations were William S. Twenhofel, United States Geological Survey (USGS), Denver, CO; William W. Dudley, USGS, Denver, CO; Randolph Stone, Lawrence Livermore National Laboratory, Livermore, CA; Frederick J. Pearson, USGS, Reston, VA; Herbert R. Shaw, USGS, Menlo Park, CA; Donald Caldwell, United States Nuclear Regulatory Commission (NRC), Washington, DC; Ben Ross, The Analytical Sciences Corp., Reading, MA; Edward Hawkins, NRC, Washington, DC; and Martin Tierney, Sandia National Laboratories, Albuquerque, NM. Working sessions of this panel were held on December 7-8, 1976, at Grand Canyon, AZ, and again on April 13, 1977, in Carlsbad, NM.
} 
The final screening criterion, "physical reasonableness," is not explicitly described in 40 CFR 191, Subpart B. As used in PA, this criterion is used to screen out those phenomena which are not believed to be physically possible at the WIPP site. Note that the distinction between "physical reasonableness" and "probability of occurrence" is not rigid, and phenomena identified as "physically unreasonable" could also be eliminated on the basis of extremely low probability.

Regulatory requirements result in the need to screen events related to human activities. The methodologies used in PA to manage them are based directly on guidance in Appendix $\mathrm{C}$ of 40 CFR 191:

...inadvertent and intermittent intrusion by exploratory drilling for resources (other than any provided by the disposal system itself) can be the most severe intrusion scenario assumed by the implementing agencies. (EPA, 1985, p. 38089)

With regard to 40 CFR 191, this guidance implies the exclusion of all deliberate human activities that disrupt the repository, as well as those inadvertent human activities that could result in consequences more severe than those of exploratory drilling. Specifically, this guidance allows for excluding consideration of the effects of events such as acts of war, direct mining of the waste, systematic drilling of multiple boreholes for resource production or other purposes, and modes of intrusion other than exploratory drilling.

\subsubsection{Summary of Screened Events and Processes}

The following is a summary of the events and processes listed in Table 8-2. As shown in Table 8-3, events and processes are either retained for consideration in PA or screened out on the basis of the criteria described in the previous section. Events and processes retained for consideration are either considered base-case conditions of the system or used for developing scenarios describing undisturbed and disturbed performance.

All of the natural events and processes listed in Table 8-2 that have been retained are part of the base-case scenario of the system. Phenomena such as erosion, sedimentation, climatic change (pluvial periods), seismic activity, and some shallow dissolution are expected to occur to some degree during the next 10,000 years and are part of the conceptual model for the 
Table 8-3 Summary of Screened Events and Processes

\begin{tabular}{|c|c|c|c|c|c|c|}
\hline \multirow[b]{2}{*}{ Events and Processes } & \multicolumn{2}{|c|}{ RETAINED } & \multicolumn{4}{|c|}{ SCREENED OUT } \\
\hline & $\begin{array}{l}\text { Base-Case } \\
\text { Conditions }\end{array}$ & $\begin{array}{l}\text { For Scenario } \\
\text { Development }\end{array}$ & $\begin{array}{c}\text { Low } \\
\text { Probability }\end{array}$ & $\begin{array}{l}\text { Physically } \\
\text { Unreasonable }\end{array}$ & $\begin{array}{c}\text { Low } \\
\text { Consequence }\end{array}$ & $\begin{array}{c}\text { Regulatory } \\
\text { Requirements }\end{array}$ \\
\hline \multicolumn{7}{|l|}{ Natural } \\
\hline Meteorite Impact & & & $\mathbf{x}$ & & & \\
\hline Erosion/Sedimentation & $\mathbf{x}$ & & & & & \\
\hline Glaciation & & & & $\mathbf{x}$ & & \\
\hline Pluvial Periods (Climate Change) & $\mathbf{x}$ & & & & & \\
\hline Sea-Level Variation & & & & $\mathbf{x}$ & & \\
\hline Hurricanes & & & & $\mathbf{x}$ & & \\
\hline Seiches & & & & $\mathbf{x}$ & & \\
\hline $\begin{array}{l}\text { Tsunamis } \\
\text { "Conventional" } \\
\text { Meteorite Impact }\end{array}$ & & & $\mathbf{x}$ & $\mathbf{x}$ & & \\
\hline Regional Subsidence or Uplift & & & & $\mathbf{x}$ & & \\
\hline Mass Wasting & & & & $\mathbf{x}$ & & \\
\hline Flooding & & & & $\mathbf{x}$ & & \\
\hline Diapirism & & & & $\mathbf{x}$ & & \\
\hline Seismic Activity & $\mathbf{x}$ & & & & & \\
\hline Volcanic Activity & & & & $\mathbf{x}$ & & \\
\hline
\end{tabular}


Table 8-3 Summary of Screened Events and Processes (continued)

\begin{tabular}{|c|c|c|c|c|c|c|}
\hline \multirow[b]{2}{*}{ Events and Processes } & \multicolumn{2}{|c|}{ RETAINED } & \multicolumn{4}{|c|}{ SCREENED OUT } \\
\hline & $\begin{array}{l}\text { Base-Case } \\
\text { Conditions }\end{array}$ & $\begin{array}{l}\text { For Scenario } \\
\text { Development }\end{array}$ & $\begin{array}{c}\text { Low } \\
\text { Probability }\end{array}$ & $\begin{array}{l}\text { Physically } \\
\text { Unreasonable }\end{array}$ & $\begin{array}{c}\text { Low } \\
\text { Consequence }\end{array}$ & $\begin{array}{c}\text { Regulatory } \\
\text { Requirements }\end{array}$ \\
\hline \multicolumn{7}{|l|}{ Natural } \\
\hline $\begin{array}{l}\text { Formation of Dissolution Cavities } \\
\text { Deep Dissolution } \\
\text { Shallow Dissolution } \\
\text { Rustler-Salado Contact } \\
\text { Nash Draw* }\end{array}$ & $\mathbf{x}$ & & $\mathbf{x}$ & $\mathbf{X}$ & & \\
\hline Formation of Interconnected & & & & $\mathbf{X}$ & & \\
\hline Faulting & & & & $\mathbf{x}$ & & \\
\hline \multicolumn{7}{|l|}{ Human-Induced } \\
\hline $\begin{array}{l}\text { Explosions } \\
\text { At Waste-Panels Location } \\
\text { Near Waste-Panels Location } \\
\text { At Surface/Warfare } \\
\text { Deep Testing }\end{array}$ & & & $\underset{\mathbf{X}}{\mathbf{X}}$ & & & $\mathbf{X}$ \\
\hline Drilling (Exploratory) & & $\mathbf{x}$ & & & & \\
\hline $\begin{array}{l}\text { Mining } \\
\text { At Waste-Panels Location } \\
\text { Near Waste-Panels Location }\end{array}$ & & $\mathbf{x}$ & & & & $\mathbf{x}$ \\
\hline
\end{tabular}

- Screening criterion depends on which mechanisms considered for origin of Nash Draw 
Compliance Status Report

Table 8-3 Summary of Screened Events and Processes (continued)

\begin{tabular}{|c|c|c|c|c|c|c|}
\hline \multirow[b]{2}{*}{ Events and Processes } & \multicolumn{2}{|c|}{ RETAINED } & \multicolumn{4}{|c|}{ SCREENED OUT } \\
\hline & $\begin{array}{l}\text { Base-Case } \\
\text { Conditions }\end{array}$ & $\begin{array}{l}\text { For Scenario } \\
\text { Development }\end{array}$ & $\begin{array}{c}\text { Low } \\
\text { Probability }\end{array}$ & $\begin{array}{l}\text { Physically } \\
\text { Unreasonable }\end{array}$ & $\begin{array}{c}\text { Low } \\
\text { Consequence }\end{array}$ & $\begin{array}{c}\text { Regulatory } \\
\text { Requirements }\end{array}$ \\
\hline \multicolumn{7}{|l|}{ Human-Induced } \\
\hline Injection Wells & & & & $\mathbf{x}$ & & \\
\hline $\begin{array}{l}\text { Withdrawal Wells } \\
\text { Water Wells } \\
\text { Oil and Gas Wells } \\
\text { At Waste-Panels Location } \\
\text { Near Waste-Panels Location } \\
\text { Geothermal Wells }\end{array}$ & & $\mathbf{x}$ & & & $\begin{array}{l}\mathbf{X} \\
\mathbf{X}\end{array}$ & $\mathbf{x}$ \\
\hline Irrigation & & & $\mathbf{x}$ & & & \\
\hline $\begin{array}{l}\text { Damming of Streams and Rivers } \\
\text { At Pecos River } \\
\text { Near Nash Draw }\end{array}$ & & & $\mathbf{X}$ & & $\mathbf{x}$ & \\
\hline $\begin{array}{l}\text { Repository- and Waste-Induced } \\
\text { Subsidence and Caving } \\
\text { Shaft \& Borehole Seal Degradation } \\
\text { Thermally Induced Fractures } \\
\text { Excavation-Induced Fractures } \\
\text { Gas Generation } \\
\text { Explosions (Gas Ignition) } \\
\text { Near Criticality } \\
\text { Critical Mass (Explosion) } \\
\text { Sustained Reaction } *\end{array}$ & $\begin{array}{l}\mathbf{X} \\
\mathbf{X} \\
\mathbf{X}\end{array}$ & & $\mathbf{x}$ & $\mathbf{x}$ & $\mathbf{X}$ & \\
\hline
\end{tabular}

* Retained for additional evaluation 
base-case scenario. Several other listed events (i.e., sea-level variations, hurricanes, seiches, and tsunamis) are restricted to coastal areas and are physically unreasonable at the WIPP location. Surficial geologic events, including regional subsidence or uplift, mass wasting, glaciation, and flooding, and all subsurface events except seismic activity and shallow dissolution of the Rustler-Salado contact are screened out as physically unreasonable or of low probability during the 10,000 year period of concern.

Of the human-induced events and processes, inadvertent explosions at the location of the waste panels are excluded by regulatory requirements limiting the presence or development of explosive mixtures in the repository; inadvertent explosions near the waste panels during warfare and nuclear testing are screened out on the basis of low probability. Irrigation and damming of valleys close enough to the WIPP to have an impact are low-probability events because of poor water and soil quality and limited water supplies. Based on the geologic setting and previous resource evaluations, both exploratory drilling for resources and the drilling of injection wells are realistic events for the WIPP, and are retained for scenario development. Intrusion by injection wells into the waste-emplacement region is not modeled explicitly in the PA, because drilling technology and the resultant consequences are assumed to be the same as for exploratory drilling.

In the category of repo id waste-induced events and processes, gas generation and shaft-seal degradation ar. of the conceptual model of the undisturbed performance of the system. Borehole seal degradation is addressed through parameter uncertainty during modeling. Excavation-induced fracturing in the host rock is considered by including the disturbed zone surrounding mined openings in the conceptual model of the base-case scenario. Caving into the rooms or drifts may occur in the short term after decommissioning, but this process has no long-term consequences on performance because of the mechanical behavior of salt. Thermally induced fracturing of the host rock is not a physically reasonable phenomenon because of the low thermal output of WIPP wastes.

As shown in Table 8-3, a total of ten events and processes are retained for consideration following screening. Seven of these are essentially certain to occur, and are included in the conceptual model for the base-case scenario of the system. The other three-exploratory drilling, potash mining near the waste panels, and water wells-are used to develop summary scenarios describing disturbed performance of the system. Exploratory drilling is subdivided into two possibilities: drilling into a waste-filled room or drift and a brine reservoir in the underlying Castile Formation (Event E1) and drilling into a waste-filled room or drift without 
penetrating a brine reservoir (Event E2); drilling of withdrawal wells is limited to water wells in areas where water quantity and quality will permit water use.

\subsubsection{Scenario Screening}

For the WIPP, the result of the scenario-selection process is a set of eight potentially significant scenarios constructed from three retained events plus the base case. No scenarios resulting from the selection process have been formally screened out by the PA process, but it is reasonable to assume that the consequences associated with subsidence due to potash mining and water wells will be minimal. The four scenarios analyzed in 1992 are discussed in the following sections, showing the analyses performed to support analysis of compliance with the appropriate regulations governing post-closure disposal system performance.

\subsubsection{Scenarios Evaluated for Determination of Compliance with 40 CFR 191}

\subsection{Undisturbed Performance (Base Case)}

As defined in 40 CFR $\$ 191.12$ (p) "undisturbed performance means the predicted behavicr of a disposal system, including consideration of the uncertainties in predicted behavior, if the disposal system is not disrupted by human intrusion or the occurrence of unlikely natural events." Applicable regulations do not define "unlikely" but the Department of Energy (DOE) interprets the probability cutoff of one chance of occurrence in 10,000 in 10,000 years presented as guidance in Appendix C of 40 CFR 191 for the Containment Requirements (\$191.13) to be a suitable working definition for the term.

No disruptive natural events with probabilities greater than one in 10,000 in 10,000 years were identified during the scenario-selection procedure, so "undisturbed performance" is the same as the "base-case" scenario. Because of the relative stability of the natural systems within the region of the WIPP disposal system, all naturally occurring events and processes retained for scenario construction (e.g., climate variability) will occur, are part of the base-case scenario, and are nondisruptive. The base-case scenario (Figure 8-1) describes the disposal system from the time of decommissioning and incorporates all expected changes in the system and associated uncertainties relative to the 10,000 years of concern for the Containment Requirements (\$191.13). Two potential pathways for migration of radionuclides dissolved in brine result from the analysis of the 1992 PA calculations. In the first path, brine may migrate either through drifts or thr $\lrcorner$ gh the disturbed rock zone (DRZ) 
surrounding the excavation and anhydrite interbeds (primarily Marker Bed [MB] 139) to the shafts and then upward toward the Culebra Dolomite Member of the Rustler Formation, which is the most permeable water-saturated unit overlying the repository. Transport may then occur laterally in the Culebra toward the subsurface regulatory boundary of the controlled area. In the second path, brine may migrate laterally toward the subsurface regulatory boundary within anhydrite interbeds in the Salado Formation. The base-case scenario corresponds to the undisturbed performance for the purposes of analyzing compliance with the Individual Protection Requirements (\$191.15) and the Groundwater Protection Requirements (40 CFR 191, Subpart C). By considering gas migration pathways to the disposal-unit boundary and, if necessary, transport of hazardous constituents in both gas and brine phases, the base-case scenario is suitable for evaluations of undisturbed performance for 40 CFR §268.6, discussed below.

\subsection{Inadvertent Human Intrusion}

Performance assessments for 40 CFR 191, Subpart B, presently concentrate on inadvertent human intrusion through exploratory drilling for resources, which has been demonstrated by past analyses to be the only event likely to lead to radionuclide releases close to or in excess of regulatory limits specified in 40 CFR $\$ 191.13$. Future drilling technology is assumed for these analyses to be comparable to technology presently in use in the region of the WIPP. Human intrusion analyses are based on an interpretation of guidance provided by the EPA (40 CFR 191, Appendix C). These interpretations and the justifications supporting the current PA intrusion rates used in calculations are described in Section 8.1.5.1.

If the waste-emplacement panels are penetrated by an exploratory borehole, it is reasonable to assume that radionuclides may reach the accessible environment by two principal pathways. First, some radionuclides will be transported up the borehole directly to the ground surface. Second, additional radionuclides transported up the borehole may migrate into overlying strata and may be transported laterally in groundwater to the subsurface regulatory boundary.

Most releases at the ground surface will be in the form of particulate waste entrained in the drilling fluid, including components from cuttings (material removed by the drill bit), cavings (material eroded from the borehole wall by the circulating drilling fluid), and spallings (material that enters the borehole as the repository depressurizes). For convenience, all particulate releases are collectively referred to in PA documentation as cuttings. For the 
1992 calculations, results referred to as cuttings include cavings but do not include spallings. Spallings will be considered for future PA when relevant models and data are available.

Modeling of particulate releases at the ground surface during drilling is discussed in detail by Berglund (1992). Release of radionuclides dissolved in brine that may flow up the borehole to the ground surface both during drilling and after degradation of plugs will be evaluated in a future PA.

Subsurface releases of radionuclides (at the controlled area boundary) following lateral transport in groundwater are believed most likely to occur in the Culebra Dolomite Member of the Rustler Formation overlying the repository, as discussed earlier in this document. For analysis purposes, subsurface transport is assumed to occur only in the Culebra, maximizing the potential for releases by this pathway. Additional discussion of flow and transport in the Culebra is provided in Volume 2 of the 1992 PA report.

Figures 8-1 and 8-2 illustrate the three representative intrusion scenarios. In the E1 scenario (Figure 8-1), a borehole penetrates the repository and a hypothetical pressurized brine reservoir in the underlying Castile Formation. In the E2 scenario (Figure 8-2), a borehole penetrates the repository and misses the hypothetical brine reservoir. In the E1E2 scenario (Figure 8-2), one borehole penetrates the repository and the hypothetical brine reservoir and a second borehole penetrates the repository but misses the pressurized brine reservoir.

In all three of these intrusion scenarios, borehole plugs are assumed to be emplaced and to fail, so that fluid flow into the Culebra Dolomite Member of the Rustler Formation is maximized. These plug configurations have been chosen to facilitate examination of the specific scenarios, and do not reflect expected conditions. In the E1 and E2 scenarios, any plugs between the repository and the Culebra are assumed to fail immediately, whereas plugs above the Culebra remain effective for 10,000 years. In the E1E2 scenario, a plug in the E1-type borehole iv tween the repository and the Culebra remains effective and forces flow through the waste and up the E2-type hole, where a plug above the Culebra forces flow laterally toward the accessible-environment boundary. Regarding borehole plugs, a more reasonable assumption is that they all behave in the same manner over the long-term. That is, all plugs fail, or all plays remain intact. As noted above, consequences of alternative assumptions about plugging in which all plugs degrade to a material with relatively high permeability (as suggested in 40 CFR 191, Appendix C) and brine is allowed to flow to the ground surface will be examined and documented in a subsequent PA. 


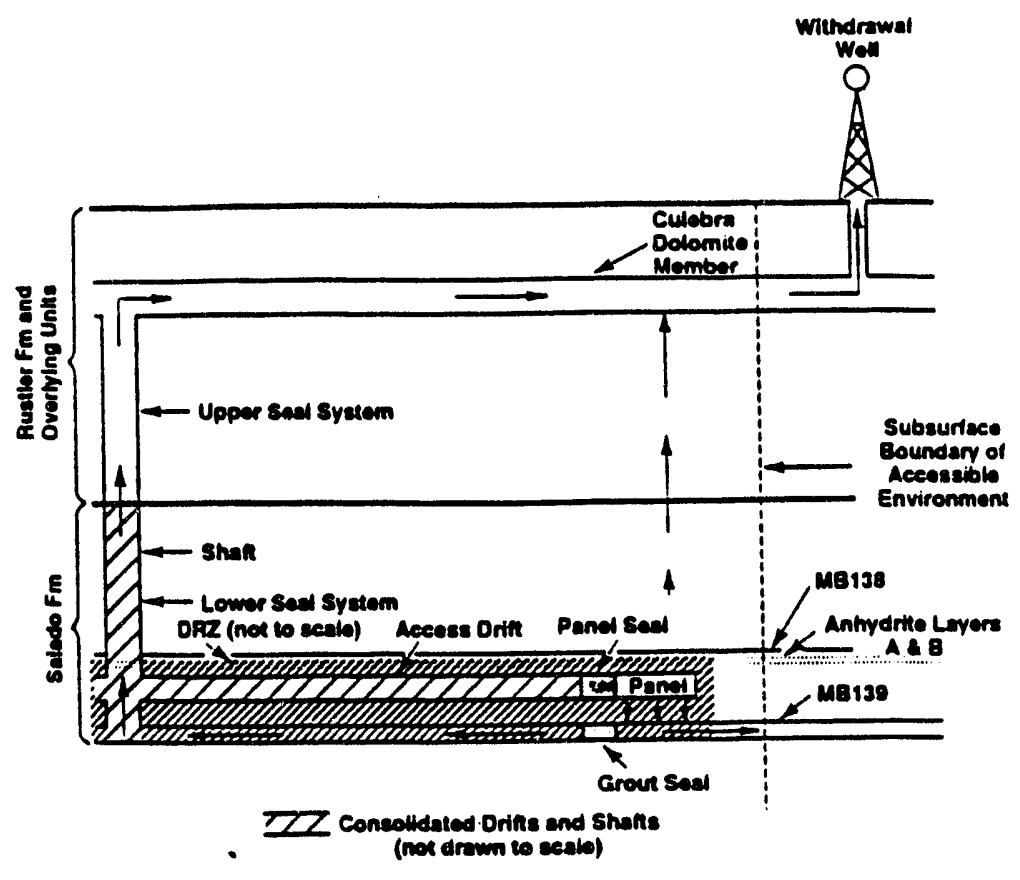

(a)

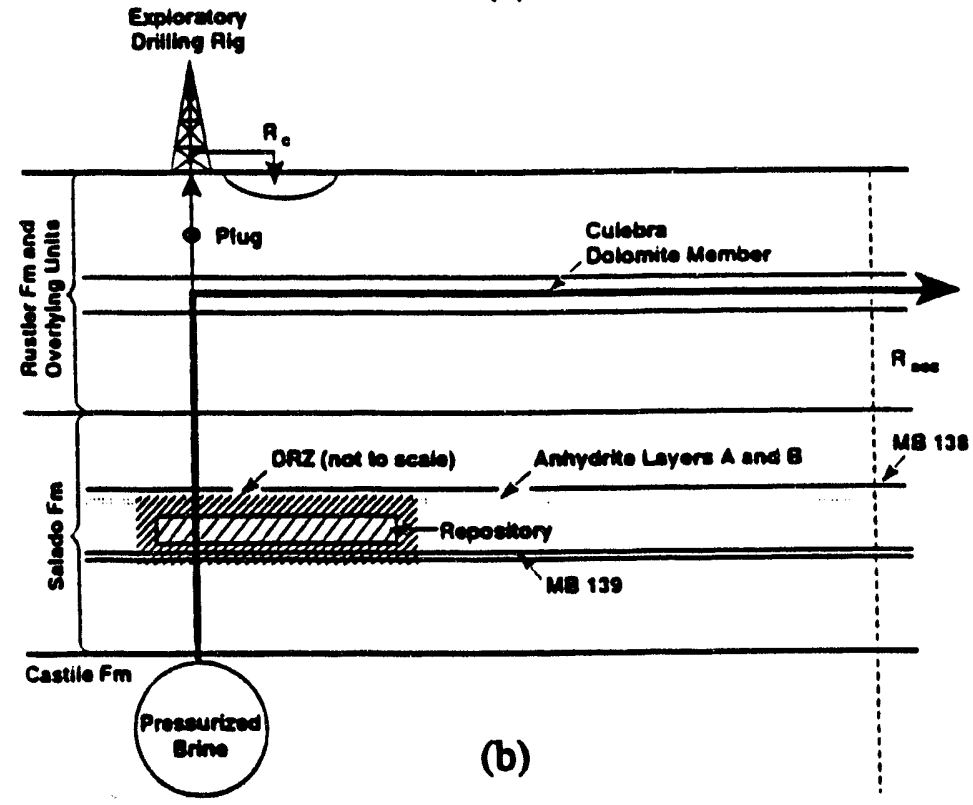

Figure 8-1 Conceptual models for (a) the undisturbed performance scenario and (b) the El scenario. Arrows indicate assumed direction and relative magnitude of flow. $R_{c}$ is the release of cuttings and eroded material. $R_{a c c}$ is the release at the subsurface boundary of the accessible environment. Illustrated plugs are assumed to remain intact for 10,000 years 


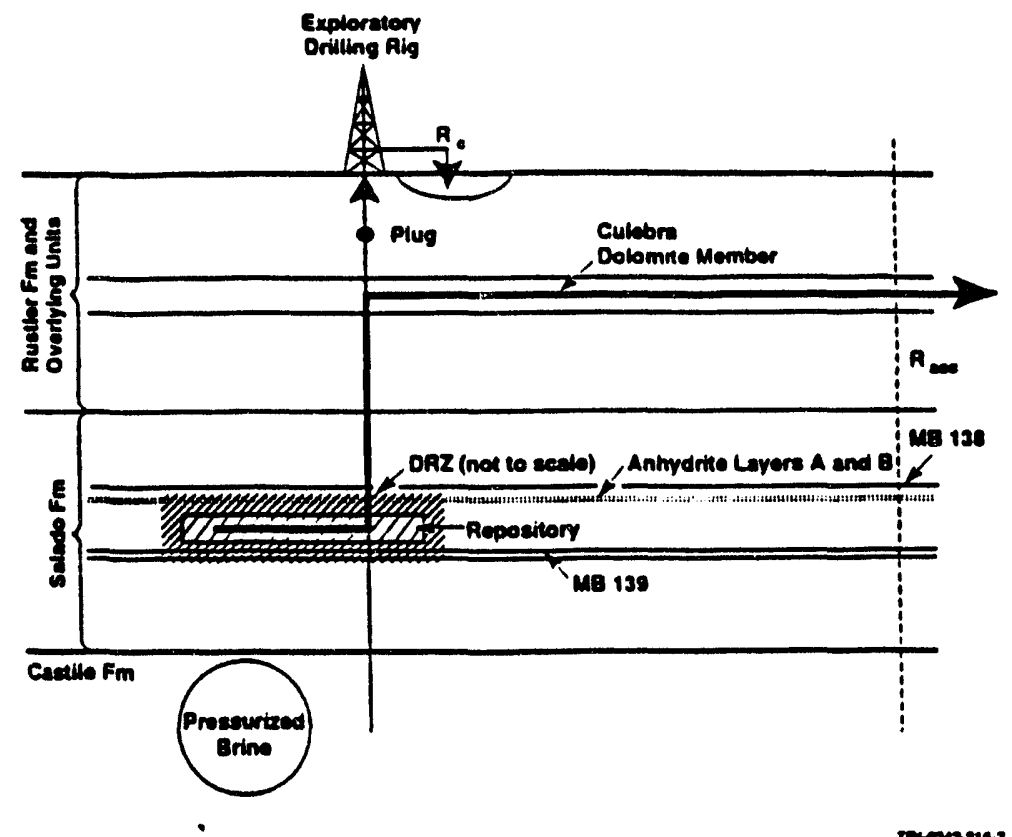

(a)

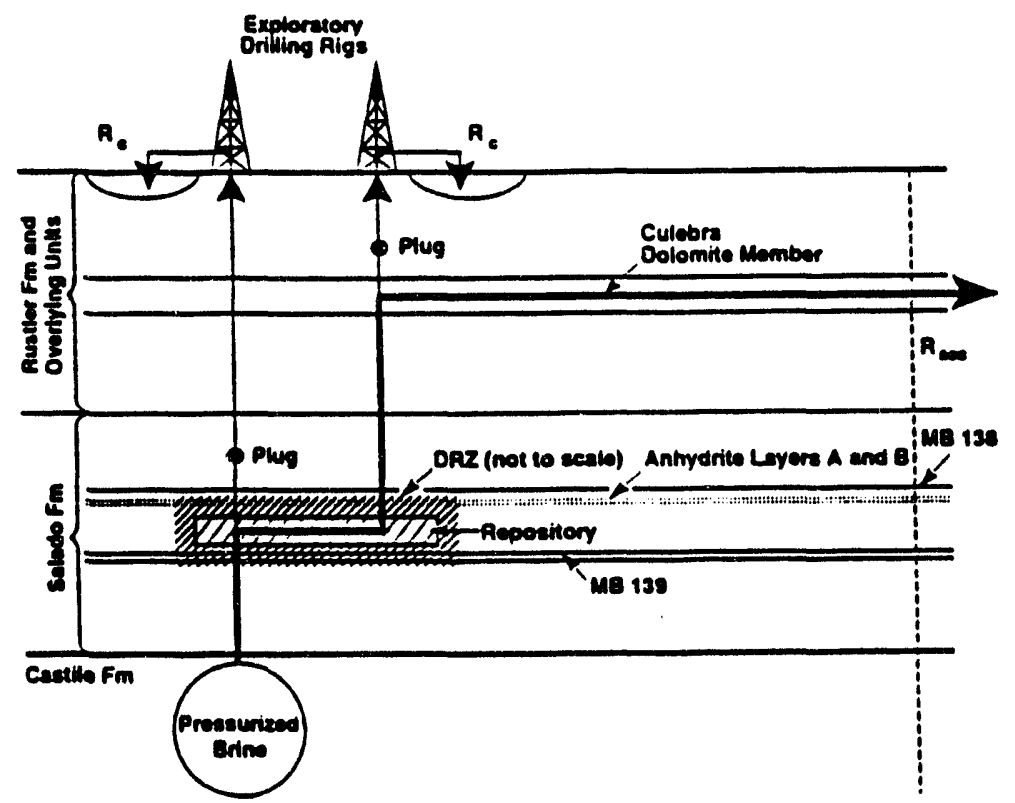

(b)

Figure 8-2 Conceptual models for (a) the E2 scenario and (b) the E1E2 scenario. Arrows indicate assumed direction and relative magnitude of flow. $R_{c}$ is the release of cuttings and eroded material. $R_{\text {acc }}$ is the release at the subsurface boundary of the accessible environment. Illustrated plugs are assumed to remain intact for 10,000 years. 
For improved computational resolution, the E1, E2, and E1E2 scenarios have been subdivided further into computational scenarios on the basis of time of intrusion and activity of the waste intersected. As discussed in Volume 2 of the 1992 PA report subsurface radionuclide releases following groundwater transport in the Culebra are calculated in the 1992 PA only for intrusions occurring 1,000 years after decommissioning. Because of the decreased time available for transport (i.e., less than 9,000 years), later intrusions are expected to result in smaller cumulative releases of radionuclides. For releases of cuttings to the surface, E1-type intrusions are assumed to have the same consequences as E2-type intrusions. Releases of cuttings are calculated for six time intervals, including intrusions at $125,175,350,1,000,3,000$, and 7,250 years. Multiple intrusions are allowed, with a maximum number of ten occurring into the $0.126 \mathrm{~km}^{2}$ area of the waste with a probability greater than 0.001 in simulations used in the 1992 analyses. Note that there are several parameters used in the construction of human intrusion scenarios that are estimated conservatively in the 1992 PA. These will undergo greater scrutiny prior to preparation of firal compliance documentation. For example, borehole fill material is taken to be silty sand as opposed to evaporite-sequence rocks. Likewise, no reasonable interpretation of "promptly detecting the repository" has been made for drilling in the vicinity of a radioactive waste repository. These, and other aspects of the 40 CFR 191, Appendix C guidance will be reevaluated and reasonable assumptions will be made and justified.

\subsubsection{Scenarios Evaluated for 40 CFR \$268.6}

Consequences of human intrusion are not evaluated for 40 CFR \$268.6. Undisturbed performance is modeled for 40 CFR $\$ 268.6$ using the same base-case scenario used for 40 CFR 191, as described in Section 8.1.4.5.1, with the exception that migration of specified RCRA hazardous constituents (e.g., heavy metals and VOCs) in either the gas or liquid phase is of interest rather than the migration of radionuclides. For the 1992 PA, transport of heavy metals and VOCs was not modeled explicitly, and gas and brine migration distances were examined as preliminary performance measures. Progress made since publishing the 1992 PA report is discussed in Section 8.1.5.2. The disposal unit boundaries for 40 CFR $\$ 268.6$ are limited to the top and bottom of the Salado Formation within the controlled area, rather than at the ground surface. 


\subsubsection{Calculation of Requlatory Performance Measures}

\subsubsection{40 CFR 191}

For the purposes of evaluating compliance with 40 CFR 191, the PA results represent risk as an ordered triplet consisting of the answers to the following three questions (Kaplan and Garrick, 1981):

1. What can happen? (scenarios)

2. How likely are things to happen? (probabilities of scenarios)

3. What are the consequences of these things (scenarios) happening?

As discussed in Section 8.1.4, the first question is answered by a systematic scenario construction procedure.

Answers to the second question, probabilities of human intrusion scenarios, are based on guidance which states: "...the likelihood of such inadvertent and intermittent drilling need not be taken to be greater than 30 boreholes per square kilometer of repository area per 10,000 years..."(EPA, 1985). Probabilities of human intrusion have been estimated in the 1992 PA for the first time using external expert judgement. Teams of experts from outside the WIPP Project were selected and organized into two panels to address 1) the nature of future societies and the possible modes of intrusion, and 2) types of markers and their potential effectiveness in deterring intrusion. The judgements elicited from these panels were used to construct an algorithm describing possible changes in drilling rate through time. The 1992 PA also presents results calculated using values for a time-invariant rate constant sampled from a distribution with a range from zero to a maximum value that corresponds to an expected value of 30 boreholes $/ \mathrm{km}^{2} / 10,000 \mathrm{yrs}$ (or 3.78 boreholes $/ 10,000 \mathrm{yr}$ in the 0.126 $\mathrm{km}^{2}$ waste-disposal area). For the 70 realizations used in the $1992 \mathrm{PA}$, the largest number of intrusions of the waste-disposal area that is included in the consequence analysis is ten (79 boreholes $/ \mathrm{km}^{2} / 10,000 \mathrm{yr}$ ), occurring with a probability of $3.5 \times 10^{-3}$. Larger numbers of intrusions are not considered consistent with requirements of $\$ 191.13$. Intrusion probabilities resulting from expert judgement are considerably lower, and yield a maximum of four intrusions in 10,000 yrs. Interpretation of expert judgement indicates that 30 boreholes $/ \mathrm{km}^{2} / 10,000 \mathrm{yrs}$ is a reasonable maximum value to use in constructing a distribution for a rate constant for intrusion. 
Answers to the third question, scenario consequences, are calculated using the computational models described in Section 8.1.2 and the Monte Carlo techniques discussed in Section 8.1.3.

\subsection{CFR \$191.13}

$\$ 191.13$ states:

...releases of radionuclides to the accessible environment for 10,000 years after disposal ... shall: 1) have a likelihood of less than one chance in 10 of exceeding the quantities calculated in Table 1 and 2) have a likelihood of less than one chance in 1000 of exceeding ten times the quantities calculated according to Table 1 .

Guidance provided in Appendix C of 40 CFR 191 suggests that:

...whenever practicable, the implementing agency will assemble all of the results of the performance assessments to determine compliance with $\$ 191.13$ into a "complementary cumulative distribution function" that indicates the probability of exceeding various levels of cumulative release. When the uncertainties in parameters are considered in a performance assessment, the effects of the uncertainties considered can be incorporated into a single such distribution function for each disposal system considered. The Agency assumes that a disposal system can be considered to be in compliance with $\S 191.13$ if this single distribution function meets the requirements of $\$ 191.13 \mathrm{a}$.

Once distribution functions have been developed for the imprecisely known parameters of interest (Section 8.1.3.1) and the sampies have been generated (Section 8.1.3.2) and propagated through the computational models (Section 8.1.2), conditional distribution functions (in the forms of a CCDF) can be produced for each set of input values (70 such conditional functions were generated in the 1992 PA). The conditional distribution functions CCDF is constructed by using the intrusion probability model (Section 8.1.5.1), calculating the summed normalized release for the appropriate number and type of intrusion (E1, E2, E1E2) and combining groundwater and drillings releases. The summed normalized release is calculated using normalizing factors from Table 1 of Appendix A of 40 CFR 191. The resulting family of conditional distribution functions can be displayed as a family of curves. For the purposes of demonstrating compliance, the DOE will use a single CCDF determined as the mean of the family of conditional distribution functions similar to the one shown in 
Figure 8-3. For the purposes of compliance analyses, replications of LHS sampling will be performed to assess the confidence in the mean CCDF. A student's T-test will be used to ensure that a statistically significant change in the mean at the $90 \%$ confidence level has not occurred.

\subsection{CFR \$191.15}

The regulatory performance measure for 40 CFR $\$ 191.15$ is the "annual committed effective dose, received through all potential pathways from the [undisturbed] disposal system, to any member of the public in the accessible environment...." The maximum annual committed effective dose during 10,000 years shall be less than 15 mrems.

Undisturbed performance is defined in $\$ 191.12$ as "the predicted behavior of a disposal system, including consideration of uncertainties in predicted behavior, if the disposal system is not disrupted by human intrusion or the occurrence of unlikely events."

No undisturbed PA calculations to date have shown any radionuclides reaching the accessible environment from the WIPP within 10,000 years. Calculated doses are, therefore, zero.

\subsection{CFR 191, Subpart C}

The regulatory performance measures for 40 CFR 191 , Subpart C, are the limits of radionuclides allowable in an underground source of drinking water (USDW) as specified in 40 CFR 141. These limits apply to radionuclide concentrations in a USDW at the accessible environment boundary for the 10,000-year undisturbed performance of the disposal system.

As noted in Section 8.1.5.1.2, no radionuclides are expected to reach the accessible environment during 10,000 years of undisturbed performance, and concentrations of radionuclides derived from WIPP are therefore zero.

\subsubsection{40 CFR $\$ 268.6$}

The regulatory performance measures for 40 CFR $\$ 268.6$ are the health-based soil concentration levels allowable for specified hazardous constituents as proposed in 40 CFR 264, Subpart S. 


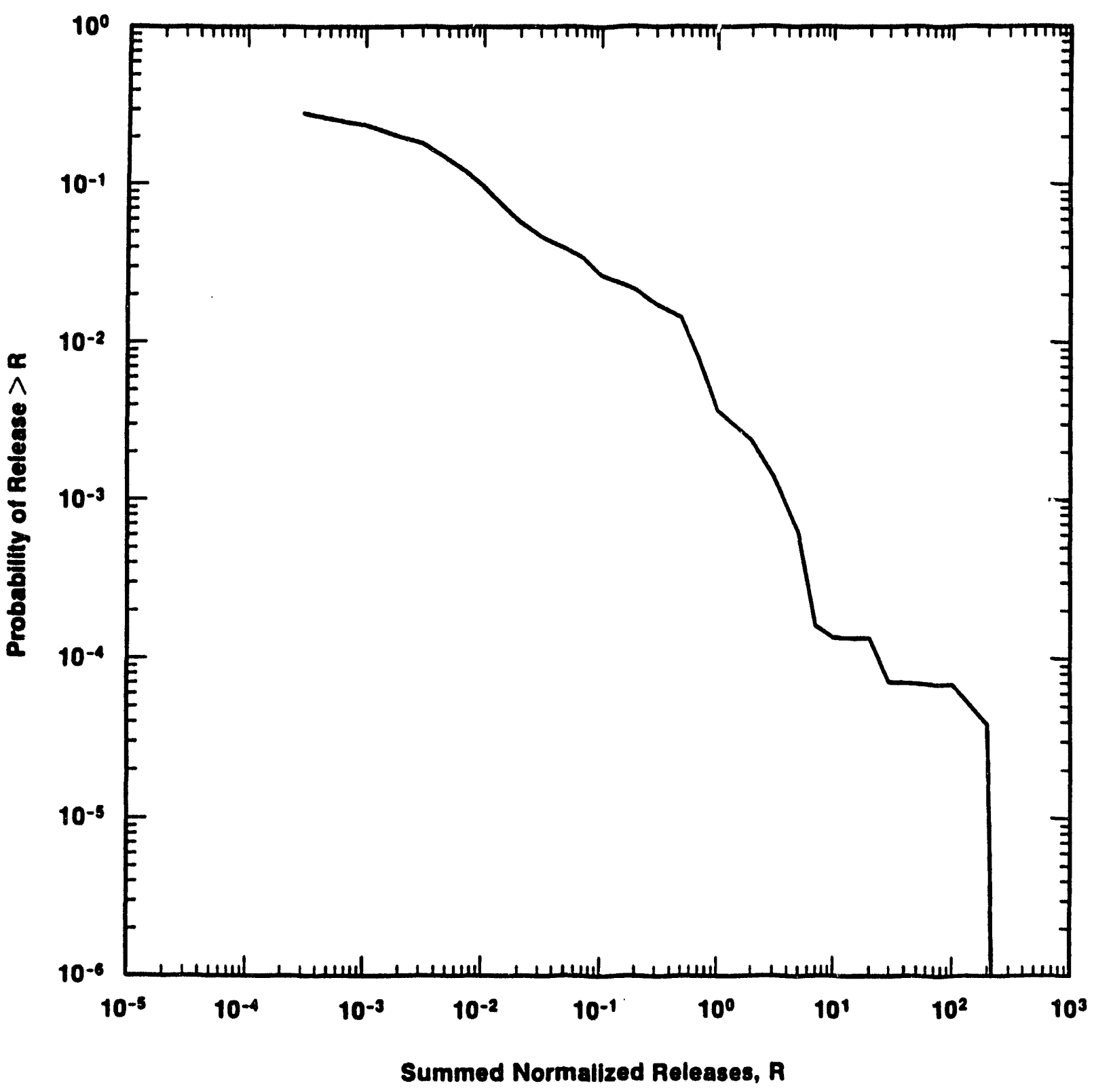

Figure 8-3 Example single CCDF derived as the mean of a family of conditional distribution functions. 
The 1992 PA did not include calculation of concentrations of specified hazardous constituents; gas and brine migration distances were used as surrogate performance measures for the purpose of sensitivity analysis. No performance measures are available at this time for preliminary comparison with the allowable limits. Since the 1992 PA report was published, components have been added to BRAGFLO to simulate transport of hazardous constituents in both the gas (VOCs) and liquid (heavy metals) phases.

Transport of VOCs includes the effects of liquid-vapor equilibria, sorption, and VOC decay. Emphasis in future compliance analyses will be placed on evaluations of compliance focused on physical processes. These evaluations will consider concentrations limited only by the initial VOC inventory and liquid-vapor phase equilibria. If necessary, data on sorption and decay may be obtained, starting with a compilation of relevant information in the open literature.

\subsection{Reasonable Expectation/Reasonable Degree of Certainty}

In addition to parameter uncertainty discussed in the previous sections, other sources of uncertainty are inherent to compliance calculations. Qualitative methods for managing uncertainty are described below.

\subsubsection{Role and Use of Expert Judgement}

40 CFR 191 Appendix C encourages the use of qualitative judgement to supplement numerical predictions. Such qualitative judgement is referred to as expert judgement. Expert judgement is the best professional opinion of experts in a particular field. It is used to synthesize what is known (existing data) to provide the required information for a particular application. Expert judgement will not be substituted for measured data without applying the reasonableness test to the acquisition of such empirical data. Expert judgement will, however, be used as a tool used to examine whatever data exist (however abundant or sparse, collected under whatever experimental conditions to provide the required information). Measured data from appropriate, practical experiments performed in a timely manner are preferred. The extent to which directly applicable data exist and to which a phenomenon is understood dictate the extent to which judgernent must be used to provide the required information. For subjects where data are sparse or nonexistent or were collected for other applications, or where the specific application requires assumptions be used for 
sensitive input parameters, formal expert judgement may be appropriate and necessary. For subjects where a great deal of directly applicable data exist and the phenomenon is well understood, less, or no judgement may be required (e.g., data may be analyzed by statistical techniques). The appropriate use of expert judgement must be evaluated on a case-by-case basis and is driven by individual circumstances.

A formalized process has been established for eliciting judgement from expert panels, and the PA program uses expert-judgement panels. Expert panels have provided probability distributions for calculations of the probability of future human intrusion at the WIPP and of the effectiveness of informational markers in deterring human intrusion. Expert panels have also provided interim cumulative probability distributions of concentrations for the various radionuclides in the repository environment and the retardation of radionuclides in the Culebra. This interim information will be replaced as appropriate measured data become available. Measured data will likely require interpretation for application over long distances and large time frames.

\subsubsection{Treatment of Uncertainty Associated with Alternative Conceptual Models}

The DOE's proposed method of dealing with past, present, and future conceptual models used in evaluating WIPP site characterization and repository performance is described below. Definitions for the terms conceptual model and alternative conceptual model are in Section 8.1.1.

The DOE employs a flexible process of dealing with conceptual model uncertainty throughout the assessment of regulatory compliance. This process is outlined in Figure 8-4. A formal approach to managing conceptual model uncertainty as part of an overall approach resolving technical issues is currently being developed.

\subsubsection{Documentation of Assumptions}

Important assumptions used in the 1992 PA for consequence modeling of the WIPP disposal system are listed in Table 8-4. Additional information about the basis for these assumptions, and their implications estimates of performance, can be found in the documentation of the 1992 PA report. Regulatory interpretations made relative to compliance with 40 CFR 191 ard $\$ 268.6$ are in Appendix A. 


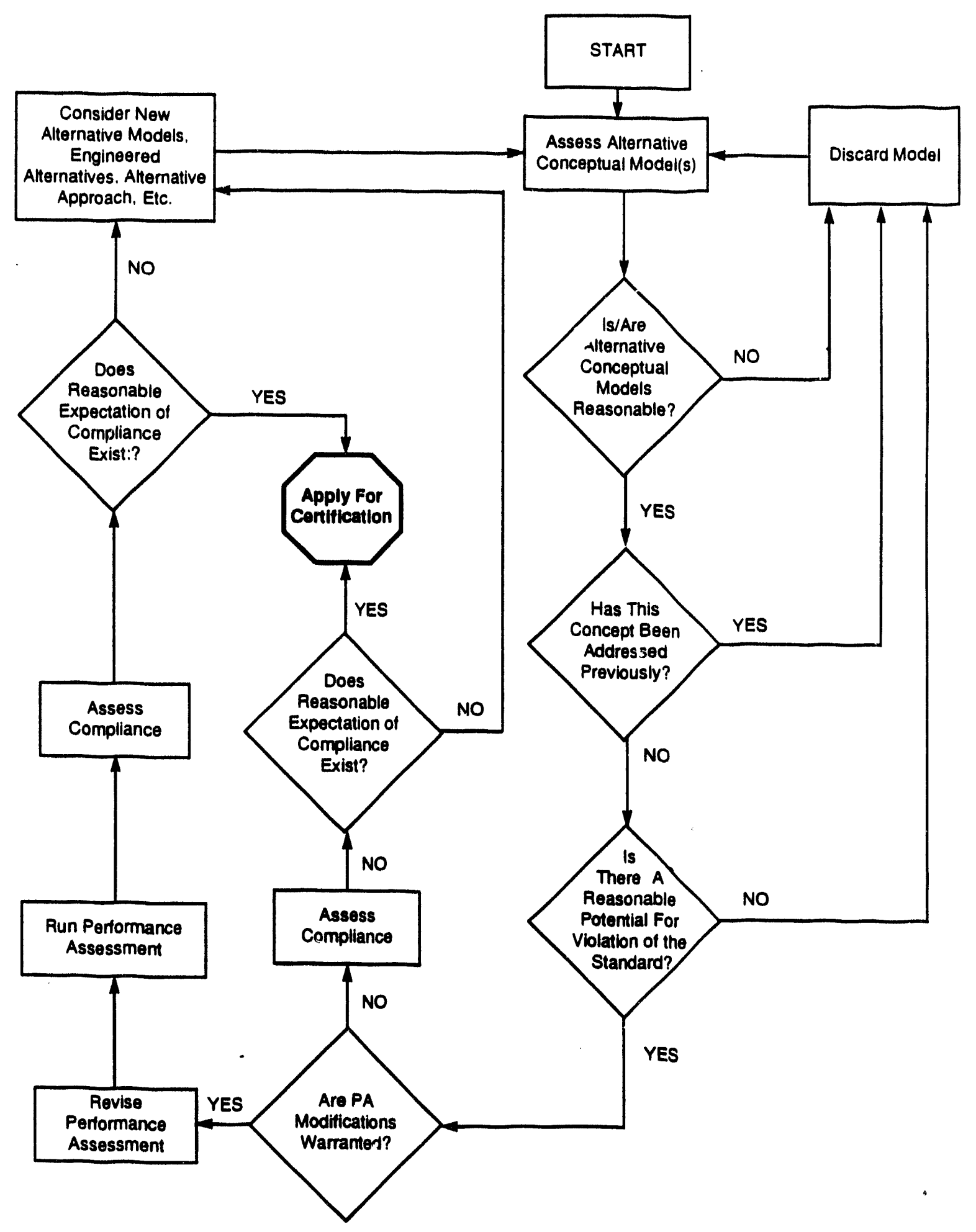

Figure 8-4 Process of Managing Uncertainty Associated with Alternative Conceptual Models 
Table 8-4 Partial List of Assumptions Made in Consequence Modeling for Disturbed Performance for the 1992 PA

\author{
Compliance-Assessment \\ System Component
}

Assumption

\section{REPOSITORY/SHAFT/ BOREHOLE MODEL}

Geologic units

Model Geometry

Waste/Backfill

Repository/Waste Interactions
Homogeneous time-invariant material properties within all units. The porosity of all materials varies slightly due to rock compressibility effects

Initial brine saturation in all geologic units

Single continuum porous media

Capillary pressure/saturation and relative permeability/saturation behavior similar to sand

Brine and gas flow obeys generalized Darcy's Law for compressible fluids in all media

Human intrusion scenarios simulated using a single horizontal panel with equivalent enclosed-volume cylindrical geometry

All material properties homogeneous throughout waste/backfill

Time- and pressure-dependent porosity determined by creep closure

No sorptive retardation in backfill

Radionuclide and gas-generation inventories extrapolated to design capacity

RH waste included in cuttings but not subsurface groundwater releases

No radionuclide transport as colloids

Gas generated by corrosion and biodegradation only (no radiolysis)

Gas generation proportional to brine saturation

Chemical reactions characterized by average stoichiometry 
Table 8-4 Partial List of Assumptions Made in Consequence Modeling for Disturbed Performance for the 1992 PA (continued)

Compliance-Assessment

System Component
Assumption
Hurnan Intrusion

\section{REPOSITORY/SHAFT MODELS}

Panel and Drift Seals (Salt Components)

Lower Shaft Seals (Salt Components)

GROUNDWATER-FLOW MODEL

Regional Hydrogeology

Rustler/Dewey Lake Hydrogeology
Brine consumption during corrosion; no gas consumed within the panel

No dissolved gas in brine phase

Radionuclide concentrations assumed to be uniform throughout panel and in equilibrium at all times

Exploratory hydrocarbon drilling only

Future drilling technology comparable to present

Arbitrary plug configurations for scenarios

Brine reservoirs in the Castile Fm. underlie portions of some waste panels

Probability of intrusion follows a Poisson process (i.e., random in space and time, with a rate constant based on expert judgement of the efficacy of passive markers)

Borehole-fill properties comparable to silty sand

Source for all intrusion boreholes for Culebra transport located above center of waste-disposal area

Reconsolidate to properties close to those of intact salt

Reconsolidate to properties close to those of intact salt

Rock properties are time invariant

Future climate variability bounded by past

2-D, confined, single porosity, Darcy flow model for Culebra

70 transmissivity fields conditioned on measured transmissivities at well locations and pilot point values represent uncertainty in field 


\title{
Table 8-4 Partial List of Assumptions Made in Consequence Modeling for Disturbed Performance for the 1992 PA (continued)
}

\author{
Compliance-Assessment \\ System Component \\ Assumption
}

Impacts of subsidence not considered

Future vertical flow through existing boreholes not considered

Variable-density effects not considered

Brine flow from intrusion borehole does not alter flow in Culebra

RADIONUCLIDE TRANSPORT MODEL

Physical Retardation

Chemical Retardation

\section{CUTTINGS/CAVINGS MODEL}

General

Drill Cuttings

Erosion/Cavings
Dual-porosity medium for transport

Retardation in both clay-lined fractures and dolomite matrix

Transport by colloids not considered

Homogeneous time-invariant waste properties

Present-day rotary drilling methods

Spalling from gas-filled waste panel not considered

Waste characterized by an effective shear strength independent of the degree of waste compaction

Erosion occurs when drilling fluid shear stress exceeds effective shear strength 


\subsection{Summary of Compliance Determination Data}

The 1992 PA produced $\mathrm{r}^{\mathrm{N}} \mathrm{lts}$ in a format defined by the requirements of 40 CFR $\$ 191.13$. These preliminary results are intended to provide program guidance through identification of controlling parameters and processes (provided in Chapter 10). A separate set of analyses was focused on the requirements of 40 CFR $\$ 268.6$, but did not include transport calculations. Performance measures relevant to 40 CFR $\$ 268.6$ are therefore not available. Instead, gas migration distance was used as a surrogate performance measure for the purpose of estimating parameter importance with respect to 40 CFR $\$ 268.6$ (see Chapter 10).

Results pertaining to the two standards are summarized separately. For preliminary comparison with 40 CFR $\$ 191.13$, results of the 1992 PA are presented in terms of a single mean CCDF. In addition, CCDFs for alternative conceptual models, which include variations in assumptions about the natural and engineered barrier systems, may be provided. Performance measures specified in 40 CFR $\$ 268.6$ were not calculated in the 1992 PA. The following sections also describe the parameters selected for consideration in the uncertainty and sensitivity analysis.

\subsection{1 $\quad$ 40 CFR 191}

\subsubsection{Parameters Chosen for 40 CFR 191 Analyses}

The 1992 PA selected 49 imprecisely known parameters for consideration in sensitivity and uncertainty analyses 40 CFR §191.13. Parameters were chosen for sampling in the 1992 PA if they fulfilled one of the three criteria: 1) the parameter proved to be at least moderately sensitive in the 1991 PA, 2) the parameter was an imprecisely known quantity in a consequence model introduced in 1992 PA, and 3) new data concerning an imprecisely known parameter suggesting significant revision of that parameter's distribution, was available by the end of April 1992. These parameters are listed in Table 8-5. The parameters and the rationale for their distributions are discussed extensively in Volume 3 of the 1992 PA report. 
Table 8-5 Parameters Sampled in the 1992 WIPP Performance Assessment for 40 CFR 191

\begin{tabular}{|c|c|}
\hline Parameter & Definition \\
\hline $\begin{array}{l}\text { Residual brine saturation for Salado } \\
\text { Formation }\end{array}$ & $\begin{array}{l}\left(\mathrm{S}_{\mathrm{lr}}\right) \text { (dimensionless). Used in BRAGFLO. Range } 0.0 \text { to } 0.4 \text {. Median } \\
0.2 \text {. Distribution: Uniform. Additional information: Section 2.3.1, } \\
\text { Volume } 3 \text { of the } 1992 \text { PA report. }\end{array}$ \\
\hline $\begin{array}{l}\text { Brooks and Corey pore-size } \\
\text { distribution parameter for Salado } \\
\text { Formation }\end{array}$ & $\begin{array}{l}\text { ( } \lambda \text { ) (dimensionless). Used in BRAGFLO. Range: } 0.2 \text { to } 10 \text {. Median } \\
0.7 \text {. Distribution: Piecewise uniform. Additional information: } \\
\text { Section 2.3.1, Volume } 3 \text { of the } 1992 \text { PA report. }\end{array}$ \\
\hline $\begin{array}{l}\text { Pointer variable (flag) for capillary } \\
\text { behavior }\end{array}$ & $\begin{array}{l}\text { Used in BRAGFLO. Range: }\{0,1\} \text {. Distribution: } 33 \% 0,67 \% 1 \text {. } \\
\text { Value of } 0 \text { selects van Genuchten-Parker model; value of } 1 \text { selects } \\
\text { Brooks-Corey model. Additional information: Section } 2.3 .1 \text {, Volume } \\
3 \text { of the } 1992 \text { PA report. }\end{array}$ \\
\hline $\begin{array}{l}\text { Brooks and Corey residual gas } \\
\text { saturation for Salado Formation }\end{array}$ & $\begin{array}{l}\left(S_{\mathrm{gr}}\right) \text { (dimensionless). Used in BRAGFLO. Range: } 0.0 \text { to } 0.4 \text {. } \\
\text { Median: } 0.2 \text {. Distribution: Uniform. Additional information: Section } \\
\text { 2.3.1, Volume } 3 \text { of the } 1992 \text { PA report. }\end{array}$ \\
\hline Borehole permeability & $\begin{array}{l}(\mathrm{k})\left(\mathrm{m}^{2}\right) \text {. Used in BRAGFLO. Range: } 1 \times 10^{-14} \text { to } 1 \times 10^{-11} \text {. Median: } \\
3.16 \times 10^{-12} \text {. Distribution: Lognormal. Additional information: Freeze } \\
\text { and Cherry, 1979, Table } 2-2 \text { (silty sand); Section } 4.2 .1 \text {, Volume } 3 \text { of } \\
\text { the } 1992 \text { PA report. }\end{array}$ \\
\hline $\begin{array}{l}\text { Initial pressure (p) of pressurized } \\
\text { brine pocket in Castile Formation }\end{array}$ & $\begin{array}{l}\text { (Pa). Used in BRAGFLO. Range: } 1.3 \times 10^{7} \text { to } 2.1 \times 10^{7} \text {. Median: } \\
1.7 \times 10^{7} \text {. Distribution: Piecewise linear. Additional information: } \\
\text { Popielak et al., 1983, p. H-52; Lappin et al., 1989, Table } 3-19 \text {; } \\
\text { Section 4.3.1, Volume } 3 \text { of the } 1992 \text { PA report. }\end{array}$ \\
\hline $\begin{array}{l}\text { Bulk storativity }\left(\mathrm{S}_{\mathrm{b}}\right) \text { of pressurized } \\
\text { brine pocket in Castile formation }\end{array}$ & $\begin{array}{l}\left(\mathrm{m}^{3} / \mathrm{Pa}\right) \text {. Used in BRAGFLO. Range: } 0.02 \text { to } 2 \text {. Median: } 0.2 \text {. } \\
\text { Distribution: Lognormal. Additional information: Section } 4.3 .1 \text {, } \\
\text { Volume } 3 \text { of the } 1992 \text { PA report. }\end{array}$ \\
\hline $\begin{array}{l}\text { Fraction of waste panel area underlain } \\
\text { by a pressurized brine pocket }\end{array}$ & $\begin{array}{l}\text { (dimensionless). Used in CCDFPERM in calculation of probability of } \\
\text { E1E2-type scenarios. Range: } 0.24 \text { to } 0.568 \text {. Median: } 0.40 . \\
\text { Distribution: Piecewise linear. Additional information: Section } 5.1 \text {, } \\
\text { Volume } 3 \text { of the } 1992 \text { PA report. }\end{array}$ \\
\hline Initial fluid (brine) saturation of waste & $\begin{array}{l}\text { (dimensionless). Used in BRAGFLO. Range: } 0 \text { to } 0.14 \text {. Median: } \\
0.07 \text {. Distribution: Uniform. Additional information: Section } 3.4 .3 \text {, } \\
\text { Volume } 3 \text { of the } 1992 \text { PA report. }\end{array}$ \\
\hline
\end{tabular}




\section{Table 8-5 Parameters Sampled in the 1992 WIPP Performance Assessment} (continued)

\begin{tabular}{|c|c|}
\hline Parameter & Definition \\
\hline $\begin{array}{l}\text { Recharge amplitude factor }\left(A_{m}\right) \text { for } \\
\text { Culebra }\end{array}$ & $\begin{array}{l}\text { (dimensionless). Used in SECO-FLOW. Range: } 1 \text { to } 1.07 \text {. Median: } \\
1.035 \text {. Distribution: Uniform. Used in definition of time dependent } \\
\text { boundary heads in Culebra, with the maximum head increasing from the } \\
\text { estimated present-day head in the Culebra in the northernmost element of } \\
\text { the regional model domain for CULCLIM }=1 \text { to the elevation of the } \\
\text { Clayton Basin spill point }(1,007 \mathrm{~m}) \text { for CULCLIM }=1.07 \text {. Additional } \\
\text { information: Section } 6.4 \text {, Volume } 4 \text { of the } 1992 \text { PA report. Uniformly } \\
\text { distributed on [0,1] and used to select value for CULCLIM by } \\
\text { preprocessor to SECO-FLOW. }\end{array}$ \\
\hline Fracture porosity $\left(\theta_{\mathrm{f}}\right)$ in Culebra & $\begin{array}{l}\text { (dimensionless). Used in SECO-FLOW and SECO-TRANSPORT. } \\
\text { Range: } 1 \times 10^{-4} \text { to } 1 \times 10^{-2} \text {. Median: } 1 \times 10^{-3} \text {. Distribution: Lognormal. } \\
\text { Additional information: Tables } 1-2 \text { and E-6, Lappin et al., 1989; Section } \\
\text { 2.6.2, Volume } 3 \text { of the } 1992 \text { PA report. }\end{array}$ \\
\hline Fracture spacing (2B) in Culebra & $\begin{array}{l}\text { (m). Used in SECO-TRANSPORT. Range: } 6 \times 10^{-2} \text { to } 8 \text {. Median: } 4 \\
\times 10^{-1} \text {. Distribution: Piecewise uniform. Additional information: } \\
\text { Beauheim et al., 1991a. }\end{array}$ \\
\hline $\begin{array}{l}\text { Clay filling fraction }\left(b_{c} / b\right) \text { in } \\
\text { Culebra }\end{array}$ & $\begin{array}{l}\text { (dimensionless), where } 2 b \text { is the fracture aperture and } 2 b_{c} \text { is the total } \\
\text { thickness of the clay lining in the fracture. Used in SECO- } \\
\text { TRANSPORT. Range: } 0 \text { to } 0.5 \text {. Median } 0 \text {. Distribution: } b_{c} / b=0 \text { has } \\
\text { probability } 0.5 \text { and } b c / b \neq 0 \text { is uniformly distributed between } 0 \text { and } 0.5 \text {. } \\
\text { Additional information: Section } 2.6 .1 \text {, Volume } 3 \text { of the } 1992 \text { PA report. }\end{array}$ \\
\hline $\begin{array}{l}\text { Porosity of clay lining fractures in } \\
\text { Culebra }\end{array}$ & $\begin{array}{l}\text { (dimensionless). Used in SECOTP. Range: } 0.05 \text { to } 0.5 \text {. Median: } 0.275 \text {. } \\
\text { Distribution: Uniform. Additional information: Section } 2.6 .2 \text {, Volume } \\
3 \text { of the } 1992 \text { PA report. }\end{array}$ \\
\hline Matrix porosity $\left(\theta_{m}\right)$ in Culebra & $\begin{array}{l}\text { (dimensionless). Used in BRAGFLO and SECO-TRANSPORT. Range: } \\
5.8 \times 10^{-2} \text { to } 2.53 \times 10^{-1} \text {. Median: } 1.39 \times 10^{-1} \text {. Distribution: Piecewise } \\
\text { uniform. Additional information: Table 4.4, Kelley and Saulnier, 1990; } \\
\text { Table E-8, Lappin et al., 1989; Section 2.6.2, Volume } 3 \text { of the } 1992 \mathrm{PA} \\
\text { report. }\end{array}$ \\
\hline Transmissivity field for Culebra & $\begin{array}{l}\text { Seventy transmissivity fields consistent with available field data were } \\
\text { constructed and ranked with respect to travel time to the accessible } \\
\text { environment. CULTRFLD is a pointer variable used to select from these } \\
70 \text { fields, with travel time increasing monotonically with CULTRFLD. } \\
\text { Used in STAFF2D and SECO-TRANSPORT. Range: } 0 \text { to } 1 \text {. Median: } \\
0.5 \text {. Distribution: Uniform. Additional information: Section } 7.5 \text {, } \\
\text { Volume } 2 \text { of the } 1992 \text { PA report; Section } 2.6 .3 \text {, Volume } 3 \text { of the } 1992 \\
\text { PA report. }\end{array}$ \\
\hline
\end{tabular}




\section{Table 8-5 Parameters Sampled in the 1992 WIPP Performance Assessment} (continued)

\section{Parameter}

Drill bit diameter

Fracture distribution coefficient $\left(K_{d}\right)$ for Am in Culebra

Fracture distribution coefficient $\left(\mathrm{K}_{\mathrm{d}}\right)$ for $\mathrm{Np}$ in Culebra

Fracture distribution coefficient $\left(\mathrm{K}_{\mathrm{d}}\right)$ for $\mathrm{Pu}$ in Culebra

Fracture distribution coefficient $\left(\mathrm{K}_{d}\right)$ for $\mathrm{Ra}$ in Culebra

Fracture distribution coefficient $\left(K_{d}\right)$ for Th in Culebra

Fracture distribution coefficient $\left(K_{d}\right)$ for $U$ in Culebra

Scale factor used in definition of gas generation rate for corrosion of steel under humid conditions

Gas generation rate for corrosion of steel under inundated conditions

Scale factor used in definition of gas generation rate due to microbial degradation of cellulosics under humid conditions

\section{Definition}

(m). Used in CUTTINGS and BRAGFLO. Range: 0.267 to 0.444 . Median: 0.355. Distribution: Uniform. Additional information: Section 4.2.2, Volume 3 of the 1992 PA report.

$\left(\mathrm{m}^{3} / \mathrm{kg}\right)$. Used in SECO-TRANSPORT. Range: $1 \times 10^{-4}$ to $1 \times 10^{3}$. Median: $9.33 \times 10^{1}$. Distribution: Piecewise loguniform. Additional information: Section 2.6.4, Volume 3 of the 1992 PA report.

$\left(\mathrm{m}^{3} / \mathrm{kg}\right)$. Used in SECO-TRANSPORT. Range: $1 \times 10^{-4}$ to $1 \times 10^{3}$. Median: 1. Distribution: Piecewise loguniform. Additional information: Section 2.6.4, Volume 3 of the 1992 PA report.

$\left(\mathrm{m}^{3} / \mathrm{kg}\right)$. Used in SECO-TRANSPORT. Range: $1 \times 10^{-4}$ to $1 \times 10^{3}$. Median: $2.04 \times 10^{2}$. Distribution: Piecewise loguniform. Additional information: Section 2.6.4, Volume 3 of the 1992 PA report.

$\left(\mathrm{m}^{3} / \mathrm{kg}\right)$. Used in SECO-TRANSPORT. Range: $1 \times 10^{-4}$ to $1 \times 10^{2}$. Median: $3.31 \times 10^{-2}$. Distribution: Piecewise loguniform. Additional information: Section 2.6.4, Volume 3 of the 1992 PA report.

$\left(\mathrm{m}^{3} / \mathrm{kg}\right)$. Used in SECO-TRANSPORT. Range: $1 \times 10^{-4}$ to $1 \times 10^{1}$. Median: $1 \times 10^{-1}$. Distribution: Piecewise loguniform. Additional information: Section 2.6.4, Volume 3 of the 1992 PA report.

$\left(\mathrm{m}^{3} / \mathrm{kg}\right)$. Used in SECO-TRANSPORT. Range: $1 \times 10^{-4}$ to 1 . Median: $7.94 \times 10^{-3}$. Distribution: Piecewise loguniform. Additional information: Section 2.6.4, Volume 3 of the 1992 PA report.

(dimensionless). Actual gas generation rate is GRCORH = GRCORHF॰GRCORI. Used in BRAGFLO. Range: 0 to 0.5. Median: 0.1. Distribution: Piecewise uniform. Additional information: Brush, 1991.

( $\mathrm{mol} / \mathrm{m}^{2}$ surface area steel $\left.\bullet \mathrm{s}\right)$. Used in BRAGFLO. Range: 0 to $1.3 \mathrm{x}$ $10^{-8}$. Median: $6.3 \times 10^{-9}$. Distribution: Piecewise uniform. Additional information: Same as GRCORHF.

(mol $/ \mathrm{kg}$ cellulosics`s). Actual gas generation rate is $\mathrm{GRMICH}=$ GRMICHF•GRMICI. Used in BRAGFLO. Range: 0 to 0.2 . Median: 0.1. Distribution: Uniform. Additional information: Same as GRCORHF. 


\section{Table 8-5 Parameters Sampled in the 1992 WIPP Performance Assessment} (continued)

\section{Parameter}

Gas generation rate due to microbial degradation of cellulosics under inundated conditions

Pointer variable used to select rate term $\left(\lambda\right.$ or $\lambda(t)$, units: $\left.\mathrm{yr}^{-1}\right)$ in Poisson model for drilling intrusions.

Permeability (k) in intact anhydrite marker beds in Salado Formation

Porosity $(\phi)$ in intact anhydrite marker beds in Salado Formation

Far field pressure (p) in Salado Formation at the MB139 elevation

Matrix distribution coefficient $\left(\mathbf{K}_{\mathbf{q}}\right)$ for Am in Culebra

Matrix distribution coefficient $\left(\mathbf{K}_{d}\right)$ for $\mathrm{Np}$ in Culebra

Matrix distribution coefficient $\left(\mathbf{K}_{d}\right)$ for Pu in Culebra

Matrix distribution coefficient $\left(\mathbf{K}_{d}\right)$ for $\mathbf{R a}$ in Culebra

Matrix distribution coefficient $\left(\mathbf{K}_{d}\right)$ for $\mathrm{Th}$ in Culebra

\section{Definition}

(mol $/ \mathrm{kg}$ cellulosics $\bullet$ ). Used in BRAGFLO. Range: 0 to $1.6 \times 10^{-8}$. Median: $3.2 \times 10^{-9}$. Distribution: Piecewise uniform. Additional information: Same as GRCORHF.

Used in CCDFPERM. Range: 0 to 1 . Median: 0.5. Distribution: Uniform. Additional information: Section 5.2, Volume 3 of the 1992 PA report.

$\left(\mathrm{m}^{2}\right)$. Used in BRAGFLO. Range: $1 \times 10^{-21}$ to $1 \times 10^{-16}$. Median: 5.0 $\mathrm{x} 10^{-20}$. Distribution: Piecewise loguniform. Correlation: 0.3 rank correlation with SALPERM. Additional information: Section 2.4.2, Volume 3 of the 1992 PA report.

(dimensionless). Used in BRAGFLO. Range: $1 \times 10^{-3}$ to $3 \times 10^{-2}$. Median: $1 \times 10^{-2}$. Distribution: Piecewise uniform. Additional information: Section 2.4.4, Volume 3 of the 1992 PA report.

Used in BRAGFLO. Range: $1.2 \times 10^{7}$ to $1.3 \times 10^{7}$. Median: $1.25 \times 10^{7}$. Distribution: Uniform. Additional information: Section 2.4.3, Volume 3 of the 1992 PA report.

$\left(\mathrm{m}^{3} / \mathrm{kg}\right)$. Used in SECO-TRANSPORT. Range: $1 \times 10^{-4}$ to $1 \times 10^{2}$. Median: $1.86 \times 10^{-1}$. Distribution: Piecewise loguniform. Additional information: Section 2.6.4, Volume 3 of the 1992 PA report.

$\left(\mathrm{m}^{3} / \mathrm{kg}\right)$. Used in SECO-TRANSPORT. Range: $1 \times 10^{4}$ to $1 \times 10^{2}$. Median: $4.78 \times 10^{-2}$. Distribution: Piecewise loguniform. Additional information: Section 2.6.4, Volume 3 of the 1992 PA report.

$\left(\mathrm{m}^{3} / \mathrm{kg}\right)$. Used in SECO-TRANSPORT. Range: $1 \times 10^{-4}$ to $1 \times 10^{2}$. Median: $2.61 \times 10^{-1}$. Distribution: Piecewise loguniform. Additional information: Section 2.6.4, Volume 3 of the 1992 PA report.

$\left(\mathrm{m}^{3} / \mathrm{kg}\right)$. Used in SECO-TRANSPORT. Range: $1 \times 10^{-4}$ to $1 \times 10^{1}$. Median: $1 \times 10^{-2}$. Distribution: Piecewise loguniform. Additional information: Section 2.6.4, Volume 3 of the 1992 PA report.

$\left(\mathrm{m}^{3} / \mathrm{kg}\right)$. Used in SECO-TRANSPORT. Range: $1 \times 10^{-4}$ to 1 . Median: $1 \times 10^{-2}$. Distribution: Piecewise loguniform. Additional information: Section 2.6.4, Volume 3 of the 1992 PA report. 
Table 8-5 Parameters Sampled in the 1992 WIPP Performance Assessment (continued)

\section{Parameter}

Matrix distribution coefficient $\left(\mathbf{K}_{\mathbf{d}}\right)$ for $\mathrm{U}$ in Culebra

Permeability $(k)$ in intact halite component of Salado Formation

Solubility of Am in brine ( $\mathrm{mol} / \ell)$

Solubility of $\mathrm{Np}$ in brine

Solubility of $\mathrm{Pu}$ in brine

Solubility of $\mathrm{Ra}$ in brine

Solubility of Th in brine

Solubility of $U$ in brine

Stoichiometric coefficient for corrosion of steel

Stoichiometric coefficient for microbial degradation of cellulosics

\section{Definition}

$\left(\mathrm{m}^{3} / \mathrm{kg}\right)$. Used in SECO-TRANSPORT. Range: $1 \times 10^{-4}$ to 1 . Median: $2.88 \times 10^{-2}$. Distribution: Piecewise loguniform. Additional information: Section 2.6.4, Volume 3 of the 1992 PA report.

$\left(\mathrm{m}^{2}\right)$. Used in BRAGFLO. Range $1 \times 10^{-24}$ to $1 \times 10^{-19}$. Median: $2 \times 10^{-}$ 21. Distribution: Piecewise loguniform. Correlation: 0.3 rank correlation with MBPERM. Additional information: Gorham et al., 1992; Howarth et al., 1991; Beauheim et al., 1991b; Section 2.3.5, Volume 3 of the 1992 PA report.

Used in PANEL. Range: $5 \times 10^{-14}$ to 1.4 . Median: $1 \times 10^{-9}$. Distribution: Piecewise loguniform. Additional information: Trauth et al., 1991; Section 3.3.5, Volume 3 of the 1992 PA report.

(mol $/ \ell$ ). Used in PANEL. Range: $3 \times 10^{-16}$ to $1.2 \times 10^{-2}$. Median: 1.0 $x$ 10.7 . Distribution: Piecewise loguniform. Additional information: Trauth et al., 1991; Section 3.3.5, Volume 3 of the 1992 PA report.

(mol/l). Used in PANEL. Range: $2.5 \times 10^{-17}$ to $5.5 \times 10^{-4}$. Median: 6 $x 10^{-10}$. Distribution: Piecewise loguniform. Additional information: Trauth et al., 1991; Section 3.3.5, Volume 3 of the 1992 PA report.

(mol/l). Used in PANEL. Range: 2 to 18.2. Median: 11. Distribution: Piecewise loguniform. Additional information: Trauth et al., 1991; Section 3.3.5, Volume 3 of the 1992 PA report.

(mol/ $\ell$ ). Used in PANEL. Range: $5.5 \times 10^{-16}$ to $2.2 \times 10^{-6}$. Median: 1 $\times 10^{-10}$. Distribution: Piecewise loguniform. Additional information: Trauth et al., 1991; Section 3.3.5, Volume 3 of the 1992 PA report.

(mol/ $\ell$ ). Used in PANEL. Range: $1 \times 10^{-15}$ to 1 . Median: $5.4 \times 10^{-4}$. Distribution: Piecewise loguniform. Additional information: Trauth et al., 1991; Section 3.3.5, Volume 3 of the 1992 PA report.

(dimensionless). Defines proportion of two different chemical reactions taking place during the corrosion process. Used in BRAGFLO. Range: 0 to 1. Median: 0.5. Distribution: Uniform. Additional information: Brush and Anderson, 1989.

(mol gas/mol $\mathrm{CH}_{2} \mathrm{O}$ ). Used in BRAGFLO. Range: 0 to 1.67. Median: 0.835. Distribution: Uniform. Additional information: Brush and Anderson, 1989. 

$\begin{array}{ll}\text { Table 8-5 } & \text { Parameters Sampled in the } 1992 \text { WIPP Performance Assessment } \\ \text { (continued) }\end{array}$

\begin{tabular}{|c|c|}
\hline Parameter & Definition \\
\hline $\begin{array}{l}\text { Scale factor used in definition of } \\
\text { transition zone and disturbed rock } \\
\text { zone porosity }\left(\phi_{z}\right) \text {, with the } \\
\text { transition zone and disturbed rock } \\
\text { zone porosity defined by TZPOR } \\
=\text { SALPOR + }(0.06 \text { - } \\
\text { SALPOR)•TZPORF. }\end{array}$ & $\begin{array}{l}\text { Used in BRAGFLO. Range: } 0 \text { to } 1 . \text { Median: } 0.5 \text {. Distribution: } \\
\text { Uniform. Additional information: Section 2.4.4, Volume } 3 \text { of the } 1992 \\
\text { PA report. }\end{array}$ \\
\hline $\begin{array}{l}\text { Fraction of total waste volume that } \\
\text { is occupied by IDB (Integrated } \\
\text { Data Base) metals and glass waste } \\
\text { category }\end{array}$ & $\begin{array}{l}\text { (dimensionless). Used in BRAGFLO. Range: } 0.276 \text { to } 0.476 \text {. Median: } \\
0.376 \text {. Distribution: Normal. Additional information: Section 3.4.1, } \\
\text { Volume } 3 \text { of the } 1992 \text { PA report. }\end{array}$ \\
\hline $\begin{array}{l}\text { Fraction of total waste volume that } \\
\text { is occupied by IDB combustible } \\
\text { waste category }\end{array}$ & $\begin{array}{l}\text { (dimensionless). Used in BRAGFLO. Range: } 0.284 \text { to } 0.484 \text {. Median: } \\
0.384 \text {. Distribution: Normal. Additional information: Section 3.4.1, } \\
\text { Volume } 3 \text { of the } 1992 \text { PA report. }\end{array}$ \\
\hline
\end{tabular}




\subsubsection{Results of PA Analyses for 40 CFR \$191.13}

Results discussed here are conditional on the conceptual and computational models used in the analyses, the selection of parameters for sampling in uncertainty analyses, and the distributions used to describe uncertainty in those parameter values. All CCDFs shown here are mean curves based on 70 separate realizations, and all display consequences of human intrusions occurring only at 1,000 years after decommissioning of the facility. Integrated releases from later intrusions are not anticipated to be greater than those from the 1,000-year events because of the additional time for radioactive decay and less time for subsurface transport (the time between intrusion and 10,000 years). Future PAs will consider consequences of intrusions throughout the 10,000-year period.

In Figure 8-5, CCDFs are shown for three alternative models for radionuclide transport in the Culebra (single-porosity fracture-only transport, and dual-porosity transport with and without chemical retardation) and two intrusion-probability models (with and without the use of expert judgement on the efficacy of passive markers). In addition, Figure 8-5 shows releases into the Culebra from the intrusion borehole with a dashed line. Comparison of these five CCDFs provides insights into the relative impacts on performance of specific compcnents and conceptual models of the natural barrier system and institutional controls at the WIPP. The uppermost CCDF in Figure 8-5, labeled "Total, Single Porosity + Cuttings, $\lambda_{0}$ " (no expert judgement on intrusion probability), represents an estimate of the performance of the disposal system with very little contribution from the natural barrier provided by the in the Culebra and no contribution from the institutional barrier that would be provided by passive markers, as required by 40 CFR $\$ 191.14$.

The segments of a CCDF shown with a dotted line and labeled "Total, Discharge from Borehole + Cuttings, $\lambda_{0}$ " display performance with no contribution whatsoever from retardation in the Culebra. This CCDF is unlike all others shown in Figure 8-5 in that releases are not calculated at the accessible environment boundary, and it is therefore not suitable for comparison, preliminary or otherwise, with 40 CFR $\$ 191.13$. The curve displays releases directly into the Culebra (with cuttings and cavings included). The CCDF is displayed here only for the comparison with the curve described in the preceding paragraph and to provide an estimate of performance taking credit only for engineered barriers and the Salado Formation. Differences between the two curves are caused by radioactive decay during transport. 


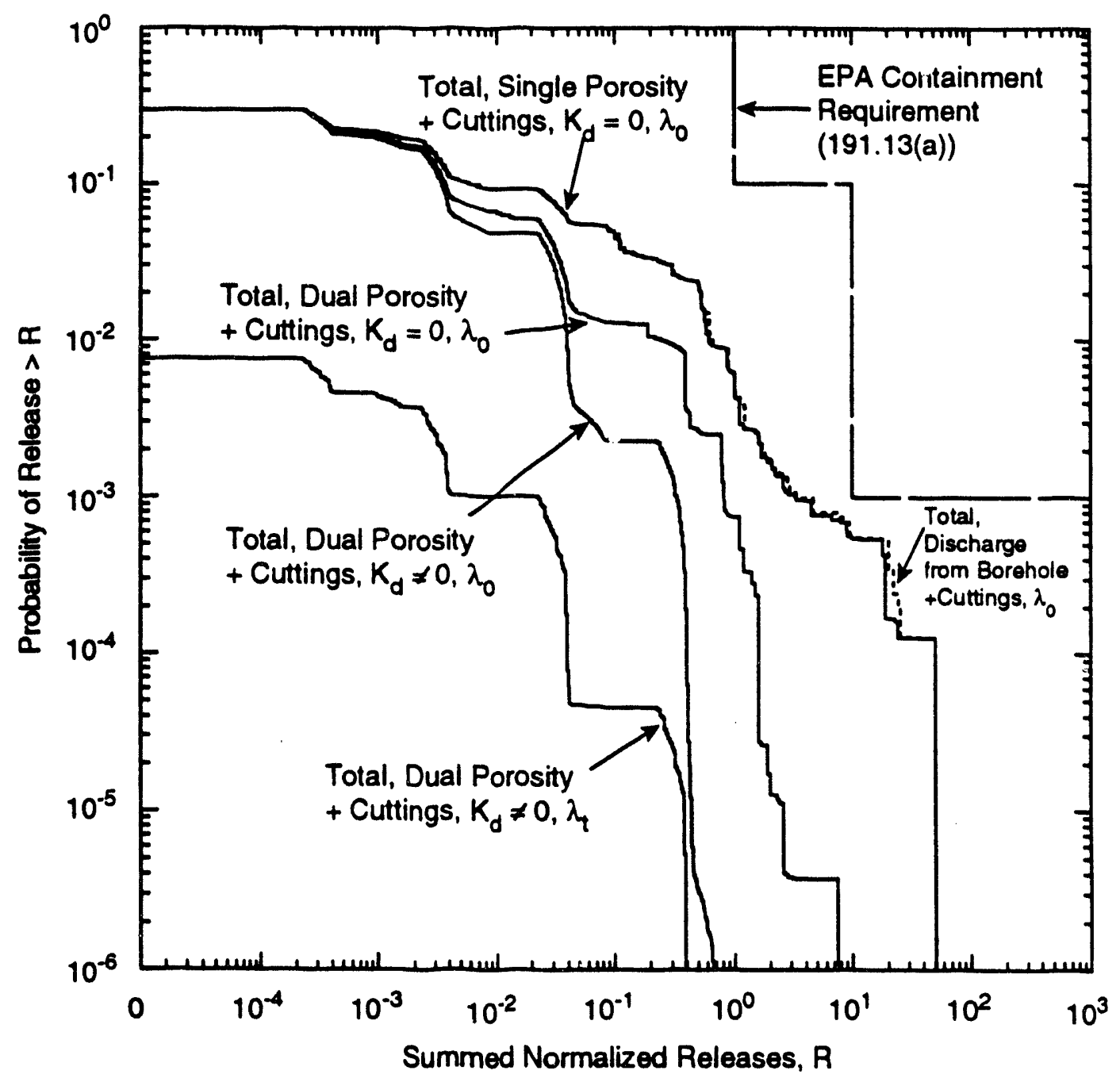

Figure 8-5

Comparison of mean CCDFs for total (cuttings plus subsurface) releases from intrusions occurring at 1,000 years showing the impact of including specific components of the natural and institutional barrier systems. Both curves shown for $K_{d} \neq 0$ are dominated completely by cuttings releases. Summed normalized releases are displayed using an inverse hyperbolic sine scale, which differs from a logarithmic scale only in the interval between zero and $10^{4}$. 
The CCDF in Figure 8-5 labeled "Total, Dual Porosity + Cuttings, $K_{d}=0, \lambda_{0}$, " represents an estimate of the performance of the disposal system if physical retardation by diffusion into the pore volume of the Culebra is included as a part of the natural barier system. The area between the first and second CCDFs is a measure of the potential regulatory impact of including physical retardation. Similarly, the next CCDF in the figure, calculated using the dual-porosity, $K_{d} \neq 0$, and no expert judgement on intrusion probability, represents an estimate of the performance of the disposal system if both physical and chemical retardation are included in the natural barrier system. The inclusion of chemical retardation reduces groundwater releases below those estimated for cuttings and cavings, and the location of this CCDF is determined entirely by releases at the surface during drilling.

The final CCDF shown here, calculated using the dual-porosity, $\mathbf{K}_{\mathrm{d}} \neq 0$, shows the effect of including expert judgement on the efficacy of passive markers in reducing the probability of human intrusion. Like the previous CCDF, the location of this curve is determined entirely by releases at the surface during drilling.

\subsubsection{CFR 8268.6}

\subsubsection{Parameters Chosen for 40 CFR \$268.6 Analyses}

Table 8-6 identifies the 25 variables sampled for the 40 CFR $\$ 268.6$ analyses, and provides information about ranges and distributions. The 19 variables unchanged from other analyses in the 1992 PA are listed first, and are followed by the six additional variables added for the 40 CFR \$268.6 analyses. The six parameters were sampled for the undisturbed calculations reported in Volume 5 of the 1992 PA report only and were not used in the calculations reported above in Section 8.3.1 or in Volume 4 of the 1992 PA report. Sampled values for these parameters are given in Appendix B, Volume 5 of the 1992 PA report.

\subsubsection{Results of PA Analyses for 40 CFR \$268.6}

The 1992 PA did not include modeling of the transport of specified hazardous constituents for 40 CFR \$268.6, and estimates of concentrations of these materials are not available. No performance measures are reported for preliminary comparison with regulatory standards. Intermediate performance measures used in sensitivity analyses are discussed in the following sections. 
Table 8-6 Parameters Sampled in the 1992 Performance Assessment for 40 CFR \$268.6

\section{Parameter}

Residual brine saturation for Salado Formation

Brooks-Corey pore-size distribution parameter for Salado Formation

Pointer variable (flag) for capillary behavior submodel.

Brooks-Corey residual gas saturation for Salado Formation

Initial liquid (brine) saturation of waste

Matrix porosity $(\Theta \mathrm{m})$ in Culebra

Scale factor used in definition of gas generation rate for corrosion of steel under humid conditions

Gas generation rate for corrosion of steel under inundated conditions

Scale factor used in definition of gas generation rate due to microbial degradation of cellulosics under humid conditions

Gas generation rate due to microbial degradation of cellulosics under inundated conditions

Permeability (k) in intact anhydrite marker beds in Salado Formation
$\left(\mathrm{S}_{\mathrm{lr}}\right)$ (dimensionless). Range 0.0 to 0.4 . Median 0.2. Distribution: Uniform.

( $\lambda$ ) (dimensionless). Range: 0.2 to 10. Median 0.7. Distribution: Piecewise uniform.

Range: 0 or 1. Distribution: $33 \% 0,67 \% 1$. Value of 0 selects van Genuchten-Parker model; value of 1 selects Brooks-Corey model.

$\left(\mathrm{S}_{\mathrm{gr}}\right)$ (dimensionless). Range: 0.0 to 0.4. Median: 0.2. Distribution: Uniform.

(dimensionless). Range: 0 to 0.14 . Median: 0.07 . Distribution: Uniform.

(dimensionless). Range: $5.8 \times 10^{-2}$ to $2.53 \times 10^{-1}$. Median: $1.39 \times 10^{-1}$. Distribution: Piecewise uniform.

(dimensionless). Actual gas generation rate is GRCORH = GRCORHF-GRCORI. Range: 0 to 0.5. Median: 0.1. Distribution: Piecewise uniform.

(mol/ $/ \mathrm{m}^{2} \bullet$ surface area steels). Range: 0 to $1.3 \times 10^{-8} \bullet \mathrm{s}$. Median: 6.3 x $10^{-9}$. Distribution: Piecewise uniform.

(mol $/ \mathrm{kg}$ cellulosicses). Actual gas generation rate is $\mathrm{GRMICH}=$ GRMICHF॰GRMICI. Range: 0 to 0.2. Median: 0.1. Distribution: Uniform.

(mol $/ \mathrm{kg} \bullet$ s cellulosics). Range: 0 to $1.6 \times 10^{-8}$. Median: $3.2 \times 10^{-9}$. Distribution: Piecewise uniform.

$\left(\mathrm{m}^{2}\right)$. Range: $1 \times 10^{-21}$ to $1 \times 10^{-16}$. Median: $5.0 \times 10^{-20}$. Distribution: Piecewise loguniform. Correlation: 0.3 rank correlation with SALPERM. 
Table 8-6 Parameters Sampled in the 1992 Performance Assessment for 40 CFR \$268.6 (continued)

Parameter

Porosity $(\phi)$ in intact anhydrite marker beds in Salado Formation

Far field pressure (p) in Salado

Formation at the MB139 elevation

Permeability (k) in intact halite component of Salado Formation

Stoichiometric coefficient for corrosion of steel

Stoichiometric coefficient for microbial degradation of cellulosics

Scale factor used in definition of transition zone and disturbed rock zone porosity $(\phi z)$, with the transition zone and disturbed rock zone porosity defined by TZPOR $=$ SALPOR $+(0.06$ SALPOR)・TZPORF.

Fraction of total waste volume that is occupied by IDB (Integrated Data Base) metals and glass waste category

Fraction of total waste volume that is occupied by IDB combustible waste category

Porosity of backfill materials in drifts and experimental region and in the shaft below the shaft seal

Permeability of panel and drift seals

\section{Definition}

(dimensionless). Range: $1 \times 10^{-3}$ to $3 \times 10^{-2}$. Median: $1 \times 10^{-2}$. Distribution: Piecewise uniform.

Range: $1.2 \times 10^{7}$ to $1.3 \times 10^{7}$. Median: $1.25 \times 10^{7}$. Distribution: Uniform.

$\left(\mathrm{m}^{2}\right)$. Range $1 \times 10^{-24}$ to $1 \times 10^{-19}$. Median: $2 \times 10^{-21}$. Distribution: Piecewise loguniform. Correlation: 0.3 rank correlation with MBPERM.

(dimensionless). Defines proportion of two different chemical reactions taking place during the corrosion process. Range: 0 to 1 . Median: 0.5 . Distribution: Uniform.

(mol gas/mol $\mathrm{CH}_{2} \mathrm{O}$ ). Range: 0 to 1.67 . Median: 0.835 . Distribution: Uniform.

Range: 0 to 1. Median: 0.5. Distribution: Uniform.

(dimensionless). Range: 0.276 to 0.476 . Median: 0.376 . Distribution: Normal.

(dimensionless). Range: 0.285 to 0.484 . Median: 0.384 . Distribution: Normal.

(dimensionless). Range: 0.01 to 0.075 . Median: 0.0425 . Distribution: Uniform.

$\left(\mathrm{m}^{2}\right)$. Range: $1.0 \times 10^{-21}$ to $1.0 \times 10^{-18}$. Also used to define porosity for panel and drift seals (see Appendix B, Volume 5 of the 1992 PA report for definition of relationship). Distribution: Lognormal. 
Table 8-6 Parameters Sampled in the 1992 Performance Assessment for 40 CFR \$268.6 (continued)

\begin{tabular}{|c|c|}
\hline Parameter & Definition \\
\hline $\begin{array}{l}\text { Permeability of the shaft for the } \\
\text { time period from } 0 \text { to } 200 \mathrm{yr}\end{array}$ & $\begin{array}{l}\left(\mathrm{m}^{2}\right) \text {. Range } 1.0 \times 10^{-19} \text { to } 5.0 \times 10^{-16} \text {. Median: } 7.0 \times 10^{-18} \text {. } \\
\text { Distribution: Lognormal. }\end{array}$ \\
\hline $\begin{array}{l}\text { Permeability of the shaft seal and } \\
\text { shaft-fill material within the Salado } \\
\text { Formation for the time period } \\
\text { from } 200 \text { to } 10,000 \mathrm{yr}\end{array}$ & $\begin{array}{l}\left(\mathrm{m}^{2}\right) \text {. Range } 1.0 \times 10^{-21} \text { to } 1.0 \times 10^{-18} \text {. Median: } 3.2 \times 10^{-20} \text {. } \\
\text { Distribution: Lognormal. Also used to define porosity for the shaft } \\
\text { seal and shaft-fill material (see Appendix B, Volume } 5 \text { of the } 1992 \mathrm{PA} \\
\text { report for relationship). }\end{array}$ \\
\hline $\begin{array}{l}\text { Permeability of the shaft-fill } \\
\text { material within the Salado } \\
\text { Formation for the period from } 0 \text { to } \\
200 \mathrm{yr}\end{array}$ & $\begin{array}{l}\left(\mathrm{m}^{2}\right) \text {. Range } 1.0 \times 10^{-19} \text { to } 1.0 \times 10^{-15} \text {. Median: } 1.0 \times 10^{-17} \text {. } \\
\text { Distribution: Lognormal. }\end{array}$ \\
\hline $\begin{array}{l}\text { Thickness of the shaft seal within } \\
\text { the Salado Formation, as modeled }\end{array}$ & (m). Range: 30 to 100 . Median: 65 . Distribution: Uniform. \\
\hline
\end{tabular}




\subsubsection{Sensitivity Analyses Results From the 1992 PA}

Sensitivity analyses can identify those parameters for which reductions in uncertainty have the greatest potential to reduce uncertainty in performance measures. Identification of sensitive parameters can help set priorities for additional research; however, because results of these analyses are conditional on the models, data distributions, and techniques used to generate them, the analyses cannot provide insight about the correctness of the conceptual models and data distributions used. Qualitative judgment about the modeling system must be used in conjunction with sensitivity analyses to set priorities for PA data acquisition and model development.

Results of sensitivity analyses for the 1992 PA are summarized below according to reggulatory performance measures. A detailed discussion of the procedure and results can be found in Volumes 4 and 5 of the 1992 PA report. For 40 CFR $\$ 191.13$, the relevant performance measure is normalized integrated discharge to the accessible environment. The 1992 PA did not include transport of specified hazardous constituents for 40 CFR §268.6; gas and brine migration distances were used as surrogate performance measures for the purpose of sensitivity analysis.

\subsubsection{1 $\quad 40$ CFR $\$ 191.13$}

The regression, partial correlation, and scatterplot sensitivity analysis results from the 1992 PA were compiled into the list of important parameters in Table 8-7. Parameters in the first category, "controlling parameters," are those for which reductions in uncertainty have the potential to affect the location of the mean CCDF so that it moves closer to the compliance limits. Conditional on the present modeling assumptions and parameter-value distributions, long-term disposal-system performance with regard to 40 CFR 191 is not sensitive to uncertainty in parameters included in the "non-controlling parameters" category.

\subsubsection{2 $\quad 40$ CFR 8268.6}

Of the 25 parameters that were selected for sampling in the analyses for 40 CFR $\$ 268.6$, six have significant effects on the performance measures considered. These six parameters are listed in Table 8-8 as "controlling", reflecting their potential impacts on gas and brine migration from the repository. The single most important parameter, as shown in the sensitivity analyses described in Volume 5, Chapter 5 of the 1992 PA report, is the initial 
Table 8-7 Significance of Sampled Parameters with Respect to 40 CFR 191, Subpart B. Results apply only to disturbed performance of the repository (human intrusion) and are conditional on modeling assumptions, the choice of parameters sampled, and the assumed parameter-value distributions

Parameter Description

Controlling Parameters (Listed in order of importance)

Drilling intensity

Intrusion borehole permeability

Salado halite permeability

Salado anhydrite permeability

Radionuclide solubilities

Culebra fracture spacing

Matrix $\mathrm{K}_{d} \mathrm{~s}$

Culebra transmissivity fields

Culebra matrix porosity

Non-Controlling Parameters (List alphabetically)

Biodegradation gas-generation rate, humid conditions

Biodegradation stoichiometric coefficient

Biodegradation gas-generation rate, inundated conditions

Brooks-Corey residual gas saturation for Salado Fm.

Brooks-Corey/van Genuchten-Parker pointer

Brooks-Corey relative permeability model exponent

Castile brine reservoir area fraction

Castile brine pressure

Castile brine reservoir storativity

Climatic recharge factor

Corrosion gas-generation rate, inundated conditions

Corrosion gas-generation rate factor, humid conditions

Corrosion stoichiometric coefficient

Culebra fracture porosity

Culebra fracture clay filling fraction

Culebra fracture clay filling porosity

Far-field pressure in Salado Fm.

Fracture $\mathbf{K}_{\mathbf{d}} \mathbf{s}$

Initial brine saturation in waste

Residual brine saturation in Salado Fm.

Salado anhydrite porosity

Transition Zone and DRZ porosity factor

Volume fraction of combustibles in waste

Volume fraction of metals and glass in waste 
Table 8-8 Significance of Sampled Parameters with Respect to 40 CFR §268.6. Results apply only to undisturbed performance of the repository (no human intrusion), and are conditional on modeling assumptions, the choice of parameters sampled and the assumed parameter-value distributions

\section{Parameter Description}

Controlling Parameters (listed in order of importance)

Initial brine saturation in waste

Salado anhydrite permeability

Biodegradation stoichiometric coefficient

Corrosion gas-generation rate, inundated conditions

Biodegradation gas-generation rate, inundated conditions

Shaft seal permeability after $200 \mathrm{yr}$

Non-Controlling Parameters (listed alphabetically)

Biodegradation gas-generation rate factor, humid conditions

Brooks-Corey/van Genuchten-Parker pointer

Corrosion gas-generation rate factor, humid conditions

Corrosion stoichiometric coefficient

Initial volume fraction of metals and glass in waste

Initial volume fraction of combustibles in waste

Lower shaft permeability, 0-200 yr

Salado anhydrite porosity

Salado halite permeability

Shaft seal permeability, $0-200 \mathrm{yr}$

Transition zone and DRZ porosity factor

Insignificant Parameters (listed alphabetically)

Brooks-Corey relative permeability model exponent

Drift and panel seal permeability

Far-field pressure in Salado Fm.

Matrix porosity of Culebra

Porosity of backfill in drifts, experimental region, and shaft below seal

Residual brine saturation in Salado Fm.

Residual gas saturation in Salado Fm. 
brine saturation of the waste. Few data are available for this parameter, but for the range of values sampled, the initial water content of the waste effectively controls the amount of gas that is generated. The total amount of gas generated, in turn, controls how much gas flows out through the various release pathways. If the overall gas-generation rate is very small, the full gas-generation potential allowed by the amount of water initially present will be realized over the course of 10,000 years, and, if the permeability of the anhydrite layers is near the lower limit of the sampled range, this time period will likely not be sufficient for gas to flow to the disposal-unit boundaries unless enough water is initially present to generate the amount of gas required to flow that far. The range of initial brine saturation currently used is not based on measured data and is expected to change to some extent. Therefore, conclusions drawn about gas and brine migration are preliminary. The other five parameters listed as "controlling" also play a major role in influencing gas and brine migration from the repository, but their effect is secondary to that of the initial brine saturation.

Most of the other sampled parameters had a smaller impact on gas and brine migration and are listed as "non-controlling" in Table 8-8. These parameters each appear in only a few of the regression analyses reported in Volume 5, Chapter 5 of the 1992 PA report.

The final category of parameters listed in Table 8-8, "insignificant", includes those that were not identified in any of the regression analyses reported in Volume 5, Chapter 5 of the 1992 PA report. Conditional on all assumptions of the 1992 PA, the distributions used for these parameters had no effect on the surrogate performance measures considered. Essentially any value could have been selected from the distributions and used as a fixed value throughout without affecting performance, implying that, unless conceptual models change, these parameters could be omitted from future samplings if the present ranges are shown to be defensible. 


\subsection{References}

Beauheim, R.L., T.F. Corbet, P.B. Davies, and J.F. Pickens, 1991a. Appendix A: "Recommendations for the 1991 Performance Assessment Calculations on Parameter Uncertainty and Model Implementation for Culebra Transport Under Undisturbed and BrineReservoir-Breach Conditions," Preliminary Comparison with 40 CFR Part 191. Subpart B for the Waste Isolation Pilot Plant, December 1991. Volume 3: Reference Data, WIPP Performance Assessment Division, Eds. R.P. Rechard, A.C. Peterson, J.D. Schreiber, H.J. Iuzzolino, M.S. Tierney, and J.S. Sandha, SAND91-0893/3, Albuquerque, NM, Sandia National Laboratories, pp. A-7 through A-18.

Beauheim, R.L., G.J. Saulnier, Jr., and J.D. Avis, 1991b. Interpretation of BrinePermeability Tests of the Salado Formation at the Waste Isolation Pilot Plant Site: First Interim Report, SAND90-0083, Albuquerque, NM, Sandia National Laboratories.

Berglund, J.W., 1992. Mechanisms Governing the Direct Removal of Wastes from the Waste Isolation Pilot Plant Repository Caused by Exploratory Drilling, SAND92-7295, Albuquerque, NM, Sandia National Laboratories.

Brush, L.H., 1991. Appendix A: "Current Estimates of Gas Production Rates, Gas Production Potentials, and Expected Chemical Conditions Relevant to Radionuclide Chemistry for the Long-Term WIPP Performance Assessment," Preliminary Comparison with 40 CFR Part 191, Subpart B for the Waste Isolation Pilot Plant, December 1991. Volume 3: Reference Data, WIPP Performance Assessment Division, Eds. R.P. Rechard, A.C. Peterson, J.D. Schreiber, H.J. Iuzzolino, M.S. Tierney, and J.S. Sandha, SAND910893/3, Albuquerque, NM, Sandia National Laboratories, pp. A-25 through A-36.

Brush, L.H. and D.R. Anderson, 1989. Appendix A: "Drum (Metal) Corrosion, Microbial Decomposition of Cellulose, Reactions Between Drum-Corrosion Products and Microbially Generated Gases, Reactions Between Possible Backfill Constituents and Gases and Water Chemical Reactions," Systems Analysis, Long-Term Radionuclide Transport, and Dose Assessments, Waste isolation Pilot Plant (WIPP), Southeastern New Mexico; March 1989, Eds. A.R. Lappin, R.L. Hunter, D.P. Garber, and P.B. Davies, SAND89-0462, Albuquerque, NM, Sandia National Laboratories, pp. A-3 through A-30. 
Cranwell, R.M., R.V. Guzowski, J.E. Campbell, and N.R. Ortiz, 1990. Risk Methodology for Geologic Disposal of Radioactive Waste: Scenario Selection Procedure, NUREG/CR-1667, SAND80-1429, Albuquerque, NM, Sandia National Laboratories (original version of this report published in 1982 under the same title and report numbers.)

Davis, P.A., N.E. Olague, and M.T. Goodrich, 1991. Approaches for the Validation of Models Used for Performance Assessment of High-Level Nuclear Waste Repositories, SAND90-0575, Albuquerque, NM, Sandia National Laboratories.

Freeze, R.A., and J.A. Cherry, 1979. Groundwater, Englewood Cliffs, NJ, Prentice-Hall, Inc.

Gorham, E., R. Beauheim, P. Davies, S. Howarth, and S. Webb, 1992. Appendix A: "Recommendations to PA on Salado Formation Intrinsic Permeability and Pore Pressure for 40 CFR 191 Subpart B Calculations," Preliminary Performance Assessment for the Waste Isolation Pilot Plant, December 1992. Volume 3: Model Parameters, Sandia WIPP Project, SAND92-0700/3, Albuquerque, NM, Sandia National Laboratories, pp. A-47 through A-67.

Helton, J.C., J.W. Garner, R.D. McCurley, and D.K. Rudeen, 1991. Sensitivity Analysis Techniques and Results for Performance Assessment at the Waste Isolation Pilot Plant, Contractor Report, SAND90-7103, Albuquerque, NM, Sandia National Laboratories.

Howarth, S.M., E.W. Peterson, P.L. Lagus, K.H. Lie, S.J. Finley, and E.J. Nowak, 1991. "Interpretation of In-Situ Pressure and Flow Measurements of the Salado Formation at the Waste Isolation Pilot Plant," Rocky Mountain Regional Meeting and Low Permeability Reservoirs Symposium. Denver. CO. April 15-17, 1991, SPE 21840, SAND90-2334C, Richardson, TX, Society of Petroleum Engineers, pp. 355-369.

Iman, R.L., and W.J. Conover, 1982. "A Distribution-Free Approach to Inducing Rank Correlation Among Input Variables," Communications in Statistics: Simulation and Computation, Vol. 11, No. 3, pp. 311-334.

Kaplan, S., and B.J. Garrick, 1981. "On the Quantitative Definition of Risk," Risk Analysis, Vol. 1, No. 1, pp. 11-27. 
Lappin, A.R., R.L. Hunter, D.P. Garber, and P.B. Davies, eds., 1989. Systems Analysis, Long-Term Radionuclide Transport, and Dose Assessments, Waste Isolation Pilot Plant (WIPP). Southeastern New Mexico; March 1989, SAND89-0462, Albuquerque, NM Sandia National Laboratories.

LaVenue, A.M., and B.S. RamaRao, 1992. A Modeling Approach To Address Spatial Variability within the Culebra Dolomite Transmissivity Field, SAND92-7306, Albuquerque, NM, Sandia National Laboratories.

Leigh, C.D., B.M. Thompson, J.E. Campbell, D.E. Longsine, R.A. Kennedy, and B.A. Napier, 1993. User's Guide for GENII-S: A Code for Statistical and Deterministic Simulations of Radiation Doses to Humans from Radionuclides in the Environment, SAND91-0561, Albuquerque, NM, Sandia National Laboratories.

McKay, M.D., W.J. Conover, and R.J. Beckman, 1979. "A Comparison of Three Methods for Selecting Values of Input Variables in the Analysis of Output from a Computer Code," Technometrics, Vol. 21, No. 2, pp. 239-245.

Popielak, R.S., R.L. Beauheim, S.R. Black, W.E. Coons, C.T. Ellingson, and R.L. Olsen, 1983. Brine Reservoirs in the Castile Formation, Waste Isolation Pilot Plant (WIPP) Project. Southeastern New Mexico, TME-3153, Carlsbad, NM, U.S. Department of Energy.

Popper, K.R., 1959. The Logic of Scientific Discovery, New York, NY, Harper and Row.

Rechard, R.P., 1989. Review and Discussion of Code Linkage and Data Flow in Nuclear Waste Compliance Assessments, SAND87-2833, Albuquerque, NM, Sandia National Laboratories.

Rechard, R.P., P.J. Roache, R.L. Blaine, A.P. Gilkey, and D.K. Rudeen, 1991. Quality Assurance Procedures for Computer Software Supporting Performance Assessments of the Waste Isolation Pilot Plant, SAND90-1240, Albuquerque, NM, Sandia National Laboratories.

Rechard, R.P., ed, 1992. User's Reference Manual for CAMCON: Compliance Assessment Methodology Controller. Version 3.0, SAND90-1983, Albuquerque, NM, Sandia National Laboratories. 
Roache, P.J., P.M. Knupp, S. Steinberg, and R.L. Blaine, 1990. "Experience with Benchmark Test Cases for Groundwater Flow, "Benchmark Test Cases for Computational Fluid Dynamics, 1990 Spring Meeting of the Fluids Engineering Division, 1990 Forum of the Canadian Society of Mechanical Engineers, Universily of Toronto, Ontario, Canada, June 4-7. 1990, Eds. I. Celik and C.J. Freitas, FED-Vol. 93, New York, NY, The American Society of Mechanical Engineers, pp. 49-56.

Salari, K., 1993. Appendix A: "Verification of the SECO-Transport Code," Preliminary Performance Assessment for the Waste Isolation Pilot Plant, December 1992. Volume 4: Uncertainty and Sensitivity Analyses for 40 CFR 191. Subpart B, WIPP Performance Assessment Department, SAND92-0700/4, Albuquerque, NM, Sandia National Laboratories, pp. A-3 through A-28.

Sandia National Laboratories (SNL), 1992. Preliminary Performance Assessment for the Waste Isolation Pilot Plant, December 1992, SAND92-0700/1-5, Albuquerque, NM, Sandia National Laboratories.

Trauth, K.M., S.C. Hora, and R.P. Rechard, 1991. "Expert Judgement as Input to Waste Isolation Pilot Plant Performance Assessment Calculations: Probability Distributions of Significant System Parameters," Mixed Waste, Proceedings of the First International Symposium, Baltimore, MD. August 26-29, 1991, Eds. A.A. Moghissi and G.A. Benda, SAND91-0625C, Baltimore, MD, Environmental Safety and Health, University of Maryland, pp. 4.3.1 through 4.3.9.

U.S. Environmental Protection Agency (EPA), 1985. "40 CFR Part 191: Environmental Standards for the Management and Disposal of Spent Nuclear Fuel, High-Level and Transuranic Radioactive Wastes; Final Rule," Federal Register, Vol. 50, No. 182, 38066-38089. 


\subsection{Regulatory Compliance Assessment}

The Department of Energy's (DOE's) strategy for compliance demonstration purposes is based on the concept of self-assessment leading to the submittal of compliance documents. This self-assessment includes a review of existing data, quantitative and qualitative reviews of applicable program elements, and calculated repository performance measures. The final goal is to demonstrate a reasonable expectation that the long-term repository performance is adequately protective to meet the applicable regulatory requirements. Included in the evaluation are: repository design and engineering, natural and engineered barriers, waste: characterization data, and events and processes such as human intrusion and geologic activity.

The regulatory standards applicable to the Waste Isolation Pilot Plant (WIPP) disposal phase are provided in Title 40 CFR 191, Subparts B and C (EPA, 1993a) and Title 40 CFR $\$ 268.6$ (EPA, 1993b). Although 40 CFR 191, Subparts B and C and 40 CFR $\$ 268.6$ have different points of compliance and environmental standards, the intent common to both these regulations is to reasonably assure protection of human health and the environment for a very long time. The regulatory compliance assessment will include a comparison of the performance assessment (PA) results to the appropriate regulatory standards. As part of this assessment, the DOE will identify and quantify the sources of uncertainty in the compliance demonstration. Uncertainties that are shown to have no impact will be included in PA, but need not be a part of a compliance application.

\subsection{Containment of Releases}

The DOE's overall objective for the WIPP facility is to safely manage and dispose of transuranic (TRU) waste in a manner that provides for the long-term isolation of radionuclides and hazardous constituents. In the case of 40 CFR 191, the assessment of compliance is made based on individual doses and radionuclide releases to the accessible environment. Under 40 CFR \$268.6, compliance must be demonstrated based on nomigration of hazardous constituents beyond the unit boundary in excess of established concentration limits.

Preliminary base-case (undisturbed) calculations for 40 CFR 191 indicate no releases to the accessible environment. Therefore, inadvertent human intrusion is the only reasonable potential cause of release, and as such, is the focus of PA efforts. The conceptual model 
chosen for this Compliance Status Report (CSR) (including human intrusion) is described below, with additional information regarding human intrusion provided in Section 9.2. This model was chosen to comply with the 1988 Modification to the Working Agreement of the Consultation and Cooperation Agreement between the Department of Energy and the State of New Mexico on the Waste Isolation Pilot Plant (DOE, 1988) in that the parameter that describes the chemical sorbtive property of the Culebra is assumed to equal zero in PA until such time as experimentally determined values are obtained, reviewed, and concurred with by the State of New Mexico. This assessment is based on results of the 1992 PA. At this time, data and numerical models are not all considered to be sufficient and qualified to be used in a compliance determination. Consequently, results from the 1992 PA as reported here are to be regarded as preliminary and have not been determined to be suitable for compliance determinations. However, as described in Chapter 7 and 10 of this document, programs are underway to complete the process of establishing data and models that are suitable for compliance determinations.

\subsubsection{CFR 191}

The determination of the WIPP's compliance with the final disposal regulations is comprised of an assessment of compliance with the containment requirements of 40 CFR 191, Subparts $B$ and $C$. The DOE has undertaken an extensive effort to assess the facility's capability to meet these requirements. The current understanding of the WIPP's ability to comply with the containment requirements of 40 CFR 191, Subparts B and C is described below. Also, as PA analyses are not yet complete, those areas that require further examination are identified.

Preliminary comparisons for estimated performance of the WIPP with the long-term requirements in 40 CFR 191 have been published iteratively since 1989. The most recent iteration of the PA process is the 1992 assessment. The 1992 PA concentrated resources on analyzing the impact of specific sources of uncertainty on the performance estimate. These publications have evaluated the consequences of human intrusion events.

Consistent with the guidance in 40 CFR 191, Appendix C, the DOE has evaluated the inadvertent and intermittent intrusion by exploratory drilling as the most severe intrusion scenario. The conceptual model used to evaluate the containment of releases in this status report includes single-porosity plus cuttings, $\mathrm{K}_{d}=0$, and intrusion rate constant, $\lambda=\lambda_{0}$ (maximum expected value of 30 boreholes in 10,000 years per $\mathrm{km}^{2}$ ). 
Improvements to the analysis have occurred as the result of the resolution of issues discussed in Chapter 6. Additional resolution of issues and improvements are anticipated as the result of the program activities described in Chapter 10. It is a reasonable expectation that the mean complementary cumulative distribution function (CCDF) is an adequate measure of compliance.

\subsubsection{CFR 8268.6}

To comply with the Resource Conservation and Recovery Act (RCRA) Land Disposal Restrictions (LDRs), the DOE must demonstrate that hazardous constituents will not migrate from the unit above regulated levels. In other words, to show "no-migration," the DOE must demonstrate that any constituents released do not exceed health-based standards at the point where they exit from the unit. This determination will depend on the concentrations, toxicities, and relative persistence of the proposed waste constituent.

During waste management operations at the WIPP facility, containment of volatile organic compounds (VOCs) will be required. Containers of TRU waste will be vented through carbon composite filters. The filters will also allow passive diffusion of VOCs from the containers during waste managennent activities. To demonstrate no-migration during the operational time period, VOC concentrations will be calculated based on headspace gas data, diffusion rates through the filters, and repository air flow rates. Although the health-based levels for releases of VOCs are very restrictive, the DOE will demonstrate compliance with the no-migration standards for releases to ambient air prior to facility closure.

In order to assess post-closure repository performance, the DOE must consider the process of closure, the long-term behavior of waste in the repository, and the effectiveness of the waste management system to isolate the waste, including seals. For purposes of a long-term nomigration demonstration, the DOE plans to use a conceptual model that is consistent with the one used for 40 CFR 191. The undisturbed performance will be the primary focus of a nomigration demonstration. The interaction between long-term variables, such as brine inflow, gas generation, and salt creep, will be defined based on available data and expert judgement. The preliminary PA results show that a no-migration demonstration is feasible.

Additional work is required to include a chemical source term and transport model that considers source term parameters of interest, such as solubility, adsorption, and diffusion. 
Based on the results of these analyses, additional information needs will be assessed. The health-based levels for chemicals in the Salado Formation are derived from exposure by ingestion. Given the geologic stability of the area; the depth, thickness, and low permeability of the salt formation; and the properties of the salt as an encapsulating medium, a long-term no-migration demonstration is feasible. Specific concerns of the Environmental Protection Agency (EPA), expressed in its final No-Migration Determination (NMD) for the test phase (EPA, 1992a), regarding long-term compliance included the generation of gas and its potential effects on the integrity of the repository. The DOE is developing conceptual models to test various theories for gas evolution and migration period.

\subsection{Human Intrusion}

During the post-decommissioning phase, the question of human intrusion must be addressed through consideration of the likelihood of intrusion and the effectiveness that can be reasorably expected from controls designed to deter intrusion. In addition, to comply with 40 CFR 191, Subpart B, an evaluation of radionuclide releases to the accessible environment must be made based on postulated human intrusion scenarios. This section evaluates humaninduced events.

\subsubsection{CFR 191}

The containment requirements of 40 CFR $\$ 191.13$ do not address human intrusion directly, 'out rather indirectly. The requirements make reference to "... all significant processes and events that may affect the disposal system..." It is the supplementary guidance, provided in Appendix $\mathrm{C}$ of the regulation, that makes specific reference to human intrusion. For example, Appendix $\mathrm{C}$ provides guidance as to the types of intrusions to be considered and the frequency of such intrusions.

The requirements contanned in 40 CFR 191 for addressing human intrusion are to be addressed only with regard to the containment requirements; human intrusion events need not be addressed for the individual protection requirements or the groundwater protection requirements.

Performance assessment for 40 CFR 191, Subpart B, concentrates on inadvertent human intrusion during exploratory drilling for resources, which is indicated in the guidance 
(40 CFR 191, Appendix C) to be the most severe intrusion scenario that need be considered. Future drilling technology and practices are, for these analyses, assumed to be comparable to technology presently in use in the region around the WIPP. Future regulations that constrain drilling are assumed to be similar to those in use today.

Subsurface releases of radionuclides following lateral transport in groundwater are believed most likely to occur in the Culebra Dolomite Member of the Rustler Formation overlying the repository. For analysis purposes, subsurface transport is assumed to occur only in the Culebra, maximizing the potential for subsurface releases by the most reasonable potential pathway (Section 2.2). Performance assessment will consider the effects of other pathways (water-bearing zones), although the natural characteristics of the Culebra and of other rock units indicate that flow in the Culebra will continue to be the dominant potential pathway. Releases into the Culebra are referred to as "subsurface" releases in the discussion in order to distinguish their longer-term consequences from those associated with "surface" releases. Surface releases occur directly and immediately as a result of drilling.

As mentioned in Section 8.1.4.5.2, the three intrusion scenarios assume that borehole properties (plugs and fill) are such that releases are maximized. This assumption may be extremely conservative relative to subsurface releases. Regarding borehole plugs, a more reasonable assumption is that they all behave in the same manner over the long-term. That is, all plugs fail or all plugs remain intact. Regarding borehole fill material, the guidance in Appendix C states:

.....the consequences of such inadvertent drilling need not be assumed to be more severe than: ...creation of a ground water flow path with a permeability typical of a borehole filled by the soil or gravel that would normally settle into an open hole over time-not the permeability of a carefully sealed borehole.

Currently, PA uses a relatively permeable borehole fill material (silty sand). Depending upon borehole plugging procedures, it may be more reasonable to consider the effect of borehole closure due to salt creep in modeling the long-term releases. This is an important characteristic to evaluate since closure of openings due to salt creep is one of the favorable characteristics that led to the selection of a deep-salt bed for the WIPP. The effect of borehole closure due to salt creep should be evaluated taking into consideration the residue of degraded plugs remaining in the borehole. 


\subsubsection{CFR \$268.6}

Under 40 CFR $\$ 268.6(b)(5)$, an analysis must be performed to identify and quantify any aspects of a no-migration demonstration that contribute significantly to uncertainty. The DOE must identify and evaluate the impacts of predictable future events that could contribute to or result in inadequate waste isolation. Natural phenomena, such as climate, geologic activity and earthquakes, are addressed in Section 9.7. Human-induced events, which may affect the isolation capabilities of the unit, also must be addressed.

In its conditional NMD for the WIPP, the EPA stated that although the variance for the WIPP is based on a finding of no-migration during the test phase, it focused on the undisturbed performance of the repository. The Agency did not specifically review or address the possible releases from the WIPP as the result of potential human intrusion scenarios, such as oil and gas exploration. The EPA did state, however, its belief that, in the context of RCRA no-migration variance decisions, the question of human intrusion is best addressed through a consideration of the likelihood of intrusion and the imposition of controls to make such intrusions unlikely events. This topic was described by the EPA in the proposed NMD for the WIPP (EPA, 1992b).

The EPA emphasized that this approach to human intrusion is consistent with its general approach under the (global) RCRA, both in permitting and variances. Under RCRA, EPA typically relies on institutional controls, both active and passive, imposed through general regulatory standards and site-specific conditions to ensure that access to a hazardous waste disposal site is appropriately restricted. The EPA stated that any WIPP disposal-phase nomigration variance will have to impose long-term passive institutional controls, such as land withdrawal, records, and markers, to ensure that the likelihood of human intrusion is appropriately reduced, even after active control of the facility has ceased and any permits at the site may have terminated.

The DOE has taken a number of steps to reduce the possibility of human intrusion after closure of the facility. The site will remain under federal jurisdiction in perpetuity, and therefore, the DOE or successor agencies will be in a position to restrict access. In addition, the DOE shall prohibit in perpetuity all subsurface mining, drilling, or resource exploration on the WIPP site unrelated to the WIPP Project. Furthermore, the federal government owns the entire surface and subsurface estate at the WIPP site. A portion of the subsurface estate is currently leased below $6,000 \mathrm{ft}(1,830 \mathrm{~m})$ for oil and/or gas production. Upon final 
closure of the WIPP site, the DOE will notify all state and county planning, deed and record offices, oil and gas commissions, and other agencies to prevent access by unknowing parties. The DOE also plans to place permanent warning markers at the site, as required by the 40 CFR 191 standards (Section 9.5). The DOE believes that these types of measures will be effective in reducing the likelihood of human intrusion into the repository and will, therefore, satisfy this aspect of the RCRA regulations.

\subsection{Groundwater Protection}

Standards for the protection of groundwater are included in 40 CFR 191. The DOE's efforts to comply with these requirements are described in this section.

\subsubsection{CFR 191}

While the concept of groundwater protection is not new to 40 CFR 191, the standard has recently been revised significantly. Subpart $C$ requires consideration of releases from the undisturbed disposal system during the first 10,000 years after disposal to any underground sources of drinking water (USDWs).

Performance analyses to date, simulating undisturbed performance with the best available models and most complete data sets, indicate that no radionuclides escape to the accessible environment during the first 10,000 years after disposal (SNL, 1992). As a result, the requirement for the protection of USDWs appears to be satisfied.

\subsection{Individual Protection}

Individual protection requirements are unique to the radioactive waste-disposal regulations in that they have no line item counterpart in the 40 CFR $\$ 268.6$ standard; they are equivalent to the health-based standards in 40 CFR \$268.6. The hazardous waste regulations do, however, have regulatory provisions designed to ensure protection of human health in waste management-related operational activities. For the purposes of the WIPP, these requirements can be referenced in the draft No-Migration Variances to the Hazardous Waste Land Disposal Prohibitions: A Guidance Manual for Petitioners (EPA, 1992c). The following section addresses the WIPP's compliance with the individual protection requirements of 40 CFR 191. 


\subsubsection{CFR 191}

The 1993 changes to 40 CFR 191 resulted in substantial changes to the individual protection requirements. Requirements were added to the standard for the calculation of annual committed effective doses.

The individual protection requirements address doses received from the undisturbed disposal system during the first 10,000 years after disposal. Preliminary assessments to date, simulating undisturbed performance with the best available models and most complete data sets, indicate that no radionuclides will be released from the repository during the 10,000 year period of regulatory interest.

\subsection{Assurance Requirements}

The 40 CFR 191 assurance requirements are intended to complement the containment requirements by providing additional safeguards. The assurance requirements are contained in 40 CFR $\$ 191.14$. The six separate requirements are:

- Active institutional controls,

- Monitoring,

- Passive institutional controls,

- Barriers,

- $\quad$ Resource disincentive (characteristics evaluation), and

- Waste removal.

\subsubsection{Active Institutional Controls}

The EPA specifies that ". . . active institutional controls over disposal sites should be maintained for as long a period of time as is practicable after disposal . . . " (40 CFR $\$ 191.14[a])$. Active institutional controls to be employed at the WIPP include the control of land use in the area, maintaining fences and buildings and guarding the facility during decontamination and decommissioning, land reclamation, and post-operational monitoring. The objectives of these activities are to provide a facility and presence at the site during restoration of the land surface to as near its original condition as feasible to avoid future preferential selection of the area for incompatible uses (if restoration is deemed desirable after consideration of the results of the expert panel on markers; see Trauth et al., 1993). 
Maintenance of these facilities during active controls also permits monitoring of the disposal system. Performance assessment assumes that active controls are maintained for 100 years; in the 1992 calculations, no intrusions were assumed to occur during the first 100 years after decommissioning.

The DOE has compiled a plan to satisfy the requirements of active institutional controls (DOE, 1991a). The long-term active institutional control program to be implemented in four discrete steps:

Step 1. Identification of long-term control measures

Step 2. Gathering of data necessary for implementing long-term control measures

Step 3. Preparation of the long-term protection plan

Step 4. Implementation of long-term control measures

Most of the long-term control measures will be implemented simultaneously with plant closure and decommissioning. However, it may be possible to implement some measures earlier. For example, salt disposal may begin prior to final plant closure, reclamation and restoration of unused disturbed areas has already begun, and guarding and maintenance activities that are already in place could evolve into post-closure activities.

\subsubsection{Monitoring}

Disposal system monitoring is a required component of a program designed to fulfill the assurance requirements. The EPA has provided guidance, in the preamble to the $40 \mathrm{CFR}$ 191 Final Rule, with regard to the monitoring requirement. The EPA states:

Disposal systems shall be monitored after disposal to detect substantial and detrimental deviations from expected performance. This monitoring shall be done with techniques that do not jeopardize the isolation of the wastes and shall be conducted until there are no significant concerns to be addressed by further monitoring.

The monitoring program described in the DOE plan is a five-step process, as outlined below:

Step 1. Identification of appropriate long-term monitoring programs

Step 2. Design and implementation of operational monitoring programs supporting long-term monitoring

Step 3. Design of post-operational monitoring programs

Step 4. Implementation of post-operational monitoring programs 
Step 5. Operation of the long-term monitoring programs

The DOE has implemented a subsidence monitoring program at the WIPP (DOE, 1990). Subsidence monuments have been installed to monitor changes in surface elevations associated with mining activities. It has been determined that between 1977 and 1981 , the regional subsidence in the vicinity of the WIPP site was less than 0.04 in. As part of the subsidence monitoring program, the DOE plans to continue to monitor site-specific subsidence.

\subsubsection{Passive Institutional Controls}

Implementation of passive controls is mandated in the assurance requirements provisions of 40 CFR 191. Specifically, $\$ 191.14(c)$ requires:

Disposal sites shall be designated by the most permanent markers, records, and other passive institutional controls practicable to indicate the dangers of the wastes and their location.

The EPA intends for the implementing agency to provide comprehensive actions that will increase the likelihood that knowledge and information about the disposal site and its contents are passed on to future generations. For the purposes of compliance with 40 CFR 191, the EPA does not assume that passive controls will prevent all possibility of intrusion, but such controls will deter any systematic development of a site.

The six steps for implementing passive institutional controls are listed below:

Step 1. Define appropriate passive institutional controls

Step 2. Develop a passive institutional control implementation plan

Step 3. Design and implement pre-closure passive institutional controls

Step 4. Implement pre-closure passive institutional controls

Step 5. Design post-closure passive institutional controls

Step $6 . \quad$ Implement post-closure passive institutional controls

The DOE will implement passive institutional controls over the entire controlled area of the WIPP. Passive institutional controls include markers warning of the presence of buried nuclear waste and identifying the boundary of the controlled area, external records about the 
WIPP repository, and continued federal ownership. DOE's strategy is to design and implement to the extent practical, passive controls that render human intrusion unlikely.

To address the issues of markers for the WIPP, two expert panels were established.

Members of the first panel identified possible future societies and postulated how they may intrude into the repository, and also developed probabilities of future society development and of various intrusions. Possible modes of inadvertent intrusion identified by the first panel were provided to a second panel as an aid in developing design characteristics for permanent markers and judging the efficacy of the markers in deterring inadvertent intrusion. A report concerning the "markers panel" has been prepared (Trauth et al., 1993). In addition, a report that describes past considerations of protective barriers to human intrusion has been prepared as a complement to the markers report (Tolan, 1993).

Records of the disposal site (i.e. geographic location, etc.) and its contents will be preserved. Experience with the survivability of long-term records (e.g. the Vatican Archives) should be incorporated into designs for a records system, as should ongoing developments in records storage, maintenance, and dissemination. Questions of what information would be most appropriate and most useful in these archives, and how it should be organized, must also be addressed. Some members of the expert panel on intrusion into the repository considered the impact of records preservation on intrusion rates and probabilities. These panel members concluded that records should specify techniques for borehole plugging, in the event that exploratory drilling results in an intrusion. Such techniques could be incorporated into legal records together with the description and location of the disposal system. The records could also contain a warning about the potential effects of drilling through the repository and into pressurized brine in the Castile Formation.

In accordance with Appendix C of the 40 CFR 191 standard, the DOE, or some successor agency, is assumed to retain ownership and administrative control over the WIPP area. The federal agency responsible for the land will institute regulations that appropriately restrict land use and development. Acreage around the WIPP is owned by the Federal government and is currently administered by the DOE. The area within the land-withdrawal boundary for the WIPP is withdrawn from appropriation and disposal under the public land laws, including the mineral leasing laws, the geothermal leasing laws, the material sale laws, and the mining laws (Section 3 of the Land Withdrawal Act [LWA]). With respect to drilling, the DOE has control of the acreage within the land-withdrawal boundary except for one section where the DOE control terminates at $6,000 \mathrm{ft}$ below grade. Additionally, grazing 
and other specific land use activities may continue to the extent that they are compatible with WIPP Land Management Plan (DOE, 1993a) restrictions.

\subsubsection{Multiple Barriers}

In prescribing multiple barriers, the EPA has specified that:

Disposal systems shall use different types of barriers to isolate the wastes from the accessible environment. Both engineered and natural barriers shall be included (40 CFR \$191.14[b]).

By requiring the use of both barrier types as an assurance requirement, the EPA intends to ensure that the impacts of the failure of any one barrier type will be minimized.

At the WIPP, natural barriers include the favorable characteristics of the salt formation and geohydroiogic setting. Engineered barriers intended to isolate wastes from the accessible environment will include seals in repository excavations and possibly backfill in wasteemplacement panels. The effectiveness of these barriers is being modeled for the PA to determine if they will contribute to a disposal system that will isolate the radioactive wastes to the levels required in the standard. In addition, the Engineered Alternatives Task Force (EATF) has evaluated additional engineering measures for the WIPP, should such measures be necessary (DOE, 1991b).

\subsubsection{Resource Characteristics Evaluation}

The EPA discourages the location of repositories in areas in which valuable natural resources are present. The standard states:

Places where there has been mining for resources, or where there is a reasonable expectation of exploration for scarce or easily accessible resources, or where there is a significant concentration of any material that is not widely available from other sources, should be avoided in selecting disposal sites. Resources to be considered shall include minerals, petroleum or natural gas, valuable geologic formations, and ground waters that are either irreplaceable because there is no reasonable alternative source of drinking water available for substantial populations or that are vital to the preservation of unique and sensitive ecosystems. Such places shall not be used for disposal of the wastes covered by this Part unless the favorable characteristics of such places 
compensate for their greater likelihood of being disturbed in the future (40 CFR §191.14[e]).

The WIPP site was selected prior to promulgation of the standard. Resource considerations were, however, included in the site selection process for the WIPP facility and are documented in the WIPP Final Environmental Impact Statement (FEIS) (DOE, 1980). Documentation of the rationale for selecting the WIPP site has been accomplished through the preparation of a summary report (DOE, 1993b). This summary report documents the extent to which resources have been considered in major project decisions.

\title{
9.5.6 Waste Removal
}

The EPA has specified that ". . [ [d]isposal systems shall be selected so that removal of most of the waste is not precluded for a reasonable period of time after disposal" (40 CFR \$191.14[f]). The EPA also states in Federal Register 50, p. 38082:

\begin{abstract}
Any current concept for mined geologic repository meets this requirement without any additional procedures or design features. For example, there is no intent to require that a repository shaft be kept open to allow future recovery. To meet this assurance requirement, it only need be technologically feasible (assuming current technology levels) to be able to mine the sealed repository and recover the waste - albeit at substantial cost and occupational risk.
\end{abstract}

The WIPP facility is a mined repository. No additional actions to meet this assurance requirement are considered necessary, and none are planned.

\subsection{Monitoring Requirements}

Monitoring programs for compliance with 40 CFR 191 are described in Section 9.5. The WIPP facility has established monitoring programs as discussed in Chapter 5. The monitoring programs at the WIPP facility are operated under approved quality assurance project plans (QAPjPs) to ensure that all data are collected in accordance with established data quality objectives (DQOs). Monitoring systems have been installed and sampling programs have been implemented in and around the WIPP facility, and background data has been collected. 


\subsubsection{CFR \$268.6}

A VOC monitoring system has been installed at the WIPP facility to verify compliance with the no-migration standards during the disposal phase. The air pathway is considered the only credible pathway for contaminant migration prior to repository closure (EPA, 1992b). The VOC Monitoring Program will verify that hazardous constituents are not migrating beyond the unit boundary at concentrations above health-based levels by sampling the underground ventilation in the exhaust air shaft. System readiness has been demonstrated, and all required quality assurance/quality control $(\mathrm{QA} / \mathrm{QC})$ activities have been implemented. Background data collected to date have been provided to the EPA in DOE's NMD annual reports (DOE, 1991c; 1993c,d).

Similar to the assurance requirements under 40 CFR \$191.14, RCRA post-closure monitoring will consist of methods designed to focus on indicators of effective long-term performance of the repository, instead of using intrusive methods to monitor for potential contaminant migration, which may compromise the integrity of the disposal unit. Long-term monitoring will focus on evaluating changes to the surrounding environment, such as hydrogeologic conditions or seismic activity.

\subsection{Infrequent Events and Processes}

Analyses of predictable events must consider both the disposal unit and the surrounding environment. For example, previously unconsidered avenues for contaminant migration may be created by earthquakes, geologic activity, or climatic changes over the long term.

The site selection process for the WIPP facility involved review of extensive geologic information for the WIPP site, consideration of the relative remoteness of the site, and the limited quantities of ground water in the area (Section 1.2). Sections 2.6 and 8.1.4.1 include a discussion of near-surface processes and events, including flooding, tornados, range fires, meteorite impact, erosion, dissolution and sedimentation. In addition, seismic activity in the region has been extensively studied. Based on the information available regarding the WIPP site and surrounding areas, the DOE believes that it can demonstrate minimal potential for any natural process or event to threaten the long-term integrity of the repository. 


\subsection{Program/Facility Modifications}

To demonstrate compliance under both 40 CFR 191 and 40 CFR $\$ 268.6$, an assessment of performance must be conducted. Portions of the engineered waste management system, portions of the naturally occurring repository, and/or the TRU waste to be disposed of in the facility may be modified as required to ensure compliance. Factors that will be considered include effectiveness of the modification with regard to longevity, degree, and confidence. Other factors include availability of proposed technology, operational constraints at DOE generator/storage sites, regulatory constraints, and cost.

Currently, the DOE is considering alternatives to additional testing and/or experimentation that may be necessary to obtain the required information. Because a significant portion of the waste to be disposed of at the WIPP facility is not yet generated, specifying waste acceptance criteria that will decrease uncertainties in the PA is a viable option. With regard to repository parameters, potential facility modifications will be evaluated. The ultimate goal of this aspect of the program is to ensure that a reasonable degree of certainty of compliance with all standards is demonstrated as quickly and as cost effectively as possible.

\subsection{Waste Acceptance/Waste Compliance}

As stated in Section 4.2.1, a performance-based waste envelope will be identified by using PA modeling and analysis as tools to predict waste parameters that may adversely affect the ability of the WIPP to isolate waste. Once identified, bounding envelopes relative to the types and forms of waste to be disposed will be developed. The applicable restrictions or criteria are defined by the DOE as performance-based waste acceptance criteria. The final waste acceptance criteria will include criteria from the PA models as well as possible conditions which may be imposed as part of the compliance application processes. The application of these waste acceptance criteria to the TRU and TRU-mixed waste inventory defines the "performance-based inventory" (i.e., the inventory acceptable for disposal in WIPP).

The waste acceptance criteria, plus restrictions or limitations from other elements of the project such as transportation and operational safety, will form the inventory control criteria. These inventory control criteria will be the basis used by the DOE to compile an inventory at individual generator sites and by which waste will be emplaced within rooms and panels. 
A fundamental element in the development of a performance-based waste envelope is a comprehensive waste characterization program that effectively identifies and quantitatively assesses parameters in the waste inventory that have been identified by PA as potentially impactive to repository performance. The DOE has designed the scope of the waste characterization program to include a baseline inventory assessment and sampling and analysis to provide the data sets necessary for PA modeling and analysis. An ultimate goal of the waste characterization program is to reduce the level and frequency of sampling and analysis required during the disposal phase, while maintaining confidence in documentation of waste generation practices.

Currently, the DOE has not yet collected sufficient waste characterization data to derive chemical prevalence or chemical concentration values. Without these values, parameter estimates to be used in PA calculations will contain considerable uncertainties. 


\subsection{References}

Sandia National Laboratories (SNL), 1992. Preliminary Performance Assessment for the Waste Isolation Pilot Plant, December 1992--Volume 1: Third Comparison with 40 CFR 191. Subpart B, SAND92-0700/1, Albuquerque, NM, Sandia National Laboratories.

Tolan, T.L., 1993. The use of Protective Barriers to Deter Inadvertent Human Intrusion into a Mined Geologic Facility for the Disposal of Radioactive Waste: A Review of Previous Investigations and Potential Concepts, SAND91-7087, Albuquerque, NM, Sandia National Laboratories.

Trauth, K.M., S.C. Hora, and R.V. Guzowski, 1993. Expert Judgment on Markers to Deter Inadvertent Human Intrusion into the Waste Isolation Pilot Plant, SAND92-1382, Albuquerque, NM, Sandia National Laboratories.

U.S. Department of Energy (DOE), 1980. Final Environmental Impact Statement, Waste Isolation Pilot Plant, DOE/EIS-0026, Volumes 1 and 2, Department of Energy Office of Environmental Restoration and Waste Management, Washington, D.C.

U.S. Department of Energy (DOE), 1988. 1988 Modification to the Working Agreement of the Consultation and Cooperation Agreement between the Department of Energy and the State of New Mexico on the Waste Isolation Pilot Plant, March 1988.

U.S. Department of Energy (DOE), 1990. Final Safety Analysis Report, WP 02-9, Revision 0, May 1990, Waste Isolation Pilot Plant, DOE/WIPP 88-025, Carlsbad, New Mexico.

U.S. Department of Energy (DOE), 1991a. A Plan for the Implementation of Assurance Requirements in Compliance with 40 CFR Pat 191.14 at the Waste Isolation Pilot Plant, DOE/WIPP 87-016, Rev. 1, Waste Isolation Pilot Plant, Carlsbad, New Mexico.

U.S. Department of Energy (DOE), 1991b. Draft Report: Evaluation of the Effectiveness and Feasibility of the Waste Isolation Pilot Plant Engineered Alternatives: Final Report of the Engineered Alternatives Task Force, DOE/WIPP 91-007, Revision 0, Carlsbad, NM, Westinghouse Electric Corporation. 
U.S. Department of Energy (DOE), 1991c. Waste Isolation Pilot Plant No-Migration Determination Annual Report for the Period November 1990 through September 1991, DOE/WIYP 92-057, Westinghouse Electric Corporation, Carlsbad, NM.

U.S. Department of Energy (DOE), 1993a. Waste Isolation Pilot Plant Land Management Plan, DOE/WIPP 93-004, 1993.

U.S. Department of Energy (DOE), 1993b. Implementation of the Resource Disincentive in 40 CFR Part 191.14(e) at the Waste Isolation Pilot Plant, DOE/WIPP 91-029, Rev. 1, Department of Energy, Carisbad NM.

U.S. Department of Energy (DOE), 1993c. Waste Isolation Pilot Plant No-Migration Determination Annual Report for the Period October 1991 through August 1992, DOE/WIPP 93-057, Revision 1, Westinghouse Electric Corporation, Carlsbad, NM.

U.S. Department of Energy (DOE), 1993d. Waste Isolation Pilot Plant No-Migration Determination Annual Report for the Period September 1992 through August 1993, DOE/WIPP 93-062, Westinghouse Electric Corporation, Carlsbad, NM.

U.S. Environmental Protection Agency (EPA), 1992a. Conditional No-Migration Determination for the Department of Energy Waste Isolation Pilot Plant (WIPP), Federal Register, Vol. 55, No. 220, November 14, 1990, Office of Solid Waste, Washington, D.C.

U.S. Environmental Protection Agency (EPA), 1992b. Notice Proposing to Grant a Conditional Variance to the Department of Energy Waste Isolation Pilot Plant (WIPP) from Land Disposal Restrictions, Federal Register, Vol. 55, No. 67, April 6, 1990, Office of Solid Waste, Washington, D.C.

U.S. Environmental Protection Agency (EPA), 1992c. "No-Migration" Variances to the Hazardous Waste Land Disposal Prohibitions: A Guidance Manual for Petitioners, Draft, EPA530-R-92-023, Office of Solid Waste, Washington, D.C.

U.S. Environmental Protection Agency (EPA), 1993a. Environmental Radiation Protection Standards for the Management and Disposal of Spent Nuclear Fuel, High-Level and Transuranic Radioactive Waste, Federal Register, Volume 58, No. 242, p. 66398, 
December 20, 1993, (58 FR 66398), Environmental Protection Agency Office of Radiation and Indoor Air, Washington, D.C.

U.S. Environmental Protection Agency (EPA), 1993b. Land Disposal Restrictions, Code of Federal Regulations, Office of the Federal Register National Archives and Records Administrative, Washington, D.C. 


\subsection{Future Test Programs}

\subsection{Summary of Future Experimental Activities Necessary to Support a Compliance Demonstration}

This section will focus on activities that will supply relevant information identified as a need in the compliance assessment. This section is intended to demonstrate a link between the information needs and the planned experiments. The subsections are presented as follows: 1) the performance of natural barriers, 2) repository design and engineered barriers, 3) waste interactions, 4) human intrusion modeling, and 5) performance assessment (PA).

At this time, data and numerical models are not all considered to be sufficient and qualified to be used in a compliance determination. Consequently, results from the 1992 PA, as reported in the Compliance Status Report, have not been determined to be suitable for compliance determinations and are to be regarded as preliminary. However, programs are underway to complete the process of establishing data and models that are suitable for compliance determinations.

The PA process has not been static since the 1992 PA report (SNL, 1992) was published. A summary of the progress made with respect to data, data distributions, scenarios, conceptual and computation model development, and any other related efforts has been included.

\subsubsection{Natural Barriers}

\subsubsection{Salado Flow and Transport}

The primary objectives of the experimental activities and model development described in the following sections are to refine the conceptual model for flow and transport in the Salado Formation and to provide the necessary parameter data to support PA calculations that employ this model. These studies support those open issues in Chapter 6 related to the availability of brine and the characteristics of the anhydrite interbeds.

\subsection{Laboratory Measurements of Two-Phase Flow Properties}

Capillary pressure, porosity, and intrinsic permeability measurements are required to properly quantify threshold pressure and relative permeability of the Salado anhydrite interbed material. All have been identified as important input parameters in previous Waste 
Isolation Pilot Plant (WIPP) PA calculations and in related sensitivity analyses and studies. The validity of using correlations based on tight sands gas data to predict Salado capillary pressure and relative permeability has not been experimentally justified. Tight gas sands data are simply the closest analog for which detailed data are available.

The current values for Salado anhydrite porosity range from $0.06 \%$ to $3.0 \%$, and the values for intrinsic permeability range from $10^{-21}$ to $10^{-16} \mathrm{~m}^{2}$. Uncertainty in threshold pressure values for the Salado Formation exists and the value estimates range from 0.5 to $50 \mathrm{MPa}$ depending upon the lithology. Neither capillary pressure nor relative permeability has been measured on Salado core samples in the laboratory, so the Brooks and Corey (1964) and Parker et al. (1987) correlations are used in the current PA models for capillary pressure and relative permeability parameters. This application is based on measurements reported in the literature and made on non-halite materials.

In the absence of empirical site-specific data describinitg the threshold pressure, capillary pressure, and relative permeability of anhydrite interbed material, PA analyses will continue to rely on existing data from analogous materials.

In addition to measurements of WIPP-specific rock and flow properties, the Salado Two-Phase Flow Program scope includes assessing coring-induced biases to justify the use of laboratory-measured rock and flow properties to represent in-situ parameters. Core damage, characterized as stress-sensitive pre-existing fractures, pervasive microcracking associated with anelastic strain recovery, or coring-induced microcracking may affect laboratory rock and flow property measurements. The purpose of this work is to quantify coring-induced damage and determine the effect this phenomenon ultimately has on the analyses.

\subsection{In-Situ Measurement of Salado Permeability and Threshold Pressure}

The most recent PA calculations show that, with respect to compliance with 40 CFR 191, Subpart B, Salado halite and anhydrite permeabilities are important parameters in PA modeling. With respect to compliance with 40 CFR \$268.6, anhydrite permeability, anhydrite porosity, and halite permeability are also important parameters. Gas threshold pressure of anhydrite interbeds is not sampled independently, but is instead correlated with the sampled parameter anhydrite permeability, contributing to that parameter's importance. 
A result of the current PA conceptual model is that in repository performance the anhydrite interbeils provide the primary path for both brine inflow to disposal rooms and gas egress from the rooms. Halite beds are important because they may serve as either sources or sinks of brine for the anhydrite interbeds. The Far-Field Permeability Testing Program is the primary source of data to PA on the permeability of anhydrite and halite layers around the WIPP repository.

The current PA model assumes that if the repository pressurizes and brine and/or gas begin to flow out of the disposal rooms, the pre-existing permeability and porosity in the anhydrite interbeds will be enhanced by fracture creation, dilation, and/or propagation as the fluid pressure within the anhydrites increases. The resulting permeability and porosity will determine the rate and distance of gas migration from the repository. The current PA model, developed since the 1992 PA report, assumes an exponential relationship between fracture porosity and the fluid pressure within the fracture. Permeability is then assumed to change in response to the aperture changes following a power-law approximation. The forms of these relationships and the value used for the parameters in the relationship have, as yet, no experimental basis.

The Far-Field Permeability Testing Program will provide direct experimental data on in-situ changes in the fracture permeability and aperture in anhydrite interbeds as a result of changes in fluid pressure within the fractures. Constant-pressure flow tests will be performed on anhydrite interbeds over a range of pressures while simultaneously measuring changes in fracture apertures. Information from these experiments will be used to test the relationships postulated in the current PA conceptual model, or failing confirmation, they will be used to generate an appropriate new conceptual model that corresponds with the data. Experiments are planned for the four anhydrite layers closest to the WIPP disposal rooms that are included in PA models of repository performance: Marker Bed (MB) 138, MB 139, and anhydrites " $a$ " and " $b$ ".

A result of the current PA model is that, as the pressure within the repository rises due to gas generation, some quantity of gas will migrate away from the repository through anhydrite interbeds. To enter the brine-saturated anhydrite interbeds, gas must overcome the capillary threshold pressure to displace brine and establish its own connected flow path. The current PA model uses a correlation between permeability and threshold pressure to define the value of threshold pressure to be used with each sampled value of permeability. The correlation used by PA was developed by Davies (1991) through a literature survey. The literature 
values were primarily for porous, instead of fractured, media. This activity supports making a limited number of in-situ measurements of gas threshold pressure in boreholes where the permeability of anhydrite interbeds has already been established. These measurements will be used to test the applicability of Davies' correlation to WIPP anhydrites.

By providing PA with actual in situ data on these parameters, sampling can be confined to realistic ranges that will support a defensible compliance decision.

\subsection{Large-Scale Brine Inflow Experiment}

40 CFR 191, Subpart B, limits the probability of specified, integrated radionuclide releases from a nuclear waste repository to the accessible environment for 10,000 years. The regulations require probabilistic calculations of the potential radionuclide release. A key component of those calculations is simulations of the repository behavior after panels are closed. It is important to quantify brine inflow into boreholes and excavations to understand the reaction of brine with the stored waste for overall WIPP PA, and for the design of repository seal systems. To address this issue of brine inflow into the repository, the Room $\mathbf{Q}$ test was initiated with the objective of obtaining a detailed set of data for model development and testing. The data/information will allow the Department of Energy (DOE) to test the model's ability to scale from small borehole brine measurements to measurements expected in a room size excavation, and identify the mechanism that contributes to the release of in-situ brine into waste storage rooms.

The planned activities at Room Q, along with an ongoing facility-wide brine inflow observation program (called the Brine Sampling and Evaluation Program), are designed to provide data relevant to the flow mechanisms related to the excavation, which provide fundamental input to the conceptual models for fluid flow in the Salado Formation.

While brine collection in Room $Q$ has provided a general indication of the amount of brine which might seep into an excavation, there were discrepancies between the volume of brine collected and previous model simulations. A potential source for the discrepancy is that the room seals were installed two years after its excavation, allowing a period where some degree of drying took place. A second potential reason for discrepancies can be attributed to the possible free flow of brine in an extremely damaged area near the surface of the room. The reason this is mentioned as a possibility is because indications of brine flow have been noted on the Room $Q$ floor outside the outer bulkhead. 
Several options exist for examination of the flow mechanisms that control brine seepage and their effects on brine flow. The first of these options is to perform a series of tests on those holes which have provided the first interpretative data to validate the current understanding of mechanistic responses of the formations to the room excavation after an extended period of time. Another testing option is to conduct a series of tests within the room for the purposes of measuring the flux of gases out of the room and identifying the presence or absence of a viable path for flow which bypasses the seals.

\title{
10.1.1.1.4 Multiphase Model Development, Testing, and PA Model Verifications
}

Performance assessment evaluates multiphase flow in the repository and surrounding formations with the BRAGFLO computer code and a conceptual model. The tasks described in this subsection evaluate the conceptual model used by PA by comparing it to alternative conceptual models and to more detailed modeled simulations.

As discussed in previous chapters, brine inflow and gas migration require some degree of quantification as part of the determination of repository performance. Brine availability will directly influence the quantities of gas generated. The response of geologic and engineered barriers to gas pressure is one of the regulatory performance measures. There are a number of assumptions made in the PA conceptual model regarding brine inflow and gas migration including the following:

\author{
Simplified Stratigraphy \\ Horizontal Repository and Layering (No Dip) \\ Single Continuum Model for Fractured Interbeds and Disturbed Rock Zone (DRZ) \\ Homogeneous Layers \\ Two-Phase Characteristic Curves for Fractured Interbeds and DRZ \\ Two-dimensional Repository Representation \\ Room Closure Coupling \\ Gas Generation/Brine Availability Coupling
}

For example, the current PA conceptual model assumes a simplified stratigraphy, or a limited number of layers with properties of a composite halite and anhydrite. As evaluated by Webb (1991), and the 1992 PA, the permeability, porosity, and iwo-phase characteristic curves of the anhydrite and adjacent halite layers significantly influence the brine inflow and gas migration from the repository, implying that a detailed representation of the stratigraphy may be necessary to adequately characterize brine inflow and gas migration. A model is 
being developed with explicit representation of each of the layers around the repository to compare with the simplified stratigraphy employed by PA.

Another assumption employed by PA is a perfectly horizontal repository. More detailed calculations are currently being perfurmed to ascertain the potential effect of dip on repository performance.

A simplified single continuum representation of fractured anhydrite interbeds is currently used by PA. An alternative representation of the fractured interbeds as a dual continuum fracture-matrix porous model is currently being developed to evaluate with PA. Specifically at issue is the porosity increase in the interbeds if a fracture were to occur. This alternative representation could result in a significant reduction in the fracture-induced porosity increase in the interbeds and thereby increase the potential gas migration distance. Similar studies will be performed for the representation of the DRZ used in the PA model concerning the gas storage potential of the DRZ.

A reasonable conceptual model cannot be defined without representing or bounding the key competing phenomena. Evaluation of many of the simplifications used in the PA model can only be performed by comparison to more complex models that examine alternate conceptual modeling approaches.

\subsubsection{Non-Salado Flow and Transport}

The rock units overlying the Salado Formation contain water-saturated units. The Culebra Dolomite Member of the Rustler Formation is the most transmissive and is believed to be the most likely long-term release pathway in the event of a repository breach by human intrusion. Numerical simulation of flow and of ravionuclide transport in the Culebra is an integral part of the WIPP PA. While sufficient information exists to characterize many aspects of this flow system, there are flow and transport assumptions that require the support of additional information. These assumptions fall into the general categories of regional scale and vertical flow, physical processes that retard radionuclide transport, and chemical processes that retard radionuclide transport. The primary objectives of the experimental activities described in the following sections are to gather additional data/information to test the models assumptions. 


\subsection{Regional-Scale Groundwater Flow and Geochemistry}

PA calculations assume that all subsurface releases to the accessible environment resulting from human intrusion scenarios occur in the Culebra Dolomite Member of the Rustler Formation. The Culebra is modeled as a perfectly confined unit, i.e., it is assumed that vertical flow into or out of the Culebra can be neglected when calculating transport paths and when calibrating stochastically generated transmissivity fields. Flow and transport are calculated in a two-dimensional, horizontal model domain. The effects of climate change are simulated by varying hydraulic heads along lateral boundaries. It has yet to be determined whether or not the current conceptual model is correct.

The results of PA, to date, are considered incomplete because:

1) It is not certain that the confined aquifer concept is a reasonable model on which to base release calculations for compliance demonstration. Modeling studies (Huang et al., 1987; Davies, 1989) have demonstrated that vertical flow across the upper and lower surfaces of the Culebra can be compatible with observed data. Ignoring vertical flow would lead to errors in calibrated transmissivity fields which, in turn, could lead to greater calculated radionuclide releases. Also, vertical flow across confining layers could result in vertical release paths and/or an additional retardation process that have not been included in PA calculations. The total impact of ignoring vertical flux on performance measures is being addressed.

2) The current PA models are not equipped to account for transient changes in the flow pattern caused by changes in climate.

3) The two-dimensional model cannot be used to evaluate scenarios that involve interactions with other portions of the hydrologic system. Examples are vertical flow through low permeability units due to degradation of casings and plugs in nearby oil and gas wells, and increased infiltration under surface catchment basins that could form as strata over future potash mines subside.

4) It has been observed that the distribution of dissolved solids in Culebra waters appears to be incompatible with the flow paths predicted by conceptual flow models developed for PA.

A three-dimensional, transient model of groundwater flow and transport is being developed to enhance the PA. The model is based on the concept of the groundwater basin. It included all strata from the top of the Salado Formation to the land surface and uses a seepage face/free surface as the upper boundary condition. Flow in the model domain is 
maintained by recharge to the water table. Recharge is specified as a function of time and location to simulate climate changes. The lateral boundaries of the model domain follow inferred groundwater divides which are assumed to be constant for the entire simulation period.

There are two objectives for the regional three-dimensional flow simulations:

1) Demonstrate that the confined aquifer model is an appropriate conceptual model to be used as a basis for PA calculations, or provide an alternative conceptual model that includes flow in all the strata between the Salado and the land surface. Simulations in which radionuclides are released along the entire length of a borehole will be performed to test the assumption that releases to units other than the Culebra will not significantly affect compliance measures and that neglecting them is conservative.

2) Perform simulations of scenarios that cannot be addressed adequately using the two-dimensional models that are currently used for PA calculations. These scenarios include the possible changes in flow rates in the Culebra caused by changes in climate, and the potential impact of vertical flow through low permeability units due to degradation of casings and plugs in nearby oil and gas wells.

\subsection{Physical Retardation Models/Non-Sorbing Tracer Tests}

In PA human-intrusion scenarios, releases of radionuclides to the accessible environment can take two routes: direct releases to the surface in drill cuttings and lateral transport through the Culebra Dolomite Member of the Rustler Formation across the WIPP site boundary. The PA conceptual model considers the Culebra to be a dual-porosity medium in which advective transport occurs through interconnected fractures while diffusion of solutes (radionuclides) from the fractures to the surrounding rock matrix retards the movement of those solutes. With matrix diffusion dual-porosity, the mean complementary cumulative distribution function (CCDF) shifts favorably two orders of magnitude. The most recent PA calculations show that Culebra fracture spacing is an important parameter as well as Culebra transmissivity fields and matrix porosity. Fracture spacing is important because it is the parameter that describes the surface area available for matrix diffusion along the transport path. The Culebra transmissivity field is important because it defines the flow path to the accessible environment as well as, with fracture porosity and hydraulic gradient, the velocity of groundwater flow. Matrix porosity is important because it represents the storage volume available to radionuclides along the transport pathway. 
Data on fracture spacing and porosity and on the Culebra transmissivity were generated by tracer and hydraulic tests conducted in the field in the WIPP vicinity. The dual-porosity model that has been used in the past for tracer-test interpretation is a continuum model (globally interconnected permeability) that treats the Culebra as a single homogeneous bed that is horizontally anisotropic. The dual-porosity conceptual model has limitations which include: 1) the model does not examine the vertical heterogeneity of the Culebra, 2) the model does not account for scaling issues (changing transport parameters as a function of transport distance), and 3) the model contains insufficient data to determine whether variations in transport behavior along different flow paths were due solely to anisotropic permeability in the Culebra or were caused by heterogeneity. Additional tracer tests of the Culebra are being designed to provide data with which to address the limitations. These experiments will test the conceptual model of the Culebra by providing an experimentally determined parameter value base. An added benefit of the tracer testing is that the long-term pumping associated with the tests will produce transient pressure responses that can be measured and interpreted to characterize transmissivity in the Culebra. Drilling new wells for these tests will also allow the collection of core samples which can be used for laboratory measurements of matrix porosity.

\subsection{Chemical Retardation Models/Laboratory Column and Field Sorbing Tracer Tests}

Work on chemically retarded transport in the Culebra is designed to test for chemical retardation mechanisms and to quantify chemical retardation parameters. This work will benefit compliance demonstration because it can be used to replace and/or corroborate expert judgment with experimental data.

In accordance with the 1988 Modification to the Working Agreement for Consultation and Cooperation, the DOE agreed to obtain laboratory data on the sorptive properties of the Culebra. These data, in consultation with the State of New Mexico, can be used to establish conservative values for use in the PA. As such, demonstrating, modeling, and quantifying chemical retardation of radionuclides remains an important element in the WIPP experimental effort.

It follows that potential release is sensitive to chemical retardation parameters. This is not an implication that a successful demonstration of compliance hinges on this issue. Rather, to establish any non-zero values for $K_{d} s$ would substantially reduce the likelihood of realizations 
that violate the 40 CFR 191 release limits (for example, the E1E2 scenario, a disturbed case intrusion event where radionuclides must migrate through a portion of intact Culebra en route to the compliance boundary. The current experimental strategy to quantify chemical retardation of radionuclides includes laboratory measurements of retarded transport of both dissolved and colloidal species during advective flow in intact Culebra cores, empirical sorption measurements on Culebra rocks, mechanistics sorption studies on minerals in Culebra rocks, and colloidal stability and transport studies.

\subsubsection{Repository Dexign and Engineered Barriers}

\subsubsection{Sealing Systems}

Seals placed in the drifts and shafts of the WIPP repository represent the only post-closure engineered barriers between the waste rooms and the accessible environment. Applicable regulations provide both direct and implied guidance for the sealing program without providing direct, quantitative performance standards for the individual seals. For example, regulatory guidance clearly indicates the need to use both natural and engineered barriers to contain the waste and indicates the need to seal shafts to limit both migration of water into waste storage areas and movement of waste from a repository. In addition, the guidance recognizes the need to design the seals to withstand forces due to rock creep and hydraulic pressures, to consider material compatibility between the seals and the host rock and between the seals and the waste, and the need to consider phenomena that can impact the longevity of the seals.

Compliance documentation requires seal designs, seal material descriptions and selection rationale, seal emplacement descriptions, and an assessment of the anticipated performance of the seals. These evaluations require the development of:

- detailed designs of seal components,

- conceptual model of the seal components/system performance,

- data on seal materials,

- data on seal constructability, and

- information/data base of lab and field measurements to support compliance statements.

The 1991 PA identified the long-term shaft seal permeability as an important parameter. In the 1992 PA, the shaft seal permeability was identified as one of the very important 
parameters related to controlling gas flow from the repository. Achieving the required permeability to control maximum expected repository gas pressures is dependent upon the degree of initial compaction achieved in emplacing the crushed salt (or salt blocks), the effectiveness of the short-term seals in preventing flow of gas or water into the crushed salt in sufficient quantities to negatively impact consolidation, and by the amount of creep closure that occurs after emplacement of the crushed salt.

Design concepts have been developed and evaluated in numerous studies. These evaluations include numerical simulations of structural and fluid-flow performance, measurements of laboratory properties of materials proposed for use in the seals, field emplacement and testing of components in small-scale seal tests and in borehole sealing tests, development and demonstration of specialty materials (e.g., salt-saturated concrete and ultrafine cementitious grout), and development of reference design configurations for the various components. PA uses estimated values for the performance of the short-term components and, in general, make the assumption that the short-term components perform sufficiently well to ensure that water does not enter the repository via the shafts and that not enough water enters the shafts to preclude or delay the consolidation of the salt components. For the long-term performance, PA calculations assume that sufficient closure of the shafts occurs to produce, in each shaft, a column of reconsolidated salt approximately $656 \mathrm{ft}(200 \mathrm{~m})$ in height with a permeability nearing that of the surrounding formation. Additional work will provide data to enhance the defensibility of these performance-related assumptions and to provide designs that have sufficient detail to determine emplacement feasibility.

Principal ongoing activities are related to the development of detailed designs for the seal components, the fielding of large-scale seal tests, additional numerical simulations of component performance, and the collection of laboratory data needed to make final decisions on seal component materials. Additional design work will provide details on performance criteria, construction processes, excavation techniques, seal emplacement area, surface preparation and tolerances, emplacement methods (including grouting techniques), material sirecifications, and quality assurance/quality control requirements. Large-scale seal tests are intended to demonstrate the feasibility of the principal construction activities and to provide data on the initial post-emplacement performance of selected components of seals. Technology demonstrations are planned for placement of large volumes of salt-saturated concrete and compaction of crushed salt to at least $85 \%$ of its original density. Such tests are needed since only a few seal placements have ever been made in salt, and the quality of the WIPP seals must be demonstrated largely through control of construction processes since 
there will be little opportunity to test the actual seals after placement. Materials tests that remain to be done in the laboratory are focused on improving the credibility of the constitutive model for crushed salt reconsolidation, confirming the compatibility of current seal materials with the host rock and the waste, and evaluating the acceptability of the range of properties that result from the variability allowed in construction specifications.

\subsubsection{Rock Mechanics}

The two principal areas of rock mechanics phenomena important to the conceptual model are creep of the salt and fracture-related concerns in the Salado Formation. The development of a technology to simulate the creep behavior is important in determining the manner and timing of the encapsulation of the waste, the response of the room to pressurization from the formation of gas, and indirectly, the conditions for the inflow of brine to the room. Creep closure is also the driving force for the compaction of crushed salt backfill, for the compaction of the waste, for the stresses imposed on the seals, and for the compaction of seal components. In the anhydrite members, fracture-related phenomena, such as the DRZ, control the extent of grouting needed near seal components as well as effects of gas pressurization. The DRZ is particularly important in assessing the performance of seal components since it must be determined if the DRZ surrounding the seals will heal with sufficiently low permeability to satisfy seal performance requirements.

Performance assessment employs the results from a model of the creep phenomena for simulations of the behavior of the rooms and the seals. Shaft seal permeability is one of the parameters identified as important for PA; creep closure is the process being relied upon to ensure that the permeability of crushed salt decreases to near that of the host rock salt. Creep closure aiso affects the void volume in the repository at any time; the void volume is critical both for evaluating gas effects in the repository and for evaluating the specific state of the waste (including its strength properties) at a particular point in time. Similarly, an understanding and predictive capability for salt creep is needed for fracture-related phenomena.

With regard to the creep phenomena, the laboratory data base has been obtained; the Munson-Dawson (M-D) constitutive model for creep continuum deformation is well developed; and very extensive series of multi-year field experiments are nearing completion. For numerous geometries of underground openings, this model has been used to satisfactorily predict the time-dependent creep of salt as a function of the stress and temperature. 
For the fracture-related phenomena, work has been accelerated over the last couple of years because of the increased emphasis on gas-related concerns. Field measurements have provided data on the conditions necessary to initiate and propagate fractures within the anhydrite. Within the salt, field measurements have provided data on the extent and permeability of the DRZ and some information on how these are expected to change over time. In addition, laboratory data on the tertiary creep (fracture) and healing of rock salt have been obtained, and a new constitutive model has been developed to simulate the formation, propagation, and healing of the fractures in salt. This model is being applied in initial simulations of WIPP observations but is not nearly as well developed as is the creep model. Current PA evaluations of seal performance assume that the DRZ surrounding the shaft seals has healed as tightly as the compacted crushed salt, i.e., has a permeability nearly as low as that of the host rock. Assumptions in PA modeling efforts related to the extent and effects of fracturing in the anhydrite are still being developed. Further efforts are required to validate the model of salt fracture (especially the healing phenomena).

In the rock mechanics area, the principal activities that are nearing completion are those related to fracture effects. Simulations of fracture behavior in the salt, particularly with regard to roof falls and rock bolt performance, are underway. Upon verification and confidence testing of the fracture formation and propagation capabilities, the focus will shift to the evaluation of the credibility of the healing phenomena since this phenomena is of significant importance to the performance of the seal components. Evaluations of the changes of the DRZ with time for older WIPP openings are underway.

\subsubsection{Disposal Room Performance}

Previous analyses have shown that the void volume in the repository at any given time (repository closure) is critical for evaluation of the effects of gas generation on repository performance. Excess gas not contained within the repository disposal rooms and drifts will be forced away from the repository potentially creating pathways for contaminant movement. It is important, therefore, to accurately estimate how the void volume within the repository that is available for gas storage varies as a function of time. A further consequence of gas-limited closure is that it may limit the rate and extent of densification of the waste and, therefore, the physical properties of the waste. In particular, the state of the waste and its strength properties are important in assessing the extent that borehole erosion or spalling of the waste may contribute to cuttings release in the event of a future human intrusion. 
The PA interbed fracture model is an approximation that needs to be confirmed or refuted by mechanistic modeling and/or experimental data. If the amount of gas cannot be totally confined within the repository, then the question, "Where does it go and how far?," must be addressed. The present conceptual model is that gas will be forced out of the repository and may migrate along interbeds. The model is empirical, assuming that flow occurs because the porosity or fracture permeability of the interbeds is enhanced by the pressurization.

If the porosity enhancement model cannot be supported by data/information, and the interbed is much less permeable to gas than expected at pressures below lithostatic, then mechanistic models involving fracture opening will be examined. These mechanistic models have strong support from the reservoir stimulation hydrofracture treatments commonly used in the petroleum industry, but are not presently a part of the PA.

Room closure estimates are uncertain when the repository is partially saturated with brine. The specific concern is whether a field theory for two-phase flow in a porous media with fractures exists and if not, if there is justification for separation of the flow, mechanical response, and gas generation models. The closure information is provided to PA as a set of curves for the porosity associated with various amounts of gas generation as a function of time. Presently, this information does not include the effects of any brine present in the room.

The issue being addressed is the quantification of the impacts of using an uncoupled approximation of closure. Calculations have shown that when the repository is largely filled with gas, the present information provided to PA and the way it is used, is an adequate representation of closure. However, if the brine saturation of the repository becomes significant, the PA results are less certain. More brine inflow implies lower gas pressurization having taken place; on the other hand, increased amount of brine present could have an impact on the release associated with a human intrusion. Fully coupled analyses are planned that will allow evaluation of the BRAGFLO method used in the 1992 PA.

Repository closure is caused by time-dependent deformation of salt surrounding the waste, which decreases the excavated volume of the repository and consolidates the waste and backfill to a denser state. The mathematical methods used to simulate the effect of these processes over thousands of years depend on the mathematical model describing the creep of halite. Closure results given to PA for PA studies currently are based on a simplified creep description developed a number of years ago. 
To improve and justify closure estimates, a second creep description, the M-D creep model for halite, should be used. The M-D model is considered the baseline model for salt creep, having been the product of a large research effort over a number of years. Although a number of indirect methods have been used to compare $M-D$ results with results from the simpler model, future work will confirm the adequacy of the present calculation results. A more complete analysis of the disposal room containing waste and backfill is not likely to be possible through additional code development.

The DOE intends to expand methods of justifying continued use of the current simplified method. The error in using the simple creep model is estimated to be small for long-term repository conditions, but could be significant for any events occurring within several hundred years of decommissioning. Most closure generally occurs within this time frame. The simpler model predicts less gas pressurization than is likely. Since waste porosity was not selected for sampling in the 1992 PA, a planned alternative is for PA to perform a sensitivity analysis of closure. This might be possible by assuming various porosity values, holding them constant with time, and observing the extent of gas migration with time.

\subsubsection{Waste Interactions}

\subsubsection{Gas Generation}

Gas quantities, rates, and species that are produced by corrosion, microbial activity, and radiolysis can influence the performance of the repository. A gas-generation model is required for technical defensibility of PA codes and to help simulate the consequences of gas on the following coupled processes:

\footnotetext{
- fracture initiation and propagation

- brine in- and out-flow

- room closure or expansion

- repository pressurization

- $\quad$ solubilities of actinides (which would in turn influence the amount of gas production by radiolysis) and other hazardous constituents

- $\quad$ potential transport of volatile organic compounds

- chemical effects of proposed backfill additives or other engineered alternatives on gas generation and brine chemistry
}

The 1992 PA used a simple average-stoichiometry gas-generation model. The model used wide ranges of gas generation rates based on short-term, single-mechanism, laboratory-scale 
research on the oxic and anoxic corrosion of steel and the aerobic and anaerobic microbial degradation of cellulosics. These PA calculations assumed that all of the steel would generate hydrogen by anoxic corrosion if sufficient water or brine were present, and only a fraction of the organic waste would generate gas by microbial processes.

This simple model predicts large net gas quantities as is does not account for synergistic effects such as passivation of steel by microbially produced $\mathrm{CO}_{2}$ and/or $\mathrm{H}_{2} \mathrm{~S}$. Alternatively, the model underestimates the amount of water present (important to actinide mobility and local hydrology) since only water-consuming processes are included. The model does not include radiolysis because of very low actinide solubilities established by an expert panel and does not account for the consumption of gases by waste and repository materials; these are reasonable assumptions.

To provide a model that describes the gas production and consumption processes from the complex mix of materials in actual contact-handled TRU waste more precisely, a reaction-path model is being developed that will simulate synergistic effects of combining the potential gas production and consumption mechanisms. The new gas-generation model is based on thermodynamic principles and uses experimental rate and species data from laboratory tests for single and multi-mechanism gas-generation conditions. Effects of the partial pressure of $\mathrm{CO}_{2}$ and $\mathrm{H}_{2} \mathrm{~S}$ and the effects of $\mathrm{Ca}(\mathrm{OH})_{2}$ (in hydrated cementitious materials) and $\mathrm{CaO}$ (a potential backfill additive) on $\mathrm{pH}$, corrosion rates, and microbial degradation rates are not currently included, but may be identified as important enough to consider in future studies.

To provide the required data base for the new reaction-path model, experimental data from longer-term, single- and multi-mechanism studies with simulated and actual TRU waste would be beneficial. Studies with simulated materials, using conditions of pressure, oxidizing potential, and $\mathrm{pH}$ that span those expected in the 10,000-yr period of regulatory interest are in progress at Argonne, Brookhaven, and Pacific Northwest National Laboratories. To provide confidence that the model can adequately simulate gas generation from actual TRU waste in the DOE complex, a series of tests are planned that will measure gas generation from the major forms of actual CH TRU waste (metals, combustibles, and sludges). These tests will include single and multi-mechanism studies using actual CH TRU waste at a larger scale than the laboratory research studies which use specially prepared, relatively small, simulated waste material samples. The new gas-generation model will be used to perform pre-test predictions of the pressure and gas species as a function of time for 
each test. In summary, the average stoichiometry model may adequately represent the gas generation related phenomena for purposes of compliance assessment. Due to the complexity of the competing phenomena related to gas generation, the relative conservatism of the model cannot be assumed a priori, rather it must be assessed on a case-by-case basis.

The main differences between the average-stoichiometry model currently used in PA and the new reaction-path model are that: 1) the reaction-path model includes all major gas-producing mechanisms, 2) the reaction-path model includes gas-consuming reactions, and 3) the reaction-path model includes interactions among gas-producing and -consuming processes, such as passivation of steel by microbially produced $\mathrm{CO}_{2}$ and $\mathrm{H}_{2} \mathrm{~S}$ and the depassivation of steel due to consumption of $\mathrm{CO}_{2}$ by $\mathrm{Ca}(\mathrm{OH})_{2}$ or $\mathrm{CaO}$ causing the destabilization of the passivating phases. The new reaction-path model and its supporting experimental data base from experiments will provide an alternative gas and brine-chemistry results for the final compliance calculations.

\subsubsection{Actinide Source Term}

Radionuclide concentrations in brines associated with a human-intrusion scenario must be determined in order to calculate the brine-transported portion of radionuclide releases to the accessible environment in the event of human intrusion. These radionuclide concentrations can occur in the form of dissolved species (dissolved ions in several oxidation states or dissolved complexes of these ions with ligands) as well as colloids. The dissolved species concentration estimates currently used in the PA modeling for radionuclides are based on the judgment of an expert panel. The expert panel was unable to develop probability distributions for colloid concentrations (called "suspended radionuclides") (Trauth et al, 1993). Currently available experimental information is not sufficient to simulate dissolved species or colloid concentrations in the relevant brines (Castile, Salado, Culebra).

Sensitivity studies for PA calculations indicate that only actinide (not all radionuclides) concentrations are needed. The Actinide Source-Term Program has been designed to meet this PA information need. The Actinide Source-Term Program includes model development, model parameter measurements, and a TRU waste test to assess the adequacy of the model.

An actinide concentration model is being developed and, in conjunction with an existing brine model, will be used to generate concentration information for the PA. The actinide concentration model includes sub-models for solubility and stable colloids. 
The solubility sub-model assumes that actinides in waste dissolve instantaneously and form kinetically favored metastable solids seen in the laboratory. This assumption results in upper-bound estimates for solubility concentrations (i.e., maximum dissolved concentrations in brine) because more thermodynamically stable solid phases with correspondingly lower solubilities may form over longer time scales. The experimental information required for this model includes development of activity coefficients and identification of solubility-controlling solids. Significant applicable information currently exists; however, the remaining solubility model parameters will be derived from ongoing laboratory experiments.

The colloid study is organized on the basis of potential colloid types. Carrier colloids do not contain actinides but have the potential to sorb actinides (examples are corrosion products, clay minerals, and bacteria). Pseudocolloids are carrier colloids that have taken on actinides by sorption. Actinide intrinsic colloids are formed by polymerization of actinide monomers in solution. The agglomeration rate of carrier colloids is being evaluated in laboratory studies. If carrier colloids that are stable in WIPP-relevant brines are identified, the sorption capacity for the actinides will be evaluated. If the agglomeration rate for the resulting pseudocolloid is slow enough to be a sensitive parameter, a model will be developed that calculates actinide pseudocolloid concentrations. The formation of actinide intrinsic colloids is being evaluated in laboratory studies. Initial studies will evaluate the formation of actinide intrinsic colloids under controlled conditions in appropriate brines. If intrinsic colloids form under controlled conditions, then their persistence under anticipated disposal room conditions will be evaluated. If actinide intrinsic colloids persist under disposal room conditions, then an equilibrium model will be developed to predict their concentrations.

The concentration model performance will be tested as required, with results from a number of tests using actual TRU waste forms mixed with Salado-like brine. The test matrix includes a variety of waste types and chemical environments. The test containers will be periodically agitated to accelerate the reactions toward steady state concentrations. Both dissolved and colloid concentrations will be measured and compared with the concentration model equilibrium predictions. 


\subsubsection{Human Intrusion Modeling}

\subsubsection{Cuttings Release Parameters}

Experimental data to confirm PA drill-cuttings removal estimates due to spalling are not available. Laboratory tests are required for measurements of the properties that simulated waste may have relative to controlling borehole enlargement during a human intrusion. As the drill penetrates the waste, material adjacent to the borehole wall may erode or may spall off into the hole, causing the borehole diameter to become greater in the vicinity of the repository. This excess diameter could allow an additional release of radioactive material during a human intrusion. The extent of release also depends on the activity of the waste, and must be determined because the removal of waste cuttings from the borehole during a human intrusion is currently one of the dominant processes in the current PA.

The assumed range of strength values for erosion used by PA is presently taken from the literature. These values are $100 \%$ clay-based soil. The accuracy of the PA cuttings release estimates is not discernible, although it is reasonable to assume that the present analysis simulates greater removal than is likely because of the extremely small values assumed for the waste erosion strength. The magnitude of the cuttings release contribution attributed to spalling is unknown, and a satisfactory model describing spallation potential is not yet available. No estimates of spallation are presently included in compliance demonstrations, and they are not likely until such a model is developed.

Spallation occurs when the fluid pressure in the borehole suddenly becomes less than the pore pressure of the gas-filled material adjacent to the borehole as the drill passes through the waste horizon. When this depressurization occurs, flow of gas into the borehole can fracture the decomposed waste and cause its removal. The laboratory experiments will consist of rapidly depressurizing samples of surrogate waste material and measuring the extent of weakening and fracture. Later in the program, fluid flow at various velocities will be used to determine the erosion potential of both spalled and unspalled samples.

If additional erosion data cannot be reasonably obtained or are identified as of lesser importance, PA will use the present erosion conceptual model, with a large range of erosion strength values. Some type of spalling model will likely be developed for future PA to either include spallation as an adequate conceptual model or show that its contribution is unimportant in cuttings release. 
An additional altemative for acquiring data/information on spalling is examination of borehole enlargement problems encountered by the petroleum industry, particularly relative to gas reservoirs.

\subsubsection{Performance Assessment}

PA provides analysis directly relevant to assessing system performance relative to compliance with the EPA standards. The following section provides a look ahead at modeling improvements and studies to be completed in support of the current PA analysis needs.

\subsubsection{Future Modeling and Studies}

The following describes changes and improvements in the PA modeling system that can be foreseen at this time as necessary for the analysis to have improved defensibility. In addition, several supporting analyses for scenario screening and conceptual model assumption testing are planned.

In the 1992 PA, intrusion scenarios only considered a single panel which amounted to a de facto assumption of panel seals successfully preventing radionuclides from the adjoining panels reaching the borehole. Future PA activities will use full-repository geometry for both undisturbed and disturbed analyses, and communication will be allowed through and around panel seals following intrusion.

Permeability and porosity of the anhydrites can now be increased in the PA as pressure approaches and exceeds lithostatic. The PA model provides an approximation of the possible effect of pressure fracturing. It is not a mechanistic model for fracturing but is instead an empirical model that needs to be confirmed or refuted by mechanistic modeling and experimental programs. If the approximation is shown to be acceptable, experimental programs could provide additional data to quantify adjustable model parameters.

Previous PAs have had no means for tracking Volatile Organic Compounds (VOC) concentrations in the gas phase. The model used in the next PA will be simplistic in the sense that it will not include sorption or decay processes (the model can simulate the processes, but data are not available to support this), but it will calculate pressure-dependent liquid-gas phase equilibria for selected VOCs, and it will allow determination of conservative VOC concentrations at the unit boundary. 
Future PA's will also consider intrusion scenarios throughout the 10,000 -yr regulatory period of interest.

\subsubsection{Supporting Studies}

Currently, the pilot point method is used in PA for calibrating transmissivities to transient head data. The automated calibration technique first used in the 1992 PA will be used again in the next PA to generate an additional 30 transmissivity fields for use in the Latin hypercube sampling. Alternative techniques under development will be considered for use in PA if found to be more appropriate.

The event and process screening procedure used to develop the scenarios analyzed in PA should be reviewed and revised as necessary to reflect new information not available when the initial screening was performed and to address concerns raised by reviewers, including the EPA.

Nuclear criticality (i.e., the possibility of fissile material within the waste achieving critical mass through chemical dissolution and precipitation or any other process) has been identified as an event that should be addressed in the scenario selection process for WIPP. Quantitative analyses of the conditions required for criticality are being conducted. The result of these analyses will be used to determine if the event should be retained for use in scenario development and consequence modeling.

Subsidence may affect flow in two primary ways: by increasing horizontal conductivity within the Culebra (or another layer); and by increasing leakage into or out of the Culebra (including recharge from the ground surface). Because the second effect requires simulation using a three-dimensional flow model, PA has been unable to address mine subsidence effects quantitatively until now. Subsidence should be examined using the SECO-FLOW 3-D code.

Brine injection into the Culebra following intrusion into a Castile reservoir is an issue that has been raised by several reviewers. Could the volume (or density) of the injected brine significantly alter flow in the Culebra? The question will be examined in specific analyses using SECO-FLOW 2D. Possible chemical effects of brine injection (i.e, dissolution or precipitation of mineral species, and changes in sorption reactions) and physical effects (i.e., changes in fracture apertures) are not currently considered. 
Questions about the consequences of brine flow to the surface should be examined. Because open-hole flow (i.e., during a blowout or controlled release during drilling) cannot be modeled as Darcy flow, computations cannot be done with the BRAGFLO code in the Monte Carlo simulations. Separate analytical calculations will be performed to identify this potential for release.

\subsubsection{Summary}

\section{Salado Flow and Transport}

The primary objectives of the experimental activities and model development is to develop and test conceptual models for flow and transport in the Salado Formation and to provide the necessary parameter data to support PA calculations that utilize these models. In the absence of a continued program in these areas, PA calculations will be left without defensible conceptual models and supporting data for Salado flow and transport.

\section{Non-Salade Flow and Transport}

The Culebra Dolomite Member of the Rustler Formation has been identified as one of the most transmissive off site pathways in the event of a repository breach by human intrusion. Numerical simulation of flow and radionuclide transport in these units is an integral part of the WIPP performance assessment calculations. While there exists sufficient information to characterize many aspects of this flow system, there are flow and transport issues that remain to be resolved. The primary objectives of the experimental activities and model development is to address the remaining issues of regional scale and vertical flow, physical processes that retard radionuclide transport, and chemical processes that retard radionuclide transport. In the absence of a continued program in these areas, PA calculations will be left without defensible conceptual models and supporting data for these unresolved issues.

\section{Sealine Systems}

Published performance assessments use estimated values for the performance of the short-term components and, in general, make the assumption that the short-term components perform sufficiently well to assure that water does not enter the repository via the shafts and that not enough water enters the shafts to preclude or delay the consolidation of the salt components. 
For the long-term performance, the assumption is made in PA calculations that sufficient closure of the shafts has occurred to produce, in each shaft, a column of crushed salt approximately $200 \mathrm{~m}$ in height that has a permeability nearing that of the surrounding formation. Additional work remains to be done to be able to defend these performance-related assumptions.

\section{Rock Mechanics}

The two principal areas of rock mechanics phenomena important to compliance are creep of the salt and fracture-related concerns in the Salado Formation. Compliance evaluations need an adequate model of the creep phenomena for use in simulations of the behavior of the rooms and the seals. Similarly, an understanding and predictive capability is needed for fracture-related phenomena. Current PA evaluations of seal performance assume that the DRZ surrounding the shaft seals has either healed as tightly as the host rock (salt), or that no DRZ remains, i.e., has a permeability as low as that of the host rock. Assumptions in PA modeling efforts related to the extent and effects of fracturing in the anhydrite are part of ongoing evaluations. Further efforts are required to test the model of salt fracture (especially healing phenomena) effects and additional efforts may be needed in evaluating the fracturing of anhydrite.

\section{Disposal Room Performance}

The PA interbed fracture model is inadequate. The present PA model for gas migration is entirely based on the premise that substantial gas flow will occur because the porosity or fracture permeability of the interbeds will be enhanced by the pressurization. Such increases in permeability are unsupported by actual experimental results. Furthermore, there is no mechanistic explanation as to how large changes in the porosity or fracture opening to allow such enhanced gas flow can occur below lithostatic pressure.

If the porosity enhancement model cannot be supported by experimental data in the future, and the interbed is much less permeable to gas than expected at pressures below lithostatic, then an alternative conceptual model must be examined. Possibly, appropriate models exist in the reservoir stimulation hydrofracture treatments commonly used in the petroleum industry, but such is not presently included as a possible alternative conceptual model in PA. 
Room closure estimates are uncertain when the repository is partially saturated with brine. Previous PA analyses have shown that the void volume in the repository at any given time (repository closure) is critical for evaluation of the effects of gas generation on repository performance. The closure information provided to PA is a set of curves for the porosity associated with various amounts of gas generation as a function of time. This information does not include the effects of any brine present in the room, i.e., the information that PA uses is uncoupled from the brine inflow and gas migration occurring within the repository, and is thus an approximation. PA closure estimates are not based on the baseline halite creep model. Closure results used for performance assessment are presently based on a simplified creep description developed a number of years ago. The simpler model may be nonconservative in the sense that less gas pressurization may be predicted than is likely.

\section{Gas Generation}

Because of the highly coupled nature of gas generation, two-phase flow (brine and gas inflow and outflow), room closure, and actinide chemistry, PA calculations using the average stoichiometry model may produce some realizations that show no violations of the EPA standards when violations could actually occur, as well as the converse. Because of its limitations, the average stoichiometry gas generation model is simply not defensible for use in final PA calculations. The new, reaction-path model and its supporting experimental data base will provide technically defensible gas and brine-chemistry results for future compliance calculations.

\section{Actinide Source Term}

Currently available experimental information is not sufficient to predict dissolved species or colloid concentrations in the WIPP relevant brines (Castile, Salado, Culebra). The only current technically defensible concentrations of actinides are inventory limited concentrations with undefined contributions from dissolved species and colloids. Preliminary performance assessment calculations indicate that inventory limited radionuclide concentrations combined with no retardation in the Culebra, with all other assumptions held consistent with the 1992 performance assessment, simulate releases in excess of the 40 CFR \$191.13[a] containment requirements. The performance assessment conceptual model for Culebra transport for the colloid portion of the radionuclide concentration must necessarily be the "no retardation in the Culebra" model since colloids are not subject to Culebra retardation processes as presently understood. 


\section{Human Intrusion Cuttings Modeling}

PA drill cuttings conceptual models do not include spallation phenomena. Removal of waste cuttings from the borehole during a human intrusion is currently one of the dominant processes determining the extent of compliance of the WIPP with 40 CFR Part 191, Subpart B. Experimental data to confirm PA drill cuttings removal estimates due to spalling are not available. Laboratory tests are required for measurements of the properties of simulated waste controlling borehole enlargement during a human intrusion. The assumed range of strength values for erosion used by PA is presently taken from the literature; the adequacy of the PA cuttings release estimates is unknown. The magnitude of the cuttings release contribution attributed to spall is unknown, and a satisfactory model describing spallation potential is not yet available. No estimates of spallation are presently included in compliance demonstrations, and are not likely until such a model is developed.

In the absence of any additional erosion data, PA may use their present conceptual model, with a large range of erosion strength values. However, some type of spall model must be developed for future compliance studies, to either include spallation as a conceptual model or show that its contribution is unimportant in cuttings release.

\section{Performance Assessment}

Experimental data is still needed to confirm or refute several important conceptual models used in PA. If experiments confirm the adequacy of PA conceptual models, they may also provide data needed to determine defensible distributions for input parameters. If experiments refute PA conceptual models, alternative models must be proposed and implemented.

One of the primary purposes of conducting iterative PAs is to provide guidance to the Project by identifying those aspects of the database and modeling system which make the largest contributions to uncertainty in the performance estimate. Additional research may reduce uncertainty by providing new data or models, and may therefore increase the level of confidence in the PA used as the basis for a compliance decision.

Uncertainty and sensitivity analyses based on the Monte Carlo methodology are the principal means used in performance assessments to identify important parameters affecting the performance measures. Because these analyses are inherently conditional on the models, 
data distributions, and specific analysis techniques used to generate them, they cannot provide insight about parameters not sampled, conceptual and computational models not used in the analysis in question, or processes that have been oversimplified in the analysis. Uncertainties related to the oversimplification of processes and the possible omission of important parameters or processes must be addressed outside of the PA modeling system, where more detailed mechanistic modeling along with data collection can evaluate the acceptability of the simplified PA models. 


\subsection{REFERENCES}

Brooks, R.H., and A.T. Corey, 1964. Hydraulic Properties of Porous Media, Hydrology Paper No. 3, Fort Collins, CO, Colorado State University.

Davies, P.B., 1991. Evaluation of the Role of Threshold Pressure in Controlling Flow of Waste-Generated Gas into Bedded Salt at the Waste Isolation Pilot Plant, SAND90-3246, Albuquerque, NM, Sandia National Laboratories.

Parker, J.C., R.J. Lenhard, and T. Kuppusamy, 1987. "A Parametric Model for Constitutive Properties Regarding Multiphase Flow in Porous Media," Water Resources Research, Vol. 23, No. 4, 618-624.

Sandia National Laboratories (SNL), 1992. Preliminary Performance Assessment for the Waste Isolation Pilot Plant. December 1992, SAND92-0700/1-5, Albuquerque, NM, Sandia National Laboratories.

Trauth, K.M., S.C. Hora, and R.P. Rechard, 1993. Expert Judgment as Input to Waste Isolation Pilot Plant Performance Assessment Calculations, Probability Distributions of Significant System Parameters, SAND91-0625, Albuquerque, NM, Sandia National Laboratories.

Webb, S.W., 1991. "Sensitivity Studies for Gas Release from the Waste Isolation Pilot Plant," Waste-Generated Gas at the Waste Isolation Pilot Plant: Papers Presented at the Nuclear Energy Agency Workshop on Gas Generation and Release from Radioactive Waste Repositories, Eds. P.B. Davies, L.H. Brush, M.A. Molecke, F.T. Mendenhall, and S.W. Webb, SAND91-2378, Albuquerque, NM, Sandia National Laboratories, pp. 4-1 through 4-14. 


\subsection{Other Federal Laws}

In order to ensure protection of human health and the environment during its pre-disposal, disposal, closure, and post-closure phases, the Waste Isolation Pilot Plant (WIPP) Project must comply with the Federal environmental statutes and implementing regulations discussed in this section. This discussion summarizes the applicable requirements and the status of WIPP activities associated with each.

\subsection{National Historic Preservation Act (16 U.S.C. $\$ 470$ et seq.)}

The National Historic Preservation Act (NHPA) was enacted to protect the nation's cultural resources; it established, among other things, the National Register of Historic Places (National Register). Since 1976, cultural resources investigations have recorded approximately 98 archeological sites and numerous isolated artifacts within the $16 \mathrm{mi}^{2}$ area enclosed by the WIPP-site boundary. Thirty-three sites recorded within the central $4 \mathrm{mi}^{2}$ area, were determined eligible for inclusion in the National Register as an archeological district. Investigations since 1980 have recorded an additional 14 individual sites outside of the central $4 \mathrm{mi}^{2}$ area that are considered eligible for inclusion in the National Register. The average site density on WIPP facility lands is 7.5 sites per $\mathrm{mi}^{2}$. A mitigation plan describing the avoidance and/or excavation of sites was submitted to the New Mexico State Historic Preservation Officer (SHPO). A determination of No Adverse Effect from WIPP facility activities on cultural resources was made by the SHPO in May 1980. A similar plan was submitted to the National Advisory Council on Historic Preservation. The Council concurred that the WIPP Mitigation Plan is appropriate to protect cultural resources.

The NHPA has been amended by the Archeological and Historic Preservation Act (16 U.S.C. \$469a et seq.), which directs Federal agencies to recover and preserve historic and archeological data that would otherwise be lost as a result of Federal construction or activities. It has also been amended by the Archeological Resources Protection Act (16 U.S.C. \$470aa et seq.), which requires a permit from the U.S. Department of the Interior (DOI) for excavation or removal of archeological resources from public or Indian lands. Both of these statutes apply to known cultural resources or resources recorded in the future on WIPP facility lands. In accordance with the WIPP Mitigation Plan, four archeological sites that could have been or that were actually disturbed by construction activities have been excavated. The Department of Energy (DOE) avoids other sites so that 
there will be no adverse effects on known cultural resources from WIPP facility activities, and no additional archeological sites have been slated for excavation.

\subsection{Endangered Species Act (16 U.S.C. $\$ 1531$ et seq.)}

The Endangered Species Act provides protection for threatened or endangered species of flora and fauna. Under Section 7 of the Act and implementing regulations in 50 CFR 402, the Environmental Protection Agency (EPA) is prohibited from authorizing activities likely to jeopardize the continued existence of any threatened or endangered species or its critical habitat. The Section 7 process may involve a biological assessment and "formal consultation," followed by the issuance of a "biological opinion" by the U.S. Fish and Wildlife Service for any species that is determined to be in potential jeopardy. The U.S. Fish and Wildlife Service lists four threatened or endangered species of plants or animals that could occur at the WIPP site: the Lee pincushion cactus (Coryphantha sneedi var. leei); the peregrine falcon (Falco peregrinis anatum); the bald eagle (Haliaeetus leucocephalus); and a fish, the Pecos gambusia (Gambusia nobilis). The U.S. Fish and Wildlife Service has determined that WIPP facility activities will have no adverse impacts on these species. In addition, no critical habitat for terrestrial endangered species has been identified at the WIPP site. Consequently, neither formal consultation nor biological opinion processes have been required for the WIPP project by the U.S. Fish and Wildlife Service under Section 7.

\subsection{Clean Air Act (42 U.S.C. $\$ 7401$ et seq.)}

The Clean Air Act (CAA) provides for the preservation, protection, and enhancement of air quality, principally in areas of special natural, recreational, scenic, or historic value. Under the CAA, the EPA has established the National Ambient Air Quality Standards (NAAQS) for six "criteria" pollutants: sulfur dioxide, particulate matter, carbon monoxide, ozone, nitrogen dioxide, and lead. These standards establish the maximum levels of each pollutant allowed in the air over a particular locality.

Hazardous air pollutant emissions are regulated under 40 CFR 61, the National Emission Standards for Hazardous Air Pollutants (NESHAPs) of the CAA. The 1990 Clean Air Act Amendments (CAAA) expanded the monitoring and permitting requirements for hazardous air pollutants (HAPs) emissions by expanding the list of regulated HAPs. Section 112 (b) of the 1990 CAAA established emission limits for 189 HAPs regulated in 40 CFR 61 . The 
New Mexico Environmental Department (NMED) is the agency responsible for enforcing most requirements of the CAA and the CAAA. The NMED promulgated the New Mexico Air Quality Control regulations, AQCR 752, Emission Standards for Hazardous Air Pollutants (HAPs), to regulate all HAPs except radionuclide emissions regulated under 40 CFR 61, Subpart H. 40 CFR 61, Subpart H, applies to the WIPP facility only with respect to future emissions of radionuclides. In the Final Safety Analysis Report (FSAR) for the WIPP facility, the doses from future anticipated WIPP facility emissions were calculated to be less than one percent of the allowable effective dose equivalent of ten millirem per year to any one member of the public. The DOE documented the expected emission levels in a data package submitted to the EPA. An emissions monitoring system was installed to comply with NESHAPs and to meet monitoring compliance requirements. The system is described in the FSAR. The emissions monitoring test results will be used to verify compliance.

The HAPs data package evaluated applicable WIPP operations, chemical inventories, material safety data sheets, and engineering designs to establish potential emission sources, and estimated from each source. Calculated emission estimates were used to determine if the WIPP is required to obtain an air permit under State or Federal regulations. The WIPP Hazardous Air Pollutanta (HAPs) Emissions Inventory was used to evaluate potential permit requirements for the following regulations:

- $\quad 112$ Clean Air Act National Emission Standards for Hazardous Air Pollutants

- Part C Clean Air Act (Prevention of Significant Deterioration - Criteria Pollutants)

- New Mexico Air Quality Control Regulation 752

- New Mexico Air Quality Control Regulation 702

Based on emission estimates, the WIPP is not required to obtain a Clean Air Act permit; however, on April 23, 1993, the New Mexico Air Quality Control Bureau determined that an Air Quality Control Regulation (AQCR) 702 operating permit will be required for the WIPP backup diesel generators. In June 1993, the DOE submitted an application for an AQCR 702 permit for the backup diesel generators. On December 7, 1993, the NMED Air Quality Bureau issued Air Quality Permit 310-M-2 to the WIPP. The WIPP has completed all equipment modifications required by the permit and will complete emission compliance testing required by the permit by February 26, 1994. 


\subsection{Clean Water Act (or Federal Water Pollution Control Act of 1972) (33 U.S.C. $\$ 1251$ et seq.)}

The Federal Water Pollution Control Act of 1982 (33 U.S.C. $\$ 1251$ et seq.) is usually referred to as the "Clean Water Act" (CWA). The major program under this act is the National Pollutant Discharge Elimination System (NPDES). This program, discussed in $\$ 402$ of the CWA, regulates the discharge of pollutants into navigable waters of the United States. The regulations implementing the NPDES that are relevant to the WIPP Project are found in 40 CFR 122, PA Administered Permit Programs: the National Pollutant Discharge Elimination System, which contains definitions and basic application requirements, standard permit conditions, and monitoring and reporting requirements for the NPDES program. However, there will be no discharges from point sources at WIPP into navigable waters that would necessitate a standard NPDES permit.

In 1990, an NPDES storm-water permit program was added to the CWA [\$402(p)] to govern the discharge of pollutants into runoff from precipitation. The NPDES storm-water permit program involves three types of permits: general, individual, and group permits. To obtain a permit, a facility submits either a Notice of Intent (NOI) for a general permit, an application for an individual permit, or an application as part of a group of applicants for a group permit. The EPA planned to cover most industrial discharges under general permits and issued the Final NPDES General Permits for Storm Water Discharges Associated with Industrial Activity in the Federal Register on September 9, 1992. These general permits cover facilities that discharge effluents associated with industrial activities in 11 states that do not have authorized NPDES programs, including New Mexico. The NPDES storm-water regulations are applicable to WIPP.

Of the other regulations that implement the standard NPDES program of the CWA, only 40 Part 459, Photographic Point Source Category, could conceivably require WIPP to obtain a standard NPDES permit, because of its photographic laboratory. However, the photographic laboratory collects all its effluents and hires a contractor to dispose of these wastes properly when it is operating; therefore, 40 CFR 459 is not applicable to the WIPP photographic laboratory.

Evaluation of NPDES storm-water compliance options for the WIPP began in July 1991. On April 2, 1992, the EPA published the final NPDES Application Deadlines, General Permit Requirements and Reporting Requirements for Storm Water Discharges Associated with 
Industrial Activity, which established the new general permit rules for minimum sampling and analytical requirements. The EPA published the Final NPDES General Permits for Storm Water Discharges Associated with Industrial Activity in the Federal Register on September 9, 1992. These general permits establish NOI requirements, prohibitions, requirements to develop and implement storm-water pollution prevention plans, and requirements to conduct site inspections for facilities with discharges that are authorized by the permit. In addition, these permits establish monitoring requirements for certain classes of facilities. A NOI to obtain a general stormwater discharge permit was submitted to the EPA on October 1, 1992. The WIPP site received an NPDES Storm Water General Permit (Permit \#NMR00A021) on December 31, 1992.

The WIPP National Pollutant Discharge Elimination System (NPDES) Storm Water Pollution Prevention Plan (SWPPP) describes how the best management practices and other requirements of the NPDES storm-water permit are being implemented at the WIPP. Requirements addressed include the identification of a pollution prevention team, the identification of potential pollution sources, and identification of past spills and leaks.

Another implementing regulation under the CWA that is potentially applicable to the WIPP Project is 40 CFR 112, Oil Pollution Prevention, which includes criteria and guidelines for the preparation and implementation of a facility's Spill Prevention, Control, and Countermeasures (SPCC) Plan.

\subsection{Safe Drinking Water Act (42 U.S.C. \$300f et seq.)}

The Safe Drinking Water Act of 1974 (SDWA), as amended, provides the regulatory strategy for protecting public water supply systems and underground sources of drinking water. As defined in implementing regulations in 40 CFR 141, these are systems that provide water for human consumption and that have at least 15 connections or regularly serve at least 25 people.

The SDWA, in Part C, also protects underground sources of drinking water (USDWS) from underground injections of contaminated fluids. Underground injection, defined as "subsurface emplacement of fluids by well injection" in \$1421(d) of the SDWA, is governed by the Underground Injection Control (UIC) program under the Part $\mathrm{C}$ regulations in 40 CFR Part 144. 
Because the WIPP facility receives water from an off-site supplier, the facility has neither developed nor does it maintain a public water supply system within the meaning of the SDWA and its implementing regulations. Also, the WIPP facility does not qualify for regulation under the UIC program because none of the transuranic (TRU) waste emplacement at the facility will be by well injection of fluids. The EPA confirmed this assertion in the revision to 40 CFR 191 published in the Federal Register on December 20, 1993 (58 FR 66398).

\subsection{Comprehensive Environmental Response, Compensation, and Liability Act (42 U.S.C. $\$ 9601$ et seq.)}

The Comprehensive Environmental Response, Compensation, and Liability Act (CERCLA), or "Superfund," and the Superfund Amendments and Reauthorization Act of 1986 (SARA) establish a comprehensive Federal strategy for responding to, and establishing liability for, releases of hazardous substances from a facility to the environment. Any spills of hazardous substances of reportable quantities will be reported to the National Response Center under the provisions of CERCLA Section 103, Notices. Penalties, and the implementing regulations in 40 CFR 302, Designation. Reportable Quantities, and Notification. Because the WIPP is currently not a CERCLA remediation site and is not expected to become one, most of the requirements of this act do not currently apply.

In CERCLA, \$102(c), Federal Agency Hazardous Waste Compliance Docket, contains a docket that provides information regarding Federal facilities that manage hazardous waste or from which hazardous substances may be or have been released. The seventh update (FR 58 7298) of the docket lists the WIPP as a new addition and requires that the WIPP prepare a Preliminary Assessment and submit it to the EPA within 18 months of the date of publication in the Federal Register, i.e., within 18 months after February 5, 1993. If deemed necessary, a site inspection report will also be due to the EPA within the same time frame.

Under Title III of SARA, or the Emergency' Planning and Community Right-to-Know Act (EPCRA) of 1986, the WIPP facility is required to provide information, such as inventories of specific chemicals used and stored, to the State Emergency Response Commission and the Local Emergency Planning Committee to ensure that emergency plans are sufficient to respond to unplanned releases of hazardous substances. The DOE has and will continue to submit the appropriate reports annually under the EPCRA. 


\subsection{Toxic Substances Control Act (15 U.S.C. \$2601 et seq.)}

The Toxic Substances Control Act (TSCA) applies primarily to manufacturers, importers, and processors of toxic chemicals for commercial purposes. The WIPP facility is not considered a manufacturer or processor of chemical products; therefore, most of the provisions of TSCA do not apply. Section 6(e) of TSCA regulates the use of polychlorinated biphenyls (PCBs) and PCB-containing items. The DOE policy prohibits the use of PCB items or equipment in DOE-installed equipment at facilities such as the WIPP facility. Therefore, TSCA would not apply to DOE-installed equipment. At the present time, TSCA does not apply to the WIPP repository because there are no plans to ship PCB-contaminated wastes to the facility. The WIPP facility will comply with TSCA regulations contained in 40 CFR $\$ 761.60$ and $\$ 761.65$, with respect to any possible future storage or disposal of PCB-contaminated materials.

\subsection{National Environmental Policy Act (42 U.S.C. \$4321 et seq.)}

The National Environmental Policy Act (NEPA) was enacted, among other things, to "assure for all Americans safe, healthful, productive, and aesthetically and culturally pleasing surroundings." It directs the Federal government to use "all practicable means" to improve and coordinate Federal plans, functions, programs, and resources to that end. NEPA contains several "action-forcing" provisions, such as using an interdisciplinary approach in planning and decision-making, ensuring appropriate consideration of unquantified environmental values, developing alternatives to proposals involving conflicts over use of resources, making environmental information generally available, and including a "detailed statement" on environmental impacts of "major Federal actions significantly affecting the quality of the human environment." Because NEPA procedural objectives and extensive public involvement requirements are detailed in Council on Environmental Quality regulations implementing NEPA in 40 CFR 1500-1508, the act has often been referred to as a "public disclosure law."

Pursuant to the requirements of NEPA, based on the environmental analysis in the Final Environmental Impact Statement (FEIS), the DOE issued a Record of Decision (ROD) (46 FR 1962) in 1981, which concluded that the Los Medaños (WIPP) site in southeastern New Mexico would be acceptable for the long-term disposal of TRU waste with minimal risk of any release of radioactivity to the environment. The FEIS ROD notes that: 
If significant new environmental data results from the SPDV [Site Preliminary and Design Validation] program or other WIPP project activities, the FEIS will be supplemented as appropriate to reflect such data, and this decision to proceed with phased construction and operation of the WIPP facility will be reexamined in the light of that supplemental National Environmental Policy Act (NEPA) review.

Consistent with this commitment, the DOE prepared additional NEPA documentation to address changes in the proposed action and the development of new geologic and hydrologic information. Changes addressed in the Final Supplement Environmental Impact Statement (FSEIS) included alterations in the composition of the waste inventory, the transportation of waste to the WIPP facility, conducting a test phase, and management of TRU waste mixed with hazardous chemical constituents. The DOE's ROD to proceed with the Test Phase was published in the Federal Register on June 22, 1990 (55 FR 25689). In this ROD, the DOE committed to prepare a new FSEIS for the disposal phase. This FSEIS will be prepared prior to receipt of waste.

\subsection{Resource Conservation and Recovery Act of 1976 (42 U.S.C. $\$ 3251$ et seq.)}

In addition to compliance with the requirements set forth in 40 CFR \$268.6, the WIPP Project must operate in accordance with other sections of Resource Conservation and Recovery Act (RCRA). Specifically, activities at the WIPP facility must comply with:

- 40 CFR 261, Identification and Listing of Hazardous Waste, as Implemented by Hazardous Waste Management Regulations (HWMR-7), Part II;

- 40 CFR 262, Standards Applicable to Generators of Hazardous Waste, as implemented by HWMR-7, Part III;

- 40 CFR 265, Interim Status Standards for Owners and Operators of Hazardous Waste Treatment. Storage, and Disposal Facilities, as implemented by HWMR-7, Part VI or 40 CFR 264, Standards for Owners and Operators of Hazardous Waste Treatment, Storage, and Disposal Facilities, Subpart X, Miscellaneous Units, as implemented by HWMR-7, Part V;

- 40 CFR 270, EPA Administered Permit Programs: Hazardous Waste Permit Program, as implemented by the New Mexico Hazardous Waste Management Regulations (HWMR-7), Part IX; 
- $\quad 40$ CFR \$268.6, Petitions to Allow Land Disposal of a Waste Prohibited Under Subpart C of Part 268; and

- 40 CFR 280, Underground Storage Tanks (UST), as implemented by the New Mexico Underground Storage Tank Regulations (USTR-1), Parts I through $\mathrm{XV}$.

Normal operations at the WIPP facility result in the generation of non-radioactive hazardous wastes that must be sent off-site for disposal. These wastes must be managed in accordance with HWMR-7, Part III (40 CFR 262). These regulations establish standards concerning allowed accumulation times, preparation of hazardous wastes for shipment, and recordkeeping and manifesting requirements. The WIPP facility is currently adhering to these regulations by designating appropriate satellite accumulation and ninety-day storage areas, properly segregating and labeling wastes in those areas, and preparing appropriate manifests for timely off-site shipment of those wastes.

As the owner and operator of a hazardous waste management unit, the DOE must obtain a RCRA permit for the WIPP facility in accordance with HWMR-7, Part IX (40 CFR 270). A RCRA permit application consists of two parts: Part A, which provides general facility information in a standardized format, and Part B, which provides detailed information required to ensure compliance with standards set forth by RCRA and to establish appropriate permit conditions. The DOE submitted a Part A application to the NMED in January 1991. Revision 3 to the Part B application requesting a RCRA permit for the proposed test-phase activities was submitted to the NMED in January 1993. In August 1993, a draft permit for test-phase activities was issued by the NMED for public comment. With the programmatic changes within the DOE organization and the decision not to test radioactive wastes at WIPP, a new revision of the WIPP RCRA permit application must be submitted to the NMED in order to obtain a RCRA permit for disposal operations.

Since the DOE submitted Part A of the RCRA permit application on January 22, 1991, the requirements for the management of hazardous waste during the period of interim status, HWMR-7, Part VI (40 CFR 265), currently apply. When the permit for disposal operations is granted, the DOE will comply with the standards of HWMR-7, Part V (40 CFR 264).

The hazardous waste disposal activities planned during the disposal phase will require that the WIPP facility meet the requirements of HWMR-7, Part V (40 CFR 264, Subpart X). These regulations establish criteria that must be considered to determine that operation of a 
permitted miscellaneous unit will occur in a manner to prevent any releases of waste constituents that would adversely affect groundwater or the subsurface environment; surface water, wetlands, or the soil surface; or air.

To maintain compliance with USTR-1 (40 CFR 280), the DOE will properly manage the existing underground storage tank equipment. This equipment includes, at present, two USTs, fueling station, and an automatic leak detection system.

Prior to disposing of untreated TRU-mixed waste at the WIPP facility, the DOE must obtain a variance from the treatment requirements of the RCRA Land Disposal Restrictions (LDRs) in accordance with 40 CFR \$268.6. The DOE petitioned the EPA for a variance for the proposed test-phase, referred to as a No-Migration Variance Petition (NMVP) and was granted a No-Migration Determination (NMD). Prior to commencing disposal operations for untreated TRU-mixed waste, the DOE must submit another petition and receive a new NMD from the EPA.

\subsection{Atomic Energy Act of 1954 (42 U.S.C. \$2011 et seq.)}

The Atomic Energy Act (AEA) establishes a national program for research, development, and use of atomic energy for both national defense and domestic civilian purposes. Section 161 of the AEA provides that the Atomic Energy Commission (succeeded for national defense purposes by the DOE) is authorized to prescribe regulations and orders to:

[G]overn any activity authorized pursuant to [the AEA], including standards, and restrictions governing the design, location, and operation of facilities used in the conduct of such activity, in order to protect health and to minimize danger to life or property.

The authority of the DOE to develop policies, issue orders, and promulgate regulations addressing environmental, safety, and health protection aspects of radioactive waste and nuclear materials is derived directly from the AEA. The DOE, under the authority of the AEA, and in accordance with various Executive Orders, uses a system of Orders, Notices, and Directives to carry out the mandate to implement effective and consistent programs to protect the public, the environment, and employees from adverse consequences resulting from DOE operations. 
The AEA also authorized the U.S. Nuclear Regulatory Commission (NRC) to serve a similar function for commercial nuclear facilities. Regulations promulgated by the NRC under the AEA establish standards for the management of special nuclear material and the protection of the public from radiation. Additional NRC requirements apply to the licensing, packaging, preparation, and transportation of radioactive materials. The NRC does not have regulatory authority over DOE facilities, but NRC standards and requirements are incorporated into DOE Orders. The NRC's requirements pertain to WIPP only in the transportation of TRU waste from the generator sites to WIPP. The containers/casks to be used for shipping the TRU waste must have received a Certificate of Compliance from the NRC.

Much of the waste to be emplaced at the WIPP is mixed (i.e., radioactive waste contaminated with hazardous constituents). This waste is subject to dual regulation: the radioactive constituents of the waste are regulated under the AEA, whereas the hazardous constituents are regulated under RCRA. Nevertheless, there may be some circumstances under which RCRA regulation of the hazardous constituents would be found to be inconsistent with AEA health and safety requirements.

The authority of the EPA to establish radiation protection standards for nuclear wastes (e.g., 40 CFR 191) is derived from the AEA, as amended: the Reorganization Plan No. 3 of 1970 and the Nuclear Waste Policy Act (NWPA) (Public Law 97-425). The standards apply to spent nuclear fuel, high-level radioactive waste as defined by the NWPA, and TRU waste that contains more than 100 nanocuries per gram of waste of alpha-emitting TRU isotopes with half-lives greater than 20 years.

The NWPA of 1982 was promulgated

... to provide for the development of repositories for the disposal of high-level radioactive waste and spent nuclear fuel, to establish a program of research, development, and demonstration regarding the disposal of high-level radioactive waste and spent nuclear fuel, and for other purposes.

This act required that the EPA promulgate standards for the protection of the general environment from off-site releases from radioactive material in repositories [\$121(a)]. The EPA responded to this requirement by promulgating 40 CFR Part 191, the Environmental Radiation Protection Standards for Management and Disposal of Spent Nuclear Fuel, High- 
Level, and Transuranic Radioactive Waste. As written, these standards consist of three subparts, A, B and C.

\subsection{Hazardous Materials Transportation Act (49 App. U.S.C. \$1801 et seq.; 49 CFR Parts 106-179)}

The Hazardous Materials Transportation Act (HMTA) provides for safe intrastate and interstate transportation of hazardous materials (including nuclear materials). The HMTA allows states to regulate the transport of hazardous/nuclear materials as long as such regulations are consistent with the HMTA or U.S. Department of Transportation (DOT) regulations. The DOT regulations for hazardous/radioactive materials are contained in 49 CFR 171-177. Specifications for the types and design of packages to be used for the transport of various types of radionuclides are contained in 49 CFR 173, Subpart I (and parallel NRC regulations in 10 CFR 71). DOT regulations in 49 CFR 177 provide a routing and quantity rule for highway shipments of radioactive material; 49 CFR 174 contains segregation rules for shipment by rail. In the Second Modification to the Agreement for Consultation and Cooperation (C\&C), dated August 4, 1987, the DOE agreed to comply with all applicable DOT regulations and the corresponding regulations of the NRC.

\subsection{Packaging and Transportation of Radioactive Material (10 CFR Part 71)}

Regulations for shipping containers and the safe packaging and transportation of radioactive materials are under the authority of the NRC and the DOT. In the C\&C the DOE agreed to comply with the applicable transportation regulations of the NRC. Packaging requirements for radioactive materials, including Type $B$ packages to be used to transport waste to the WIPP facility, are detailed in DOT regulations (49 CFR 173, Subpart I), which reference the NRC regulations. In turn, the NRC regulations in $10 \mathrm{CFR} 71$ reference the DOT regulations in 49 CFR 173.

The NRC requirements for shipping containers apply to the certification of the Transuranic Package Transporter (TRUPACT-II) shipping container by the NRC. The container will be used to transport radioactive contact-handled TRU waste to the WIPP facility. The TRUPACT-II container was certified by the NRC on August 30,1989, after compliance with 10 CFR Part 71 requirements for Type B packaging was demonstrated. 
No container to trarisport remote-handled (RH) TRU waste has been certified. When the DOE completes that activity, the Type B packaging will be submitted to the NRC for certification prior to use.

\subsection{Department of Energy National Security and Military Applications of Nuclear Energy Authorization Act of 1980 (Public Law 96-164)}

This Act, which authorized the WIPP Project, provides as follows:

Notwithstanding any other provision of law, the Waste Isolation Pilot Plant is authorized as a defense activity of the Department of Energy...for the express purpose of providing a research and development facility to demonstrate the safe disposal of radioactive wastes resulting from the defense activities and programs of the United States....

The statute provides for DOE consultation and cooperation with appropriate officials of the State of New Mexico with respect to the public health and sufety concerns and for a written agreement between the DOE and the appropriate officials of the State of New Mexico setting forth the procedures under which to carry out consultation and cooperation. In compliance, the DOE has entered into two agreem $r$ ith the State of New Mexico: the C\&C Agreement and the Working Agreem e C\&C Agreement. Both agreements have been modified several times. The most wuent modification of the C\&C Agreement is the Second Modification to the C\&C Agreement, dated August 4, 1987. The Working Agreement for the C\&C Agreement was last modified in March 1988. The agreements are implemented through the DOE and the New Mexico Radioactive Waste Consultation Task Force. In addition, the DOE interfaces regularly with the NMED and the New Mexico Legislature's Radioactive and Hazardous Waste Committee.

\subsection{Waste Isolation Pilot Plant Land Withdrawal Act (PL 102-579)}

The WIPP Land Withdrawal Act (LWA) (P.L. 102-579) provides for the transfer of the 16 $\mathrm{mi}^{2}$ of WIPP site lands from the Secretary of the Interior to the Secretary of Energy and withdraws the lands from entry, sale, or disposition; appropriation under mining laws; and operation of the mineral and geothermal leasing laws. Pursuant to the LWA, the DCE submitted the Waste Isolation Pilot Plant Land Management Plan to the U.S. Congress in October 1993. This plan provides for the management of activities including grazing, 
hunting and trapping, wildlife habitat, the disposal of salt tailings, groundwater production, preservation of cultural resources, and reclamation on the land transferred to the DOE.

Compliance with the following statutes or regulations is required under the Act:

- $\quad$ Taylor Grazing Act

- Subchapter IV of the Federal Land Policy and Management Act

- $\quad$ Public Rangelands Improvement Act

- $\quad$ Materials Act of 1947

- $\quad$ Federal Mine Safety and Health Act of 1977

- $\quad$ Solid Waste Disposal Act

- $\quad 40$ CFR 191 Management and Disposal Regulations

- $\quad 29$ CFR $\$ 1910.120$

- Clean Air Act

- $\quad$ Safe Drinking Water Act

- Toxic Substance Control Act

- $\quad$ Comprehensive Environmental Response, Compensation and Liability Act

- $\quad$ All other applicable Federal Laws pertaining to public health and safety of the environment

The law provides prerequisites for the DOE and the EPA prior to initiating the Disposal Phase including EPA review and approval of key WIPP programmatic documents. Roles and responsibilities for the DOI, Department of Labor (DOL), Environmental Evaluation Group (EEG), National Academy of Sciences (NAS), and State of New Mexico are defined.

\subsection{Federal Land Policy and Management Act (43 U.S.C. \$\$1701- 1782)}

The Federal Land Policy and Management Act (FLPMA) was enacted to ensure, among other things, that:

...public lands be managed in a manner that will protect the quality of scientific, scenic, historical, ecological, environmental, air and atmospheric, water resource, and archeological values; that, where appropriate, will preserve and protect certain public lands in their natural condition; that will provide food and habitat for fish and wildlife and domestic animals; and that will provide for outdoor recreation and human occupancy and use....

The FLPMA's Title II, Land Use Planning: Land Acquisition and Disposition, directs the Secretary of the Interior to prepare and maintain an inventory of all public lands and to 
develop and maintain, with public involvement, land use pians regardless of whether subject public lands have been classified as withdrawn, set aside, or otherwise designated. Under Title V, Rights-of-Way, of the FLPMA, the Secretary of the Interior is authorized to grant, issue, or renew rights-of-way over, upon, under or through public lands.

The policy and commitment of the FLPMA is also addressed in another significant Congressional Act. As a result of the LWA, the DOE was given statutory authority and responsibility for the management of the withdrawn land consistent with the FLPMA and other applicable laws such as the Public Rangelands Improvement Act and the Taylor Grazing Act. Furthermore, the LWA directs the DOE to produce a WIPP land management plan to provide for grazing, hunting and trapping, wildlife habitat, the disposal of salt tailings, and mining, subject to the applicable implementing regulations of the FLPMA. The DOE submitted this plan to the U.S. Congress in October 1993.

A process is established in the FLPMA implementing regulations of 43 CFR 1600, Planning, Programming, Budgeting, for the development, approval, maintenance, amendment and revision of resource management plans for public lands administered by the Bureau of Land Management (BLM). This part states the objective of resource management planning as being to guide and control future management actions and the development of subsequent, more detailed and limited scope plans for resources and uses consistent with the principles of Title II of the FLPMA. The DOE will maintain the Land Management Plan consistent with the processes and requirements outlined in these regulations.

Another of the implementing regulations of the FLPMA establishes procedures for the orderly and timely processing of applications, grants, permits, amendments, assignments and terminations for rights-of-way and permits over, upon, under, or through public lands. In particular, 43 CFR 2800, Rights-of-Way, Principles and Procedures, provides guidelines for the use of right-of-way and temporary use permit areas, and establishes requirements for the submission and processing of right-of-way grant and temporary use permit applications.

These regulations remain applicable to the WIPP facility because of the necessity to establish rights-of-way for the construction and phased operation of the WIPP. 


\subsection{Taylor Grazing Act (43 U.S.C. $\$ 315$ et seq.)}

The Taylor Grazing Act is intended to prohibit injury to public grazing lands by preventing overgrazing and soil deterioration. The act promotes the orderly use of and improvement to public grazing lands by establishing grazing districts and a grazing permit system. Under the LWA, the DOE may permit grazing to continue where established before enactment of the LWA, subject to applicable regulations including the Taylor Grazing Act. The WIPP Land Management Plan provides for grazing on the WIPP site.

\subsection{Public Rangelands Improvement Act (43 U.S.C. \$1901 et seq.)}

The Public Rangelands Improvement Act establishes a national policy and commitment to:

- Inventory and identify current public rangeland conditions and trends;

- $\quad$ Manage, maintain, and improve the condition of public rangelands so that they become as productive as is feasible; and

- $\quad$ Continue the policy of protecting wild, free-roaming horses and burros, while at the same time facilitating the removal and disposal of excess wild, free-roaming horses and burros that post a threat to themselves, their habitat, and other rangeland values.

Under the LWA, DOE must inventory and administer WIPP facility lands as public rangelands. The WIPP Land Management Plan provides for these activities.

\subsection{Executive Order 12548-Grazing Fees}

Portions of the lands within the WIPP-site boundary are leased for livestock grazing. Executive Order (EO) 12548-Grazing Fees orders the establishment of fees for grazing of domestic livestock on public rangelands. The Secretary of Interior establishes, collects, and administers grazing fees. 


\subsection{Materials Act of 1947 (30 U.S.C. $\$ 601$ et seq.)}

The Materials Act of 1947 pertains to the disposal of mineral materials (including, but not limited to, sand, stone, gravel, pumice, cinders, and clay) on public lands. The disposal of vegetative materials (e.g., yucca, manzanita, mesquite, cactus, and timber or forest products) is also addressed. Under the LWA, and in accordance with the WIPP Land Management Plan, the DOE must dispose of salt tailings in accordance with the Materials Act.

\subsection{Federal Mine Safety and Health Act of 1977 (30 U.S.C. $\$ 801$ et seq.)}

Under the Federal Mine Safety and Health Act (MSHA) of 1977, the DOL is responsible for developing and enforcing regulations and standards to protect mine workers. Under a Memorandum of Understanding (MOU) between the DOE and DOL, effective July 9, 1987, the Mine Safety and Health Administration conducts periodic health and safety compliance inspections of WIPP facility underground operations. Additionally, the WIPP LWA requires MSHA to inspect the WIPP facility no less than four times each year in the same manner as it evaluates mine sites under the Federal Mine Safety and Health Act of 1977. MSHA must provide the results of its inspections to the Secretary of Energy who must make the results publicly available. The WIPP Management and Operating Contractor must take actions to ensure prompt and effective correction of any deficiency. This includes suspending specific activities as necessary to address identified health and safety deficiencies.

MSHA also may, at the request of the DOE, participate in investigations in the event of an accident or fatality at the WIPP facility.

\subsection{Bald and Golden Eagle Protection Act (16 U.S.C. \$\$668-668d)}

The Bald and Golden Eagle Protection Act makes it unlawful to take (capture, kill, or destroy), molest, or disturb bald (American) and golden eagles, their nests, or their eggs anywhere in the United States. A permit must be obtained from the DOI to relocate a nest that interferes with resource development or recovery operations. The act potentially applies to the WIPP facility because there is a possibility that bald and golden eagles could be present on WIPP facility lands. 
Surveys to identify raptor nests on WIPP facility lands since 1985 have not recorded any bald or golden eagle nests near operational activities. Through the Cooperative Raptor Research and Management Program at the WIPP facility, the DOE will continue to monitor for raptor nests on WIPP lands and near operational buildings.

\subsection{Migratory Bird Treaty Act (16 U.S.C. \$703 et seq.)}

The Migratory Bird Treaty Act is intended to protect birds that have common migration patterns between the United States and Canada, Mexico, Japan, and Russia. The act stipulates that it is unlawful to indiscriminately "kill . . . any migratory bird." It regulates the harvest of migratory birds by specifying the mode of harvest, hunting seasons, bag limits, etc. Although the WIPP facility is not located within a major migration corridor, there is the potential for migratory birds to be present on WIPP facility lands. As required by the Migratory Bird Treaty Act, the DOE will consult annually with the U.S. Fish and Wildlife Service with respect to impacts on migratory birds from the hunting activities permitted on WIPP facility lands.

\subsection{Noise Control Act of 1972 (42 U.S.C. $\$ 4901$ et seq.)}

According to the Noise Control Act's policy clause in $\$ 2(a)(3)$, the primary responsibility for noise control is vested in state and local governments. Federal regulation is deemed essential only for commercial noise sources requiring national uniformity of treatment (e.g., aircraft noise). However, federal agencies are required to comply with federal, state, interstate, and local requirements respecting control and abatement of environmental noise "to the fullest extent consistent with their authority" [\$\$4(a) and (b)(1), (2)].

DOE facilities are required to comply with the Occupational Safety and Health Administration (OSHA) standards in 29 CFR 1910, which include the Occupational Noise Exposure standards in 29 CFR $\$ 1910.95$. Any WIPP facility noise sources that exceed these standards will be mitigated. For example, noise dampers have been installed in the WIPP facility underground air exhaust fans. There are no noise sources at the WIPP facility that would affect the general public. 


\subsection{Federal Insecticide, Fungicide, and Rodenticide Act (7 U.S.C. $\$ 136$ et seq.)}

The Federal Insecticide, Fungicide, and Rodenticide Act (FIFRA) authorizes the EPA to regulate the registration, certification, use, storage, disposal, transportation, and recall of pesticides. The EPA, at its discretion, may exempt federal agencies from any FIFRA provisions if emergency conditions exist (40 CFR 166). Recommended procedures for storage and disposal of pesticides and pesticide containers are contained in 40 CFR 165. FIFRA standards are considered mandatory for DOE facilities. The DOE will comply with the standards of FIFRA at the WIPP facility.

\subsection{National Defense Authorization Act-Fiscal Year 1989}

The DOE has entered into a contract with the New Mexico Institute of Mining and Technology to conduct independent reviews of the health and safety aspects of the design, construction, and operations of the WIPP facility, as required by $\$ 1433$ (a) of the National Defense Authorization Act of 1989, P.L. 100-456, as amended by $\$ 3152$ of the National Defense Authorization Act for FY 1994, P.L. 103-160. The EEG performs the reviews for the Institute. The DOE will cooperate, as appropriate, with the EEG reviews of health and safety practices at the WIPP facility. 


\subsection{Compliance Summary}

The Compliance Status Report (CSR) has been prepared to summarize the progress that the DOE has made toward completing actions needed to demonstrate compliance with the two regulations that impose long term performance standards on the Waste Isolation Pilot Plant (WIPP) facility as a repository for transuranic (TRU) mixed waste. These regulations are 40 CFR 191 entitled "Environmental Radiation Protection Standards for Management and Disposal of Spent Nuclear Fuel, High-Level and Transuranic Radioactive Wastes" and 40 CFR 268 entitled "Land Disposal Restrictions." The primary emphasis in the CSR is in the following four areas:

- Adequacy of basic site and facility information

- Adequacy of waste information

- $\quad$ Adequacy of data and code quality assurance

- $\quad$ Adequacy of the conceptual model development and associated performance assessment

These four areas are interrelated and cannot be evaluated independently. For example, the conceptual model for the WIPP involves the generation of gas. Quantifying the inputs to the conceptual model depends on conclusions reached regarding geologic and hydrologic properties of the Salado Formation and the characteristics of the TRU waste.

Because of the inter-relationship between properties and processes, it is difficult to draw conclusions regarding the adequacy of data and analyses until nearly all needed data are collected and all needed analyses are completed. Consequently, this CSR has served to focus on areas where additional data collection would be most beneficial to the compliance program. In most cases, these data collection programs are either underway or are planned in the near future and include additional data regarding Culebra hydrology and transport, waste solubility, Salado hydrology and transport, waste degradation processes, waste characterization, and others. Some of these programs offer greater potential benefit than others. For example, establishing any non-zero retardation coefficients for the Culebra may eliminate the need for additional solubility data. Likewise, the use of near field observations of brine inflow may eliminate the need for of inclusion of a gas fracturing model in the PA and the inclusion of a spallings component in the human intrusion model. 
The CSR has also served to focus another compliance need. This is the establishing of reasonable interpretations of the regulatory standards and the associated guidance. In the past, for the purposes of conducting analyses, many interpretations were made conservatively. Such conservative interpretations may not be reasonable and may result in unnecessary conservatism in the compliance demonstrations. For example, current analyses assume that passive controls will become ineffective after some period of time (the earliest intrusions modeled in the 1992 PA occurred 125 years after decommissioning). This period of time ranges from 125 years to 7,250 years after closure. This assumption is based on guidance that states that the EPA does not believe that passive controls will be effective in eliminating human intrusion. However, under the solid waste regulations, the EPA also states the belief that controls can be effective in reducing the potential for intrusions to appropriate levels. In order to reconcile these two viewpoints, the DOE must implement of the guidance in a manner that emphases the development and implementation of effective passive controls.

These data needs, both fulfilled and unfulfilled have been identified in this CSR associated with issues, and are discussed generally in Chapter 6 and 10. A summary of these issues has been prepared and is presented in Table 12-1. A status of the issue is shown and a summary discussion of the data need provided. This summary is intended to put the information needs into relatively simple terms. 


\section{Table 12-1 Compliance Summary}

\begin{tabular}{|c|c|c|c|}
\hline ISSUES & STATUS & DESCRIPTION/RESOLUTION & COMMENTS \\
\hline Breccia Pipes & Resolved & $\begin{array}{l}\text { Columnar collapse structures called breccia pipes are know to } \\
\text { occur in southeastern New Mexico. Geophysical techniques } \\
\text { were employed to gather data. Known breccia pipes were } \\
\text { mapped and tested. The nearest observed breccia pipes occur } \\
\text { over the Capitan Reef. None exist at the site. }\end{array}$ & $\begin{array}{l}\text { Breccia pipes are not included in the conceptual } \\
\text { model for PA. No additional studies of breccia } \\
\text { pipes are required for compliance } \\
\text { demonstration purposes. }\end{array}$ \\
\hline $\begin{array}{l}\text { Borehole and } \\
\text { Shaft Plugging }\end{array}$ & Open & $\begin{array}{l}\text { Boreholes at and around the WIPP site, as well as shafts, are } \\
\text { potential conduits for transport of contaminants from the } \\
\text { repository. Seal and plug designs were developed. These } \\
\text { designs have been revised and are being documented. The } \\
\text { modifications simplify the designs and provide a basis for } \\
\text { establishing the extent of large scale seal tests. PA results are } \\
\text { being integrated with design considerations to better establish } \\
\text { the performance requirements for the seal components. (See } \\
\$ 10.1 .2 .1 \text { and } \$ 10.1 .5 .1)\end{array}$ & $\begin{array}{l}\text { PA results indicate that long-term permeability } \\
\text { of the shaft seals is one of the "very important" } \\
\text { parameters in retarding gas flow, that short- } \\
\text { term permeability of the shaft seals is an } \\
\text { "important" parameter, and that the panel seal } \\
\text { permeability is of lesser importance if it is } \\
\text { assumed that the DRZ throughout the } \\
\text { repository is interconnected and does not heal. }\end{array}$ \\
\hline$\S 6.1 .1 . \mathrm{B}$ & & & \\
\hline
\end{tabular}




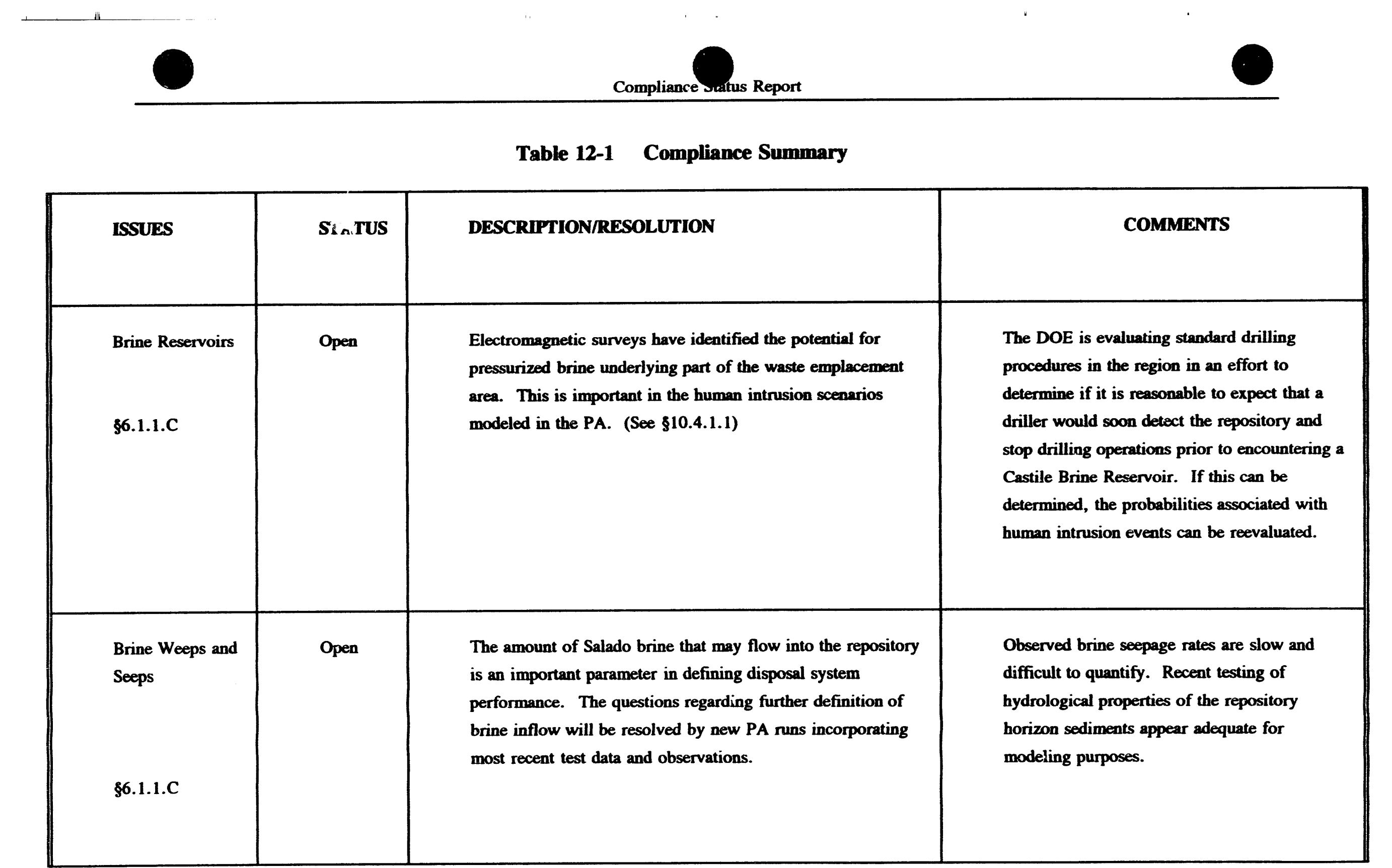


Table 12-1 Compliance Summary

\begin{tabular}{|c|c|c|c|}
\hline ISSUES & STATUS & DESCRIPTION/RESOLUTION & COMMENTS \\
\hline $\begin{array}{l}\text { Dissolution } \\
\text { \$6.1.1.E }\end{array}$ & Resolved & $\begin{array}{l}\text { One of the primary site selection criteria was to locate an area } \\
\text { where the potential for dissolution is insignificant for tens of } \\
\text { thousands of years. Evidence has been collected in sufficient } \\
\text { quantity to dismiss shallow, deep, and point source dissolution } \\
\text { as potentially disruptive processes at the WIPP facility. }\end{array}$ & $\begin{array}{l}\text { It is reasonable to expect that the repository } \\
\text { will not be affected by dissolution. No further } \\
\text { studies of dissolution are required for the } \\
\text { purposes of compliance demonstrations. }\end{array}$ \\
\hline Igneous Activity & Resolved & $\begin{array}{l}\text { The presence of an igneous dike in the vicinity raised the } \\
\text { question of the presence or absence of igneous activity around } \\
\text { WIPP. Data/Information were gathered relative to an igneous } \\
\text { dike } 9 \text { miles north of the WIPP site. There is no evidence to } \\
\text { indicate that igneous activity will disrupt the WIPP facility. }\end{array}$ & $\begin{array}{l}\text { It is reasonable to expect that igneous activity } \\
\text { will not affect the WIPP repository. No } \\
\text { further studies of igneous activity are necessary } \\
\text { for the purposes of demonstrating compliance. }\end{array}$ \\
\hline \$6.1.1.F & & & \\
\hline
\end{tabular}


Table 12-1 Compliance Summary

\begin{tabular}{|c|c|c|c|}
\hline ISSUES & STATUS & DESCRIPTION/RESOLUTION & COMMENTS \\
\hline Karst & Resolved & $\begin{array}{l}\text { Karst is a common feature of the limestone areas of } \\
\text { southeastern New Mexico. Hydrological evidence obtained } \\
\text { does not preclude the existence of karst. The surface and } \\
\text { subsurface features near the WIPP site that were suspected to } \\
\text { be features associated with karst were investigated. Studies } \\
\text { indicate that karst is not a process at the WIPP that will result } \\
\text { in significant consequence. }\end{array}$ & $\begin{array}{l}\text { It is reasonable to expect that karst will not } \\
\text { affect the performance of the WIPP repository. } \\
\text { No further investigations of karst are required } \\
\text { for the purposes of compliance demonstrations. }\end{array}$ \\
\hline $\begin{array}{l}\text { Natural } \\
\text { Background } \\
\text { Radiation }\end{array}$ & Resolved & $\begin{array}{l}\text { Background radioactivity data were needed for the WIPP site. } \\
\text { In an effort to characterize background radiological conditions } \\
\text { of the WIPP site area, an aerial survey was performed. Two } \\
\text { human-induced anomalies were identified in the region. A } \\
\text { radiological baseline program has also been in existence for } \\
\text { some nine years. }\end{array}$ & $\begin{array}{l}\text { The aerial survey and the radiological baseline } \\
\text { data/information have established a reasonable } \\
\text { radiological baseline for the purposes of } \\
\text { compliance demonstrations. }\end{array}$ \\
\hline$\$ 6.1 .1 . \mathrm{H}$ & & & \\
\hline
\end{tabular}


Table 12-1 Compliance Summary

\begin{tabular}{|c|c|c|c|}
\hline ISSUES & STATUS & DESCRIPTION/RESOLUTION & COMMENTS \\
\hline $\begin{array}{l}\text { Paleoclimate and } \\
\text { Climatic Changes } \\
\text { \$6.1.1.I }\end{array}$ & Resolved & $\begin{array}{l}\text { WIPP site hydrology may be sensitive to changes in climate. } \\
\text { A compliance summary of paleoclimatic information collected } \\
\text { in Southeastern New Mexico has been used to develop a } \\
\text { reasonable expectation for future climatic variation at the } \\
\text { WIPP. This reasonable expectation is used in PA evaluations. }\end{array}$ & $\begin{array}{l}\text { No further studies of the range of climate } \\
\text { changes are required. }\end{array}$ \\
\hline Resources & Open & $\begin{array}{l}\text { Oil, gas, and potash resources in the area of the WIPP have } \\
\text { been estimated by several methods. The reasons for the } \\
\text { assessments were twofold; 1) to determine the appropriate } \\
\text { compensation to lessees for access denial, and 2) to assess } \\
\text { inadvertent drilling into the repository as a function of } \\
\text { potential resource targets. Resources are typical of the area. } \\
\text { The increased probability of human intrusion due to resources } \\
\text { has been incorporated into the PA based on guidance in } 40 \\
\text { CFR } 191 \text { Appendix C. (See } \$ 10.1 .4)\end{array}$ & $\begin{array}{l}\text { The DOE believes that effective passive } \\
\text { controls can be developed and implemented in } \\
\text { accordance with } 40 \text { CFR } 191 \text { that reduce the } \\
\text { likelihood of inadvertent human intrusion. The } \\
\text { consequence of such intrusions will still be } \\
\text { assessed in the PA as required since EPA } \\
\text { guidance states that passive institutional } \\
\text { cratrols should not be assumed to completely } \\
\text { rule out the possibility of intrusion. }\end{array}$ \\
\hline
\end{tabular}


Table 12-1 Compliance Summary

\begin{tabular}{|c|c|c|c|}
\hline ISSUES & STATUS & DESCRIPTION/RESOLUTION & COMMENTS \\
\hline $\begin{array}{l}\text { Salt Deformation } \\
\$ 6.1 .1 . \mathrm{K}\end{array}$ & Resolved & $\begin{array}{l}\text { Salt deformation was considered important as a site-selection } \\
\text { criterion. Drilling information and seismic data have been } \\
\text { acquired. These data/information indicate that the central } \\
\text { portion of the WIPP facility, where the repository is situated, } \\
\text { is not significantly deformed. Salt deformation was } \\
\text { encountered one mile north of the WIPP site center when } \\
\text { drilling WIPP-12. }\end{array}$ & $\begin{array}{l}\text { Geological data indicate that it is a reasonable } \\
\text { expectation that no significant deformation } \\
\text { occurring from natural processes will occur at } \\
\text { the WIPP over the period of regulatory } \\
\text { interest. No further studies related to salt } \\
\text { deformation are required for the purposes of } \\
\text { demonstrating compliance. }\end{array}$ \\
\hline Seismic Activity & Resolved & $\begin{array}{l}\text { Distant instrumental data supplemented by data collected at the } \\
\text { WIPP site and historical non-instrumental records indicate } \\
\text { most regional seismic activity occurs near Kermit, Texas and } \\
\text { may be related to oil field injection activities. Seismic motion } \\
\text { studies indicate that the expected acceleration value for } 1,000 \\
\text { year acceleration is less than } 0.06 \mathrm{~g} \text {. }\end{array}$ & $\begin{array}{l}\text { A } 0.1 \mathrm{~g} \text { acceleration value was used in the } \\
\text { design basis for the facility. This is a } \\
\text { conservative value, and no further studies are } \\
\text { required for the purposes of compliance } \\
\text { demonstration. }\end{array}$ \\
\hline
\end{tabular}


Table 12-1 Compliance Summary

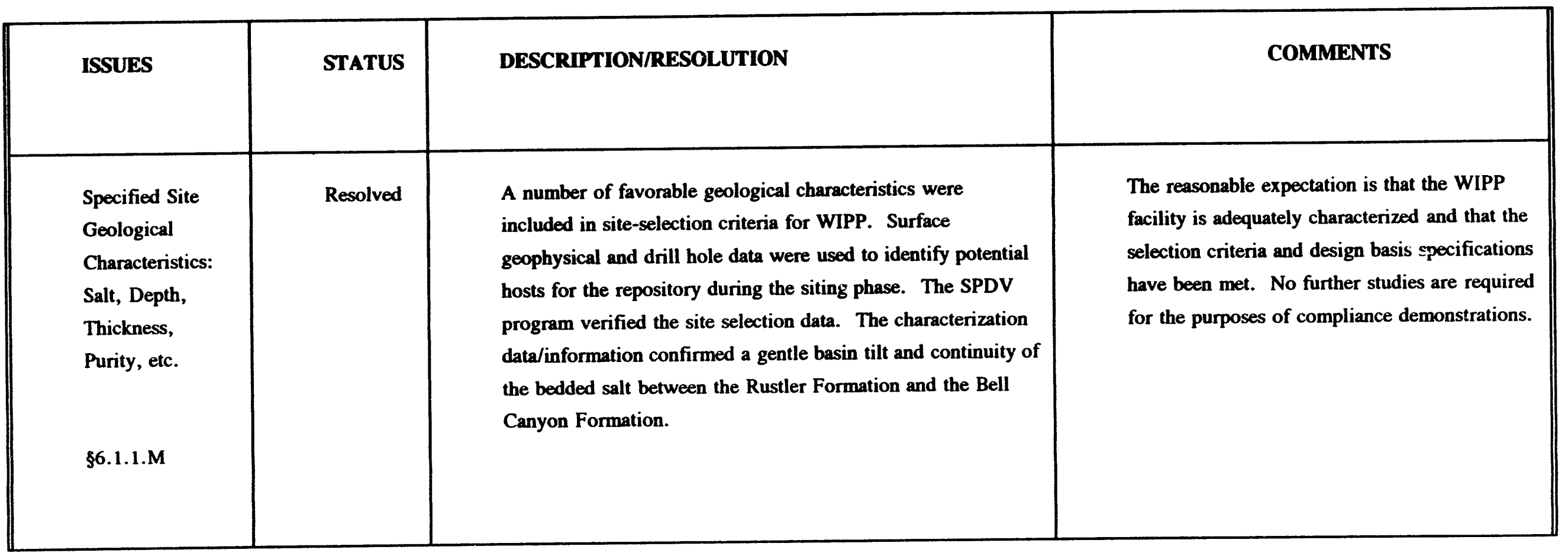


Table 12-1 Compliance Summary

\begin{tabular}{|c|c|c|c|}
\hline ISSUES & STATUS & DESCRHPTION/RESOLUTION & COMMENTS \\
\hline Subsidence & Open & $\begin{array}{l}\text { Subsidence is important from both a natural and induced } \\
\text { standpoint. Natural subsidence from tectonic activity is } \\
\text { generally a broad-scale event. It is not a reasonable } \\
\text { expectation that such regional subsidence is a process that will } \\
\text { disrupt the repository. Natural subsidence due to salt } \\
\text { dissolution in the Rustler formation is known to be limited. } \\
\text { Induced subsidence due to mining of the WIPP is controlled } \\
\text { using low extraction ratios and by filling mined areas with } \\
\text { waste and/or salt. Reviews have requested that DOE evaluate } \\
\text { the effects of subsidence outside the controlled area on } \\
\text { regional groundwater flow. This scenario is being } \\
\text { incorporated into the PA. (See } \$ 10.1 .5 .2 \text { ) }\end{array}$ & $\begin{array}{l}\text { The potential for subsidence that could } \\
\text { significantly impact repository performance is } \\
\text { limited by mining practices at WIPP and } \\
\text { control of resources within the Land } \\
\text { Withdrawal Area. The effect of induced } \\
\text { subsidence due to potash mining, at or near the } \\
\text { WIPP repository on the regional groundwater } \\
\text { flow system, is being addressed by numerical } \\
\text { modeling studies. }\end{array}$ \\
\hline
\end{tabular}




\section{Table 12-1 Compliance Summary}

\begin{tabular}{||l|l|l|l|l||}
\hline ISSUES & STATUS & DESCRIPTION/RESOLUTION & COMMENTS \\
\hline $\begin{array}{l}\text { Tectonic } \\
\text { Stability/Faulting }\end{array}$ & Resolved & $\begin{array}{l}\text { Faulting or tectonic disruption could create release pathways. } \\
\text { Observations that the site is tectonically stable include 1) no } \\
\text { major faulting, 2) site reflection studies and exploratory } \\
\text { drilling data indicate low salt deformation in an area one to } \\
\text { two miles north, 3) geodetic surveys show that regional } \\
\text { subsidence across the site is less than five mm/yr, 4) } \\
\text { aeromagnetic and gravity surveys indicate no significant } \\
\text { igneous activity, 5) heat flow surveys confirmed that the site } \\
\text { has no geothermal gradient. }\end{array}$ & $\begin{array}{l}\text { Based on these observations, the reasonable } \\
\text { expectation is that the W!'P facility will } \\
\text { remain tectonically stable. No tectonic events } \\
\text { or processes need be included in the conceptual } \\
\text { model. No further studies are necessary for } \\
\text { the purposes of compliance demonstrations. }\end{array}$ & \\
\hline \$6.1.1.0 & & &
\end{tabular}


Table 12-1 Compliance Summary

\begin{tabular}{|c|c|c|c|}
\hline ISSUES & STATUS & DESCRIPTION/RESOLUTION & COMMENTS \\
\hline $\begin{array}{l}\text { Identification and } \\
\text { quantification of } \\
\text { chemical } \\
\text { processes that } \\
\text { retard } \\
\text { radionuclide } \\
\text { transport in the } \\
\text { Rustler } \\
\text { Formation, } \\
\text { particularly the } \\
\text { Culebra member } \\
\text { \$6.1.1.P }\end{array}$ & Open & $\begin{array}{l}\text { Sorptive properties of the Culebra member appear to be } \\
\text { important parameters for transport calculations. The DOE } \\
\text { agreed in the C\&C Agreement with the State of New Mexico, } \\
\text { to conduct laboratory studies related to Culebra retardation } \\
\text { factors. The DOE committed to develop a range of } \\
\text { conservative, but reasonable values based on the most } \\
\text { conservative experimental value(s) obtained. The DOE } \\
\text { agreed to consult with the State prior to selecting the } \\
\text { appropriate values. The DOE also committed to use } \mathrm{K}_{\mathrm{d}} \\
\text { values equal to zero if such experimental data are not } \\
\text { obtained. Core flow testing will test chemical retardation cn a } \\
\text { small scale. These data will likely lead to the experimental } \\
\text { values to be used for } \mathrm{K}_{\mathrm{d}} \text { 's. (See } \$ 10.1 .1 .2 .3 \text { ) }\end{array}$ & $\begin{array}{l}\text { Based on expert judgment and limited } \\
\text { laboratory studies it is reasonable to assume } \\
\text { that } K_{d} \text { values are non zero. It is a reasonable } \\
\text { expectation that the appropriate conceptual } \\
\text { model for the repository include non zero } K_{d} \\
\text { values. The development of non-zero } K_{d} \\
\text { values, based on laboratory measurements and } \\
\text { corroborated by existing data could } \\
\text { significantly affect the result of PA. }\end{array}$ \\
\hline $\begin{array}{l}\text { Thermal } \\
\text { Expansion }\end{array}$ & Resolved & $\begin{array}{l}\text { Thermal considerations were raised when the WIPP program } \\
\text { included high level waste. Plans now include only waste with } \\
\text { low thermal outputs. Calculations show that thermal impacts } \\
\text { are insignificant. }\end{array}$ & $\begin{array}{l}\text { It is a reasonable expectation that thermal } \\
\text { expansion will be of no consequence to the } \\
\text { repository. No further studies are required for } \\
\text { the purposes of compliance demonstrations. }\end{array}$ \\
\hline$\$ 6.1 .2 . \mathrm{A}$ & & & \\
\hline
\end{tabular}


Table 12-1 Compliance Summary

\begin{tabular}{|c|c|c|c|}
\hline ISSUES & STATUS & DESCRIPTION/RESOLUTION & COMMENTS \\
\hline $\begin{array}{l}\text { What is the best } \\
\text { approach to } \\
\text { simulating salt } \\
\text { creep? }\end{array}$ & Resolved & $\begin{array}{l}\text { Measured salt creep in the WIPP facility did not fit existing } \\
\text { models. DOE identified a need to develop a new conceptual } \\
\text { model for salt creep. Successful comparisons of the } \\
\text { predictive technology based on the modified Munson-Dawson } \\
\text { (M-D) model, material parameters, and Tresca flow potential, } \\
\text { together with updated stratigraphy and measured field } \\
\text { behavior, indicate that room closure can be predicted } \\
\text { reasonably. }\end{array}$ & $\begin{array}{l}\text { It is a reasonable expectation that PA modeling } \\
\text { will be consistent with the M-D model and will } \\
\text { be acceptable for the purposes of demonstrating } \\
\text { compliance. No further studies are necessary } \\
\text { at this time for compliance demonstration } \\
\text { purposes. }\end{array}$ \\
\hline$\$ 6.1 .2 . \mathrm{B}$ & & & \\
\hline
\end{tabular}


Table 12-1 Compliance Summary

\begin{tabular}{|c|c|c|c|}
\hline ISSUES & STATUS & DESCRIPTION/RESOLUTION & COMMENTS \\
\hline $\begin{array}{l}\text { Subissue: } \\
\text { Uncertainty }\end{array}$ & Resolved & $\begin{array}{l}\text { Uncertainty was identified arising from differences in 1) } \\
\text { physics and numerical method, and 2) the calculational } \\
\text { procedures, between the numerical codes proposed for use in } \\
\text { the analysis of room response. To resolve this uncertainty, a } \\
\text { nine code benchmarking exercise was conducted. Results } \\
\text { indicated that the variation between codes was acceptable. } \\
\text { Code problem input quality was assessed via refereed blind } \\
\text { parallel calculations. The results of these exercises indicate } \\
\text { that there are three codes with acceptable capabilities for the } \\
\text { purposes of performing PA calculations. }\end{array}$ & $\begin{array}{l}\text { It is a reasonable expectation that PA modeling } \\
\text { will be consistent with the M-D model. No } \\
\text { further study is required for the purposes of } \\
\text { compliance demonstrations. }\end{array}$ \\
\hline$\S 6.1 .2$. B.1 & & & \\
\hline
\end{tabular}


Table 12-1 Compliance Summary

\begin{tabular}{|c|c|c|c|}
\hline ISSUES & STATUS & DESCRIPTION/RESOLUTION & COMMENTS \\
\hline $\begin{array}{l}\text { Subissue: } \\
\text { Constitutive } \\
\text { description and } \\
\text { material } \\
\text { properties. }\end{array}$ & Resolved & $\begin{array}{l}\text { A discrepancy was identified between the predicted and } \\
\text { measured in-situ room closure data. The discrepancy was } \\
\text { resolved through the use of a creep model based on } \\
\text { multimechanism deformation steady state with work } \\
\text { hardening/recovery transient creep. The analysis also } \\
\text { included a 3-dimensional test with different excavation } \\
\text { dimensions. }\end{array}$ & $\begin{array}{l}\text { The successful comparisons demonstrate that } \\
\text { the simulation technology based on the M-D } \\
\text { model is appropriate, and it is a reasonable } \\
\text { expectation that PA modeling will be consistent } \\
\text { with the M-D model. No further studies are } \\
\text { required for the purposes of compliance } \\
\text { demonstrations. }\end{array}$ \\
\hline$\$ 6.1 .2$. B.2 & & & \\
\hline
\end{tabular}


Table 12-1 Compliance Summary

\begin{tabular}{|c|c|c|c|}
\hline ISSUES & STATUS & DESCRIPTION/RESOLUTION & COMMENTS \\
\hline $\begin{array}{l}\text { Rock Mechanics } \\
\text { Concerns for Seal } \\
\text { Performance } \\
\text { \$6.1.2.C }\end{array}$ & Open & $\begin{array}{l}\text { Simulations of the performance of seals and seal systems } \\
\text { under repository conditions was needed. Technology is being } \\
\text { developed for simulation of seal performance. The current } \\
\text { model is based on the M-D Creep model, coupled 'vith a } \\
\text { pressure and time dependent accumulation of fracture damage } \\
\text { to simulate tertiary creep and eventual failure. The model has } \\
\text { been incorporated into the numerical codes, material } \\
\text { parameters have been determined and preliminary simulations } \\
\text { of the DRZ have been conducted. The model also includes } \\
\text { the healing kinetics of repressurized fractures. (See } \\
\$ 10.1 .2 .1 \text { ) }\end{array}$ & $\begin{array}{l}\text { Seal emplacement exercises and performance } \\
\text { tests will be conducted to evaluate emplacement } \\
\text { feasibility and effectiveness. The tests will } \\
\text { also include post-emplacement evaluacions to } \\
\text { ensure that final seal design specifications are } \\
\text { met. These examinations and evaluations will } \\
\text { likely demonstrate that the seals can meet } \\
\text { required performance based criteria. }\end{array}$ \\
\hline
\end{tabular}


Table 12-1 Compliance Summary

\begin{tabular}{|c|c|c|c|}
\hline ISSUES & STATUS & DESCRIPTION/RESOLUTION & COMMENTS \\
\hline $\begin{array}{l}\text { Focus on Culebra } \\
\text { Dolomite }\end{array}$ & Resolved & $\begin{array}{l}\text { Significant emphasis has been placed on the Culebra member } \\
\text { of the Rustler formation as the principle flow path for } \\
\text { radionuclide releases. This has been to the near exclusion of } \\
\text { other layers. The hydrologic properties of the other layers } \\
\text { indicate that this is an acceptable assumption. Several } \\
\text { reviewers have asked for a reconsideration of the flow in } \\
\text { other water bearing units. Current numerical codes can } \\
\text { provide this analysis. }\end{array}$ & $\begin{array}{l}\text { Modeling all releases in the Culebra is } \\
\text { conservative, because regional transmissivity } \\
\text { data in other water bearing Rustler units } \\
\text { indicate that they are less transmissive than the } \\
\text { Culebra. If documentation is required, it can } \\
\text { be obtained through the application of } \\
\text { numerical codes to other water bearing units } \\
\text { within the Rustler and overlying formations. }\end{array}$ \\
\hline $\begin{array}{l}\text { Reconciling } \\
\text { present-day } \\
\text { distribution of } \\
\text { solutes with } \\
\text { Culebra Flow } \\
\text { direction }\end{array}$ & Open & $\begin{array}{l}\text { The current distribution of solutes in the Culebra appear to be } \\
\text { inconsistent with flow directions across the site. Several } \\
\text { hypotheses have been advanced but the issue has yet to be } \\
\text { reconciled. Simulations will be performed to test the } \\
\text { hypotheses. (See } \$ 10.1 .1 .1 \text { ) }\end{array}$ & $\begin{array}{l}\text { This topic will be revisited during an } \\
\text { examination of the regional recharge model, in } \\
\text { order to confirm that it is a reasonable } \\
\text { expectation that the current Culebra flow } \\
\text { directions are accurate. }\end{array}$ \\
\hline$\$ 6.1 .3 . \mathrm{B}$ & & & \\
\hline
\end{tabular}




\section{Table 12-1 Compliance Summary}

\begin{tabular}{|c|c|c|c|}
\hline ISSUES & STATUS & DESCRIPTION/RESOLUTION & COMMENTS \\
\hline $\begin{array}{l}\text { Rustler Formation } \\
\text { Recharge } \\
\text { \$6.1.3.C }\end{array}$ & Open & $\begin{array}{l}\text { Recharge areas and rates for the Rustler have not been } \\
\text { conclusively identified. Various conceptual models have been } \\
\text { proposed involving different recharge areas and flow } \\
\text { directions. An examination of data around the WIPP site will } \\
\text { be performed in light of an overall basin-wide recharge } \\
\text { model. (See } \$ 10.1 .1 .2 .1 \text { ) }\end{array}$ & $\begin{array}{l}\text { The various alternative models will be } \\
\text { addressed and their inclusion or exclusion } \\
\text { documented in the compliance application. }\end{array}$ \\
\hline $\begin{array}{l}\text { Model for } \\
\text { Culebra Flow and } \\
\text { Transport }\end{array}$ & Open & $\begin{array}{l}\text { A dual porosity model to simulate transport through the } \\
\text { Culebra is used by PA. There are alternative models that } \\
\text { may describe transport more accurately. These will be } \\
\text { evaluated using additional sorbing tracer tests. } \\
\text { (See } \$ 10.1 .1 .2 .2 \text { ) }\end{array}$ & $\begin{array}{l}\text { If current models can be demonstrated to be } \\
\text { conservative and if compliance calculations are } \\
\text { within the limits for containment, then } \\
\text { additional tracer tests may not be needed. }\end{array}$ \\
\hline$\$ 6.1 .3 . C$ & & & \\
\hline
\end{tabular}


Table 12-1 Compliance Summary

\begin{tabular}{|c|c|c|c|}
\hline ISSUES & STATUS & DESCRIPTION/RESOLUTION & COMMENTS \\
\hline $\begin{array}{l}\text { Transmissivity } \\
\text { Variation in the } \\
\text { Culebra Dolomite } \\
\text { \$6.1.3.E }\end{array}$ & Open & $\begin{array}{l}\text { Over six orders of magnitude variations in transmissivity in } \\
\text { the Culebra has been observed. This variation heavily affects } \\
\text { the treatment of transport assumptions. Geostatistical } \\
\text { approaches to defining transmissivity are being pursued. The } \\
\text { final result will be a quantification of the uncertainty in } \\
\text { transmissivity. (See } \$ 10.1 .1 .2 .1 \text { and } \$ 10.1 .5 .2)\end{array}$ & $\begin{array}{l}\text { Data from } 42 \text { measurements are available for } \\
\text { the WIPP vicinity. It is reasonable to assume } \\
\text { that the geostatistical methods will show a high } \\
\text { degree of correlation between the empirical } \\
\text { data collected in the region, and site specific } \\
\text { Culebra transmissivities. Quantified } \\
\text { uncertainty relative to Culebra transmissivity } \\
\text { values will allow the DOE to make decisions } \\
\text { regarding the need for additional study such as } \\
\text { tracer tests. }\end{array}$ \\
\hline $\begin{array}{l}\text { Brine Content of } \\
\text { Salado Evaporites } \\
\text { §6.1.3.F }\end{array}$ & Open & $\begin{array}{l}\text { Early NAS studies concluded halite to be suitable because it } \\
\text { was dry. Numerous experimental programs have been } \\
\text { conducted to study the quantity of brine in the Salado } \\
\text { Formation and its availability to migrate into the repository. } \\
\text { Information on coupling between the hydrological and } \\
\text { geomechanical models will be obtained through further } \\
\text { analysis. ( } \$ 10.1 .1 .1 .3)\end{array}$ & $\begin{array}{l}\text { Observed brine seepage rates are slow and } \\
\text { difficult to quantify. The coupling between the } \\
\text { hydrological and geomechanical regions are not } \\
\text { well understood. }\end{array}$ \\
\hline
\end{tabular}


Table 12-1 Compliance Summary

\begin{tabular}{|c|c|c|c|}
\hline ISSUES & STATUS & DESCRIPTION/RESOLUTION & COMMENTS \\
\hline $\begin{array}{l}\text { Effects of Gas } \\
\text { Generation }\end{array}$ & Open & $\begin{array}{l}\text { If sufficient brine is present in the repository, several process } \\
\text { of waste degradation will produce gas. This gas could impact } \\
\text { the performance of the repository if sufficient quantities are } \\
\text { generated. The effects of gas have been incorporated into the } \\
\text { conceptual model. (See } \$ 10.1 .2 .3 \text { and } \$ 10.1 .31 \text { ) }\end{array}$ & $\begin{array}{l}\text { The possibility of an impact upon repository } \\
\text { performance from gas generation was } \\
\text { recognized by the EPA-OSW in the No- } \\
\text { Migration Determination. They suggested that } \\
\text { the DOE evaluate the effects of gas on natural } \\
\text { and engineered barriers. The current approach } \\
\text { in PA is to use the permeability data reported } \\
\text { by Beauheim in the conceptual model. This } \\
\text { model does not consider some of the } \\
\text { observational data from the Brine Sampling and } \\
\text { Evaluation Program. The observational } \\
\text { program indicates significantly less brine than } \\
\text { the permeability measurements. This } \\
\text { difference should be reconciled. }\end{array}$ \\
\hline
\end{tabular}


Table 12-1 Compliance Summary

\begin{tabular}{|c|c|c|c|}
\hline ISSUES & STATUS & DESCRIPTION/RESOLUTION & COMMENTS \\
\hline $\begin{array}{l}\text { Effects of } \\
\text { Groundwater } \\
\text { Below the Salado } \\
\text { and Castile } \\
\text { Formations }\end{array}$ & Resolved & $\begin{array}{l}\text { One of the postulated processes includes the movement of } \\
\text { water from underlying units into the WIPP causing } \\
\text { dissolution. Field tests of the underlying formations, } \\
\text { including brine saturations have led to conclusions that these } \\
\text { brines are no threat to the repository. This process has been } \\
\text { screened out based on low probability. }\end{array}$ & $\begin{array}{l}\text { The reasonable expectation is that brines from } \\
\text { formations will not affect the repository. No } \\
\text { further work is needed in this area for } \\
\text { compliance demonstrations. }\end{array}$ \\
\hline$\$ 6.1 .3 . \mathrm{H}$ & & & \\
\hline $\begin{array}{l}\text { CCDF } \\
\text { Confidence } \\
\text { Bounds }\end{array}$ & Open & $\begin{array}{l}\text { Appropriate confidence bounds will be developed around the } \\
\text { mean CCDF. This issue will likely remain open until } 40 \text { CFR } \\
194 \text { is issued. All CCDF's presented in WIPP PA do not } \\
\text { address the confidence associated with the models or data } \\
\text { assumptions used in the analyses. }\end{array}$ & $\begin{array}{l}\text { The use of the mean CCDF is considered to be } \\
\text { a reasonable way to represent the results of } \\
\text { performance assessment modeling. The } \\
\text { regulations suggest using a single CCDF. For } \\
\text { compliance with } 40 \text { CFR } \$ 191.15 \text {, the EPA } \\
\text { suggests using the mean or median distribution } \\
\text { (whichever is larger). }\end{array}$ \\
\hline
\end{tabular}




\section{Table 12-1 Compliance Summary}

\begin{tabular}{|c|c|c|c|}
\hline ISSUES & STATUS & DESCRIPTION/RESOLUTION & COMMENTS \\
\hline Scenarios & Resolved & $\begin{array}{l}\text { After credible events and processes were identified for the } \\
\text { WIPP, a technique was needed to combine them into } \\
\text { reasonable scenarios. A logic diagram procedure was } \\
\text { developed which allowed the development of scenarios and the } \\
\text { propagation of probabilities. }\end{array}$ & $\begin{array}{l}\text { This approach appears to be both reasonable } \\
\text { and appropriate. No additional work is needed } \\
\text { in this area for compliance demonstration } \\
\text { purposes. }\end{array}$ \\
\hline $\begin{array}{l}\text { Complexity and } \\
\text { Realism of PA } \\
\text { Models }\end{array}$ & Resolved & $\begin{array}{l}\text { As the conceptual model for the WIPP became more and } \\
\text { more complex, the need to develop and implement multi- } \\
\text { dimensional numerical codes has been identified. Formal } \\
\text { system-level sensitivity analyses have been performed since } \\
\text { the } 1990 \text { PA. }\end{array}$ & $\begin{array}{l}\text { The current 3-dimensional codes are reasonable } \\
\text { for the conceptual model at WIPP. Quaity } \\
\text { assurance of these codes needs to be completed } \\
\text { prior to submittal of compliance } \\
\text { documentation. }\end{array}$ \\
\hline \$6.1.4.C & & & \\
\hline
\end{tabular}


Table 12-1 Compliance Summary

\begin{tabular}{|c|c|c|c|}
\hline ISSUES & STATUS & DESCRIPTION/RESOLUTION & COMMENTS \\
\hline $\begin{array}{l}\text { Uncertainty in } \\
\text { Radionuclide } \\
\text { Solubility and } \\
\text { Retardation. } \\
\$ 6.1 .4 . D\end{array}$ & Open & $\begin{array}{l}\text { Characterization of uncertainty in radionuclide solubility and } \\
\text { retardation. The current PA uses expert panel values for } \\
\text { actinide solubilities and zero volumes for colloid } \\
\text { concentrations. These values are considered to have a great } \\
\text { deal of uncertainty associated with them. A laboratory } \\
\text { program is planned to resolve the uncertainty. (See } \\
\$ 10.1 .1 .2 .3 \text { ) }\end{array}$ & $\begin{array}{l}\text { Laboratory data will be used to support the } \\
\text { expert judgement by providing waste specific } \\
\text { and WIPP brine specific data. }\end{array}$ \\
\hline
\end{tabular}


Table 12-1 Compliance Summary

\begin{tabular}{|c|c|c|c|}
\hline ISSUES & STATUS & DESCRIPTION/RESOLUTION & COMMENTS \\
\hline Human Intrusion & Resolved & $\begin{array}{l}40 \text { CFR } 191 \text { requires the inclusion of inadvertent human } \\
\text { intrusion regardless of the effectiveness of passive controls. } \\
\text { Two approaches have been taken to identify drilling rates. } \\
\text { These are the use of expert judgment and the use of the } \\
\text { maximum rate in the guidance. }\end{array}$ & $\begin{array}{l}\text { Since the applicable regulations require both } \\
\text { the consideration of human intrusion and } \\
\text { reduction of the likelihood of human intrusion } \\
\text { to acceptable levels, the DOE must reconsider } \\
\text { its approach to this issue. Focus should be } \\
\text { placed on ensuring passive controls reduce the } \\
\text { likelihood to acceptable levels. This can be } \\
\text { accomplished by using site specific } \\
\text { characteristics to develop durale markers, } \\
\text { assuring proper information is recorded in } \\
\text { strategic locations, and anaintaining federal } \\
\text { ownership. Human intrusion will continue to } \\
\text { be included for the purposes of generating the } \\
\text { mean CCDF. }\end{array}$ \\
\hline $\begin{array}{l}\text { Climate Change } \\
\text { \$6.1.4.F }\end{array}$ & Open & $\begin{array}{l}\text { Climatic changes are among the anticipated processes that can } \\
\text { reasonably be modeled for the repository. Reasonable values } \\
\text { for future variations in climate have been included in the } 1992 \\
\text { PA for the undisturbed case. (See } \$ 10.1 .1 .2 .1 \text { ) }\end{array}$ & $\begin{array}{l}\text { The effects of climate ch sige are currently } \\
\text { being investigated as a part of a regional, } \\
\text { three-dimensional flow modeling regime. }\end{array}$ \\
\hline
\end{tabular}


Table 12-1 Compliance Summary

\begin{tabular}{|c|c|c|c|}
\hline ISSUES & STATUS & DESCRIPTION/RESOLUTION & COMMENTS \\
\hline $\begin{array}{l}\text { Two-Phased Flow } \\
\text { and Gas } \\
\text { Generation } \\
\text { \$6.1.4.G }\end{array}$ & Resolved & $\begin{array}{l}\text { Gas generation and 2-phase flow were identified in } 1989 \text { as } \\
\text { needed additions to the conceptual model. Both of these have } \\
\text { since been added to the conceptual model. }\end{array}$ & $\begin{array}{l}\text { No additional activity is required in this area } \\
\text { for compliance demonstrations. The new } \\
\text { reaction path model for gas generation will } \\
\text { provide more precise gas and brine chemistry } \\
\text { results for final compliance calculations. }\end{array}$ \\
\hline $\begin{array}{l}\text { Transmissivity of } \\
\text { the Culebra } \\
\$ 6.1 .4 . \mathrm{H}\end{array}$ & Open & $\begin{array}{l}\text { One of several Culebra flow issues involves how the } \\
\text { transmissivity field is generated. Several techniques have } \\
\text { been used in the past. Several tochniques are being } \\
\text { benchmarked using a carefully controlled test problem. } \\
\text { (See } \$ 10.1 .1 .2 .1 \text { and } \$ 10.1 .5 .2 \text { ) }\end{array}$ & $\begin{array}{l}\text { It is anticipated that completion of this process } \\
\text { will enhance the defensibility of the Culebra } \\
\text { flow model. }\end{array}$ \\
\hline
\end{tabular}




\section{Table 12-1 Compliance Summary}

\begin{tabular}{|c|c|c|c|}
\hline ISSUES & STATUS & DESCRIPTION/RESOLUTION & COMMENTS \\
\hline $\begin{array}{l}\text { Displays of } \\
\text { Uncertainty }\end{array}$ & Resolved & $\begin{array}{l}\text { Displaying uncertainty in performance estimates resulting } \\
\text { from alternative conceptual models for waste-form properties } \\
\text { and radionuclide transport in the Culebra is considered useful. } \\
\text { Alternative conceptual models for waste solubility and for } \\
\text { transport in the Culebra have been developed to manage the } \\
\text { uncertainty that currently exists. Techniques to display } \\
\text { outcomes for purposes of dual comparison have been } \\
\text { developed. }\end{array}$ & $\begin{array}{l}\text { Comparative displays of alternative conceptual } \\
\text { models allow the DOE to decide which } \\
\text { additional research and evaluation would be } \\
\text { most beneficial. Where additional data cannot } \\
\text { be obtained in a practical manner, the most } \\
\text { conservative alternative may be used. These } \\
\text { displays continue to be used as an evaluation } \\
\text { tool. }\end{array}$ \\
\hline $\begin{array}{l}\text { Coupling of } \\
\text { Models }\end{array}$ & Open & $\begin{array}{l}\text { Creep closure is not yet fully coupled within the BRAGFLO } \\
\text { code. This coupling is needed since creep is one of the } \\
\text { primary natural phenomena that governs repository } \\
\text { performance. (See } \$ 10.1 .1 .1 .4 \text { and } \$ 10.1 .2 .3 \text { ) }\end{array}$ & $\begin{array}{l}\text { Partial coupling is included in the } 1992 \text { PA. } \\
\text { This coupling is considered to be required to } \\
\text { provide a reasonable numerical simulation of } \\
\text { the important processes within the disposal } \\
\text { system. }\end{array}$ \\
\hline
\end{tabular}


Table 12-1 Compliance Summary

\begin{tabular}{|c|c|c|c|}
\hline ISSUES & STATUS & DESCRIPTION/RESOLUTION & COMMENTS \\
\hline $\begin{array}{l}\text { Fracture } \\
\text { Modeling }\end{array}$ & Open & $\begin{array}{l}\text { Evaluation of pressure-dependent fracturing of anhydrite } \\
\text { interbeds in the Salado is needed. In 1993, PA calculations } \\
\text { began using approximations of possible changes in fluid flow } \\
\text { properties. Work is underway to evaluate the adequacy of } \\
\text { these approximations. (See } \$ 10.1 .1 .2 \text { and } \$ 10.1 .1 .1 .4 \text { ) }\end{array}$ & $\begin{array}{l}\text { In the } 1992 \mathrm{PA} \text {, the mean value of pressure } \\
\text { does not exced lithostatic. Comments by the } \\
\text { NAS and other reviewers have encouraged } \\
\text { inclusion of fracturing into the conceptual } \\
\text { model. Including fracturing may be necessary } \\
\text { to reasonably represent all significant processes } \\
\text { within the disposal system. }\end{array}$ \\
\hline $\begin{array}{l}\text { Confirmation of } \\
\text { the adequacy of } \\
\text { two dimensional } \\
\text { models. }\end{array}$ & Open & $\begin{array}{l}\text { Confirmation of the adequacy of 2-D modeling with 3-D } \\
\text { modeling is necessary. 3-D analyses have begun and upon } \\
\text { completion the 2-D models will be verified or modified. The } \\
\text { current conceptual model requires 3-D modeling to achieve } \\
\text { adequate simulation. These 3-D models will be compared to } \\
\text { their 2-D counterparts. (See \$10.1.1.1.4) }\end{array}$ & $\begin{array}{l}\text { Preliminary 3-D versions of BRAGFLO and } \\
\text { SECO FLOW and TRANSPORT are now } \\
\text { available. This validation activity needs to be } \\
\text { completed to support compliance } \\
\text { demonstrations. }\end{array}$ \\
\hline$\$ 6.1 .4 . \mathrm{L}$ & & & \\
\hline
\end{tabular}


Table 12-1 Compliance Summary

\begin{tabular}{|c|c|c|c|}
\hline ISSUES & STATUS & DESCRIPTION/RESOLUTION & COMMENTS \\
\hline $\begin{array}{l}\text { Event/Process } \\
\text { Screening } \\
\$ 6.1 .4 . \mathrm{M}\end{array}$ & Open & $\begin{array}{l}\text { The process that was used screen scenarios needs to be } \\
\text { reexamined. A detailed analyses of scenarios not previously } \\
\text { considered has begun and will provide a basis for screening } \\
\text { process decisions. (See } \$ 10.1 .5 .2 \text { ) }\end{array}$ & $\begin{array}{l}\text { Documentation of past screening processes and } \\
\text { decisions will be needed for compliance } \\
\text { documentation. }\end{array}$ \\
\hline $\begin{array}{l}\text { Alternate uses of } \\
\text { Groundwater }\end{array}$ & Resolved & $\begin{array}{l}\text { Several reviewers have suggested that groundwater from the } \\
\text { Culebra may be used for other activities such as dust control, } \\
\text { fire suppression or drilling. This water could be contaminated } \\
\text { following a human intrusion event. }\end{array}$ & $\begin{array}{l}\text { This does not need to be considered as part of } \\
\text { the conceptual model since such use is not } \\
\text { common today in the immediate vicinity of the } \\
\text { WIPP and since commercial use of } \\
\text { groundwater is currently regulated. It is } \\
\text { reasonable to assume it will remain regulated } \\
\text { in the future. No future studies are required } \\
\text { for the purposes of compliance demonstrations. }\end{array}$ \\
\hline
\end{tabular}




\section{Table 12-1 Compliance Summary}

\begin{tabular}{|c|c|c|c|}
\hline ISSUES & STATUS & DESCRIPTION/RESOLUTION & COMMENTS \\
\hline Criticality & Resolved & $\begin{array}{l}\text { Several reviewers have suggested consideration of a criticality } \\
\text { event within the repository. Additional studies will continue } \\
\text { to verify that sustained reaction is not credible due to low } \\
\text { potential for adequate dissolution and repreciptation to support } \\
\text { the reaction. (See } \$ 10.1 .5 .2)\end{array}$ & $\begin{array}{l}\text { Criticality is not a reasonable expectation. No } \\
\text { further activity is needed for compliance } \\
\text { demonstrations. }\end{array}$ \\
\hline $\begin{array}{l}\text { DatalCode } \\
\text { Quality } \\
\text { Assurance }\end{array}$ & Open & $\begin{array}{l}\text { Only data and numerical codes whose quality can be } \\
\text { documented are to be used in compliance submittals. DOE is } \\
\text { in the process of assessing the status of data and code quality. }\end{array}$ & $\begin{array}{l}\text { The pedigree of data and codes must be } \\
\text { established for compliance submittals. Where } \\
\text { quality is inadequate, remedial actions may be } \\
\text { appropriate. }\end{array}$ \\
\hline$\$ 7.0$ & & & \\
\hline
\end{tabular}


Table 12-1 Compliance Summary

\begin{tabular}{|c|c|c|c|}
\hline ISSUES & STATUS & DESCRIPTION/RESOLUTION & COMMENTS \\
\hline $\begin{array}{l}\text { Permanent } \\
\text { Markers } \\
\text { Reference Design }\end{array}$ & Open & $\begin{array}{l}\text { EPA's guidance in Appendix C of } 40 \text { CFR Part } 191 \text { states that } \\
\text { passive institutional controls such as permanent markers } \\
\text { should be considered when judging the likelihood and } \\
\text { consequences of inadvertent exploratory drilling. The } \\
\text { appendix also states that the likelihood of such drilling need } \\
\text { not be taken to be greater than } 30 \text { boreholes per square } \\
\text { kilometer of repository area per } 10,000 \text { years. Consistent } \\
\text { with this guidance, a reference design is needed for the } \\
\text { permanent markers which will be constructed at the WIPP site } \\
\text { after the facility is decommissioned. This design goal will be } \\
\text { such that markers will persist for } 10,000 \text { years, thereby } \\
\text { making inadvertent intrusion reasonably unlikely. }\end{array}$ & $\begin{array}{l}\text { Although permanent markers will not be } \\
\text { constructed until the operation of the WIPP is } \\
\text { complete, a reference design is needed now. } \\
\text { Technological advances and the results of } \\
\text { ongoing studies of permanent markers systems } \\
\text { may be incorporated into the final design. The } \\
\text { development of a reference design in the near } \\
\text { term will support the position that intrusion is } \\
\text { unlikely and performance assessment } \\
\text { calculations inay be based on an assumed rate } \\
\text { of inadvertent drilling intrusions that is below } \\
\text { the } 30 \text { boreholes per square kilometer } \\
\text { maximum rate identified in the EPA guidance. }\end{array}$ \\
\hline
\end{tabular}


Table 12-1 Compliance Summary

\begin{tabular}{|c|c|c|c|}
\hline ISSUES & STATUS & DESCRIPTION/RESOLUTION & COMMENTS \\
\hline $\begin{array}{l}\text { TRU Waste } \\
\text { Characterization }\end{array}$ & Open & $\begin{array}{l}\text { Information regarding the quantities and compositions of the } \\
\text { inventories of both existing and to-be-generated TRU mixed } \\
\text { wastes is needed to support the compliance evaluations } \\
\text { including an estimate of the variability in the radionuclide } \\
\text { content and other waste-related parameters of interest in long- } \\
\text { term repository performance. The inventory of radionuclides } \\
\text { to be emplaced in the WIPP will be characterized to the extent } \\
\text { necessary to predict the potential migration of these } \\
\text { constituents. This information will be incorporated into the } \\
\text { performance-assessment models. }\end{array}$ & $\begin{array}{l}\text { Performance-assessment analyses and } \\
\text { sensitivity studies require a radionuclide source } \\
\text { term of } \mathrm{RH} \text { and } \mathrm{CH} \text { waste packages that may } \\
\text { affect gas generation and radionuclide } \\
\text { transport. The inventory of organic and metal } \\
\text { constituents that may affect gas generation by } \\
\text { corrosion, biological processes, and radiolysis } \\
\text { will be developed for the } \mathrm{RH} \text { waste packages } \\
\text { and will be updated for the } \mathrm{CH} \text { waste } \\
\text { packages. }\end{array}$ \\
\hline
\end{tabular}


Table 12-1 Compliance Summary

\begin{tabular}{|c|c|c|c|}
\hline ISSUES & STATUS & DESCRIPTION/RESOLUTION & COMMENTS \\
\hline $\begin{array}{l}\text { Hazardous Waste } \\
\text { Characterization }\end{array}$ & Open & $\begin{array}{l}\text { The composition and behavior of hazardous constituents in the } \\
\text { underground waste-emplacement rooms must be understood to } \\
\text { support compliance evaluations. Understanding emission of } \\
\text { gases from waste containers, including gas generation rates, is } \\
\text { also a part of this work. Evaluation of the potential for the } \\
\text { migration of hazardous constituents by liquid and gas-phase } \\
\text { transport requires information regarding the solubilities of } \\
\text { hazardous constituents in brine, equilibrium vapor pressures } \\
\text { or organic constituents, the potential for the formation and } \\
\text { transport of colloids, and phase partitioning. Published } \\
\text { degradation rates will serve as the basis for identifying ranges } \\
\text { of degradation rates for use in the RCRA compliance model(s) } \\
\text { and to identify the need for additional experimental data. }\end{array}$ & $\begin{array}{l}\text { The organic compounds listed by the EPA as } \\
\text { hazardous are predominantly hydrocarbons or } \\
\text { chlorinated hydrocarbons. These compounds } \\
\text { are thermodynamically unstable and tend to } \\
\text { react to form an assemblage of stable } \\
\text { compounds such as carbon dioxide, methane, } \\
\text { water, and chloride ions. Hazardous organic } \\
\text { constituents will degrade by a combination of } \\
\text { chemical and microbial processes, often } \\
\text { involving the formation of intermediate } \\
\text { degradation products. }\end{array}$ \\
\hline$\$ 4.1 .4$ and $\$ 4.1 .6$ & & & \\
\hline
\end{tabular}


Table 12-1 Compliance Summary

\begin{tabular}{|c|c|c|c|}
\hline ISSUES & STATUS & DESCRIPTION/RESOLUTION & COMMENTS \\
\hline $\begin{array}{l}\text { VOC Emissions } \\
\text { From Containers } \\
\$ 9.6 .1\end{array}$ & Open & $\begin{array}{l}\text { The quantities and characteristics of volatile organic (VOCs) } \\
\text { that might be emitted from TRU waste containers in the WIPP } \\
\text { underground are important compliance information. } \\
\text { Emissions of VOCs during the operation of the facility will be } \\
\text { regulated under RCRA and the DOE Occupational Standards. } \\
\text { A series of laboratory-scale experiments is being performed to } \\
\text { study VOC transport mechanisms in drums containing } \\
\text { simulated and actual wastes and to provide sufficient data to } \\
\text { develop and test the model. In addition, the VOC-adsorption } \\
\text { capacity and transport properties of carbon composite filters } \\
\text { normally used on waste drums are being measured. } \\
\text { (See \$10.1.5.1) }\end{array}$ & $\begin{array}{l}\text { Information describing the effectiveness of } \\
\text { waste packaging materials in limiting the } \\
\text { movement of VOCs and the VOC-adsorption } \\
\text { capacity and transport properties of carbon } \\
\text { composite filters will be used in predicting the } \\
\text { quantities of VOCs that will be emitted from } \\
\text { waste drums, once the drums are emplaced in } \\
\text { the WIPP underground. }\end{array}$ \\
\hline
\end{tabular}




\section{Appendix A: Regulatory Interpretations}

The following regulatory interpretations are used for assessing compliance of the Waste Isolation Pilot Plant (WIPP) with the long-term environmental standards set forth in 40 CFR 191 and 40 CFR \$268.6. The issues discussed below are those portions of the regulations that are contentious and/or subject to interpretation; they are presented to describe the Department of Energy's (DOE) approach to compliance in an effort to gain clarity from the regulating agencies. A substantial portion of the interpretations have been taken from the Regulatory Criteria Document (RCD), and the remaining are intended to describe the DOE's approach for WIPP site-specific compliance.

\section{Regulatory Interpretations Pertaining to 40 CFR 191}

1. In the context of Subpart A of the regulation, the site boundary is that point at which the general public may be exposed to releases resulting $\mathrm{m}$ management and storage activities. For the WIPP, the boundary is the perimeter of the 16-section area defined in the WIPP Land Withdrawal Act (LWA).

Ref.: 40 CFR $\$ 191.03(b), \$ 191.02$

2. The management of radioactive wastes will begin at the WIPP site when radioactive wastes are first received at the site.

Ref.: 40 CFR $\$ 191.02$

3. Individuals at the WIPP site are not considered to be "members of the public" when they are at the site. When they are not at the WIPP site, they are considered to be mernbers of the public.

Ref.: 40 CFR $\$ 191.02$

4. The WIPP facilicy's compliance with the dose limits of 40 CFR $\$ 191.03(\mathrm{~b})$ shall be evaluated for a member of the public in the general environment who resides at the site boundary (see interpretation \#1).

Ref.: 40 CFR \$191.03(b) 
5. Only the radioactive components of waste to be disposed of in the WIPP are subject to 40 CFR 191. The hazardous wastes, as defined in 40 CFR $\$ 260.10$ are subject to regulation under the provisions of RCRA.

Ref.: 40 CFR $\$ 191.01$

6. The disposal system is "any combination of engineered and natural barriers that isolate spent nuclear fuel or radioactive waste after disposal." For the purposes of the WIPP this will include the combination of the repository/shaft system and the controlled area. The repository/shaft system includes the underground workings, all emplaced materials, and the altered zones within the host rock resulting from construction of the underground workings and the shafts.

Ref.: 40 CFR \$191.12(a)

7. "Encapsulating or stabilizing matrix" includes boxes, drums, and/or other containers or packaging materials to inhibit waste from movement.

Ref.: 40 CFR $\$ 191.12(\mathrm{c})$

8. Backfill, if used, is a separate engineered feature and is part of the disposal system; backfill is not part of the waste form.

Ref.: 40 CFR $\$ 191.12$

9. Natural barriers are the geologic, hydrologic, geomechanical, and geochemical components of the disposal system that contribute to the capability of the system to meet the radionuclide release limits.

Ref.: 40 CFR \$191.14(d)

10. Engineered barriers are repository design features and engineered components that are intended to contribute to the performance of the disposal system. Engineered barriers may include, but are not limited to, backfill; drift, shaft, borehole, and panel plugs and seals; and waste form and packaging.

Ref.: 40 CFR \$191.14(d)

11. The natural and engineered barriers form a multiple barrier system designed to increase confidence that the performance requirements will be met.

Ref.: 40 CFR \$191.14(d) 
12. The DOE is the "implementing agency" (except for those specific implementation responsibilities granted to the Environmental Protection Agency (EPA) under the WIPP LWA) for the geologic disposal of defense-generated transuranic waste in the WIPP. The DOE 40 CFR 191 compliance determination will be made using a documented, decision-making process. The compliance decision will be made by the DOE Headquarters office prior to submittal of the certification application to the EPA.

Ref.: 40 CFR \$191.12(s)

13. The DOE will submit documentation to the EPA regarding the WIPP facility's compliance with 40 CFR 191 so that the EPA may certify whether or not the WIPP will comply with the final disposal requirements of 40 CFR 191.

\section{Ref.: WIPP LWA;}

14. "Events" are phenomena that occur instantaneously or within a relatively short time interval. "Processes" are phenomena that occur over a significant portion of the 10,000 years of regulatory concern.

Ref.: 40 CFR $\$ 191.12(q)$

15. The "reasonable expectation" standard is equivalent to the "reasonable degree of certainty" standard of 40 CFR \$268.6. It is a burden of proof greater than the "preponderance of the evidence" standard, but not as great as the "beyond a reasonable doubt" standard. The standard requires that reasonably trustworthy information and data be provided such that the totality of the facts and circumstances are sufficient, given the DOE's or the EPA's scientific and technical expertise, to warrant a "firm belief" that performance measures will be met. Quantification of these terms is not appropriate. Assessment of compliance to a "reasonable expectation" or a "reasonable degree of certainty" is, therefore, a qualitative assessment of the quantitative results.

The definition will pertain primarily to the adequacy and completeness of information upon which a compliance determination will be based. The adequacy and appropriateness of simulation modeling and associated assumptions and uncertainties are key to this definition. Uncertainties will be systematically evaluated. Since uncertainty will always exist in any analysis of events occurring in a 10,000-year 
timeframe, it is important that the implications of the uncertainties with regard to repository performance evaluations be understood.

Ref.: 40 CFR §191.13(a); 40 CFR §191.24(a)(1); 40 CFR 191, Appendix C; EPA, 1992a

16. Uncertainty analyses evaluate uncertainty in performance estimates that result both from the existence of alternative conceptual models and from the uncertainty about imprecisely known input variables.

Ref.: 40 CFR \$191.13(b); \$191.24(a)(1);40 CFR 191, Appendix C

17. Sensitivity analyses determine the contribution of individual input variables to the uncertainty in model predictions. Model input includes the parameters describing the physical system, the events and processes involved, and conceptualizations of the disposal system.

Ref.: 40 CFR \$268.6; EPA, 1992b

18. Compliance of the disposal system performance with regard to 40 CFR \$191.13(a)(1) and $\$ 191.13(a)(2)$ shall be evaluated by performing long-term predictions (i.e. computational models, analytical theories) that are supported by laboratory and field investigations as well as expert judgement where appropriate.

Ref.: 40 CFR §191.13(a); 40 CFR 191, Appendix C

19. All components of the geologic disposal system shall be considered when predicting the system performance unless it can be demonstrated that a component makes a negligible contribution to the overall system performance.

Ref.: 40 CFR $\$ 191.13 ; 40$ CFR 191, Appendix C

20. The results of performance assessments (PAs) shall, to the extent practicable, be presented in a single "'complementary cumulative distribution function' that indicates the probability of exceeding various levels of cumulative release."

Ref.: 40 CFR \$191.13; 40 CFR 191, Appendix C 
21. The PAs shall consider the likelihood and consequences of events and processes that may disturb the disposal system.

Ref.: 40 CFR $\$ 191.13 ; 40$ CFR 191, Appendix C.

22. The PAs will not consider processes and events "that are estimated to have less than one chance in 10,000 of occurring over 10,000 years."

Ref.: 40 CFR \$191.13; 40 CFR 191, Appendix C.

23. Other processes and events will not be included in performance simulations if it is demonstrated that the consequence does not significantly change the probability distribution of cumulative releases.

Ref.: 40 CFR $\$ 191.13 ; 40$ CFR 191, Appendix C.

24. Numerical predictions shall be supplemented with quantitative and qualitative information as appropriate in order to provide a sufficient basis for making a decision of compliance.

Ref.: 40 CFR \$191.13; 40 CFR 191, Appendix C.

25. The basis for advancing the argument that the geologic disposal system complies with 40 CFR $\$ 191.13(a)(1)$ and $\$ 191.13(a)(2)$ shall be documented. The record(s) shall include the quantitative and qualitative evidence that was used to prepare compliance calculations as well as supplementary information (e.g. evidence that supports the process models, parameter ranges, geometric conceptual model(s), hypotheses, simplifying assumptions used, and numerical models).

Ref.: 40 CFR $\$ 191.13 ; 40$ CFR 191, Appendix C.

26. A formal review process shall be conducted by the DOE to examine the record containing the basis for the PA analyses used to demonstrate compliance with 40 CFR \$191.13(a). The objective of the review is to establish whether the DOE has a reasonable expectation that the requirements will be met.

Ref.: 40 CFR \$191.13; 40 CFR 191, Appendix C.

27. Only those wastes that have been screened by the compliance analyses will be emplaced in the WIPP.

Ref.: 40 CFR §191.13; 40 CFR 191, Appendix C. 
28. New information relevant to the performance of the disposal system will be evaluated as appropriate, until the repository shafts are sealed.

Ref.: 40 CFR §191.13; 40 CFR 191, Appendix C.

29. The envelope of waste included in the compliance analyses shall be consistent with the range of waste characteristics accepted for disposal.

Ref.: 40 CFR \$191.13; 40 CFR 191, Appendix C.

30. Access control is any combination of barriers (such as fences and gates, for example) and guard patrols designed to limit access to the controlled area to authorized personnel and activities.

Ref.: 40 CFR §191.14(a)

31. Active institutional controls shall include those activities necessary to support postclosure monitoring (40 CFR \$191.14(b)), site reclamation and restoration, decontamination and decommissioning, and implementation of the passive institutional control program.

Ref.: 40 CFR $\$ 191.14(a)$

32. Active institutional controls shall not be considered to be effective for more than 100 years after shaft sealing in the PAs addressing 40 CFR $\$ 191.13($ a) requirements. Ref.: 40 CFR \$191.14(a)

33. Access control shall be maintained within the controlled area, during the period in which active institutional controls are in effect.

Ref.: 40 CFR $\$ 191.14(a)$

34. Active institutional controls extend to the surface and subsurface boundaries of the controlled area.

Ref.: 40 CFR \$191.14(a)

35. Substantial and detrimental deviations from the expected performance are deviations that would potentially alter the finding that there is a reasonable expectation that the disposal system will comply with 40 CFR \$191.13(a) requirements.

Ref.: 40 CFR 191, Appendix C 
36. The expected performance of the disposal system is the "predicted behavior" from the PA of the disposal system under undisturbed conditions.

Ref.: 40 CFR $\$ 191.15(a) ; 40$ CFR $\$ 191.24(a)(1)$

37. Predicted behavior of the disposal system means the performance of the disposal system calculated using the undisturbed performance scenario and the PA approach developed for $\$ 191.13(a)$.

38. The monitoring program shall be designed to collect information about the parameters used in the PA analyses of undisturbed disposal system performance.

Ref.: 40 CFR \$191.14(b)

39. The monitoring program shall be designed such that the monitoring methods employed do not significantly impact the performance of the disposal system. Ref.: 40 CFR \$191.14(b)

40. The monitoring program is intended to confirm that the disposal system, or key components of the system, is functioning as expected for a significant time period after closure through the period of active institutional control (e.g. 10's of years). Ref.: 40 CFR $\$ 191.14(\mathrm{~b})$

41. The monitoring methods will not impact the isolation capability of the site. For example, if remote sensors are installed in boreholes surrounding the disposal system, the boreholes should not create pathways for transport of contaminants from the repository to the accessible environment.

Ref.: 40 CFR \$191.14(b)

42. Monitoring systems shall be maintained for the duration of the Active Institutional Control period, to the extent practicable.

Ref.: 40 CFR \$191.14(b)

43. Although the post-closure monitoring requirement does not become effective until the shafts are sealed, confidence must be available prior to beginning operations, that the monitoring objectives can ultimately be achieved. Therefore, prior to beginning disposal operation, a plan describing the approach to developing and implementing a post-closure monitoring program will be prepared. At a minimum, the plan shall 
discuss 1) the methodology for identifying components to be monitored, 2) required research and development activities and schedules, and 3) PA integration with the monitoring program.

Ref.: 40 CFR \$191.14(b)

44. Passive institutional controls shall, to the extent practicable, be designed with the goal of eliminating the probability of inadvertent human intrusion for the 10,000 year period of repository performance. The PA should not be based on the assumption that intrusions are eliminated.

Ref.: 40 CFR $\$ 191.14(c), 40$ CFR 191, Appendix C

45. Marker systems, record-keeping systems, and other passive institutional controls shall be evaluated and tested during the Disposal Operations Phase, considering at a minimum, the durability of marker system components and messages, and the accessibility and ability to interpret the messages and records.

Ref.: 40 CFR \$191.14(c)

46. Results from the testing program for passive controls will be incorporated into the final design of the marker and records systems prior to closure of the repository.

Ref.: 40 CFR \$191.14(c)

47. The controlled area shall be identified by passive institutional controls that incorporate principles determined adequate and appropriate by expert judgement and by testing. Ref.: 40 CFR \$191.14(c)

48. Calculation of the maximum controlled area shall be based on the outer boundary of the location of the waste in the repository.

Ref.: 40 CFR $\$ 191.14(c)$

49. Performance of the disposal system shall be evaluated based on the projected contributions of both natural and engineered barriers.

Ref.: 40 CFR \$191.14(d) 
50. The engineered barrier system shall be designed to be physically and geochemically compatible with the natural barrier system so that interactions with the natural system do not compromise the ability of the repository to meet applicable release limits.

Ref.: 40 CFR \$191.14(d)

51. The characteristics and radionuclide content of the emplaced waste shall be considered when evaluating the contributions of the barriers to disposal system performance.

Ref.: 40 CFR \$191.14(d)

52. Site resource exploration and extraction potential shall be evaluated, and the results included in disposal system suitability assessments for compliance with 40 CFR \$191.13.

Ref.: 40 CFR $\$ 191.14(\mathrm{e})$

53. The use of terms such as "reasonable expectation of exploration" and "easily accessible resources" lead to the interpretation that the agency's intent is to evaluate resource potential based on current, or near-term future projections of resource value. Additionally, projections of resource value will be evaluated based on currently available technology. Both the historical record and reasonable expectations of future resource extraction and use will be considered.

Ref.: 40 CFR \$191.14(e)

54. Because the WIPP site was evaluated and selected prior to promulgation of 40 CFR 191 , compliance with the provisions of 40 CFR $\$ 1 \$ 1.14(\mathrm{e})$ may be demonstrated by documentation of the process used and its results.

Ref.: 40 CFR \$191.14(e)

55. With regard to the 40 CFR $\$ 191.14(f)$ requirement pertaining to the removal of waste, the EPA states (50 FR 38082) that "any current concept for a mined geologic repository meets this requirement without any additional procedures or design features." The provision is based on the presumption that the current technology that allowed the emplacement of the waste would also allow its removal subsequent to disposal regardless of the cost or impact of the removal. Consequently, the removal provision does not require specific design features or additional procedures to support the capability to remove waste. EPA's intent was to preclude the use of certain disposal concepts other than the geologic repository. 
Ref.: 40 CFR $\$ 191.14(f)$

56. Annual committed effective dose is calculated in accordance with the method described in Appendix B of the standard.

Ref.: 40 CFR $\$ 191.15(b)$

57. Potential pathways from the disposal system to humans include pathways through geohydrologic media from the controlled area to the accessible environment, and then through terrestrial, aquatic, atmospheric, or biological media in the accessible environment.

Ref.: 40 CFR $\$ 191.15(a)$

58. The PA model(s) shall be used to estimate the annual committed effective dose from the disposal system to any member of the public in the accessible environment for 10,000 years after disposal.

Ref.: 40 CFR 191, Appendix C.

59. Assessments of undisturbed performance shall not consider water wells within the boundary of the controlled area. Wells at, and within a reasonable area of the boundary shall be considered.

Ref.: 40 CFR 191, Appendix C.

60. The PA model(s) shall consider all potential pathways associated with undisturbed performance including the assumption that individuals consume two liters per day of drinking water from sources of groundwater that are present outside the controlled area.

Ref.: 40 CFR $\$ 191.24(a)(1)$

61. Calculations of releases for undisturbed performance analyses will use the approach developed for calculating releases for 40 CFR \$191.13(a), eliminating human intrusion and unlikely natural events from the analysis.

62. A review process similar to that to be performed for 40 CFR \$191.13(b) will be performed in order to demonstrate a "reasonable expectation" that the Individual Protection Requirements under 40 CFR $\$ 191.15$ will be met. 
63. Human intrusion scenarios that will be evaluated are "those realistic possibilities that may be usefully mitigated by repository design, site selection, or use of passive controls (although passive institutional controls should not be assumed to completely rule out the possibility of intrusion)." Therefore, intermittent, inadvertent intrusion by exploratory drilling for resources (other than any resources provided by the disposal system itself) is the most severe intrusion scenario that must be assumed by the DOE for the WIPP.

Ref.: 40 CFR 191, Appendix C

64. Performance assessment shall be based on the assumption "that passive institutional controls or the intruders' own exploratory procedures are adequate for the intruders to soon detect, or be warned of, the incompatibility of the area with their activities." "Soon detect" shall be defined based on reasonable interpretations of drilling practices and expert judgement. "Soon detect" cannot be strictly interpreted based on current drilling practices since currently, drillers do not worry about encountering underground waste repositories during their operations. Once such repositories are in place, exploratory drillers may become aware of their existence in areas where they are looking for resources. Any resource extraction, such as oil and gas extraction, as well as potash mining, is not considered within the controlled area due to the fact that resource extraction, in all forms is a deliberate process and any resultant intrusion would not be inadvertent process.

Ref.: 40 CFR 191, Appendix C.

65. The likelihood of exploratory drilling resulting in inadvertent and intermittent intrusion "need not be taken to be greater than 30 boreholes per square kilometer of repository area per 10,000 years." Based on a waste-emplacement region (for both CH and RH TRU wastes) of $0.126 \mathrm{~km}^{2}$, this limit is equivalent to a maximum value for drilling frequency at the WIPP of 3.8 holes in 10,000 years. Strict enforcement and voluntary compliance with regulations constraining drilling practices is assumed. Ref.: 40 CFR 191, Appendix C.

66. The consequences of "inadvertent drilling need not be assumed to be more severe than: 1) direct release to the land surface of all the ground water in the repository horizon that would promptly flow through the newly created borehole to the surface due to natural lithostatic pressure - or (if pumping would be required to raise water to the surface) release of $200 \mathrm{~m}^{3}$ of ground water pumped to the surface if that much 
water is readily available to be pumped; and 2) creation of a ground water flow path with a permeability typical of a borehole filled by the soil or gravel that would normally settle into an open hole over time - not the permeability of a carefully sealed borehole." For the purposes of the WIPP, the properties of the intrusion borehole will be similar to plugged and abandoned holes in the region of the facility (drilled through the Salado Formation).

Ref.: 40 CFR 191, Appendix C. 


\section{Regulatory Interpretations Pertaining to 40 CFR \$268.6}

1. The WIPP underground facilities constitute the waste management unit subject to the 40 CFR \$268.6 no-migration requirements.

Ref.: EPA, 1990a

2. The hazardous waste management unit for the WIPP is the mined portion of the Salado Formation.

Ref.: EPA, 1990a

3. The unit boundary for the WIPP is that portion of the Salado Formation that is within the land withdrawal area.

Ref.: EPA, 1990a

4. "Migration of hazardous constituents" means the movement beyond the unit boundary of hazardous constituents in concentrations exceeding applicable media-specific EPAapproved health-based levels for ground water, surface water, soil, and air.

Ref.: EPA, 1990a; 40 CFR \$268.6

5. "Hazardous constituents" or "constituents" are those constituents listed under Appendix VIII to 40 CFR 261.

Ref.: EPA, 1990a; 40 CFR $\$ 268.2(b)$

6. The emplacement of hazardous waste in the WIPP is "land disposal" as defined by 40 CFR 8268.2(c).

Ref.: EPA, 1990a; 40 CFR $\$ 268.2(c)$

7. The EPA Office of Solid Waste and Emergency Response in Washington, D.C. is the organization responsible for acting on the DOE's petition for a no-migration variance for the WIPP.

Ref.: EPA, 1990a

8. The "reasonable degree of certainty" standard is equivalent to the "reasonable expectation" standard of 40 CFR 191. It is a burden of proof greater than the "preponderance of the evidence" standard, but not as great as the "beyond a reasonable doubt" standard. The standard requires that reasonably trustworthy 
information and data be provided such that the totality of the facts and circumstances are sufficient, given the EPA's scientific and technical expertise, to warrant a "firm belief" that performance measures will be met. Quantification of these terms is not appropriate. Assessment of compliance to a "reasonable expectation" or a "reasonable degree of certainty" is, therefore, a qualitative assessment of the quantitative results.

The definition will pertain primarily to the adequacy and completeness of information provided to the regulator by the DOE which will be the basis for an EPA determination. The adequacy and appropriateness of simulation modeling and associated assumptions and uncertainties are key to this definition. Uncertainties will be systematically evaluated. Since uncertainty will always exist in any analysis predicted, potential of events occurring in a 10,000-year timeframe, it is important that the implications of the uncertainties with regard to repository performance evaluations be understood.

Ref.: 40 CFR \$268.6(a); EPA, 1992a

9. The demonstration of no-migration shall include information on the geologic conditions at the site and simulation modeling of the expected behavior of the repository, including the migration of hazardous constituents. The modeling shall predict the behavior of the repository from the time of waste emplacement to 10,000 years after closure.

Ref.: EPA, 1992b; 40 CFR \$268.6

10. In support of the modeling demonstration, quality assurance and quality control information shall be provided in the No-Migration Variance Petition (NMVP) which will include a demonstration of the adequacy of the models for the intended purpose. For the purposes of satisfying the requirements of $\$ 268.6(\mathrm{~b})(3)$, this demonstration of adequacy will show that the models are appropriate for the WIPP-specific waste and the WIPP site.

Ref.: EPA, 1992b; 40 CFR \$268.6(b)(4)

11. A rationale shall be developed and documented for the selection of the hazardous constituents to be the subject of the modeling demonstration. The rationale shall be based on characterization of hazardous constituents with respect to variables most likely to influence the health or environmental hazards associated with a given 
constituent. These include factors influencing migration from the unit such as source concentration and physical characteristics, and the relative persistence and toxicities of the constituents.

Ref.: EPA, 1992b

12. Separate sets of indicator chemicals shall be used to determine migration potential by the air and soil pathways appropriate for assessment of risk during the operations and post-closure phases, respectively.

Ref.: EPA, 1992b; 40 CFR $\$ 268.6(a)$ and (b)

13. "For as long as the waste remains hazardous" is interpreted as meaning a 10,000-year modeling demonstration of the predicted performance of the repository. This interpretation is consistent with EPA regulations regarding the underground injection of hazardous wastes [40 CFR $\$ 148.20(a)(1)(i)$ ] and the disposal of radioactive waste [(40 CFR \$191.13(a)].

Ref:: EPA, 1992b

14. The use of permanent markers shall be considered in the qualitative evaluation of the likelihood of the occurrence of human intrusion. A demonstration that permanent markers have a high probability of effectively serving their intended purpose over a 10,000-year time period will support the qualitative judgement that the likelihood of inadvertent human intrusion is sufficiently low so that the analysis of the behavior of the repository need not be based on the assumption that human intrusion occurs.

If the occurrence of human intrusion is qualitatively judged to be reasonably unlikely, the modeling demonstration shall be based on the assumption that human intrusion is not a reasonable expectation. The qualitative judgement of the likelihood of human intrusion shall be based primarily on an evaluation of the expected effectiveness of permanent markers.

Ref.: EPA, 1990a

15. Passive institutional controls shall be designed to persist and be effective for 10,000 years.

16. Models used to support a NMVP shall be validated (to the extent practicable) and verified. Model verification is the process of demonstrating that a computational 
model (computer code) correctly implements the mathematical and numerical procedures on which it is based. The process is intended to demonstrate that the numerical values produced by one or a group of computational procedures correspond to the mathematical formulas on which they are based. The process of model validation will involve an aitempt (to the extent practicable) to demonstrate that a numerical model is adequate and appropriate for the problem being addressed, that it was logically developed and is supported (to the extent practicable) by observational data, and the limitations of the model are well understood. Model validation can be performed for models used for computational (short-term) determinations; however, it is impossible to provide direct validation for conceptual models designed to predict processes and events that may occur over a 10,000-year time period. This notwithstanding, the adequacy of these models for the intended purpose will be demonstrated.

Ref.: EPA, 1992b

17. Human intrusion shall be evaluated qualitatively by considering the likelihood of the intrusion event and the predicted effectiveness of imposed controls designed to make such intrusions unlikely.

Ref.: EPA, 1990a

18. The conceptual models used for the no-migration demonstration shall not be inconsistent with those used for the 40 CFR 191 PA for their intended use.

19. EPA-approved health-based levels shall be identified for each of the selected constituents. For many hazardous constituents in various environmental media, EPAapproved health-based limits have been defined by the EPA. In cases where an EPAapproved health-based level does not exist for a constituent of interest, an appropriate level shall be proposed.

Ref.: EPA, 1992b

20. If health-based criteria do not exist for a constituent, the DOE will propose a healthbased level using the toxicity testing guidelines contained in 40 CFR Parts 797 and 798 and the Agency guidelines for assessing health risks (51 FR 33992, 34006, 34014 , and 34082) or equivalent. Toxicity of the hazardous constituents shall be ranked based on EPA Reference Doses for noncarcinogens and Slope Factors for carcinogens or equivalent. 
If no health-based level can be determined for a constituent, that constituent must not exceed analytical detection limits. Use of the analytical detection limits should be based on methodology prescribed in "Test Methods for Solid Waste, Physical/Chemical Methods," EPA Publication SW-846, Third Edition, or equivalent, with the lowest possible detection level indicated therein for each hazardous constituent. If health-based levels are below analytical detection limits for a constituent, the DOE must demonstrate, using modeling, that the health-based levels will be met.

Ref.: EPA, 1992b

21. Some of the hazardous constituents to be emplaced in the WIPP, such as lead, will not degrade with time and will remain hazardous for time periods far exceeding the predictive capabilities of models. For this reason, the EPA states in its Federal Register notice of April 6, 1990 that it believes "that a final determination concerning the WIPP's conformance with the no-migration standard over the long term must rest on the Agency's professional judgement regarding the containment properties of the Salado formation within the vicinity of the WIPP, and on any transformation or immobilization of wastes within the unit."

Ref.: EPA, 1990b

22. The WIPP NMVP shall evaluate long-term issues including: extent and effects of gas generation; effects of any fluid inflow into the repository and quantification of inflow; influence of the "disturbed rock zone" around the mined repository; waste container corrosion; generation of flammable gas and mitigation measures; and the adequacy of waste characte-ization information.

23. The specific wastes to be emplaced in the geologic repository shall be identified in the NMVP. The NMVP shall describe all wastes from all generator sites covered by the petition.

Ref.: EPA, 1992b; 40 CFR \$268.6(b)(2)

24. Waste analysis will include sampling and analyses and the use of knowledge of materials and processes generating the waste.

25. Background air, soil and water quality shall be characterized for underground and surface locations prior to waste receipt to establish a basis for evaluating monitoring 
results. Background air, soil and water quality will be determined at the time the NMVP is made using the most appropriate environmental monitoring data/information available.

Ref.: 40 CFR $\$ 268.6(c)$

26. The NMVP shall include a detailed description of the regional and site-specific surface water and ground water hydrology.

Ref.: 40 CFR \$268.6(a)

27. With regard to the WIPP, partial closure is interpreted to mean the sealing or bulkheading of a waste emplacement room or an underground access way prior to emplacement of shaft seals.

28. Sufficient information will be provided in the NMVP to justify the design of the monitoring program and to demonstrate that monitoring locations will be suitable to detect migration at the earliest practicable time.

Ref.: 40 CFR \$268.6(c)

29. For NMVP transport analyses, four potential environmental release pathways will be considered: air, ground water, surface water, and soil.

30. The quality of data sets important to the demonstration of compliance with the nomigration standard shall be documented. The use of these data sets will be confirmed through interactions with the regulatory agencies. They are likely to include, among others, those generated through the WIPP Environmental Monitoring Program, the Radiological Baseline Program, the VOC Monitoring Program, geological and geotechnical characterization programs, and experimental programs.

Ref.: 40 CFR \$268.6(b)(4)

31. To the extent necessary and practicable, the simulation model results for hazardous constituent migration shall be compared with actual field measurements to demonstrate that the modeling results are representative of the actual physical system, there is a high degree of correlation between the model and measured data, and there are no computational errors in the computer code.

Ref.: U.S. EPA, 1992; 40 CFR $\$ 268.6(b)(3)$ 
32. The selection process for modeling assumptions for the purposes of a no-migration demonstration will include the test of reasonableness, i.e., when assumptions involve a high degree of uncertainty, they will be conservative and tend toward overestimating rather than underestimating the potential for migration to occur.

Ref.: EPA, 1992b

33. Analyses of the airborne migration of hazardous constituents from the WIPP during operations (including closure) will be performed by evaluating quantities and concentrations of volatile organic compounds available for release, potential transport mechanisms and pathways, and the flow paths and flow rates of background ventilation air in the underground. Airborne dispersion modeling for the risk assessment portion of the NMVP will use the UNAMAP 6 version of the Industrial Source Complex (ISC) model (most current version), or equivalent.

34. A quality assurance and quality control plan that addresses all aspects of the NMVP will be prepared. The plan will address: waste and environmental monitoring, sampling, and analysis activities; field measurements of the facility setting, such as geophysical exploration, ground water monitoring, weather observations, and topographic mapping; confirmation of computations, codes, models, and methods used in calculating critical facility parameters; control of construction activities to ensure compliance with design specifications, where relevant to the "no-migration" demonstration; and evaluation of the integrity of construction materials, where relevant to the demonstration. The quality assurance and quality control plan shall be consistent with and abide by the Carlsbad Area Office (CAO) Quality Assurance Requirements Description (QARD), as defined in Chapter 7.

Ref.: EPA, 1992b; 40 CFR \$268.6(b)(4)

35. Vadose zone or ground water monitoring will not be conducted during the PostDecommissioning Phase because the results of such monitoring would not be meaningful. The location of such monitoring systems within the unit boundary could also potentially create a pathway for the migration of hazardous constituents.

36. The quality of previously acquired data, which will be used to support the WIPP NMVP, will be assessed relevant to meeting quality assurance requirements established for the petition. 
37. During the partial closure period, no monitoring specific to sealed rooms will be conducted. Any gas emissions from sealed rooms will be detected by a VOC monitoring system designed to monitor emissions from waste containers in unsealed rooms.

38. The impact of predictable future events that can reasonably be expected to contribute to inadequate waste isolation will be evaluated. It shall be demonstrated to a reasonable degree of certainty whether predictable future events will result in the migration of hazardous constituents beyond the unit boundary in concentrations exceeding EPA-approved, health-based limits. Predictable future events are earthquakes, floods, severe storm events, droughts, meteorite impact, tornadoes, range fires, climatic fluctuations, and geologic activity. The potential for such natural events occurring during the period in which the wastes remain hazardous shall be evaluated. For natural events with a reasonable probability of occurring during that period, the potential impacts and consequences with regard to the ability of the facility to isolate wastes from the environment shall be estimated. These conditions are equivalent to the conditions under 40 CFR $\$ 191.15$.

Ref.: EPA, 1992b; 40 CFR $\$ 268.6(b)(5)$

39. The DOE will prepare a plan for monitoring for the migration of hazardous constituents. The design of the plan will be justified. The plan will demonstrate that monitoring locations are appropriate, and monitored at a sufficient frequency to detect migration at the earliest practicable time. "Practicable" means available and capable of being done after taking into consideration cost, existing technology, and logistics in light of overall project purposes.

Ref.: EPA, 1992b; 40 CFR §268.6(a)(4); 40 CFR §268.6(c)

40. Long-term monitoring methods will be designed and performed only in a manner that will not contribute to the degradation of the waste isolation capabilities of the repository.

41. The NMVP shall state the maximum volume of restricted waste intended to be emplaced in the facility. Only the quantities of waste specified in the NMVP shall be accepted.

Ref.: EPA, 1992b 
42. Polychlorinated biphenyls are those halogenated organic compounds defined in accordance with 40 CFR 761.3. Waste containing concentrations of polychlorinated biphenyls at concentrations equal to or greater than 500 parts per million will not be accepted.

Ref.: 40 CFR $\$ 268.6(n)$

43. No liquid hazardous wastes, except for residual quantities, will be accepted for emplacement. 


\section{REFERENCES}

U. S. Environmental Protection Agency (EPA), 1992a. No-Migration Variance from Land Disposal Restrictions for Exxon Company. U.S.A. Billings, Montana. New South Land Treatment Unit, Federal Register, Vol. 58, No. 142, Office of Solid Waste, July 27, 1993.

U. S. Environmental Protection Agency (EPA), 1992. "No Migration" Variances to the Hazardous Waste Land Disposal Prohibitions: A Guidance Manual for Petitioners, Draft, EPA530-R-92-023, Office of Solid Waste, Washington, D.C.

U. S. Environmental Protection Agency (EPA), 1990a. Conditional No-Migration Determination for the Department of Energy Waste Isolation Pilot Plant (WIPP), Federal Register, Vol. 55, No. 220, November 14, 1990, Office of Solid Waste, Washington, D.C.

U. S. Environmental Protection Agency (EPA), 1990b. Notice Proposing to Grant a Conditional Variance to the Department of Energy Waste Isolation Pilot Plant (WIPP) from Land Disposal Restrictions, Federal Register, Vol. 55, No. 67, April 6, 1990, Office of Solid Waste, Washington, D.C. 


\section{ACRONYMS}

AEA

ANL-E

ANSI

AQCR

ARMs

ASME

ASQC

BLM

BSEP

BIR

C\&C

CAA

CAAA

CAM

CAMCON

CAO

CCDF

CERCLA

CFR

$\mathrm{CH}$

CSR

CWA

DMG

DOE

DOL

DOI

DOT

DQO

DRZ
Atomic Energy Act

Argonne National Laboratory-East

American National Standards Institute

Air Quality Control Regulation

Area Radiation Monitors

American Society of Mechanical Engineers

American Society for Quality Control

Bureau of Land Management

Brine Sampling and Evaluation Program

Baseline Inventory Report

Consultation and Cooperation

Clean Air Act

Clean Air Act Amendments

Continuous Air Monitors

Compliance Assessment Methodology Controller

Carlsbad Area Office (DOE)

Complementary Cumulative Distribution Function

Comprehensive Environmental Response, Compensation, and Liability Act

Code of Federal Regulations

Contact Handled

Compliance Status Report

Clean Water Act

Delaware Mountain Group

U.S. Department of Energy

U.S. Department of Labor

U.S. Department of Interior

U.S. Department of Transportation

Data Quality Objective

Disturbed Rock Zone 
EATF Engineeered Alternative Task Force

EDO

Environmental Data Operation

EEG

Environmental Evaluation Group

EFB

Exhaust Filter Building

EM

EMP

Office of Environmental Restoration and Waste Management (DOE)

EO

Environmental Monitoring Plan

EPA

Executive Order

EPCRA

Environmental Protection Agency

EPP

Emergency Planning and Community Right-to-Know Act

ESAAB

Experimental Program Plan

Energy Systems Acquisition Advisory Board (DOE)

FAS

Fixed Air Samplers

FEIS

Final Environmental Impact Statement

FFCA

Federal Facillities Compliance Act

FIFRA

Federal Insecticide, Fungicide, and Rodenticide Act

FLPMA

Federal Land Policy and Management Act

FPZ

Fracture Process Zone

FSAR

Final Safety Analysis Report

HAPs

HEPA

HMTA

HR

HSWA

HWMR

IDB

IDC

IMWIR

INEL
Hazardous Air Pollutants

High Efficiency Particulate Air

Hazardous Materials Transportation Act

Handford Reservation

Hazardous and Solid Waste Amendments

Hazardous Waste Management Regulations

Integrated Data Base

Item Description Code

Interim Mixed Waste Inventory Report

Idaho National Engineering Laboratory 


\begin{tabular}{|c|c|}
\hline LANL & Los Alamos National Laboratory \\
\hline LDR & Land Disposal Restrictions \\
\hline LHS & Latin Hypercube Sampling \\
\hline LLNL & Lawrence Livermore National Laboratory \\
\hline LWA & Land Withdrawal Act \\
\hline MB & Marker Bed \\
\hline MOU & Memorandum of Understanding \\
\hline MSHA & Mine and Safety Health Administration \\
\hline NAAQS & National Ambient Air Quality Standards \\
\hline NAS & National Academy of Sciences \\
\hline NEC & Nuclear Energy Commission \\
\hline NEPA & National Environmental Policy Act \\
\hline NES & Nonradiological Environmental Surveillance \\
\hline NESHAPs & National Emission Standards for Hazardous Air Pollutants \\
\hline NHPA & National Historic Preservation Act \\
\hline NMD & No-Migration Determination \\
\hline NMED & New Mexico Environmental Department \\
\hline NMVP & No-Migration Variance Petition \\
\hline NOI & Notice of Intent \\
\hline NPDES & National Pollutant Discharge Elimination System \\
\hline NQA & Nuclear Quality Assurance \\
\hline NRC & Nuclear Regulatory Commission \\
\hline NTS & Nevada Test Site \\
\hline NWPA & Nuclear Waste Policy Act \\
\hline OMP & Occupational Monitoring Plan \\
\hline ORNL & Oak Ridge National Laboratories \\
\hline OSHA & Occupational Safety and Health Administration \\
\hline PA & Performance Assessment \\
\hline PCB & Polychorinated Biphenyl \\
\hline PDP & Performance Demonstration Program \\
\hline
\end{tabular}


QA

QC

QAMS

QAPD

QAPP

QAPjP

QARD

QMP

RBP

RCD

RCRA

RCSMP

RES

RFP

RH

ROD

RTR

SARA

SDWA

SEIS

SHPO

SNL

SOP

SPCC

SPDV

SRS

SWPPP

SWB

TCLP

TDS

TLV

TRANSCOM
Quality Assurance

Quality Control

Quality Assurance Monitoring System

Quality Assurance Program Description

Quality Assurance Program Plan

Quality Assurance Project Plan

Quality Assurance Requirements and Description

Quality Management Plan

Radiological Baseline Program

Regulatory Criteria Document

Resource Conservation and Recovery Act

Regulatory Compliance Strategy and Management Plan

Radiological Environmental Surveillance

Rocky Flats Plant

Remote Handled

Record of Decision

Real-Time Radiography

Superfund Amendments and Reauthorization Act

Safe Drinking Water Act

Supplement Environmental Impact Statement

State Historic Preservation Officer

Sandia National Laboratories

Standard Operating Procedure

Spill Prevention, Control, and Countermeasures

Site and Preliminary Design Validation

Savannah River Site

Storm Water Pollution Prevention Plan

Standard Waste Box

Toxicity Characteristic Leaching Procedure

Total Dissolved Solids

Threshold Limit Values

Transportation Tracking and Communications System 


$\begin{array}{ll}\text { TRU } & \text { Transuranic } \\ \text { TRUPACT } & \begin{array}{l}\text { Transuranic Package Transporter } \\ \text { Toxic Substances Control Act }\end{array} \\ \text { UIC } & \text { Underground Injection Control } \\ \text { USDW } & \text { Underground Source of Drinking Water } \\ \text { USGS } & \text { U.S. Geological Survey } \\ \text { UST } & \text { Underground Storage Tanks } \\ \text { USTR } & \text { Underground Storage Tanks Regulations } \\ & \\ \text { VOC } & \text { Volatile Organic Compound } \\ \text { WAC } & \text { Waste Acceptance Criteria } \\ \text { WACCC } & \text { Waste Acceptance Criteria Certification Committee } \\ \text { WCPP } & \text { Waste Characterization Program Plan } \\ \text { WHB } & \text { Waste Handling Building } \\ \text { WIPP } & \text { Waste Isolation Pilot Plant } \\ \text { WWIS } & \text { WIPP Waste Information System }\end{array}$




\section{MODEL CODES AND PARAMETERS}

BRAGFLO

CCDFPERM

CULCLIM

CULTRFLD

CUTTINGS

GENII-S

GRASP-INV

GRCORH

GRCORHF

GRCORI

GRMICH

GRMICHF

GRMICI

MBPERM

PANEL

SALPERM

SALPOR

SANCHO

SECO-FLOW

SECOTP

SECO-TRANSPORT

STAFF2D

TZPOR 
THIS PAGE

\title{
INTENTIONALLY LEFT
}

\author{
BLANK
}




\section{Glossary of Terms}

Accessible Environment

Actinide Source Term

Adsorption

Alternative Conceptual Model(s)

Alternative Container

Materials

Anhydrite

Aquifer

Backfill
"1) [T] he atmosphere, 2) land surfaces, 3) surface waters, 4) oceans, and 5) all of the lithosphere that is beyond the controlled area" (40 CFR \$191.12[k]).

The fraction of the total radionuclide inventory of a disposal room or repository that can be mobilized for transport to the accessible environment.

1) Bonding, frequently ionic, of a substance to soil or some other medium. A substance is said to be adsorbed if the concentration in the boundary region of a soil particle is greater than in the interior of the continuous phase. 2) Adherence of gas molecules, or of ions or molecules in solution, to the surface of solids with which they are in contact.

An alternative set of assumptions that describe the same system for the same purpose and are consistent with the existing information.

Container materials, other than mild steel, that reduce and/or eliminate gas generation from corrosion in the range of expected Waste Isolation Pilot Plant environments.

A mineral consisting of anhydrous calcium sulfate $\left(\mathrm{CaSO}_{4}\right)$. It is gypsum without water but is denser, harder, and less soluble.

A body of rock that is sufficiently permeable to conduct groundwater and yield significant quantities of groundwater to wells and springs.

Material placed around the waste containers, filling the open space in the disposal room. 
Barrier

Base Case

Bell Canyon Formation

Bentonite

Borehole

Brine

Brine Pocket
"[A]ny material or structure that prevents or substantially delays movement of water and/or radionuclides toward the accessible environment. For example, a barrier may be a geologic structure, a canister, a waste form with physical and chemical characteristics that significantly decrease the mobility of radionuclides, or a material placed over and around waste, provided that the material or structure substantially delays movement of water or radionuclides" (40 CFR \$191.12[d]). Barriers also prevent or delay the movement of hazardous constituents.

The base case for the Waste Isolation Pilot Plant performance assessment is the behavior of the repository in the absence of human intrusion. Also called the "undisturbed performance" of the repository.

A sequence of rock strata that form the uppermost formation of the Delaware Mountain Group (Early Permian).

A commercial term applied to expansive clay materials containing montmorillonite (smectite) as the essential mineral.

1) A hole drilled from the surface for purposes of geologic or hydrologic testing, injection, or exploration for resources; sometimes referred to as a drillhoie. 2) A manmade hole in the wall, floor, or ceiling of a subsurface room used for verifying geology, making observations, or emplacing canisters of remotehandled transuranic waste.

Saline water containing $\mathrm{Ca}, \mathrm{Na}, \mathrm{K}, \mathrm{Cl}$, and minor amounts of other elements located in deep sedimentary basins.

See brine reservoir. 
Brine Reservoir

Buffered Humid

Conditions

Calibrate

Cavings

Certifier

Chemical Source

Term

Colloidal Solution
A volume of brine of limited extent trapped within fractures and/or intergranular pore space of a host rock and usually pressurized relative to normal formation fluids. Such pockets may exist under various conditions of stress and solute concentration. Pressurized brine pockets have been observed in the Castile Formation.

Under long-term conditions, the absolute (and relative) humidities within the Waste Isolation Pilot Plant are expected to be buffered by the activity of water in adjacent portions of the Salado Formation.

To vary parameters of an applied computational model within a reasonable range until differences between observed data and computed values are minimized.

During exploratory drilling, waste that erodes from the borehole wall in response to the upward-flowing drilling fluid within the annulus formed by the drill pipe and the borehole wall.

In the context of 40 CFR 19i, the "certifier" is the U.S. Environmental Protection Agency which must certify whether the Department of Energy has demonstrated that the Waste Isolation Pilot Plant is in compliance with the requirements of the standard.

The potentially mobile fraction of the hazardous constituents inventory that could be transported beyond the unit boundary. Hazardous constituents may be mobilized as volatile organic compound emissions mixed with carrier gases produced by microbial degradation, corrosion of metals, and/or radiolysis.

A liquid colloidal suspension is often referred to as a solution. Since colloidal particles are larger than molecules, it is technically incorrect to call such "dispersions" solutions; however, this term is used widely in the literature. 
Complementary Cumulative 1) A graphical representation of the probability of exceeding Distribution Function the radionuclide release limits specified in 40 CFR 191 (ordinate) compared to the consequences of exceeding the limits (abscissa). The consequence measure for releases, as defined by the Containment Requirements of 40 CFR 191, is the normalized sum of releases of individual radionuclides.

Compliance Evaluation The process of assessing the regulatory compliance of a mined geologic waste repository. 40 CFR 191 and 40 CFR \$268.6 require such evaluations be made to demonstrate that prescribed performance measures will be achieved. These regulations also require a reasonable degree of certainty/reasonable assurance in the compliance evaluation and subsequent determinations.

Computational Model

The computational model is the implementation of the mathematical model. The implementation may be through analytical or numerical means. Often the analytical solution is numerically evaluated (e.g., numerical integration or evaluation of complex functions); hence, both solution techniques are typically coded on the computer. Consequently, the computational model is often called a computer model.

Computer Model A computer code to implement a corresponding mathematical model either by evaluating an analytical solution or by using a numerical technique.

Conceptual Model

A set of assumptions, usually qualitative, used to describe and represent a system for some analytical purpose. For a physical system, these assumptions address the system's geometry and dimensionality, initial and boundary conditions, time dependence, material properties, internal processes, and any other characteristics relevant to its behavior. The assumptions should be consistent with one another and with the known properties of the system within the context of its intended analytical purpose. 
Conditional Distribution

Function

Confirmation

Consultation and

Cooperation

Agreement

Contact-Handled

Waste
A summary representation of risk. A display of information pertaining to events that may occur, the likelihood of their occurrence, and the consequences of their occurrence. Families of conditional distribution functions are used to display complementary cumulative distribution functions and can be used to infer the relative accuracy of the complementary cumulative distribution function.

For the purposes of this document, a term used to indicate support or establishment of certainty and/or validity of models used in reference to specific performance issues of the repository over any specific timeframe of interest. In general, laboratory and field experiments at the Waste Isolation Pilot Plant and elsewhere are conducted to provide data in support of this type of activity, such as for the gas generation model. Confirmation is used in a mechanistic sense and is not intended to have specific legal implications (see validation).

An agreement that affirms the intent of the Secretary of Energy to consult and cooperate with the State of New Mexico with respect to State public health and safety concerns. The term "Agreement" means the July 1, 1981, Agreement for Consultation and Cooperation, as amended by the November 30 , 1984, "First Modification," the August 4, 1987, "Second Modification," and the March 22, 1988, modification to the Working Agreement.

Transuranic waste that has a measured radiation dose rate at the container surface of 200 millirems per hour or less and can be safely handled without special equipment when placed in containers. 
Controlled Area

Creep

Creep Closure

Cuttings

Decommissioning

Decommissioning Phase

Desaturate
The controlled area means "1) a surface location, to be identified by passive institutional controls, that encompasses no more than 100 square $\mathrm{km}$ and extends horizontally no more than five $\mathrm{km}$ in any direction from the outer boundary of the original location of the radioactive wastes in a disposal system; and 2) the subsurface underlying such a surface location" (40 CFR $\$ 191.12[\mathrm{~g}])$.

A very slow, usually continuous, time-dependent movement of soil or rock; refers to the geologic phenomenon experienced as the gradual flow of salt under high compressive loading.

Closure of underground openings, especially openings in salt, by plastic flow of the surrounding rock under lithostatic pressure.

During exploratory drilling, waste contained in the cylindrical volume created by the cutting action of the drill bit through the waste. This volume is equal to the cross-sectional area of the drill bit multiplied by the repository thickness.

Actions taken upon abandonment of the repository to reduce potential environmental, health, and safety impacts, including repository sealing as well as activities to stabilize, reduce, or remove radioactive materials or demolish surface structures.

The term "decommissioning phase" means the period of time beginning with the end of the disposal phase and ending when all shafts at the Waste Isolation Pilot Plant repository have been backfilled and sealed.

To remove liquid from a material to reduce the degree of saturation. If all the liquid is removed from pores and cracks, the material is said to be completely dried. 
Disposal

Disposal Facility

Disposal Phase

Disposal Room

Disposal System

Disturbed Rock Zone

Dose
The term "disposal" means permanent isolation of transuranic waste from the accessible environment with no intent of recovery, whether or not such isolation permits the recovery of such waste. Disposal of waste in a mined geologic repository occurs when the waste has been emplaced and all the shafts to the repository are sealed.

A facility or part of a facility into which hazardous waste is intentionally placed and in which hazardous waste will remain after closure.

The term "disposal phase" means the period of time during which transuranic waste is disposed of at the Waste Isolation Pilot Plant, beginning with the initial emplacement of transuranic waste underground for disposal and ending when the last container of transuranic waste is emplaced underground for disposal.

An excavated cavity in the Waste Isolation Pilot Plant underground in which transuranic waste will be emplaced during disposal operations.

The disposal system is any combination of engineered and natural barriers that isolate transuranic waste after disposal. For the purposes of the Waste Isolation Pilot Plant, this will include the combination of the repository/shaft system and the controlled area.

That portion of the geologic barrier of which the physical and/or chemical properties may have changed significantly as a result of underground construction activities.

A general term indicating the amount of energy adsorbed per unit mass from incident radiation. 
Dose Equivalent

Drift

Emplacement

Engineered Barriers

Event

Federal Facilities

Compliance Act

Flowpath
The product of absorbed dose and modifying factors that take into account the biological effect of the absorbed dose. While dose includes only physical factors, dose equivalent includes both physical and biological factors and provides a radiationprotection scale applicable to all types of radiation. Units are rem for individual and person-rem for a population group.

A horizontal passageway in a mine.

At the Waste Isolation Pilot Plant, the placing of radioactive wastes in the repository.

Backfill, seals, and any other man-made barrier components of the disposal system.

A phenomenon that occurs instantaneously or within a short time interval relative to the timeframe of interest.

An amendment, promulgated in 1992, to the Solid Waste Disposal Act. Title I of the act grants the U.S. Environmental Protection Agency administrative enforcement authority against any department, agency, or instrumentality of the executive, legislative, or judicial branch of the Federal Government. In regard to mixed wastes, sovereign immunity for federal agencies is waived, consistent with a schedule provided in the act. In addition, the act requires that the Department of Energy prepare an inventory of mixed wastes and mixed waste treatment capacities and technologies. For those mixed wastes for which treatment capacities or technologies do not exist, the Department must prepare plans for the development of the capacities or technologies.

The path traveled by a "zero charged," "floating" particle released into a groundwater-flow field. 
Gas Generation Model

A computational model that can simulate and/or predict the rate and quantity of gases generated by waste transformation processes in a disposal room of the decommissioned repository.

Gas Generation Rate

The combined gas production rate from all species of gases produced as a result of transuranic waste transformations such as corrosion, microbial degradation, and/or radiolysis at any given time. The rate of gas production throughout the history of the repository is expected to vary depending on repository conditions with respect to humidity, total or partial brine inundation, competitive reactions that absorb specific gases, and the ability of the repository to retain the gases generated. The term is also applied to individual gases.

Generator and/or

Storage Sites

Refers to the ten Department of Energy sites nationwide where transuranic wastes are generated and/or stored as a result of activities associated with nuclear weapons production.

Getters

Substances that sorb gases, such as $\mathrm{CO}_{2}$, and may be added with other potential backfill materials to mitigate the pressure buildup in the repository.

Grout

A mortar or cement slurry (of high water content) used to plug potential fluid-flow paths in geologic or engineered structures.

Hazardous Constituent Those chemicals identified in Appendix VIII of 40 CFR 261.

Hazardous Waste

A hazardous waste as defined in 40 CFR \$261.3.

Horizon

In geology, an interface indicative of a particular position in a stratigraphic sequence. For instance, the waste-emplacement horizon at the Waste Isolation Pilot Plant is the level about 650 $\mathrm{m}(2,150 \mathrm{ft})$ deep in the Salado Formation where openings are mined for waste disposal. 
Host Rock

Human Intrusion

Land Withdrawal Act

Latin Hypercube

Sampling

Lithostatic Pressure

Long Term

Mean

Median
The rock unit, in this case the Salado Formation, in which the radioactive waste is to be emplaced.

Inadvertent human disruptions of a mined geologic repository that could result in loss of containment of the waste. The most severe disruption would occur through inadvertent, intermittent intrusion by exploratory drilling (into the repository) for resources (40 CFR 191, Appendix C).

The Waste Isolation Pilot Plant (Public Law 102-579).

Withdraws the land at the Waste Isolation Pilot Plant site from "entry, appropriation, and disposal," transfers jurisdiction of the land from the Secretary of the Interior to the Secretary of Energy, reserves the land for activities associated with the development and operation of the Waste Isolation Pilot Plant, and includes many other requirements and provisions pertaining to the protection of public health and the environment.

A Monte Carlo sampling technique that divides the range of each variable into intervals of equal probability and samples from each interval.

Subsurface pressure due to the weight of overlying rock or soil.

Refers to the 10,000 years after shaft sealing for which performance assessment calculations and models assess the behavior of the repository with respect to compliance with 40 CFR 191 and 40 CFR \$268.6.

The average value. For a given set of $n$ values, the mean is the sum of their values divided by $n$.

The median of a set of data is the value such that half of the observations are less than that value and half are greater than that value. 
Methanogenesis

Migration

Miscellaneous Hazardous

Waste Management Unit

Mixed Waste

Model Validation

Model Verification
The generation of methane through the decomposition of organic matter in wastes.

In the context of 40 CFR \$268.6, "migration" means the movement of hazardous constituents beyond the boundary of a hazardous waste management unit in concentrations exceeding applicable regulatory levels.

A waste management unit where hazardous waste is treated, stored, or disposed of and that is not a container, tank, surface impoundment, pile, land treatment unit, landfill, incinerator, boiler, industrial furnace, underground injection well, or unit eligible for a research, development, and demonstration permit (40 CFR §260.10).

Mixed waste contains both radioactive and hazardous components, as defined by the Atomic Energy Act and the Resource Conservation and Recovery Act, respectively.

The process of ensuring through sufficient testing of a model using actual site data, that a conceptual model and corresponding mathematical and computer models correctly simulate a physical process with sufficient accuracy.

The process of ensuring (e.g., through tests on ideal problems) that a computer code (computational model) correctly performs the necessary functional operations (such as solving the mathematical model). Given that a computer code correctly solves the mathematical model, the physical assumptions of the mathematical model must then be checked through validation. 
Monte Carlo Sampling

A random sampling technique used in computer simulations to obtain approximate solutions to mathematical or physical problems. Monte Carlo sampling is used in conjunction with Latin Hypercube techniques to sample a range of variables. The range is divided into intervals of equal probability, and one value is randomly selected from each interval. The selected values from each interval are combined to generate vectors. The procedure ensures that the distribution tails are sampled; also, it is more efficient than simple random sampling.

Munson Dawson Model

A simulation model developed to help predict the behavior, particularly the rate of room closure, of Waste Isolation Pilot Plant underground openings.

Natural Barriers

The repository host rock and surrounding geologic structures and formations. The natural barriers extend from the engineered barrier to the compliance boundary.

No-Migration

Adequate isolation of RCRA-regulated constituents such that "no-migration" of hazardous-waste constituents beyond the unit boundary occurs for as long as the wastes remain hazardous.

Panel

A group of several underground rooms connected by drifts. Within the Waste Isolation Pilot Plant, a panel consists of seven rooms connected by drifts at each end.

Passive Institutional Controls

"1) [P]ermanent markers placed at a disposal site, 2) public records and archives, 3) government ownership and regulations regarding land or resource use, and 4) other methods of preserving knowledge about the location, design, and contents of a disposal system

(40 CFR \$191.12[e]). 
Performance Assessment

Performance-Based Waste Acceptance Criteria

Performance-Based Waste Envelope

Performance-Based Waste Inventory

Permeability

Public Law 96-164

Public Law 102-579
A term used to denote quantitative activities carried out to evaluate the long-term ability of the Waste Isolation Pilot Plant to effectively isolate the waste, ensure long-term health and safety of the public by complying with 40 CFR 191 and 40 CFR \$268.6, and supply data/information to the compliance analysis for demonstrating regulatory compliance. The final analysis of compliance will consist of a qualitative assessment of the quantitative results of the performance assessment.

Waste-acceptance criteria based on the results of performance assessment models, operational assessments, and possible conditions which may be imposed as a part of the regulatory process.

The bounding characteristics of wastes acceptable for the Waste Isolation Pilot Plant, based on the expected repository performance.

That portion of the waste inventory which will meet the Performance-Based Waste Acceptance Criteria.

In hydrology, the capacity of a rock sediment or soil to transmit fluids.

The U.S. Department of Energy National Security and Military Applications of Nuclear Energy Act of 1980. Public Law 96-164 directed the Department of Energy to proceed with the design and development of the Waste Isolation Pilot Plant.

See Land Withdrawal Act 
Real-Time Radiography

Reasonable

Release

Rem

Remote-Handled

Waste

Repository
A nondestructive, nonintrusive examination technique that enables a qualitative (and in some cases semiquantitative) evaluation of the contents of a waste container. Real-Time Radiography utilizes $x$-rays to inspect the contents of the waste container and allows the operator to view events in progress (real time). Real-Time Radiography is used to examine and verify the physical form of the waste for certain waste forms, identify individual waste components, and verify the absence of certain noncompliant items, as applicable.

1) Not conflicting with reason. 2) Not extreme or excessive.

3) Having the faculty of reason. 4) Possessing sound judgement.

Movement of regulated substances into the accessible environment as defined in 40 CFR 191 or beyond the unit boundary as defined for 40 CFR $\$ 268.6$.

Roentgen equivalent in man - a special unit of dose equivalent which is the product of absorbed dose, a quality factor which rates the biological effectiveness of the radiation types producing the dose, and other modifying factors (usually equal to one). If the quality and modifying factors are unity, one rem is equal to one rad. 100 rem = one Sievert (SI units). Also expressed in terms of mrem. 1 rem $=1,000$ mrem.

Transuranic wastes that have a measured radiation dose rate at the container surface of between 200 mrems per hour and 1,000 rem per hour and, therefore, must be shielded for safe handling.

The portion of the Waste Isolation Pilot Plant underground system within the Salado Formation, including the access drifts, waste panels, and experimental areas, but excluding the shafts. 
Repository/Shaft

System

Resource Conservation and Recovery Act Permit Application

Room

Salado Formation

Saturated

Scenario

Seal

DOE/WIPP 94-019
The Waste Isolation Pilot Plant underground workings, including the shafts, all engineered and natural barriers, and the altered zones within the Salado Formation and overlying units resulting from construction of the underground workings.

An application, which is submitted by the owner/operator of a hazardous waste management unit to the state (if authorized by the Environmental Protection Agency) or to the Environmental Protection Agency, for a Resource Conservation and Recovery Act permit to operate the unit. A Resource Conversation and Recovery Act permit application consists of two parts: Part A and Part B.

An excavated cavity within a panel in the underground. Within the Waste Isolation Pilot Plant, a room is $10 \mathrm{~m}$ wide, $4 \mathrm{~m}$ high, and $91 \mathrm{~m}$ long.

A geologic formation of Late Permian age in southeastern New Mexico. At the Waste Isolation Pilot Plant site, it is composed of salt beds with minor amounts of anhydrite ( 45 numbered anhydrite marker beds, Marker Bed 101 through Marker Bed 145) and clay. It is the host unit for the Waste Isolation Pilot Plant repository.

A condition in which all connected pores in a given volume of material contain fluid.

A combination of naturally occurring or human-induced events and processes that represents realistic future changes to the repository, geologic, and geohydrologic systems that could cause or promote the escape of radionuclides and/or hazardous constituents from the repository.

An engineered barrier designed to isolate the waste and to impede groundwater flow in the shafts. 
Sludge

Solubility

Solute

Solvent

Spallings

Transmissivity
Refers to de-watered contact-handled transuranic wastes containing both organic and inorganic constituents that must meet the Waste Acceptance Criteria for shipment and disposal at the Waste Isolation Pilot Plant repository. High sludges refers to contact-handled transuranic waste where the sludge component constitutes 50 percent or more of the waste volume; low sludges are the same type of waste containing less than $\mathbf{5 0}$ percent by volume of sludge.

The ability or tendency of one substance to blend uniformly with another (e.g., solid in liquids, liquid in liquid, gas in liquid, and gas in gas). Solids vary from 0 to $100 \%$ in their degree of solubility in liquids depending on the chemical nature of the substance(s); to the extent that they are soluble they lose their crystalline form and become molecularly or ionically dispersed in the solvent to form a true solution. Liquids and gases are often said to be miscible in other liquids and gases rather than soluble.

A substance which is dissolved in another substance called the solvent. The solute is uniformly dispersed in the solvent either molecularly or ionically.

A substance capable of dissolving another substance (solute) to form a uniform dispersed mixture (solution) at the molecular or ionic level. Solvents are, accordingly, characterized as either polar or non-polar. Water is strongly polar; hydrocarbon solvents are non-polar.

During exploratory drilling, waste surrounding the eroded borehole that is transported by waste-generated gas escaping to the lower-pressure borehole.

For a confined aquifer, the product of hydraulic conductivity and aquifer thickness. 
Transuranic Waste

Trend

True Solution

Uncertainty Analysis

Undisturbed

Performance
The term "transuranic waste" means waste containing more than 100 nanocuries of alpha-emitting transuranic isotopes per gram of waste, with half-lives greater than 20 years, except for:

1) high-level radioactive waste, 2) waste that the Secretary has determined, with the concurrence of the Administrator, does not need the degree of isolation required by the disposal regulations, or 3) waste that the Nuclear Regulatory Commission has approved for disposal on a case-by-case basis in accordance with 10 CFR 61.

In geology, the general tendency or course of geologic material.

A uniformly dispersed mixture at the molecular or ionic level, of one or more substances (solute) in one or more substances (solvent). Solutions that exhibit no change relative to internal energy upon mixing and complete uniformity of cohesive forces are ideal.

1) An evaluation to determine the uncertainty in model predictions that results from imprecisely known input variables.

2) Determination of the degree of uncertainty in the results of a calculation based on uncertainties in the input parameters and underlying assumptions. Such an analysis requires definition of a system, description of the uncertainties in the factors that are to be investigated, and the characteristics of the system that is to be simulated.

"[T]he predicted behavior of a disposal system, including consideration of the uncertainties in predicted behavior, if the disposal system is not disrupted by human intrusion or the occurrence of unlikely natural events" (40 CFR \$191.12(p)). 
Unit Boundary

Volatile Organic

Compounds

Waste Acceptance

Criteria

Waste Characterization

Waste Characterization

Program

Working Agreement
In the context of the test-phase 40 CFR $\$ 268.6$ No-Migration Determination, the Waste Isolation Pilot Plant unit boundary is that portion of the Salado Formation that falls within the land area controlled by the Department of Energy.

RCRA-regulated organic compounds which readily pass into the vapor state and are present in contact-handled transuranicmixed waste.

A set of conditions established for permitting transuranic wastes to be packaged, shipped, managed, and disposed of at the Waste Isolation Pilot Plant.

Sampling, monitoring, and analysis activities to determine the nature of the waste.

The processes of contact-handled transuranic waste analysis to support the No-Migration Determination, Part B of the Resource Conservation and Recovery Act permit application, other permits, transportation requirements, and the experimental program requirements. These analyses include documentation of waste generation processes, visual characterization of waste components, Real-Time Radiography analysis, and passiveactive neutron waste assay for radionuclide content. Waste matrix and headspace gas chemical analyses are also part of the characterization program.

Appendix B of the Agreement of Consultation and Cooperation, which sets forth the working details of that Agreement. 


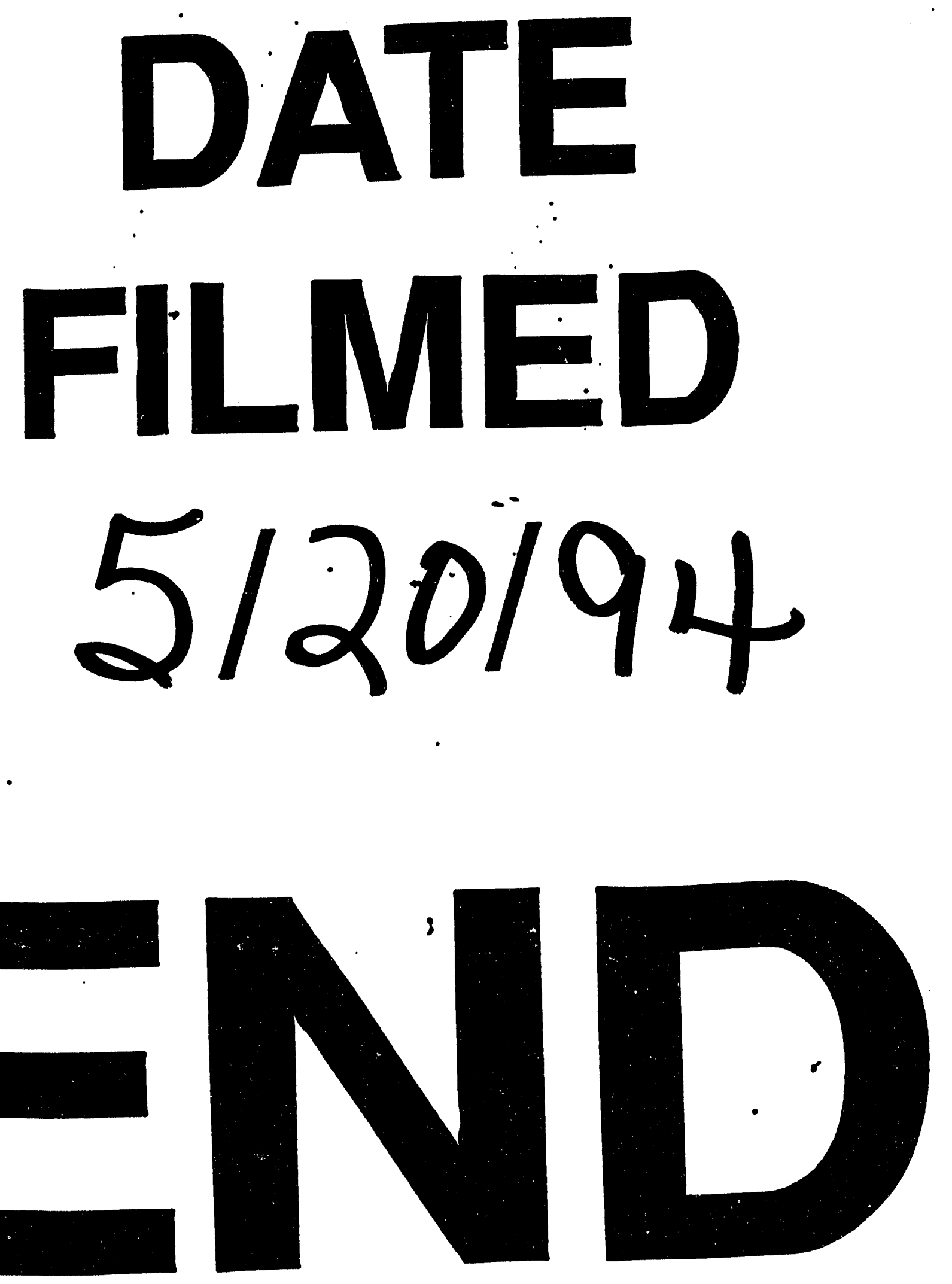




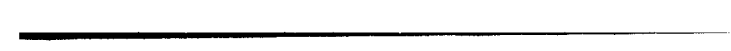

$-$
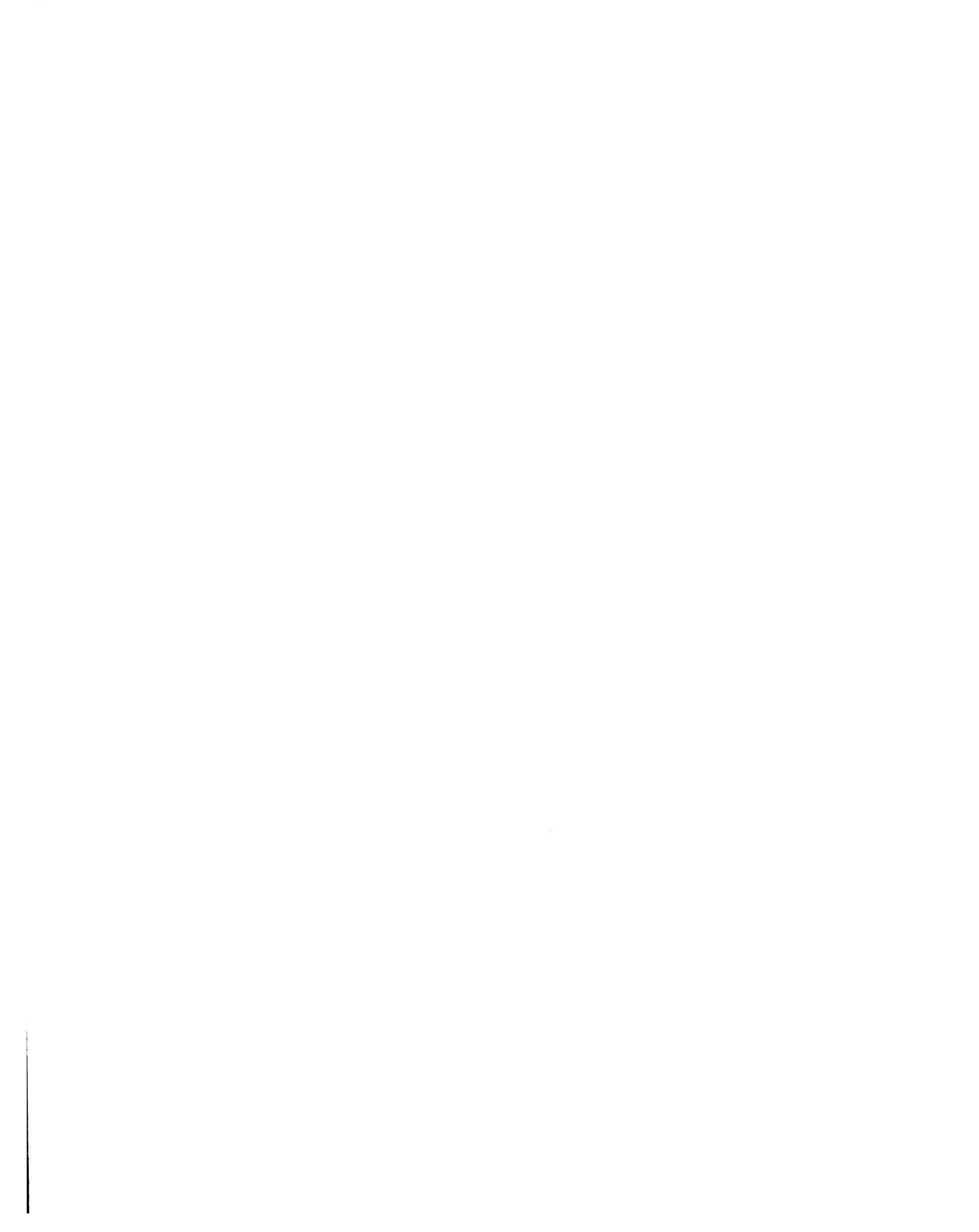